\title{
Effect of salinity on biodegradation of MSW in bioreactor landfills
}

By

\section{Salem Al-Kaabi}

A thesis presented to the Faculty of Graduate Studies and Research in partial fulfillment of the requirements for the degree of

\author{
Doctor of Philosophy \\ in \\ Environmental Engineering*
}

Department of Civil and Environmental Engineering

Carleton University, Ottawa, Ontario

Canada

January 2007

* The Doctor of Philosophy in Engineering Program is a joint program with the University of Ottawa administered by the Ottawa-Carleton Institute for environmental Engineering

(C) Copyright, Salem Al-Kaabi, 2007 


$\begin{array}{ll}\begin{array}{l}\text { Library and } \\ \text { Archives Canada }\end{array} & \begin{array}{l}\text { Bibliothèque et } \\ \text { Archives Canada }\end{array} \\ \begin{array}{l}\text { Published Heritage } \\ \text { Branch }\end{array} & \begin{array}{l}\text { Direction du } \\ \text { Patrimoine de l'édition }\end{array} \\ \begin{array}{l}\text { 395 Wellington Street } \\ \text { Ottawa ON K1A ON4 }\end{array} & \begin{array}{l}\text { 395, rue Wellington } \\ \text { Ottawa ON K1A ON4 } \\ \text { Canada }\end{array}\end{array}$

Your file Votre référence ISBN: 978-0-494-23285-9 Our file Notre référence ISBN: 978-0-494-23285-9

NOTICE:

The author has granted a nonexclusive license allowing Library and Archives Canada to reproduce, publish, archive, preserve, conserve, communicate to the public by telecommunication or on the Internet, loan, distribute and sell theses worldwide, for commercial or noncommercial purposes, in microform, paper, electronic and/or any other formats.

The author retains copyright ownership and moral rights in this thesis. Neither the thesis nor substantial extracts from it may be printed or otherwise reproduced without the author's permission.
AVIS:

L'auteur a accordé une licence non exclusive permettant à la Bibliothèque et Archives Canada de reproduire, publier, archiver, sauvegarder, conserver, transmettre au public par télécommunication ou par l'Internet, prêter, distribuer et vendre des thèses partout dans le monde, à des fins commerciales ou autres, sur support microforme, papier, électronique et/ou autres formats.

L'auteur conserve la propriété du droit d'auteur et des droits moraux qui protège cette thèse. $\mathrm{Ni}$ la thèse ni des extraits substantiels de celle-ci ne doivent être imprimés ou autrement reproduits sans son autorisation.
In compliance with the Canadian

Privacy Act some supporting forms may have been removed from this thesis.

While these forms may be included in the document page count, their removal does not represent any loss of content from the thesis.
Conformément à la loi canadienne sur la protection de la vie privée, quelques formulaires secondaires ont été enlevés de cette thèse.

Bien que ces formulaires aient inclus dans la pagination, il n'y aura aucun contenu manquant.

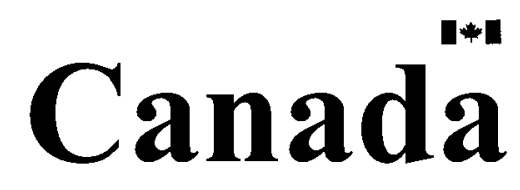




\begin{abstract}
Bioreactor landfills require sufficient moisture to optimize the biodegradation processes and methane generation. In arid regions, this is problematic given the lack of fresh water supplies. Saline water can be used but may inhibit the biodegradation of the municipal solid waste (MSW) in landfills. Sludge may be used to enhance the biodegradation of MSW under saline conditions.
\end{abstract}

For this research, two groups of laboratory scale bioreactor cells were used to study the impact of saline water and sludge addition on the biodegradation of MSW in bioreactor landfills. The first group (R1-R4) operated without sludge addition. The second group (R5-R8) operated with addition of sludge. The salt concentrations in the two groups were $0 \%, 0.5 \%, 1 \%$, and $3 \%(\mathrm{w} / \mathrm{v})$ respectively. All bioreactors were operated at neutral $\mathrm{pH}$ levels with leachate recycle.

The methane yield was $70.6,61.7$ and $47.5 \mathrm{~L} / \mathrm{kg}$ dry waste for bioreactors $\mathrm{R} 1, \mathrm{R} 2$ and $\mathrm{R} 4$, respectively; and $84.7,78.7,72.6$ and $59.0 \mathrm{~L} / \mathrm{kg}$ dry waste for bioreactors $\mathrm{R} 5, \mathrm{R} 6, \mathrm{R} 7$ and R8, respectively. The high salt content $(3 \%)$ inhibited the MSW biodegradation as evidenced by the methane yield, the percentage peak reduction in leachate concentration and the settlement that occurred during the study. Sludge addition was able to improve the methane yield at all salt contents.

A mathematical model was developed to simulate the biodegradation of the MSW in bioreactor landfills operating under saline conditions and to predict the leachate strength (aqueous organic acid and volatile fatty acid (VFA)), and the volume of landfill gas $\left(\mathrm{CH}_{4}\right.$ 
and $\mathrm{CO}_{2}$ ) produced. Sensitivity analysis indicated that the hydrolysis rate constant, methanogenic parameters $\left(\mu_{\mathrm{M}}, \mathrm{k}_{\mathrm{dM}}, \mathrm{K}_{\mathrm{SM}}\right)$, and initial concentration of methanogenic biomass had a significant impact on peaks of the VFA and daily methane produced, as well as the time required to reach them.

The model has been calibrated by comparing the simulation results to the experimental $1 \mathrm{D}$ bioreactor measurements. The results of methane production showed good agreement between the model and experimental data. Both the model parameters and the salt inhibition constants ( $\mathrm{K}_{\mathrm{I}}$ and $\mathrm{m}$ ) were determined from these simulations. 
- To my parents and my family

-To the memory of H.H. Sheikh Zayed bin Sultan Al Nahyan, Former President of the United Arab Emirates 


\section{Acknowledgments}

I would like to thank first and foremost God for giving me the gift of understanding and perseverance to undertake such a demanding project, and for his patience and love during those moments when I thought that this project would be unsurmountable.

I want to thank my parents for their love and encouragement; they are the reason why I want to become a better person and son. My special gratitude goes to them for taking care of my own family during my long periods of absence.

I want to thank my wife and children for their unwavering support during the three years that my dream took to become a reality.

Thank you Professor Paul Van Geel for your excellent guidance during my work, for challenging me at every step of my research, and especially, for your support and friendship. Professor Mostafa Warith, I do not know where I would be now without your direction in setting up the experiments, and your support.

I special thanks goes to my sponsors, the Government of Abu Dhabi (ADIA) for providing me with the student scholarship and for approving the funds destined for my experimental work; and the Al-Ain Municipality for permitting my extended leave of absence to complete my PhD.

I want to thank all the friends who with their encouragement and support helped me realized my goals; thank you especially Mustafa and Laura.

And finally, I would not have been able to carry out my experimental work without the expert advice of lab technicians Marie and Jim. 


\section{Table of Contents}

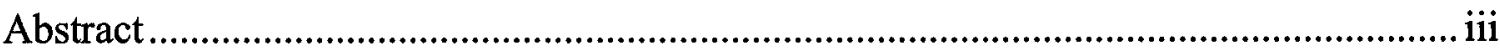

Acknowledgments..................................................................................................... vi

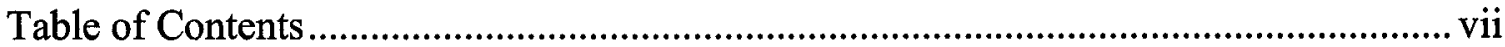

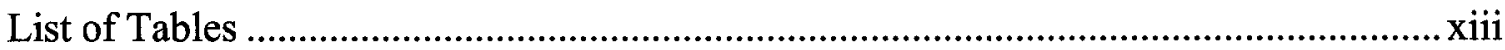

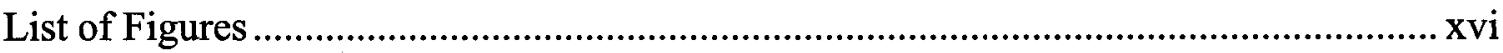

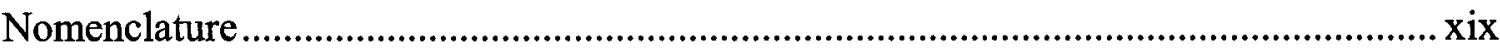

Chapter 1: Introduction ............................................................................................................... 1

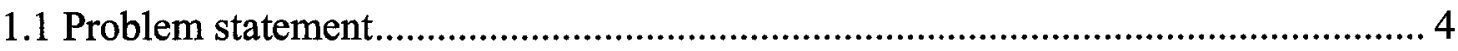

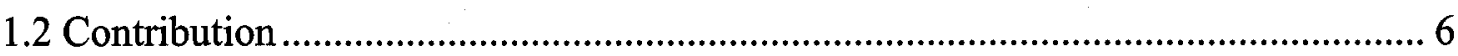

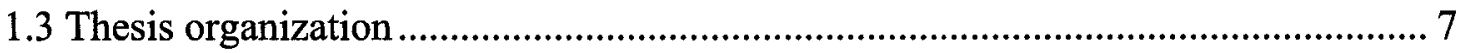

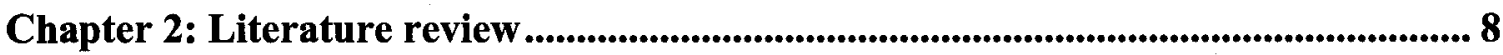

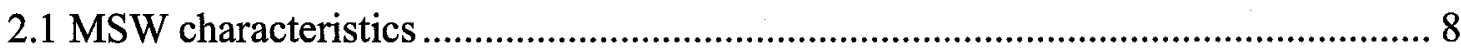

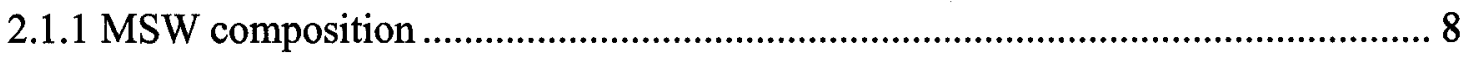

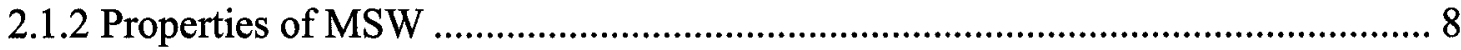

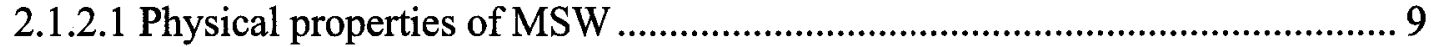

2.1.2.2 Chemical properties of MSW ................................................................. 11

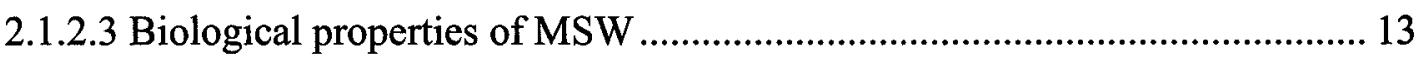

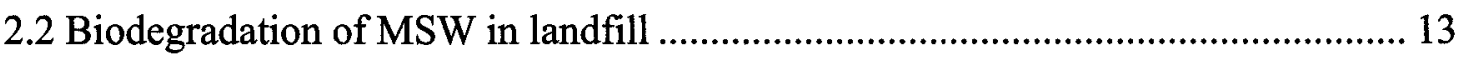

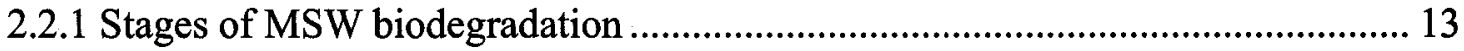

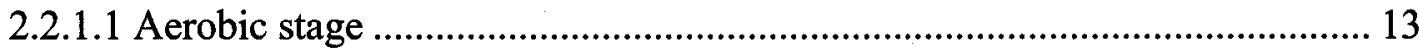

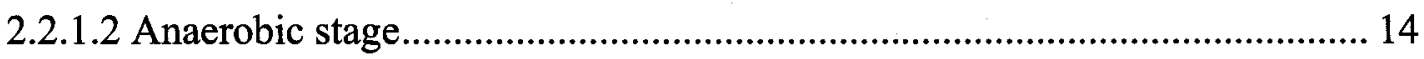

2.2.2 Phases of MSW biodegradation in the landfill ........................................... 17

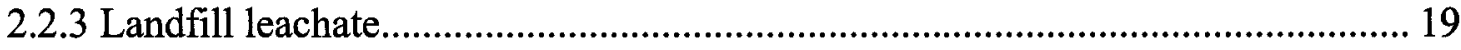

2.2.3.1 Landfill leachate generation....................................................................... 19

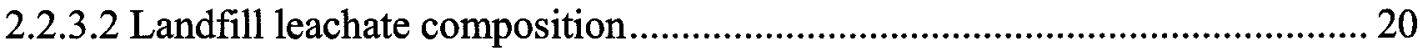

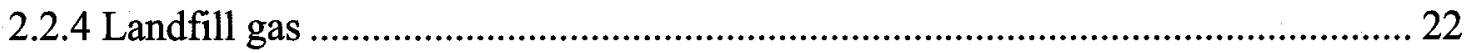

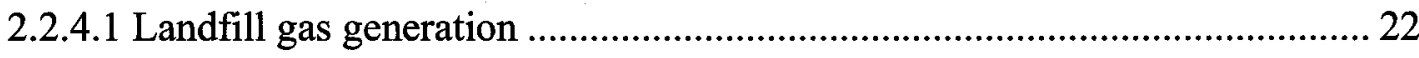

2.2.4.2 Landfill gas composition...................................................................... 23

vii 


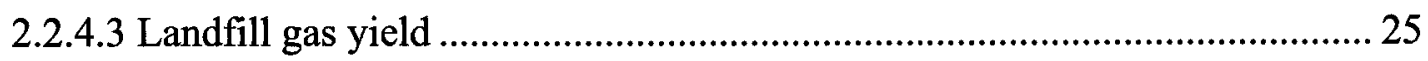

2.2.5 Factors controlling the biodegradation of MSW in landfills .............................. 29

2.2.5.1 Moisture content and movement................................................................ 29

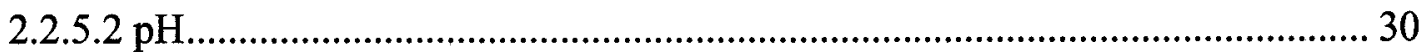

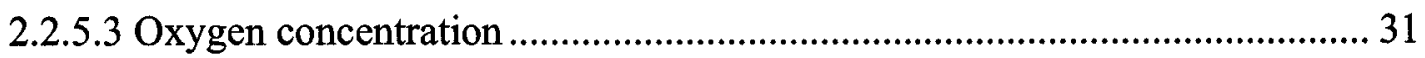

2.2.5.4 Hydrogen concentration............................................................................ 31

2.2.5.5 Nutrients and trace metals........................................................................... 31

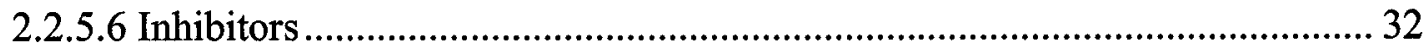

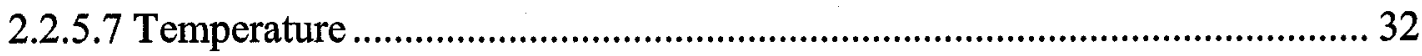

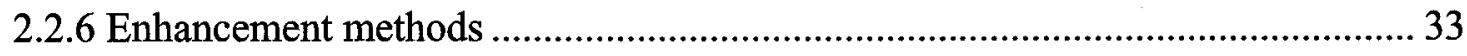

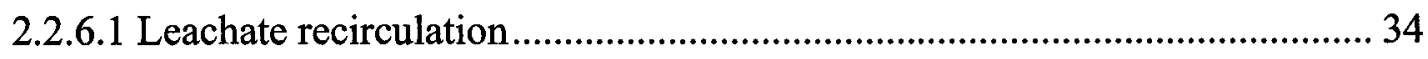

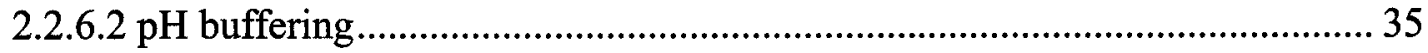

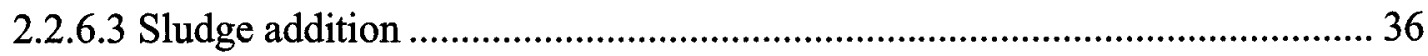

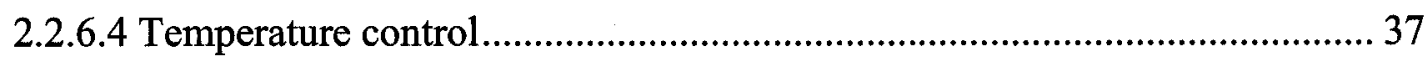

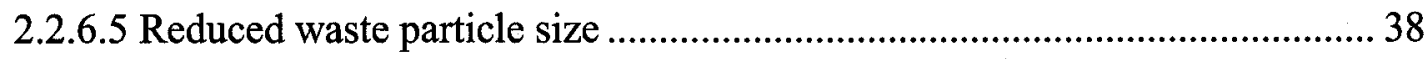

2.2.6.6 Lift design, daily cover and compaction of waste .......................................... 39

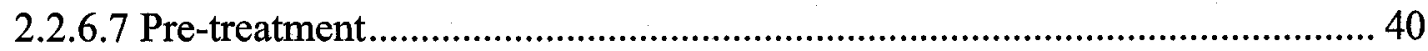

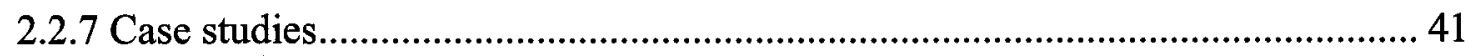

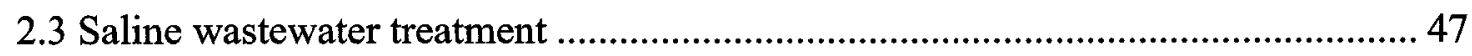

2.3.1 Halophilic organism classification................................................................. 48

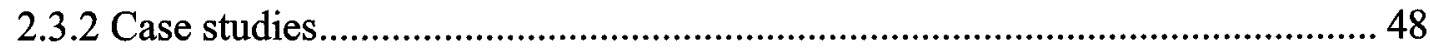

2.4 Existing models................................................................................................... 51

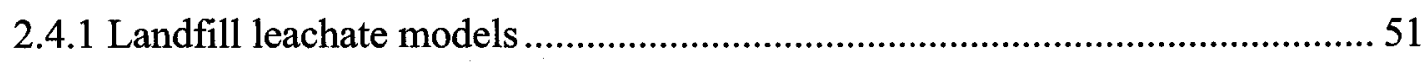

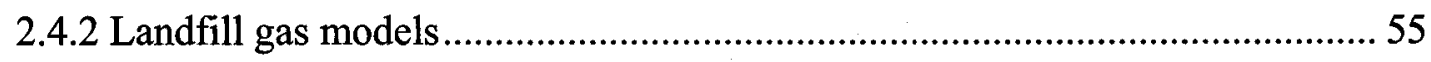

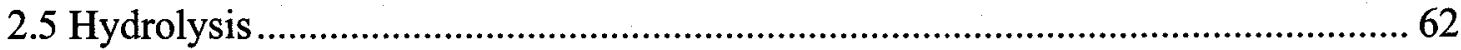

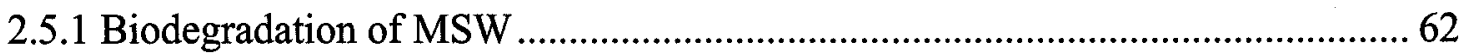

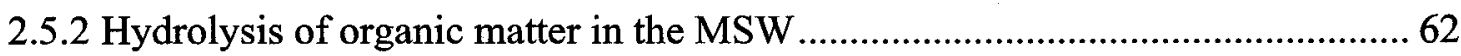

2.5.3 Mathematical description of hydrolysis kinetics ................................................ 63

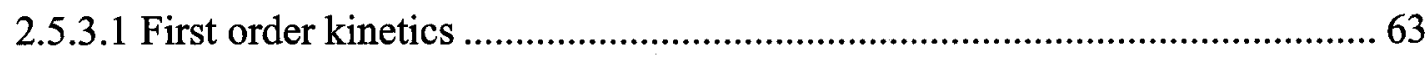

2.5.3.2 Surface based kinetics................................................................................... 65

2.6 Summary of literature review ................................................................................ 66 
Chapter 3: Materials and Methods ..................................................................................... 67

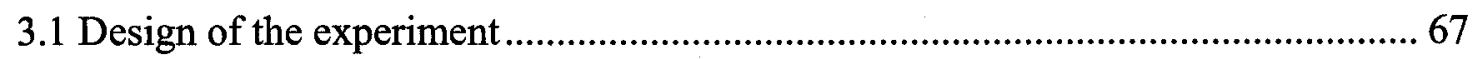

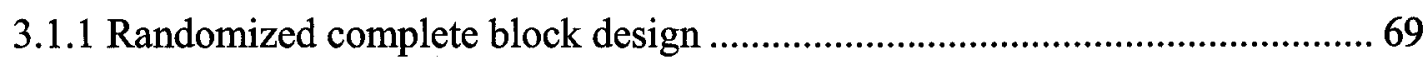

3.2 Composition of MSW and sludge and 1D column construction ............................. 70

3.2.1 Composition of MSW and sludge ................................................................... 70

3.2.2 1D bioreactor construction............................................................................ 70

3.3 Experimental methods and operations ………………….................................. 72

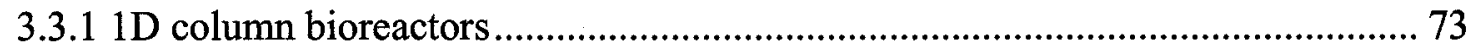

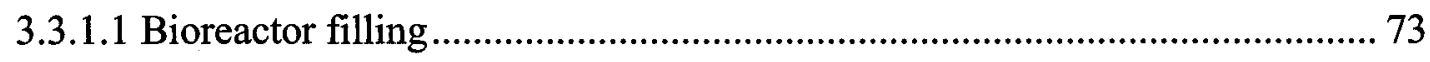

3.3.1.2 Water addition and leachate recirculation.................................................. 73

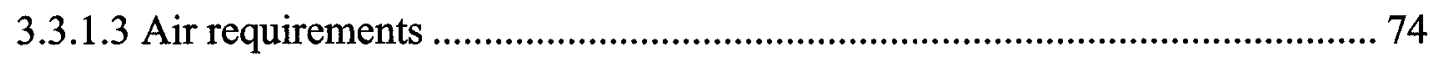

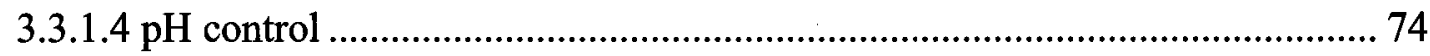

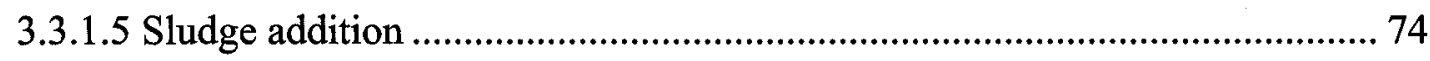

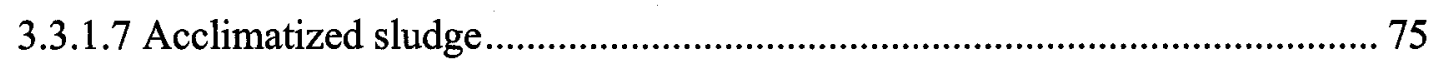

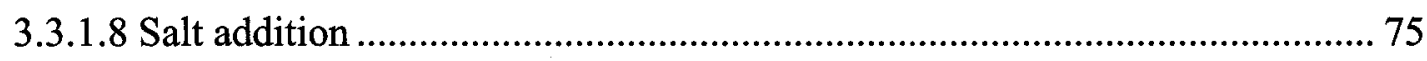

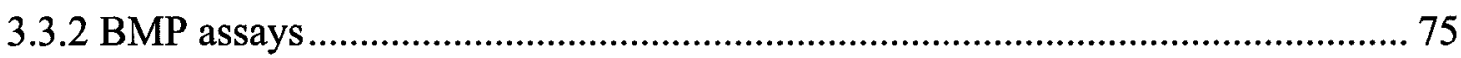

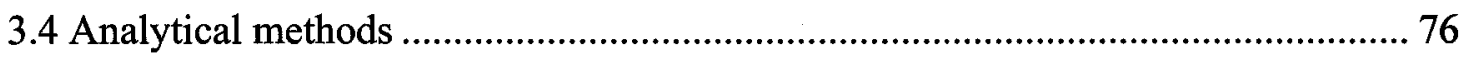

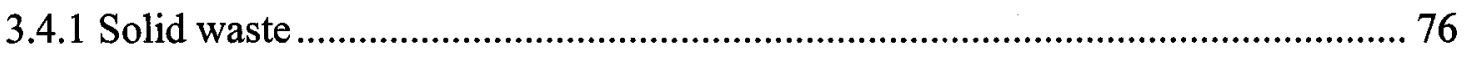

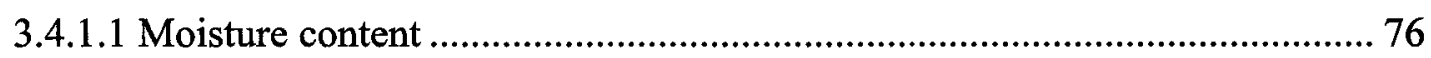

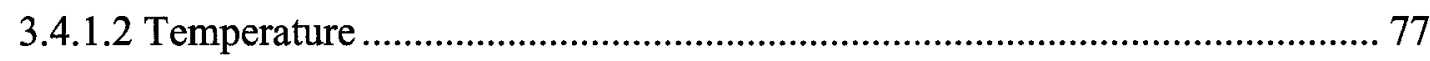

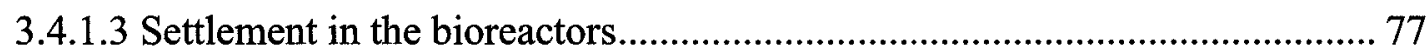

3.4.2 Landfill biogas generation ................................................................................ 78

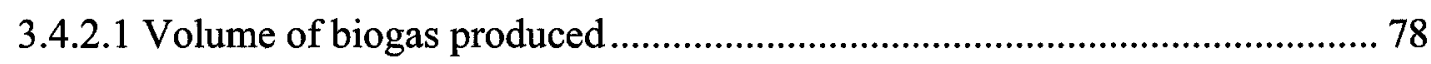

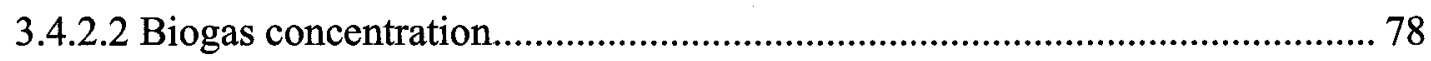

3.4.2.3 Biochemical methane potential (BMP) ...................................................... 79

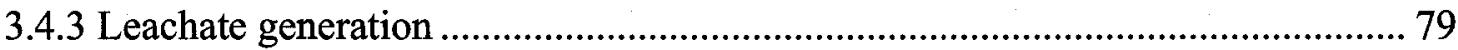

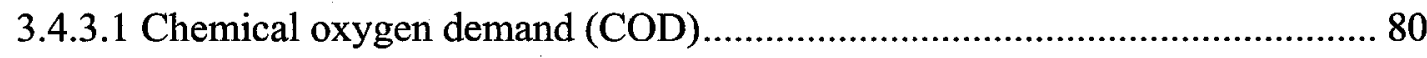

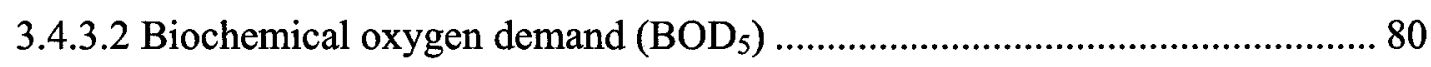

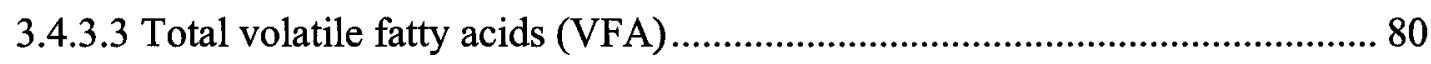

3.4.3.4 $\mathrm{pH}$

3.4.3.5 Total solids (TS) and total volatile solids (TVS) ………............................. 81 


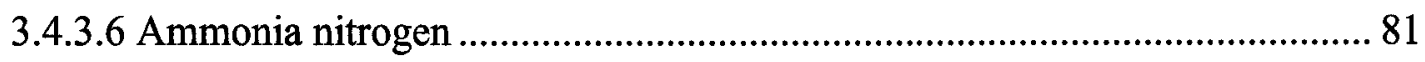

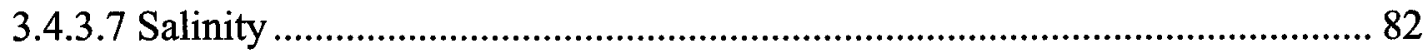

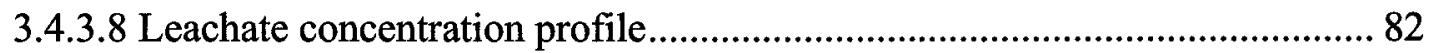

Chapter 4: Model development ................................................................................................ 83

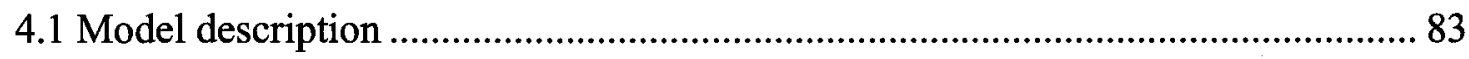

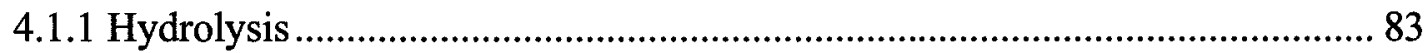

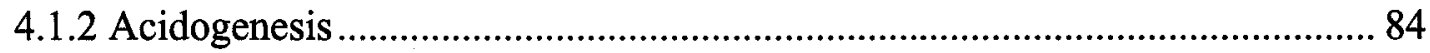

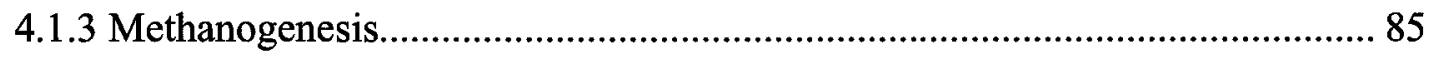

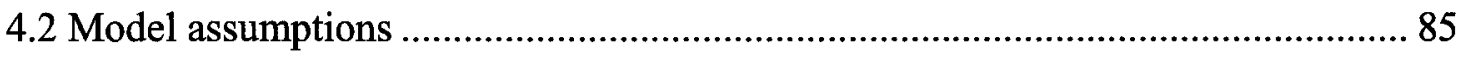

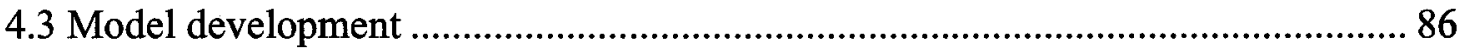

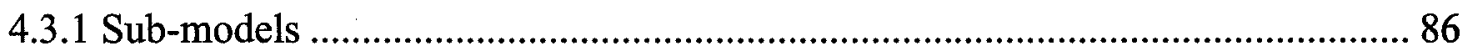

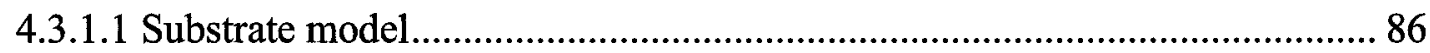

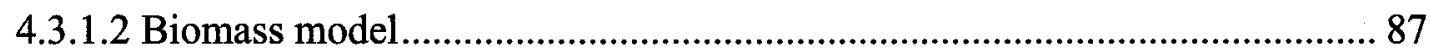

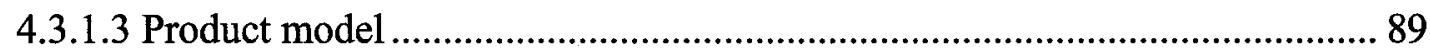

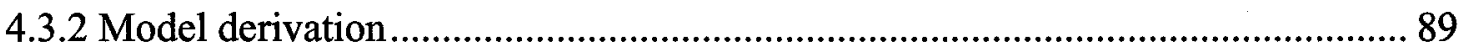

4.3.2.1 Aqueous organic acids carbon ................................................................... 90

4.3.2.2 Acidogenic biomass carbon ....................................................................... 91

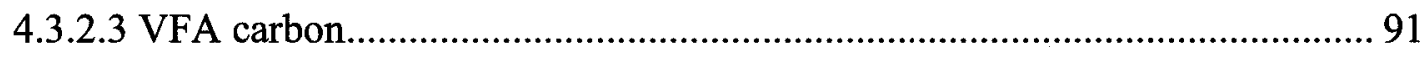

4.3.2.4 Methanogenic biomass carbon................................................................... 92

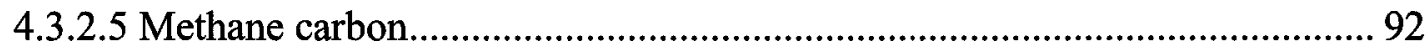

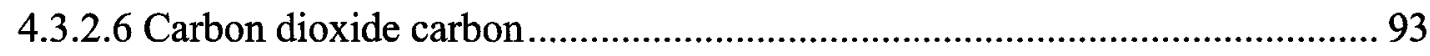

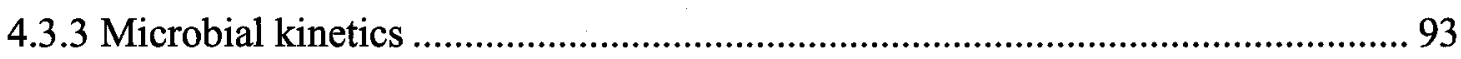

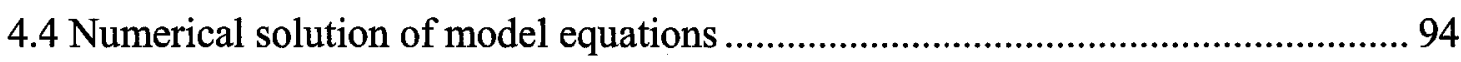

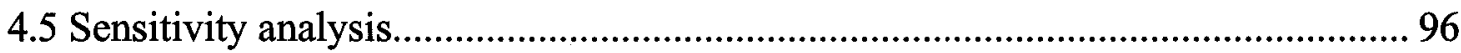

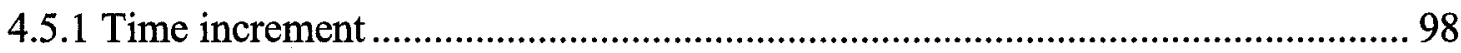

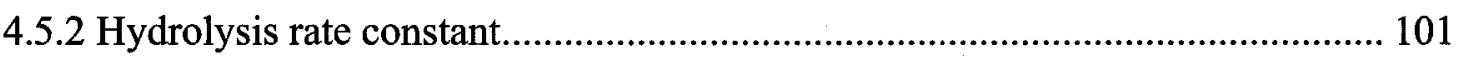

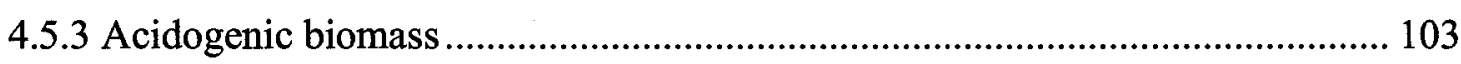

4.5.3.1 Maximum specific growth rate of acidogenic biomass ............................... 103

4.5.3.2 Decay rate of acidogenic biomass............................................................ 105

4.5.3.3 Half saturation constant of acidogenic biomass........................................... 107 


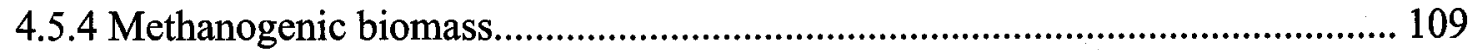

4.5.4.1 Maximum specific growth rate of methanogenic biomass .......................... 109

4.5.4.2 Decay rate of methanogenic biomass .................................................. 110

4.5.4.3 Half saturation constant of methanogenic biomass ..................................... 112

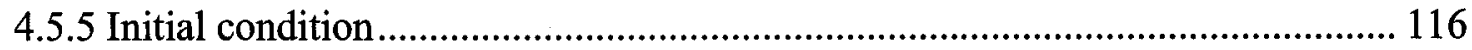

4.5.5.1 Initial aqueous organic acid concentration ................................................... 116

4.5.5.2 Initial VFA concentration ..................................................................... 118

4.5.5.3 Initial acidogenic biomass concentration...................................................... 118

4.5.5.4 Initial methanogenic biomass concentration................................................. 121

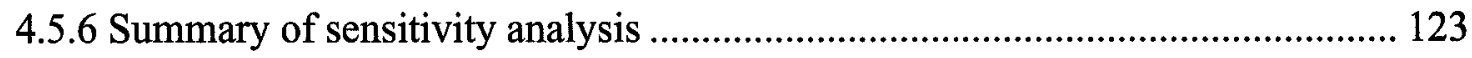

Chapter 5: Results and discussion...................................................................................... 124

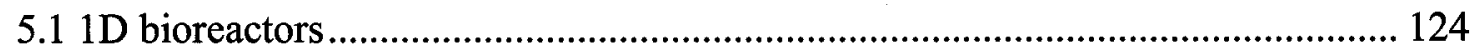

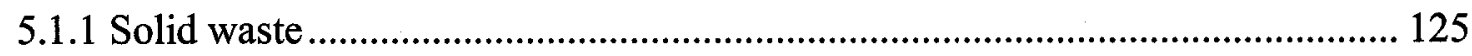

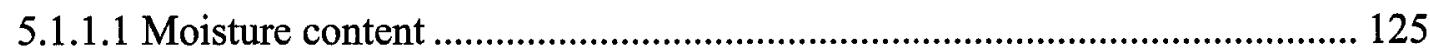

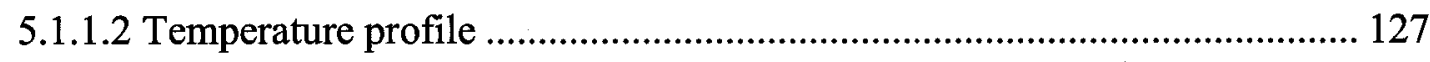

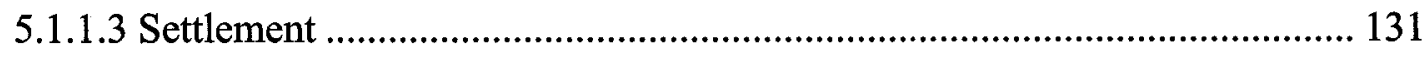

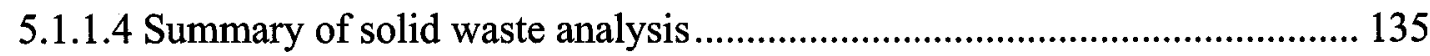

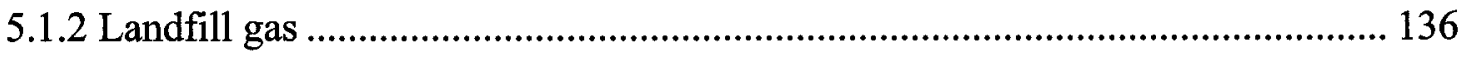

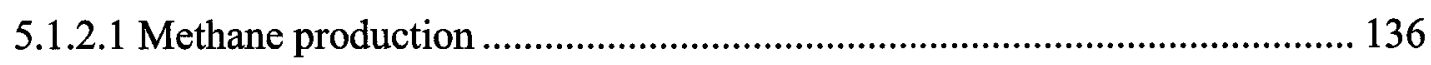

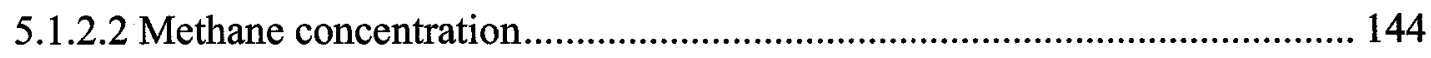

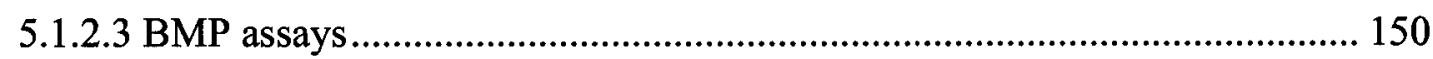

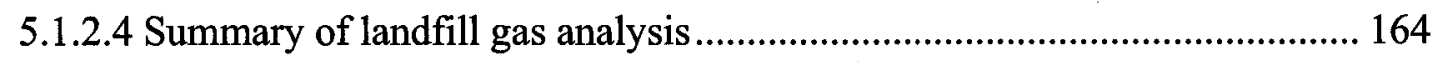

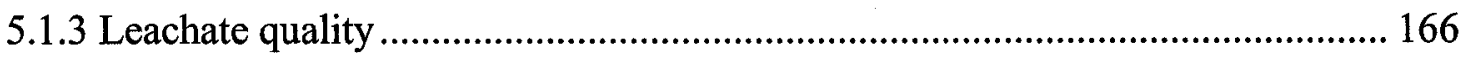

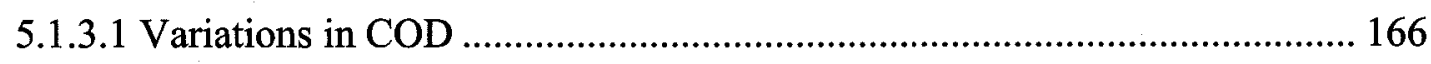

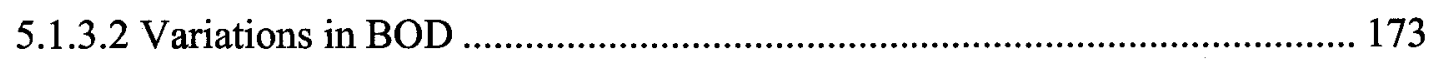

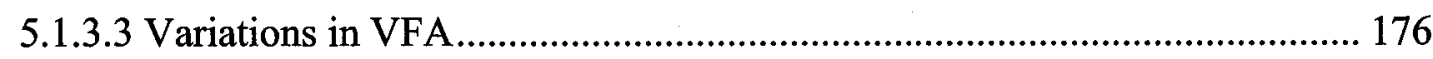

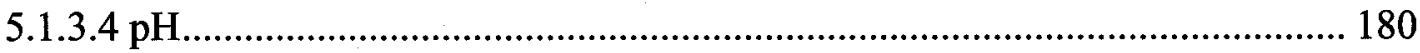

5.1.3.5 Variations in TVS ........................................................................... 183

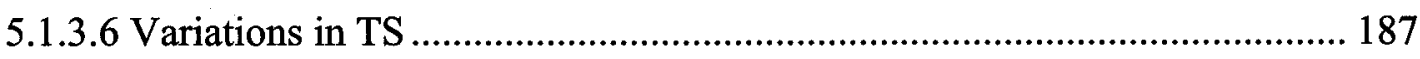

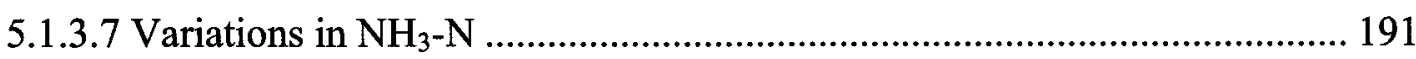




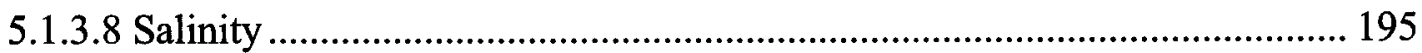

5.1.3.9 Vertical Concentration profile in bioreactors ........................................... 196

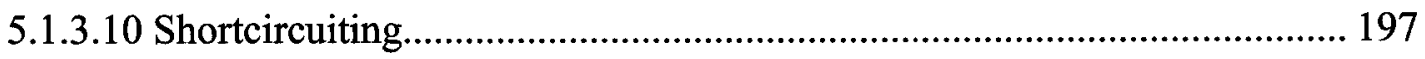

5.1.3.11 Summary of leachate quality analysis....................................................... 199

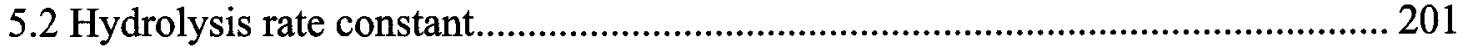

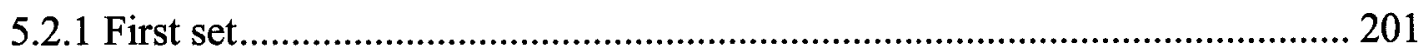

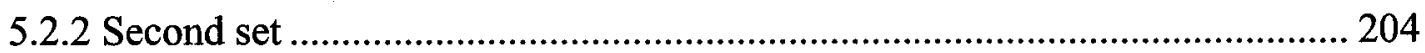

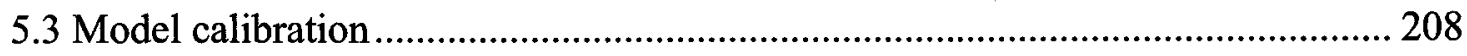

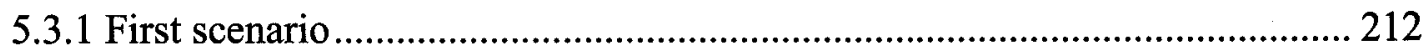

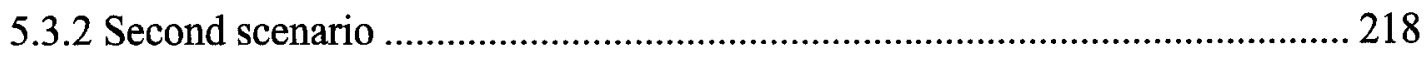

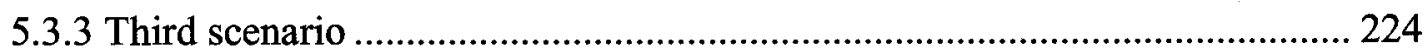

Chapter 6: Conclusions and recommendations ........................................................... 231

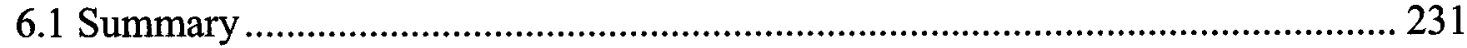

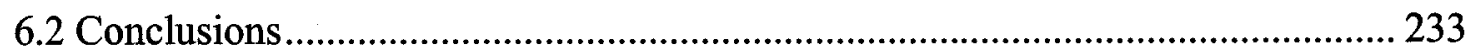

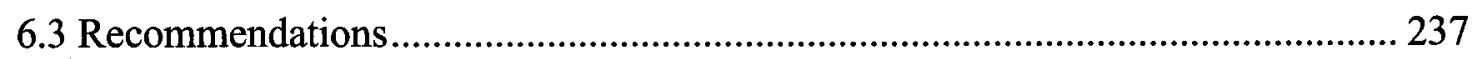

References......................................................................................................................... 248

Appendix A: Results of experimental works..................................................................259

Appendix B: Results of statistical analysis...........................................312

xii 


\section{List of Tables}

Table 1.1: Water resources in Arabian Peninsula countries .............................................. 6

Table 2.1: Waste composition in different countries....................................................... 9

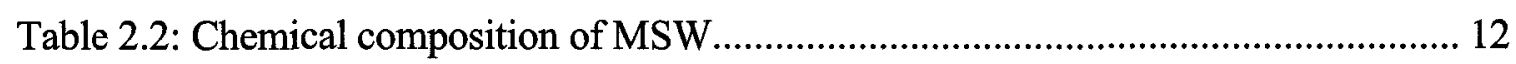

Table 2.3: Biodegradable fraction of selected components based on lignin content .......... 12

Table 2.4: Composition of leachate from landfills ........................................................ 21

Table 2.5: Typical composition of landfill gas........................................................... 24

Table 2.6: Typical concentrations of VOCs compounds in landfills gases ...................... 24

Table 2.7: Methane yield based on the stoichiometric method ...................................... 26

Table 2.8: Gas and Methane yield based on the biodegradability Method ........................ 26

Table 2.9: Laboratory scale studies (based on $40 \%(\mathrm{w} / \mathrm{w})$ initial moisture content) .......... 27

Table 2.10: Methane yield in field scale studies ......................................................... 28

Table 2.11: Methane yield in anaerobic digestion studies............................................ 29

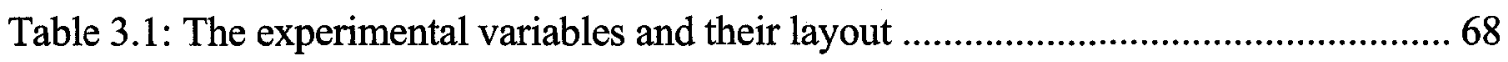

Table 3.2: Density, initial moisture content and mass of wastes in bioreactors.................. 72

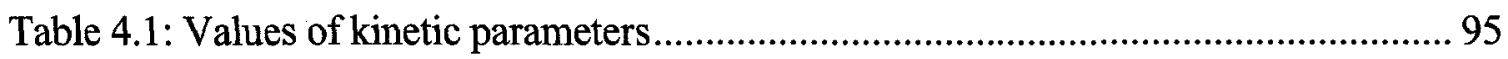

Table 4.2: Range of input parameters used in the sensitivity analysis............................ 98

Table 4.3: Impact of changing the hydrolysis rate constant ........................................ 101

Table 4.4: Impact of changing the maximum growth rate of the acidogenic biomass ... 103

Table 4.5: Impact of changing the decay rate of acidogenic biomass .......................... 105

Table 4.6: Impact of changing the half saturation constant of acidogenic biomass ....... 107

Table 4.7: Impact of changing the maximum growth rate of methanogenic biomass .... 110

Table 4.8: Impact of changing the decay rate of methanogenic biomass ..................... 112

Table 4.9: Impact of changing the half saturation constant of methanogenic biomass ... 114

Table 4.10: Impact of changing the initial condition of aqueous organic acids ............ 116

Table 4.11: Impact of changing the initial condition of VFA................................... 118

Table 4.12: Impact of changing the initial condition of acidogenic biomass ................ 121

Table 4.13: Impact of changing the initial condition of methanogenic biomass ........... 123

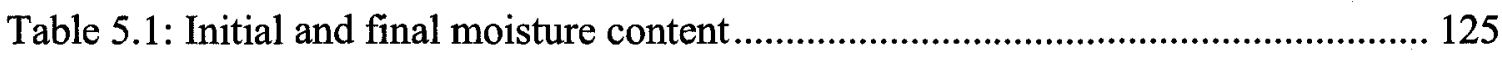

Table 5.2: Profile of final moisture content ............................................................ 126 
Table 5.3: Temperature profile and statistical analysis

Table 5.4: Average settlement that occurred in bioreactors .................................... 132

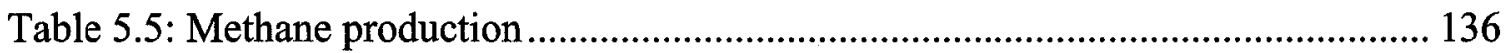

Table 5.6: Statistical analysis for daily methane production and methane yield............ 144

Table 5.7: Methane concentration (expressed as a percentage of the biogas) ................ 147

Table 5.8: Results of methane produced from first set of BMP assays ........................ 151

Table 5.9: Statistical analysis of methane production from the first set of BMP assays 154

Table 5.10: Results of methane produced from the second set of BMP assays.............. 155

Table 5.11: Statistical analysis of methane production from the second set of BMP assays 158

Table 5.12: Results of methane produced from the third set of BMP assays ................. 159

Table 5.13: Statistical analysis of methane production from the third set of BMP assays 163

Table 5.14: Results of COD concentration and percentage peak reduction in two stages

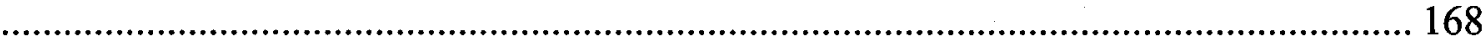

Table 5.15: Statistical analysis for the mean and percentage peak reduction in COD concentration

Table 5.16: Results of BOD concentration and percentage peak reduction in two stages

Table 5.17: Statistical analysis for the mean and percentage peak reduction in BOD concentration 176

Table 5.18: Results of VFA concentration and percentage peak reduction in two stages 179

Table 5.19: Statistical analysis for the mean and percentage peak reduction in VFA concentration

Table 5.20: Results of $\mathrm{pH}$ values in leachate samples from all bioreactors

Table 5.21: Results of TVS concentration and percentage peak reduction in two stages

Table 5.22: Statistical analysis for the mean and percentage peak reduction in TVS concentration

Table 5.23: Results of TS concentration and percentage peak reduction in two stages 189

Table 5.24: Statistical analysis for the mean and percentage peak reduction in TS concentration

Table 5.25: Results of $\mathrm{NH}_{3}-\mathrm{N}$ concentration and percentage peak reduction in two stages

Table 5.26: Statistical analysis for the mean and percentage peak reduction of $\mathrm{NH}_{3}-\mathrm{N}$ concentration

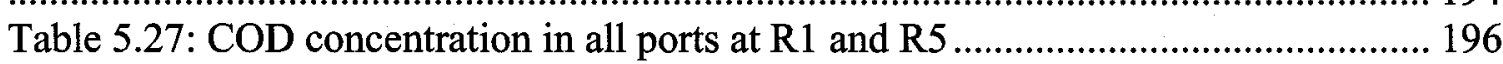

Table 5.28: First set of shortcircuiting analysis .................................................. 198

Table 5.29: Second set of shortcircuiting analysis................................................. 199 
Table 5.30: Results of methane produced from BMP to estimate $\mathrm{k}_{\mathrm{h}}$ using $20 \%(\mathrm{v} / \mathrm{v})$ of

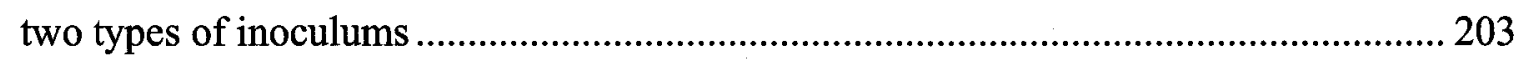

Table 5.31: Results of methane produced from BMP to estimate $\mathrm{k}_{\mathrm{h}} \mathrm{using} 30 \%(\mathrm{v} / \mathrm{v})$

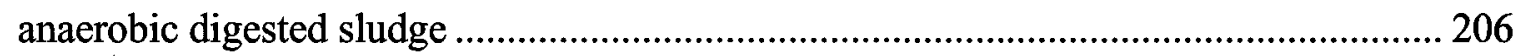

Table 5.32: Initial biodegradable carbon content in waste components...................... 209

Table 5.33: Range of kinetic parameters used in model calibration............................... 211

Table 5.34: Parameters used in the model calibration of the first scenario ................... 217

Table 5.35: Parameters used in the model calibration of the second scenario .............. 223

Table 5.36: Parameters used in the model calibration of the third scenario ................... 230 


\section{List of Figures}

Figure 1.1: Overview on proposed Solid Waste Management facilities and sites in Abu

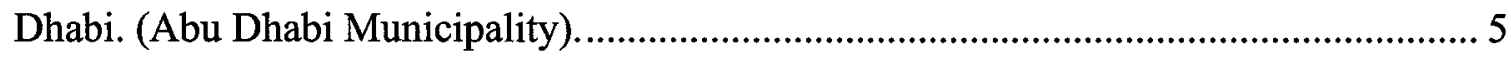

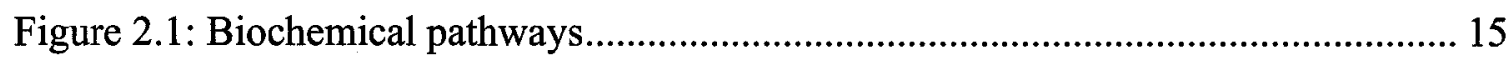

Figure 2.2: Biological decomposition phases in the landfill bioreactor ......................... 18

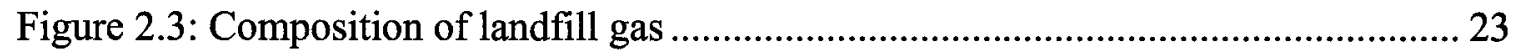

Figure 3.1: The overall design experiment variables.................................................69

Figure 3.2: Flow diagram of 1D bioreactor landfill.................................................... 71

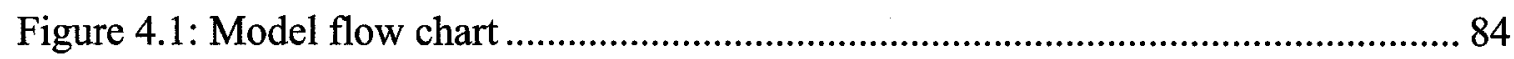

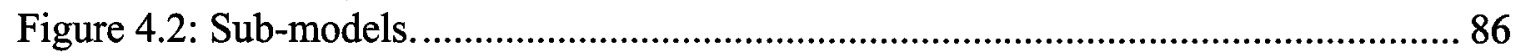

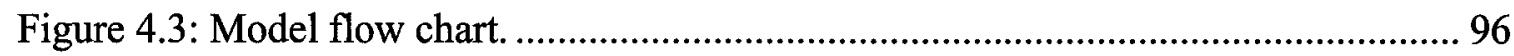

Figure 4.4: Impact of time steps on simulated solid carbon concentration and total biogas

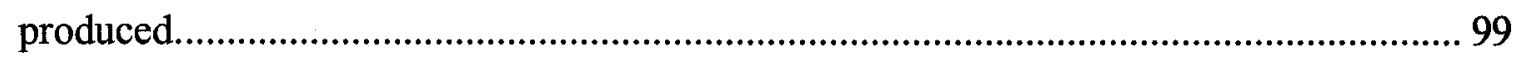

Figure 4.5: Impact of time steps on simulated total mass balance.............................. 100

Figure 4.6: Impact of changing the hydrolysis rate constant. .................................... 102

Figure 4.7: Impact of changing the maximum growth rate of the acidogenic biomass.. 104

Figure 4.8: Impact of changing the decay rate of acidogenic biomass.......................... 106

Figure 4.9: Impact of changing the half saturation constant of acidogenic biomass...... 108

Figure 4.10: Impact of changing the maximum growth rate of methanogenic biomass. 111

Figure 4.11: Impact of changing the decay rate of methanogenic biomass.................... 113

Figure 4.12: Impact of changing half saturation constant of methanogenic biomass..... 115

Figure 4.13: Impact of changing the initial condition of aqueous acid. ....................... 117

Figure 4.14: Impact of changing the initial condition of VFA. .................................. 119

Figure 4.15: Impact of changing the initial condition of acidogenic biomass.............. 120

Figure 4.16: Impact of changing the initial condition of methanogenic biomass........... 122

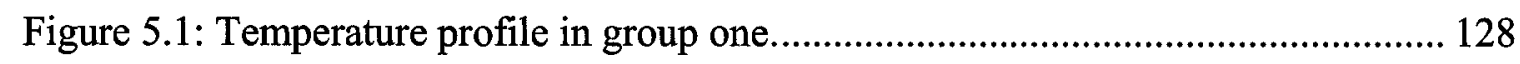

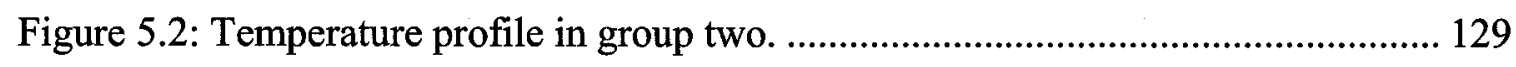

Figure 5.3: Percentage settlement that occurred in the aerobic and anaerobic stages, and total settlement. 
Figure 5.4: Daily methane production in group one................................................ 137

Figure 5.5: Daily methane production in group two..................................................... 138

Figure 5.6: Average daily methane production, methane yield and accumulative methane

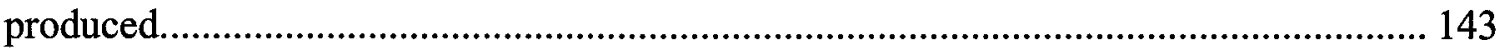

Figure 5.7: Methane composition in group one ....................................................... 145

Figure 5.8: Methane composition in group two........................................................ 146

Figure 5.9: Daily methane production and methane concentration in the first set of BMP

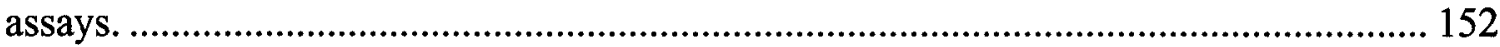

Figure 5.10: Accumulative methane production in the first set of BMP assays............. 153

Figure 5.11: Daily methane production and methane concentration in the second set of

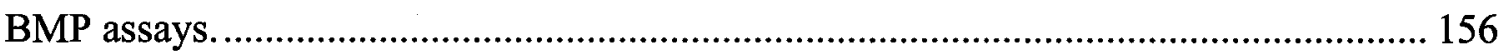

Figure 5.12: Accumulative methane production in second set of BMP assays.............. 157

Figure 5.13: Daily methane production and methane concentration in the third set of

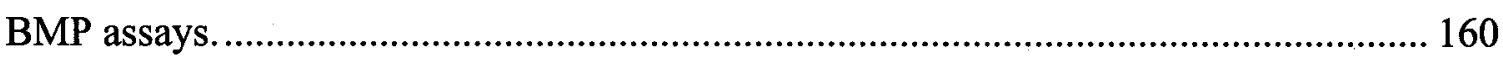

Figure 5.14: Accumulative methane production in third set of BMP assays................... 161

Figure 5.15: COD variation in all bioreactors and percentage COD peak reduction in two stages.

Figure 5.16: BOD variation in all bioreactors and percentage BOD peak reduction in two stages. 174

Figure 5.17: VFA variation in all bioreactors and percentage VFA peak reduction in two stages.

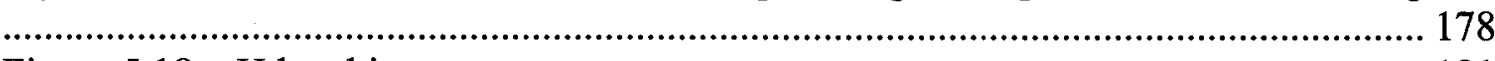

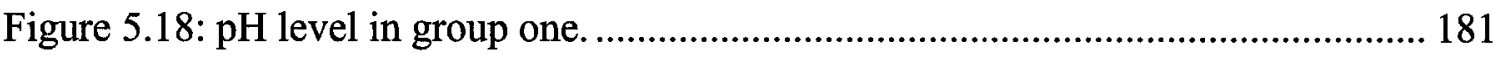

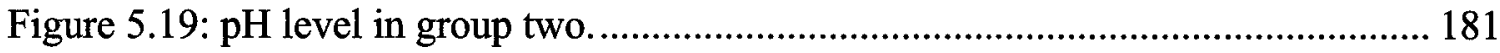

Figure 5.20: TVS variation in all bioreactors and percentage TVS peak reduction in two stages.

Figure 5.21: TS variations in all bioreactors and percentage TS peak reduction in two stages.. 188

Figure 5.22: $\mathrm{NH}_{3}-\mathrm{N}$ variation in all bioreactors and percentage $\mathrm{NH}_{3}-\mathrm{N}$ peak reduction in two

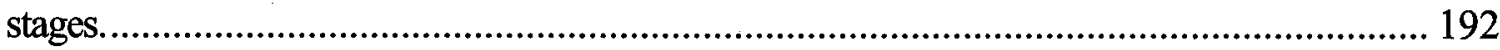

Figure 5.23: Salinity concentrations in group one........................................................ 195

Figure 5.24: Salinity concentrations in group two........................................................ 195

Figure 5.25: Accumulative methane production and methane concentration in first set of $\mathrm{k}_{\mathrm{h}} \ldots 202$ Figure 5.26: Accumulative methane production and methane concentration for the second set and hydrolysis rate constant at $23^{\circ} \mathrm{C}$.................................................................. 205

Figure 5.27: Model calibration first scenario.................................................................... 213

xvii 


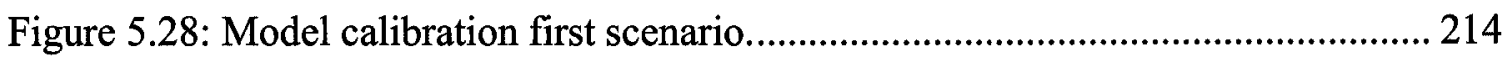

Figure 5.29: Model calibration first scenario ......................................................... 215

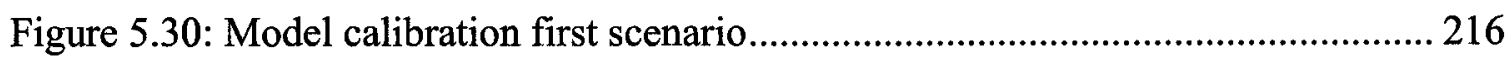

Figure 5.31: Model calibration second scenario ………………………....................... 219

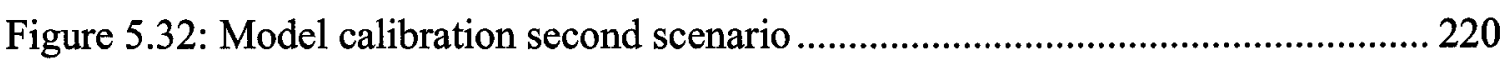

Figure 5.33: Model calibration second scenario …………………………………….... 221

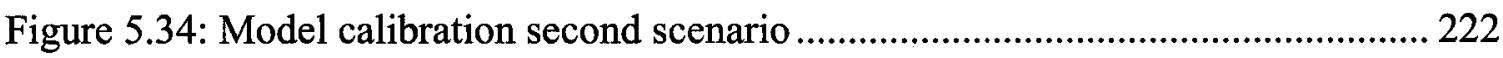

Figure 5.35: Model calibration third scenario................................................................. 226

Figure 5.36: Model calibration third scenario............................................................. 227

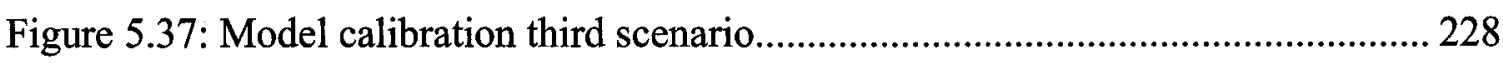

Figure 5.38: Model calibration third scenario................................................................. 229 


\section{Nomenclature}

COD: Chemical oxygen demand

BOD: Biochemical oxygen demand

VFA: Volatile fatty acids

BMP: Biochemical methane potential

$\mathrm{C}^{\mathrm{g}}$ : generation rate of aqueous organic acids carbon concentration $\left(\mathrm{M} / \mathrm{L}^{3}\right)$

$\mathrm{C}^{\mathrm{d}}$ : depletion rate of aqueous organic acids carbon concentration $\left(\mathrm{M} / \mathrm{L}^{3}\right)$

$\mathrm{C}_{(S)}:$ solid organic carbon $\left(\mathrm{M} / \mathrm{L}^{3}\right)$

$\mathrm{C}_{(a q)}$ : aqueous organic carbon $\left(\mathrm{M} / \mathrm{L}^{3}\right)$

$C_{(X A)}:$ acidogenic biomass carbon $\left(\mathrm{M} / \mathrm{L}^{3}\right)$

$\mathrm{C}_{(V F A)}$ : VFA carbon concentration $\left(\mathrm{M} / \mathrm{L}^{3}\right)$

$C_{(X M)}$ : methanogenic biomass carbon $\left(\mathrm{M} / \mathrm{L}^{3}\right)$

$\mathrm{C}_{(\mathrm{CH} 4)}$ : methane carbon concentration $\left(\mathrm{M} / \mathrm{L}^{3}\right)$

$\mathrm{C}_{(\mathrm{CO})}$ : carbon dioxide concentration $\left(\mathrm{M} / \mathrm{L}^{3}\right)$

$k_{h}$ : hydrolysis rate constant $\left(\mathrm{T}^{-1}\right)$

$\mu_{A}$ : maximum specific growth rate constant of acidogenic biomass $\left(\mathrm{T}^{-1}\right)$

$K_{S A}$ : half saturation constant of acidogenic biomass $\left(\mathrm{M} / \mathrm{L}^{3}\right)$

$k_{d A}$ : decay rate constant of acidogenic biomass $\left(\mathrm{T}^{-1}\right)$

$Y_{A}$ : mass of acidogenic biomass formed per mass of carbon utilized (M/ M)

$\mu_{M}$ : maximum growth rate constant of methanogenic biomass $\left(\mathrm{T}^{-1}\right)$

$K_{S M}$ : half saturation constant of methanogenic biomass (M/L)

$k_{d M}$ : decay rate constant of methanogenic biomass $\left(\mathrm{T}^{-1}\right)$

$Y_{M}$ : mass of methanogenic biomass formed per mass of VFA utilized (M/M)

xix 
$\mathrm{Y}_{C H 4}$ : methane carbon fractional formation yield coefficient (M/M)

$Y_{H A C}:$ VFA carbon fractional formation yield coefficient $(\mathrm{M} / \mathrm{M})$

I: salt content concentration $\%(\mathrm{w} / \mathrm{v})$

$K_{I}$ : inhibition constant due to salt content (same concentration unit as I)

m: inhibition constant due to salt content (dimensionless)

$C_{b k}$ : biodegradable carbon in the $\mathrm{k}$ component of waste ( $\mathrm{M}$ biodegradable carbon $/ \mathrm{M}$ dry $\mathrm{k}$ component of waste)

$C_{k}$ : carbon content in the $\mathrm{k}$ component of waste (M carbon / $\mathrm{M}$ dry $\mathrm{k}$ component of waste)

$B F_{k}$ : biodegradable fraction of carbon content ( $\mathrm{M}$ biodegradable carbon / $\mathrm{M}$ carbon)

$M_{k}$ : dry mass of k component (M dry k component) 


\section{Chapter 1}

\section{Introduction}

Landfills have been widely used for municipal solid waste (MSW) disposal all over the world. Landfill disposal is the most commonly used waste management method in many countries. The chemical, biological and physical processes that take place in the landfill promote the biodegradation of waste and result in the production of leachate and landfill gas (LFG). Leachate can cause contamination of groundwater and surface water and the landfill gases $\left(\mathrm{CH}_{4} \& \mathrm{CO}_{2}\right)$ are green house gases, which can absorb heat and prevent it from escaping from the atmosphere thereby contributing to causing global climate change.

The conventional landfill (dry tomb) is designed to minimize problems associated with the production of leachate and gas emissions by controlling the water flow using barrier liners and low permeability covers. The low moisture content in the conventional landfill can result in a slow biodegradation rate, which extends landfill life and leads to long term monitoring. The cost of monitoring and long term care of the landfill can be very high. Leachate that is produced must be collected and stored or treated if it is to be discharged from the site. In addition, the landfill gases must be controlled to reduce the problems associated with gaseous emissions and odor problems (Reinhart, 1996).

The process based approach that promotes waste biodegradation and uses the landfill space as a treatment method rather than a storage method is the landfill bioreactor. The basic concept of a bioreactor landfill is to accelerate the biodegradation of the MSW in the landfill by controlling the moisture content and providing the required nutrients for 
the microorganisms to degrade the organic components. One method to control the moisture content in MSW is by recycling leachate. The bioreactor not only enhances the biodegradation but also stabilizes the landfill as quickly as possible (Warith et al., 1999). Acceleration is accomplished through the addition of water in order to bring the moisture content to an approximate range of 35 to 60 percent (weight basis). The bioreactor landfill thereby avoids the concerns related to future liner failure and leachate contamination because the waste decomposes within 5 to 10 years, which is considerably less than the typical service life of these systems. Landfill stabilization means that the environmental performance measurement parameters (i.e. landfill gas composition and generation rate, waste temperature and leachate concentrations) remain at steady levels, and should not increase if there is any failure beyond 5 to 10 years of bioreactor process implementation (Barlaz et al., 1990; Warith, 2003).

Bioreactor landfills and accelerated waste biodegradation systems have several advantages over conventional landfills. Increased methane production can result when biological processes in the landfill are accelerated. Bioreactor landfills can produce elevated amounts of methane in short periods of time, making it a valuable source of energy. Methane gas could then be collected and used to improve the cost-effectiveness of landfill gas recovery and utilization. Leachate recirculation not only reduces the cost of treatment, but also lowers the strength of leachate, which lessens its potential for soil and groundwater contamination, a process referred to as "in situ treatment". Finally, bioreactor landfills have great economic benefits due to the reduction of cost associated with avoiding long term monitoring and maintenance and the reduction in the delay of the final site utilization after closure (Reinhart et a1., 2002). 
Enhancement technologies that can be used to increase the biodegradation rate in landfill bioreactors include leachate recycling, control of moisture content and moisture flow, buffering, sludge addition, nutrient addition, temperature control, shredding and lift design (Komils et al., 1999).

The bioreactor landfill offers great advantages in the biodegradation of MSW, which could be employed in arid and semi-arid regions. However, bioreactor landfills require a certain amount of moisture to initiate the biodegradation process, which is problematic in arid and semi-arid regions where fresh water supplies are scarce. It is therefore the purpose of this study to examine the utilization of saline water, readily available in many arid areas, to control the moisture content in the landfill, thereby facilitating the use of this new bioreactor technology in those regions. To date, experimental studies on the impact of saline water on the biodegradation of MSW in landfills have not been reported. It is the hope that this study will serve as a steppingstone to future research in this field.

Laboratory scale 1D bioreactor experiments were run with recycled leachate, $\mathrm{pH}$ control by addition of buffer to the leachate recycle, and with or without sludge addition. The 1D bioreactor experiments were designed to estimate the effect of using saline water on the biodegradation of MSW and to enhance the performance of bioreactor landfills operating under saline conditions by sludge addition.

BMP assays were designed to estimate the hydrolysis rate constant of MSW at different salt contents. 


\subsection{Problem statement}

The United Arab Emirates (UAE) lies in the eastern corner of the Arabian Peninsula. It is an arid country with a mean annual rainfall of $80-160 \mathrm{~mm}$ and very limited sources of useable groundwater. The climate is characterized by long hot summers $\left(45-50^{\circ} \mathrm{C}\right)$ and short cool winters $\left(14-23^{\circ} \mathrm{C}\right)$ (www.alain-airport.gov.ae).

The rapid urban and industrial developments of the UAE in recent years have caused an increase in MSW generation, thereby creating a demand in landfill construction, as shown in Figure 1.1.

Landfilling is still the primary method of MSW disposal in arid countries. However, bioreactor landfills would offer greater advantages, as discussed earlier.

The bioreactor landfill is a sanitary landfill in which moisture content, temperature, nutrients, and inoculums are managed in a controlled manner to achieve rapid biodegradation of MSW. To optimize the rapid MSW biodegradation, moisture content of the waste must be established and maintained at field capacity which is problematic in countries of the Arabian Peninsula that face shortages of fresh water supplies, as shown in Table 1.1. One solution to this problem is to use brackish water which is available in the area and has a salt content in the range of 500 to $20,000 \mathrm{ppm}$ (www.unu.edu). 


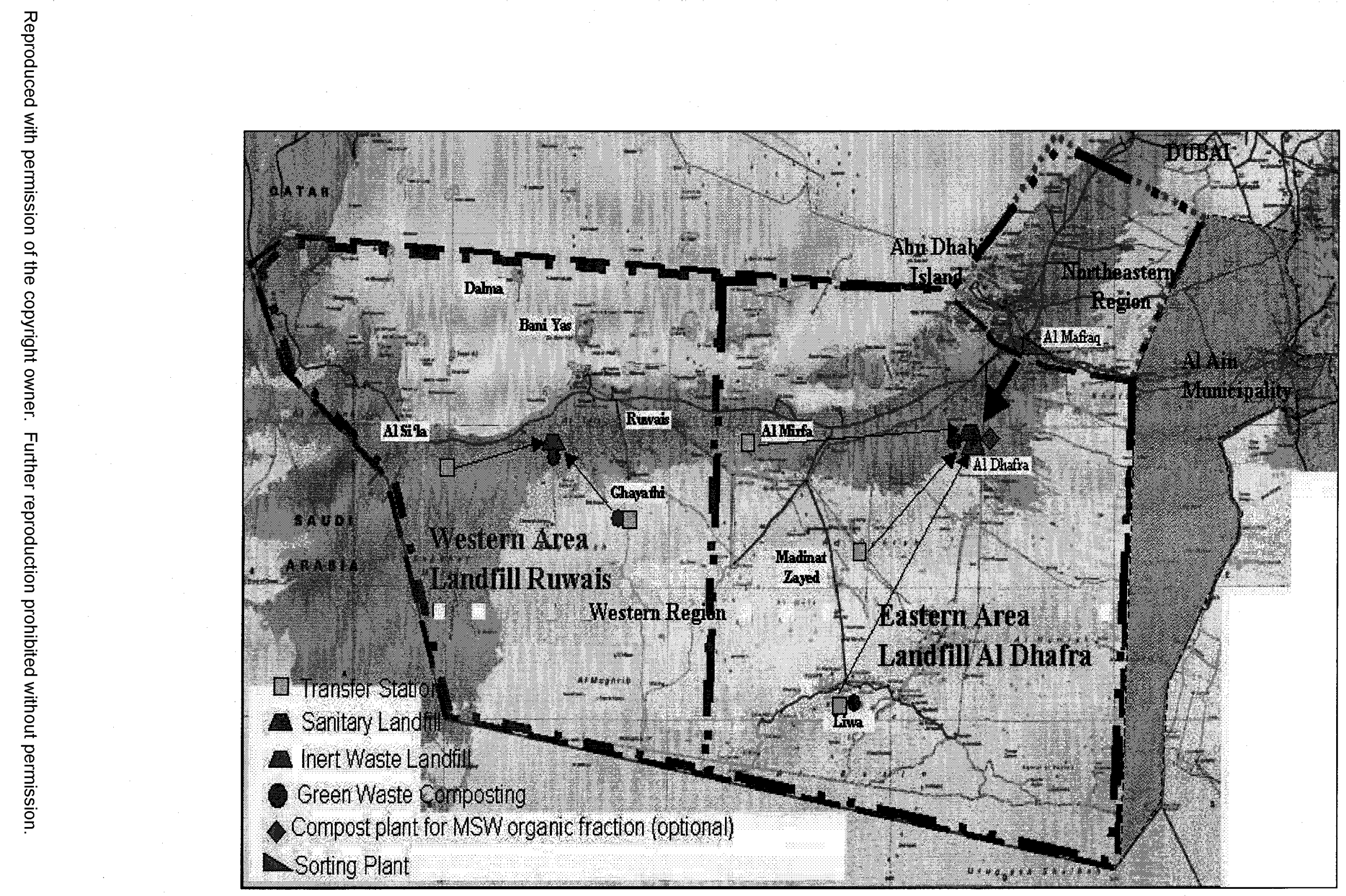

Figure 1.1: Overview on proposed Solid Waste Management facilities and sites in Abu Dhabi. (Abu Dhabi Municipality). 
Table 1.1: Water resources in Arabian Peninsula countries

\begin{tabular}{|c|ccc|}
\hline Country & $\begin{array}{c}\text { Average annual } \\
\text { rainfall }(\mathbf{m m})\end{array}$ & $\begin{array}{c}\text { Groundwater } \\
\text { recharge (mcm) }\end{array}$ (1) $^{(\mathbf{m})}$ & $\begin{array}{c}\text { Groundwater use } \\
\text { (mcm) }^{(1)}\end{array}$ \\
\hline Saudi Arabia & $33-550$ & 3,850 & 14,430 \\
Kuwait & $30-140$ & 160 & 80 \\
Bahrain & $30-140$ & 100 & 166 \\
Qatar & $20-150$ & 50 & 190 \\
UAE & $\mathbf{8 0 - 1 6 0}$ & $\mathbf{1 2 5}$ & $\mathbf{9 0 0}$ \\
Oman & $80-400$ & 550 & 645 \\
\hline
\end{tabular}

(1) Million cubic meter

\subsection{Contribution}

This study aims at contributing to research in bioreactor landfills in the following areas:

1. Examine the effect of salinity on the biodegradation of municipal solid waste under different operational conditions.

2. Enhance the performance of bioreactor landfills operating under saline conditions by sludge addition.

3. Develop a mathematical model to simulate the long term performance of bioreactor landfills operating under saline conditions and to estimate the parameters needed for the model. 


\subsection{Thesis organization}

The thesis contains six chapters.

Chapter 1: Offers a general introduction to this research, the problem statement and the objectives.

Chapter 2: Presents a literature review on the following topics: characteristics and biodegradation of MSW in landfills, treatment of saline wastewater, previous models (leachate and gas), hydrolysis process and methods used to estimate the hydrolysis rate constant.

Chapter 3: Provides the methodology used to address the objectives of this study, as well as the experimental setup and analytical method used to measure the parameters.

Chapter 4: Presents the model development, assumptions and derivation, as well as the model sensitivity to hydrolysis rate constant, kinetics of biomass and initial conditions.

Chapter 5: Provides the results obtained from 1D bioreactor and BMP assay experiments. Results from 1D bioreactors include moisture content, temperature, settlement, biogas produced, effluent COD, BOD, VFA, pH, TVS, TS, salinity, vertical concentration profile in the bioreactors, and an evaluate of potential shortcircuiting. Results from BMP assays are presented in terms of methane concentration and daily production. This chapter also include the results of the determination of the hydrolysis rate constant and model calibration. In addition, statistical analysis for these results are provided.

Chapter 6: Presents a summary, conclusions and suggestions for future studies that could be used to improve and build upon this research. 


\section{Chapter 2}

\section{Literature review}

The purpose of this chapter is to offer a background on landfill systems in order to illustrate the processes taking place during the biodegradation of MSW. The first section covers the characteristics of MSW. Section two deals with the biodegradation of MSW in landfills. The third and fourth sections present studies conducted on saline wastewater treatment and a review of previous models, respectively. The last section of this chapter covers the hydrolysis process and methods used to estimate the hydrolysis rate constant.

\subsection{MSW characteristics}

\subsubsection{MSW composition}

The term MSW is commonly used to describe the waste originating in residential, commercial, institutional and, in some cases, industrial sources (Franklin, 2002). Primary MSW consists of organics, paper, plastics, textiles, metals and glass. There are many factors affecting the composition of MSW such as consumer habits, lifestyle and income; MSW management; the weather and seasons. As a result, the composition of MSW can vary from one area to another and from country to country, as shown in Table 2.1.

\subsubsection{Properties of MSW}

It is important to know the physical, chemical, and biological properties of MSW, since these properties are useful in the design and alternative operations of landfills (e.g. expected quality of leachate produced and the theoretical yield of gas generated per $\mathrm{kg}$ of waste). 
Table 2.1: Waste composition in different countries

\begin{tabular}{|l|cccccc|}
\hline Country & Organic & Paper & Plastic & Glass & Metal & Other \\
\hline Canada $^{1}$ & 34 & 28 & 11 & 7 & 8 & 13 \\
Mexico $^{1}$ & 52 & 14 & 4 & 6 & 3 & 20 \\
USA $^{1}$ & 23 & 38 & 9 & 7 & 8 & 16 \\
Japan $^{1}$ & 26 & 46 & 9 & 7 & 8 & 12 \\
Australia $^{1}$ & 50 & 22 & 7 & 9 & 5 & 8 \\
Denmarkk $^{1}$ & 37 & 30 & 7 & 6 & 3 & 17 \\
Finland $^{1}$ & 32 & 26 & 0 & 6 & 3 & 35 \\
France $^{1}$ & 25 & 30 & 10 & 12 & 6 & 17 \\
Greece $^{1}$ & 49 & 20 & 9 & 5 & 5 & 13 \\
Luxembourg $^{1}$ & 44 & 20 & 8 & 7 & 3 & 17 \\
Netherlands $^{1}$ & 43 & 27 & 9 & 4 & 5 & 8 \\
Norway $^{1}$ & 18 & 31 & 6 & 4 & 5 & 36 \\
Portugal $^{1}$ & 35 & 23 & 12 & 5 & 3 & 22 \\
Spain $^{1}$ & 44 & 21 & 11 & 7 & 4 & 13 \\
Switzerland $^{1}$ & 27 & 28 & 15 & 3 & 3 & 24 \\
Turkey $^{1}$ & 64 & 6 & 3 & 2 & 1 & 24 \\
Kuwait $^{2}$ & 58 & 18 & 12 & 4.5 & 5 & 2.5 \\
Average $^{2}$ & $\mathbf{3 8}$ & $\mathbf{2 6}$ & $\mathbf{8}$ & $\mathbf{6}$ & $\mathbf{5}$ & $\mathbf{1 8}$ \\
\hline
\end{tabular}

(1) World Bank

(2) Al-Yaqout et al. (2005)

\subsubsection{Physical properties of MSW}

The most important physical properties of MSW are moisture content, density, field capacity and hydraulic conductivity.

\section{- Moisture content and density}

There are different factors affecting the moisture content of MSW such as the waste composition, humidity and rain, and season of the year (Dixon et al., 2005). The moisture content of waste can be measured by using either the volumetric or weight basis methods. 
Oweis et al. (1990) stated that the initial moisture content in the waste is in the range of $10 \%-20 \%$ by volume. The initial moisture varies from $15 \%$ to $40 \%$ by weight (Tchobanouglous et al., 1993).

Tchobanouglous et al. (1993) found that the dry density of MSW in the delivered vehicles varied on average from 180 to $415 \mathrm{~kg} / \mathrm{m}^{3}$ and that it would increase to $800 \mathrm{~kg} / \mathrm{m}^{3}$ after compaction was performed in the landfill site.

\section{- Field capacity}

The field capacity of MSW is the upper limit of moisture that can be held in the waste before gravity drainage (Oweis et al., 1990). Generally speaking, there will be no leachate generation until the field capacity of the waste is exceeded. The field capacity is a function of the waste density, porosity, and the stage of waste decomposition (Tchobanouglous et al., 1993).

Oweis et al. (1990) stated that the field capacity of waste is commonly in the range of $20 \%-35 \%$ by volume. Tchobanouglous et al. (1993) reported that the field capacity of uncompacted waste from residential and commercial sources is in the range of $50 \%$ to $60 \%$ by weight, or $30 \%$ by volume.

\section{- Hydraulic conductivity}

Waste hydraulic conductivity is important to landfill designers because it affects the leachate pressure distribution in waste layers (Dixon et al., 2005). The hydraulic conductivity of MSW varies from upper to lower layers within a landfill and it is dependent upon the type of waste, moisture content, effective stress and density of waste 
or compaction. Fang (1983) found, based on laboratory tests, that the hydraulic conductivity for dense waste was $7 \cdot 10^{-4} \mathrm{~cm} / \mathrm{s}$ and $15 \cdot 10^{-3} \mathrm{~cm} / \mathrm{s}$ for loose waste.

Based on core samples collected from the Keele Valley landfill, Bleike et al. (1995) found that as the density of waste increased with the depth of landfill from 500 to 1250 $\mathrm{kg} \mathrm{m} \mathrm{m}^{-3}$, the hydraulic conductivity decreased from $2 \cdot 10^{-3}$ to $2.5 \cdot 10^{-5} \mathrm{~cm} / \mathrm{s}$. Also, they reported that as the effective stress increased from 0 to $1150 \mathrm{kPa}$, the hydraulic conductivity decreased from $2 \cdot 10^{-3}$ to $2 \cdot 10^{-5} \mathrm{~cm} / \mathrm{s}$. This agreed with results presented by Oweis et al. (1986) and Powrie et al. (1999). Oweis et al. (1986) found that by increasing the unit weight from 600 to $1200 \mathrm{~kg} \mathrm{~m}^{-3}$, the hydraulic conductivity decreased from $10^{-2.8}$ to $10^{-5} \mathrm{~cm} / \mathrm{s}$. Powrie et al. (1999), on the other hand, found that the hydraulic conductivity of fresh waste decreased by three orders of magnitude to approximately $10^{-5} \mathrm{~cm} / \mathrm{s}$ after placement and burial to a depth of $60 \mathrm{~m}$ due to compression.

Based on a leachate pumping test for MSW landfill, Oweis et al. (1998) found that the hydraulic conductivity is approximately $10^{-3} \mathrm{~cm} / \mathrm{s}$. Also, they concluded that in the absence of site-specific data, the reasonable value for hydraulic conductivity is $10^{-3} \mathrm{~cm} / \mathrm{s}$ for good compaction.

\subsubsection{Chemical properties of MSW}

Knowing the chemical composition of the MSW constituents is an important factor in selecting the optimum treatment process (e.g. landfilling, or combustion) and estimating the theoretical amount of biogas to be produced in the landfill.

Several methods are used to characterize the chemical composition of MSW. These are proximate analysis (for organic and inorganic, as well as easy, moderate and hard 
biodegradable matter); chemical compounds (for lipids, carbohydrates, lignin and protein); and ultimate analysis (for carbon, hydrogen, oxygen, nitrogen and sulphur) (Tchobanouglous et al., 1993). Table 2.2 shows the chemical composition of MSW in terms of organic, inorganic and ultimate analysis methods. Table 2.3 shows the biodegradable fraction of selected components based on lignin content (Tchobanouglous et al., 1993).

Table 2.2: Chemical composition of MSW

\begin{tabular}{|l|cccccc|}
\hline \multirow{2}{*}{ Components } & \multicolumn{7}{|c|}{ \% dry weight basis } \\
\cline { 2 - 7 } & Carbon & Hydrogen & Oxygen & Nitrogen & Sulphur & Ash \\
\hline Food waste & 48 & 6.4 & 37.6 & 2.6 & 0.4 & 5 \\
Yard waste & 47.8 & 6 & 38 & 3.4 & 0.3 & 4.5 \\
Paper waste & 43.5 & 6 & 44 & 0.3 & 0.2 & 6 \\
Textile waste & 55 & 6.6 & 31.2 & 4.6 & 0.15 & 2.5 \\
Wood waste & 49.5 & 6 & 42.7 & 0.2 & 0.1 & 1.5 \\
Plastics waste & 60 & 7.2 & 22.8 & - & - & 10 \\
Metals waste & 4.5 & 0.6 & 4.3 & 0.1 & - & 90.5 \\
Glass waste & 0.5 & 0.1 & 0.4 & 0.1 & - & 98.9 \\
Ash/dirt/fines & 26 & 3 & 2 & 0.5 & 0.5 & 68 \\
Leather waste & 60 & 8 & 11.6 & 10 & 0.4 & 10 \\
Rubber waste & 78 & 10 & - & 2 & - & 10 \\
\hline
\end{tabular}

Table 2.3: Biodegradable fraction of selected components based on lignin content

\begin{tabular}{|l|cccc|}
\hline Components & $\begin{array}{c}\text { Moisture } \\
\text { content \% } \\
\text { (w/w) }\end{array}$ & $\begin{array}{c}\text { VS, percent } \\
\text { of TS }\end{array}$ & $\begin{array}{c}\text { Lignin } \\
\text { content, } \\
\text { percent of TS }\end{array}$ & $\begin{array}{c}\text { Biodegradable } \\
\text { fraction (BF) }\end{array}$ \\
\hline Food & $50-80$ & $95-98$ & 0.4 & 0.82 \\
Paper & & $96-99$ & 21.9 & 0.22 \\
Newsprint & $4-10$ & $90-95$ & 0.4 & 0.82 \\
Office paper & $4-8$ & - & - & 0 \\
Plastics & $1-4$ & & 4.1 & 0.72 \\
Textile & $6-15$ & & & \\
\hline
\end{tabular}




\subsubsection{Biological properties of MSW}

The organic content of MSW can be converted into biogas and intermediate products as a result of a series of biological reactions taking place in the landfill. The following section covers the mechanisms and bacteria groups involved in the biodegradation of MSW.

\subsection{Biodegradation of MSW in landfill}

This section covers the following topics: stages and phases involved in the biodegradation process, production of leachate and biogas, factors controlling the biodegradation process, enhancement methods and case studies. The biodegradation of solid waste has been studied by Barlaz et al. (1989); Pohland et al. (1999); Christensen et al. (1989); Warith (2003); Reinhart (1996) and Tchobanouglous et al. $(1977,1993)$.

\subsubsection{Stages of MSW biodegradation}

The biodegradation of MSW in the landfill occurs over two stages (aerobic and anaerobic), each stage containing its own bacteria groups and products.

\subsubsection{Aerobic stage}

The aerobic stage takes place in a short period of time, its duration being determined by the amount of oxygen that is present in the waste. In turn, the amount of oxygen present in the waste is dependent on the permeability of the soil cover and waste compaction. In this stage, the organic waste reacts with oxygen in the presence of aerobic bacteria to produce carbon dioxide, water, biomass and heat (Tchobanouglous et al., 1977). After a short time, the activity of the aerobic bacteria will decline due to depletion in oxygen concentration, causing the landfill to shift to the anaerobic stage. 


\subsubsection{Anaerobic stage}

The anaerobic biodegradation of MSW follows three sequenced biochemical reactions involving three different groups of anaerobic bacteria. In the anaerobic stage, bacteria groups convert waste into biogas $\left(\mathrm{CH}_{4}, \mathrm{CO}_{2}\right)$ as end products, and organic acids as intermediate products, as shown in Figure 2.1.

Three groups of anaerobic bacteria are mainly involved in the biodegradation of solid waste in the landfills. These groups are:

- Fermentative and hydrolytic bacteria.

Ferments are large, heterogeneous bacteria. The role of these bacteria is to solubilize and convert complex wastes to smaller, more soluble compounds. The hydrolysis process is caused by extracellular enzymes which are produced by these bacteria (Christensen et al., 1989).

- Acidogenic bacteria.

These are also large, heterogeneous bacteria. The role of these bacteria is to produce VFA (volatile fatty acids), $\mathrm{H}_{2}$, and $\mathrm{CO}_{2}$. The acidogenic bacteria are relatively tolerant to low $\mathrm{pH}$ and have a much higher rate of growth than the methanogenic bacteria (Barlaz et al., 1989).

- Methanogenic bacteria.

The methanogenic bacteria are sensitive to changes in $\mathrm{pH}$ and require very low redox potential and hydrogen concentration. This group of bacteria is responsible for the production of $\mathrm{CH}_{4}$ and $\mathrm{CO}_{2}$ (Barlaz et al., 1989). 


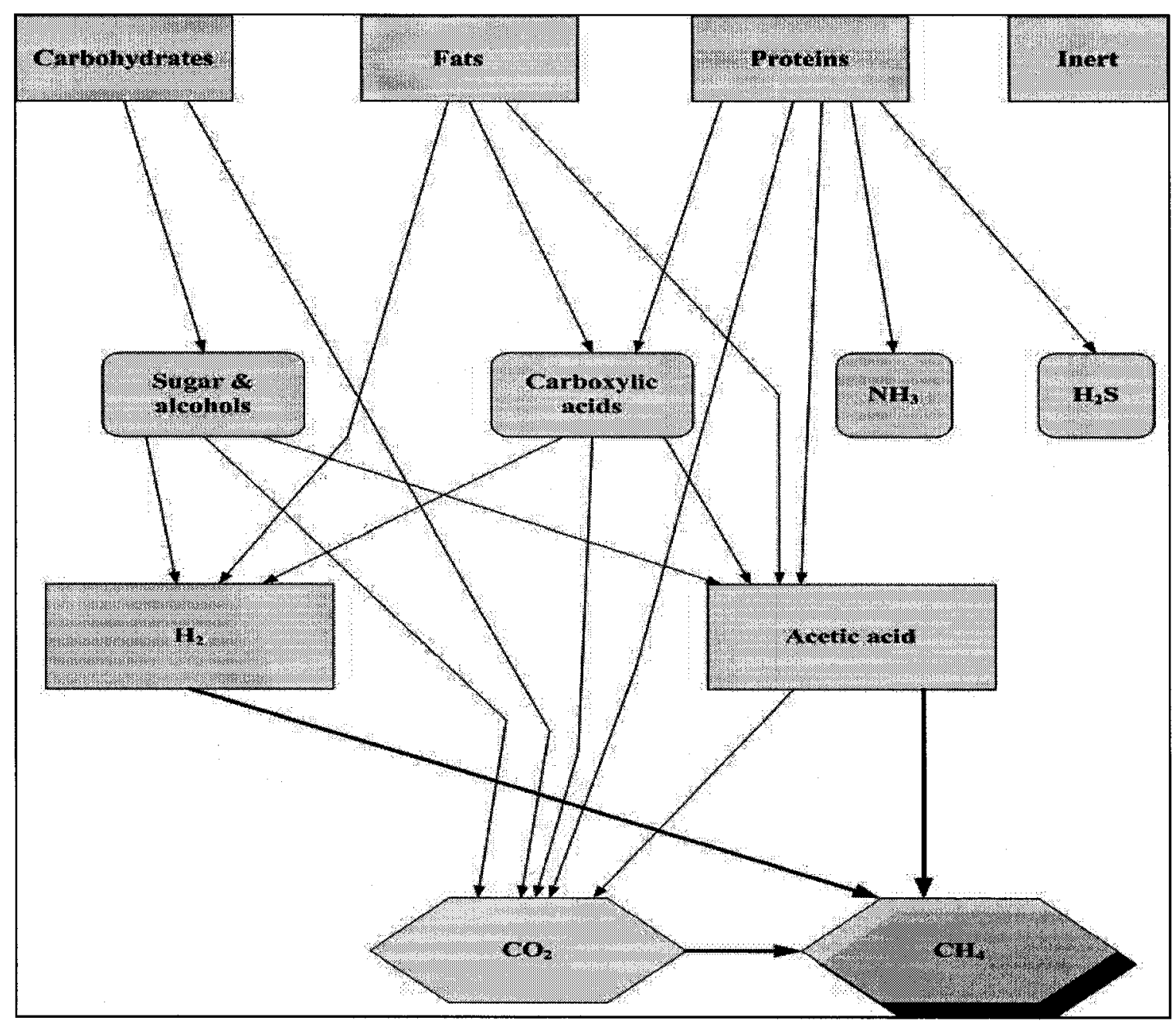

Figure 2.1: Biochemical pathways (adapted from Young, 1989)

There are four steps involved in the biodegradation of $\mathrm{MSW}$ to biogas $\left(\mathrm{CH}_{4}\right.$ and $\left.\mathrm{CO}_{2}\right)$ : hydrolysis, acidogenesis, acetogenesis and methanogenesis.

- Hydrolysis.

The hydrolysis process is a very important step in the biodegradation of solid waste in the landfill. In the hydrolysis step, the complex organic compounds are solubilized and converted into smaller sized organic compounds by extracellular enzymes. This step is important because microorganisms cannot deal with large molecules. Only smaller organic molecules can pass through the membrane cell of bacteria (Grady et al., 1999). 
The carbohydrate, fats and proteins are reduced to lower molecules as described by the following reactions (White et al., 2004):

$$
\left(\mathrm{C}_{6} \mathrm{H}_{10} \mathrm{O}_{5}\right)_{\mathrm{n}}+\mathrm{H}_{2} \mathrm{O} \rightarrow \mathrm{n} \mathrm{C}_{6} \mathrm{H}_{12} \mathrm{O}_{6}
$$

The end results of hydrolysis are solubilization of waste to sugars, alcohols, fatty acids and amino acids, as shown in Figure 2.1

- Acidogenesis.

In this stage, the end products of hydrolysis are oxidized to organic acids. The organic acids are then broken into acetic acid, as shown in the following reactions (White et al., 2004):

$$
\begin{aligned}
& \mathrm{C}_{6} \mathrm{H}_{12} \mathrm{O}_{6} \rightarrow \mathrm{CH}_{3}\left(\mathrm{CH}_{2}\right)_{2} \mathrm{COOH}+2 \mathrm{H}_{2}+2 \mathrm{CO}_{2} \\
& \mathrm{C}_{6} \mathrm{H}_{12} \mathrm{O}_{6}+2 \mathrm{H}_{2} \rightarrow 2 \mathrm{CH}_{3} \mathrm{CH}_{2} \mathrm{COOH}+2 \mathrm{H}_{2} \mathrm{O} \\
& \mathrm{C}_{6} \mathrm{H}_{12} \mathrm{O}_{6}+2 \mathrm{H}_{2} \mathrm{O} \rightarrow 2 \mathrm{CH}_{3} \mathrm{COOH}+4 \mathrm{H}_{2}+\mathrm{CO}_{2}
\end{aligned}
$$

There are two major types of acidogenic bacteria. The first bacterium (Hydrogen producing) gains its energy by converting alcohol and longer chain acids into acetic acid and hydrogen in reaction 2. The second bacterium (Hydrogen consuming) produces acetic acid from catabolized carbohydrate, hydrogen and organic compounds as in reactions 3 and 4 . It will help to maintain a low partial pressure for hydrogen, which is important for the hydrogen producing bacteria and methanogenesis process. An increase in the partial pressure of hydrogen will reduce the rate of acid formation, thus decreasing the proportion of glucose converted to acetic acid and increasing propionic and butyric acids which reduce the $\mathrm{pH}$ and inhibit the methanogenesis process (El-Fadel, 1991). 
- Acetogenesis.

In this stage, conversion of propionic and butyric acids into acetic acid occurs as described in the following reactions (El-Fadel, 1991):

$$
\begin{aligned}
& \mathrm{CH}_{3}\left(\mathrm{CH}_{2}\right)_{2} \mathrm{COOH}+2 \mathrm{H}_{2} \mathrm{O} \rightarrow 2 \mathrm{CH}_{3} \mathrm{COOH}+2 \mathrm{H}_{2} \\
& \mathrm{CH}_{3} \mathrm{CH}_{2} \mathrm{COOH}+2 \mathrm{H}_{2} \mathrm{O} \rightarrow \mathrm{CH}_{3} \mathrm{COOH}+3 \mathrm{H}_{2}+\mathrm{CO}_{2}
\end{aligned}
$$

- Methanogenesis.

Methane is produced either from acetic acid or carbon dioxide reduction with hydrogen, as shown in the following reactions (White et al., 2004):

$$
\begin{aligned}
& \mathrm{CH}_{3} \mathrm{COOH} \rightarrow \mathrm{CH}_{4}+\mathrm{CO}_{2} \\
& 4 \mathrm{H}_{2}+\mathrm{CO}_{2} \rightarrow \mathrm{CH}_{4}+2 \mathrm{H}_{2} \mathrm{O}_{2}
\end{aligned}
$$

\subsubsection{Phases of MSW biodegradation in the landfill}

The phases and microbial processes of MSW biodegradation in the landfill have been reviewed by a number of researchers (e.g. Veeken et al., 2000; Pohland et al., 1996; 1999; Barlaz et al., 1989,1996; Warith et al., 1998, 2003; Christensen et al., 1989; Reinhart, 1996; White et al., 2004; Zacharof et al., 2004).

The biodegradation of MSW can be divided into five distinct phases, depending on the leachate concentration and landfill gas composition. During each phase, different groups of bacteria are dominant, in accordance with the conditions existing within the landfill (Reinhart, 1996). These phases are:

- Phase I (aerobic). This phase is short and starts after the disposal of MSW. In this phase, easily degradable organic compounds are converted into carbon dioxide, see Figure 2.2 (Phase I). 


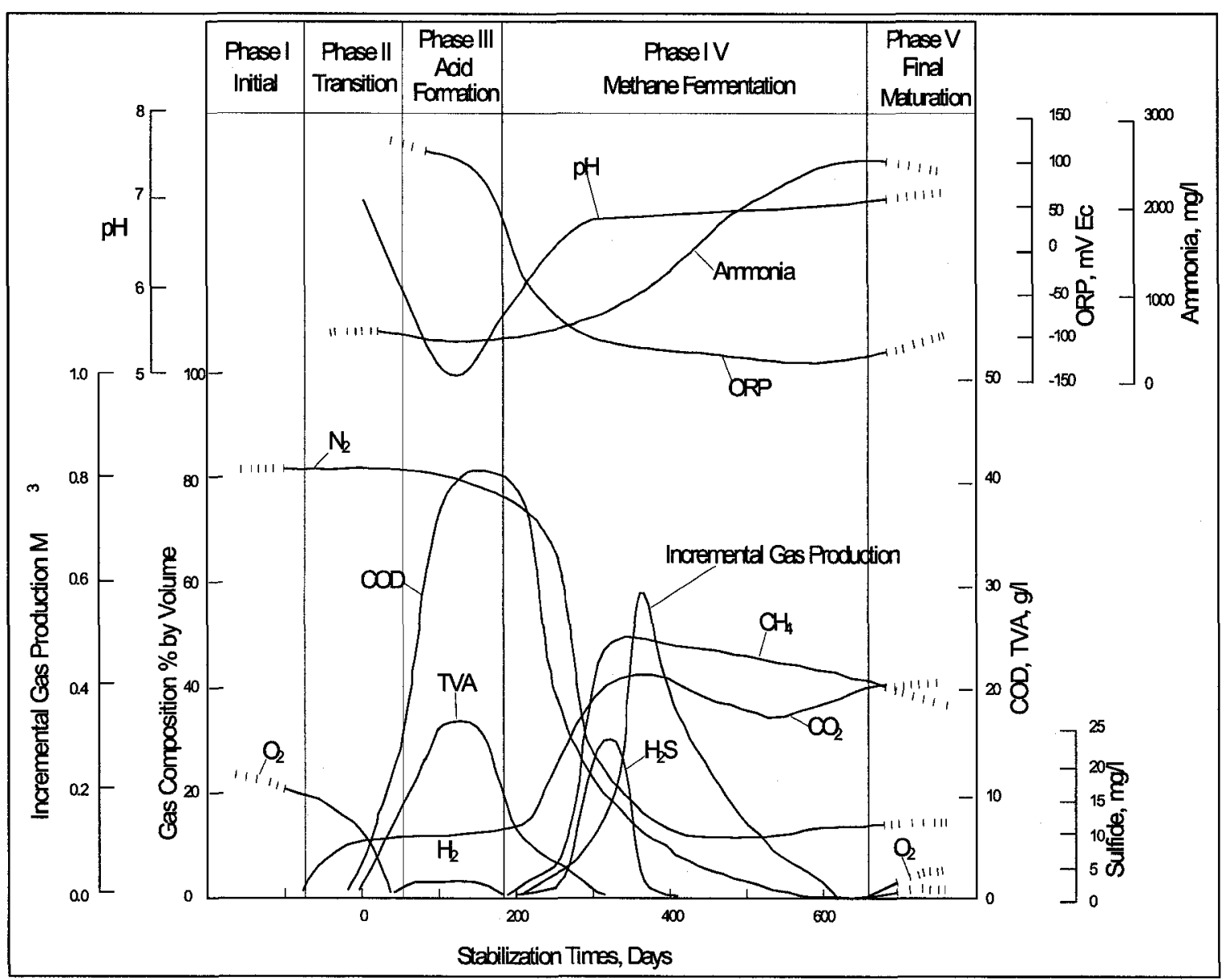

Figure 2.2: Biological decomposition phases in the landfill bioreactor (adapted from Pohland et al., 1996).

- Phase II (transition). It begins with the depletion of $\mathrm{O}_{2}$ in the waste. The landfill shifted into anaerobic conditions. Two processes occur during this phase: hydrolysis and acidogenesis. The results of these processes are that the volatile fatty acids (VFA) and COD concentrations start to increase at the end of this phase, see Figure 2.2 (Phase II).

- Phase III (acid formation). The acidogenic bacteria become dominant in this phase. The result of that is a rapid generation of (VFA), carbon dioxide, hydrogen and low 
$\mathrm{pH}$ of leachate. The VFA concentration reaches its maximum concentration, see Figure 2.2 (Phase III).

- Phase IV (methane formation). Low methane generation begins. As methane generation increases, the concentration of VFA decreases and the $\mathrm{pH}$ rises. The composition of methane reaches a steady state. The dominant bacteria in this phase are methanogenic. The high rate of methane produced maintains the concentration of VFA at a low value and the pH stabilizes above 7, see Figure 2.2 (Phase IV).

- Phase V (maturation). This phase starts when the rate of methane produced is very low as a result of the removal of nutrients and available biodegradation material.

The duration of each phase is dependent on many factors which will be covered in Section 2.2.5.

\subsubsection{Landfill leachate}

Leachate is the soluble product of chemical, physical and biological reactions, as well as the washout of fines and colloids (Anderottola, 1992). As mentioned before, leachate is produced when the field capacity of the MSW is exceeded.

\subsubsection{Landfill leachate generation}

Leachate generation from landfills has been studied by Purushottam et al. (1997); Farquhar (1989); Anderottola (1992); Reinhart et al. (1996); Rees (1980) and; El-Fadel et al. (1997a).

The production rate of leachate from a landfill is controlled by several factors, such as initial water content of waste, volume of rainfall entering the waste, site climate and hydrology, site operation and management, pre-treatment and composition, and depth and 
density of waste (El-Fadel et al., 1997a; Rees, 1980; Farquhar, 1989). The volume of leachate generation from a landfill site can be estimated by the water budget or HELP (Hydrological Evaluation of Landfill Performance) models (Purushottam et al., 1997).

\subsubsection{Landfill leachate composition}

Landfill leachate typically contains water, heavy metals, organic material as the product of decomposition, and inorganic components such as ammonia, sulphate and metal cations (Reinhart et al., 1996).

Leachate composition is dependent on several factors, namely biological, chemical, and physical processes taking place in the landfill (status of decomposition); the age of the landfill; and initial waste composition. Leachate composition varies according to the following five phases, as shown in Figure 2.2.

- Phase I (aerobic). This phase is short and limited by the presence of $\mathrm{O}_{2}$ in the landfill. Figure 2.2 (Phase I) shows how in this phase proteins are degraded into amino acids and converted into $\mathrm{CO}_{2}$, water, nitrate and sulphates. Also, carbohydrates are converted into $\mathrm{CO}_{2}$ and water, whereas fats are converted into fatty acids which are further degraded into simple catabolics. In reality, this phase is short and no large amount of leachate is generated.

- Phase II (Figure 2.2). In the transition phase, the landfill shifted into anaerobic stage due to the depletion of oxygen and the fact that the anaerobic microorganisms became active. At the end of this phase, the $\mathrm{pH}$ drops to less than 6 and the COD and ammonia appears in the leachate.

- Phase III (Figure 2.2). The continuation of the hydrolysis process is followed by an increase in the VFA concentration (end product of acidogenic stage) which cause a 
decrease in the $\mathrm{pH}$ and solubilize the inorganic ions such as $\mathrm{SO}_{4}{ }^{2-}, \mathrm{Ca}^{2+}, \mathrm{Mg}$ and $\mathrm{Na}^{+}$. The highest COD and ammonia concentrations and the lowest $\mathrm{pH}$ values are observed in this phase (Anderottola, 1992).

- Phase IV (Figure 2.2). It starts with a low methane generation rate. The $\mathrm{pH}$ of leachate is increased as a result of the VFA conversion into methane and $\mathrm{CO}_{2}$. Based on this, the concentration of inorganic ions decreases in the leachate. The leachate produced in this phase is described by low values of COD and high $\mathrm{pH}(6.8-8)$.

- Phase V (Figure 2.2). During this phase, there is no biological activity since the nutrients and available substrates are removed. There is no major difference in the leachate concentration from the previous phase.

Table 2.4 summarizes the landfill leachate concentration in different phases of the stabilization process (Reinhart et al., 1996).

Table 2.4: Composition of leachate from landfills

\begin{tabular}{|c|c|c|c|c|}
\hline \multirow{2}{*}{ Parameter } & Phase II & Phase III & Phase IV & Phase V \\
\cline { 2 - 5 } & Transition & Acid formation & $\begin{array}{c}\text { Methane } \\
\text { fermentation }\end{array}$ & Final maturation \\
\hline BOD (mg/l) & $100-1000$ & $1000-57700$ & $600-3400$ & $4-120$ \\
COD (mg/l) & $480-18000$ & $18000-71000$ & $580-9760$ & $31-900$ \\
$\begin{array}{c}\text { VFA (mg/l) as } \\
\text { Acetic Acid }\end{array}$ & $100-3000$ & $3000-18800$ & $250-4000$ & 0 \\
BOD/COD & $0.23-0.87$ & $0.4-0.8$ & $0.17-0.64$ & $0.02-0.13$ \\
$\begin{array}{c}\text { Ammonia } \\
\text { (mg/l N) }\end{array}$ & $120-125$ & $2-1030$ & $6-430$ & $6-430$ \\
pH & 6.7 & $4.7-7.7$ & $6.3-8.8$ & $7.1-8.8$ \\
\hline
\end{tabular}




\subsubsection{Landfill gas}

Landfill gas is a mixture of gases produced during the biodegradation of MSW in the landfill. They are mainly generated in the anaerobic stage. The production of landfill gas from MSW biodegradation has been researched by several authors. This section covers generation, composition and yield of gas produced from this process.

\subsubsection{Landfill gas generation}

The rate and composition of landfill gas vary according to the stabilization stages and composition of the MSW.

Changes in the generation rate and composition of gas can be described by eight-phases (as in the old landfills), as shown in Figure 2.3. In phase I, oxygen is consumed by the composting of organic matter into $\mathrm{CO}_{2}$. The concentration of nitrogen does not change during this phase (Christensen et al., 1996). In phase II, after the oxygen is consumed, the anaerobic decomposition starts with the production of $\mathrm{CO}_{2}$ and $\mathrm{H}_{2}$. The percentage of $\mathrm{N}_{2}$ is reduced compared to $\mathrm{CO}_{2}$ and $\mathrm{H}_{2}$. Phase III begins with the production of methane, while $\mathrm{CO}_{2}$ and $\mathrm{H}_{2}$ decrease. In phase IV, methane is stabilized around $50 \%-60 \%$ whereas the $\mathrm{CO}_{2}$ is oxidized into $\mathrm{CH}_{4}$. At the end of phase $\mathrm{V}$, the lower rate of methane production causes air diffusion into the upper part of the landfill and reduces the $\mathrm{CH}_{4}$ percentage. The $\mathrm{N}_{2}$ appears at the end of this phase. In phase VI, methane produced in the center of the landfill is oxidized to $\mathrm{CO}_{2}$ as it migrates through the upper part of the landfill. The concentration of $\mathrm{N}_{2}$ and $\mathrm{CO}_{2}$ is increased during this phase. Phase VII, methane formation is negligible and $\mathrm{CO}_{2}$ decreases to a low percentage. The percentage of $\mathrm{N}_{2}$ is increased and the $\mathrm{O}_{2}$ starts to appear in the landfill. Phase VIII, the percentage of $\mathrm{CO}_{2}$ is now negligible and the gases are mainly $\mathrm{N}_{2}$ and $\mathrm{O}_{2}$ which diffuse into the landfill. 


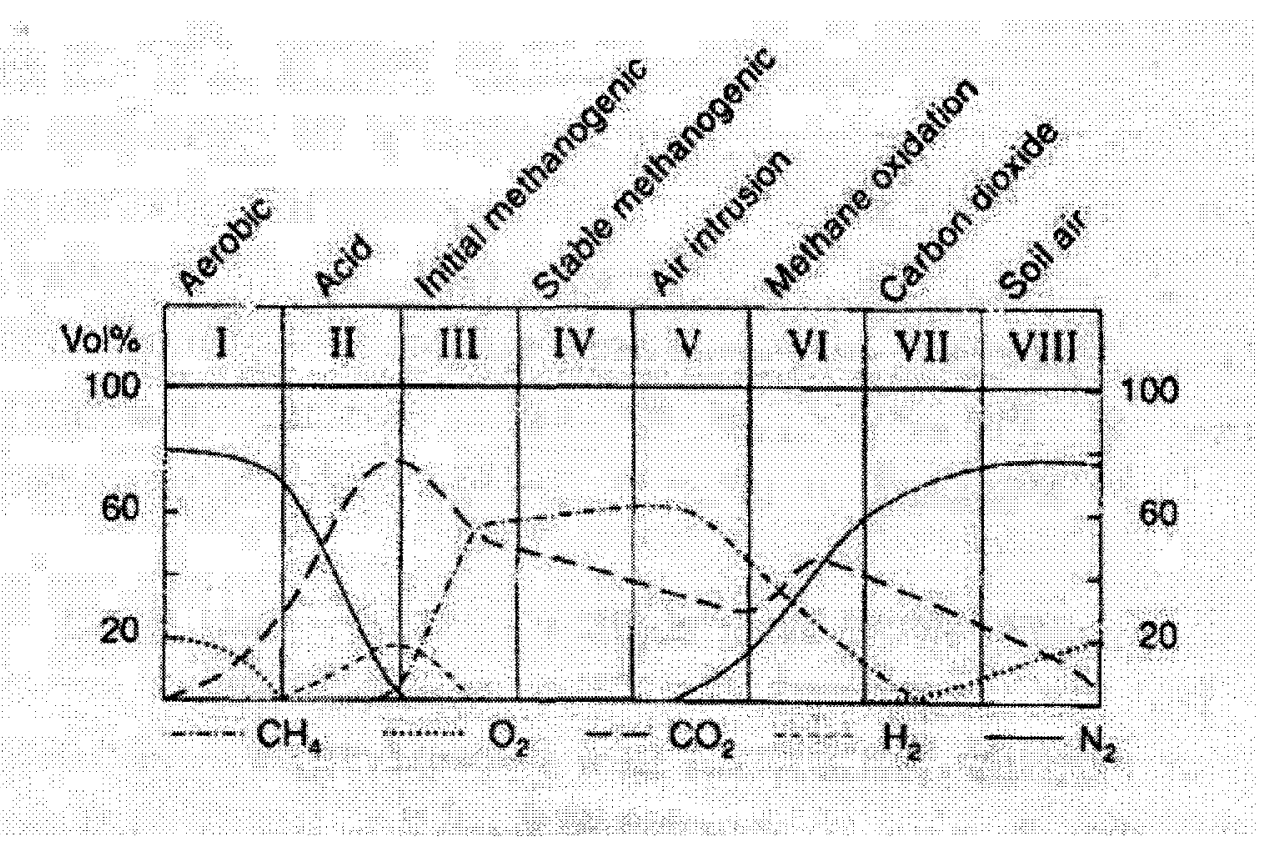

Figure 2.3: Composition of landfill gas (adapted from Christensen et al., 1996).

\subsubsection{Landfill gas composition}

Landfill gases can be classified into three groups: (1) major components which consist of methane and carbon dioxide; (2) minor components which consist of ammonia, hydrogen, hydrogen sulfide, nitrogen, and carbon monoxide; and (3) trace compounds, mainly volatile organic compounds (VOC) (Tchobanouglous et al., 1977; and Dewalle et al., 1978). Table 2.5 shows the composition of major and minor compounds in landfill gases, whereas Table 2.6 shows the concentration of various VOC in landfill gases (Tchobanouglous et al., 1993).

The composition of landfill gas depends on the activity of the bacteria involved, the available substrate and other factors which will be covered in Section 2.2.5. 
Table 2.5: Typical composition of landfill gas

\begin{tabular}{|l|c|}
\hline \multicolumn{1}{|c|}{ Component } & Percent (volume basis) \\
\hline Methane & $45-65$ \\
Carbon dioxide & $40-60$ \\
Nitrogen & $2-5$ \\
Oxygen & $0.1-1$ \\
Hydrogen sulfides & $0-1$ \\
Ammonia & $0.1-1$ \\
Hydrogen & $0-0.2$ \\
Carbon monoxide & $0-0.2$ \\
Trace constituents & $0.01-0.6$ \\
\hline
\end{tabular}

Table 2.6: Typical concentrations of VOCs compounds in landfills gases

\begin{tabular}{|llll|}
\hline & \multicolumn{3}{c|}{ Concentration, ppbV } \\
\cline { 2 - 4 } Compound & Median & Mean & Maximum \\
\hline Acetone & 0 & 6,838 & 240,000 \\
Benzene & 932 & 2,057 & 39,000 \\
Chlorobenzene & 0 & 82 & 1,640 \\
Chloroform & 0 & 245 & 12,000 \\
1,1-Dichloroethane & 0 & 2,801 & 36,000 \\
Dichloromethane & 1,150 & 25,694 & 620,000 \\
1,1-Dichloroethene & 0 & 130 & 4,000 \\
Diethylene chloride & 0 & 2,835 & 20,000 \\
trans-1, 2-Dichloroethane & 0 & 36 & 850 \\
Ethylene dichloride & 0 & 59 & 2,100 \\
Ethyl benzene & 0 & 7,334 & 87,500 \\
Methyl ethyl ketone & 0 & 3,092 & 130,000 \\
1,1, 1-Trichloroethane & 0 & 615 & 14,500 \\
Trichloroethylene & 0 & 2,079 & 32,000 \\
Toluene & 8,125 & 34,907 & 280,000 \\
$1,1,2,2-$-Tetrachloroethane & 0 & 246 & 16,000 \\
Tetrachloroethylene & 260 & 5,244 & 180,000 \\
Vinyl chloride & 1,150 & 3,508 & 32,000 \\
Styrenes & 0 & 1,517 & 87,000 \\
Vinyl acetate & 0 & 5,663 & 240,000 \\
Xylenes & 0 & 2,651 & 38,000 \\
\hline
\end{tabular}




\subsubsection{Landfill gas yield}

Methane yield is defined as the total amount of methane generated per unit weight (dry or wet) of MSW (El-Fadel et al., 1996a). The methane yield is a function of waste composition. Eleazer (1997) found that the methane yield increased as cellulose and hemicelluose content increased. The methane yield was reviewed by El-Fadel et al. (1996a). There are two approaches to estimating this yield: theoretical and experimental.

Theoretical approach. This approach uses the stoichiometric and biodegradability methods to estimate the gas yield. The stoichiometric method is based on several assumptions, such as whether or not complete biodegradation of waste has occurred; the biodegradation product only includes $\mathrm{CH}_{4}$ and $\mathrm{CO}_{2}$; the balance of substrates and nutrients is available at all times in all places in the landfill, and no portion of the degraded matter is utilized into cell growth (Ham 1979). The following equation is commonly used to estimate the theoretical landfill gas yield:

$$
\begin{gathered}
C_{a} H_{b} O_{c} N_{d} S_{e}+\left(a-\frac{b}{4}-\frac{c}{2}+\frac{3 d}{4}+\frac{e}{2}\right) H_{2} O \Rightarrow\left(\frac{a}{2}+\frac{b}{8}-\frac{c}{4}-\frac{3 d}{8}-\frac{e}{4}\right) C_{4}+ \\
\left(\frac{a}{2}-\frac{b}{8}+\frac{c}{4}+\frac{3 d}{8}+\frac{e}{4}\right) \mathrm{CO}_{2}+d \mathrm{NH}_{3}+e \mathrm{H}_{2} \mathrm{~S}
\end{gathered}
$$

Using this method, the estimated yield of the landfill gas is $440 \mathrm{~L} / \mathrm{kg}$ dry waste with a composition of $53 \%$ methane and $46 \% \mathrm{CO}_{2}(\mathrm{Ham}, 1980)$. El-Fadel et al. (1997) reported, based on the stoichiometric method, that the estimated methane yield is in the range of 220-270 L/kg dry waste after complete decomposition. Table 2.7 summarizes the estimated methane yield based on this method. 
Table 2.7: Methane yield based on the stoichiometric method

\begin{tabular}{|lc|}
\hline Sources & Methane (L/kg dry waste) \\
\hline Barlaz et al. 1989 & 373 carbohydrate \\
& 274 protein \\
Ham et al. 1989 & 270 \\
El-Fadel et al. 1996a & $220-270$ \\
Peer et al.1993 & $230-270$ \\
\hline
\end{tabular}

In reality, these assumptions are not valid because there are variations in climate conditions, complete decomposition takes a long time, the substrate/nutrient ratio is not always balanced, organic matter in the landfill is converted into biogas, and bacteria cell growth and flushing with leachate occur.

The biodegradability method estimates the gas yield based on equation [9] and individual waste components. Waste components can be rapidly or slowly biodegradable (Tchobanouglous et al., 1993). Based on this method, the estimated gas yield is in the range of $120-310 \mathrm{~L} / \mathrm{kg}$ dry waste and the estimated methane yield is in the range of $60-$ $230 \mathrm{~L} \mathrm{CH}_{4} / \mathrm{kg}$ dry waste. Table 2.8 summarizes the estimated gas and methane yield based on this method.

Table 2.8: Gas and Methane yield based on the biodegradability Method

\begin{tabular}{|l|cc|}
\hline Source & Gas yield (L/kg dry waste) & Methane (L/kg dry waste) \\
\hline Ham, 1979 & $120-310$ & $60-155$ \\
Barlaz et al., 1990 & $120-350$ & $60-175$ \\
Ham et al., 1989 & $100-300$ & $50-150$ \\
Peer et al., 1993 & - & $60-230$ \\
\hline
\end{tabular}


Experimental approach. In the experimental approach, the landfill gas yield can be obtained from laboratory or field scale studies or anaerobic digestion studies.

Laboratory scale studies. The amount of biogas produced by biodegradation of MSW can be measured in the laboratory. The biodegradation of MSW can be controlled and enhanced by manipulating environmental factors such as $\mathrm{pH}$, temperature, moisture, nutrients, etc. The range of methane yield from lab scale studies varies from no generation to $107 \mathrm{~L} \mathrm{CH}_{4} / \mathrm{kg}$ dry waste. Table 2.9 summarizes the methane yield from different studies.

Table 2.9: Laboratory scale studies (based on $40 \%(\mathrm{w} / \mathrm{w})$ initial moisture content)

\begin{tabular}{|c|c|c|}
\hline Source & $\begin{array}{l}\text { Methane yield } \\
\text { (L /kg dry } \\
\text { waste) }\end{array}$ & Condition \\
\hline $\begin{array}{l}\text { Ham et al., } \\
1989\end{array}$ & $0.01-30$ & Run for approximately $1-3$ years, $53 \% \mathrm{CH}_{4}$ \\
\hline $\begin{array}{l}\text { Barlaz et al., } \\
1989\end{array}$ & $77-107$ & $\begin{array}{l}\text { Shredded wastes, } \mathrm{pH} \text { control and leachate recycle at } \\
41^{\circ} \mathrm{C} \text { and moisture of } 73 \% \text { (wt basis) }\end{array}$ \\
\hline $\begin{array}{l}\text { Leuschner et } \\
\text { al., } 1982\end{array}$ & $\begin{array}{l}R 1=0.07 \\
R 2=0 \\
R 3=35 \\
R 4=47 \\
R 5=63 \\
R 6=22\end{array}$ & $\begin{array}{l}\text { The experiments were run for } 365 \text { days } \\
\text { control without leachate recycle. } \\
\text { with leachate recycle and anaerobic sludge addition } \\
\text { with leachate recycle and buffer addition } \\
\text { with leachate recycle, buffer and nutrients addition } \\
\text { with leachate recycle, buffer and anaerobic sludge } \\
\text { with leachate recycle, buffer, nutrients, and septic } \\
\text { tank sludge. }\end{array}$ \\
\hline $\begin{array}{l}\text { San et al., } \\
2001\end{array}$ & $\begin{array}{l}\mathrm{R} 1=9 \\
\mathrm{R} 2=35\end{array}$ & $\begin{array}{l}\text { The experiments were run for } 275 \text { days } \\
\text { without leachate recycle } \\
\text { with leachate recycle. }\end{array}$ \\
\hline $\begin{array}{l}\text { Sponza et al., } \\
2004\end{array}$ & $\begin{array}{l}\mathrm{R} 1=28 \\
\mathrm{R} 2=69\end{array}$ & $\begin{array}{l}\text { The experiments were run for } 225 \text { days } \\
\text { volume of leachate recycle was } 30 \%(\mathrm{v} / \mathrm{v}) \text { of MSW } \\
\text { volume of leachate recycle was } 10 \%(\mathrm{v} / \mathrm{v}) \text { of MSW }\end{array}$ \\
\hline $\begin{array}{c}\text { Sponza et al., } \\
2005\end{array}$ & $\begin{array}{l}\mathrm{R} 1=23 \\
\mathrm{R} 2=26\end{array}$ & $\begin{array}{l}\text { The experiments were run for } 57 \text { days. All reactors } \\
\text { run with leachate recycle. } \mathrm{R} 1 \text { with raw MSW, R2 }\end{array}$ \\
\hline
\end{tabular}




\begin{tabular}{|c|l|l|}
\hline $\begin{array}{c}\text { Ağdağ et al., } \\
2005\end{array}$ & $\begin{array}{l}\mathrm{R} 3=26 \\
\mathrm{R} 1=33 \\
\mathrm{R} 3=40\end{array}$ & $\begin{array}{l}\text { with compacted MSW and R3 with shredded MSW. } \\
\text { run with leachate recycle. } \mathrm{R} 1 \text { without buffer, } \mathrm{R} 2 \\
\text { with } 3 \mathrm{~g} / \mathrm{l} \text { of buffer and } \mathrm{R} 3 \text { with } 6 \mathrm{~g} / 1 \text { of buffer } \\
\left(\mathrm{NaHCO}_{3}\right) .\end{array}$ \\
\hline $\begin{array}{c}\text { Chiemchaisri } \\
\text { et al., 2002 }\end{array}$ & $\begin{array}{l}\mathrm{R} 1=39 \\
\mathrm{R} 2=51 \\
\mathrm{R} 3=52\end{array}$ & $\begin{array}{l}\text { The experiments were run for } 240 \text { days and all } \\
\text { reactors run with leachate recycle, pH control, and } \\
\text { digested sludge but with different frequency of } \\
\text { leachate recycle. The frequency was 4, 8 and } 15 \\
\text { times per month for R1, R2 and R3, respectively. }\end{array}$ \\
\hline
\end{tabular}

Field scale studies. Pilot cells are representative of real landfill conditions because they are built within a landfill and are subject to similar waste composition, climate and field conditions. The methane yield produced from pilot studies is in the range of $40-140 \mathrm{~L}$ $\mathrm{CH}_{4} / \mathrm{kg}$ dry waste. Table 2.10 summarizes the methane yield from different studies.

Table 2.10: Methane yield in field scale studies

\begin{tabular}{|l|c|l|}
\hline Source & Methane yield (L/kg dry) & Conditions \\
\hline Halvadakis et al., 1988 & 40 (control) & $\begin{array}{l}\text { (Mountain view project) } \\
\text { Enhanced cell with leachate } \\
\text { recycle and pH neutralized. }\end{array}$ \\
\hline Laquidara et al., 1986 & 63 (enhancement) & From site for 20 years. \\
\hline
\end{tabular}

Anaerobic digestion studies. The biodegradation of MSW in anaerobic digestion studies occurs under optimum conditions for methanogenic bacteria. The methane yield based on digestion studies is in the range of $210-260 \mathrm{~L} \mathrm{CH}_{4} / \mathrm{kg}$ of waste (Rees, 1980; Ham, 1979). The reasons for the highest yield in digesters compared to the other experimental studies (lab and field) are seeding with sewage sludge, mixing to provide uniform conditions in terms of substrates and nutrients, and good control of variables such as 
temperature, time and moisture content. Table 2.11 summarizes the methane yield of anaerobic digestion studies.

Table 2.11: Methane yield in anaerobic digestion studies.

\begin{tabular}{|lc|}
\hline Source & Methane yield (L/kg wet) \\
\hline Ham, 1979 & $210-260$ \\
Rees, 1980 & $230-260$ \\
Ham et al., 1989 & $210-260$ \\
\hline
\end{tabular}

Based on these two approaches, it appears that the total amount of methane generated from the biodegradation of MSW is in the range of no generation to $270 \mathrm{~L} / \mathrm{kg}$ dry waste. The following section will address the factors influencing the amount of methane produced through the biodegradation of MSW.

\subsubsection{Factors controlling the biodegradation of MSW in landfills}

The biodegradation of MSW in landfills is dependent on a number of factors, including moisture content, $\mathrm{pH}$, oxygen concentration, hydrogen concentration, waste composition (characteristics), the availability of nutrients and biomass, the presence of inhibitors, and temperature. These factors have been studied by several authors (Rees, 1980; Barlaz et al., 1982; Klink et al., 1982; Baldwin et al., 1998 and Kasali et al., 1989) and reviewed by Barlaz et al. (1989); Christensen et al. (1992); El-Fadel et al. (1996a); Röhrs et al. (1998) and Warith (2003).

\subsubsection{Moisture content and movement}

Moisture is essential for the activity of all microorganisms in the landfill. The moisture content therefore is one of the most critical factors controlling the biodegradation of MSW. 
Many researches have shown that the methane production rate increases by increasing the moisture content of the MSW. Rees (1980) found from existing literature that by increasing the water content from $25 \%$ to $60 \%(\mathrm{wt})$, the rate of gas production and the percentage of methane in the gas are increased. Baldwin (1994) studied the moisture content in three landfills over 1-6 years and found that wastes with high moisture content are more quickly decomposed. The effects of increased moisture content are: limitation of oxygen diffusion from the atmosphere into the landfill; exchange of substrate, nutrients and microorganisms; dilution of inhibitors and improved distribution of enzymes and microorganisms within the landfill (Klink et al., 1982; Christensen et al., 1996). Furthermore, Klink et al. (1982) concluded that moisture movement through the MSW increased the methane production rate from $25 \%$ to $50 \%$, compared to no movement of moisture at the same moisture content levels.

\subsubsection{2 pH}

The $\mathrm{pH}$ of leachate produced from a landfill can have a significant effect on the stabilization of methane production. The fermentative and acidogenic microorganisms have a wider range of $\mathrm{pH}$ compared to methanogenic bacteria. The ideal methanogenic bacteria activity occurs in environmental conditions within a $\mathrm{pH}$ range of 6.8 to 8.0 (Warith, 2003). Any drop in the $\mathrm{pH}$ value below 6.8 will slow down the activity and growth of methanogenic microorganisms. In a well-established methanogenic media, if the methanogenic activity is inhibited by other factors $\left[\mathrm{O}_{2}, \mathrm{H}_{2}\right.$, etc.], the conversion of acetic acid to $\mathrm{CH}_{4}$ and $\mathrm{CO}_{2}$ decreases and leads to an accumulation of the acids, thereby decreasing the $\mathrm{pH}$ which in turn may stop the generation of methane (Christensen et al., 1996). 


\subsubsection{Oxygen concentration}

The activity of anaerobic microorganisms is affected by the presence of oxygen. Thus, the absence of oxygen in the landfill is required in order to grow methanogens and degrade the MSW into $\mathrm{CH}_{4}$ and $\mathrm{CO}_{2}$.

Christensen et al. (1996) reported that the methanogenic bacteria required very low redox potentials (below -330 mv). In reality, the oxygen that diffuses from the atmosphere into the landfill is consumed by aerobic bacteria in the top layers of the landfill (aerobic zone) (Warith, 2003).

\subsubsection{Hydrogen concentration}

The fermentative and acidogenic bacteria produce hydrogen during the biodegradation of MSW, while the methanogenic bacteria use the hydrogen as a substrate to produce methane. Low partial pressure of hydrogen is required for the acidogenic processes (by hydrogen producing bacteria) and methanogenesis processes.

An increase in the partial pressure of hydrogen causes the generation of propionic and butyric acids with no further conversion, resulting in an accumulation of volatile organic acids which reduce the $\mathrm{pH}$ and inhibit the methanogenic bacteria. The conversion of propionic acid requires a hydrogen pressure lower than $9 \cdot 10^{-5}$ atmospheres (Christensen et al., 1989).

\subsubsection{Nutrients and trace metals}

Microorganisms in the landfill require various nutrients for their activity, such as nitrogen and phosphorous, as well as traces of heavy metals like zinc, iron, copper, potassium, calcium, and cobalt. Rees (1980) and Christensen et al. (1996) found from existing 
literature that all the necessary nutrients and traces of heavy metals are available in most landfills, but heterogeneous insufficient mixing of the wastes may result in nutrient limited environments. The optimal ratios needed in order to enhance the biodegradation are 100:0.44:0.08 for organic matter expressed as chemical oxygen demand (COD), nitrogen and phosphorous (McCarty, 1964).

\subsubsection{Inhibitors}

There are a number of elements or compounds that can inhibit the biodegradation of MSW (methane production) besides $\mathrm{O}_{2}, \mathrm{H}_{2}, \mathrm{pH}$ (acidity) and high concentrations of heavy metals. These inhibitors are carbon dioxide, sulphate, and high concentrations of cations such as sodium, magnesium, and ammonium. The $\mathrm{CO}_{2}$ acts as an inhibitor by raising the redox potential which has an effect on the acetic acid conversion to methane (Christensen et al., 1996).

Rees (1980) reported that high sulphate concentrations inhibit the methanogenic bacteria for two reasons: reduction of $\mathrm{SO}_{4}{ }^{2-}$ to $\mathrm{S}^{2-}$, which is toxic; and competition for common substrate between methanogenic and sulphate reducing bacteria.

These cations in low concentrations are required for biodegradation, but in high concentrations they inhibit the methanogenic bacteria.

To the author's knowledge, there has been no studies to evaluate the impact of $\mathrm{Cl}$ on the biodegradation of MSW.

\subsubsection{Temperature}

Similar to other microbial processes, the biodegradation rate of microorganisms involved in the MSW decomposition is highly affected by temperature. Methane production 
increases with an increase in temperature (Dewalle et al., 1978). The optimum temperature for methane production in mesophilic waste decomposition is in the range of $30^{\circ} \mathrm{C}$ to $40^{\circ} \mathrm{C}$, whereas $60^{\circ} \mathrm{C}$ is the optimum temperature for thermophilic waste decomposition (Ham et al., 1994 and Barlaz et al., 1990).

Hartz et al. (1982) recommended that the optimum temperature for methane generation is in the range of $36^{\circ} \mathrm{C}$ to $41^{\circ} \mathrm{C}$. Ham et al. (1992) concluded that gas production rates at $30^{\circ} \mathrm{C}, 35^{\circ} \mathrm{C}$ and $40^{\circ} \mathrm{C}$ are much higher than rates at $20^{\circ} \mathrm{C}$ and $45^{\circ} \mathrm{C}$.

\subsubsection{Enhancement methods}

The biodegradation of MSW in bioreactor landfills can be enhanced through different methods. In all cases, the purpose is to control and manipulate the influencing factors in a positive manner in order to accelerate the biodegradation of MSW. There are many advantages to enhancing the biodegradation of MSW, including more rapid waste stabilization and increased gas production; lower leachate treatment costs through recirculation to the landfill; reduced length and cost of post closure activities; and greater landfill airspace availability due to increased settlement during the operation rather than the post closure stage, as is the case in conventional landfills (Reinhart et al., 2002).

The technologies used to enhance the biodegradation of MSW are studied by Dewalle et al. (1978), Klink et al. (1982), Stegmann (1983), Laquidara et al. (1986), Pacey (1989), Brummeler et al. (1990), Bae et al. (1998), San et al. (2001), Chan et al. (2002), Chiemchaisri et al. (2002), Warith (2003), and reviewed by Barlaz et al. (1990), Christensen et al. (1992), Stegmann et al. (1996), Warith et al. (1998), Komilis et al. (1999a). 
These enhancement methods are leachate recycle, $\mathrm{pH}$ buffering, sludge addition, temperature control, reduced waste particle size, improved lift design, daily cover and waste compaction, and pre-treatment of MSW. They will all be discussed in the following sections.

\subsubsection{Leachate recirculation}

Leachate recirculation is the process by which the leachate collected at the base of the landfill is recycled or reintroduced in the landfill in order to control the moisture content. The advantages and impact of leachate recirculation on the biodegradation of MSW were covered by Ham et al. (1982, 1992), Barlaz et al. (1996), Baldwin et al. (1997), San et al. (2001), Reinhart et al. (1996, 2002), Warith et al. (1998, 2002, 2003), and Sponza et al. (2004). The advantages of leachate recirculation lie both in the rapid reduction of the organic content present in the leachate itself which reduces the cost of treatment; and the potential transformation of waste into energy, as it increases the rate of methane production. Leachate recirculation provides optimum conditions for enhancing biodegradation by increasing the moisture content and movement, and by distributing the nutrients throughout the landfill. Both moisture content and moisture movement are necessary settings for bacteria growth and the establishment of methanogenic conditions. They also provide better contact between insoluble substrates, soluble nutrients and microorganisms (Klink et al., 1982).

Ham et al. (1982 and 1994) and Baldwin (1997) studied the effect of moisture content on the biodegradation of MSW and concluded that moisture content has a positive effect on gas production. Dewalle et al. (1978) found that the highest gas production was at $40 \%$ - 
$50 \%(\mathrm{w} / \mathrm{w})$ moisture content, while the lowest was at $12 \%$. Also, leachate recirculation treats the leachate through the landfill (in situ treatment) because the organic compounds in the leachate are reduced with the recirculation due to the biological activity within the landfill (Sponza et al., 2004).

\subsubsection{2 pH buffering}

The methanogenic bacteria are sensitive to $\mathrm{pH}$ and could be inhibited by acidic conditions. This understanding has led to adding buffer to the leachate prior to recycling it back to the bioreactor landfill. Leachate recirculation with a buffering system to control the $\mathrm{pH}$ causes a shorter acidogenic stage compared to leachate recirculation without a buffering system (Komilis et al., 1999a).

In a study conducted by Warith (2002), the reactor with buffered and nutrients amended recycled leachate resulted in the greatest reduction of COD concentration over time. Also, a study by San et al. (2001) found that the highest degree of stabilization occurred in a reactor with a three-time per week recirculation and $\mathrm{pH}$ control by addition of buffer. Ağdağ et al. (2005) studied the effect of alkalinity addition to leachate recycle on the biodegradation of MSW in an anaerobic bioreactor. It was observed that lower COD, VFA concentrations and $\mathrm{BOD}_{5} / \mathrm{COD}$ ratios were obtained in the bioreactors with alkalinity addition in comparison to the bioreactor (control) without alkalinity addition. Lab scale experiment results recommend the addition of buffer to leachate recycle, especially in the acid generation phase, to maintain the $\mathrm{pH}$ at a neutral level. This helps to establish a methanogenic condition. 


\subsubsection{Sludge addition}

The effect of sludge addition on the MSW biodegradation is covered by Leuschner (1982), Pacey (1989) and Warith (2002). They concluded that the addition of sewage sludge has both a positive and a negative effect on the MSW biodegradation and methane generation.

The positive effects of sludge addition occur after the methanogenic bacteria are already established and the landfill environment is optimum ( $\mathrm{pH}$ neutral) for methanogenic bacteria (Christensen et al., 1992). This positive effect can be attributed to the following factors: 1) sludge can be a source of nutrients and active methanogenic bacteria, and; 2) sludge increases the moisture content.

The negative effect of sludge addition to fresh waste is attributed to the acid accumulation that is associated with it which decreases the $\mathrm{pH}$ and inhibits the methanogenic bacteria (Barlaz et al., 1990).

Rees (1980) and Leuschner (1982) found that the anaerobic digested sewage sludge is an excellent source of microbial inoculum, whereas the septic tank sludge is a poor one. Also, Komilis et al. (1999a) concluded that adding anaerobic digested sludge to MSW produces three times more methane than adding primary sludge.

It appears that the addition of anaerobic digested sludge with buffering enhanced the biodegradation and increased methane generation. Buffering controls the $\mathrm{pH}$ of the landfill around neutral, allowing the methanogenic bacteria in the anaerobic sludge to acclimatize to the landfill environment faster than without buffer addition. 
The addition of old waste or ashes to new waste could improve biodegradation by diluting the acids produced during the acidogenic stage, thereby enhancing the methane formation stage. The percentage of ash should not exceed $10 \%$ in weight (Komilis et al., 1999a).

\subsubsection{Temperature control}

The direct effect of temperature on bacteria activity could be manipulated to optimize the biodegradation of MSW in the bioreactor landfill. Thus, it is necessary to realize the temperature constraints on individual microorganisms in order to control the activity of bacteria and enhance waste stabilization.

Dewalle et al. (1978) found that by increasing the temperature from $17^{\circ} \mathrm{C}$ to $26^{\circ} \mathrm{C}$, gas production rose from $0.88 \mathrm{~mL} / \mathrm{kg}$.day to $1.07 \mathrm{~mL} / \mathrm{kg} \cdot$ day. Baldwin et al. (1998) investigated the effect of temperature on a large scale using two different landfills, one located in Florida and the other in Wisconsin. The Florida landfill $\left(30^{\circ} \mathrm{C}\right)$ had a more rapid decomposition compared to the Wisconsin landfill $\left(22^{\circ} \mathrm{C}\right)$. Kasali et al. (1989) found that by increasing the temperature of MSW with a $60 \%(w / w)$ moisture content from $18.7^{\circ} \mathrm{C}$ to $30^{\circ} \mathrm{C}$ caused a 2.6 fold increase in the methanogenic rate, while a 7.8 fold increase when the temperature rose from $18.7^{\circ} \mathrm{C}$ to $40^{\circ} \mathrm{C}$.

Based on the experimental work, the optimum temperature for enhancing the MSW biodegradation is in the range of $30^{\circ} \mathrm{C}-40^{\circ} \mathrm{C}$. 


\subsubsection{Reduced waste particle size}

Shredding or reducing the particle size of MSW has several advantages, such as providing more landfill space and greater MSW stabilization. The arguments for shredding are: 1) it increases homogeneity and distribution of waste within the landfill, 2) it improves the contact surface area of the waste, 3 ) it promotes better contact between the organic matter and microorganisms (Christensen et al., 1992).

Ham et al. (1982) found that the shredding of waste increases the rate of decomposition and methane production. Some authors (Buirid et al., 1981 and Dewalle et al., 1978) have concluded that refuse with 2.5 to $3.5 \mathrm{~cm}$ particle sizes produced $32 \%$ more methane than refuse with 1 to $1.5 \mathrm{~cm}$ particle sizes in a period of 90 days. This is due to the fact that the smaller particle size increases the rate of hydrolysis and acid formation which in turn decreases the $\mathrm{pH}$ and postpones the production of methane.

Based on Ham et al. (1982)'s study, if the negative effect of smaller particle sizes in the initial stage of biodegradation can be controlled (by adding buffer or pre-composting), shredding may enhance the biodegradation process, since the hydrolysis is the ratelimiting step (El-Fadel et al., 1996b; Pareek et al., 1999; Naranjo et al., 2004; Yildiz et al., 2004).

Sponza et al. (2005) reported that the shredding of MSW has a positive effect on the rate of biological degradation in anaerobic bioreactors with leachate recycle. They compared three types of reactors. The first reactor was loaded with raw waste, the second with shredded waste, and the third with compacted waste. At the end of the experiments (57 days later), they found that the reactor with waste shredding had the lowest COD and VFA concentrations and the highest methane percentage. 


\subsubsection{Lift design, daily cover and compaction of waste}

The enhancement of waste biodegradation in the landfill is also affected by the lift thickness, daily cover and compaction of waste.

The lift thickness has an adverse effect on the biodegradation of waste. Ham et al. (1982) found that the cell with a $2 \mathrm{~m}$ deep lift produced higher leachate concentrations and took a longer time to stabilize than the cell with a $1.2 \mathrm{~m}$ deep lift. By doubling the lift depth from 1.2 to $2.4 \mathrm{~m}$, the concentration of leachate and stabilization time are doubled as well.

Similarly, the daily cover has a negative effect on the biodegradation of waste because it decreases the initial stage of $\mathrm{O}_{2}$ diffusion into the waste which in turn diminishes the initial composting phase. If a low permeability soil is used as a daily cover, it could create barriers between the lift and it may impact leachate distribution and landfill gas flow into the collection system. A soil cover more permeable than the waste can direct leachate to the sides. Use of alternative covers that do not create such barriers can reduce these effects. On the other hand, positive effects of daily cover soil may be expected if the soil adds buffer to the landfill (e.g. contain lime) (Christensen et al., 1992).

Ham et al. (1982) found that the cell without cover produced a high leachate concentration, but it was followed by a rapid decrease. It appears that the lack of daily cover enhances the aerobic activity and prevents a long acidogenic stage. The short acidogenic period leads to the rapid establishment of the methanogenic stage.

Likewise, waste compaction has an adverse effect on the biodegradation of waste in the landfill. Ehring et al. (1980) found that cells with low-density waste have shorter periods 
of high leachate concentration. This means that there is an enhancement in the acidogenic stage. Dewalle et al. (1978) found that gas production decreased when the density of the waste was increased. Rees et al. (1982) concluded that by increasing the waste density from 0.2 to 0.47 tonne $/ \mathrm{m}^{3}$, there was a decrease in gas production due to acid accumulation, which in turn decreased the $\mathrm{pH}$ and inhibited the methanogenic bacteria.

\subsubsection{Pre-treatment}

The objective of the pre-treatment of MSW is to enhance the acidogenic stage and decrease the accumulation of organic acids. This method is based on the stabilization of part of the waste through aerobic processes which will dilute the organic acids and cause a balance between the acidic phase and the methanogenic bacteria. This method was studied by Ham et al. (1982); Stegmann (1983); Beker (1987); and Brummeler et al. (1990) and was reviewed by Komilis et al. (1999b).

Ham et al. (1982), Stegmann (1983) and Baker (1987) found that by placing fresh waste on top of the composted waste layer caused a shorter acidogenic stage and enhanced the methanogenic stage. This is due to the fact that the composted layer acts as an anaerobic filter which has the ability to treat leachate as it passes through. The composted bottom layer can be prepared by the following procedure: a layer $(1.5 \mathrm{~m}-2 \mathrm{~m})$ of waste is placed without compaction, so that the easy degradable material can be decomposed aerobically with leachate recycle. The leachate concentration and the temperature of the waste can be used as indicators for the progress of the aerobic process. After one year of the placement, the waste layer is compacted and an additional layer of fresh waste can be added on top (Stegmann, 1983). The author suggested that efforts should be made to 
reduce the time required for aerobic decomposition of the first layer by injecting air through perforated pipes.

\subsubsection{Case studies}

Leuschner (1982) studied the effects of different enhancement methods. He used six reactors in his study. Reactor 1 was run as a control with simulated rainfall only. All other reactors were run with leachate recycle and addition of water. Reactor 2 was run with anaerobically digested sewage sludge, while reactor 3 was run with buffer addition. Reactor 4 was run with nitrogen and phosphorous addition and reactors 5 and 6 were run similarly to reactor 4 but with addition of anaerobic digested sewage sludge and septic tank sludge, respectively. The additions were practiced over the first 150 days of operation, and from then until the end of the experiments (365 days), only leachate recycle was added.

The total methane produced was $2.46,0,1275,1642,2340$ and $835 \mathrm{~L}$ at standard temperature and pressure (STP) for R1 through R6, respectively. The methane yield was $0.07,0,35,46.86,65$ and $23.19 \mathrm{~L} / \mathrm{kg}$ dry waste, respectively, based on the assumption that the initial moisture content was $40 \% \mathrm{w} / \mathrm{w}$ of total MSW used in the experiments. The reason why no methane was produced in $\mathrm{R} 2$ was that the $\mathrm{pH}$ remained below 6 until day 340. He found that using septic tank sludge as a source of inoculum caused high volatile acids in the leachate and decreased the $\mathrm{pH}$.

Brummeler et al. (1990) studied the effect of air injection as a pre-treatment step on the biodegradation of organic fractions of MSW. The study was conducted using two types of reactors both containing $60 \mathrm{~kg}$ of organic waste. The first one was operated with air 
injection and the second without it. In the first reactor, air was injected for two weeks at a flow rate of $750 \mathrm{~L} / \mathrm{h}$. Then, part of the composted waste was mixed with digested sludge in a $6 \mathrm{~L}$ reactor at a ratio of 0.04 of seed/substrate total solids (TS).

They found that there was no methane detected for the first 100 days in the non-treated (no air injection) reactor. The reason for it was that high organic acids reduced the $\mathrm{pH}$ to 5.5 which inhibited the methanogenic bacteria. In the treated reactor, the methane production rate increased with an increase of volatile solids (VS) degraded during the composting stage. The highest methane production rate was observed at $23.5 \% \mathrm{VS}$ reduction. The initial composting step therefore can be used to accelerate the biodegradation of MSW in the bioreactor landfill.

Bae et al. (1998) studied the effects of leachate recycling and sludge addition on methane production from MSW in a bioreactor landfill. In this experimental study, the first reactor (R1) operated as a control, the second reactor (R2) operated with recycled leachate only and in the third reactor (R3), the leachate generated was first treated by an anaerobic digester, and then the effluent from the digester was recycled back to R3. The cumulative biogas production from R3 was approximately 15,676 liters in 430 days, which is approximately 10-30 times greater than the other reactors. Also, the composition of methane reached $25 \%, 45 \%$, and $60 \%$ on day 180 in $\mathrm{R} 1, \mathrm{R} 2$ and $\mathrm{R} 3$, respectively. The highest $\mathrm{CH}_{4}$ composition in $\mathrm{R} 3$ was due to the addition of active methanogenic bacteria. Similarly, the COD concentration in R3 dropped sharply to below $10,000 \mathrm{mg} / \mathrm{l}$ on day 260 days and decreased to $2000 \mathrm{mg} / \mathrm{l}$ on day 360 days, whereas the COD concentration 
for the other reactors decreased slowly and reached approximately $60,000 \mathrm{mg} / \mathrm{l}$ and $50,000 \mathrm{mg} / \mathrm{l}$ on day 360 days in $\mathrm{R} 1$ and $\mathrm{R} 2$, respectively.

The experiments conducted by San et al. (2001) identify the effect of leachate recirculation frequency on the waste degradation in a bioreactor landfill. They used two reactors in their study. The first one was operated with recirculation of leachate and the second one without it (single pass). The reactor with leachate recycle was operated with a recirculation frequency of 1 to 4 times per week.

The COD concentration of the leachate in the single pass reactor decreased due to dilution and washout mechanism.

The total gas produced at the end of the experiment was $269 \mathrm{~L}$ of gas in the recycle reactor and $70 \mathrm{~L}$ for the single pass reactor.

Chan et al. (2002) studied the effects of leachate recirculation, sewage sludge addition and the addition of marine dredging material on biogas production and MSW biodegradation. The mixture composed of MSW, sewage sludge and marine sediment (75:20:5 fresh weight basis) was placed in a column with a $15 \mathrm{~cm}$ diameter and $150 \mathrm{~cm}$ length at a constant temperature of $38^{\circ} \mathrm{C}$. The experiment was conducted with and without leachate recirculation. The total biogas produced at the end of the experiment was $1139 \mathrm{~L}$ in the bioreactor with leachate recirculation and $395 \mathrm{~L}$ in the bioreactor without recirculation. The $\mathrm{pH}$ of both reactors was in the range of 5.8-6.5 and the COD concentration in the bioreactor with recirculation was lower than the bioreactor without recirculation. 
Chiemchaisri et al. (2002) examined the impact of different frequencies of leachate recirculation on the biodegradation of MSW in a bioreactor landfill. A mixture of MSW and digested sludge at a ratio of 5:1 (on dry weight basis) was placed in three anaerobic bioreactors made of PVC with a diameter of $30 \mathrm{~cm}$ and a height of $100 \mathrm{~cm}$. However, it is the opinion of this authors that the 5:1 ratio (on dry basis) may be in error as anaerobic digested sludge has a high moisture content and to add the digested sludge at 5:1 ratio on a dry basis would result in a large volume of sludge being added. Reactors 1,2 and 3 were operated at recirculation frequencies of 15,8 , and 4 times per month for 245 days, respectively, with $\mathrm{pH}$ control. The lowest $\mathrm{COD}$ concentration was found in reactors 1 and 2. Similarly, the highest biogas production occurred in reactors 1 and 2 with 496 and 493 $\mathrm{L}$, respectively, at the end of the experiment.

Warith (2002) also studied the effect of several enhancement technologies, including moisture increase, nutrient addition and sewage sludge addition on the biodegradation of MSW in a bioreactor landfill. In his experiments, leachate was recycled four times per week for the first 6 months. Three sets of bioreactors were used in this study. The first reactor was used only for control purposes with leachate recirculation. Nutrients and bicarbonate $\left(\mathrm{NaHCO}_{3}\right)$ were added with recycled leachate to the second reactor. Sewage sludge was added with the recycled leachate to the third reactor at $5 \%$ of the total leachate volume. The concentration of BOD and COD started to decline after the third week in all three reactors because of an increase in $\mathrm{pH}$ and the onset of the methanogenic stage. The concentration of BOD and COD in the reactor amended with $\mathrm{pH}$ control and nutrients reached the minimum value faster than in the other reactors. A higher degree of settlement was achieved in the reactor with sludge addition. The settlements (difference 
between the height of MSW layer at the beginning of the experiment and at the end) reached were $50 \%$ in the sludge amended reactor, $40 \%$ in the nutrient amended reactor and $37 \%$ in the control reactor.

In their study, Sponza et al. (2004) compared the effect of leachate recycling at different recirculation rates on the biodegradation of MSW in anaerobic bioreactor landfills. Three Plexiglas reactors were used in this experiment with a diameter of $30 \mathrm{~cm}$ and a height of $100 \mathrm{~cm}$. The first reactor (R1) operated without recycle (single pass), the second reactor (R2) operated with leachate recirculation at a rate of $9 \mathrm{~L} / \mathrm{d}$ and the third reactor $(\mathrm{R} 3)$ operated at $21 \mathrm{~L} / \mathrm{d}$. The increased leachate recirculation in $\mathrm{R} 3$ had less impact on the COD concentration in comparison to $\mathrm{R} 2$. The methane gas production was increased from 10 to $64 \mathrm{~L}$ in $\mathrm{R} 2$ and from 9 to $50 \mathrm{~L}$ in $\mathrm{R} 3$ from day 5 to day 50 . The lower methane production for $\mathrm{R} 3$ in comparison to $\mathrm{R} 2$ may have been due to the increased leachate recirculation which caused washout of active methanogenic bacteria. On the other hand, however, the gas produced from the recycled reactors was one and a half times greater than the gas produced from the single pass reactor. Also, the methane content was higher with leachate recycle. The methane content for the single pass reactor was approximately 10\%-25\% and for R2 and R3 was approximately $40 \%-60 \%$. The results showed that the 9 L/day recirculation rate accelerated the methane production and waste stabilization faster than the $21 \mathrm{~L} /$ day recirculation rate.

One can generally conclude from all these studies that:

- An increase in moisture content and leachate recirculation has a positive effect on the waste stabilization process. 
- Smaller size waste particles increase the rate of hydrolysis.

- Too much leachate recycle inhibits the methane production due to the washout of active bacteria.

- Ideal temperature for methane production is in the range of $30^{\circ} \mathrm{C}-40^{\circ} \mathrm{C}$.

- $\mathrm{pH}$ should be maintained above 6.8 to enhance methane production.

- Daily cover causes negative effects: it delays the biodegradation of MSW, and it affects the leachate distribution and biogas collection system. However, it has a positive effect on the biodegradation of MSW, if it contains buffer.

- Deeper waste lifts result in higher COD concentrations in the leachate likely due to an increased acidogenic phase.

- Buffering of leachate and the addition of sludge and nutrients both enhance the biodegradation and methane production.

- Pre-treatment (air injection) enhances the acidogenic stage and decreases the accumulation of organic acids in the beginning of the experiment which creates a suitable environment for the methanogenic biomass to take place sooner. 


\subsection{Saline wastewater treatment}

No studies have been conducted to determine the impact of salinity or chloride on the biodegradation of MSW. However, researchers have evaluated the impact of salinity on wastewater treatment and a summary of these studies are presented below.

The high salt content in wastewater reduces the efficiency of conventional treatment processes through the loss of activity by microorganisms. It was found that only $7 \%-18 \%$ of sewage bacteria can grow in wastewater that contains $2.8 \%$ to $7 \%(\mathrm{w} / \mathrm{v})(28,000 \mathrm{mg} / \mathrm{l}$ to $70,000 \mathrm{mg} / \mathrm{l}$ ) concentration of salt (Woolard et al., 1994). There are three problems associated with using conventional wastewater treatment processes to treat saline wastewater. First, conventional wastewater processes are sensitive to rapid changes in salt concentration, which causes a reduction in the COD removal efficiency, an increase in the suspended solids in the effluent and a loss of active biomass. Usually, a gradual increase in salt concentration will cause fewer problems, compared to a rapid shift in salt concentration. Second, an increase in salt concentration causes a disruption of the metabolic function of microorganisms and reduces the kinetics of biodegradation. The solution to this problem is a lower F/M (food to microorganism) ratio in order to increase the efficiency of the process. The third problem relates to high suspended solids in the effluent, resulting in low sediment efficiency due to a reduction in the population of protozoa and the build up of filamentous organisms (Kargi et al., 1996, 1998; Woolard et al., 1994; Hamoda et al., 1995). An approximate 30\% decrease in BOD removal efficiency is observed when fresh wastewater treated by the activated sludge process was dosed with 3\% (w/v) salt concentration (Kargi et al., 1997). 
The suitable solution to improve the efficiency of using conventional processes in order to treat saline wastewater lies in using salt tolerant halophilic organisms, marine sediment or a combination of halophilic organisms and activated sludge. Activated sludge with salt tolerant halophilic organisms was successfully used to treat saline wastewater in different processes with high COD removal efficiency at salt concentrations from $3 \%-5 \%$ (w/v) (Woolard et al., 1994; Kargi et al., 1996, 1997, 1998, 2002; Santos et al., 2001).

The biological treatment of saline wastewater by marine sediment was studied by several researchers (Aspe et al., 1997; Kargi et al., 1997; Vidal et al., 1997; Panswad et al., 1998; Gharsallah et al., 2002).

\subsubsection{Halophilic organism classification}

The halophilic organisms can be classified as non-halophilic, marine, moderately halophilic and extremely halophilic, based on salt requirements for optimum growth and the halophilic microorganism's adaptability to saline environments. Non-halophilic bacteria grow in a medium containing less than $1 \%(\mathrm{w} / \mathrm{v})$ salt concentration, and marine bacteria grow in $1 \%-3 \%(\mathrm{w} / \mathrm{v})$ salt concentration. Moderate halophilic bacteria grow in a medium of $3 \%-15 \%$ and extreme halophilic bacteria grow in $25 \%(\mathrm{w} / \mathrm{v})$ salt concentration. Most strains of extreme halophilic bacteria grow by anaerobic fermentation and nitrate reduction (Barbara et al, 1984; Woolard et al., 1994; Rosa et al., 2001).

\subsubsection{Case studies}

This section covers lab scale experiments conducted to assess the impact of salt concentration on microbial activity. Several experiments have been undertaken regarding 
the treatment of saline wastewater using halophilic bacteria, marine sediment and activated sludge.

\section{- Halophilic bacteria}

Woolard et al. (1994) examined the removal of phenol from saline wastewater with a sequencing batch reactor (SBR) using halophilic bacteria. The SBR achieved 95\% removal of phenol at $15 \%$ salt concentration and showed very stable removal rates during the seven-month period of the study.

Kargi et al. (1996) outlined the effect of salt concentration on the biological treatment of saline wastewater in batch operations in their various studies. Saline wastewater $(0-5 \%$ w/v) was placed in an aeration tank. The results showed that the increase in salt concentration caused a reduction in the COD removal efficiency. The COD removal efficiency was approximately $85 \%$ for the salt free environment and it decreased to approximately $60 \%$ at $5 \%(\mathrm{w} / \mathrm{v})$ salt concentration.

In another experiment, Kargi et al. (1998) used halophilic organisms to treat saline wastewater using a rotating biodisc contactor. Halophilic organisms and activated sludge were used as inoculums in this study at $(50 / 50)$ volume basis. The results showed that COD removal was $95 \%$ at $1 \%(\mathrm{w} / \mathrm{v})$ salt concentration and that it was reduced to $60 \%$ at $10 \%(w / v)$ salt concentration after 4 hours of operation.

In a later experiment, Kargi et al. (2002) used halophilic bacteria to enhance the biological treatment of saline wastewater. The experiment was run with both the halophilic bacteria free and halophilic bacteria supplemented activated sludge. The 
results exhibited a little difference in COD removal efficiency for both processes at $1 \%$ (w/v) salt concentration with $80 \%$ and $90 \%$ for halophilic bacteria free and halophilic bacteria supplemented activated sludge, respectively. At 9 hours of batch operation and the initial COD concentration at $2300 \mathrm{mg} / 1$, the COD removal was $85 \%$ with halophilic bacteria supplemented activated sludge and $58 \%$ with halophilic bacteria free sludge at $5 \%(w / v)$ salt concentration.

- Marine sediment

Vidal et al. (1997) studied the treatment of saline wastewater by anaerobic filters with marine sediment as anaerobic inoculums without nutrient addition. The results showed that the efficiency of COD removal was $70 \%$ with an organic loading rate of $9.5-14.3$ $\mathrm{g} / \mathrm{l} \cdot \mathrm{d}$ and $3 \%(\mathrm{w} / \mathrm{v})$ salt concentration.

Panswad et al. (1998) compared the impact of saline wastewater on anaerobic/anoxic/ aerobic treatments with and without acclimated seeds. The results showed that the COD removal efficiency decreased from $97 \%$ to $60 \%$ as the salt concentration increased from 0 to $30 \mathrm{~g} / 1$ without seeds, whereas the COD removal dropped from $90 \%$ to $71 \%$ with acclimated seeds as the salt concentration increased from 0.5 to $3 \%(w / v)$ salt concentration .

From these case studies, it can be concluded that:

- Increased salt concentrations caused a decrease in the efficiency of COD removal.

- Using both halophilic bacteria and activated sludge improved COD removal efficiency.

- Use of acclimated seeds in anaerobic/anoxic/aerobic treatments of saline wastewaters seemed to enhance COD removal efficiency. 


\subsection{Existing models}

This section provides a review of some mathematical models that have been developed to study the biodegradation of solid waste in landfills. Mathematical modeling is an important tool to understanding the steps (hydrolysis, acidogenesis and methanogenesis) involved in the biodegradation process and predicting the behavior of contaminants and biogas production. These models are based on analytical or numerical solutions of equations governing the quality of leachate generation and biogas production during solid waste biodegradation. Several mathematical models have been developed to simulate the landfill stabilization in terms of leachate quality and biogas production.

\subsubsection{Landfill leachate models}

This section covers the models that were developed to predict leachate quality and quantity. The objectives, formulations and validation of these models are explained below.

The mathematical model of Straub et al. (1982a) was used to predict the movement and concentration of inorganic compounds of leachate in sanitary landfills. The model was based on the theory of unsaturated flow and contaminant transport in porous media. The equations in the model were solved by explicit finite difference methods and the required kinetic parameters were obtained from the soil literature. The model was applied to simulate data reported from an experimental landfill column by Qasim et al. (1970). The authors concluded that the model exhibited good behavior and showed good agreement with the experimental results. 
Straub et al. (1982b) also developed a mathematical model for the dissolution, transport and decay of organic compounds in unsaturated sanitary landfills. The model was based on a single well-mixed reactor and a cascade reactor concept and on unsaturated contaminant transport in porous media. The dissolution of solid organic waste into liquid was assumed to follow first order kinetics. Monod kinetics models were used for microbial growth and substrate utilization of both aerobic and anaerobic biomass. The gas produced in the anaerobic stage was estimated according to the mass of COD consumed. The kinetics required were obtained from the aerobic treatment of leachate and municipal wastewater treatment and the anaerobic digestion of organic acids. The model was applied to simulate data obtained from experiments done by Pohland (1975). Straub et al. (1982b) found the simulated COD concentration followed the trend of experimental results. They concluded that the aerobic stage is negligible over the stabilization time of a landfill, and that the leachate recirculation accelerated waste stabilization.

The same unsaturated flow model was used by Korfiatis et al. (1984). They developed a mathematical model to predict unsaturated flow through the solid waste in laboratory columns. The model was based on the theory of unsaturated flow through porous media, and the hydraulic parameters required were obtained from small scale experiments. The model was calibrated and verified with estimated data from laboratory columns. They concluded that the moisture transport through solid waste could be described by unsaturated flow in porous media. Leachate quality and solute transport were not modeled. 
Demetracopoulos et al. (1986) expanded the model of Korfiatis et al. (1984) based on Straub et al. (1982b). They developed a mathematical model for the generation and transport of leachate in sanitary landfills. The model was based on the continuous stirred tank reactor (CSTR) in series model and the theory of unsaturated flow in porous media. First order kinetics were applied for the dissolution of solid organic into the leachate, and Monod kinetics were used to simulate the microbial growth and substrate utilization. The parameters required for the model were obtained from the literature. They concluded that the model showed reasonable behavior within the range of values used. The results from the model were not verified with actual data.

Gonullu (1994 a, b) developed an analytical model to predict the organic and inorganic contaminants in leachate from landfills. The models were based on these assumptions: the landfill is a well-mixed reactor; the organic compounds and microorganisms are uniformly distributed; and the initial concentrations of contaminants entering through input flow are ignored. In the model, dissolution, mass transfer, biological decomposition and microbial growth processes are the main factors controlling the leachate concentration. The results of the model showed good agreement with the experimental results of three studies obtained from the literature.

Gau et al. (1998) developed a mathematical model to estimate the leachate quality from MSW landfills combined with incinerated residuals. They considered the effect of adsorption, desorption and biodegradation of easy and difficult organic compounds in the leachate quality. The model was calibrated with anaerobic and semi-anaerobic landfill columns. They concluded that model results were approximately similar to the experimental results. 
Katsiri et al. (1999) presented a mathematical model to predict the concentration of organic matter in leachate produced with and without leachate recirculation. First order kinetics was used for the solubilization rate, whereas the Monod kinetics were applied for the biodegradation and microbial rates. The model was based on a single, fully mixed reactor. The kinetics required were obtained from six laboratory columns. The model was calibrated with data obtained from studies published by other researchers. They concluded that the landfill could be depicted as a single, fully mixed reactor due to the very slow rates of reaction, and that solid waste stabilization was accelerated by leachate recirculation.

Lee et al. (2001) developed a mathematical model to predict the contaminant concentration in leachate from landfills. The model was based on the following factors: saturated flow equations for 1D, solubilization of organic matter (hydrolysis step), and microbial growth for aerobic and anaerobic biodegradation. The model was solved by the finite difference method and was applied to emphasize the effect of leachate recirculation and continuous input of clean water without leachate recirculation on the landfill stabilization. The results of the model were compared with two case studies (leachate recycle and single pass) and close agreement was observed. They found from the sensitivity analysis of the model that the landfill stabilization was sensitive to the kinetics parameters (yield coefficient, maximum utilization rate, and anaerobic microbial endogenous decay and half saturation coefficient).

Chanthikul et al. (2004) proposed a mathematical model to simulate the leachate concentration from sanitary landfills. The model was based on the mass balance of the 
contaminants in the solid and liquid phases with and without leachate recirculation. The model was solved by fourth order Runge - Kutta methods and was calibrated with two experimental results published by Pohland (1975). The results showed the same profile of the experimental results. They concluded that the model could be used to optimize the recirculation ratio, which enhances the biodegradation rate.

\subsubsection{Landfill gas models}

El-Fadel et al. (1996b) developed a mathematical model to simulate the biodegradation of solid waste and biogas generation in a sanitary landfill. The model was based on biokinetic equations describing the microbial processes, time dependent transport and generation of gas and heat. The biodegradation process occurred in three stages: hydrolysis, acidogenesis and methanogenesis. They assumed hydrolysis to be the rate limiting step in the biodegradation process and was represented by first order kinetics. Monod kinetics were used to simulate the growth rate of acidogenic and methanogenic biomass. The effect of $\mathrm{pH}$ inhibition on the methanogenic growth rate was also included. In El-Fadel et al. (1997b) several runs were performed to assess the model sensitivity to the hydrolysis rate constant, the kinetics constant of acidogenic and methanogenic biomass $\left(\mu, \mathrm{k}_{\mathrm{d}}, \mathrm{k}_{\mathrm{s}}\right)$ and initial carbon concentrations (solid, aqueous, acetic acid, acidogenic and methanogenic). They concluded that the hydrolysis rate is the most important parameter in gas generation in landfills. Gas generation showed greater sensitivity to the methanogenic kinetics than to the acidogenic kinetics, and the initial concentrations of acetic acid and methanogenic biomass had a more important impact on gas generation than aqueous and acidogenic biomass. 
In El-Fadel et al. (1996c) the model was used to simulate data from the Mountain View controlled landfill. The results of the model showed good agreement with the field data. They concluded that the model could be used to predict the rate and total production of biogases in landfills.

Al-Yousfi et al. (1998) developed a numerical (PITTLEACH) model to predict the leachate quality and quantity and biogas generation from municipal solid waste, for both single pass and leachate recirculation. The model consisted of four phases. In the first phase, the water budget method was used to estimate the net percolation rate of water flow into the waste layer. In the second phase, leachate generation and transport rates were estimated by using the theory of moisture flow through unsaturated porous media. The third step was to simulate the anaerobic process involved in landfill stabilization, including hydrolysis, acid formation and methane fermentation. In the fourth phase, the effect of acetic acids ( $\mathrm{pH}$ inhibition) on the methanogenic biomass was modeled. The model was calibrated with experiments done by Yari (1986) and Pohland et al. (1992). The model results were close to the experimental results for both scenarios (single pass and leachate recirculation).

Pareek et al. (1999) developed a mathematical model to predict the methane and carbon dioxide production from landfill reactors operated under sulphate reducing and methane producing conditions. The model was based on biochemical processes responsible for the biodegradation of solid waste in landfills. These processes were hydrolysis, acidogenesis, methanogenesis and sulfidogenesis. Hydrolysis was assumed to be the rate limiting step in the process and followed first order reaction, whereas the Monod kinetics were applied 
for the growth of acidogenic and methanogenic bacteria. A multiplicative model was applied to estimate the growth rate of the sulfidogenic bacteria. The values of kinetics required were taken from the literature. The model was calibrated with four experiments run for 700 days. The simulated methane production was in good agreement with the measured values in all reactors, but the carbon dioxide production was not so accurate in the sulphate reducing reactors for the first 100 days. They concluded that the moisture factor and initial concentration of biomass and acetic acid were important factors in controlling the microbial growth rates and methane production.

Suk et al. (2000) proposed a numerical model to predict the change in leachate concentration and gas production by microbial activity in landfills. The model included gas and water flows, interphase mass transfer of solids and water phase solutes, microbial growth and death, and aerobic and anaerobic biodegradation. The model was applied to measure gas composition and leachate qualities of the experiments done by Lee (1997). The results of the model matched the experimental data.

Haarstick et al. (2001) developed a mathematical model to simulate the biodegradation of organic wastes (easily and slowly degraded), biogas generation and heat release. The model was based on physical, chemical, thermodynamic and microbial processes occurring in landfills. The biodegradation of organic waste was assumed to follow three biochemical reactions: hydrolysis, acidogenesis and methanogenesis in which Monod kinetics were used for all of them. The specific growth rate was considered to be effected by inhibition terms included substrate limiting, inhibitory substrate, temperature, and $\mathrm{pH}$. 
The temperature effect is taken into account in the hydrolysis rate constant, and in the acidogenic and methanogenic bacteria kinetics. The effect of $\mathrm{pH}$ on the biodegradation rate is also taken into account by including an inhibition term in the maximum growth rate and expressed as non competitive inhibition.

The kinetics required for the model were obtained from the literature. The model was not calibrated with real data.

IWA task group (2002) developed an anaerobic digestion model (ADM1). The model described the anaerobic biodegradation process in four steps: solubilization, acidogenesis, acetogenesis, and methanogenesis. The solubilization step is divided into disintegration and hydrolysis processes of which the first is a largely non biological process and converts the composite particulate substrate to carbohydrates, protein, and lipids. In the hydrolysis process, the carbohydrates, protein and lipids are converted into amino acids and long chain fatty acids by extracellular enzymes. First order kinetics were used to represent the disintegration and hydrolysis processes; whereas Monod kinetics were used to describe the growth of other groups of biomass. Inhibition of $\mathrm{pH}$ (all groups), hydrogen (acetogenic groups), and free ammonia (methanogenic groups) was linked to Monod kinetics (growth rate). The $\mathrm{pH}$ inhibition was represented using one of two empirical equations; whereas hydrogen and free ammonia were simulated using a noncompetitive equation.

Naranjo et al. (2004) modified the model of Haarstrick et al. (2001) by assuming the hydrolysis followed first order kinetics. The model was calibrated with experiments. They used the model to simulate the effect of temperature and water content on acetate 
and methane production. The model showed results similar to the experiments. They concluded that temperature had an impact on the growth and activity of bacteria and that an increase in water content enhanced methane production.

Zacharo et al. (2004) developed a mathematical model to simulate the hydrological and biochemical processes taking place in solid waste landfills. They used a statistical velocity model to represent the water flow through the waste. The waste biodegradation was assumed to follow three steps: hydrolysis, acidogenesis and methanogenesis; and employed a simplified methodology for the rate of biodegradation to reduce the parameter requirements. The model was used to simulate case studies. Sensitivity analysis showed uncertain results. They found the model was sensitive to depth of waste, infiltration rate, waste heterogeneity and biodegradation rate constants. In the end, they concluded that the model could be used as a tool for modeling landfill processes and that further improvements were required to assess the model's performance.

Yadiz et al. (2004) proposed a mathematical model to simulate the landfill leachate behavior, distribution of moisture through the landfill, and methane production. They assumed that landfills consisted of cells and that each cell consisted of several layers. Also, they considered each layer as a completely mixed reactor having uniformly distributed solid wastes, moisture, gases and microorganisms. The model was based on the governing equations that describe leachate production, solubilization of inorganic and organic matter, degradation of soluble organic matter, the growth of acidogenic and methanogenic microorganisms, and their inhibition by acetic acid, and change in $\mathrm{pH}$ over time. The solubilization of inorganic solid waste was assumed to have followed zero 
order kinetics, whereas the solubilization of organic solid waste was assumed to be a function of the concentration difference in leachate and microbial activity. The growth rate of acidogenic and methanogenic microorganisms were described by the Monod kinetics, and it included an inhibition term for acetic acid. The model was solved by the fourth order Runge-Kutta method and calibrated with real landfill data from the Keele Valley landfill. The values of the kinetics required for the model were determined by using a trial and error procedure with the data obtained from the landfill. These values were then compared with the literature. There was good agreement between the predicted and observed results from the Keele Valley landfill. The authors concluded that the model had the potential to be used during the design of landfills to estimate the quality and quantity of leachate and methane production for different operation conditions.

White et al. (2003, 2004) developed a mathematical model to simulate solid waste biodegradation and gas generation in landfills. The model included biochemical biodegradation of solid waste, and transport of leachate and gas. The biodegradation part was based on the model proposed by Young (1989) and El-Fadel et al. (1996a) and was assumed to occur in three stages: hydrolysis, acidogenesis and methanogenesis. The Monod kinetics were used to simulate the growth rate of biomass in all stages. The moisture content and effect of $\mathrm{pH}$ inhibition on the biomass growth rates were included in the model. The required kinetics for the model were obtained from the literature. The model was used to simulate case studies but was not calibrated with real data. White et al. (2003, 2004) concluded that the model could be used for laboratory and field tests to investigate the geotechnical and hydrogeological properties of biodegrading solid waste. 
From the review of all of these models it is concluded that:

- Each layer could be assumed as a completely mixed reactor containing uniformly distributed solid waste, moisture, gases and bacteria.

- Those model which describe the biodegradation process in three steps are the best tools to represent this study.

- Hydrolysis is the rate limiting step and could be assumed to follow first order kinetics, and

- Inhibition terms such as substrate limiting, inhibitory substrate, $\mathrm{pH}$ and temperature could be included in the Monod kinetics (growth rate of biomass term) to represent the influence of the environment on the biodegradation process. 


\subsection{Hydrolysis}

As mentioned before, the biodegradation of MSW in landfills takes place in two stages, aerobic and anaerobic. There are three steps involved in the anaerobic stage: hydrolysis, acidogenesis and methanogenesis. This section offers a brief description of the hydrolysis process in the biodegradation of MSW and the methods used to estimate its rate constant $\left(\mathrm{k}_{\mathrm{h}}\right)$.

\subsubsection{Biodegradation of MSW}

The bacteria involved in the biodegradation cannot consume the complex substrate directly. The complex organic molecules must be reduced in size to pass through the cell membrane (Metcalf et al., 2003). The hydrolysis reactions play two important roles in the biodegradation process of solid waste. First, these reactions solubilize the waste and then they convert the soluble material into desired biodegradable material. Extracellular enzymes are responsible for the solubilization and size reduction of waste and they are produced by fermentative bacteria (Grady et al., 1999).

\subsubsection{Hydrolysis of organic matter in the MSW}

In terms of chemical composition, solid waste can be divided into three major groups of complex organics: carbohydrates, proteins and lipids.

- Hydrolysis of carbohydrates

Cellulose is used to present the hydrolysis of carbohydrates. The hydrolysis of cellulose is performed by a mixture of cellulolytic enzymes like exo-glucansases, endo-glucansases and cellobiases (Paulostathis et al., 1991). 
- Hydrolysis of proteins

Proteins are hydrolyzed by two groups of enzymes, protease and peptidases, into polypeptides and amino acids. The amino acids produced are fermentative to volatile fatty acids, carbon dioxide, hydrogen, ammonia and reduced sulfur (Paulostathis et al., 1991). Heukelekian (1958) stated that the hydrolysis of proteins under anaerobic conditions is slower than the hydrolysis rate of carbohydrates under the same conditions.

- Hydrolysis of lipids

Lipids are hydrolyzed into long chain fatty acids and glycerol by lipases enzymes. The long chain fatty acids are degraded by B-oxidation, whereas the glycerol is degraded via glyceroldehyde phosphate. The products are further utilized into volatile fatty acids, carbon dioxide and hydrogen gas (Paulostathis et al., 1991).

\subsubsection{Mathematical description of hydrolysis kinetics}

The biodegradation of MSW is a multi-step process. When the process occurs in multistep reactions, the rate of one step is usually very much slower than the other steps. The slowest step is called the rate limiting step or determining step (Hill, 1977). Hydrolysis is the rate limiting step in the anaerobic biodegradation of MSW. In literature, there are two types of models used to describe the hydrolysis process: first order and surface based kinetics.

\subsubsection{First order kinetics}

First order kinetics are used to explain the biodegradation of complex compounds into soluble smaller compounds with the assumption that hydrolysis is the rate limiting step. There are two methods to estimate the first order hydrolysis rate constant. The first 
method is based on the change of solid waste concentration and it is studied by (Borzacconi et al., 1997 and Christo et al., 2000).

$\frac{d C_{(S)}}{d t}=-\left(k_{h} C_{(S)}\right)$

Where,

$C_{(\mathrm{s})}:$ solid organic concentration $\left(\mathrm{M} / \mathrm{L}^{3}\right)$

$k_{h}$ : hydrolysis rate constant $\left(\mathrm{T}^{-1}\right)$

Borzacconi et al. (1997) used two reactors filled with different compositions of waste to determine the rate of hydrolysis. The hydrolysis rate constant was calculated by evaluating the increase of the organic matter concentration (COD) in the soluble phase. This means the rate of soluble organic matter formation was equal to the rate of loss of solid organic matter. The experiment was stopped once methane was produced. They found the hydrolysis rate constant was $0.0016 \mathrm{~d}^{-1}$ for the reactor containing higher food waste content, and $0.0008 \mathrm{~d}^{-1}$ for the lower food waste content reactor.

The second method is based on assumptions of first order kinetics and no intermediate product (VFA) in the biodegradation process. This means the methanogenic biomass prevents the accumulation of VFA during the biodegradation process. So, this method can only be applied to estimate the hydrolysis constant under methanogenic conditions. In this method, the methane produced is used to calculate the hydrolysis rate constant of the substrate. This method was used by Veeken et al. (1999) and Jokela et al. (2005) to estimate the hydrolysis rate constant.

$Y=Y_{u} \cdot\left(1-\exp \left(-k_{h} \cdot t\right)\right)$

Where, 
$Y$ : cumulative methane at time $\mathrm{t}(\mathrm{L})$

$Y_{u}:$ maximum methane produced $(\mathrm{L})$

Veeken et al. (1999) determined the hydrolysis rate constant for six compounds of biowaste (filter paper, grass, orange peelings, straw, bark, leaves and whole wheat bread) using equation (11). They found the hydrolysis rate constant in the range of 0.003 to 0.15 $\mathrm{d}^{-1}$ at $35^{\circ} \mathrm{C}$.

Jokela et al. (2005) estimated the hydrolysis rate constant for different types of grey waste (newspaper, textiles, diaper and cartons) by using biochemical methane potential (BMP) assays and equation (11). The hydrolysis of the grey waste was in the range of 0.021 to $0.107 \mathrm{~d}^{-1}$ at $35^{\circ} \mathrm{C}$.

\subsubsection{Surface based kinetics}

This method estimates the hydrolysis rate constant based on the surface area available for the hydrolysis. In this method, it is assumed that enzyme activity is present in excess to hydrolyse complex substrates and the hydrolysis rate constant depends only on the surface area available for the hydrolytic enzymes (Vavilin, 1996).

Sanders et al. (2001) used the surface based method to determine the hydrolysis rate constant. They assumed the particles of the substrate are spherical and are degraded from the outside. The following formula was used:

$$
\frac{d M}{d t}=-k_{s b k} A
$$

Where $M$ is the mass (M), $t$ is the time (T), $k_{s b k}$ is the surface based hydrolysis constant and $A$ is the available surface for hydrolysis $\left(\mathrm{L}^{2}\right)$. Three substrates containing starch with 
different particle size distributions were used in the experiments and the surface based hydrolysis constant was $0.4 \pm 0.1\left(\mathrm{M} / \mathrm{L}^{2} / \mathrm{T}\right)$. It showed that the surface of particulate substrate was the key factor in the hydrolysis process.

\subsection{Summary of literature review}

- From the bioreactor landfill lab experiments it can be concluded that in order to enhance the biodegradation of MSW, settlement and methane production, pretreatment (air injection) and leachate recycle with $\mathrm{pH}$ control and the addition of anaerobic digested sludge offers the best approach.

- The case studies of saline wastewater treatment showed that the use of halophilic bacteria, marine sediment and activated sludge has a positive impact on the efficiency of conventional processes.

- The majority of model studies assumed that the biodegradation of MSW in landfills followed three stages (hydrolysis, acidogenesis and methanogenesis). The hydrolysis step is assumed to follow first order kinetics and Monod kinetics were used to describe the growth rate of both, the acidogenic and methanogenic biomasses.

- Also, most of the model studies divided the landfill into cells or layers and assumed each layer as a completely mixed reactor.

- The hydrolysis rate constant is often assumed to be the rate limiting step and can be estimated using two different methods, first order kinetics and surface area.

- First order kinetics could be calculated from methane produced in the BMP assays or from the decrease of solid concentration in bioreactors, and

- The surface area method estimated the hydrolysis rate constant based on the surface area available for the hydrolysis. 


\section{Chapter 3}

\section{Materials and Methods}

This chapter covers the experimental work and methods that were used to accomplish the objectives of this study. Two types of experimental work were involved: 1D bioreactors and BMP (biochemical methane potential) assays. The 1D bioreactors consisted of two groups. The first group was designed to study the impact of salinity on the biodegradation of MSW under different operational conditions. The second group was aimed at studying the effect of sludge addition on the performance of bioreactor landfills operating under saline conditions. The BMP assays on the other hand were conducted to estimate the anaerobic hydrolysis rate constant of the biodegradation process at different salt contents. The materials and procedures used in this research are presented and discussed in the following sections.

\subsection{Design of the experiment}

In order to study the impact of saline water and sludge addition on the biodegradation of MSW in an anaerobic bioreactor landfill, two groups of laboratory scale bioreactor cells were used. The first group of 1D bioreactors consisted of four bioreactors. The first bioreactor (R1) functioned as a control, using tap water (without salt), whereas the second (R2), third (R3) and fourth (R4) bioreactors were run at $0.5 \%, 1.0 \%$ and $3.0 \%$ (w/v) salt content, respectively. The second group of 1D bioreactors also consisted of four bioreactors. Bioreactor (R5) was run with sludge and without salt addition. Bioreactor six (R6), seven (R7) and eight (R8) were run with sludge addition and $0.5 \%$, $1.0 \%$ and $3.0 \%(\mathrm{w} / \mathrm{v})$ salt content, respectively. All bioreactors were operated with air 
injection (first two weeks), leachate recycle and the $\mathrm{pH}$ was controlled at a neutral level through addition of buffer $\left(\mathrm{NaHCO}_{3}\right)$ to the leachate recycle. The bioreactors were placed in $23 \pm 2^{\circ} \mathrm{C}$ room temperature. Table 3.1 shows the experimental variables and their layout.

In the first group of $1 \mathrm{D}$ bioreactor experiments, bioreactor R1 acted as a control to examine the impact of salt concentration on bioreactors R2, R3 and R4. In the second group of $1 \mathrm{D}$ bioreactor experiments, bioreactor R5 was used as a control for bioreactors R6, R7 and R8 to examine the effect of salt concentration when sludge is added to enhance the biodegradation of MSW in the presence of salt.

Also, bioreactor R1 was used as a control for bioreactor R5 to examine the impact of sludge addition on the biodegradation of MSW without salt addition. Bioreactors R2, R3 and R4 were used as controls for bioreactors R6, R7 and R8 in order to determine the impact of sludge addition on the biodegradation of MSW in the presence of salt.

Table 3.1: The experimental variables and their layout

\begin{tabular}{|l|c|c|c|c|}
\hline Bioreactors & $\begin{array}{c}\text { Sludge } \\
\text { addition }\end{array}$ & $\begin{array}{c}\text { Salt } \\
\text { concentration } \\
(\mathbf{w} / \mathbf{v})\end{array}$ & $\begin{array}{c}\text { Air injection } \\
\text { during initial } \\
\text { aerobic phase }\end{array}$ & $\begin{array}{c}\text { pH control of } \\
\text { leachate } \\
\text { recycle }\end{array}$ \\
\hline R1 & - & $0 \%$ & Yes & Yes \\
R2 & - & $0.5 \%$ & Yes & Yes \\
R3 & - & $1.0 \%$ & Yes & Yes \\
R4 & - & $3.0 \%$ & Yes & Yes \\
R5 & Yes & $0 \%$ & Yes & Yes \\
R6 & Yes & $0.5 \%$ & Yes & Yes \\
R7 & Yes & $1.0 \%$ & Yes & Yes \\
R8 & Yes & $3.0 \%$ & Yes & Yes \\
\hline
\end{tabular}


The second type of experiment was the BMP assay. The BMP was designed to estimate the anaerobic hydrolysis of biodegradation in the presence of salt (Jokela et al. 2005). The BMP assays consisted of four flasks (BR1, BR2, BR3 and BR4). The first flask (BR1) was run without salt, whereas the second (BR2), third (BR3) and fourth (BR4) were run at $1.0 \%, 2.0 \%$ and $3.0 \%(\mathrm{w} / \mathrm{v})$ salt content, respectively.

\subsubsection{Randomized complete block design}

The experiments were set up to explore the interaction between biodegradation of MSW in the bioreactor landfill with or without sludge addition and salinity levels. The runs were designed as randomized complete block designs as shown in Figure 3.1.

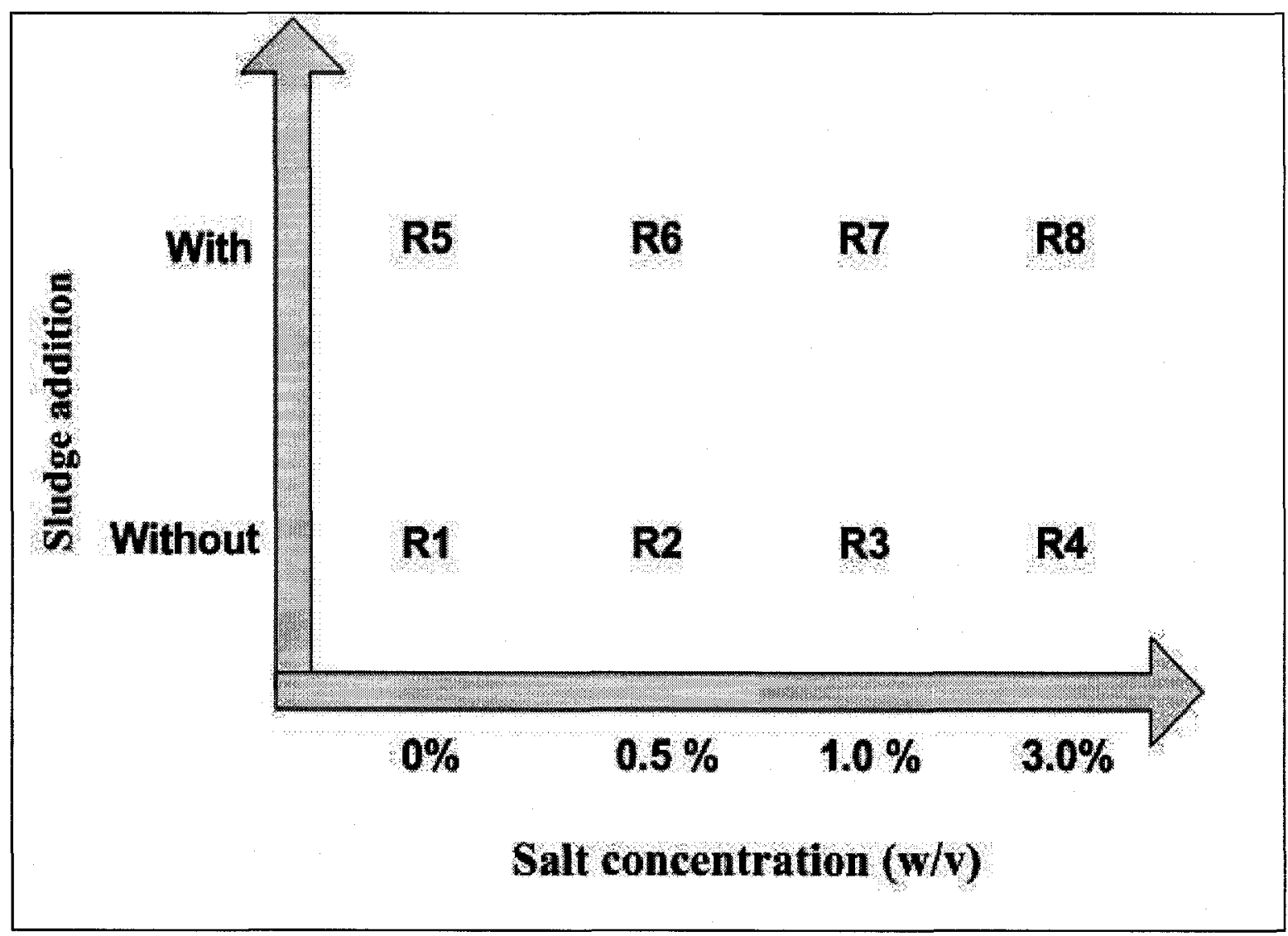

Figure 3.1: The overall design experiment variables. 


\subsection{Composition of MSW and sludge and 1D column construction}

\subsubsection{Composition of MSW and sludge}

The solid waste used in this study was collected from Carleton University (organic and plastics wastes), Lobe company (shredded paper) and Canadian Tire (textile waste). The composition of MSW used in this study was similar to the composition used in studies carried out by Bae et al. (1998), Katsiri et al. (1999), San et al. (2001), Sponza et al. (2004), Ledakowicz et al. (2004), and Al-Yaqout et al. (2005) and to the waste composition in the UAE.

The solid waste composition based on a weight basis was $60 \%$ organic (food), $20 \%$ paper, $15 \%$ plastics and $5 \%$ textile. The wastes were shredded into small pieces to an approximate size of $3 \mathrm{~cm}$ to $5 \mathrm{~cm}$. There were two types of sludge used in this research; both obtained from the sewage treatment plant in Ottawa. Aerobic sludge was used in the aerobic stage (first two weeks) and the anaerobic digested sludge was used in the anaerobic stage.

\subsubsection{D bioreactor construction}

The 1D bioreactors were designed to simulate the effect of salt concentration on the MSW biodegradation with and without sludge addition. Figure 3.2 shows the configuration of the complete lab scale bioreactor. The bioreactors were made from PVC pipes with $8 \mathrm{~mm}$ thickness. Each bioreactor was $30 \mathrm{~cm}$ in diameter and $125 \mathrm{~cm}$ in height.

At the bottom of the bioreactor, a $7-10 \mathrm{~cm}$ thick layer of gravel acted as a drainage layer to collect the leachate at the base of the bioreactor cell. A geotextile covered the gravel layer to prevent migration of fines into the drainage layer. Then the bioreactor was 
packed with $1 \mathrm{~m}$ of MSW and compacted manually in thin lifts. Table 3.2 shows the density and initial moisture content in the bioreactors.

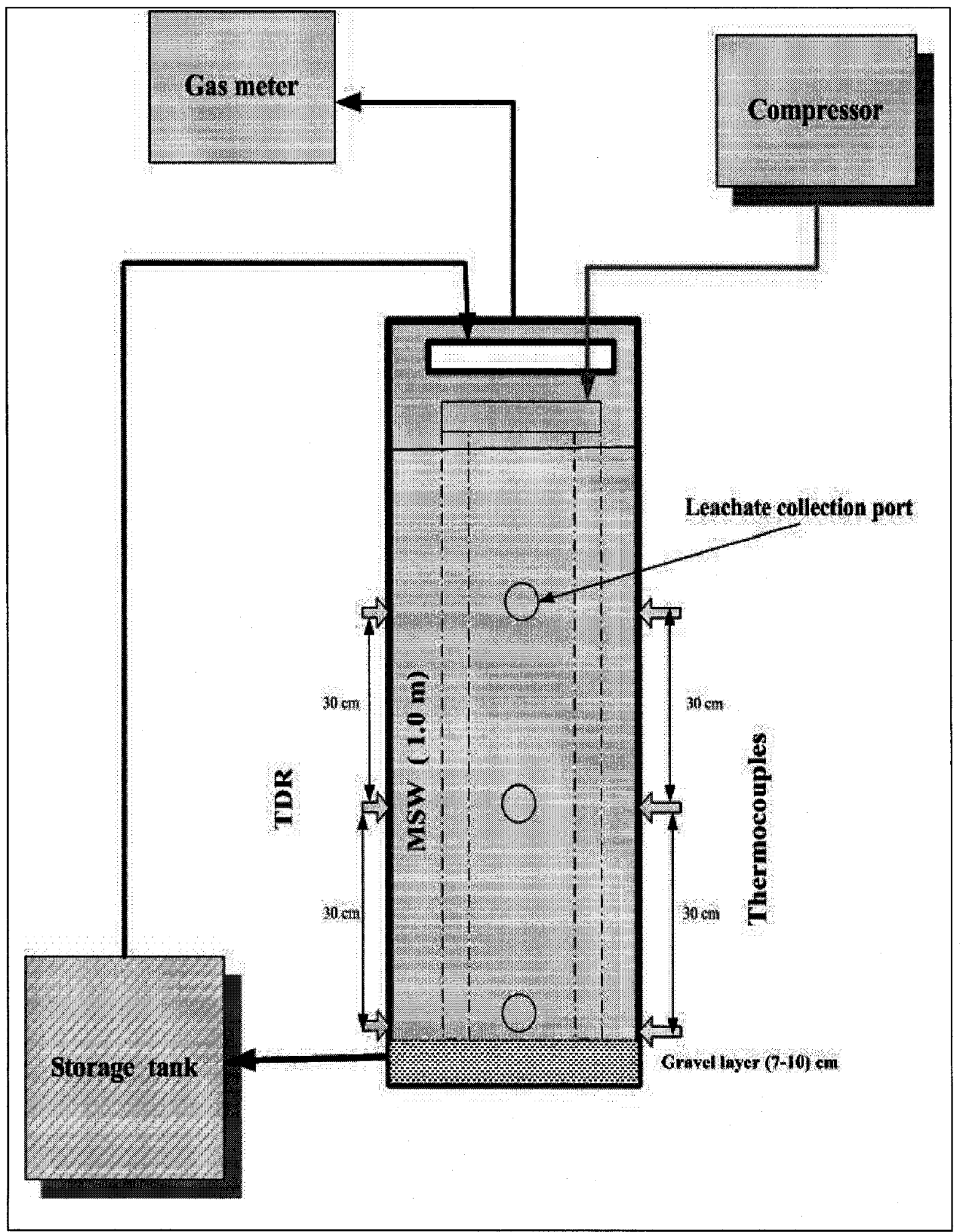

Figure 3.2: Flow diagram of $1 \mathrm{D}$ bioreactor landfill. 
The bioreactors were operated under aerobic conditions through air injection for the first 16 days of the experiments. For uniform air distribution in the bioreactor, two perforated PVC pipes with a diameter of $1.9 \mathrm{~cm}$ were placed in the solid waste and connected to an air compressor. Following the initial 16 days, all bioreactors were sealed with a PVC sheet and operated under anaerobic conditions until the end of the study, approximately 1 year. The PVC sheet was equipped with one vent and two valves. The vent was connected to a gas meter to measure the volume of biogas produced whereas the two valves were used for leachate recycle and air injection.

Table 3.2: Density, initial moisture content and mass of wastes in bioreactors

\begin{tabular}{|c|ccc|}
\hline Parameters & $\begin{array}{c}\text { Density } \\
\mathbf{k g} / \mathbf{m}^{\mathbf{3}}\end{array}$ & $\begin{array}{c}\text { Initial moisture } \\
\text { (Wt. basis) }\end{array}$ & $\begin{array}{c}\text { Mass of waste } \\
\mathbf{~ k g}\end{array}$ \\
\hline R1 & 479 & $39.0 \%$ & 33.5 \\
R2 & 490 & $40.0 \%$ & 34.3 \\
R3 & 516 & $36.1 \%$ & 36.1 \\
R4 & 517 & $44.0 \%$ & 36.2 \\
R5 & 502 & $42.0 \%$ & 35.1 \\
R6 & 493 & $41.8 \%$ & 34.5 \\
R7 & 504 & $43.0 \%$ & 35.3 \\
R8 & 517 & $41.2 \%$ & 36.2 \\
\hline
\end{tabular}

\subsection{Experimental methods and operations}

This section covers the operation methods of $1 \mathrm{D}$ column bioreactors and BMP assays. 


\subsubsection{D column bioreactors}

\subsubsection{Bioreactor filling}

The bioreactors were filled with MSW, and the waste was compacted in thin lifts. The height of each lift was in the range of 0.1 to $0.15 \mathrm{~m}$. The average density of the waste was in the range of 479 to $517 \mathrm{~kg} / \mathrm{m}^{3}$. Table 3.2 shows the initial moisture content and density in the bioreactors.

The volume of the waste in the bioreactors was approximately $0.07 \mathrm{~m}^{3}$ and the mass of the wastes was in the range 33.5 to $36.2 \mathrm{~kg}$.

\subsubsection{Water addition and leachate recirculation}

Once the waste was placed in the bioreactors, water was added into the waste through the leachate recycle valve to increase the moisture content. The bioreactors received a constant quantity of water, $3 \mathrm{~L}$ per day, in order to attain field capacity (typically in the range of $45 \%$ to $60 \%$ by wt.). The total volume of water added to each bioreactor was approximately $7 \mathrm{~L}$ before leachate was generated. The addition of water was stopped when the volume of leachate generation reached $7 \mathrm{~L}$. The leachate generated was collected at the bottom of the bioreactor and allowed to gravity drain into a 5 gallon storage container. The leachate was recycled daily in the aerobic stage and three times per week in the anaerobic stage. Once the leachate was drained into the container, the drainage valve was closed to prevent any leakage of biogas.

The volume of leachate recycled was approximately $10 \%(\mathrm{v} / \mathrm{v})$ of the MSW in bioreactor or $7 \mathrm{~L}$ (Chugh et al., 1998), and kept constant during the study. 


\subsubsection{Air requirements}

Air was supplied to the 8 bioreactors to maintain aerobic conditions and to satisfy the oxygen demand required by the organic waste decomposition (stoichiometric demand) for 16 days (Brummeler et al., 1990). Anderson (1990) suggested that the suitable aeration rate for the MSW containing moisture of $50-70 \%$ was in the range of 0.6 to 1.8 $\mathrm{m}^{3}$ air/( $\cdot \mathrm{kg}$ waste). Haug (1993) also provided the general formula $-\mathrm{C}_{64} \mathrm{H}_{104} \mathrm{O}_{37} \mathrm{~N}-$ for the total organic fraction of MSW. Based on this formula, and assuming the organics were totally degraded, the equation for oxidation of carbon was expressed as:

$$
\mathrm{C}_{64} \mathrm{H}_{104} \mathrm{O}_{37} \mathrm{~N}+70.75 \mathrm{O}_{2} \rightarrow 64 \mathrm{CO}_{2}+50.5 \mathrm{H}_{2} \mathrm{O}+\mathrm{NH}_{3}
$$

Taking 3 as a safety factor, $16.63 \mathrm{~m}^{3}$ air kg-1 $\mathrm{MSW}$ (dry) $\left(25^{\circ} \mathrm{C}\right.$ and at 1 atm pressure) was supplied. Assuming all the refuse was oxidized in the 16-day aerobic stage, $1.04 \mathrm{~m}^{3}$ air $\mathrm{d}^{-1} \mathrm{~kg}^{-1} \mathrm{MSW}$ (dry) needed to be supplied. Thus, based on the dry weight of the wastes in each bioreactor, approximately $21 \mathrm{~m}^{3}$ of air per day was injected into each bioreactor.

\subsubsection{4 pH control}

The leachate $\mathrm{pH}$ was adjusted to neutral through the addition of buffer $\left(\mathrm{NaHCO}_{3}\right)$ before recycling the leachate back to the bioreactor. The addition of buffer was stopped when the $\mathrm{pH}$ stabilized around 7.

\subsubsection{Sludge addition}

Two types of sludge were added to the second group of bioreactors (R5 through R8). Waste activated sludge (WAS) was used in the aerobic stage and anaerobic digested sludge (ADS) was used in the anaerobic stage. In the aerobic stage, $5 \%(\mathrm{v} / \mathrm{v})(350 \mathrm{~mL})$ of WAS was added once a week to the leachate recycle, or $800 \mathrm{~mL}$ of WAS added during 
the aerobic stage. In the anaerobic stage, $5 \%(\mathrm{v} / \mathrm{v})(350 \mathrm{~mL})$ of ADS was added once a week to the leachate recycle until its volume reached $20 \%$ of the leachate's volume; that is, $1400 \mathrm{~mL}$ of ADS was added for a period of one month.

\subsubsection{Acclimatized sludge}

A $600 \mathrm{~mL}$ sample of anaerobic digested sludge was poured into a $2000 \mathrm{~mL}$ bottle. The bottle was placed in an incubator at a constant temperature $\left(35^{\circ} \mathrm{C}\right)$ and in shaking mode (100 rpm). Initially, the sludge was fed with $60 \mathrm{~mL}$ of leachate containing $0.2 \%(\mathrm{w} / \mathrm{v})$ salt content and shaken for one day. The following day, the shaker was stopped and 60 $\mathrm{mL}$ of this mixture was taken from the bottle using a syringe. After that the bottle was fed again with $60 \mathrm{~mL}$ of leachate but this time containing $0.3 \%(\mathrm{w} / \mathrm{v})$ salt content and shaken for one day. This procedure was repeated until the salt content reached $2 \%(\mathrm{w} / \mathrm{v})$. After that the acclimatized sludge was used in the BMP assays as an inoculum.

\subsubsection{Salt addition}

The salt used in this study was sodium chloride $(\mathrm{NaCl})$. The salt concentration in the recycled leachate was maintained at a constant value for each operating condition by adding $\mathrm{NaCL}$ to the leachate recycle, as needed.

\subsubsection{BMP assays}

The BMP was designed to estimate the hydrolysis rate constant of MSW biodegradation operating under saline conditions. One kilogram of MSW (60\% organic (food), 20\%

paper, $15 \%$ plastic and $5 \%$ textile $(\mathrm{w} / \mathrm{w})$ ) was used in the BMP assays. The mixture of wastes was shaken with distillated water for 1 day. Then, the supernatant was filtered with a $0.45 \mu \mathrm{m}$ membrane filter (Veeken et al., 1999 and Jokela et al., 2005). Required nutrients (100:0.44:0.08 for COD: $\mathrm{N}: \mathrm{P})$ and buffer $\left(\mathrm{NaHCO}_{3}\right)$ were added into the 
supernatant. A sample of $250 \mathrm{~mL}$ from the supernatant was placed in $500 \mathrm{~mL}$ serum bottles. ADS acclimatized with supernatant was used as inoculums at a rate of $30 \%(\mathrm{v} / \mathrm{v})$ or $75 \mathrm{~mL}$ for each $250 \mathrm{~mL}$ sample. The ratio of volatile solids content of supernatant to volatile solid of inoculum was set to be around 2 to ensure that there was enough inoculum to avoid any accumulation of VFA (Veeken et al. 1999). Then, salt was added to BR2, BR3 and BR4. The headspace of the bottles was flushed with nitrogen gas and they were sealed with rubber septa. A needle was placed in the rubber and connected with a small valve to measure the volume and composition of biogas produced. After sealing, all the bottles were placed in an incubator at a constant temperature $\left(35^{\circ} \mathrm{C}\right)$ and shaking mode $(100 \mathrm{rpm})$. The volume and composition of biogas produced were measured at regular intervals.

\subsection{Analytical methods}

In order to record the progress of biodegradation within the bioreactors, a combination of parameters (solid waste, leachate and biogas) were monitored throughout the experiments.

\subsubsection{Solid waste}

Solid waste samples were collected from all bioreactors and analyzed at the beginning and at the end of the study for the moisture content and settlement. In addition, temperature was measured in different layers of the solid waste during the first 35 days of the operation.

\subsubsection{Moisture content}

Moisture content was measured according to method 2540 B (APHA, 1992). In this analysis, a sample of $80-100 \mathrm{~g}$ of wet waste, which had been used in each bioreactor, 
was dried at $105^{\circ} \mathrm{C}$ for 24 hours. The moisture content was expressed as a percentage of weight loss during the drying process divided by the dried weight of the sample.

At the beginning of the study, the moisture content described the initial moisture, and it was analyzed by taking three samples of waste from each bioreactor. At the end of this study, the moisture content was analyzed at different depths (three layers). Then three samples of waste were taken from each of these layers.

\subsubsection{Temperature}

The temperature of the waste during the experiment was measured by inserting thermocouple probes (K-type from OMEG Company) in the bioreactors at $14 \mathrm{~cm}, 44 \mathrm{~cm}$ and $74 \mathrm{~cm}$ from the bottom as shown in Figure 3.2. The temperature was recorded in the aerobic stage and in the first 20 days of the anaerobic stage. Later on, the thermocouple probes were removed to prevent any leakage through their wires.

\subsubsection{Settlement in the bioreactors}

Settlement in the bioreactors was estimated by measuring the change in the distance between the top of the bioreactor and the surface of the compacted MSW. This distance was measured at four different points in order to estimate the most accurate height of the MSW settlement. The distance was measured at the beginning ( 0 day) of bioreactor operations, at the end of the aerobic stage and at the end of the experiments. The settlement that occurred during the aerobic stage was equal to the difference between the distance at day 0 and the distance at the end of the aerobic stage; whereas the total settlement (aerobic and anaerobic stages) was equal to the difference between the distance at day 0 and the distance at the end of the study. 


\subsubsection{Landfill biogas generation}

The volume and composition of biogas produced from the 1D bioreactors and BMP assays during the biodegradation were measured during the experiments.

\subsubsection{Volume of biogas produced}

The volume of biogas produced from the bioreactors and BMP assays was measured using the wet-tip meter and liquid displacement methods, respectively. The wet-tip meter and liquid displacement were calibrated once during the study using a $60 \mathrm{~mL}$ syringe. The volume of biogas produced was recorded daily.

\subsubsection{Biogas concentration}

The biogas composition was analyzed with a (SRI 8610 C) gas chromotograph (GC) which had a TCD- HID detector and two columns (6' silica Gel and 3' Molecular sieve). The composition of biogas was determined by injecting $0.5 \mathrm{~mL}$ of sampled biogas into a GC in which the carrier gas (helium) was controlled at the flow rate of $32 \mathrm{~mL} / \mathrm{min}$. The composition of biogas produced from the bioreactors was analyzed three times per week in the first two months of the anaerobic stage, and from that moment until the end of the study it was analyzed once a week.

The composition of the biogas produced from the BMP assays was analyzed three times per week until it reached $60 \%(\mathrm{v} / \mathrm{v})$ methane composition and from then on, the biogas was analyzed once a week until the end of the runs. Figure 3.3 shows a sample graph from the GC. The first peak is $\left(\mathrm{N}_{2}+\mathrm{O}_{2}\right)$, the second peak is methane, and the third peak is carbon dioxide. 


\subsubsection{Biochemical methane potential (BMP)}

The BMP was used to determine the amount of methane that could be produced from leachate generation (substrate) sampled from the experimental bioreactors. The BMP test was carried out twice during the experiment at the peak leachate concentration (COD), and at one point along the decline of leachate concentration (COD). Two types of inoculums were used in the BMP test. The first inoculum was anaerobic digested sludge; and the second, anaerobic digested sludge acclimatized with salt.

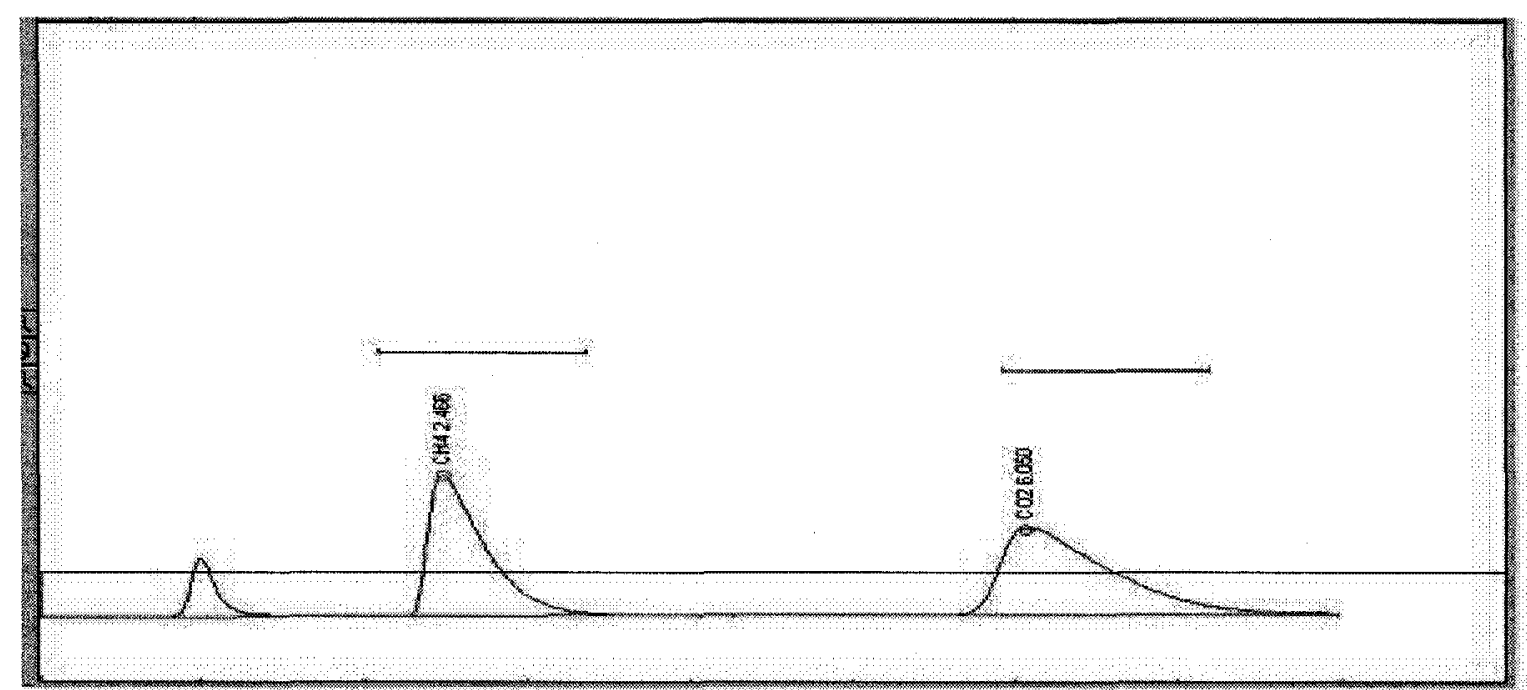

Figure 3.3: Sample of GC result.

\subsubsection{Leachate generation}

Two hundred milliliter leachate samples were collected from all bioreactors and analyzed in the laboratory three times per week during the aerobic stage; twice per week during the first month of anaerobic stage; once a week from day 40 to day 200 and twice a month from day 200 to the end of the experiments. The leachate parameters, $\mathrm{COD}, \mathrm{BOD}_{5}$, VFA, $\mathrm{pH}, \mathrm{TVS}, \mathrm{TS}, \mathrm{NH}_{3}-\mathrm{N}$, salinity, and leachate profile were measured as indicated in the following subsections. 


\subsubsection{Chemical oxygen demand (COD)}

The COD was analyzed according to the $5220 \mathrm{D}$ method (APHA, 1992). This method involves oxidation of organic and inorganic matter using potassium dichromate (digestion solution). The COD was analyzed in duplicate by adding $2.5 \mathrm{~mL}$ of diluted leachate to a mixture of digestion solution and sulphuric acid in tubes, and putting the tubes in the oven at $150^{\circ} \mathrm{C}$ for 2 hours. Then the tubes were removed from the oven and cooled to room temperature. The oxygen consumed in the oxidation was measured using a PerkinElmer 2380 spectrophotometer at $600 \mathrm{~nm}$ and a calibration curve. The calibration curve was generated twice during the study using a potassium hydrogen phthalate solution.

\subsubsection{Biochemical oxygen demand $\left(\mathrm{BOD}_{5}\right)$}

$\mathrm{BOD}_{5}$ measured the amount of oxygen consumed for the biodegradation of organic matter during 5 days incubated at $20^{\circ} \mathrm{C}$. The $\mathrm{BOD}_{5}$ test requires a small amount (e.g. 1 $\mathrm{mL}$ ) of the sample diluted in a $300 \mathrm{~mL}$ bottle. A number of dilutions were required to obtain the initial $\mathrm{BOD}_{5}$ when $\mathrm{BOD}_{5}$ concentrations were high. The $\mathrm{BOD}_{5}$ was measured according to method $5210 \mathrm{~B}$ (APHA, 1992). The dissolved oxygen (DO) in the samples was measured by a DO Meter (Model 50B, YSI Incorporated Company) and was calibrated three times during the study.

\subsubsection{Total volatile fatty acids (VFA)}

The VFA were analyzed according to the method presented by Anderson et al. (1992). The test was carried out by using $50 \mathrm{~mL}$ of leachate as follows: the $\mathrm{pH}$ of the sample was measured; the sample was titrated with $0.1 \mathrm{~N}$ sulphuric acid through two stages. The first stage was to $\mathrm{pH} 5.1$ and the second stage was from $\mathrm{pH} 5.1$ to 3.5 . Then the VFA and bicarbonate were calculated using formulas presented by Anderson et al. (1992). 


\subsubsection{4 pH}

The change in the $\mathrm{pH}$ level can be used as an indicator for the progress of the biodegradation process in the bioreactors. It reflects the establishment of the acidogenic and methanogenic stages. The $\mathrm{pH}$ of leachate was measured in duplicate using a model $420 \mathrm{~A} \mathrm{pH}$ meter which was calibrated using a buffer solution of $\mathrm{pH} 4$ and 7 . The $\mathrm{pH}$ was measured immediately after sampling ( $20 \mathrm{~mL}$ of leachate) to avoid any change due to $\mathrm{CO}_{2}$ stripping.

\subsubsection{Total solids (TS) and total volatile solids (TVS)}

The TS was measured according to method 2540 B (APHA, 1992) by placing $25 \mathrm{~mL}$ of leachate in the oven at $105^{\circ} \mathrm{C}$ for 24 hours. The TS was equal to the weight that remained after placing a sample in the oven.

The TVS was measured according to method 2540 E (APHA, 1992) by placing the TS sample (dried residue) in the furnace at $550^{\circ} \mathrm{C}$ for 2 hours. The ash was cooled in a desiccator before weighing the sample. The TVS was equal to the weight that is lost in the furnace.

\subsubsection{Ammonia nitrogen}

The dissolved ammonia nitrogen was measured according to standard methods (APHA, 1992) by using an ammonia gas-detecting probe (VWR cat. No. 14002-794). A VWR $\mathrm{NH}_{3}$ probe and $\mathrm{pH}$ meter were used to measured the ammonia nitrogen concentration. First the $\mathrm{pH}$ of the sample ( $50 \mathrm{~mL}$ of leachate) was raised to above than 11 by adding 2 $\mathrm{mL}$ of $10 \mathrm{~N} \mathrm{NaOH}$ to the sample. Then the ammonia probe was placed in the sample while mixing with a magnetic stirrer and when the reading was stabilized, the $\mathrm{mV}$ value was recorded. A calibration curve was prepared once during the study using known 
concentrations of ammonia solutions. The $\mathrm{mV}$ values were converted into concentrations using a calibration curve.

\subsubsection{Salinity}

Salinity of the leachate was measured according to method 2520 (APHA, 1992) by using Chloride electrode (ORION $9617 \mathrm{BN}$ ) and a calibration curve. The calibration curve was prepared five times during the study using known concentrations of chloride standard. First the leachate samples needed to be diluted to fit within the calibration curve ( 0 to $1000 \mathrm{mg} / 1 \mathrm{Cl})$. The leachate samples obtained from bioreactors operated at $3 \%(\mathrm{w} / \mathrm{v})$ salt content were diluted 30 times, and 10 times those obtained from bioreactors operated at 0.5 and $1 \%(\mathrm{w} / \mathrm{v})$. Then the chloride electrode was placed in a sample $(20 \mathrm{~mL})$ of diluted leachate while the sample was being mixed with a magnetic stirrer. When the reading was stabilized, the $\mathrm{mV}$ value was recorded. Then the calibration curve was used to convert the $\mathrm{mV}$ values into $\mathrm{Cl}$ concentrations. Finally, the formula proposed by (APHA, 1992) was used to estimate the salinity concentration in the leachate samples.

\subsubsection{Leachate concentration profile}

To estimate the leachate concentration (COD) at different depths, leachate samples from $\mathrm{R} 1$ and R5 were collected from three ports located at 10, 40 and $70 \mathrm{~cm}$ from the bottom of the bioreactors using trays, as shown in Figure 3.2. Then the leachate collected on each tray was removed and analyzed for COD. This analysis was repeated three times for R1 and once for R5 during the study. 


\section{Chapter 4}

\section{Model development}

A mathematical model was developed to simulate the biodegradation of the MSW and to predict the leachate strength (aqueous organic and VFA) and the volume of landfill gas $\left(\mathrm{CH}_{4}\right.$ and $\left.\mathrm{CO}_{2}\right)$ produced. The following sections describe the model formulation, assumptions, and derivation, plus the sensitivity analysis performed.

\subsection{Model description}

The conceptual model describes the biodegradation of solid waste into methane and carbon dioxide as end products, and VFA as an intermediate product. As mentioned in Chapter 2, the biodegradation process occurs over three stages: hydrolysis, acidogenesis and methanogenesis. Figure 4.1 shows the biodegradation pathways incorporated into the model.

\subsubsection{Hydrolysis}

During the hydrolysis stage, solid waste first solubilizes and converts to aqueous organic acids. According to several researchers (Halvadakis 1983; El-Fadel et al., 1996b; Pareek et al., 1999; Naranjo et al., 2004; Yildiz et al., 2004), hydrolysis is the rate limiting step in the solid waste biodegradation process and is assumed to follow first order kinetics with respect to solid organic concentration:

$$
C_{s}+H_{2} \mathrm{O} \stackrel{\text { Enzyme }}{\longrightarrow} C_{a q}
$$

Where,

$\mathrm{C}_{(\mathrm{S})}$ : solid organic carbon $\left(\mathrm{M} / \mathrm{L}^{3}\right)$

$C_{(a q)}$ : aqueous organic acids carbon $\left(\mathrm{M} / \mathrm{L}^{3}\right)$ 
This reaction requires moisture $\left(\mathrm{H}_{2} \mathrm{O}\right)$ and enzymes produced by fermentative bacteria (hydrolysis bacteria) to occur.

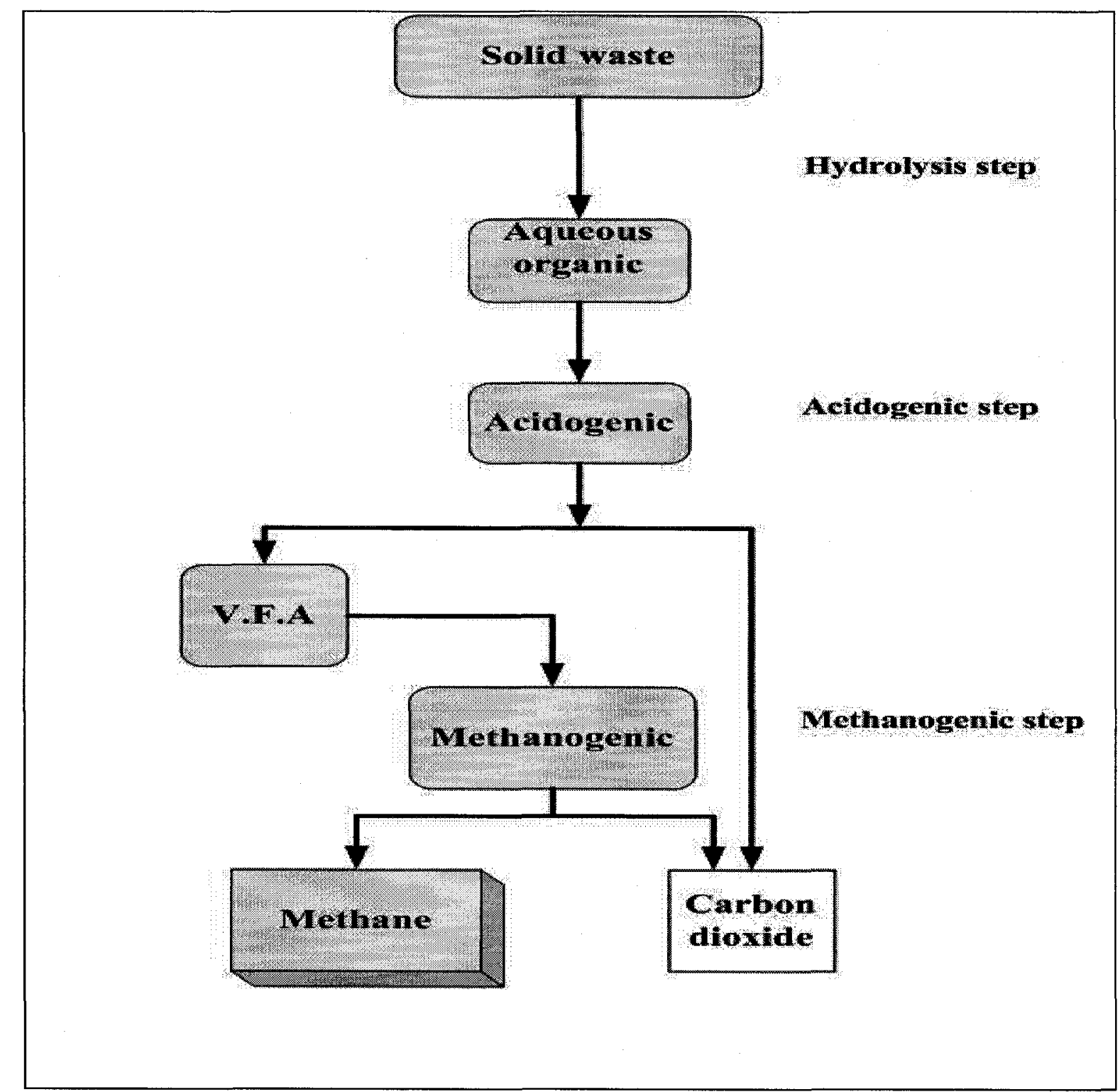

Figure 4.1: Model flow chart (Modified El-Fadel et al. 1996b).

\subsubsection{Acidogenesis}

In the acidogenic stage, acidogenic bacteria used the end product of the hydrolysis stage (aqueous organic acids) as substrate to produce VFA, carbon dioxide and biomass cells. Monod kinetics were used to describe the growth rate of acidogenic bacteria. 


\subsubsection{Methanogenesis}

In the methanogenic stage, methanogenic bacteria produced methane, carbon dioxide and biomass cells by utilizing the VFA as substrate. Inhibition of methanogenic bacteria by salt content was incorporated into the Monod kinetics and used to describe the growth rate of methanogenic bacteria.

\subsection{Model assumptions}

There were eight assumptions for the modeling of MSW biodegradation in the bioreactor.

1. The hydrolysis rate constant is the limiting step in the biodegradation of MSW and followed first order kinetics.

2. There is one hydrolysis rate constant for all the solid waste components.

3. There are two types of organisms (acidogenic and methanogenic) involved in the biodegradation of soluble organic matter.

4. Monod kinetics are used to simulate the growth of acidogenic and methanogenic organisms.

5. The inhibition of salt content is applied to the hydrolysis rate constant and methanogenic bacteria because the acidogenic bacteria parameters have less effect on the biogas produced.

6. Acetic acid represents all organic acid generated during the acidogenic stage.

7. The decay of biomass goes to the biodegradable product (VFA or $\mathrm{CH}_{4}$ and $\mathrm{CO}_{2}$ ) at the same ratio as the aqueous phase conversion.

8. Methane generation from hydrogen and carbon dioxide is negligible due to the limitation of hydrogen in the bioreactor landfill and the fact that methane generation from VFA is the dominant process. 


\subsection{Model development}

The mathematical model consists of mass balance equations and sub-models. Both were applied to the acidogenic and methanogenic stages. It is important to note that all concentration are expressed in terms of mass of carbon per unit volume.

\subsubsection{Sub-models}

The sub-models are substrate, biomass and product models as shown in Figure 4.2.

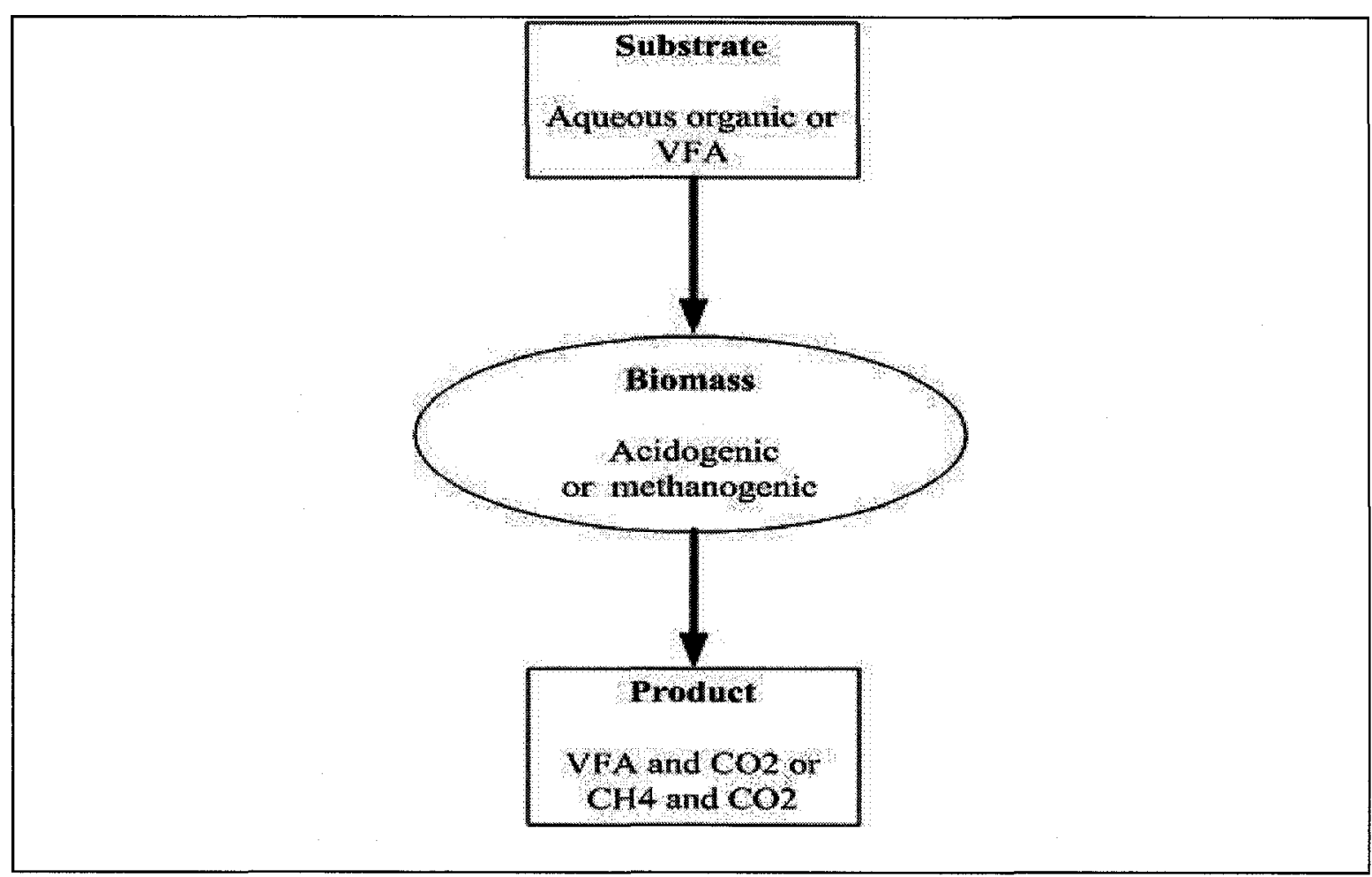

Figure 4.2: Sub-models.

\subsubsection{Substrate model}

The substrate's rate of change in terms of carbon concentration is a function of the biomass growth rate as shown in the following formula:

$$
\frac{d C_{j}}{d t}=-\frac{1}{Y_{i}} \frac{\mu_{i} C_{j}}{K_{S i}+C_{j}} C_{X i}
$$

Where, 
$\frac{d C_{j}}{d t}$ : change in substrates carbon concentration with time (aqueous organic acids or VFA) $\left(\mathrm{M} / \mathrm{L}^{3} \cdot \mathrm{T}\right)$

$C_{j}$ : substrate (aqueous organic acids or VFA) carbon concentration $\left(\mathrm{M} / \mathrm{L}^{3}\right)$

$C_{x i}$ : biomass (acidogenic or methanogenic) carbon concentration $\left(\mathrm{M} / \mathrm{L}^{3}\right)$

$\mu_{i}$ : maximum specific growth rate constant of biomass (acidogenic or methanogenic) $\left(\mathrm{T}^{-1}\right)$

$K_{S i}$ : half saturation constant of biomass (acidogenic or methanogenic) $\left(\mathrm{M} / \mathrm{L}^{3}\right)$

$Y_{i}$ : mass of biomass (acidogenic or methanogenic) formed expressed as equivalent carbon mass per mass of (aqueous organic acids or VFA) carbon utilized (M/M)

The remaining fraction $\left(1-Y_{i}\right)$ is converted into biodegradation products; VFA and carbon dioxide for the acidogenic stage; and methane and carbon dioxide for the methanogenic stage. The fraction of carbon converted to each biodegradation product is defined by a fractional formation yield coefficient.

\subsubsection{Biomass model}

The rate of change in biomass carbon concentration is equal to the difference between the growth rate and the decay, as shown in the following formula:

$\frac{d C_{X i}}{d t}=\left[\frac{\mu_{i} C_{j}}{K_{S i}+C_{j}}-k_{d i}\right] C_{X i}$

Where,

$\frac{d C_{X i}}{d t}$ : change in biomass (acidogenic or methanogenic) carbon concentration with time $\left(\mathrm{M} / \mathrm{L}^{3} \cdot \mathrm{T}\right)$

$k_{d i}$ : decay rate constant of biomass (acidogenic or methanogenic) $\left(\mathrm{T}^{-1}\right)$ 
Since salinity is assumed to have an influence on the methanogenic biomass, an inhibition term to simulate the effect of the saline environment was included in the Monod kinetics (growth rate term), which in turn was used to simulate the methanogenic biomass. There are three types of inhibition terms namely competitive, uncompetitive and noncompetitive, as stated in Appendix B (Lehninger, 1975). Since the model will be used to reproduce the $1 \mathrm{D}$ bioreactors which operated at neutral $\mathrm{pH}$, the suitable inhibition term is the competitive formulation. The Monod kinetics used to describe the methanogenic biomass is shown in the following formula:

$$
\mu=\frac{\mu_{M} C_{j}}{K_{S M}\left(1+\left(\frac{I}{K_{I}}\right)^{m}\right)+C_{j}}-k_{d M}
$$

Where,

$\mu_{M}$ : maximum specific growth rate constant of methanogenic biomass $\left(\mathrm{T}^{-1}\right)$

$K_{S M}:$ half saturation constant of methanogenic biomass $(\mathrm{M} / \mathrm{L})$

$k_{d M}$ : decay rate constant of methanogenic biomass $\left(\mathrm{T}^{-1}\right)$

$I$ : concentration of salt content $\%(\mathrm{w} / \mathrm{v})$

$K_{I}$ : inhibition constant due to salt content ( $K_{I}$ has same concentration unit as $\left.I\right)$ at which the rate is $50 \%$ of the uninhibited rate (IWA, 2002 and Batstone et al., 2006).

$\mathrm{m}$ : inhibition constant due to salt content (dimensionless).

The value of $K_{I}$ could not be estimated from the results of the 1D bioreactors because these bioreactors operated over a narrow range of salt content $(0.5,1$, and 3$)(w / v) \%$. Therefore, the $K_{I}$ and $m$ were used as empirical fitting parameters and have been estimated through model calibration. They are both presented in Tables 5.34 through 5.36 . 


\subsubsection{Product model}

The rate of change in the product's carbon concentration is equal to the sum of the fraction $\left(1-Y_{i}\right)$ of the biodegradation of substrate (aqueous organic acids or VFA) that is not converted into biomass and decay of biomass involved in the biodegradation process as is shown in the following formula:

$$
\frac{d C_{G}}{d t}=\left[\left(\frac{1}{Y_{i}}-1\right) \frac{\mu_{i} C_{S}}{K_{S i}+C_{S}}+k_{d i}\right] C_{X i}
$$

Where,

$$
\begin{aligned}
& \frac{d C_{G}}{d t} \text { : change in total carbon concentration of all products with time }\left(\mathrm{VFA} \text { and } \mathrm{CO}_{2}\right. \text { or } \\
& \left.\quad \mathrm{CH}_{4} \text { and } \mathrm{CO}_{2}\right)\left(\mathrm{M} / \mathrm{L}^{3} \cdot \mathrm{T}\right)
\end{aligned}
$$

The change in the individual product carbon concentration are equal to equation [18] multiplied by the corresponding fractional formation yield as detailed in Sections 4.3.2.3 and 4.3.2.5 for the VFA and methane factions, respectively.

\subsubsection{Model derivation}

As mentioned before, first order kinetics was applied to the hydrolysis of solid carbon wastes. So, the rate of change in solid carbon concentration is described as follows:

$$
\frac{d C_{S}}{d t}=-\left(k_{h} C_{S}\right)
$$

Where,

$\frac{d C_{S}}{d t}$ : change in solid carbon concentration with time $\left(\mathrm{M} / \mathrm{L}^{3} \cdot \mathrm{T}\right)$

$k_{h}$ : hydrolysis rate constant $\left(\mathrm{T}^{-1}\right)$

As the hydrolysis products are generated, the organic carbon is eventually converted into one of six forms, including aqueous organic acids, acidogenic biomass, VFA, 
methanogenic biomass, methane and carbon dioxide. Mass balance and sub-models were applied to every form of carbon to provide the concentration change at any time.

\subsubsection{Aqueous organic acids carbon}

The aqueous organic acids are the product of the hydrolysis stage and also the substrate for the acidogenic biomass. By applying a carbon mass balance, the rate change of aqueous organic acid is equal to the difference between the generation term (hydrolysis products) and depletion term (acidogenic growth rate). The substrate sub-model is applied to the depletion term. The net rate of aqueous organic carbon change was obtained as follows:

$$
\begin{aligned}
& \frac{d C_{(a q)}}{d t}=\frac{d C^{g}}{d t}-\frac{d C^{d}}{d t} \\
& \frac{d C_{(a q)}}{d t}=\left(k_{h} C_{S}\right)-\left(\frac{1}{Y_{A}}\right)\left(\frac{\mu_{A} C_{(a q)}}{K_{S A}+C_{(a q)}}\right) C_{(X A)}
\end{aligned}
$$

Where,

$\frac{d C^{g}}{d t}$ : generation rate of aqueous organic acids carbon concentration $\left(\mathrm{M} / \mathrm{L}^{3} \cdot \mathrm{T}\right)$ $\frac{d C^{d}}{d t}$ : depletion rate of aqueous organic acids carbon concentration $\left(\mathrm{M} / \mathrm{L}^{3} \cdot \mathrm{T}\right)$

$\frac{d C_{(a q)}}{d t}$ : change in aqueous organic acids carbon concentration with time $\left(\mathrm{M} / \mathrm{L}^{3} \cdot \mathrm{T}\right)$

$Y_{A}$ : mass of acidogenic biomass formed per mass of $\mathrm{C}_{(\mathrm{aq})}$ utilized (M/M)

$\mu_{A}$ : maximum specific growth rate constant of acidogenic biomass $\left(\mathrm{T}^{-1}\right)$

$K_{S A}:$ half saturation constant of acidogenic biomass $\left(\mathrm{M} / \mathrm{L}^{3}\right)$

$k_{d A}$ : decay rate constant of acidogenic biomass $\left(\mathrm{T}^{-1}\right)$

$C_{X A}:$ acidogenic biomass carbon $\left(\mathrm{M} / \mathrm{L}^{3}\right)$ 


\subsubsection{Acidogenic biomass carbon}

As mentioned before, Monod kinetics were used to describe the growth rate of the acidogenic biomass. The change in acidogenic carbon concentration is described by biomass sub-model and is equal to the difference between the growth rate (using aqueous organic acids as substrate) and the decay rate of acidogenic biomass. The net rate of acidogenic carbon concentration change was calculated as follows:

$$
\frac{d C_{(X A)}}{d t}=\left(\frac{\mu_{A} C_{(a q)}}{K_{S A}+C_{(a q)}}\right) C_{(X A)}-k_{d A} C_{(X A)}
$$

Where,

$\frac{d C_{(X A)}}{d t}$ : change in acidogenic biomass carbon concentration $\left(\mathrm{M} / \mathrm{L}^{3} \cdot \mathrm{T}\right)$

\subsubsection{VFA carbon}

VFA is generated from the biodegradation of aqueous organic acids and from the decay of the acidogenic biomass. Also, VFA is consumed by the methanogenic biomass which uses it as a substrate. The net rate change in VFA carbon concentration is equal to the difference between the generation and depletion terms. The product sub-model is used to describe the generation term where the biomass sub-model is used to describe the depletion term. The change in the VFA carbon concentration is calculated as:

$$
\begin{aligned}
\frac{d C_{(V F A)}}{d t}=Y_{H A C} & {\left[\left(1-Y_{A}\right)\left(\frac{1}{Y_{A}}\right)\left(\frac{\mu_{A} C_{(a q)}}{K_{S A}+C_{(a q)}}\right)+k_{d A}\right] C_{(X A)} } \\
& -\left[\left(\frac{1}{Y_{M}}\right)\left(\frac{\mu_{M} C_{(V F A)}}{\left.K_{S M}\left(1+\left(\frac{I}{K_{I}}\right)^{m}\right)+C_{(V F A}\right)}\right)\right] C_{(X M)}
\end{aligned}
$$

Where, 
$\frac{d C_{(V F A)}}{d t}$ : change in VFA carbon concentration $\left(\mathrm{M} / \mathrm{L}^{3} \cdot \mathrm{T}\right)$

$Y_{M}$ : mass of methanogenic biomass formed per mass of $\mathrm{C}_{(\mathrm{VFA})}$ utilized (M/M)

$Y_{H A C}:$ VFA carbon fractional formation yield coefficient (M/M)

$C_{(X M)}:$ methanogenic biomass carbon $\left(\mathrm{M} / \mathrm{L}^{3}\right)$

Where $\mathrm{Y}_{H A C}$ represents the fraction of the carbon in the biodegradation products that is VFA. The remaining fraction $\left(1-\mathrm{Y}_{H A C}\right)$ is carbon dioxide.

\subsubsection{Methanogenic biomass carbon}

The methanogenic biomass uses the VFA as a substrate to produce methane, carbon dioxide and biomass cells. The change in methanogenic carbon concentration is described by biomass sub-model and is equal to the difference between the growth rate (using VFA as substrate) and the decay rate of the methanogenic biomass. The net rate of methanogenic carbon concentration change is calculated as follows:

$$
\frac{d C_{(X M)}}{d t}=\left(\frac{\mu_{M} C_{(V F A)}}{K_{S M}\left(1+\left(\frac{I}{K_{I}}\right)^{m}\right)+C_{(V F A)}}\right) C_{(X M)}-k_{d M} C_{(X M)}
$$

Where,

$\frac{d C_{(X M)}}{d t}:$ change in methanogenic biomass carbon concentration $\left(\mathrm{M} / \mathrm{L}^{3} \cdot \mathrm{T}\right)$

\subsubsection{Methane carbon}

Methane is produced from the biodegradation of VFA and decay of the methanogenic biomass. The product sub-model is applied to describe the methane carbon concentration as follows: 
$\frac{d C_{(C H 4)}}{d t}=Y_{C H 4}\left[\left(1-Y_{M}\right)\left(\frac{1}{Y_{M}}\right)\left(\frac{\mu_{M} C_{(V F A)}}{K_{S M}\left(1+\left(\frac{I}{K_{I}}\right)^{m}\right)+C_{(V F A)}}\right)+k_{d M}\right] C_{(X M)}$

Where,

$\frac{d C_{(\mathrm{CH} 4)}}{d t}$ : change in methane carbon concentration $\left(\mathrm{M} / \mathrm{L}^{3} \cdot \mathrm{T}\right)$

Where $\mathrm{Y}_{\mathrm{CH} 4}$ represents the fraction of the VFA and decayed methanogenic biomass that is converted to methane. The remainder $\left(1-Y_{C H 4}\right)$ is converted to carbon dioxide.

\subsubsection{Carbon dioxide carbon}

Carbon dioxide is produced by acidogenic and methanogenic biomasses. Carbon dioxide is generated by the biodegradation of aqueous organic acids carbon and the decay of the acidogenic biomass (first term), and the biodegradation of VFA and the decay of the methanogenic biomass (second term).

$$
\begin{aligned}
\frac{d C_{(\mathrm{CO} 2)}}{d t}=\left(1-Y_{H A C}\right) & {\left[\left(1-Y_{A}\right)\left(\frac{1}{Y_{A}}\right)\left(\frac{\mu_{A} C_{(a q)}}{K_{S A}+C_{(a q)}}\right)+k_{d A}\right] C_{(X A)}+} \\
& \left(1-Y_{C H 4}\right)\left[\left(1-Y_{M}\right)\left(\frac{1}{Y_{M}}\right)\left(\frac{\mu_{M} C_{(V F A)}}{K_{S M}\left(1+\left(\frac{I}{K_{I}}\right)^{m}\right)+C_{(V F A)}}\right)+k_{d M}\right] C_{(X M)}
\end{aligned}
$$

Where,

$\frac{d C_{(\mathrm{CO} 2)}}{d t}$ : change in carbon dioxide concentration $\left(\mathrm{M} / \mathrm{L}^{3} \cdot \mathrm{T}\right)$

\subsubsection{Microbial kinetics}

The kinetics parameters required for the model are hydrolysis rate constant, specific growth rate constant, half saturation constant, decay rate constant and yield coefficient of 
acidogenesis and methanogenesis. Also the inhibition constants $\left(K_{I}\right.$ and $\left.m\right)$ due to the effect of salt addition in the methanogenic biomass are required.

The hydrolysis rate constant was estimated from the BMP assays at different salt content conditions. The kinetics parameters for the acidogenic and methanogenic biomass and inhibition constants ( $\mathrm{K}_{\mathrm{I}}$ and $\mathrm{m}$ ) were estimated by calibrating the model with the data collected from 1D bioreactors. Table 4.1 presents the range of the kinetics parameters reported in the literature.

\subsection{Numerical solution of model equations}

The set of the model equations was solved numerically for a completely mixed single layer of the MSW using the implicit finite difference method. In the literature, most of the models were solved as a complete mix single layer, which showed good agreement with reality. Likewise, the results of $1 \mathrm{D}$ bioreactors showed no statistical difference in the mean moisture content, temperature and concentration profile within each bioreactor, as indicated in Chapter five.

A computer program created in Matlab was developed to implement the solution of model equations. The numerical solution provides the carbon concentration of the solid waste, aqueous acids, acidogenic biomass, VFA, methanogenic biomass, methane, carbon dioxide and accumulative biogases. The flow chart of the model solution is shown in Figure 4.3. 
Table 4.1: Values of kinetic parameters

\begin{tabular}{|l|l|l|}
\hline Parameter & Unit & Literature \\
\hline Hydrolysis & $\mathrm{d}^{-1}$ & $(0.2-2)^{\mathrm{c}, \mathrm{e}}$ \\
Hydrolysis rate constant (readily), $\mathrm{k}_{\mathrm{h}}$ & $\mathrm{d}^{-1}$ & $(0.00002-0.1)^{\mathrm{c}, \mathrm{e}, \mathrm{f}, \mathrm{g}}$ \\
Hydrolysis rate constant (slowly), $\mathrm{k}_{\mathrm{h}}$ & $\mathrm{d}^{-1}$ & $0.1-0.4^{\mathrm{d}}$ \\
Hydrolysis rate constant (food waste), $\mathrm{k}_{\mathrm{h}}$ & $\mathrm{d}^{-1}$ & \\
Acidogenesis & $\mathrm{d}^{-1}$ & $(0.5-30)^{\mathrm{a}, \mathrm{b}, \mathrm{c}, \mathrm{e}}$ \\
Growth rate, $\mu_{\mathrm{A}}$ & $\mathrm{kg} \mathrm{m}^{-3}$ & $(0.03-5)^{\mathrm{b}, \mathrm{c}}$ \\
Half saturation constant, $\mathrm{K}_{\mathrm{SA}}$ & $\mathrm{d}^{-1}$ & $(0.004-0.4)^{\mathrm{a}, \mathrm{b}, \mathrm{c}}$ \\
Rate of decay, $\mathrm{k}_{\mathrm{dA}}$ & $\mathrm{kg} \mathrm{kg}^{-1}$ & $(0.1-0.5)^{\mathrm{a}, \mathrm{c}}$ \\
Yield, $\mathrm{Y}_{\mathrm{A}}$ & & \\
Methanogenesis & $\mathrm{d}^{-1}$ & $(0.1-0.5)^{\mathrm{a}, \mathrm{b}, \mathrm{c}, \mathrm{e}}$ \\
Growth rate, $\mu_{\mathrm{M}}$ & $\mathrm{kg} \mathrm{m}^{-3}$ & $(0.0003-2.5)^{\mathrm{a}, \mathrm{b}}$ \\
Half saturation constant, $\mathrm{K}_{\mathrm{SM}}$ & $\mathrm{day}^{-1}$ & $(0.005-0.04)^{\mathrm{a}, \mathrm{b}, \mathrm{c}, \mathrm{e}}$ \\
Rate of decay, $\mathrm{k}_{\mathrm{dM}}$ & $\mathrm{kg} \mathrm{kg}^{-1}$ & $(0.05-0.82)^{\mathrm{a}, \mathrm{b}, \mathrm{c}}$ \\
Yield, $\mathrm{kg}_{\mathrm{M}}$ & $(0.6-0.7)^{\mathrm{a}}$ \\
Methane fraction yield, $\mathrm{Y}_{\mathrm{CH} 4}$ & $0.9^{\mathrm{a}}$ \\
VFA formation yield, $\mathrm{Y}_{\mathrm{HAC}}$ & & \\
\hline
\end{tabular}
a, El-Fadel et al. 1996.
b, Yildiz et al. 2004.
c, Naranjo et al. 2004.
d, Alvarez et al. 2000.
e, Haarstrick et al. 2001.
f, Borzacconi et al. 1997.
g, Jokela et al. 2005. 


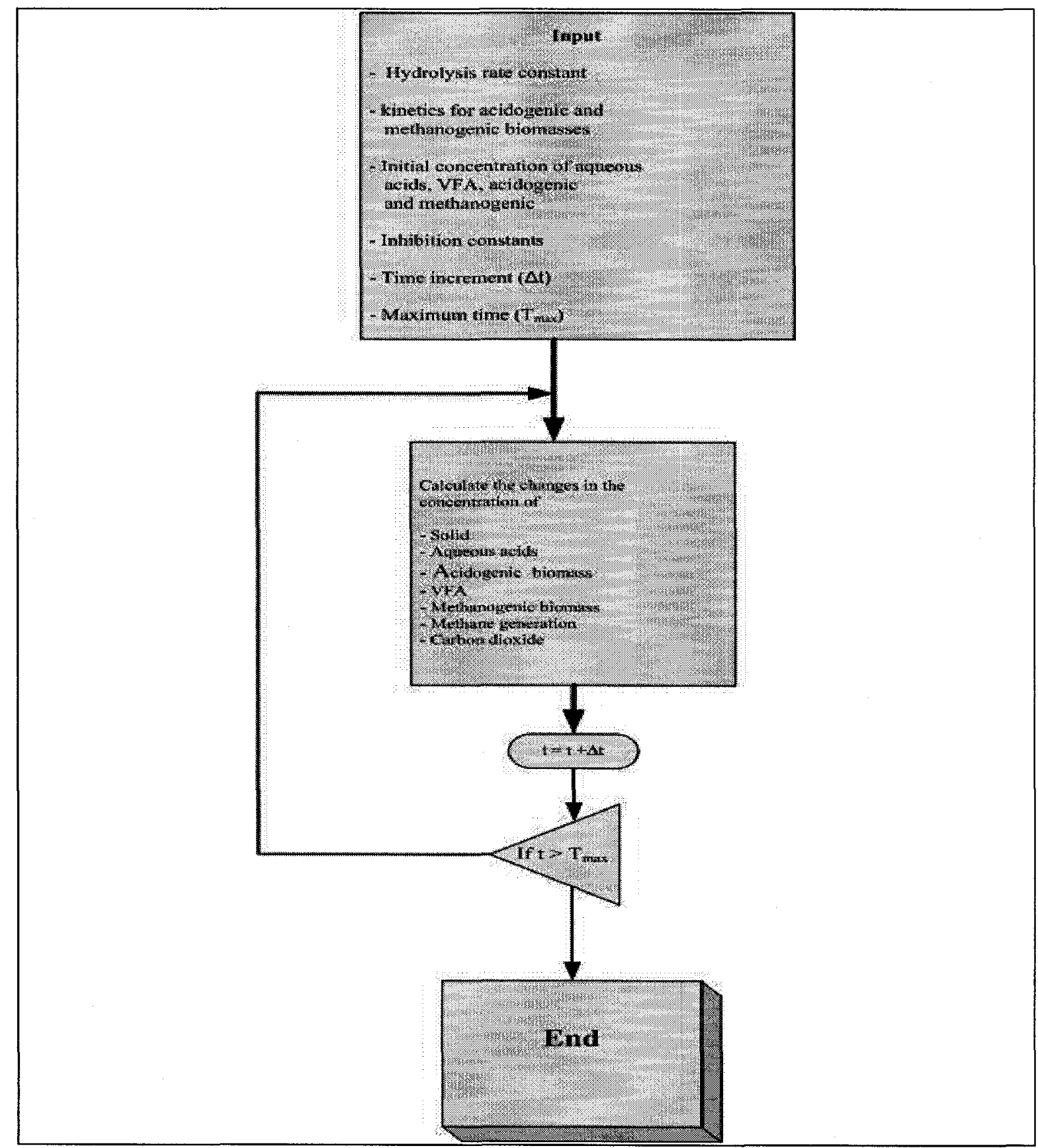

Figure 4.3: Model flow chart.

\subsection{Sensitivity analysis}

The sensitivity analysis was performed to investigate the performance of the model with respect to changes in model input parameters over a reasonable range. The sensitivity analysis helps to understand the behavior of the system being modeled and evaluates which parameters have significant impact on the model performance. 
The input parameters were divided into three groups. Hydrolysis rate constant was the first group, whereas the kinetics $\left(\mu, k_{d}, K_{S}\right)$ of acidogenesis and methanogenesis were within the second group. The third group was the assumed initial concentrations of aqueous acids, VFA, and acidogenic and methanogenic biomasses at the beginning of the simulation. The inhibition constants $\left(\mathrm{K}_{\mathrm{I}}\right.$ and $\left.\mathrm{m}\right)$ are not included in the sensitivity analysis because any changes in these constants produce the same results as increasing the half saturation constant of methanogenic biomass.

The model performance was investigated based on the peak concentration of aqueous acids, VFA and the peak daily methane produced; and the time $\left(T_{p}\right)$ taken to reach each peak. Also, the lag time for methane production was estimated. The lag time $\left(\mathrm{T}_{5 \%}\right)$ was estimated in terms of the time required for the accumulative methane mass to reach

$5 \%$ of the total methane produced in the base condition. A systematic procedure was used to examine the sensitivity of the input parameters in the performance of the model. Only one input parameter was changed while the other parameter values were kept constant at the base value as shown in Table 4.2.

The range of the input parameters was chosen according to the range found in the literature. The results of changing the input parameters were compared to the base scenario and are presented in the following sections. 
Table 4.2: Range of input parameters used in the sensitivity analysis

\begin{tabular}{|lc|c|cc|}
\hline & & Base & \\
\hline Hydrolysis $\left(\mathrm{d}^{-1}\right)$ & 0.0007 & $\mathbf{0 . 0 0 1}$ & 0.004 & 0.007 \\
\hline Acidogenic & & & & \\
$\mu_{\mathrm{A}}\left(\mathrm{d}^{-1}\right)$ & 2 & $\mathbf{3}$ & 6 & 9 \\
$\mathrm{k}_{\mathrm{dA}}\left(\mathrm{d}^{-1}\right)$ & 0.008 & $\mathbf{0 . 0 3}$ & 0.06 & 0.09 \\
$\mathrm{~K}_{\mathrm{SA}}\left(\mathrm{kg} / \mathrm{m}^{3}\right)$ & 0.1 & $\mathbf{0 . 5}$ & 1 & 1.5 \\
\hline Methanogenic & & & & \\
$\mu_{\mathrm{M}} \quad\left(\mathrm{d}^{-1}\right)$ & 0.15 & $\mathbf{0 . 2 5}$ & 0.35 & 0.5 \\
$\mathrm{k}_{\mathrm{dM}}\left(\mathrm{d}^{-1}\right)$ & 0.0025 & $\mathbf{0 . 0 0 5}$ & 0.0075 & 0.01 \\
$\mathrm{~K}_{\mathrm{SM}}\left(\mathrm{kg} / \mathrm{m}^{3}\right)$ & 0.1 & $\mathbf{0 . 5}$ & 0.75 & 1 \\
\hline Initial condition & & & & \\
$\mathrm{C}_{(\mathrm{aq})} \quad\left(\mathrm{kg} / \mathrm{m}^{3}\right)$ & 0.00001 & $\mathbf{0 . 0 0 0 1}$ & 0.0005 & 0.001 \\
$\mathrm{C}_{(\mathrm{VFA})}\left(\mathrm{kg} / \mathrm{m}^{3}\right)$ & 0.00001 & $\mathbf{0 . 0 0 0 1}$ & 0.0005 & 0.001 \\
$\mathrm{C}_{(\mathrm{XA})} \quad\left(\mathrm{kg} / \mathrm{m}^{3}\right)$ & 0.00005 & $\mathbf{0 . 0 0 0 5}$ & 0.0025 & 0.005 \\
$\mathrm{C}_{(\mathrm{XM})}\left(\mathrm{kg} / \mathrm{m}^{3}\right)$ & 0.000005 & $\mathbf{0 . 0 0 0 0 5}$ & 0.00025 & 0.0005 \\
\hline
\end{tabular}

\subsubsection{Time increment}

Since the model was solved by the finite difference method, it was sensitive to time increments. The model was run at different smaller and smaller time steps until there was no significant change in the model output due to the magnitude of the time step. Figures 4.4 and 4.5 show that there was no difference in the model output at $0.1,0.5,0.75$ and 1 day time increment steps. The initial total mass was $0.30075 \mathrm{~kg}$ carbon $/ \mathrm{m}^{3}$ and the final total mass at the end of the simulation run $\left(2000\right.$ days) was $0.301955,0.30208,0.302206$, and $0.302332 \mathrm{~kg}$ carbon $/ \mathrm{m}^{3}$ for 0.25 , $0.5,0.75$, and 1 day time steps, respectively. The percentage increase in the total mass balance with respect to initial mass was $0.4,0.5,0.6$, and $0.8 \%$ for $0.25,0.5,0.75$, and 1 day time steps, respectively. 

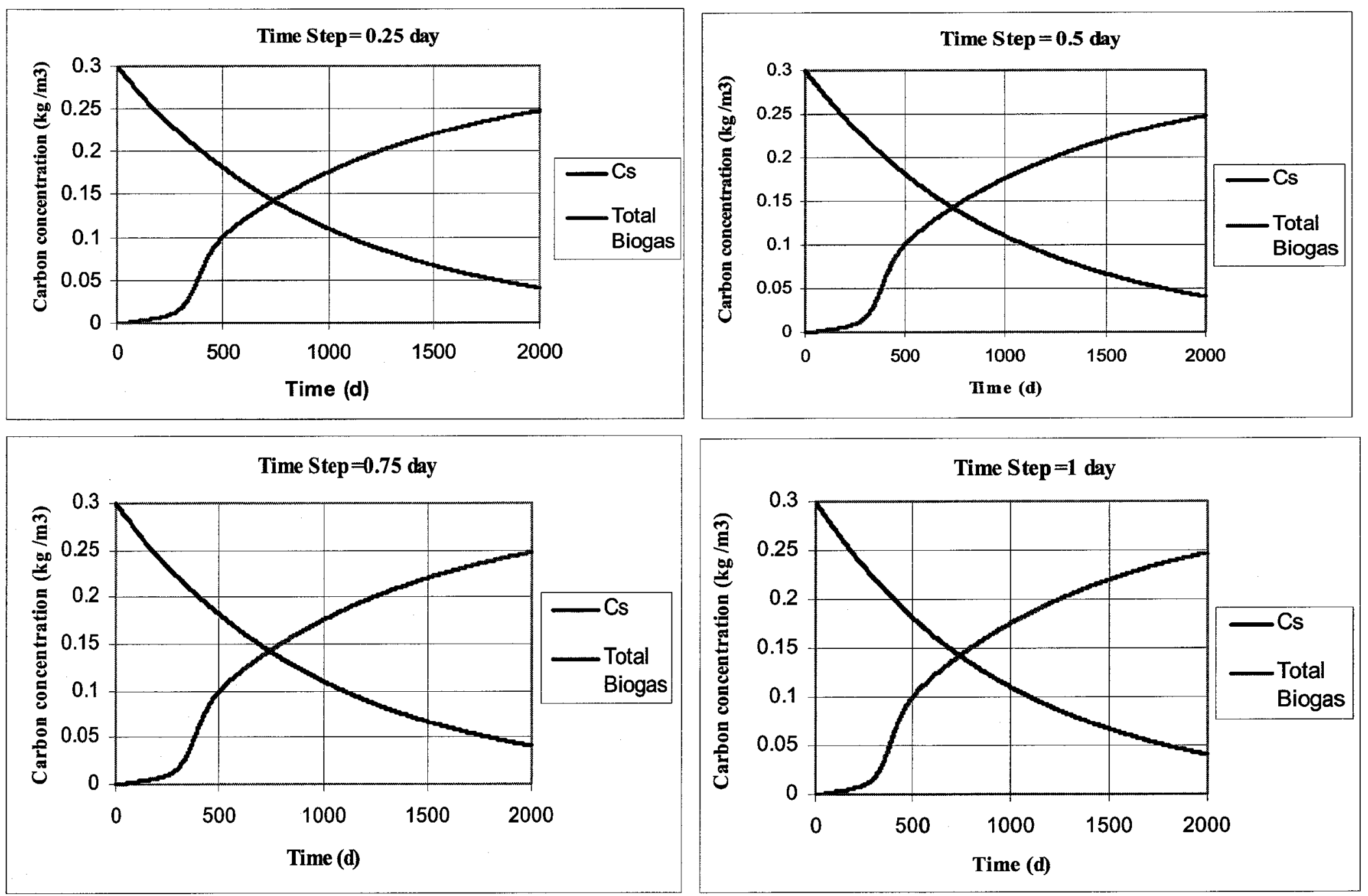

Figure 4.4: Impact of time steps on simulated solid carbon concentration and total biogas produced. 

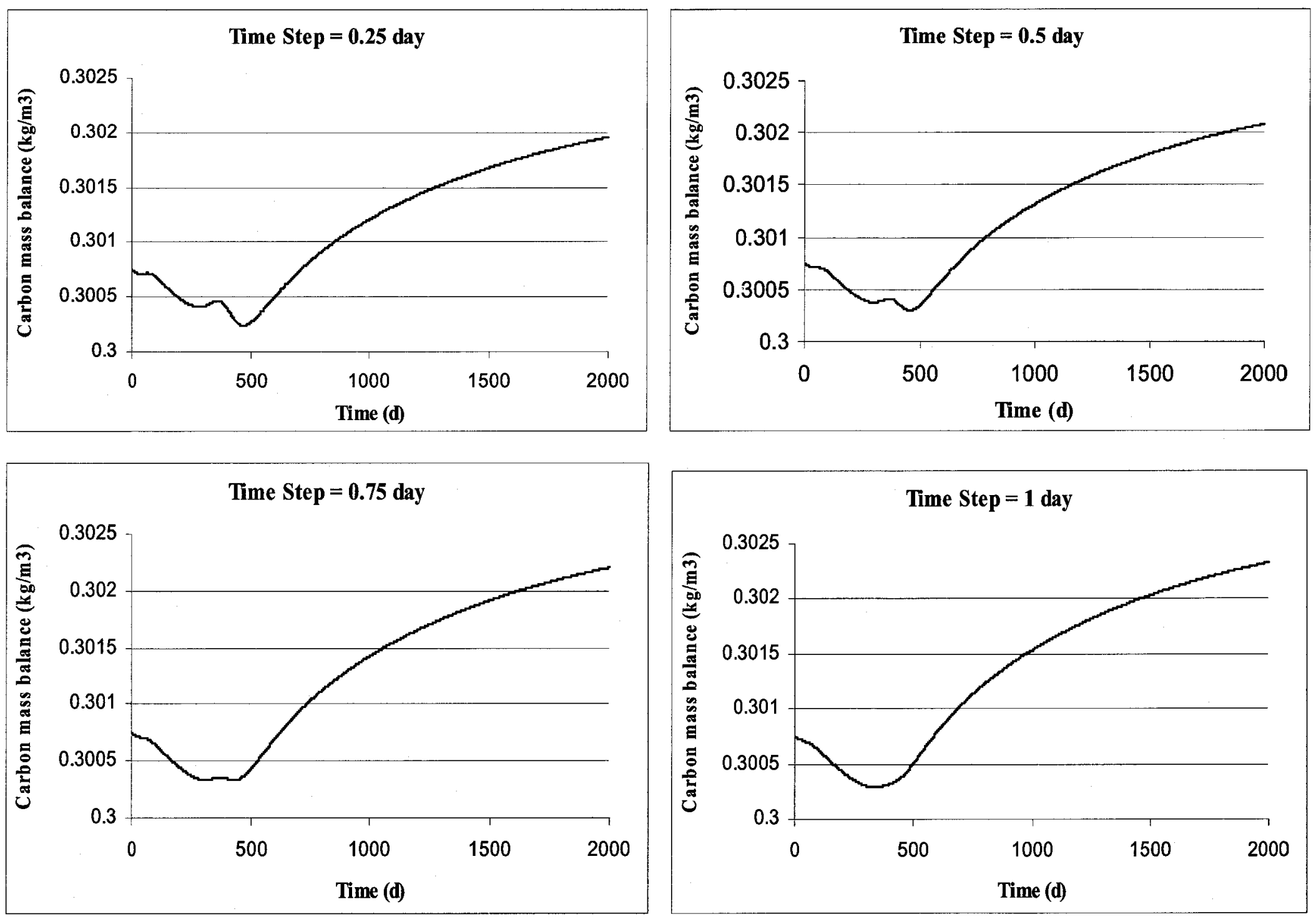

Figure 4.5: Impact of time steps on simulated total mass balance. 
The output of the model in terms of overall carbon mass balance, solid carbon and accumulative biogases production showed that the appropriate time increment was 1 day.

\subsubsection{Hydrolysis rate constant}

The peak VFA, daily methane production and lag time $\left(\mathrm{T}_{5 \%}\right)$ were highly sensitive to change in the hydrolysis rate constant as shown in Table 4.3 and Figure 4.6 . (Note that certain concentration axis in Figures 4.6 through 4.16 are multiplied by the scientific notation $10^{-\mathrm{x}}$ which appears immediately above the axis).

Table 4.3: Impact of changing the hydrolysis rate constant

\begin{tabular}{|c|c|cccc|}
\hline \multicolumn{2}{|c|}{ Hydrolysis rate constant $\left(\mathbf{d}^{-1}\right)$} & $\mathbf{k}_{\mathbf{h}}=\mathbf{0 . 0 0 0 7}$ & $\mathbf{k}_{\mathbf{h}}=\mathbf{0 . 0 0 1}$ & $\mathbf{k}_{\mathbf{h}}=\mathbf{0 . 0 0 4}$ & $\mathbf{k}_{\mathbf{h}}=\mathbf{0 . 0 0 7}$ \\
\hline C $_{\text {VFA }}$ & Peak $\left(\mathrm{kg} / \mathrm{m}^{3}\right)$ & 0.048 & 0.0563 & 0.1067 & 0.136213 \\
& $\mathrm{~T}_{\mathrm{p}}(\mathrm{d})$ & 360 & 301 & 158 & 123 \\
\hline $\mathbf{C}_{\mathbf{C H} 4}$ & Peak $\left(\mathrm{kg} / \mathrm{m}^{3}\right)$ & 0.000246 & 0.000341 & 0.001128 & 0.001685 \\
& $\mathrm{~T}_{\mathrm{p}}(\mathrm{d})$ & 473 & 389 & 210 & 170 \\
\hline Acc. CH4 & $\mathrm{T}_{5 \%}(\mathrm{~d})$ & 378 & 306 & 150 & 115 \\
\hline
\end{tabular}

By increasing the hydrolysis rate constant by a factor of 7 from 0.001 to $0.007 \mathrm{~d}^{-1}$, the peak of VFA and daily methane produced increased by a factor of 2.42 and 5, respectively; and the time to reach the peaks was shorten by 178 and 219 days, respectively. Also, the lag time $\left(\mathrm{T}_{5 \%}\right)$ was 191 days shorter at $\mathrm{k}_{\mathrm{h}}=0.007 \mathrm{~d}^{-1}$.

The same results were observed when the hydrolysis rate constant was decreased to 0.0007. The VFA and daily methane produced took a longer time to reach their peaks by 59 and 84 days, respectively, and the lag time $\left(T_{5 \%}\right)$ increased by 72 days. 

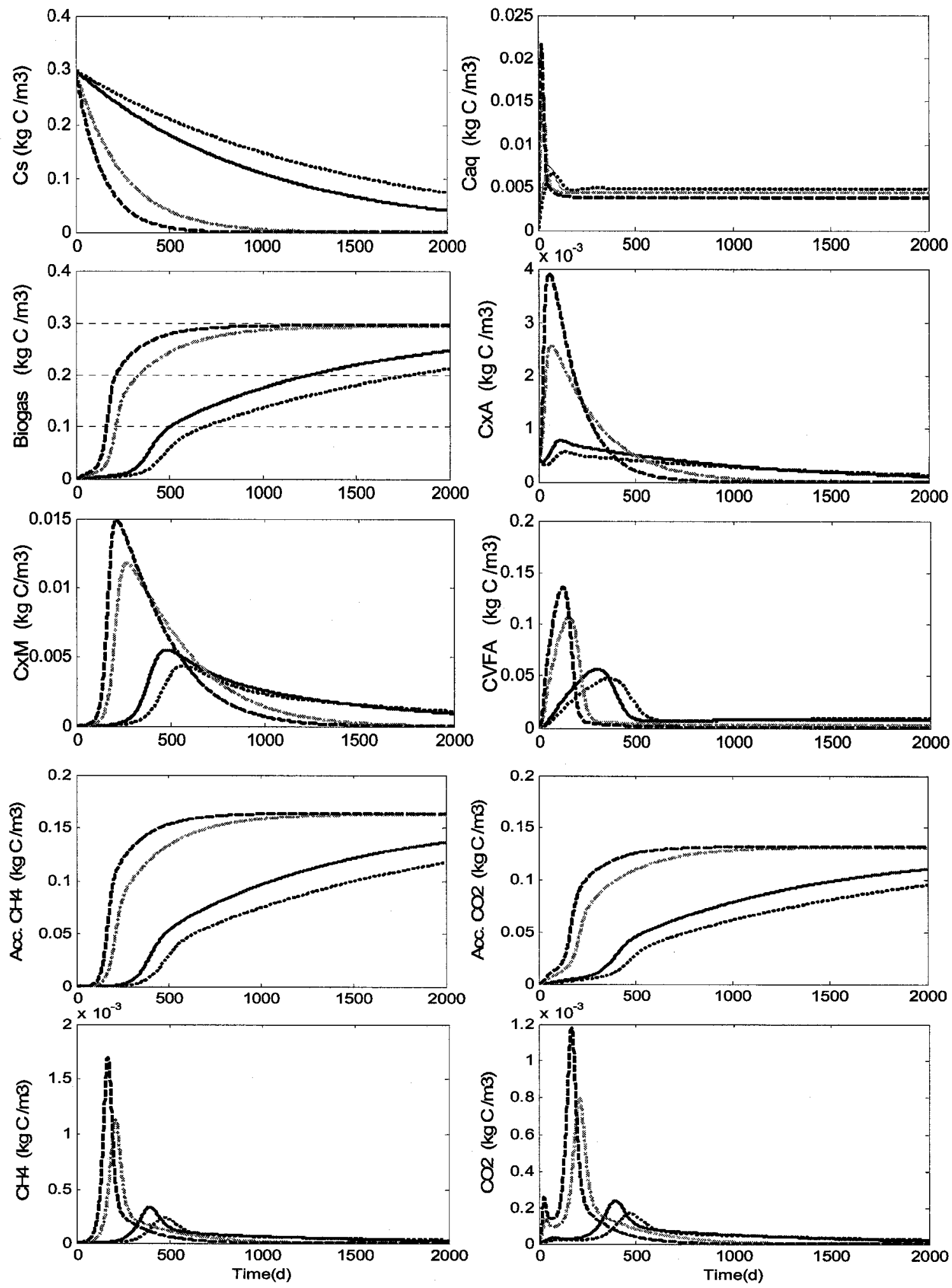

kh=0.001

kh $=0.0007$

$\mathrm{kh}=0.004$

kh=0.007

Figure 4.6: Impact of changing the hydrolysis rate constant. 


\subsubsection{Acidogenic biomass}

In general, changing the acidogenic parameters $\left(\mu_{\mathrm{A}}, \mathrm{k}_{\mathrm{dA}}, \mathrm{K}_{\mathrm{SA}}\right)$ had a minor impact on the VFA, and daily methane produced. On the other hand, they had a significant effect on the formation of aqueous organic acids. The reason was that the acidogenic biomass used the aqueous organic acids as a substrate. The results are presented in Tables 4.4 through 4.6 and Figures 4.7 through 4.9.

\subsubsection{Maximum specific growth rate of acidogenic biomass}

Table 4.4 and Figure 4.7 show the effect of changing the maximum specific growth rate of the acidogenic biomass $\left(\mu_{\mathrm{A}}\right)$. When the maximum specific growth rate of the acidogenic biomass increased by a factor of three, the aqueous organic acids $\left(C_{a q}\right)$ were consumed faster and their peak concentration decreased significantly (67\%), as well as the time to reach this peak (32 days).

In addition, a minor effect on the peak VFA and daily methane produced was observed

Table 4.4: Impact of changing the maximum growth rate of the acidogenic biomass

\begin{tabular}{|c|ccccc|}
\hline \multicolumn{2}{|c}{ Acidogenic growth rate $\left(\mathrm{d}^{-\mathbf{1}}\right)$} & $\boldsymbol{\mu}_{\mathbf{A}}=\mathbf{2}$ & $\boldsymbol{\mu}_{\mathbf{A}}=\mathbf{3}$ & $\boldsymbol{\mu}_{\mathbf{A}}=\mathbf{6}$ & $\boldsymbol{\mu}_{\mathbf{A}}=\mathbf{9}$ \\
\hline \multirow{2}{*}{$\mathbf{C}_{\mathbf{a q}}$} & Peak $\left(\mathrm{kg} / \mathrm{m}^{3}\right)$ & 0.011533 & $\mathbf{0 . 0 0 7 5 2 8}$ & 0.003697 & 0.002459 \\
& $\mathrm{~T}_{\mathrm{p}}(\mathrm{d})$ & 77 & $\mathbf{5 5}$ & 32 & 23 \\
\hline $\mathbf{C}_{\text {VFA }}$ & Peak $\left(\mathrm{kg} / \mathrm{m}^{3}\right)$ & 0.056636 & $\mathbf{0 . 0 5 6 3}$ & 0.055976 & 0.055882 \\
& $\mathrm{~T}_{\mathrm{p}}(\mathrm{d})$ & 314 & $\mathbf{3 0 1}$ & 289 & 284 \\
\hline & & & & & \\
$\mathbf{C}_{\mathbf{C H} 4}$ & Peak $\left(\mathrm{kg} / \mathrm{m}^{3}\right)$ & 0.000342 & $\mathbf{0 . 0 0 0 3 4 1}$ & 0.00341 & 0.00034 \\
& $\mathrm{~T}_{\mathrm{p}}(\mathrm{d})$ & 401 & $\mathbf{3 8 9}$ & 379 & 372 \\
\hline Acc. $\mathbf{C H}_{\mathbf{4}}$ & $\mathrm{T}_{5 \%}(\mathrm{~d})$ & 320 & $\mathbf{3 0 6}$ & 294 & 290 \\
\hline
\end{tabular}



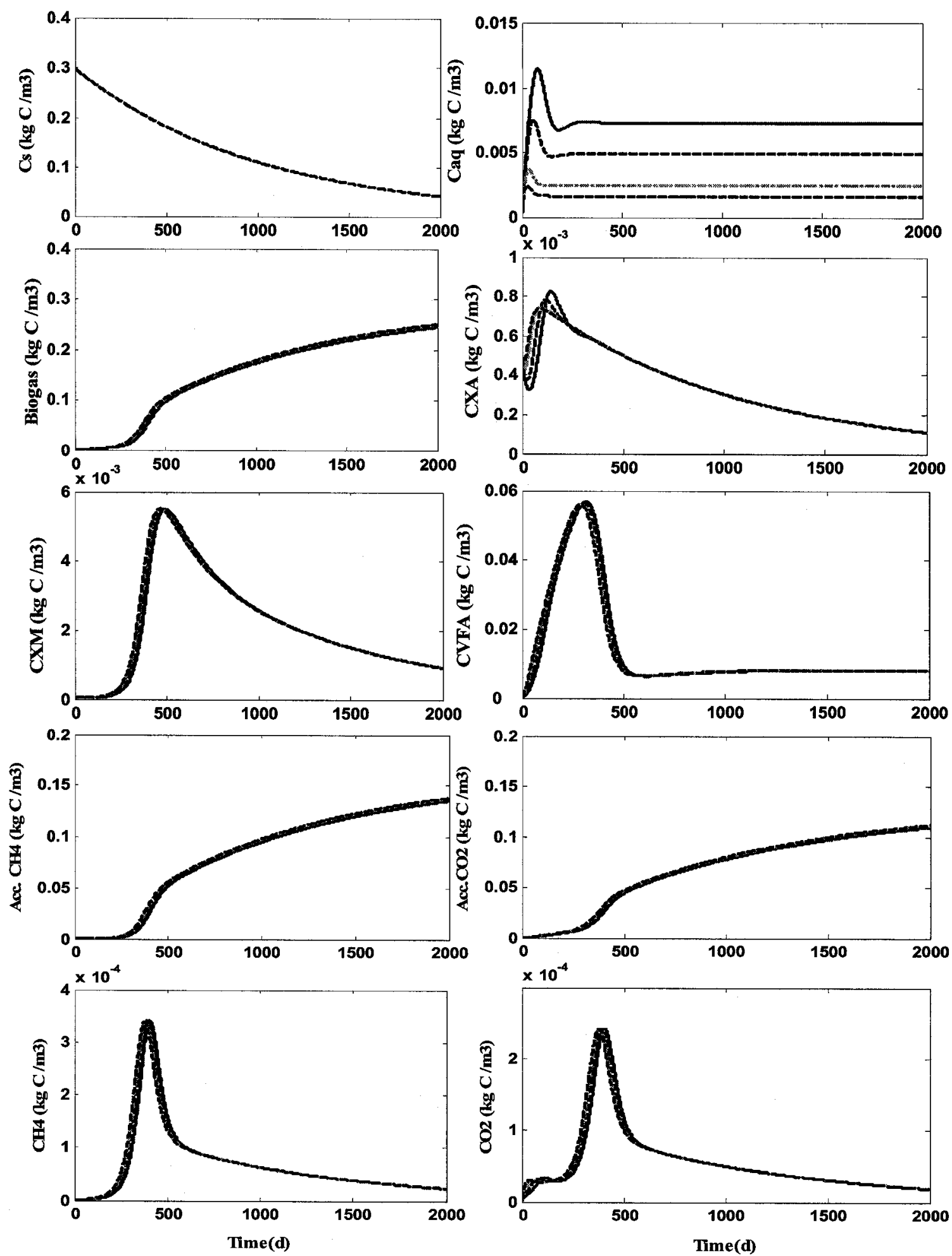

$\mathbf{U A}=\mathbf{2}$

$\mathrm{UA}=\mathbf{3}$

UA $=6$

$\mathrm{UA}=9$

Figure 4.7: Impact of changing the maximum growth rate of the acidogenic biomass. 
when the $\mu_{\mathrm{A}}$ was increased by a factor of three. The time $\left(\mathrm{T}_{\mathrm{p}}\right)$ to reach the peak VFA concentration and daily methane production was shortened by 17 days. A consequence of that was observed in the lag time $\left(\mathrm{T}_{5 \%}\right)$ of accumulative methane which occurred 16 days earlier.

When the $\left(\mathrm{u}_{\mathrm{A}}\right)$ decreased to $2 \mathrm{~d}^{-1}$, the $\left(\mathrm{C}_{\mathrm{aq}}\right)$ took longer time to be consumed and its peak concentration increased significantly $(53 \%)$, as well as the time to reach this peak (22 days). The result of that was an increase in the time to reach the peaks ( $\left.T_{p}\right)$ of VFA, daily methane production and lag time $\left(\mathrm{T}_{5 \%}\right)$ by approximately 15 days.

\subsubsection{Decay rate of acidogenic biomass}

Table 4.5 and Figure 4.8 show the results of changing the decay rate of the acidogenic biomass $\left(k_{d A}\right)$. By increasing the $k_{d A}$ by a factor of three, its concentration $\left(C_{X A}\right)$ decreased by $43 \%$, the result being that the peak aqueous organic acid concentration $\left(\mathrm{C}_{\mathrm{aq}}\right)$

Table 4.5: Impact of changing the decay rate of acidogenic biomass

\begin{tabular}{|c|c|c|c|c|c|}
\hline \multicolumn{2}{|c|}{ Acidogenic decay $\left(d^{-1}\right)$} & $k_{d A}=0.008$ & $\mathbf{k}_{\mathrm{dA}}=\mathbf{0 . 0 3}$ & $k_{d A}=0.06$ & $\mathrm{k}_{\mathrm{dA}}=0.09$ \\
\hline $\mathbf{C}_{\mathrm{aq}}$ & $\begin{array}{c}\text { Peak }\left(\mathrm{kg} / \mathrm{m}^{3}\right) \\
\mathrm{T}_{\mathrm{p}}(\mathrm{d})\end{array}$ & $\begin{array}{c}0.005017 \\
35\end{array}$ & $\begin{array}{c}0.007528 \\
55\end{array}$ & $\begin{array}{c}0.014342 \\
86\end{array}$ & $\begin{array}{c}0.023916 \\
115\end{array}$ \\
\hline$\overline{C_{\text {VFA }}}$ & $\begin{array}{c}\text { Peak }\left(\mathrm{kg} / \mathrm{m}^{3}\right) \\
\mathrm{T}_{\mathrm{p}}(\mathrm{d})\end{array}$ & $\begin{array}{c}0.056278 \\
292\end{array}$ & $\begin{array}{c}0.0563 \\
301\end{array}$ & $\begin{array}{c}0.056481 \\
324\end{array}$ & $\begin{array}{c}0.057612 \\
354\end{array}$ \\
\hline $\mathrm{C}_{\mathrm{CH} 4}$ & $\begin{array}{c}\text { Peak }\left(\mathrm{kg} / \mathrm{m}^{3}\right) \\
\mathrm{T}_{\mathrm{p}}(\mathrm{d})\end{array}$ & $\begin{array}{c}0.000343 \\
380\end{array}$ & $\begin{array}{c}0.000341 \\
389\end{array}$ & $\begin{array}{c}0.0034 \\
412\end{array}$ & $\begin{array}{c}0.00034 \\
438\end{array}$ \\
\hline$\overline{C_{\mathbf{X A}}}$ & Peak $\left(\mathrm{kg} / \mathrm{m}^{3}\right)$ & 0.002301 & 0.000783 & 0.00048 & 0.00045 \\
\hline Acc. $\mathrm{CH}_{4}$ & $\mathrm{~T}_{5 \%}(\mathrm{~d})$ & 297 & 306 & 329 & 357 \\
\hline
\end{tabular}



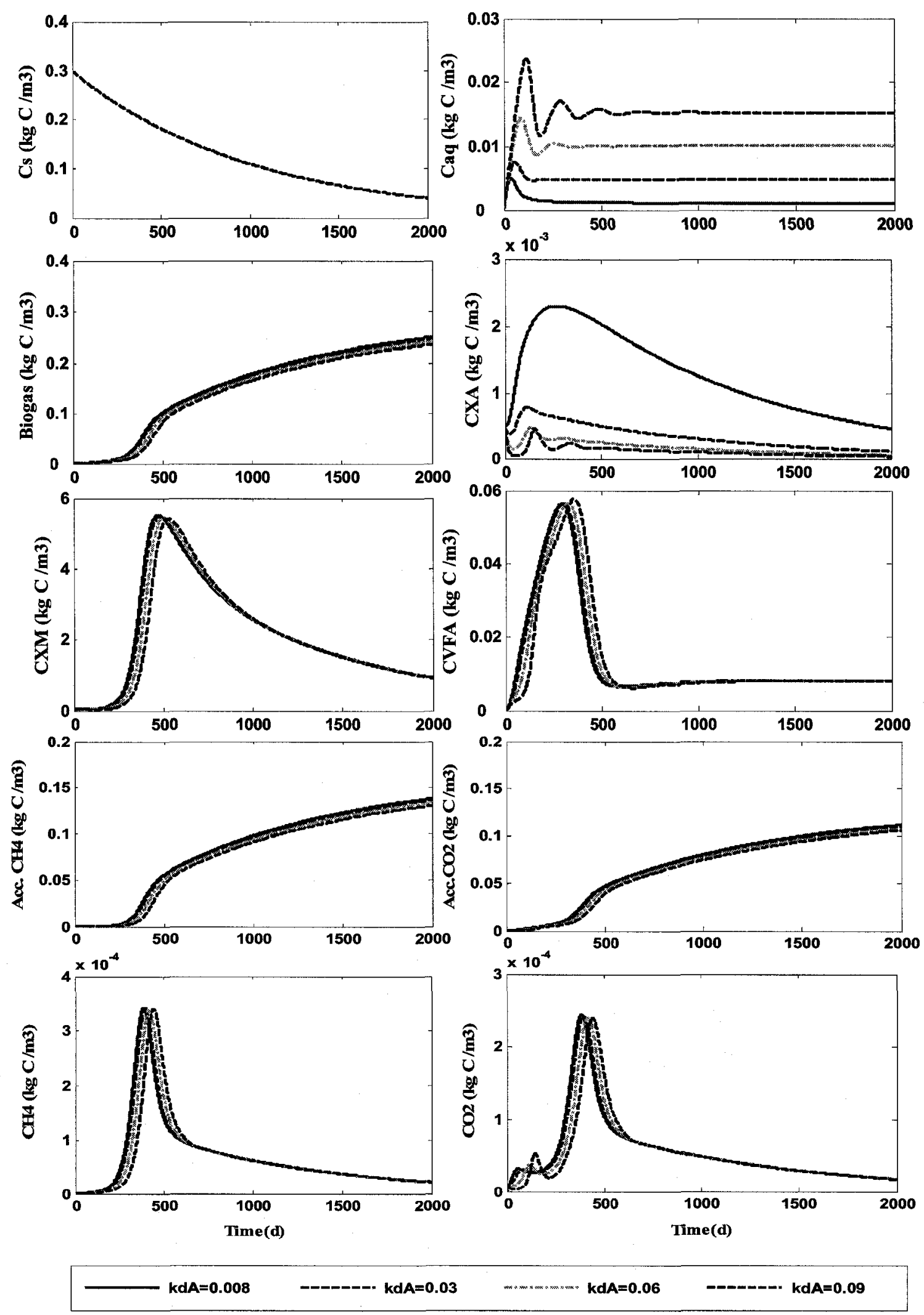

Figure 4.8: Impact of changing the decay rate of acidogenic biomass. 
increased by $217 \%$ over the base and the time to reach the peak increased as well by 60 days. Minor changes were observed in the peak VFA and daily methane produced. The time to reach their peaks and lag time $\left(\mathrm{T}_{5 \%}\right)$ of accumulative methane was delayed by approximately 50 days.

By decreasing the $k_{d A}$ to $0.008 \mathrm{~d}^{-1}$, the acidogenic concentration increased faster, and aqueous organic acids were consumed, thereby decreasing their peaks by $33.5 \%$ of the base and shortening their time to reach the peak by 20 days. Consequently, the time required to reach the peaks of VFA and daily methane produced, as well as the lag time $\left(\mathrm{T}_{5 \%}\right)$ of accumulative methane, occurred earlier by 9 days.

\subsubsection{Half saturation constant of acidogenic biomass}

Increasing the $\mathrm{K}_{\mathrm{SA}}$ showed similar results to decreasing the $\mu_{\mathrm{A}}$ and increasing the $\mathrm{k}_{\mathrm{dA}}$ as shown in Table 4.6 and Figure 4.9.

Table 4.6: Impact of changing the half saturation constant of acidogenic biomass

\begin{tabular}{|c|ccccc|}
\hline \multicolumn{2}{|c|}{$\begin{array}{c}\text { Half saturation constant } \\
\text { of acidogenic }\left(\mathbf{k g} / \mathbf{m}^{3}\right)\end{array}$} & $\mathbf{K}_{\mathbf{S A}}=\mathbf{0 . 1}$ & $\mathbf{K}_{\mathbf{S A}}=\mathbf{0 . 5}$ & $\mathbf{K}_{\mathbf{S A}}=\mathbf{1}$ & $\mathbf{K}_{\mathbf{S A}}=1.5$ \\
\hline \multirow{2}{*}{$\mathbf{C}_{\mathrm{aq}}$} & Peak $\left(\mathrm{kg} / \mathrm{m}^{3}\right)$ & 0.001495 & $\mathbf{0 . 0 0 7 5 2 8}$ & 0.015487 & 0.02377 \\
& $\mathrm{~T}_{\mathrm{p}}(\mathrm{d})$ & 16 & $\mathbf{5 5}$ & 96 & 134 \\
\hline \multirow{2}{*}{$\mathbf{C}_{\text {VFA }}$} & Peak $\left(\mathrm{kg} / \mathrm{m}^{3}\right)$ & 0.055814 & $\mathbf{0 . 0 5 6 3}$ & 0.05703 & 0.058917 \\
& $\mathrm{~T}_{\mathrm{p}}(\mathrm{d})$ & 282 & $\mathbf{3 0 1}$ & 324 & 344 \\
\hline \multirow{2}{*}{$\mathbf{C}_{\mathbf{C H} 4}$} & Peak $\left(\mathrm{kg} / \mathrm{m}^{3}\right)$ & 0.00034 & $\mathbf{0 . 0 0 0 3 4 1}$ & 0.00343 & 0.000342 \\
& $\mathrm{~T}_{\mathrm{p}}(\mathrm{d})$ & 369 & $\mathbf{3 8 9}$ & 415 & 444 \\
\hline \multirow{2}{*}{$\mathbf{C}_{\mathbf{X A}}$} & Peak $\left(\mathrm{kg} / \mathrm{m}^{3}\right)$ & 0.000735 & $\mathbf{0 . 0 0 0 7 8 3}$ & 0.000864 & 0.009456 \\
& $\mathrm{~T}_{\mathrm{p}}(\mathrm{d})$ & 82 & $\mathbf{1 1 1}$ & 162 & 211 \\
\hline Acc. $\mathbf{C H}_{4}$ & $\mathrm{~T}_{5 \%}(\mathrm{~d})$ & 289 & $\mathbf{3 0 6}$ & 333 & 359 \\
\hline
\end{tabular}



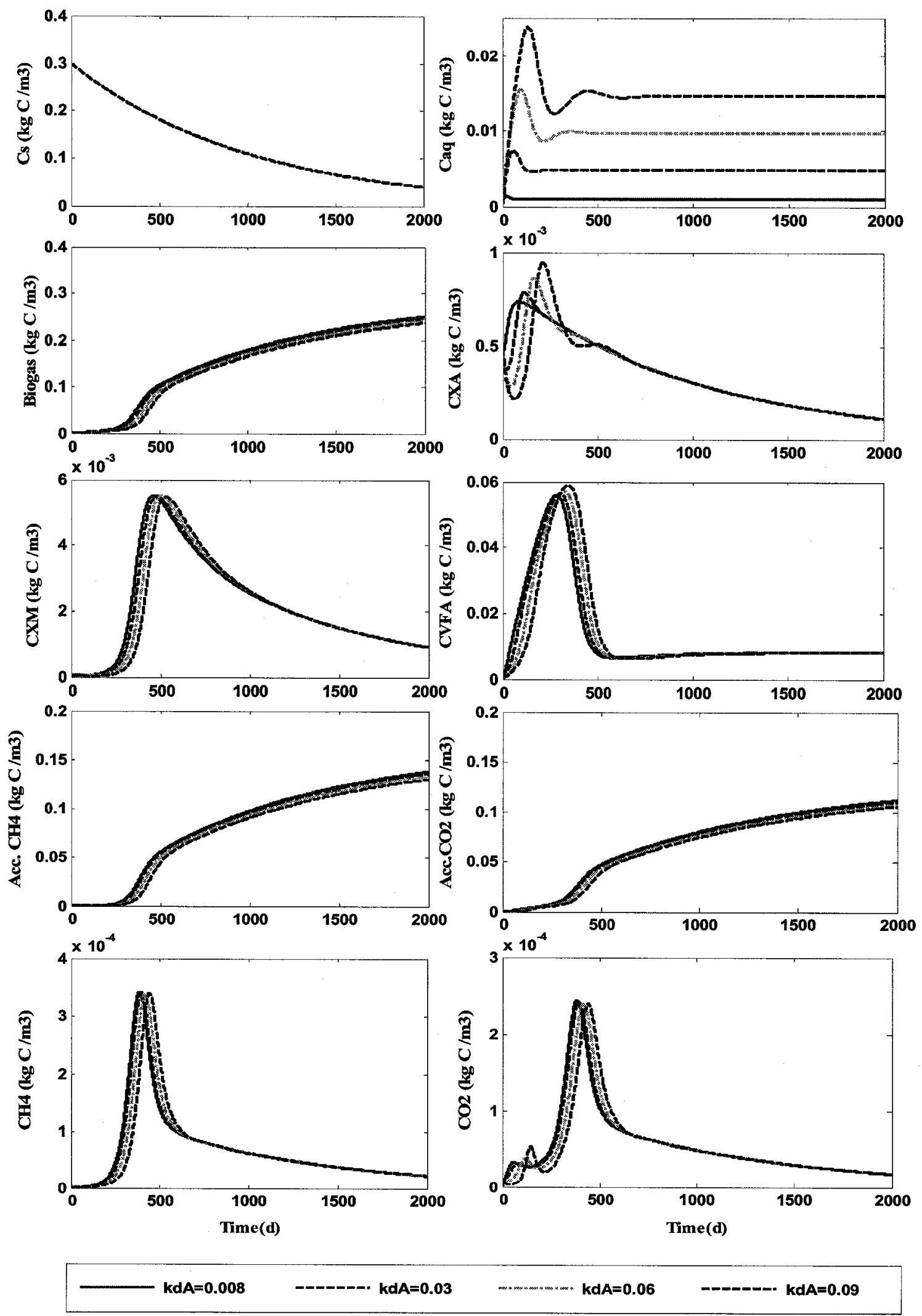

Figure 4.9: Impact of changing the half saturation constant of acidogenic biomass. 
There was an increase by $215 \%$ in the concentration of aqueous organic acids when the $\mathrm{K}_{\mathrm{SA}}$ was increased by a factor of three above the base as the concentration of acidogenic biomass was decreased. Also, the time to reach the peak concentration of acidogenic biomass was almost doubled. The $\mathrm{K}_{\mathrm{SA}}$ had a limited impact on the peaks of VFA and daily methane produced, and just altered the time to reach their peak by 43 and 55 days, respectively.

By decreasing the $\mathrm{K}_{\mathrm{SA}}$ by a factor of five below the base, the peak of aqueous organic acids concentration decreased by $80 \%$ and the time required to reach this peak was shortened by 39 days. The reason for that was that the peak of acidogenic biomass concentration was reached 29 days earlier than the base. The process in terms of $\mathrm{T}_{5 \%}$ and time required to reach the peaks of VFA and daily methane produced occurred earlier by 17 days.

It is clear from Figures 4.7 through 4.9 that the rate of methane producing as illustrated by the peak rate and $T_{5 \%}$, was relatively insensitive to the change in acidogenic parameters.

\subsubsection{Methanogenic biomass}

Generally speaking, changes in the methanogenic parameters $\left(\mu_{M}, k_{d M}, K_{S M}\right)$ had a significant impact on peaks of the VFA and daily methane produced, as well as the time required to reach them.

\subsubsection{Maximum specific growth rate of methanogenic biomass}

Increasing $\mu_{M}$ by a factor of two from the base, caused a decrease in the time required to reach the peak of methanogenic biomass concentration by 132 days as shown in Table 
4.7 and Figure 4.10 . The consequence of that was a $35 \%$ decrease in the peak VFA concentration and the peak concentration occurred 105 days earlier. Furthermore, the peak daily methane production was reached 132 days earlier and the lag time $\left(\mathrm{T}_{5 \%}\right)$ of accumulative methane production was reduced by 97 days.

Table 4.7: Impact of changing the maximum growth rate of methanogenic biomass

\begin{tabular}{|c|c|c|c|c|c|}
\hline \multicolumn{2}{|c|}{ Methanogenic growth rate $\left(\mathrm{d}^{-1}\right)$} & \multirow{2}{*}{$\begin{array}{c}\mu_{M}=0.15 \\
0.07761\end{array}$} & \multirow{2}{*}{$\begin{array}{r}\mu_{M}=0.25 \\
0.0563\end{array}$} & \multirow{2}{*}{$\begin{array}{c}\boldsymbol{\mu}_{\mathrm{M}}=\mathbf{0 . 3 5} \\
0.045681\end{array}$} & \multirow{2}{*}{$\begin{array}{l}\boldsymbol{\mu}_{\mathbf{M}}=\mathbf{0 . 5} \\
0.03677\end{array}$} \\
\hline $\mathrm{C}_{\mathrm{VF}}$ & Peak $\left(\mathrm{kg} / \mathrm{m}^{3}\right)$ & & & & \\
\hline & $\mathrm{T}_{\mathrm{p}}(\mathrm{d})$ & 424 & 301 & 243 & 196 \\
\hline \multirow[t]{2}{*}{$\mathrm{C}_{\mathrm{CH} 4}$} & Peak $\left(\mathrm{kg} / \mathrm{m}^{3}\right)$ & 0.000324 & 0.000341 & 0.000348 & 0.000353 \\
\hline & $T_{p}(d)$ & 551 & 389 & 315 & 257 \\
\hline \multirow{2}{*}{$\mathrm{C}_{\mathbf{X M}}$} & Peak $\left(\mathrm{kg} / \mathrm{m}^{3}\right)$ & 0.006191 & $\mathbf{0 . 0 0 5 5 0 8}$ & 0.005023 & 0.0045279 \\
\hline & $\mathrm{T}_{\mathrm{p}}(\mathrm{d})$ & 644 & 477 & 396 & 345 \\
\hline Acc. CH4 & $\mathrm{T}_{5 \%}(\mathrm{~d})$ & 420 & 306 & 253 & 209 \\
\hline
\end{tabular}

On the other hand, decreasing the $\mu_{\mathrm{M}}$ to $0.15 \mathrm{~d}^{-1}$ caused a $38 \%$ increase in the peak of VFA concentration and the peak concentration was delayed by 123 days because the methanogenic biomass took longer (167 days) to reach maximum concentration. In other words, it took a longer time to consume the VFA. The result of this was a 162-day delay in reaching the peak of daily methane production and an increase of 114 days in the lag time to reach $5 \%$ accumulative methane production.

\subsubsection{Decay rate of methanogenic biomass}

As expected, the response to increasing decay rate $\left(\mathrm{k}_{\mathrm{dM}}\right)$ was opposite to the response of increasing the maximum growth rate $\left(\mu_{\mathrm{M}}\right)$ as shown in Table 4.8 and Figure 4.11. 

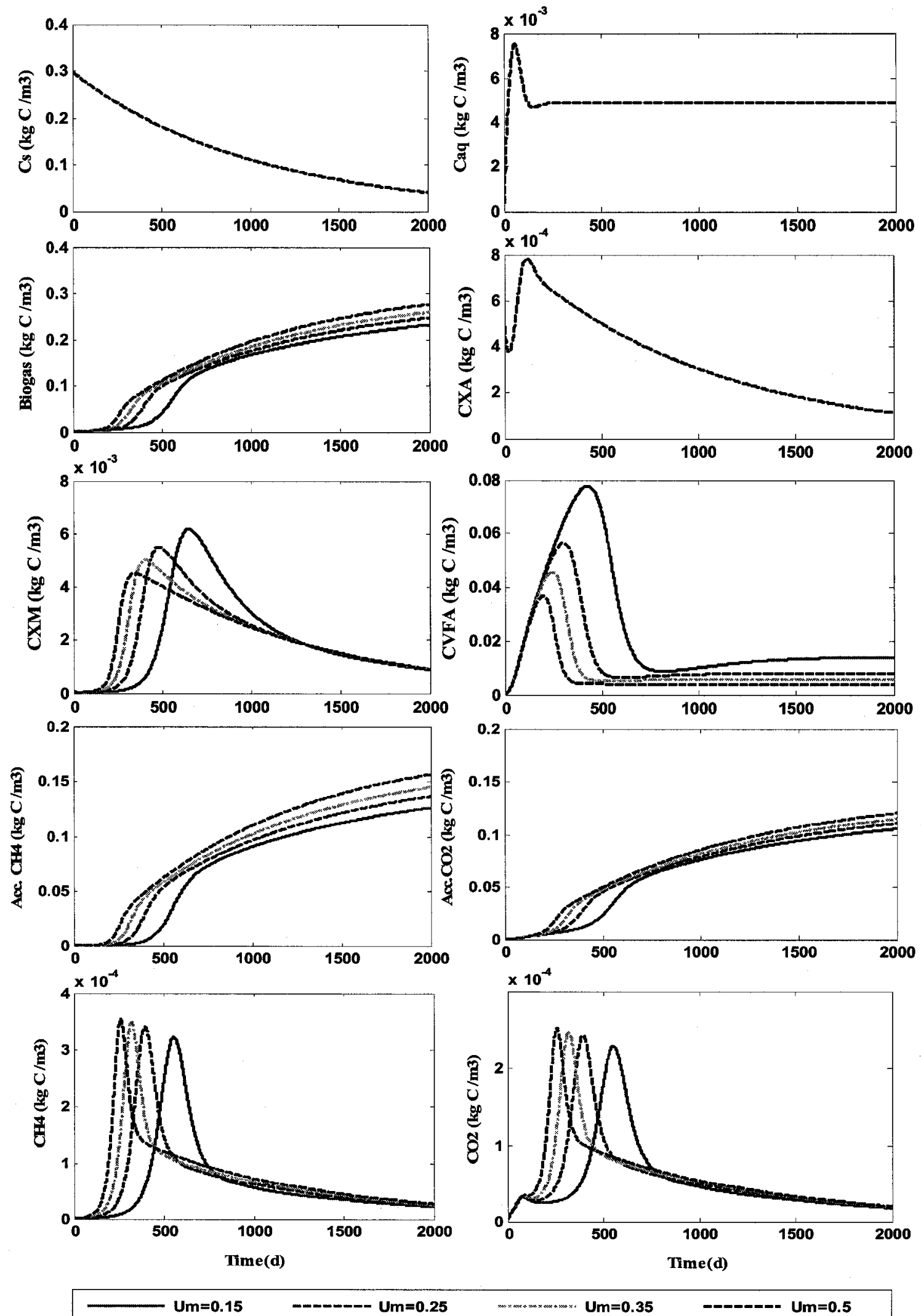

$+\mathrm{Um}=\mathbf{0 . 3 5}$

--_---- Um=0.5

Figure 4.10: Impact of changing the maximum growth rate of methanogenic biomass. 
Increasing the $\mathrm{k}_{\mathrm{dM}}$ by a factor of two above the base caused a $25 \%$ decline in the peak methanogenic biomass concentration which allowed VFA to accumulate, thus increasing the peak VFA concentration by $21 \%$ and the time to reach this peak by 60 days. This resulted in a 70-day increase in the time to reach the peak of methane production and a 60 -day delay in the lag time to reach $5 \%$ accumulative methane production.

Table 4.8: Impact of changing the decay rate of methanogenic biomass

\begin{tabular}{|c|ccccc|}
\hline \multicolumn{2}{|c|}{$\begin{array}{c}\text { Methanogenic decay } \\
\left(\mathbf{d}^{-1}\right)\end{array}$} & $\mathbf{k}_{\mathbf{d M}}=\mathbf{0 . 0 0 2 5}$ & $\mathbf{k}_{\mathbf{d M}}=\mathbf{0 . 0 0 5}$ & $\mathbf{k}_{\mathbf{d M}}=\mathbf{0 . 0 0 7 5}$ & $\mathbf{k}_{\mathbf{d M}}=\mathbf{0 . 0 1}$ \\
\hline $\mathbf{C}_{\text {VFA }}$ & Peak $\left(\mathrm{kg} / \mathrm{m}^{3}\right)$ & 0.051275 & $\mathbf{0 . 0 5 6 3}$ & 0.06189 & 0.068072 \\
& $\mathrm{~T}_{\mathrm{p}}(\mathrm{d})$ & 275 & $\mathbf{3 0 1}$ & 329 & 361 \\
\hline $\mathbf{C}_{\mathbf{C H} \mathbf{4}}$ & Peak $\left(\mathrm{kg} / \mathrm{m}^{3}\right)$ & 0.00033 & $\mathbf{0 . 0 0 0 3 4 1}$ & 0.000352 & 0.000366 \\
& $\mathrm{~T}_{\mathrm{p}}(\mathrm{d})$ & 358 & $\mathbf{3 8 9}$ & 425 & 459 \\
\hline $\mathbf{C}_{\mathbf{X M}}$ & Peak $\left(\mathrm{kg} / \mathrm{m}^{3}\right)$ & 0.00693 & $\mathbf{0 . 0 0 5 5 0 8}$ & 0.00469 & 0.004124 \\
\hline Acc. $\mathbf{C H}_{\mathbf{4}}$ & $\mathrm{T}_{5 \%}(\mathrm{~d})$ & 282 & $\mathbf{3 0 6}$ & 334 & 366 \\
\hline
\end{tabular}

A decrease in the $\mathrm{k}_{\mathrm{dM}}$ by factor of two caused a $26 \%$ increase in the methanogenic biomass concentration, which in turn accelerated the VFA depletion, shortened the time to reach the peak methane production by 31 days and reduced the lag time to reach $5 \%$ accumulative methane production by 24 days.

\subsubsection{Half saturation constant of methanogenic biomass}

$\mathrm{K}_{\mathrm{SM}}$ showed similar results to the $\mathrm{k}_{\mathrm{dM}}$, as shown in Table 4.9 and Figure 4.12 ; that is, increasing the $\mathrm{K}_{\mathrm{SM}}$ by a factor of two above the base caused a longer time ( 220 days) for the methanogenic biomass to reach the maximum concentration. Consequently, there was a $49 \%$ increase in the peak VFA concentration and the time to reach this peak increased 

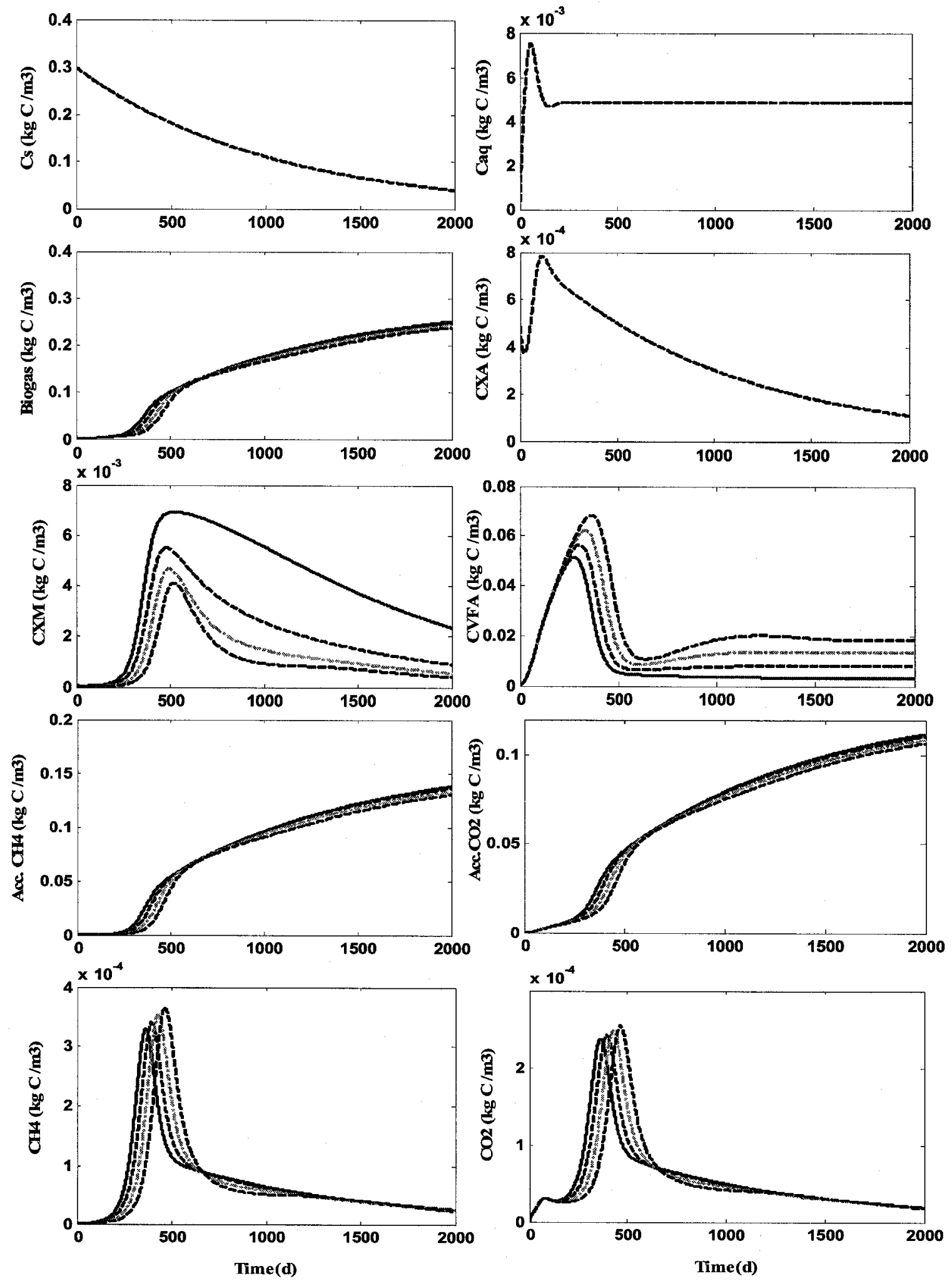

$k d M=0.0025$

$\mathbf{k d M}=\mathbf{0 . 0 0 5}$

$\mathrm{sdM}=0.0075$

$--m-0.01$

Figure 4.11: Impact of changing the decay rate of methanogenic biomass. 
as well by 162 days. A delay in the VFA consumption resulted in an increase in the time to reach the peak of daily methane produced by 208 days and a lag time to reach $5 \%$ accumulative methane production by 150 days.

Table 4.9: Impact of changing the half saturation constant of methanogenic biomass

\begin{tabular}{|c|c|c|c|c|c|}
\hline \multicolumn{2}{|c|}{$\begin{array}{c}\text { Half saturation of } \\
\text { methanogenic }\left(\mathrm{kg} / \mathrm{m}^{3}\right)\end{array}$} & $K_{S M}=0.1$ & $K_{S M}=0.5$ & $K_{S M}=0.75$ & $K_{S M}=1.0$ \\
\hline \multirow[t]{2}{*}{$\mathrm{C}_{\text {VFA }}$} & Peak $\left(\mathrm{kg} / \mathrm{m}^{3}\right)$ & 0.022901 & 0.0563 & 0.07117 & 0.084059 \\
\hline & $\mathrm{T}_{\mathrm{p}}(\mathrm{d})$ & 129 & 301 & 385 & 463 \\
\hline \multirow{2}{*}{$\mathrm{C}_{\mathrm{CH} 4}$} & Peak $\left(\mathrm{kg} / \mathrm{m}^{3}\right)$ & 0.000347 & 0.000341 & 0.000333 & 0.000323 \\
\hline & $\mathrm{T}_{\mathrm{p}}(\mathrm{d})$ & 166 & 389 & 492 & 597 \\
\hline \multirow{2}{*}{$\mathbf{C}_{\mathbf{X M}}$} & Peak $\left(\mathrm{kg} / \mathrm{m}^{3}\right)$ & 0.003805 & 0.005508 & 0.00599 & 0.00627 \\
\hline & $\mathrm{T}_{\mathrm{p}}(\mathrm{d})$ & 357 & 477 & 593 & 697 \\
\hline Acc. $\mathrm{CH}_{4}$ & $\mathrm{~T}_{5 \%}(\mathrm{~d})$ & 145 & 306 & 384 & 456 \\
\hline
\end{tabular}

Decreasing the $\mathrm{K}_{\mathrm{SM}}$ by a factor of five below the base, caused a decrease in the time required to reach the peak of methanogenic biomass concentration by 120 days. The result of that was a decrease in the peak VFA concentration by $59 \%$ and the time required to reach this peak by 172 days; and a decrease in the time required to reach the peak daily methane production and lag time to reach 5\% accumulative methane production by 223 and 161 days, respectively.

The biodegradation process, in terms of peaks VFA concentration and daily methane production, time to reach their peaks, and time required to reach $5 \%$ accumulative methane production proved to be highly sensitive to any change in the methanogenic parameters as illustrated in Figures 4.10 through 4.12. 

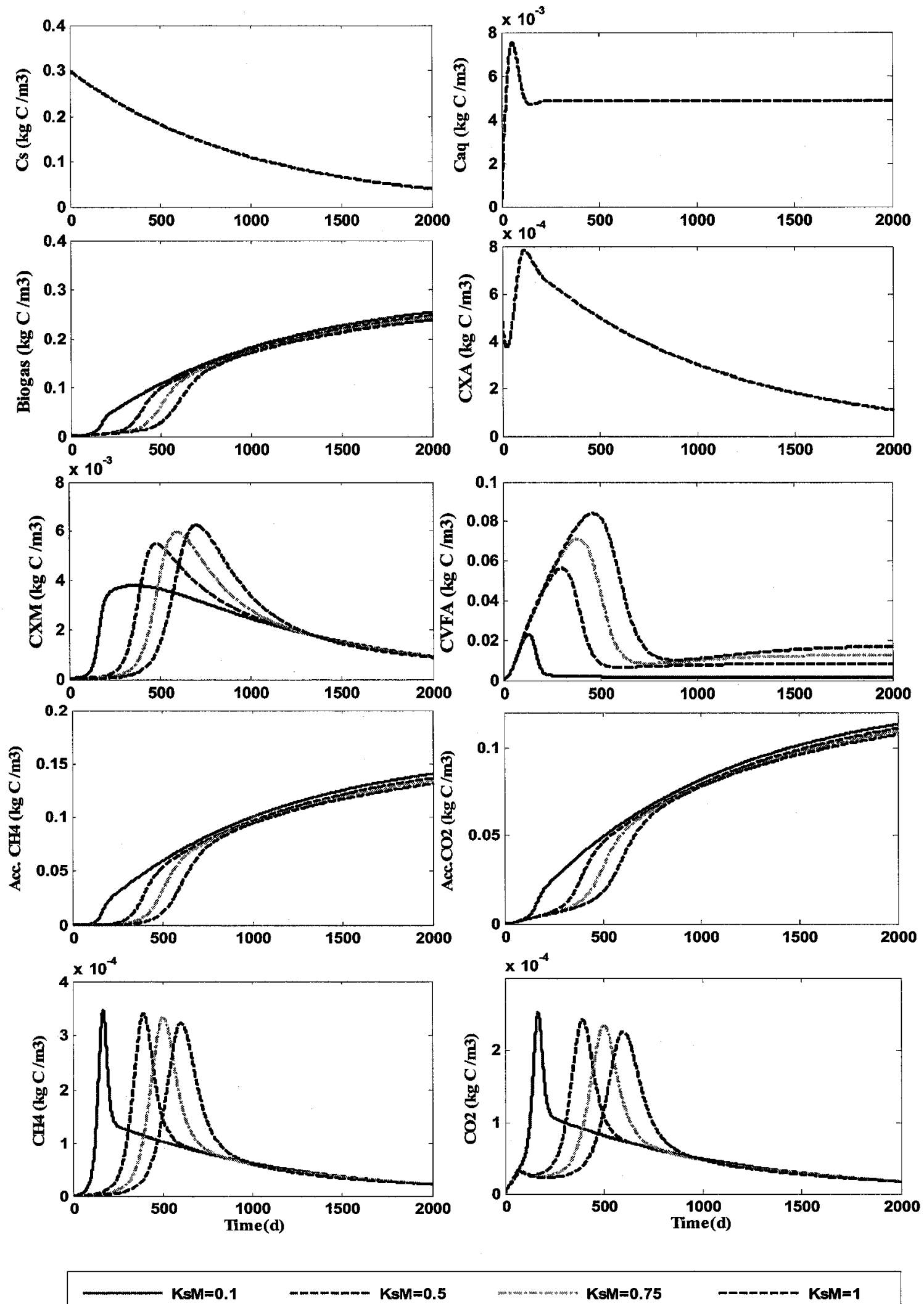

$\mathrm{KsM}=0.75$

$\mathrm{KsM}=1$

Figure 4.12: Impact of changing half saturation constant of methanogenic biomass. 


\subsubsection{Initial condition}

In general, minor variations were observed by changing the initial concentration of aqueous acids, VFA and acidogenic biomass. However, major variations occurred by changing the initial concentration of methanogenic biomass.

\subsubsection{Initial aqueous organic acid concentration}

Increasing the initial concentration of aqueous organic acids $\left(\mathrm{C}_{\mathrm{aq}}\right)$ by a factor of 10 above the base, caused no significant impact on the peaks of VFA, daily methane produced and the lag time to reach $5 \%$ accumulative methane production, as shown in Table 4.10 and Figure 4.13. The process in terms of time required to reach the peak VFA and daily methane production, and lag time to reach $5 \%$ accumulative methane production is decreased by approximately 5 days when the $C_{a q}$ increased by a factor of 10 .

Also there was no significant impact observed when the $C_{a q}$ decreased by a factor of 10 below the base.

Table 4.10: Impact of changing the initial condition of aqueous organic acids

\begin{tabular}{|c|ccccc|}
\hline $\begin{array}{c}\text { Aqueous organic acids } \\
\left(\mathbf{k g} / \mathbf{m}^{\mathbf{3}}\right)\end{array}$ & $\mathbf{C}_{\mathrm{aq}}=\mathbf{0 . 0 0 0 0 1}$ & $\mathbf{C}_{\mathbf{a q}}=\mathbf{0 . 0 0 0 1}$ & $\mathbf{C}_{\mathrm{aq}}=\mathbf{0 . 0 0 0 5}$ & $\mathbf{C}_{\mathbf{a q}}=\mathbf{0 . 0 0 1}$ \\
\hline $\mathbf{C}_{\mathbf{V F A}}$ & Peak $\left(\mathrm{kg} / \mathrm{m}^{3}\right)$ & 0.056307 & $\mathbf{0 . 0 5 6 3}$ & 0.05626 & 0.05623 \\
& $\mathrm{~T}_{\mathrm{p}}(\mathrm{d})$ & 301 & $\mathbf{3 0 1}$ & 299 & 297 \\
\hline $\mathbf{C}_{\mathbf{C H} 4}$ & Peak $\left(\mathrm{kg} / \mathrm{m}^{3}\right)$ & 0.000341 & $\mathbf{0 . 0 0 0 3 4 1}$ & 0.000341 & 0.000341 \\
& $\mathrm{~T}_{\mathrm{p}}(\mathrm{d})$ & 389 & $\mathbf{3 8 9}$ & 387 & 384 \\
\hline \multirow{2}{*}{$\mathbf{C}_{\mathbf{X M}}$} & Peak $\left(\mathrm{kg} / \mathrm{m}^{3}\right)$ & 0.005508 & $\mathbf{0 . 0 0 5 5 0 8}$ & 0.005509 & 0.005513 \\
& $\mathrm{~T}_{\mathrm{p}}(\mathrm{d})$ & 478 & $\mathbf{4 7 7}$ & 476 & 473 \\
\hline Acc. $\mathbf{C H}_{4}$ & $\mathrm{~T}_{5 \%}(\mathrm{~d})$ & 307 & $\mathbf{3 0 6}$ & 303 & 302 \\
\hline
\end{tabular}



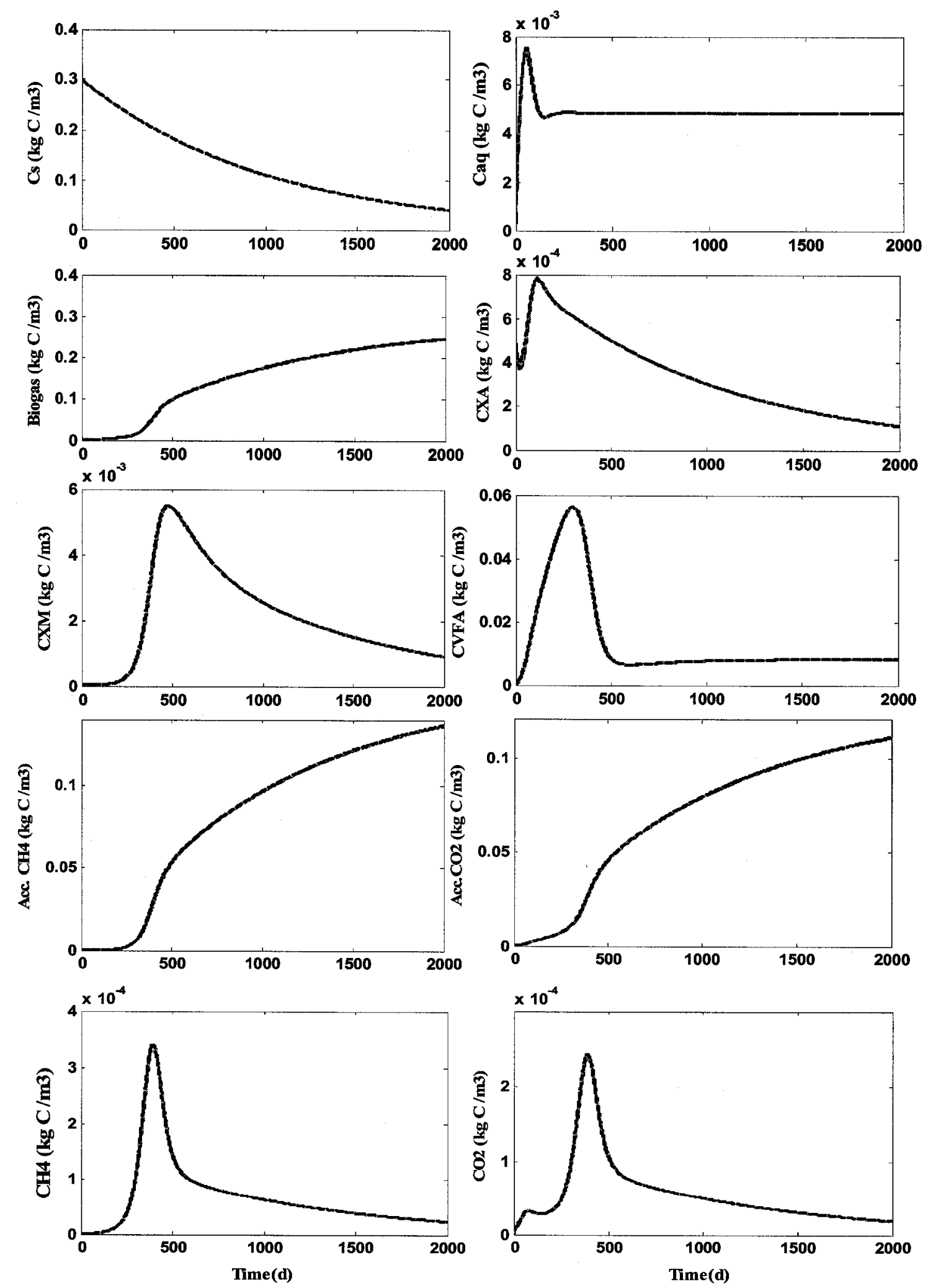

$\mathrm{Caq}=\mathbf{0 . 0 0 0 0 1}$

Caq $=0.0001$

Caq $=0.0005$

$\mathrm{Caq}=0.001$

Figure 4.13: Impact of changing the initial condition of aqueous acid. 


\subsubsection{Initial VFA concentration}

Increasing the initial concentration of VFA by a factor of 10 showed similar results to the increase in the initial concentration of aqueous organic acids. Table 4.11 and Figure 4.14 show the results of changing the initial concentration of VFA.

Table 4.11: Impact of changing the initial condition of VFA

\begin{tabular}{|c|c|c|c|c|c|}
\hline \multicolumn{2}{|c|}{ VFA $\left(\mathrm{kg} / \mathrm{m}^{3}\right)$} & $\mathrm{C}_{\mathrm{VFA}}=0.00001$ & $C_{\text {VFA }}=0.0001$ & $C_{\text {VFA }}=0.0005$ & $C_{\text {VFA }}=0.001$ \\
\hline $\mathrm{C}_{\text {VFa }}$ & $\begin{array}{c}\text { Peak }\left(\mathrm{kg} / \mathrm{m}^{3}\right) \\
\mathrm{T}_{\mathrm{p}}(\mathrm{d})\end{array}$ & $\begin{array}{c}0.056309 \\
301\end{array}$ & $\begin{array}{c}0.0563 \\
301\end{array}$ & $\begin{array}{c}0.05629 \\
299\end{array}$ & $\begin{array}{c}0.056213 \\
296\end{array}$ \\
\hline $\mathrm{C}_{\mathrm{CH} 4}$ & $\begin{array}{c}\text { Peak }\left(\mathrm{kg} / \mathrm{m}^{3}\right) \\
\mathrm{T}_{\mathrm{p}}(\mathrm{d})\end{array}$ & $\begin{array}{c}0.000341 \\
389\end{array}$ & $\begin{array}{c}0.000341 \\
389\end{array}$ & $\begin{array}{c}0.000341 \\
388\end{array}$ & $\begin{array}{c}0.000341 \\
384\end{array}$ \\
\hline $\mathbf{C}_{\mathbf{X M}}$ & $\begin{array}{c}\text { Peak }\left(\mathrm{kg} / \mathrm{m}^{3}\right) \\
\mathrm{T}_{\mathrm{p}}(\mathrm{d})\end{array}$ & $\begin{array}{c}0.005507 \\
478\end{array}$ & $\begin{array}{c}0.005508 \\
477\end{array}$ & $\begin{array}{c}0.00551 \\
476\end{array}$ & $\begin{array}{c}0.005513 \\
472\end{array}$ \\
\hline Acc. $\mathrm{CH}_{4}$ & $\mathrm{~T}_{5 \%}$ & 307 & 306 & 304 & 302 \\
\hline
\end{tabular}

\subsubsection{Initial acidogenic biomass concentration}

Increasing the initial acidogenic biomass concentration $\left(\mathrm{C}_{\mathrm{XA}}\right)$ by a factor of 10 above the base caused a $36 \%$ decrease in the peak aqueous acid concentration, which in turn decreased the time required to reach the peak VFA, daily methane production and lag time to reach $5 \%$ accumulative methane production by 23,22 , and 28 days, respectively. There was no significant difference in the peak VFA and daily methane produced, as shown in Figure 4.15 and Table 4.12.

As expected, the response to decreasing the $\mathrm{C}_{\mathrm{XA}}$ by a factor of 10 below the base was a $101 \%$ increased in the peak $\mathrm{C}_{\mathrm{aq}}$. The result of this was an increase in the time required to 

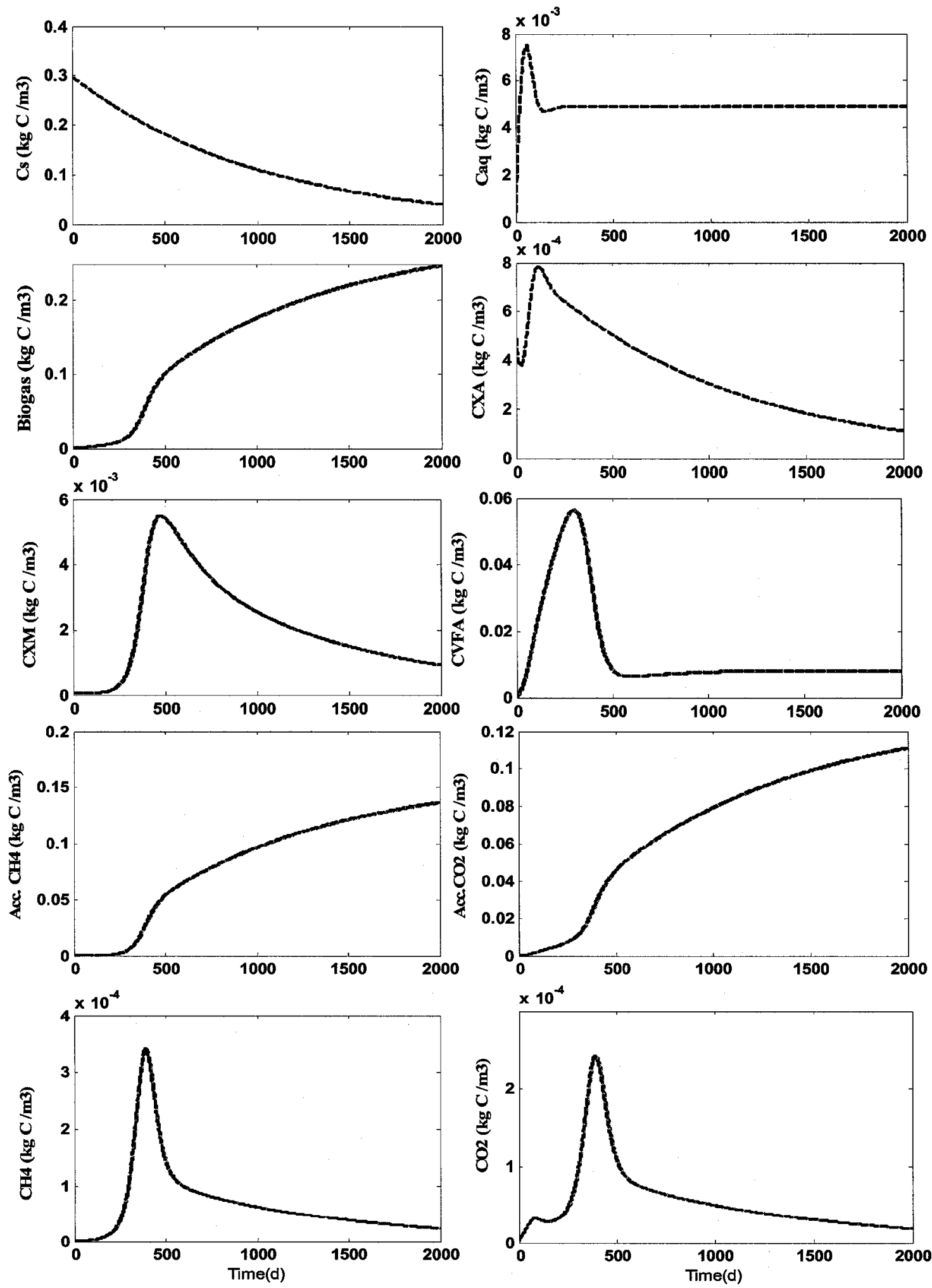

CVFA $=0.00001$

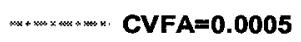

- CUAA=0.001

Figure 4.14: Impact of changing the initial condition of VFA. 

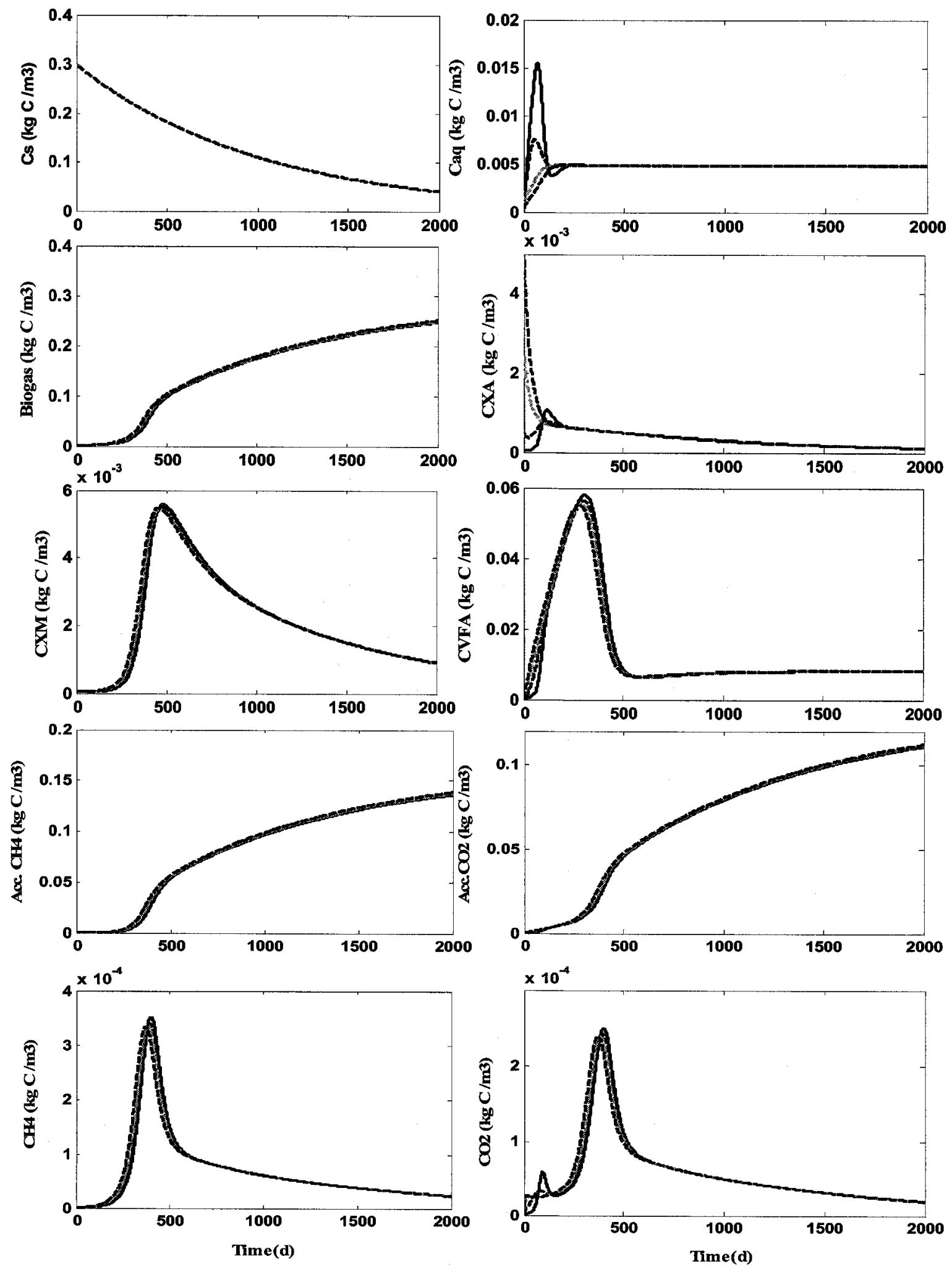

CXA=0.00005 CXA=0.0005 CXA=0.0025 -

Figure 4.15: Impact of changing the initial condition of acidogenic biomass. 
reach the peak VFA and daily methane production, and the lag time to reach $5 \%$ accumulative methane production by 7,7 , and 9 days, respectively.

Table 4.12: Impact of changing the initial condition of acidogenic biomass

\begin{tabular}{|c|ccccc|}
\hline \multicolumn{2}{|c}{$\begin{array}{c}\text { Acidogenic biomass } \\
\left(\mathbf{k g} / \mathbf{m}^{3}\right)\end{array}$} & $\mathbf{C}_{\mathbf{X A}}=\mathbf{5 E - 5}$ & $\mathbf{C}_{\mathbf{X A}}=\mathbf{5 E}-4$ & $\mathbf{C}_{\mathbf{X A}}=\mathbf{2 . 5 E - 3}$ & $\mathbf{C}_{\mathbf{X A}}=5 \mathrm{E}-3$ \\
\hline $\mathbf{C}_{\mathbf{a q}}$ & Peak $\left(\mathrm{kg} / \mathrm{m}^{3}\right)$ & 0.015585 & $\mathbf{0 . 0 0 7 7 5 2 8}$ & 0.00493 & 0.00493 \\
\hline $\mathbf{C}_{\mathrm{VFA}}$ & Peak $\left(\mathrm{kg} / \mathrm{m}^{3}\right)$ & 0.05784 & $\mathbf{0 . 0 5 6 3}$ & 0.05536 & 0.055087 \\
& $\mathrm{~T}_{\mathrm{p}}(\mathrm{d})$ & 308 & $\mathbf{3 0 1}$ & 290 & 278 \\
\hline $\mathbf{C}_{\mathbf{C H} 4}$ & Peak $\left(\mathrm{kg} / \mathrm{m}^{3}\right)$ & 0.000352 & $\mathbf{0 . 0 0 0 3 4 1}$ & 0.0003359 & 0.000336 \\
& $\mathrm{~T}_{\mathrm{p}}(\mathrm{d})$ & 396 & $\mathbf{3 8 9}$ & 380 & 367 \\
\hline Acc. $\mathbf{C H}_{4}$ & $\mathrm{~T}_{5 \%}(\mathrm{~d})$ & 315 & $\mathbf{3 0 6}$ & 294 & 278 \\
\hline
\end{tabular}

\subsubsection{Initial methanogenic biomass concentration}

Increasing the initial concentration of the methanogenic biomass $\left(\mathrm{C}_{\mathrm{XM}}\right)$ by a factor of 10 above the base caused 38\% reduction in the VFA peak concentration, and the time to reach its peak occurred 78 days earlier, as shown in Figure 4.16 and Table 4.13. The result of this was the peak of daily methane production occurred 79 days earlier and the lag time to reach $5 \%$ accumulative methane production was reduced by 107 days.

In addition, by decreasing $\mathrm{C}_{\mathrm{XM}}$ by a factor of 10 , the opposite impact was observed. The VFA were accumulated and their peak concentration and time to reach their peak increased by $30 \%$ and 72 days, respectively. Consequently, the peak of daily methane production was delayed by 71 days and the lag time to reach $5 \%$ accumulative methane production increased by 84 days. 

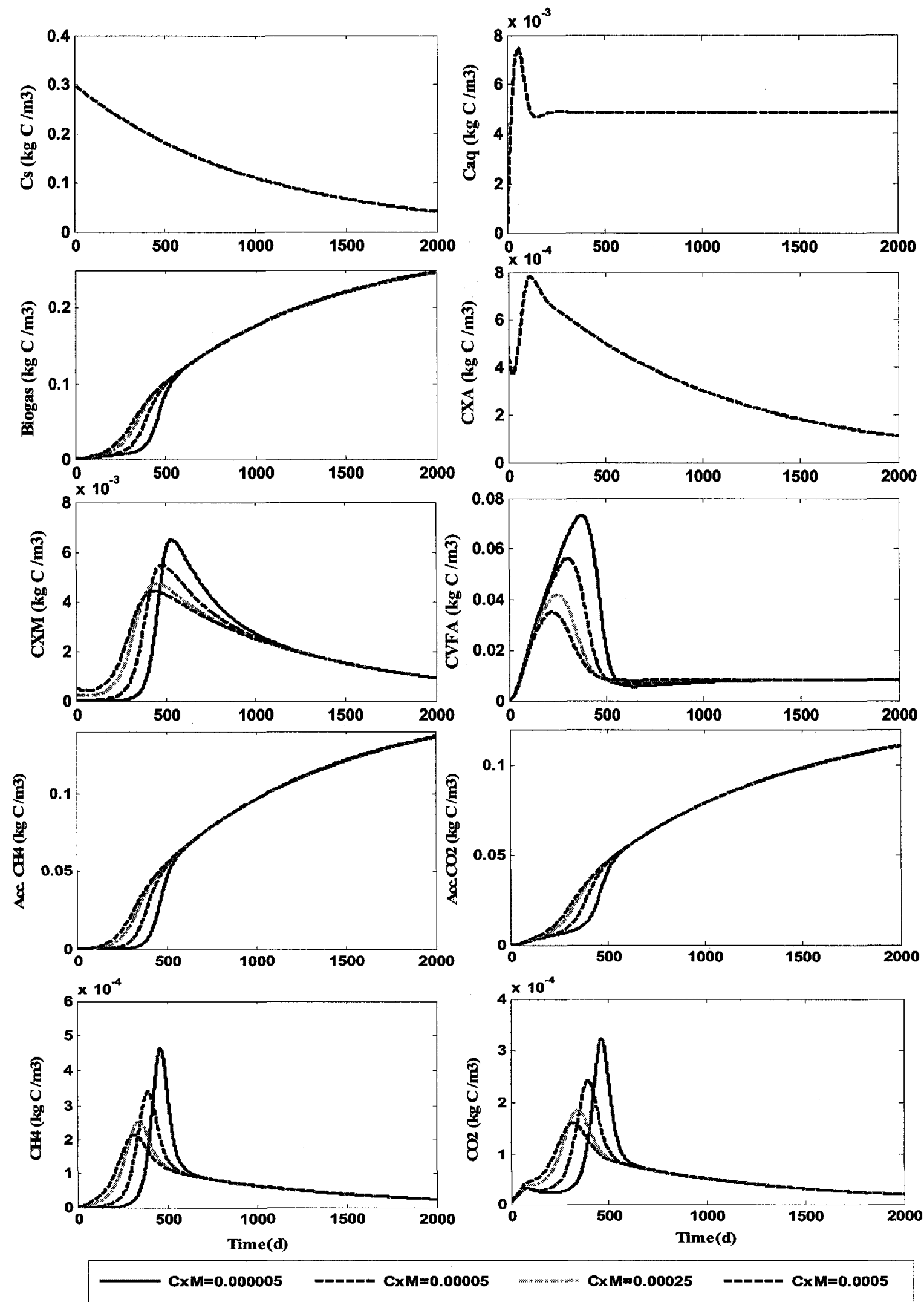

Figure 4.16: Impact of changing the initial condition of methanogenic biomass. 
Table 4.13: Impact of changing the initial condition of methanogenic biomass

\begin{tabular}{|c|c|c|c|c|c|}
\hline \multicolumn{2}{|c|}{$\begin{array}{c}\text { Methanogenic biomass } \\
\left(\mathrm{kg} / \mathrm{m}^{3}\right)\end{array}$} & $\mathrm{C}_{\mathrm{XM}}=5 \mathrm{E}-6$ & $\mathrm{C}_{\mathrm{XM}}=5 \mathrm{E}-5$ & $\mathrm{C}_{\mathrm{XM}}=2.5 \mathrm{E}-4$ & $C_{X M}=5 E-4$ \\
\hline \multirow{2}{*}{$\mathrm{C}_{\mathrm{VFA}}$} & Peak $\left(\mathrm{kg} / \mathrm{m}^{3}\right)$ & 0.072945 & 0.0563 & 0.04188 & 0.0349315 \\
\hline & $T_{p}(d)$ & 373 & 301 & 247 & 223 \\
\hline \multirow{2}{*}{$\mathrm{C}_{\mathrm{CH} 4}$} & Peak $\left(\mathrm{kg} / \mathrm{m}^{3}\right)$ & 0.000466 & 0.000341 & 0.0002528 & 0.000217 \\
\hline & $\mathrm{T}_{\mathrm{p}}(\mathrm{d})$ & 460 & 389 & 350 & 310 \\
\hline \multirow{2}{*}{$\mathrm{C}_{\mathbf{X M}}$} & Peak $\left(\mathrm{kg} / \mathrm{m}^{3}\right)$ & 0.006505 & 0.005508 & 0.004749 & 0.004439 \\
\hline & $\mathrm{T}_{\mathrm{p}}(\mathrm{d})$ & 531 & 477 & 446 & 432 \\
\hline Acc. $\mathrm{CH}_{4}$ & $\mathrm{~T}_{5 \%}(\mathrm{~d})$ & 390 & 306 & 234 & 199 \\
\hline
\end{tabular}

\subsubsection{Summary of sensitivity analysis}

- The highly sensitive parameter in the model was the hydrolysis rate constant.

- The model showed more sensitivity to methanogenic parameters $\left(\mu_{M}, k_{d M}, K_{S M}\right)$ than to acidogenic parameters $\left(\mu_{\mathrm{A}}, \mathrm{k}_{\mathrm{dA}}, \mathrm{K}_{\mathrm{SA}}\right)$.

- No significant impact was observed when changing the acidogenic biomass parameters on the peaks VFA and daily methane production, only a small variation in the time to reach the peaks.

- The model showed more sensitivity to initial concentration of methanogenic biomass than other initial concentrations $\left(\mathrm{C}_{\mathrm{aq}}, \mathrm{C}_{\mathrm{VFA}}\right.$, and $\left.\mathrm{C}_{\mathrm{XA}}\right)$.

- There were no significant variations occurred when changing the initial concentrations of $\mathrm{C}_{\mathrm{aq}}$ and $\mathrm{C}_{\mathrm{VFA}}$ in terms of the values and time to reach the peaks of VFA and daily methane production.

- The initial concentration of $\mathrm{C}_{\mathrm{XA}}$ causes a significant impact only on the peak of $\mathrm{C}_{\mathrm{aq}}$ concentration. Also, a slight shift occurred in the time to reach the peak VFA and daily methane production. 


\section{Chapter 5}

\section{Results and discussion}

This chapter provides an overview of the results obtained from two groups of experiments (1D bioreactors and BMP assays) conducted to study the effect of salinity on the performance of MSW bioreactors operated with and without sludge addition and to estimate the hydrolysis rate constant at different salt content. Also, the results of model calibration are included.

It is divided into three sections. The first section covers the results obtained from the 1D bioreactors. The second section presents the result from the BMP assays to determine the hydrolysis rate constant. Finally, the model calibration and parameter estimates are covered in the third section. The complete experimental data discussed in this chapter are presented in Appendix A and the statistical tables are included in Appendix B. All statistical analysis were conducted at $5 \%$ significance level.

\subsection{D bioreactors}

This section presents the behavior of two groups of 1D bioreactors operated under different saline conditions $(0,0.5,1,3) \%(w / v)$, one group without sludge addition (group one, R1-R4) the other group with sludge addition (group two, R5-R8). Three major topics are discussed in this section. First, solid waste results, including initial and final moisture content, temperature profile, and settlements. Second, results of landfill gases, including methane generation and concentration produced from 1D bioreactors and BMP assays. Third, results of leachate quality, including variations in effluent $\mathrm{COD}, \mathrm{BOD}, \mathrm{VFA}, \mathrm{pH}$, 
TVS, TS, $\mathrm{NH}_{3}-\mathrm{N}$, salinity, vertical concentration (in terms of COD) profile within the bioreactors, and potential shortcircuiting.

\subsubsection{Solid waste}

This subsection covers the change in the moisture content, temperature and settlement that occurred during the study.

\subsubsection{Moisture content}

The moisture content of MSW samples were measured before packing them into the bioreactors (initial) and at the end of the study (final). The initial and final moisture content (weight basis) are shown in Table 5.1

Table 5.1: Initial and final moisture content

\begin{tabular}{|l|l|cccc|cccc|}
\hline \multicolumn{2}{|c|}{ Moisture content } & R1 & R2 & R3 & R4 & R5 & R6 & R7 & R8 \\
\hline \multirow{3}{*}{ Mean } & Initial & 0.39 & 0.40 & 0.36 & 0.44 & 0.42 & 0.42 & 0.43 & 0.41 \\
\cline { 2 - 9 } & Final & 0.63 & 0.62 & 0.64 & 0.61 & 0.63 & 0.63 & 0.63 & 0.65 \\
\cline { 2 - 9 } & Average $^{1}$ & \multicolumn{1}{|c|}{0.41} \\
\cline { 2 - 9 } & Average $^{2}$ & \multicolumn{10}{|c}{0.63} \\
\hline \multirow{2}{*}{ P-value } & Stages $^{3}$ & \multicolumn{10}{|c}{0.000} \\
\end{tabular}

(1) Average initial moisture content.

(2) Average final moisture content.

(3) Comparison between the mean initial and final moisture content $\left(\mathrm{F}_{\mathrm{k}-1, \mathrm{n}-\mathrm{k}}=\mathrm{F}_{1,14}\right)^{*}$.

*) Where $\mathrm{k}$ is the number of groups and $\mathrm{n}$ is the number of observations (One way ANOVA). For more details see Appendix B.

The range of initial moisture varied from 0.39 to 0.44 . The average initial moisture content was 0.41 , whereas the average final moisture content was 0.63 . The final moisture content of MSW represents the field capacity. 
Table 5.2 shows final moisture content (w/w) in different layers (top, mid and bottom). The average moisture content was $0.60,0.63$ and 0.65 in the top, mid and bottom layers, respectively. The highest moisture content was recorded in the bottom layer which agreed

Table 5.2: Profile of final moisture content

\begin{tabular}{|c|c|c|c|c|c|c|c|c|c|}
\hline \multicolumn{2}{|c|}{ Moisture content } & $\mathrm{R} 1$ & $\mathrm{R} 2$ & $\mathrm{R} 3$ & $\mathrm{R} 4$ & $\mathrm{R} 5$ & R6 & $\mathrm{R} 7$ & $\mathrm{R} 8$ \\
\hline \multirow{5}{*}{$\begin{array}{l}\text { Mean } \\
\text { layer }\end{array}$} & Top (T) & 0.59 & 0.58 & 0.61 & 0.57 & 0.61 & 0.62 & 0.62 & 0.63 \\
\hline & $\operatorname{Mid}(\mathrm{M})$ & 0.61 & 0.63 & 0.64 & 0.62 & 0.63 & 0.63 & 0.63 & 0.64 \\
\hline & Bottom (B) & 0.67 & 0.64 & 0.66 & 0.63 & 0.64 & 0.64 & 0.64 & 0.67 \\
\hline & Average & 0.63 & 0.62 & 0.64 & 0.61 & 0.63 & 0.63 & 0.63 & 0.65 \\
\hline & $\begin{array}{l}\text { Average of } \\
\text { layers }\end{array}$ & \multicolumn{3}{|c|}{$0.60^{\mathrm{T}}$} & \multicolumn{2}{|c|}{$0.63^{\mathrm{M}}$} & \multicolumn{3}{|c|}{$0.65^{\mathrm{B}}$} \\
\hline \multirow{2}{*}{ P-value } & Layers ${ }^{1}$ & 0.07 & 0.39 & 0.16 & 0.59 & 0.13 & 0.27 & 0.39 & 0.39 \\
\hline & Bioreactors $^{2}$ & \multicolumn{8}{|c|}{0.26} \\
\hline
\end{tabular}

(1) Comparison of the mean final moisture content in all layers within each bioreactor $\left(\mathrm{F}_{2,6}\right)$.

(2) Comparison of the mean final moisture content in all bioreactors $\left(\mathrm{F}_{7,64}\right)$.

with the results presented by Chiemchaisri et al. (2002). They found there was little difference in moisture content in the experiments that they performed with various bioreactors and that moisture content was higher in the bottom part than in the upper part of their bioreactors.

\section{Statistical analysis}

The objective of the statistical analysis was to investigate whether there was any significant difference 1) between the mean initial and final moisture contents, 2) in the vertical moisture profile within the bioreactors, and 3) in the mean final moisture content in all bioreactors. 
First, the P-value of Stages ${ }^{3}$ was less than 0.05 as shown in Table 5.1. That means that there was a significant difference between the mean initial and final moisture contents in the bioreactors.

Second, the P-value of Layers ${ }^{1}$ was more than 0.05 in all bioreactors as shown in Table 5.2. This indicates that there was no significant difference in the mean final moisture content in all layers within each bioreactor. In other words, there was no significant difference in the vertical moisture profile in the bioreactors.

Third, the P-value of Bioreactors ${ }^{2}$ was more than 0.05 as shown in Table 5.2, meaning that there was no significant difference in the mean of final moisture content in all bioreactors.

\subsubsection{Temperature profile}

Table 5.3 summarizes the temperature profile and statistical analysis. The variations of temperature in all bioreactors are shown in Figures 5.1 and 5.2.

Table 5.3: Temperature profile and statistical analysis

\begin{tabular}{|c|c|c|c|c|c|c|c|c|c|}
\hline \multicolumn{2}{|c|}{ Temperature $\left({ }^{\circ} \mathrm{C}\right)$} & $\mathrm{R} 1$ & R2 & $\overline{\mathrm{R} 3}$ & $\mathrm{R} 4$ & $\mathrm{R} 5$ & R6 & R7 & $\mathrm{R} 8$ \\
\hline \multirow{5}{*}{$\begin{array}{l}\text { Mean } \\
\text { layer }\end{array}$} & Top (T) & 26.09 & 25.49 & 25.21 & 24.59 & 24.40 & 24.01 & 24.35 & 24.86 \\
\hline & Mid (M) & 26.49 & 25.59 & 26.19 & 25.61 & 24.93 & 24.70 & 25.38 & 25.80 \\
\hline & Bottom (B) & 24.88 & 24.50 & 24.75 & 24.44 & 23.70 & 23.80 & 23.56 & 24.23 \\
\hline & Average & 25.81 & 25.19 & 25.38 & 24.88 & 24.34 & 24.17 & 24.43 & 24.96 \\
\hline & $\begin{array}{l}\text { Average of } \\
\text { layers }\end{array}$ & \multicolumn{3}{|c|}{$24.88^{\mathrm{T}}$} & \multicolumn{2}{|c|}{$25.60^{\mathrm{M}}$} & \multicolumn{3}{|c|}{$24.23^{\mathrm{B}}$} \\
\hline \multirow{2}{*}{ P-value } & Layers 1 & 0.38 & 0.15 & 0.06 & 0.28 & 0.36 & 0.51 & 0.10 & 0.07 \\
\hline & Bioreactors $^{2}$ & \multicolumn{8}{|c|}{0.009} \\
\hline
\end{tabular}

(1) Comparison of the mean temperature in all layers within each bioreactor $\left(F_{2,36}\right)$.

(2) Comparison of the mean temperatures in all bioreactors $\left(\mathrm{F}_{7,304}\right)$. 

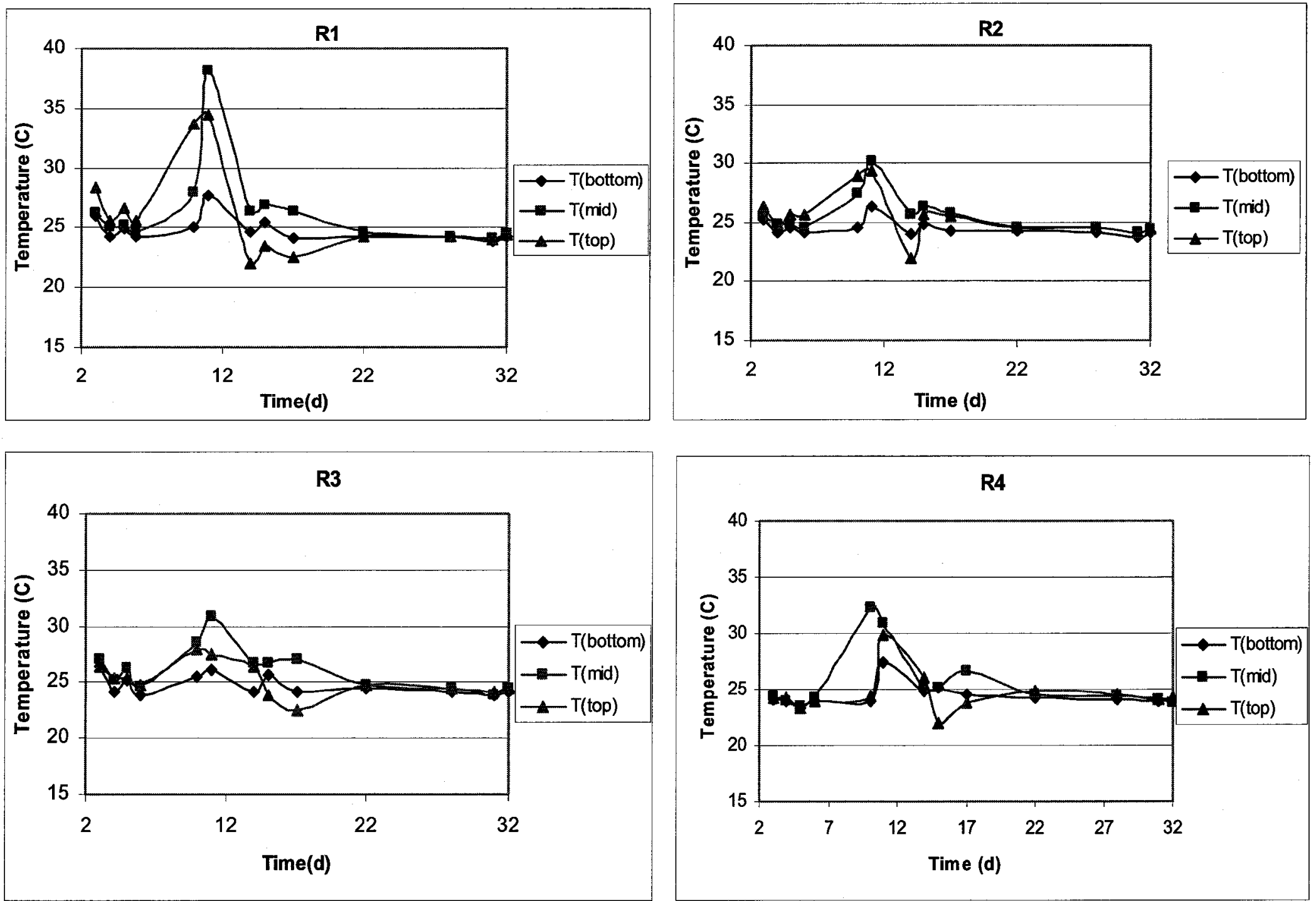

Figure 5.1: Temperature profile in group one. 

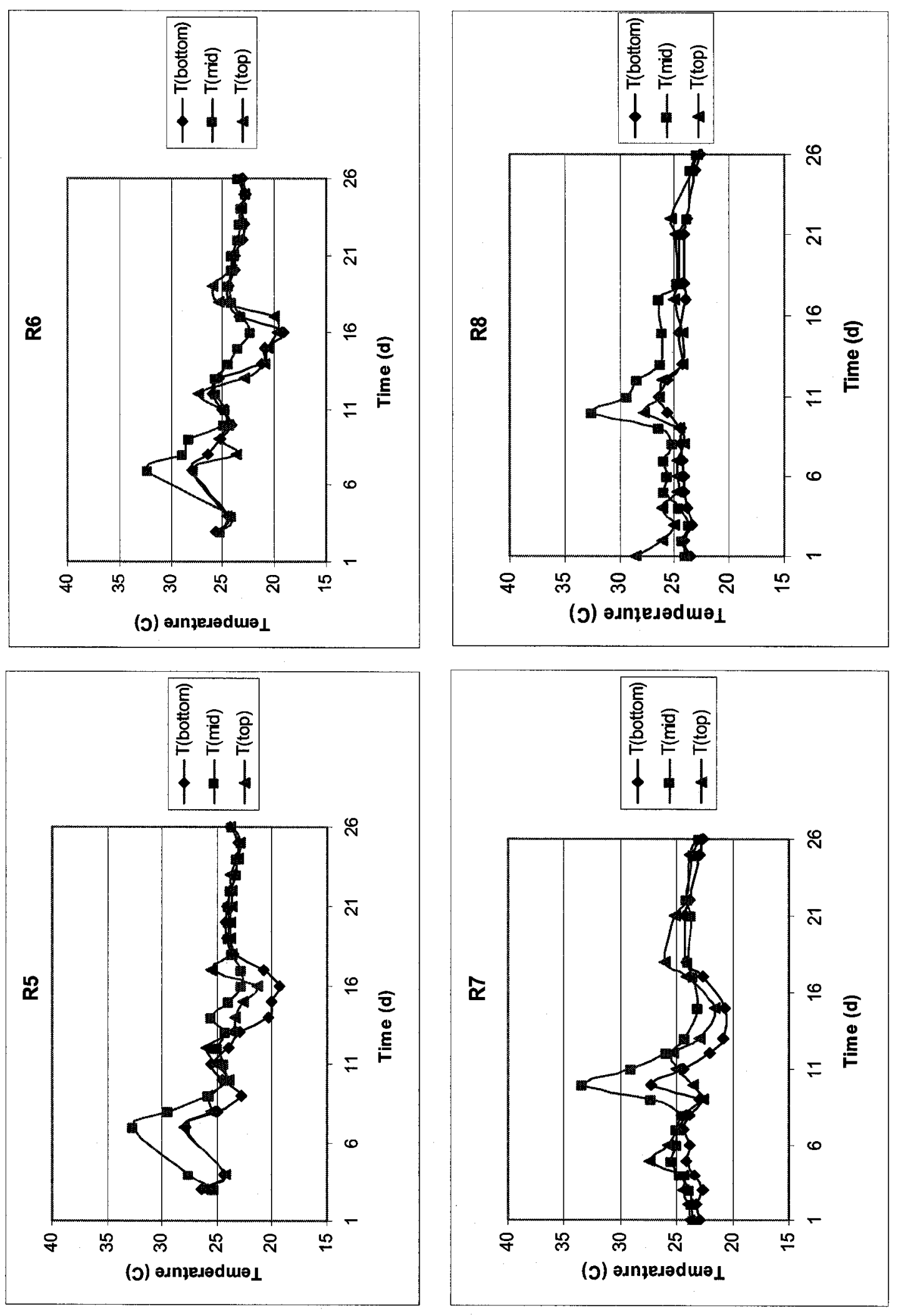

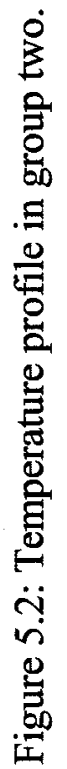


Generally speaking, in the aerobic stage the temperature increased from approximately $25^{\circ} \mathrm{C}$ to above $30^{\circ} \mathrm{C}$ (mid layer) then decreased to lower than $25^{\circ} \mathrm{C}$ in all layers at the end of this study. This can be used as an indicator for the aerobic biodegradation activity because it constitutes an exothermic reaction. The temperature increased as a result of the high biodegradation rate and then returned to ambient temperature when this rate slowed down. In the last days of the aerobic stage, the temperature of the top layer reached approximately $20^{\circ} \mathrm{C}$ in R5, R6 and R7 which is attributed to the cooling effect of air and low biodegradation rate.

In the anaerobic stage, the temperature (in all layers) stayed above ambient temperature by $1-2^{\circ} \mathrm{C}$. The thermocouples were removed from the bioreactors when the temperature remained $1-2^{\circ} \mathrm{C}$ above the ambient temperature to prevent any gas leakage through their wires.

There was a small variation in temperature along the vertical profile of the bioreactors. The highest average temperature was recorded in the mid layer $\left(25.6^{\circ} \mathrm{C}\right)$, and the lowest in the bottom layer $\left(24.2^{\circ} \mathrm{C}\right)$. Those observations coincided with the results obtained from Chiemchaisri et al. (2002). They found that the temperature fluctuated within a range of 26 to $35^{\circ} \mathrm{C}$ in anaerobic bioreactors, whereas the ambient temperature was $30-32^{\circ} \mathrm{C}$, and the temperature at the bottom part of the bioreactors was slightly lower than the upper part.

The low temperature at the bottom layer could be attributed to the cooling effect of leachate at the base of the bioreactors. The leachate was kept in the bioreactor by closing the drainage valve to minimize the shortcircuiting. 


\section{Statistical analysis}

The purpose of the statistical analysis was to investigate whether there was any significant variation 1) in the temperature along the vertical profile of a bioreactor and, 2) in the mean temperature of all bioreactors.

First, the P-value of Layers ${ }^{1}$ was more than 0.05 in all bioreactors as shown in Table 5.3. This indicates that there was no significant difference in the mean temperature of the layers within each bioreactor. In other words, there was no significant variation of temperature along the vertical profile of the bioreactors.

Second, the P-value of Bioreactors ${ }^{2}$ was less than 0.05 as shown in Table 5.3. This illustrates that there was a significant difference in the mean temperature of the bioreactors, indicating that the biodegradation rate may have been different from one bioreactor to another.

\subsubsection{Settlement}

Several factors influencing the MSW settlement process include waste composition, density, biodegradation rate and porosity.

Table 5.4 shows the percentage of settlement that took place in the bioreactors with respect to initial height at different stages, plus the statistical analysis. The settlement that occurred in the aerobic stage was $21.4,21,17.9,15.8,22,20.7,18.2$, and $16.1 \%$, whereas in the anaerobic stage was $13.8,13.0,12.2,9.3,19.2,18.1,16.4$, and $15.0 \%$ in $\mathrm{R} 1$ through $\mathrm{R} 8$, respectively. The total settlement percentages in the bioreactors were 35.2 , $33.9,30.1,25.1,41.2,38.9,34.5$ and $31.0 \%$ in $\mathrm{R} 1$ through $\mathrm{R} 8$, respectively. The average settlement in the aerobic stage was greater than the anaerobic stage. The total settlement 
percentage in group two was higher than group one and it decreased by increasing the salt content. Figure 5.3 shows the variation in the average settlement that occurred in the aerobic and anaerobic stages, and the total settlement with salt contents. It was found that sludge addition enhanced the solid waste biodegradation as suggested by the settlements that took place in the aerobic and anaerobic stages.

Table 5.4: Average settlement that occurred in bioreactors

\begin{tabular}{|c|c|c|c|c|c|c|c|c|c|}
\hline \multicolumn{2}{|c|}{$\%$ Average settlement } & R1 & $\mathrm{R} 2$ & R3 & R4 & R5 & R6 & R7 & $\mathrm{R} 8$ \\
\hline \multirow{5}{*}{ Stages } & Aerobic & 21.38 & 20.98 & 17.90 & 15.83 & 21.98 & 20.73 & 18.15 & 16.08 \\
\hline & Anaerobic & 13.79 & 12.96 & 12.24 & 9.26 & 19.19 & 18.14 & 16.38 & 14.96 \\
\hline & Total & 35.17 & 33.94 & 30.14 & 25.08 & 41.16 & 38.86 & 34.53 & 31.04 \\
\hline & Average & \multicolumn{4}{|c|}{$19.13^{\text {Aerobic }}$} & \multicolumn{4}{|c|}{$14.61^{\text {Anaerobic }}$} \\
\hline & Average $^{T}$ & \multicolumn{4}{|c|}{$31.08^{\mathrm{G} 1}$} & \multicolumn{4}{|c|}{$36.40^{\mathrm{G} 2}$} \\
\hline \multirow{8}{*}{ P-value } & \multirow{3}{*}{ Aerobic } & \multicolumn{4}{|c|}{ Bioreactors $^{2}$} & \multicolumn{4}{|c|}{0.000} \\
\hline & & \multicolumn{4}{|c|}{ Groups $^{3}$} & \multicolumn{4}{|c|}{0.311} \\
\hline & & \multicolumn{4}{|c|}{ Salt content ${ }^{4}$} & \multicolumn{4}{|c|}{0.000} \\
\hline & & \multicolumn{4}{|c|}{ Bioreactors $^{2}$} & \multicolumn{4}{|c|}{0.000} \\
\hline & Anaerobic & \multicolumn{4}{|c|}{ Groups $^{3}$} & \multicolumn{4}{|c|}{0.001} \\
\hline & & \multicolumn{4}{|c|}{ Salt content ${ }^{4}$} & \multicolumn{4}{|c|}{0.009} \\
\hline & Total & \multicolumn{4}{|c|}{ Groups $^{3}$} & \multicolumn{4}{|c|}{0.001} \\
\hline & & \multicolumn{4}{|c|}{ Salt content ${ }^{4}$} & \multicolumn{4}{|c|}{0.001} \\
\hline
\end{tabular}

(1) Average total settlement in the two groups.

(2) Comparison of the mean settlement in all bioreactors $\left(\mathrm{F}_{7,24}\right)$.

(3) Comparison of the mean settlements of the two groups $\left(\mathrm{F}_{\mathrm{k}-1,(\mathrm{n}-1)(\mathrm{k})(\mathrm{k}-1)}=\mathrm{F}_{1,3}\right)^{*}$.

(4) Comparison of the mean settlement at different salt contents $(0,0.5,1,3) \%(\mathrm{w} / \mathrm{v})\left(\mathrm{F}_{3,3}\right)$.

*) Where (k-1) is the degree of freedom between the groups, and (n-1) is the degree of freedom between the blocks (Two way ANOVA).

The results of settlement in this study agreed with the results offered by Stessel et al. (1992); Youcai et al. (2002); and Jin et al. (2006). Stessel et al. (1992) found that settlement in bioreactors operated under aerobic conditions was $14.4 \%$ of initial height of the waste in a bioreactor run with $10 \%(\mathrm{v} / \mathrm{v})$ leachate recycle (of waste volume) 

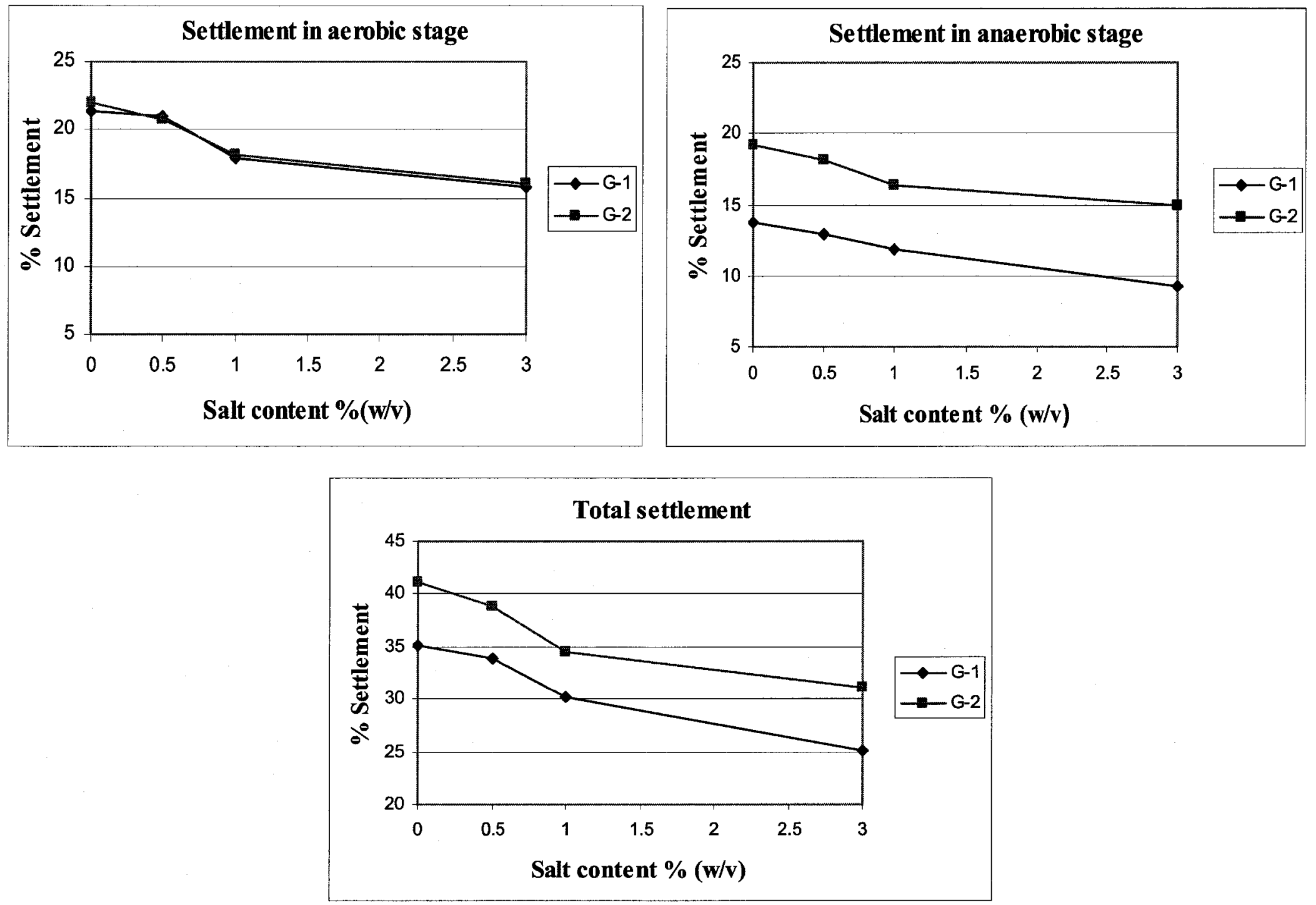

Figure 5.3: Percentage settlement that occurred in the aerobic and anaerobic stages, and total settlement. 
and $0.00227 \mathrm{~m}^{3} / \mathrm{s}$ air flow during 16 days. Youcai et al. (2002) found the settlement in bioreactors operated under anaerobic conditions was in the range of 2.5 to $22.5 \%$ of the initial height of the waste at the end of experiments (300 days). Jin et al. (2006) run experiments in aerobic (18 days) followed by anaerobic conditions for 72 days. They found the settlement in the bioreactor operated with biosolid was $20 \%$ of initial height of the waste during the aerobic stage and the total settlement was $25 \%$ at the end of the study (100 days).

\section{Statistical analysis}

The aim of the statistical analysis was to find if there was any significant difference in the following: 1) the mean settlement of MSW in bioreactors during the aerobic and anaerobic stages, 2) between the mean settlement of the two groups under aerobic and anaerobic conditions and their total settlements, and 3) in the mean settlement at different salt contents under aerobic and anaerobic conditions as well as their total settlement.

First, the P-values of Bioreactors ${ }^{2}$ in aerobic and anaerobic were less than 0.05 as shown in Table 5.4. This indicates that there were significant differences in the mean settlement in bioreactors during the aerobic and anaerobic stages. That means there may have been a variation in the biodegradation rate from one bioreactor to another during two stages.

Second, the P-value of Group ${ }^{3}$ was more than 0.05 in the aerobic stage and less than 0.05 in the anaerobic stage, suggesting that there was no significant difference between the mean settlements of the two groups in the aerobic stage, but there was a significant difference in the anaerobic stage. 
Third, the P-values of Salt Content ${ }^{4}$ were less than 0.05 in the aerobic and anaerobic stages, and when considering the total settlements. This indicates that there was a significant difference in the mean of settlements at different salt contents $(0,0.5,1$ and 3$)$ $\%(\mathrm{w} / \mathrm{v})$ in the aerobic and anaerobic stages and total settlements. Tables $1.3 .5,1.3 .6$, and 1.3.8 in Appendix B show multiple comparisons of the mean settlement in the aerobic, anaerobic, and total settlement stages, respectively.

The difference was observed in the mean settlement at $1 \%$ and $3 \%$ salt contents compared to the mean of $0 \%(\mathrm{w} / \mathrm{v})$ of the aerobic and total settlement stages, whereas, the difference was only significant at $3 \%$ when compared to $0 \%$ in the anaerobic stage.

\subsubsection{Summary of solid waste analysis}

- There was no statistical difference in the moisture content along the vertical profile of the bioreactors.

- There was no statistical difference in the temperature within the layers of the bioreactors. Temperature is a good indicator of the biodegradation rate in the aerobic stage.

- The total settlement was higher in bioreactors operated with sludge addition and decreased with increasing the salt content. The results of total settlement agreed with the results of methane yield and percentage peak reduction of leachate quality during the aerobic and anaerobic stages. This emphasizes that sludge addition enhances the biodegradation in terms of settlement.

- Statistically, there were significant differences in the mean settlement at different salt contents indicating that the high salt content inhibited the biodegradation of MSW. 


\subsubsection{Landfill gas}

This subsection covers methane production and concentrations produced from the 1D bioreactors and BMP assays. BMP assays were carried out to determine the amount of methane produced from leachate generated in the $1 \mathrm{D}$ bioreactors.

\subsubsection{Methane production}

Table 5.5 summarizes the methane yield, total methane produced and time required to reach $10,50,70$ and $80 \%$ of total methane generated in the control (R1). The variation in daily methane production in all bioreactors is shown in Figures 5.4 and 5.5. There was a leakage in R3 and hence no data are reported for R3.

In $\mathrm{R} 1$, methane production started on day 20 . Daily methane production increased progressively to reach its maximum value of $11.9 \mathrm{~L} / \mathrm{d}$ on day 58 . From that moment on, it gradually declined to $3.1 \mathrm{~L} / \mathrm{d}$ on day 115 . Methane production increased again to $8.1 \mathrm{~L} / \mathrm{d}$

Table 5.5: Methane production

\begin{tabular}{|c|ccc|cccc|}
\hline & $\mathrm{R} 1$ & $\mathrm{R} 2$ & $\mathrm{R} 4$ & $\mathrm{R} 5$ & $\mathrm{R} 6$ & $\mathrm{R} 7$ & $\mathrm{R} 8$ \\
\hline $\begin{array}{c}\text { Yield (L/kg dry } \\
\text { waste) }\end{array}$ & 70.59 & 61.66 & 47.53 & 84.72 & 78.73 & 72.60 & 59 \\
\hline $10^{1}$ & 50 & 53 & 120 & 80 & 82 & 98 & 117 \\
\hline $50 \%^{1}$ & 146 & 214 & 284 & 157 & 172 & 221 & 258 \\
\hline $70 \%^{1}$ & 199 & 287 & - & 210 & 226 & 279 & 313 \\
\hline $80 \%^{1}$ & 231 & 319 & - & 235 & 252 & 295 & 343 \\
\hline At the end & $100 \%$ & $88 \%$ & $67 \%$ & $120 \%$ & $110 \%$ & $101 \%$ & $87 \%$ \\
\hline $\begin{array}{c}\text { Average daily } \\
\text { CH4 (L) }\end{array}$ & 3.89 & 3.42 & 2.60 & 4.85 & 4.35 & 4.11 & 3.38 \\
\hline $\begin{array}{c}\text { Total CH4 (L) } \\
\text { produced }\end{array}$ & 1442.6 & 1269.0 & 963.6 & 1724.7 & 1580.8 & 1460.9 & 1256.0 \\
\hline
\end{tabular}

(1) Time (d) to reach $10,50,70$ and $80 \%$ of accumulative methane produced in R1.

(2) Percentage of accumulative methane produced compared to R1 at the end of study. 

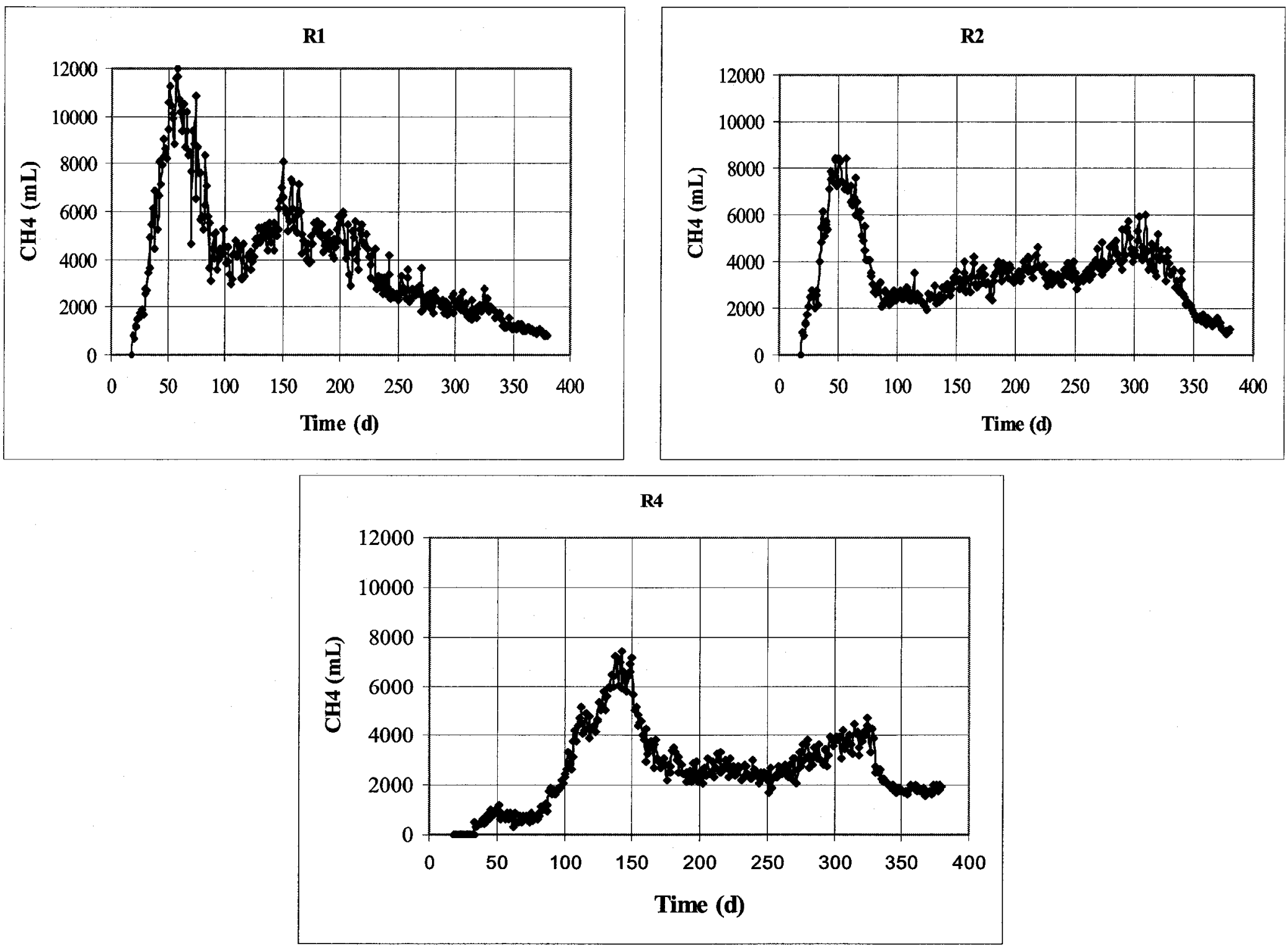

Figure 5.4: Daily methane production in group one. 

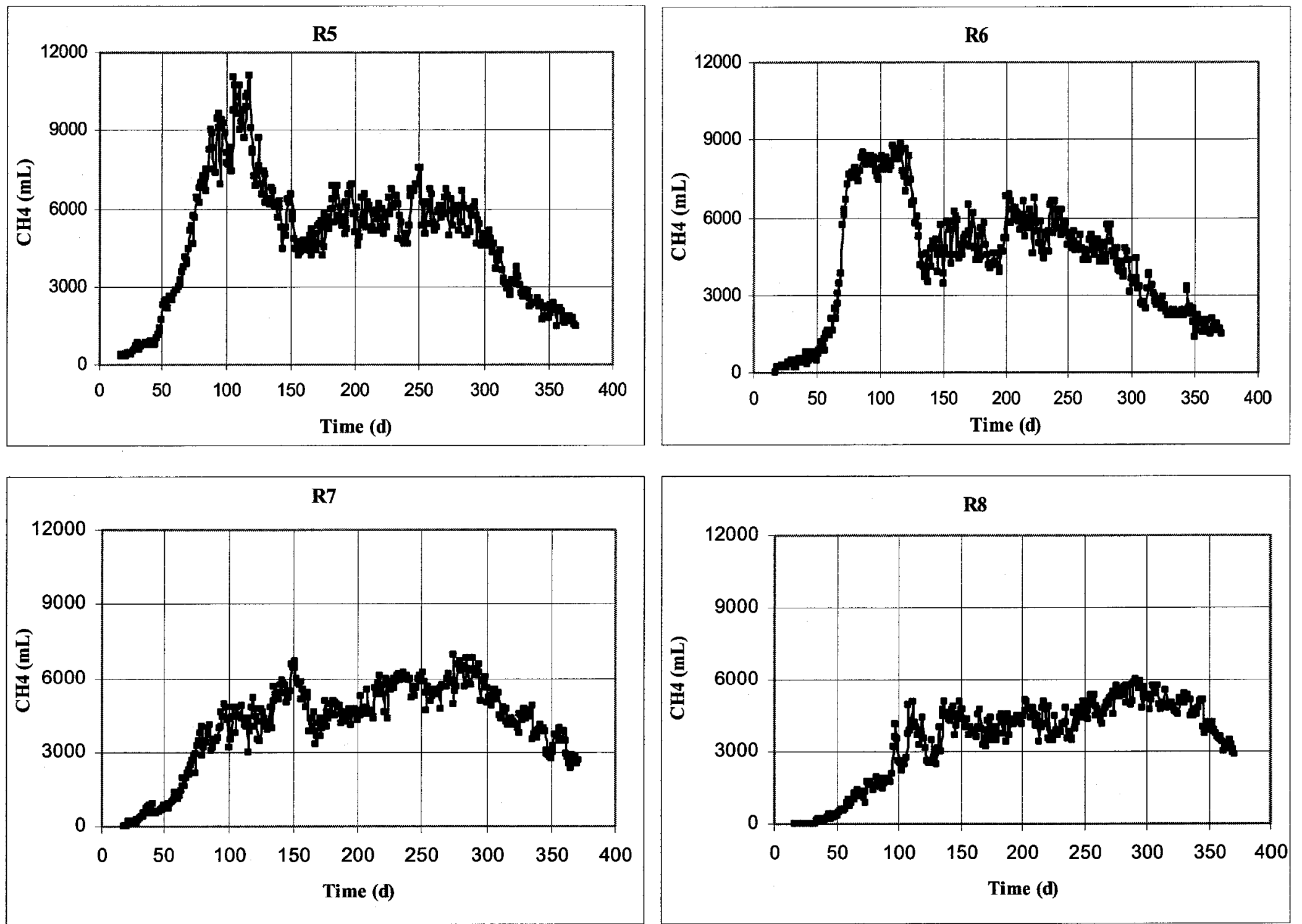

Figure 5.5: Daily methane production in group two. 
on day 150 , subsequently falling to a level of approximately $0.785 \mathrm{~L} / \mathrm{d}$ towards the end of the study. The total methane produced in this bioreactor was $1442.6 \mathrm{~L}$ and the methane yield was $70.6 \mathrm{~L} / \mathrm{kg}$ dry waste. The time required to reach $10,50,70$ and $80 \%$ of the total methane produced was $50,146,199$, and 231 days, respectively.

$\mathrm{R} 2$ behaved similarly to R1 at first. Methane production also started on day 20. By day 50 , a maximum daily methane production of $8.44 \mathrm{~L} / \mathrm{d}$ was reached. After this peak, daily production exhibited a slow decline, reaching $2.06 \mathrm{~L} / \mathrm{d}$ on day 87 and remaining below 3 L/d until day 147 . Between days 148 and 250 , the daily methane production stayed in the range of $3-4.5 \mathrm{~L} / \mathrm{d}$. Following day 250, methane production went up to $6 \mathrm{~L} / \mathrm{d}$ on day 309. Afterwards, it slowly dropped to $1.07 \mathrm{~L} / \mathrm{d}$ towards the end of the study. The total methane produced in this bioreactor was $1269 \mathrm{~L}$ and the methane yield was $61.7 \mathrm{~L} / \mathrm{kg}$ dry waste. At the end of this study, R2 produced $88 \%$ of the total methane produced in R1.

An increase in the lag time of methane production and the time required to reach its first peak was observed in R4 (33 days and 142, respectively), as compared to R1. Following R4 peak methane production of $7.43 \mathrm{~L} / \mathrm{d}$, the methane production dropped to $2.18 \mathrm{~L} / \mathrm{d}$ on day 176 . The daily methane production remained constant $(2.82 \mathrm{~L} / \mathrm{d})$ between days 176 and 278 , followed by a second peak on day 325 of $4.7 \mathrm{~L} / \mathrm{d}$. Towards the end of this study, this latest value decreased to $1.95 \mathrm{~L} / \mathrm{d}$. The quantity of methane produced in this bioreactor was $963.6 \mathrm{~L}$ or $67 \%$ of the total methane produced in $\mathrm{R} 1$. The methane yield was $47.5 \mathrm{~L} / \mathrm{kg}$ dry waste and the time required to reach 10 and $50 \%$ of the total methane produced in control (R1) was 120 and 284 days, respectively. The methane production never reached $70 \%$ of $\mathrm{R} 1$. As the results of $\mathrm{R} 4$ showed, higher concentrations of salt in 
the bioreactor increased the lag time of methane production and lowered the amount of daily methane produced.

In R5, methane production took place a bit earlier (day 17). Production was slow and steady for the first 45 days, followed by a significant increase which extended to day 106 when it reached its first peak value of $11.04 \mathrm{~L} / \mathrm{d}$. This peak was followed by a sharp drop to $4.2 \mathrm{~L} / \mathrm{d}$ on day 156 . On day 186 , methane production rose again to $6.8 \mathrm{~L} / \mathrm{d}$, and then remained constant at around $5.88 \mathrm{~L} / \mathrm{d}$ until day 293 , when it started a gradual decline to $1.48 \mathrm{~L} / \mathrm{d}$ towards the end of the study. The total amount of methane produced by this bioreactor was $1724.7 \mathrm{~L}$, surpassing R1's production by $20 \%$. The methane yield was $84.7 \mathrm{~L} / \mathrm{kg}$ dry waste.

Methane production in R6 started on day 19, and then similarly to R5, it increased slowly during the first 50 days, continuing with a dramatic rise until it reached a maximum of $8.85 \mathrm{~L} / \mathrm{d}$ on day 117 . After this increase, the daily methane fell rapidly to $3.46 \mathrm{~L} / \mathrm{d}$ on day 150. From that moment and until day 250 , the average daily methane production was 5.4 $\mathrm{L} / \mathrm{d}$, gradually decreasing to $1.5 \mathrm{~L} / \mathrm{d}$ at the end of this study. The total methane produced was $1580.8 \mathrm{~L}$, which was more than the total methane produced in $\mathrm{R} 1$ by $10 \%$. The methane yield was $78.7 \mathrm{~L} / \mathrm{kg}$ dry waste.

A small delay in the onset of methane production (day 21) was observed in R7, as compared to R5. Also, like in R5 and R6, daily methane production slowly increased during the first 57 days, followed by a gradual ascent to its first peak of $6.68 \mathrm{~L} / \mathrm{d}$ on day 151. After this peak, methane production fell to $3.27 \mathrm{~L} / \mathrm{d}$ on day 168 , then rising to its second peak of $6.7 \mathrm{~L} / \mathrm{d}$ on day 289 , only to be followed by a steady and final descent to 
$2.66 \mathrm{~L} / \mathrm{d}$ toward the end of this study. The total amount of methane produced in this bioreactor was $1460.9 \mathrm{~L}$, that is, $1 \%$ over the total methane produced by $\mathrm{R} 1$. The methane yield was $72.6 \mathrm{~L} / \mathrm{kg}$ dry waste.

Methane production started on day 33 in R8. The daily methane production increased slowly reaching a maximum of $5.06 \mathrm{~L} / \mathrm{d}$ on day 111 . Next, it decreased to $2.5 \mathrm{~L} / \mathrm{d}$ on day 125 , rising again to $5 \mathrm{~L} / \mathrm{d}$ on day 137 . Between days 137 and 250 , methane production averaged $4.2 \mathrm{~L} / \mathrm{d}$, and then it slightly went up to $5.92 \mathrm{~L} / \mathrm{d}$ on day 295 . From day 295 , methane production started its slow decline to $2.88 \mathrm{~L} / \mathrm{d}$ towards the end of this study. The total methane produced in this bioreactor was $1256 \mathrm{~L}$ and it was $87 \%$ of the total methane produced in $\mathrm{R} 1$. The methane yield was $59 \mathrm{~L} / \mathrm{kg}$ dry waste. The time required to reach $10,50,70$ and $80 \%$ of the total methane produced in control (R1) was $117,258,313$, and 343 days, respectively.

The rate of methane production in group two was slow during the first 50 days. The reason being that the addition of anaerobic digested sludge increased the VFA in the bioreactors, which in turn inhibited the methanogenic bacteria by lowering the $\mathrm{pH}$. The addition of anaerobic digested sludge was terminated on day 35 . After this day, there was a significant increase in the daily methane production in R5, R6, R7 and R8.

The highest methane yield and average daily methane production were observed in R5. Both parameters were higher in bioreactors operated with anaerobic digested sludge addition (group two) than in bioreactors operated without sludge addition (group one), and they decreased as the salt content increased. The accumulative methane production in bioreactors of group two was higher than in bioreactors of group one as shown in Figure 
5.6. This emphasizes that the anaerobic digested sludge enhanced the waste biodegradation, and that the high salt content inhibited it as shown by the average of daily methane production, methane yield, value of the peaks, and total methane produced.

Leuschner et al. (1982) found the methane yield was $35 \mathrm{~L} / \mathrm{kg}$ dry waste after 365 days from their experiments for a bioreactor operated with leachate recycle and buffer addition, and $63 \mathrm{~L} / \mathrm{kg}$ dry waste for a bioreactor operated with leachate recycle and addition of buffer, nutrients and anaerobic digested sludge. Ağdağ et al. (2005) found the methane yield was $40 \mathrm{~L} / \mathrm{kg}$ dry waste after 100 days from their experiments run with leachate recycle and buffer addition. Chiemchaisri et al. (2002) found the methane yield was $51.6 \mathrm{~L} / \mathrm{kg}$ dry waste after 240 days from their anaerobic bioreactor operated with addition of buffer and anaerobic digested sludge. San et al. (2001) found the total methane produced was $34.4 \mathrm{~L} / \mathrm{kg}$ dry waste after 275 days from their anaerobic bioreactor operated with leachate recycle.

The methane yield in this study was higher than what was reported in the literature. This could be attributed to the following reasons: higher organic contents, longer operation time, and the effect of injecting air in the first 16 days of operation (aerobic stage). The injection of air enhanced the acidogenic phase, which in turn triggered an earlier methanogenic phase.

\section{Statistical analysis}

Table 5.6 shows the results of the statistical analysis performed on the daily methane production and methane yield. It shows the P-values of Bioreactors ${ }^{1}$, Group ${ }^{2}$, Salt content $^{3}$, and Yield ${ }^{4}$ were less than 0.05 . This indicates the following: 

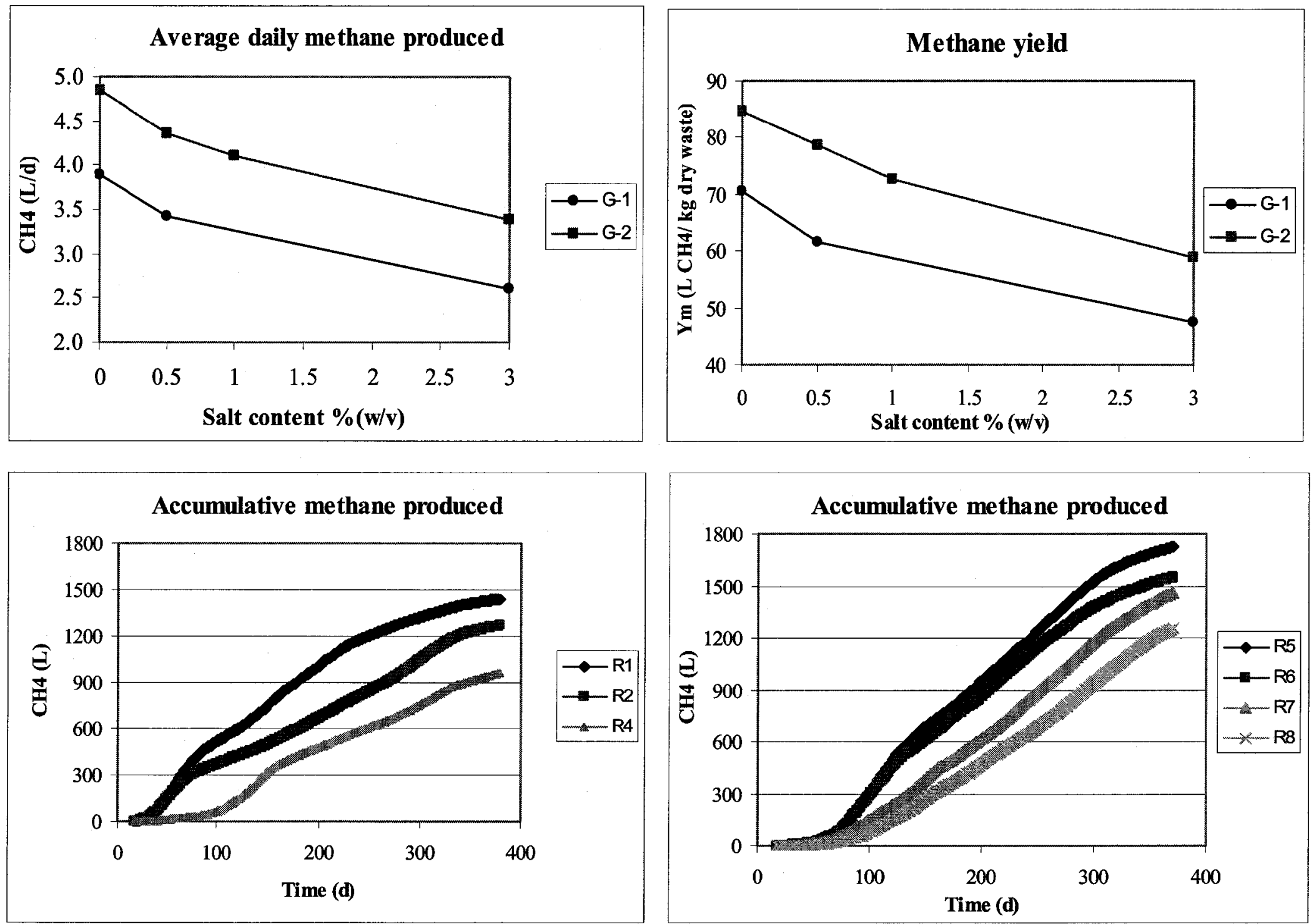

Figure 5.6: Average daily methane production, methane yield and accumulative methane produced. 
1) There was a significant difference in the mean daily methane production in all bioreactors (P-value of Bioreactors $\left.{ }^{1}<0.05\right)$. Table 2.1.4 in Appendix B shows multiple comparisons between the mean daily methane production in all bioreactors.

2) A significant variation occurred in the mean daily methane production in the two groups and at different salt contents (P-values of Mean $\left.\mathrm{CH} 4^{2}<0.05\right)$.

3) Also, a significant difference was observed in the mean methane yield in the two groups and at different salt contents (P-values of Yield $\left.{ }^{4}<0.05\right)$. The difference was in the mean methane yield at $1 \%$ and $3 \%$ compared to the mean of $0 \%(w / v)$ salt contents, as shown in Table 2.1.6 in Appendix B.

In general, the statistical analysis shows there were significant differences in the mean of daily methane production and methane yield 1) in all bioreactors, 2) between the two groups, and 3) at different salt contents.

Table 5.6: Statistical analysis for daily methane production and methane yield

\begin{tabular}{|c|c|c|c|c|c|}
\hline \multicolumn{2}{|c|}{ Methane production } & & & & \\
\hline \multirow{3}{*}{$\mathbf{P}$-value } & Bioreactors $^{1}$ & \multicolumn{4}{|c|}{0.000} \\
\hline & Mean $\mathrm{CH}^{2}$ & Groups & 0.000 & Salt content & 0.000 \\
\hline & Yield $^{3}$ & Groups & 0.001 & Salt content & 0.002 \\
\hline
\end{tabular}

(1) Comparison of the mean daily methane production in all bioreactors $\left(F_{6,2501}\right)$.

(2) Comparison of the mean daily methane production as a function of groups and salt contents $\left(\mathrm{F}_{1,3}^{\mathrm{G}}\right.$ and $\left.\mathrm{F}_{3,3}^{\mathrm{S}}\right)$.

(3) Comparison of the mean methane yield as a function of groups and salt contents $\left(\mathrm{F}_{1,3}^{\mathrm{G}}\right.$ and $\left.\mathrm{F}_{3,3}^{\mathrm{S}}\right)$.

\subsubsection{Methane concentration}

The methane concentration (expressed as a percentage of biogas) in all bioreactors is shown in Figures 5.7 and 5.8. Table 5.7 summarizes the lag time of methane production, 

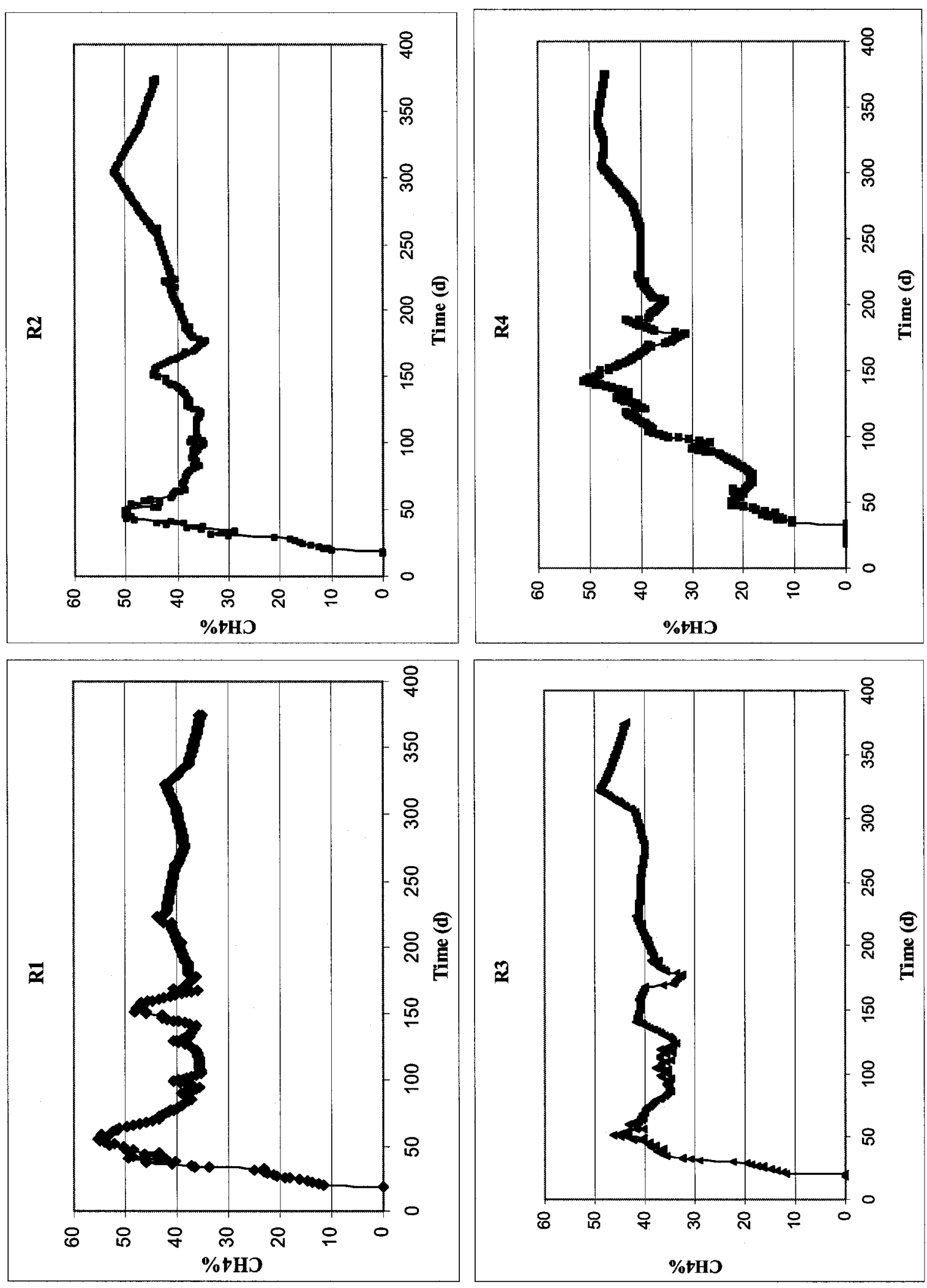

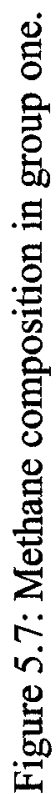



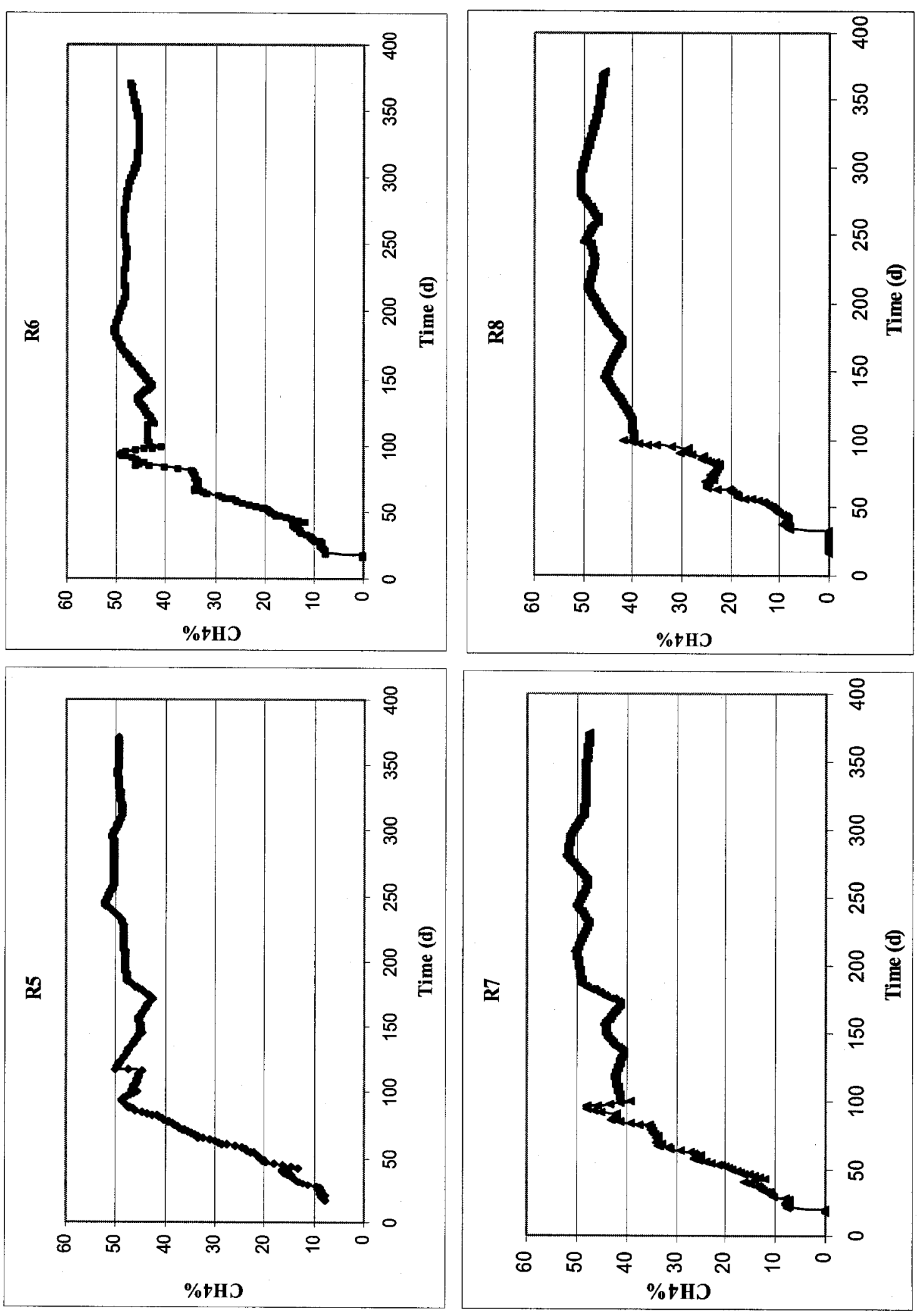

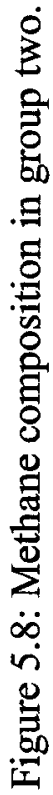


Table 5.7: Methane concentration (expressed as a percentage of the biogas)

\begin{tabular}{|c|c|c|c|c|c|c|c|c|c|}
\hline \multicolumn{2}{|l|}{$\% \mathrm{CH} 4$} & $\mathrm{R} 1$ & $\mathrm{R} 2$ & R3 & $\mathrm{R} 4$ & R5 & $\mathrm{R} 6$ & R7 & R8 \\
\hline \multicolumn{2}{|c|}{ Lag time (d) } & 20 & 20 & 21 & 33 & 17 & 19 & 21 & 33 \\
\hline \multicolumn{2}{|c|}{ Time to reach $40 \%$} & 36 & 39 & 47 & 111 & 79 & 84 & 85 & 99 \\
\hline \multicolumn{2}{|l|}{ Mean } & 41.4 & 39.3 & 39.5 & 37.0 & 43.5 & 41.6 & 41.9 & 39.4 \\
\hline \multirow{3}{*}{ P-value } & Bioreactors ${ }^{1}$ & \multicolumn{8}{|c|}{0.000} \\
\hline & Group $^{2}$ & \multicolumn{8}{|c|}{0.000} \\
\hline & Salt content ${ }^{3}$ & \multicolumn{8}{|c|}{0.000} \\
\hline
\end{tabular}

(1) Comparison of the mean methane concentration in all bioreactors $\left(\mathrm{F}_{7,2863}\right)$.

(2) Comparison of the mean methane concentration of the two groups $\left(\mathrm{F}_{2,2870) \text {. }}\right.$.

(3) Comparison of the mean methane concentration at $0,0.5,1$ and $3 \%$ (w/v) salt contents $\left(\mathrm{F}_{3,2868}\right)$.

time required to reach $40 \%$ of methane concentration in the biogas produced and statistical analysis of methane concentration in all bioreactors. In general, the methane concentration follows the trend of daily methane production.

In $\mathrm{R} 1$, methane concentration in the biogas produced initially was $11.7 \%$ on day 20 , and climbed to $55.2 \%$ by day 55 . Then it decreased to $35.5 \%$ on day 95 . Between days 100 and the end of the study, the average methane concentration was $40.2 \%$.

Initially, methane was produced in R2 on day 20 and its concentration in biogas was $10 \%$. Then the methane concentration rose to a maximum of $50.2 \%$ on day 50 . After that, it declined to $35.2 \%$ on day 124 . From day 125 and until the end of the study, the average methane concentration was $42.6 \%$.

Methane concentration in the biogas produced in R3 was $11.7 \%$ on day 21 . Following that point, it reached a maximum of $46.4 \%$ on day 52 and then it declined to $34.1 \%$ on day 125 . From then on, the average methane concentration was $42.2 \%$. 
In $\mathrm{R} 4$, methane production started on day 33 and its concentration in biogas was $10.7 \%$. Then it increased slowly to reach $51.3 \%$ on day 141 , followed by a drop to $31.2 \%$ on day 178. From that moment, it increased and stayed around $40 \%$. The average of methane concentration from day 180 to the end of the study was $44.6 \%$.

Methane concentration in the biogas produced in R5 was $7.7 \%$ on day 17 . Subsequently, the methane concentration increased slowly to reach $20 \%$ on day 48 . Next, it increased dramatically surpassing the $40 \%$ value on day 79 . It reached its first peak of $48.7 \%$ on day 94 and it remained between 42.6 and $52.3 \%$ thereafter. From day 100 until the end of the study, the average methane concentration was $48.4 \%$.

In $\mathrm{R} 6$, the initial methane concentration in biogas was $7.4 \%$ on day 19. Then it rose slowly to reach $20.4 \%$ on day 54 , climbing further above $40 \%$ by day 84 . It reached the first peak of $49.2 \%$ on day 94 and stayed between 40.8 and $50.4 \%$ thereafter. From day 100 until the end of the study, the average methane concentration was $46.6 \%$.

The concentration of methane in the biogas produced from R7 was $7.75 \%$ on day 21 . Then the methane concentration increased slowly and reached above $20 \%$ by day 52 . It continued rising sharply to reach above $40 \%$ on day 85 . The methane concentration reached its first peak of $48 \%$ on day 95 , remaining between 39 and $52 \%$ thereafter. From day 100 until the end of the study, the average methane concentration was $47 \%$.

The initial methane concentration in the biogas produced from R8 was $8.1 \%$ on day 33 . Then it rose slowly and reached above $40 \%$ on day 99 . From that point on, the methane concentration remained between 39.7 and $50.7 \%$ and the average methane concentration for the same period was $46.7 \%$. 
A comparison of the trend in methane concentration between the bioreactors without sludge addition (group one) and with sludge addition (group two) indicates that the bioreactors with sludge addition lagged in terms of the time taken to reach the peak methane concentration, the average methane concentration after the peak was reached were higher in the bioreactors operated with sludge addition. The result was a higher mean methane concentration for R5 through R8 in comparison to R1 through R4 as indicated in Table 5.7 .

\section{Statistical analysis}

Table 5.7 shows the results of the statistical analysis on methane concentration in all bioreactors. It shows the P-values for Bioreactors ${ }^{1}$, Group ${ }^{2}$, and Salt content ${ }^{3}$, were less than 0.05 . This indicates that there were significant differences in the mean methane concentration 1) in all bioreactors, 2) between the two groups, and 3) at different salt contents. Table 2.2.4 in Appendix B shows multiple comparisons between the mean of methane concentration in all bioreactors. It shows that there was no significant difference between the mean of methane concentration in R1 and other reactors, except R4. 


\subsubsection{BMP assays}

This part presents the results of BMP assays that were used to determine the amount of methane produced from leachate generated in the $1 \mathrm{D}$ bioreactors. Three sets of BMP assays were carried out during the study. In the first set, the leachate used was taken at the growth phase of leachate concentration, whereas, in the second set, the leachate was taken at the decline phase of leachate concentration. The third set of BMP assays was designed to compare the effect of using two types of inoculums on methane production. The two types of inoculums were anaerobic digested sludge (ADS) and acclimatized anaerobic digested sludge (AAD).

\section{$>$ First set}

In this set, $300 \mathrm{~mL}$ of leachate produced from each bioreactor was used as a substrate for the BMP assays with addition of $20 \%(\mathrm{v} / \mathrm{v})$, or $60 \mathrm{~mL}$ of anaerobic digested sludge as an inoculum. The concentrations of leachate (TVS) used were 12270, 10310, 10692, 15360, 15920, 13720, 12204 and $14800 \mathrm{mg} / 1$ in R1 through R8, respectively as shown in Table

\section{8 .}

Table 5.8 summarizes the results of the BMP assays, including lag time of methane production, time required to reach the peak of daily methane production, total methane produced, methane yield, and hydrolysis rate constants. The variations in daily methane production, methane concentration and accumulative methane generated are shown in Figures 5.9 and 5.10 .

The total methane produced was higher in group two of BMP assays because of their higher leachate concentration (TVS); however, the methane yield was higher for group two and decreased with increasing salt content. 
Table 5.8: Results of methane produced from first set of BMP assays

\begin{tabular}{|c|c|c|c|c|c|c|c|c|}
\hline & $\mathrm{R} 1$ & $\mathrm{R} 2$ & R3 & R4 & R5 & R6 & R7 & R8 \\
\hline $\begin{array}{l}\text { Salt content } \\
\%(v / v)\end{array}$ & 0 & 0.5 & 1 & 3 & 0 & 0.5 & 1 & 3 \\
\hline $\begin{array}{l}\text { Initial TVS } \\
\text { (mg/l) }\end{array}$ & 12270 & 10310 & 10692 & 15360 & 15920 & 13720 & 12204 & 14800 \\
\hline $\begin{array}{l}\text { Duration } \\
\text { Time (d) }\end{array}$ & \multicolumn{8}{|c|}{24} \\
\hline Lag time (d) & 0 & 1 & 2 & 10 & 0 & 1 & 1 & 6 \\
\hline $\begin{array}{l}\text { Time to reach } \\
\text { peak (d) }\end{array}$ & 10 & 15 & 15 & 20 & 13 & 13 & 14 & 22 \\
\hline $\begin{array}{l}\text { Total CH4 } \\
(\mathrm{mL})\end{array}$ & 1562 & 1296 & 1092 & 242 & 2052 & 1678 & 1364 & 336 \\
\hline $\begin{array}{l}\mathrm{Y}_{\mathrm{m}}(\mathrm{mL} / \mathrm{g} \mathrm{VS} \\
\text { added }\end{array}$ & 424 & 419 & 340 & 53 & 429 & 408 & 373 & 76 \\
\hline $\mathrm{k}_{\mathrm{h}}\left(\mathrm{d}^{-1}\right)$ & 0.10 & 0.062 & 0.063 & 0.029 & 0.062 & 0.058 & 0.058 & 0.039 \\
\hline
\end{tabular}

\section{Statistical analysis}

Table 5.9 summarizes the results of statistical analysis conducted on daily methane production, lag time of methane production, time to reach the peak daily methane produced, and methane yield.

The P-value of $\mathrm{BMP}^{1}$ was less than 0.05 . This indicates that there was a significant difference in the mean daily methane production of all BMP assays, but no significant difference between the mean daily methane production in the two groups, as suggested by the P-value of Group ${ }^{2}$. The difference was in R4 and R8 compared to R1, as shown in Table 2.3.4 in Appendix B.

The mean lag time of methane production, the mean time required to reach the peak daily methane production, and mean methane yield showed similar statistical results. There was no significant difference between the two groups, but there was a significant 

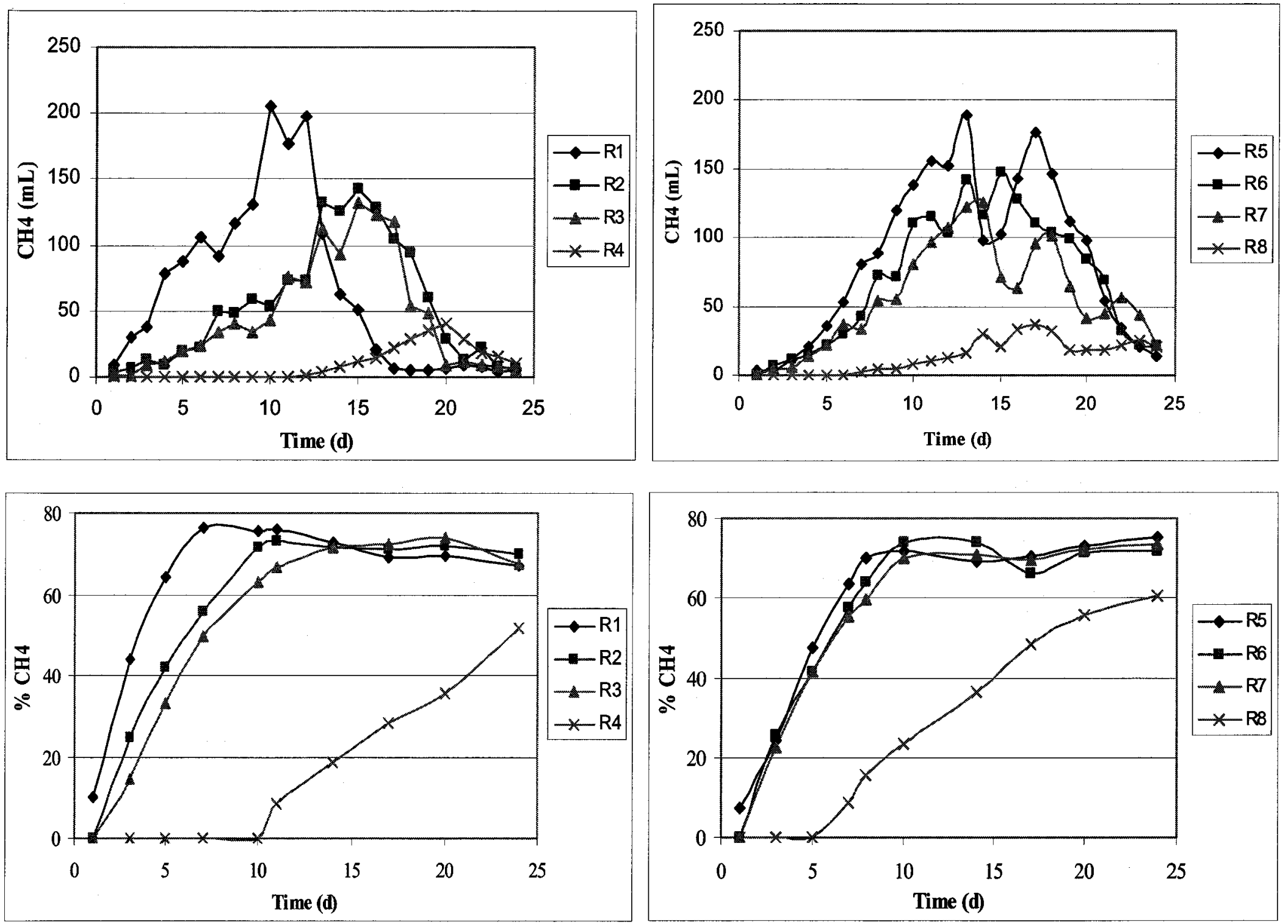

Figure 5.9: Daily methane production and methane concentration in the first set of BMP assays. 

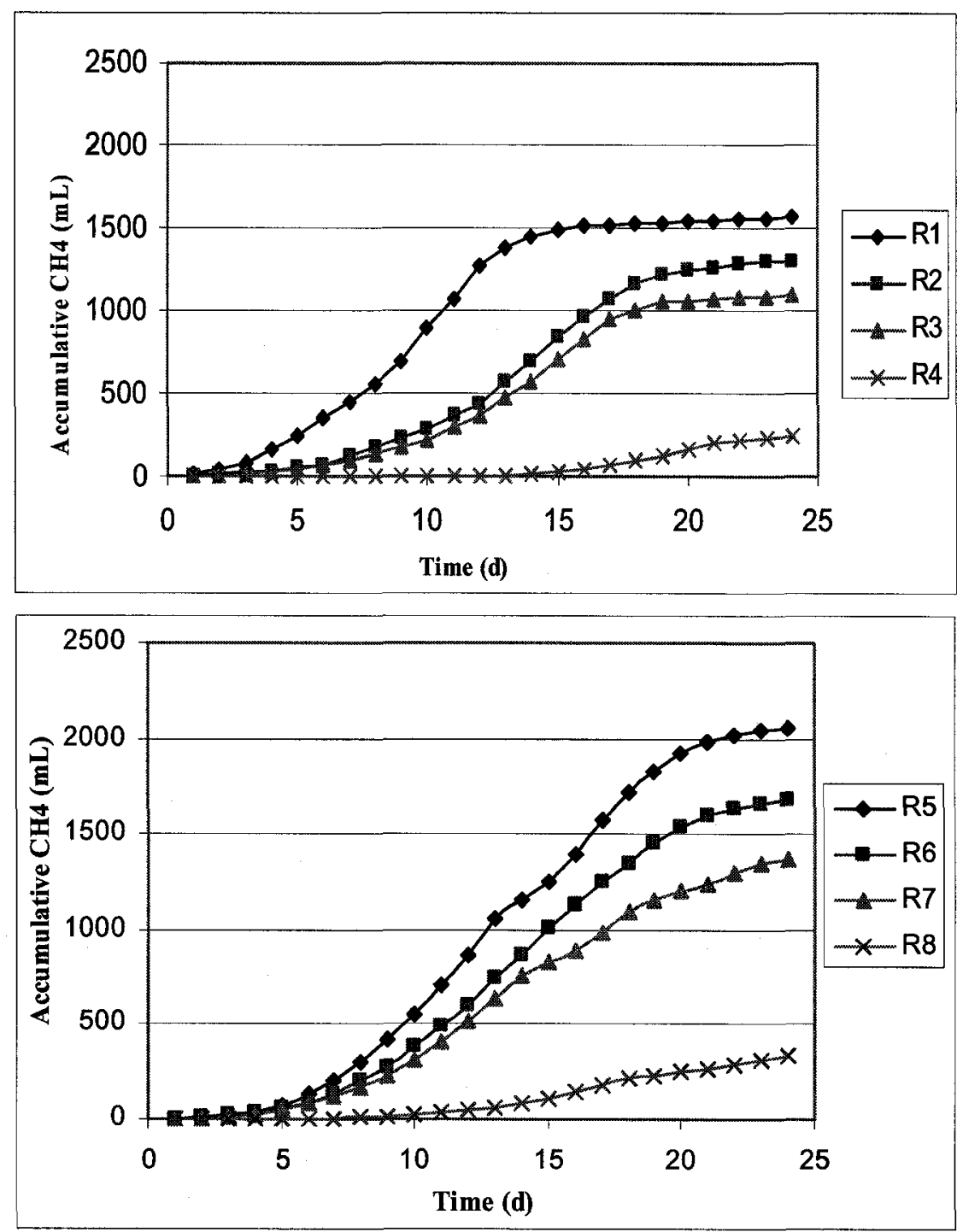

Figure 5.10: Accumulative methane production in the first set of BMP assays.

difference at different salt contents. The difference was at $3 \%$ compared to $0 \%(\mathrm{w} / \mathrm{v})$ salt content in the case of the lag time and the time required to reach the peak daily methane production, whereas it was at $1 \%$ and $3 \%(\mathrm{w} / \mathrm{v})$ in the methane yield, as shown in Tables 2.3.5, 2.3.7, and 2.3.9, respectively in Appendix B. 
The results of the statistical analysis emphasize that the high salt content (3\%) increased both the lag time and the time required to reach the peak of the daily methane production, and decreased significantly the methane yield compared to lower salt contents.

Table 5.9: Statistical analysis of methane production from the first set of BMP assays

\begin{tabular}{|c|c|c|c|c|c|}
\hline \multirow{5}{*}{$\mathrm{P}$-value } & $\mathrm{BMP}^{1}$ & \multicolumn{4}{|c|}{0.000} \\
\hline & Group $^{2}$ & \multicolumn{4}{|c|}{0.152} \\
\hline & Lag time ${ }^{3}$ & Groups & 0.278 & Salt content & 0.027 \\
\hline & Peak $^{4}$ & Groups & 0.703 & Salt content & 0.037 \\
\hline & $Y_{m}^{5}$ & Groups & 0.222 & Salt content & 0.000 \\
\hline
\end{tabular}

(1) Comparison of the mean daily methane production from all BMP assays $\left(\mathrm{F}_{7,184}\right)$.

(2) Comparison of the mean daily methane production in the two groups $\left(\mathrm{F}_{1,190}\right)$.

(3) Comparison of the mean lag time methane production from BMP assays in the two groups and at different salt contents $\left(\mathrm{F}_{1,3}^{\mathrm{G}}\right.$ and $\left.\mathrm{F}_{3,3}^{\mathrm{S}}\right)$.

(4) Comparison of the mean time to reach the peak daily methane production from BMP assays in the two groups and at different salt contents $\left(\mathrm{F}_{1,3}^{\mathrm{G}}\right.$ and $\left.\mathrm{F}_{3,3}^{\mathrm{S}}\right)$.

(5) Comparison of the mean methane yield from BMP assays in the two groups and at different salt contents $\left(\mathrm{F}_{1,3}^{\mathrm{G}}\right.$ and $\left.\mathrm{F}_{3,3}^{\mathrm{S}}\right)$.

\section{Second set}

In this set, $250 \mathrm{~mL}$ of leachate generated from each bioreactor were taken at the decline phase of leachate concentration and used in the BMP assays. The concentrations of leachate (TVS) were $5170,8700,9512,13333,10500,12050,11886$ and $12408 \mathrm{mg} / 1$ in R1 through $R 8$, respectively.

Table 5.10 summarizes the results of methane produced from the second set of BMP assays including lag time, time to reach the maximum daily production, total methane produced, stabilization time (time required to reach a low daily methane production rate), and hydrolysis rate constant. Figures 5.11 and 5.12 show the variations in daily methane 
production, methane concentration and accumulative methane produced in all BMP assays.

The lag time of methane production increased from 1 day in R1 to 6 days in R4 in group one, and from no lag time in $\mathrm{R} 5$ to 5 days in $\mathrm{R} 8$ in group two. The lag times of R4 and R8 in this set were shorter than the first set. The reason for that was bioreactors R4 and R8 produced biogas which contained $40 \%(\mathrm{v} / \mathrm{v})$ methane, meaning that the leachate taken from these bioreactors contained biomass already acclimatized to high salt contents.

Table 5.10: Results of methane produced from the second set of BMP assays

\begin{tabular}{|l|cccc|cccc|}
\hline & $\mathrm{R} 1$ & $\mathrm{R} 2$ & $\mathrm{R} 3$ & $\mathrm{R} 4$ & $\mathrm{R} 5$ & $\mathrm{R} 6$ & $\mathrm{R} 7$ & $\mathrm{R} 8$ \\
\hline $\begin{array}{l}\text { Salt content } \\
\%(\mathrm{v} / \mathrm{v})\end{array}$ & 0 & 0.5 & 1 & 3 & 0 & 0.5 & 1 & 3 \\
\hline $\begin{array}{l}\text { Initial TVS } \\
(\mathrm{mg} / \mathrm{l})\end{array}$ & 5170 & 8700 & 9512 & 13333 & 10500 & 12050 & 11886 & 12408 \\
\hline $\begin{array}{l}\text { Duration time } \\
\text { (d) }\end{array}$ & 24 & 30 & 36 & 69 & 28 & 36 & 46 & 57 \\
\hline Lag time (d) & 1 & 2 & 3 & 6 & 0 & 1 & 2 & 5 \\
\hline $\begin{array}{l}\text { Time to reach } \\
\text { peak (d) }\end{array}$ & 10 & 17 & 18 & 52 & 17 & 21 & 25 & 44 \\
\hline $\begin{array}{l}\text { Total CH4 } \\
\text { (mL) }\end{array}$ & 685 & 1161 & 1252 & 1522 & 1427 & 1573 & 1543 & 1551 \\
\hline $\begin{array}{l}\text { Stabilization } \\
\text { time }(\mathrm{d})\end{array}$ & 22 & 30 & 36 & 69 & 28 & 36 & 43 & 57 \\
\hline $\begin{array}{l}\mathrm{Y}_{\mathrm{m}}(\mathrm{mL} / \mathrm{g} \mathrm{VS} \\
\text { added })\end{array}$ & 442 & 445 & 439 & 381 & 453 & 435 & 433 & 417 \\
\hline $\mathrm{k}_{\mathrm{h}}\left(\mathrm{d}^{-1}\right)$ & 0.074 & 0.044 & 0.04 & 0.017 & 0.06 & 0.035 & 0.03 & 0.018 \\
\hline
\end{tabular}

\section{Statistical analysis}

Table 5.11 summarizes the statistical analysis for daily methane production, lag time of methane production, time to reach the peak daily methane produced, stabilization time, and methane yield. 

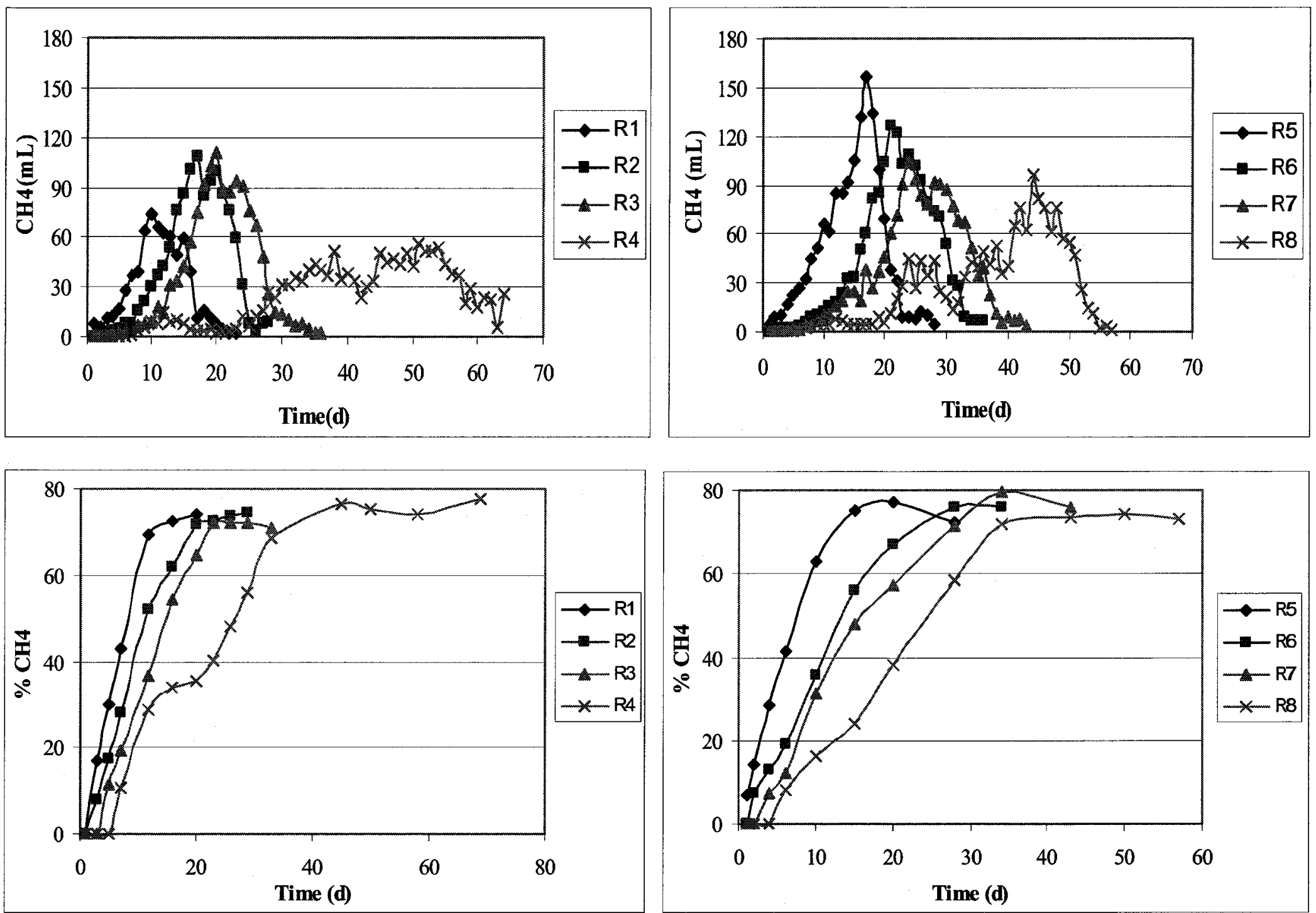

Figure 5.11: Daily methane production and methane concentration in the second set of BMP assays. 

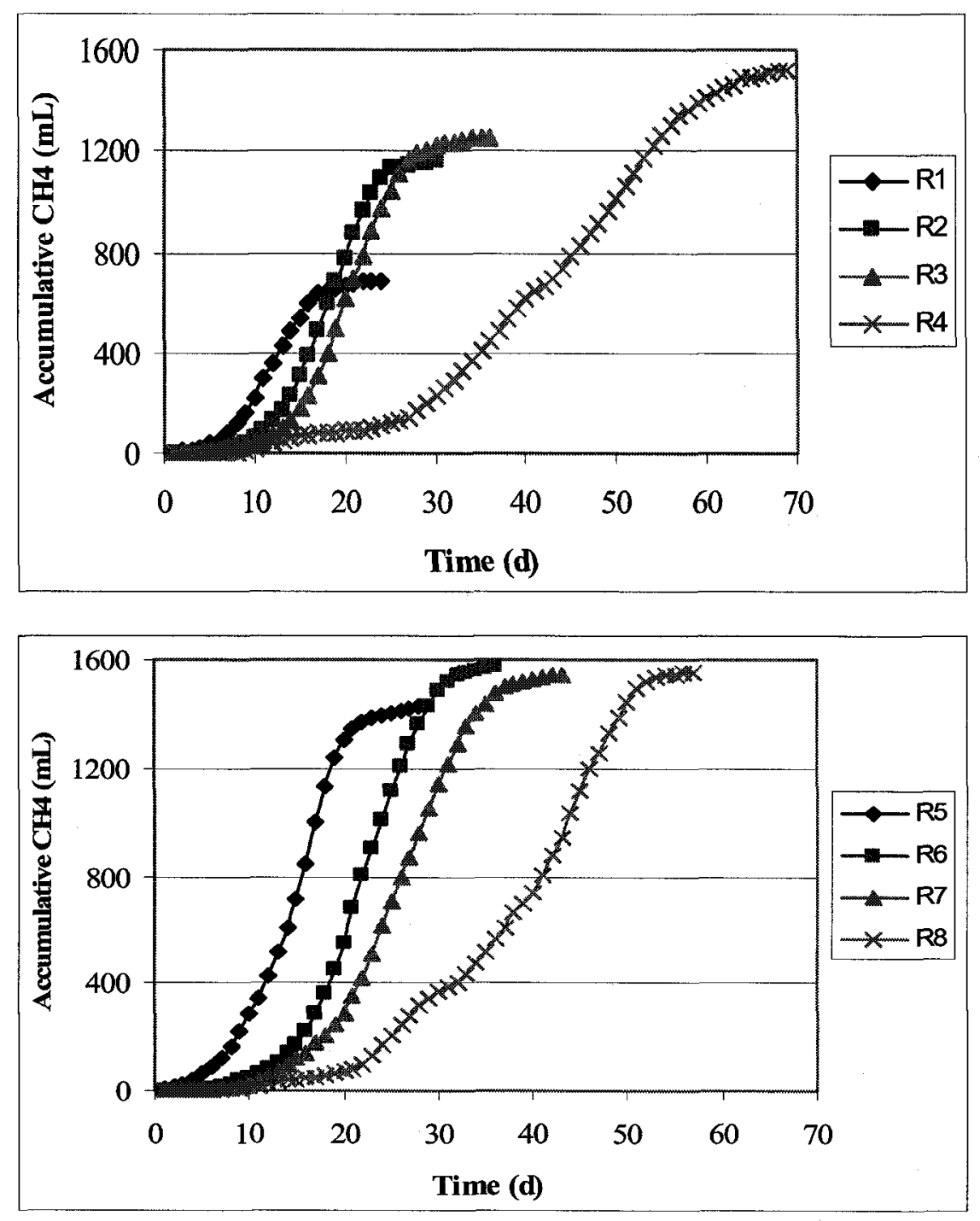

Figure 5.12: Accumulative methane production in second set of BMP assays.

The P-value of $\mathrm{BMP}^{1}$ and Group ${ }^{2}$ were less than 0.05 . This indicates that there were significant differences in the mean daily methane production in all BMP assays, and between the mean daily methane produced in the two groups as proposed. The difference was between the mean daily methane production in R5 and both R4 and R8, and between R6 and R4, as shown in Table 2.3.12 in Appendix B. 
The mean lag time of methane production, mean time required to reach the peak daily methane production, and mean stabilization time showed similar statistical results. There was no significant difference between the two groups, but there was a significant difference at different salt contents. The difference was observed at $3 \%$ compared to $0 \%$ (w/v) salt content, as shown in Tables 2.3.15, 2.3.17, and 2.3.19 in Appendix B.

There was no significant different between the mean methane yield in two groups and at different salt contents.

Table 5.11: Statistical analysis of methane production from the second set of BMP assays

\begin{tabular}{|c|c|c|c|c|c|}
\hline \multirow{6}{*}{ P-value } & $\mathrm{BMP}^{1}$ & \multicolumn{4}{|c|}{0.001} \\
\hline & Group $^{2}$ & \multicolumn{4}{|c|}{0.037} \\
\hline & Lag time ${ }^{3}$ & Groups & 0.537 & Salt content & 0.008 \\
\hline & Peak $^{4}$ & Groups & 0.534 & Salt content & 0.019 \\
\hline & $\begin{array}{l}\text { Stabilization } \\
\text { time }^{5}\end{array}$ & Groups & 0.762 & Salt content & 0.032 \\
\hline & $Y_{\mathrm{m}}{ }^{6}$ & Groups & 0.512 & Salt content & 0.132 \\
\hline
\end{tabular}

(1) Comparison of the mean daily methane production from all BMP assays $\left(\mathrm{F}_{7,313}\right)$.

(2) Comparison of the mean daily methane production in the two groups $\left(\mathrm{F}_{1,314}\right)$

(3) Comparison of the mean lag time methane production from BMP assays in the two groups and at different salt contents $\left(\mathrm{F}_{1,6}^{\mathrm{G}}\right.$ and $\left.\mathrm{F}_{3,4}^{\mathrm{S}}\right)$.

(4) Comparison of the mean time to reach the peak of daily methane production from BMP assays in the two groups and at different salt contents $\left(\mathrm{F}_{1,3}^{\mathrm{G}}\right.$ and $\left.\mathrm{F}_{3,3}^{\mathrm{S}}\right)$.

(5) Comparison of the mean stabilization time for BMP assays in the two groups and at different salt contents $\left(\mathrm{F}_{1,3}^{\mathrm{G}}\right.$ and $\left.\mathrm{F}^{\mathrm{S}}{ }_{3,3}\right)$.

(6) Comparison of the mean methane yield from BMP assays in the two groups and at different salt contents $\left(\mathrm{F}_{1,3}^{\mathrm{G}}\right.$ and $\left.\mathrm{F}^{\mathrm{S}}{ }_{3,3}\right)$. 


\section{Third set}

The leachate used in this set was taken from R1 (TVS $=9464 \mathrm{mg} / \mathrm{l})$ and run at $0,1,2$, and $3 \%(\mathrm{w} / \mathrm{v})$ salt contents with addition of $20 \%(\mathrm{v} / \mathrm{v})$ or $50 \mathrm{~mL}$ of inoculum. Two types of inoculum were used in this set: anaerobic digested sludge (ADS) and acclimatized anaerobic digested sludge (AAD).

Table 5.12 summarizes the results of methane produced from the third set of BMP assays including lag time, time to reach the peak daily methane production, mean and total methane produced, stabilization time, and hydrolysis rate constant. Figures 5.13 and 5.14 show the variation in daily methane production, methane concentration, and accumulative methane produced.

Table 5.12: Results of methane produced from the third set of BMP assays

\begin{tabular}{|l|cccc|cccc|}
\hline $\mathrm{CH}_{4}(\mathrm{~mL})$ & $\mathrm{N} 0 \%$ & $\mathrm{~N} 1 \%$ & $\mathrm{~N} 2 \%$ & $\mathrm{~N} 3 \%$ & $\mathrm{~S} 0 \%$ & $\mathrm{~S} 1 \%$ & $\mathrm{~S} 2 \%$ & $\mathrm{~S} 3 \%$ \\
\hline $\begin{array}{l}\text { Salt content } \\
\%(\mathrm{v} / \mathrm{v})\end{array}$ & 0 & 1 & 2 & 3 & 0 & 1 & 2 & 3 \\
\hline $\begin{array}{l}\text { Initial TVS } \\
\text { (mg/l) }\end{array}$ & \multicolumn{7}{|c|}{9464} \\
\hline $\begin{array}{l}\text { Duration time } \\
\text { (d) }\end{array}$ & 40 & 40 & 59 & 64 & 40 & 40 & 58 & 64 \\
\hline Lag time (d) & 0 & 2 & 10 & 14 & 0 & 0 & 2 & 4 \\
\hline $\begin{array}{l}\text { Time to reach } \\
\text { peak (d) }\end{array}$ & 14 & 26 & 39 & 52 & 16 & 22 & 37 & 49 \\
\hline Peak (mL)/d & 160 & 103 & 96 & 69 & 144 & 100 & 70 & 67 \\
\hline $\begin{array}{l}\text { Mean CH4 } \\
(\mathrm{mL})\end{array}$ & 33.1 & 31.1 & 20.8 & 18.4 & 32.5 & 30.2 & 22.9 & 19.2 \\
\hline Total CH4 (mL) & 1323 & 1243 & 1208 & 1179 & 1300 & 1207 & 1326 & 1229 \\
\hline $\begin{array}{l}\text { Stabilization } \\
\text { time (d) }\end{array}$ & 24 & 40 & 54 & 64 & 23 & 38 & 49 & 64 \\
\hline $\mathrm{k}_{\mathrm{h}}\left(\mathrm{d}^{-1}\right)$ & 0.074 & 0.031 & 0.019 & 0.014 & 0.068 & 0.041 & 0.028 & 0.013 \\
\hline
\end{tabular}



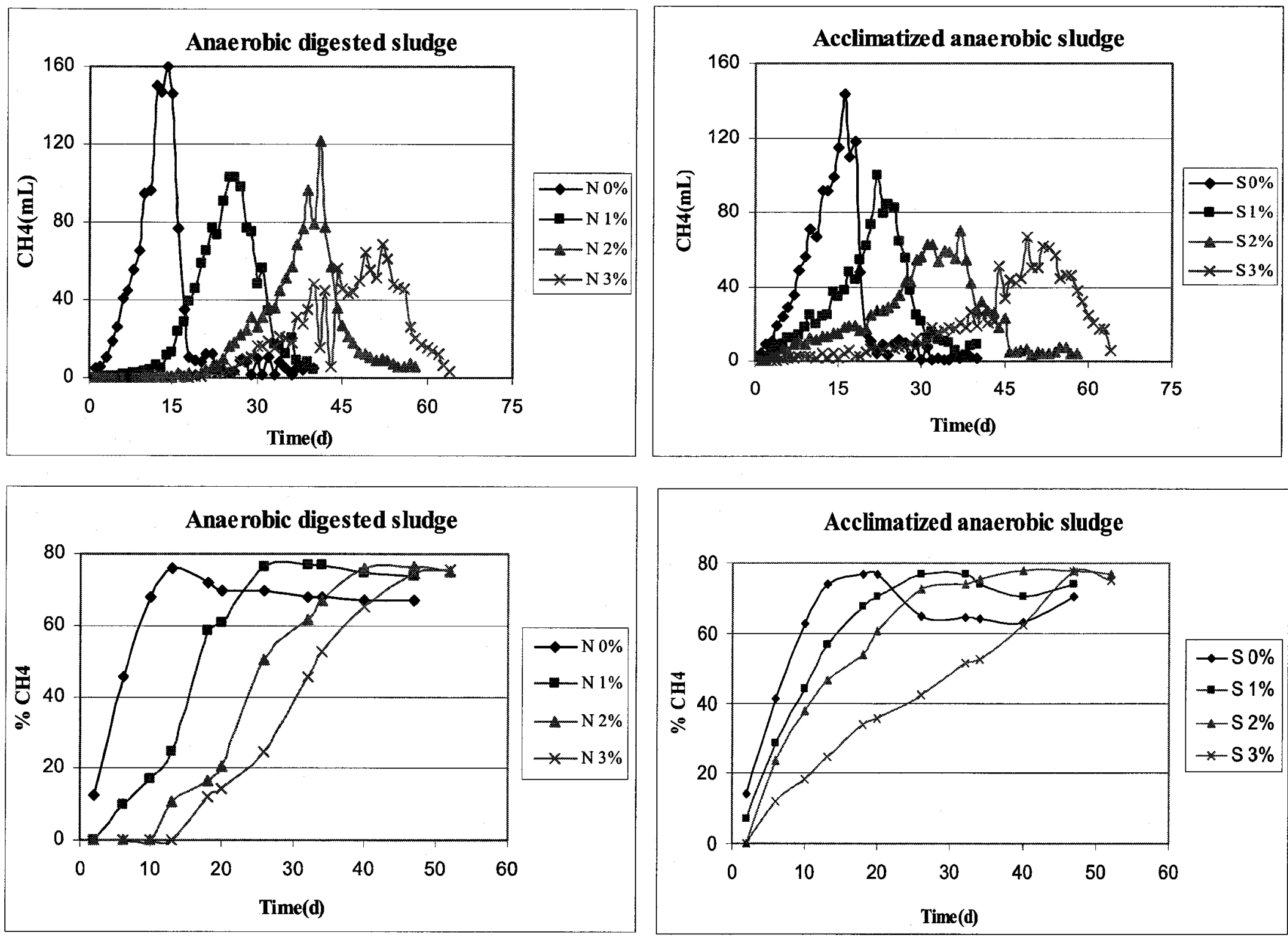

Figure 5.13: Daily methane production and methane concentration in the third set of BMP assays. 

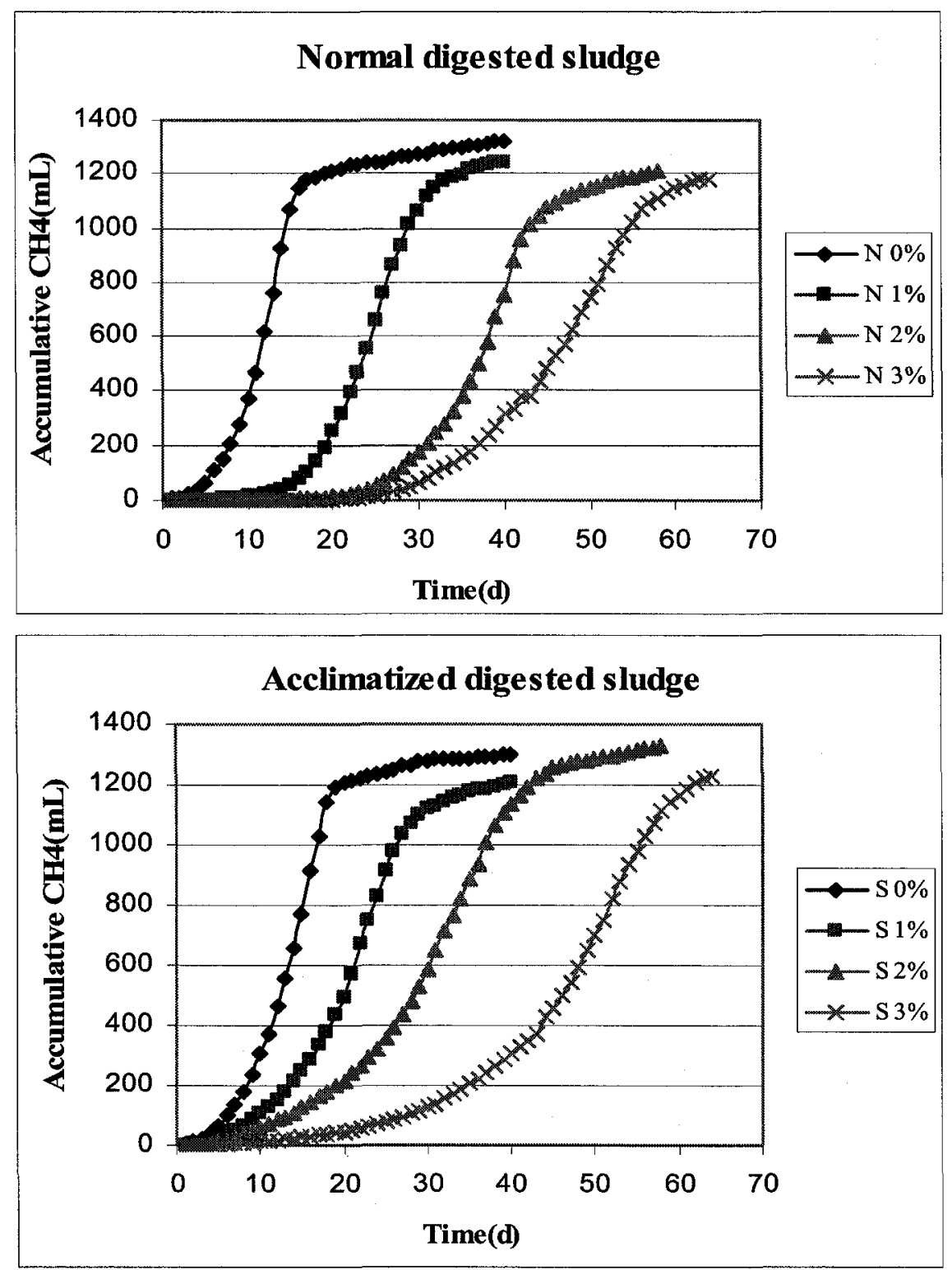

Figure 5.14: Accumulative methane production in third set of BMP assays.

The lag time of methane production increased from no lag time in $\mathrm{R} 1$ to 14 days in $\mathrm{R} 4$ in the ADS group; and from no lag time in R5 to 4 days in R8 in the AAD group. Also, the time required to reach the peak of methane production was slightly shorter in the AAD group compared to the ADS group. There seems to be limited improvement with AAD. This is supported by the statistical analysis. 


\section{Statistical analysis}

Table 5.13 summarizes the statistical analysis for mean daily methane production in all BMP assays, lag time of methane production, time to reach the peak of daily methane produced, total methane produced, stabilization time, and average daily methane produced in the two groups and at different salt contents.

The P-value of BMP $^{1}$ was less than 0.05. This indicates that there was a significant difference in the mean daily methane production in all BMP assays, but there was no significant difference between the mean daily methane produced in the two groups, as suggested by the P-value of Group ${ }^{2}$. Table 2.3.24 in Appendix B shows multiple comparisons in the mean daily methane produced in all BMP assays.

The P-values for lag time ${ }^{3}$ and Total $\mathrm{CH}_{4}{ }^{5}$ were more than 0.05 , which means that there was no significant difference in the mean lag time and total methane produced in the two groups, and at different salt contents.

The time required to reach the peak daily methane production, stabilization time, and average daily methane production showed similar statistical results. The P-values of Peak ${ }^{4}$, Stabilization time ${ }^{6}$, and Mean $\mathrm{CH}_{4}$ production ${ }^{7}$ were more than 0.05 in the groups and less than 0.05 in the salt content. This indicates that there was no significant difference between the mean of the two groups, but there was a significant difference in the mean of time required to reach the peak daily methane production, the stabilization time, and the average methane production at different salt contents. Tables 2.3.26, 2.3.29 and 2.3.31 in Appendix B show multiple comparisons in the mean time required to reach 
Table 5.13: Statistical analysis of methane production from the third set of BMP assays

\begin{tabular}{|c|c|c|c|c|c|}
\hline \multirow{7}{*}{ P-value } & $\overline{\mathrm{BMP}^{1}}$ & \multicolumn{4}{|c|}{0.037} \\
\hline & Group $^{2}$ & \multicolumn{4}{|c|}{0.914} \\
\hline & Lag time $^{3}$ & Groups & 0.127 & Salt content & 0.184 \\
\hline & Peak $^{4}$ & Groups & 0.275 & Salt content & 0.001 \\
\hline & Total $\mathrm{CH}_{4}{ }^{5}$ & Groups & 0.501 & Salt content & 0.324 \\
\hline & $\begin{array}{l}\text { Stabilization } \\
\text { time }^{6}\end{array}$ & Groups & 0.161 & Salt content & 0.000 \\
\hline & $\begin{array}{l}\text { Mean } \mathrm{CH}_{4} \\
\text { production }\end{array}$ & Groups & 0.657 & Salt content & 0.002 \\
\hline
\end{tabular}

(1) Comparison of the mean daily methane production from all BMP assays $\left(\mathrm{F}_{7,396}\right)$.

(2) Comparison of the mean daily methane production in the two groups $\left(\mathrm{F}_{7,402}\right)$.

(3) Comparison of the mean lag time of methane production from BMP assays in the two groups and at different salt contents $\left(\mathrm{F}_{1,3}^{\mathrm{G}}\right.$ and $\left.\mathrm{F}_{3,3}^{\mathrm{S}}\right)$.

(4) Comparison of the mean time to reach the peak daily methane production from BMP assays in the two groups and at different salt contents $\left(\mathrm{F}_{1,3}^{\mathrm{G}}\right.$ and $\left.\mathrm{F}_{3,3}^{\mathrm{S}}\right)$.

(5) Comparison of the mean total methane produced from BMP assays in the two groups and at different salt contents $\left(\mathrm{F}_{1,3}^{\mathrm{G}}\right.$ and $\left.\mathrm{F}_{3,3}^{\mathrm{S}}\right)$.

(6) Comparison of the mean stabilization time for BMP assays in the two groups and at different salt contents $\left(\mathrm{F}_{1,3}^{\mathrm{G}}\right.$ and $\left.\mathrm{F}_{3,3}^{\mathrm{S}}\right)$.

(7) Comparison of the mean daily methane production from BMP assays in the two groups and at different salt contents $\left(\mathrm{F}_{1,3}^{\mathrm{G}}\right.$ and $\left.\mathrm{F}_{3,3}^{\mathrm{S}}\right)$.

the peak daily methane production, mean stabilization time, and mean daily methane production, respectively.

Results from statistical analysis suggest that no significant difference was observed when using the two types of inoculum in the BMP assays. 


\subsubsection{Summary of landfill gas analysis}

$1 \mathrm{D}$ bioreactors

- The saline water inhibited the biodegradation of MSW, as illustrated by the results of methane yield, mean daily methane production and lag time.

- The increase in salt content causes a reduction in the volume of total and daily methane production and methane yield; and an increase in the lag time, the time to reach the peak of daily methane production and the stabilization time.

- The highest methane production was recorded in R5, bioreactor with sludge addition and $0 \%$ salt content, and it decreased by increasing the salt content in all bioreactors. Group two, which operated with sludge addition, showed a higher methane yield and total methane production than group one, which operated without sludge addition.

- The addition of anaerobic digested sludge enhanced the biodegradation of MSW operated at different salt conditions, as suggested by the results of methane yield, lag time and mean methane production.

- Statistically speaking, there were significant differences in the mean daily methane production, methane concentration and methane yield 1) between the two groups, 2) in all bioreactors, and 3$)$ at different salt contents $(0,0.5,1$ and $3 \%)(w / v)$.

\section{BMP assays}

- Results from the BMP assays were consistent with the results from the 1D bioreactors. The increase in salt concentration caused an increase in the lag phase of methane production, and a decrease in the peak and volume of methane production. 
- There was a significant difference in the mean of daily methane produced from the BMP assays in all sets.

- There was a significant difference in the mean lag time and the time to reach the peak of daily methane production at different salt contents $(0,0.5,1$ and $3 \%)(w / v)$ in the BMP assays of the first and second sets. The difference was observed at $3 \%(\mathrm{w} / \mathrm{v})$ salt content compared to $0 \%$.

- Statistically, no significant difference was observed when using the two types of inoculums, salt acclimatized anaerobic digested sludge vs. the un-acclimatized anaerobic digested sludge, in the BMP assays, but there was a significant difference in the mean time required to reach the peak daily methane, stabilization time, and average daily methane production at different salt contents $(0,0.5,1$ and $3 \%)(\mathrm{w} / \mathrm{v})$. The difference was observed at the mean of $3 \%$ compared to the mean of $0 \%(\mathrm{w} / \mathrm{v})$ salt content. This emphasizes that high salt contents inhibited the biodegradation of MSW, as suggested by the results of the BMP assays. 


\subsubsection{Leachate quality}

This part covers the variation in the leachate produced from 1D bioreactors, the results of the concentration profile with depth and the evaluation of potential shortcircuiting. The analysis on the leachate included effluent: COD, BOD, VFA, $\mathrm{pH}, \mathrm{TVS}, \mathrm{TS}, \mathrm{NH}_{3}-\mathrm{N}$, salinity, vertical concentration (in terms of COD) profile within the 1D bioreactors and potential shortcircuiting.

\subsubsection{Variations in COD}

The variation in the COD concentration for all the bioreactors is shown in Figure 5.15. Table 5.14 summarizes the results of COD concentration in all bioreactors, as well as the peak concentration, percentage reduction in peak concentrations and mean COD peak reduction in the two groups during the aerobic and anaerobic stages. The percentage peak reduction is calculated based on the peak and end concentration in aerobic and anaerobic stages.

Generally speaking, the COD concentration in the aerobic stage decreased to its lowest value on day 17 as a result of the onset of air injection on day 2 . The average dissolved oxygen in the leachate generated from bioreactors during the aerobic stage was $8.46 \mathrm{mg} / 1$.

The greatest percentage of COD peak reduction occurred in bioreactors operated with sludge addition (group two) and the COD peak reduction decreased as a result of an increase in salt content. The mean COD peak reduction in the aerobic stage was $55.4 \%$ in group one and $71.4 \%$ in group two. In addition, the COD peak reduction decreased from $69 \%$ in $\mathrm{R} 1(0 \%)$ to $43 \%$ in $\mathrm{R} 4(3 \%)$ in group one, and from $80 \%$ in $\mathrm{R} 5(0 \%)$ to $57 \%$ in R8 (3\%) in group two. This indicates that the biodegradation of MSW was inhibited by 

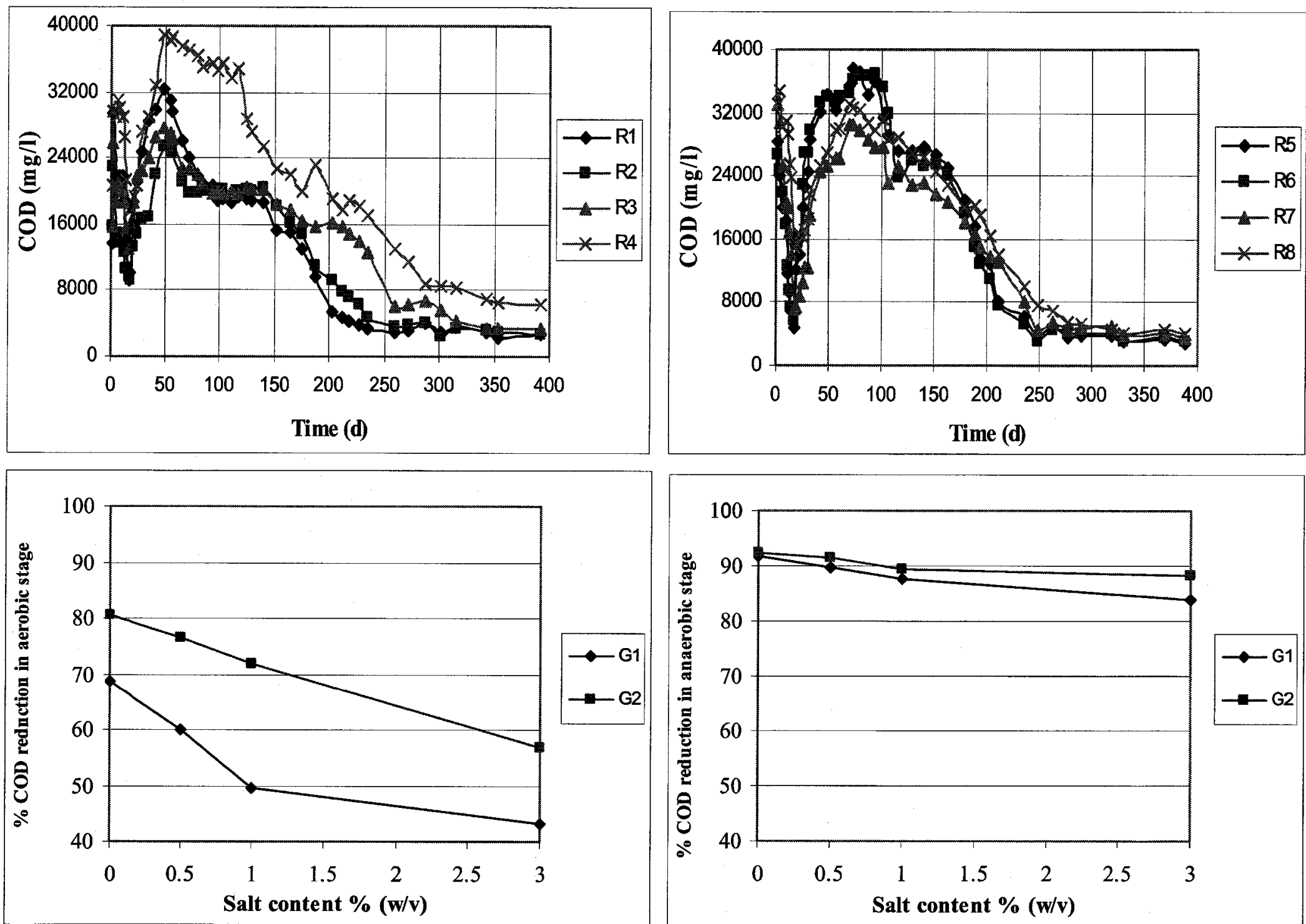

Figure 5.15: COD variation in all bioreactors and percentage COD peak reduction in two stages. 
Table 5.14: Results of COD concentration and percentage peak reduction in two stages

\begin{tabular}{|l|cccc|cccc|}
\hline COD(mg/l) & R1 & R2 & R3 & R4 & R5 & R6 & R7 & R8 \\
\hline First peak & 29550 & 22950 & 25800 & 30933 & 24045 & 24650 & 30650 & 34800 \\
\hline End of aerobic & 9267 & 9133 & 13000 & 17600 & 4700 & 5800 & 8550 & 15050 \\
\hline $\begin{array}{l}\text { \% Reduction in } \\
\text { aerobic }\end{array}$ & 69 & 60 & 50 & 43 & 80 & 76 & 72 & 57 \\
\hline Second peak & 32400 & 26600 & 27600 & 38800 & 37685 & 36800 & 33200 & 33631 \\
\hline End of anaerobic & 2700 & 2775 & 3425 & 6250 & 2925 & 3100 & 3550 & 4120 \\
\hline $\begin{array}{l}\text { \% Reduction in } \\
\text { anaerobic }^{2}\end{array}$ & 92 & 90 & 88 & 84 & 92 & 92 & 89 & 88 \\
\hline Mean $^{3}$ & $55.4^{\mathrm{G} 1}$ & & & $71.4^{\mathrm{G} 2}$ & \\
\hline Mean $^{4}$ & $88.2^{\mathrm{G} 1}$ & & & $90.2^{\mathrm{G} 2}$ & \\
\hline
\end{tabular}

(1) Percentage reduction in COD peak concentration during the aerobic stage.

(2) Percentage reduction in COD peak concentration during the anaerobic stage.

(3) Mean COD percentage peak reduction during aerobic stage.

(4) Mean COD percentage peak reduction during anaerobic stage.

the saline condition, as evidenced by the COD percentage peak reduction; and that the sludge addition improved COD peak reduction under a saline environment, as suggested by the COD percentage peak reduction outcome in group two.

Overall, in the anaerobic stage, COD concentrations in all bioreactors increased dramatically at the beginning of this stage, due to the lack of oxygen and transition to the anaerobic phase, allowing the COD concentration to increase as the hydrolysis continued. This increase was followed by a drop in COD concentrations in all bioreactors as a result of an increase in the methanogenic activity and a subsequent rise in the daily methane production (daily methane production played a major role in the COD variation).

In R1, the COD concentration increased from $9267 \mathrm{mg} / \mathrm{l}$ on day 17 to $32400 \mathrm{mg} / \mathrm{l}$ on day 49 as a result of hydrolysis and acidogenic bacteria. Several significant changes occurred 
in the COD concentration after methane production started. When the daily methane production reached more than $2 \mathrm{~L} / \mathrm{d}$ or $2000 \mathrm{~mL} / \mathrm{d}$ on day 48 , the COD concentration started to fall from $32400 \mathrm{mg} / \mathrm{l}$. Between days 98 and approximately 140, the COD concentration stabilized around $18700 \mathrm{mg} / \mathrm{l}$ due to a decline in the daily methane production during the same period. After that, daily methane production rose again and the COD concentration decreased from $18700 \mathrm{mg} / 1$ to approximately $2850 \mathrm{mg} / \mathrm{l}$ on day 260. From that point on, there was a small change in the COD concentration due to a decline in daily methane production. The COD peak reduction in this bioreactor in the anaerobic stage was $92 \%$.

There was a significant rise in the COD concentration of $\mathrm{R} 2$ as it shifted to the anaerobic condition. It increased from $9833 \mathrm{mg} / 1$ on day 17 to $26600 \mathrm{mg} / \mathrm{l}$ on day 55 . Following this increase, the COD concentration fell to $19700 \mathrm{mg} / \mathrm{l}$ on day 72 as the daily methane production increased and reached its maximum. Between day 72 and 140, the COD concentration stayed around $19000 \mathrm{mg} / \mathrm{l}$ as the daily methane production decreased to its minimum and stabilized around $2.2 \mathrm{~L} / \mathrm{d}$. After that, the COD concentration declined to $3350 \mathrm{mg} / \mathrm{l}$ on day 260 due to a rise in the daily methane production, which reached its maximum value for the second time. From then on, a small variation was observed in the COD concentration because of the steady decline in daily methane production. The COD peak reduction in $\mathrm{R} 2$ was $90 \%$.

The COD concentration of $\mathrm{R} 3$ almost followed the same trend of $\mathrm{R} 2$ in the first 150 days. From day 150 until day 300, the COD concentration in $\mathrm{R} 3$ was higher than $\mathrm{R} 2$. At the end of the study, the COD concentration was $3425 \mathrm{mg} / \mathrm{l}$. The COD peak reduction in this bioreactor in the anaerobic stage was $88 \%$. 
In $\mathrm{R} 4$, the COD concentration increased significantly from $17600 \mathrm{mg} / \mathrm{l}$ to $38800 \mathrm{mg} / \mathrm{l}$ on day 49. The methane production started on day 33 (50 days from the beginning of the experiment), but the rate was less than $2 \mathrm{~L} / \mathrm{d}$ in the first 100 days. Consequently, the COD went down slowly, from $38800 \mathrm{mg} / 1$ to $34800 \mathrm{mg} / \mathrm{l}$ on day 117 . Then it dropped rapidly as the daily methane climbed to reach its maximum value. Between days 175 and 228, the COD concentration stabilized around $19000 \mathrm{mg} / \mathrm{l}$ as the daily methane reached its minimum value in the same period. Then the COD dropped to $8812 \mathrm{mg} / \mathrm{l}$ on day 287 because of the increase in daily methane production. After this, there was no significant change in the COD concentration. The COD peak reduction in R4 during the anaerobic stage was $84 \%$.

The COD concentration in R5 increased sharply from $4700 \mathrm{mg} / 1$ on day 17 to $34250 \mathrm{mg} / 1$ on day 48. From that moment and until day 73 , it increased slowly and reached 37685 $\mathrm{mg} / \mathrm{l}$. As the daily methane production increased above $2 \mathrm{~L} / \mathrm{d}$, the COD concentration started to decrease, reaching $27112 \mathrm{mg} / \mathrm{l}$ on day 129 . Between day 129 and 151 , it stayed around $26000 \mathrm{mg} / \mathrm{l}$ as a result of a decline in the daily methane production. Subsequently, the COD concentration decreased sharply to 3825 on day 249 because the daily methane production increased again. After that, there was no significant variation in the COD concentration. The COD peak reduction in R5 during the anaerobic stage was $92 \%$.

R6 showed similar trend to R5. The COD peak reduction in this bioreactor during the anaerobic stage was $92 \%$.

In $\mathrm{R} 7$, the COD concentration initially rose rapidly from $8550 \mathrm{mg} / 1$ on day 17 to 24600 $\mathrm{mg} / \mathrm{l}$ on day 42 . After day 42 , as methane production started, the rate of increase in COD 
concentration slowed down, although this rate was low for the following 50 days. It increased quickly causing a reduction in the COD concentration from $33200 \mathrm{mg} / \mathrm{l}$ on day 73 to $4500 \mathrm{mg} / 1$ on day 249 . From that moment on, there were small variations in the COD concentration. The COD peak reduction in R7 during the anaerobic stage was $89 \%$. R8 showed a similar behavior to $\mathrm{R} 7$. The COD peak reduction in the anaerobic stage was $88 \%$ in this bioreactor.

In the anaerobic stage, the mean of COD percentage peak reduction of group two $(90 \%)$ was higher than group one $(88 \%)$. The percentage of COD peak reduction was reduced by increasing the salt content as shown in Figure 5.15 .

\section{Statistical analysis}

Table 5.15 shows the statistical analysis for the mean of COD concentration and COD percentage peaks reduction during the aerobic and anaerobic stages. Five observations could be made from the statistical analysis:

- COD concentration

1) The P-value of Bioreactors ${ }^{1}$ was less than 0.05 . This emphasizes that there was a significant difference in the mean COD concentration in all bioreactors during the experiment. The difference was only in R4 compared to R1 as shown in Table 3.1.5 in Appendix B.

2) The P-value of Group ${ }^{2}$ was more than 0.05 . This indicates that there was no significant difference between the mean COD concentration in the two groups. 
Table 5.15: Statistical analysis for the mean and percentage peak reduction in COD concentration

\begin{tabular}{|c|c|c|c|c|c|}
\hline \multirow{4}{*}{ P-value } & Bioreactors 1 & \multicolumn{4}{|c|}{0.000} \\
\hline & Group $^{2}$ & \multicolumn{4}{|c|}{0.116} \\
\hline & Reduction $^{3}$ & Groups & 0.006 & Salt content & 0.016 \\
\hline & Reduction $^{4}$ & Groups & 0.069 & Salt content & 0.039 \\
\hline
\end{tabular}

(1) Comparison of the mean COD concentration in all bioreactors $\left(\mathrm{F}_{7,356}\right)$.

(2) Comparison of the mean COD concentration in the two groups $\left(\mathrm{F}_{1,362}\right)$.

(3) Comparison of the mean COD percentage peak reduction in the two groups and at different salt contents during the aerobic stage $\left(\mathrm{F}_{1,3}^{\mathrm{G}}\right.$ and $\left.\mathrm{F}_{3,3}{ }_{3,3}\right)$.

(4) Comparison of the mean COD percentage peak reduction in the two groups and at different salt contents during the anaerobic stage $\left(\mathrm{F}_{1,3}^{\mathrm{G}}\right.$ and $\left.\mathrm{F}_{3,3}^{\mathrm{S}}\right)$.

- COD percentage peak reduction

3) The P-values of Reduction ${ }^{3}$ were less than 0.05 . This means there were significant differences in the mean COD percentage peak reduction during aerobic stage 1) between the two groups, and 2$)$ at different salt contents $(0,0.5,1$, and 3$) \%(w / v)$. The difference was at $3 \%$ compared to $0 \%(\mathrm{w} / \mathrm{v})$ salt content as shown in Table 3.1.6 in Appendix B.

4) The P-value of Reduction ${ }^{4}$ (Groups) was more than 0.05 . This means there was no significant difference between the mean COD percentage peak reduction in the two groups during the anaerobic stage.

5) The P-value of Reduction ${ }^{4}$ (Salt content) was less than 0.05 . This indicates that there was a significant difference in the mean COD percentage peak reduction at different salt contents during the anaerobic stage. The difference was in the mean COD percentage peak reduction at $3 \%$ compared to $0 \%(\mathrm{w} / \mathrm{v})$ salt content as shown in Table 3.1 .7 in Appendix B. 


\subsubsection{Variations in BOD}

The BOD concentration in the leachate samples showed a similar trend to the COD concentration in all bioreactors. Figure 5.16 shows the BOD concentrations in all bioreactors and BOD percentage peak reduction during the aerobic and anaerobic stages. Table 5.16 summarizes the BOD concentrations in all bioreactors and BOD percentage peak reduction during the aerobic and anaerobic stages.

The highest BOD percentage peak reduction during the aerobic stage was observed in the second group of bioreactors and it decreased by increasing the salt content in both groups, as shown in Figure 5.16. Also, Figure 5.16 shows that the BOD peak reduction decreased from $71 \%$ in $\mathrm{R} 1(0 \%)$ to $46 \%$ in $\mathrm{R} 4(3 \%)$ in group one, and from $88 \%$ in $\mathrm{R} 5$ $(0 \%)$ to $58 \%$ in $\mathrm{R} 8(3 \%)$ in group two.

Initially, the BOD concentration increased in all bioreactors at the beginning of the anaerobic stage, as a result of low methanogenic activity which facilitated the accumulation of organic acids from the hydrolysis and acidogenesis steps. BOD peak reductions during this stage were $94,92,87,84,95,95,91$ and $89 \%$ in $\mathrm{R} 1$ through $\mathrm{R} 8$, respectively.

The results of BOD percentage peak reduction showed the following:

1) Sludge addition (group two) enhanced the biodegradation of MSW during both stages.

2) Bioreactors operated at high salt content required a longer time to consume the organic matter as suggested by the BOD peak reduction in bioreactors ( $R 4$ and $\mathrm{R} 8$ ). 

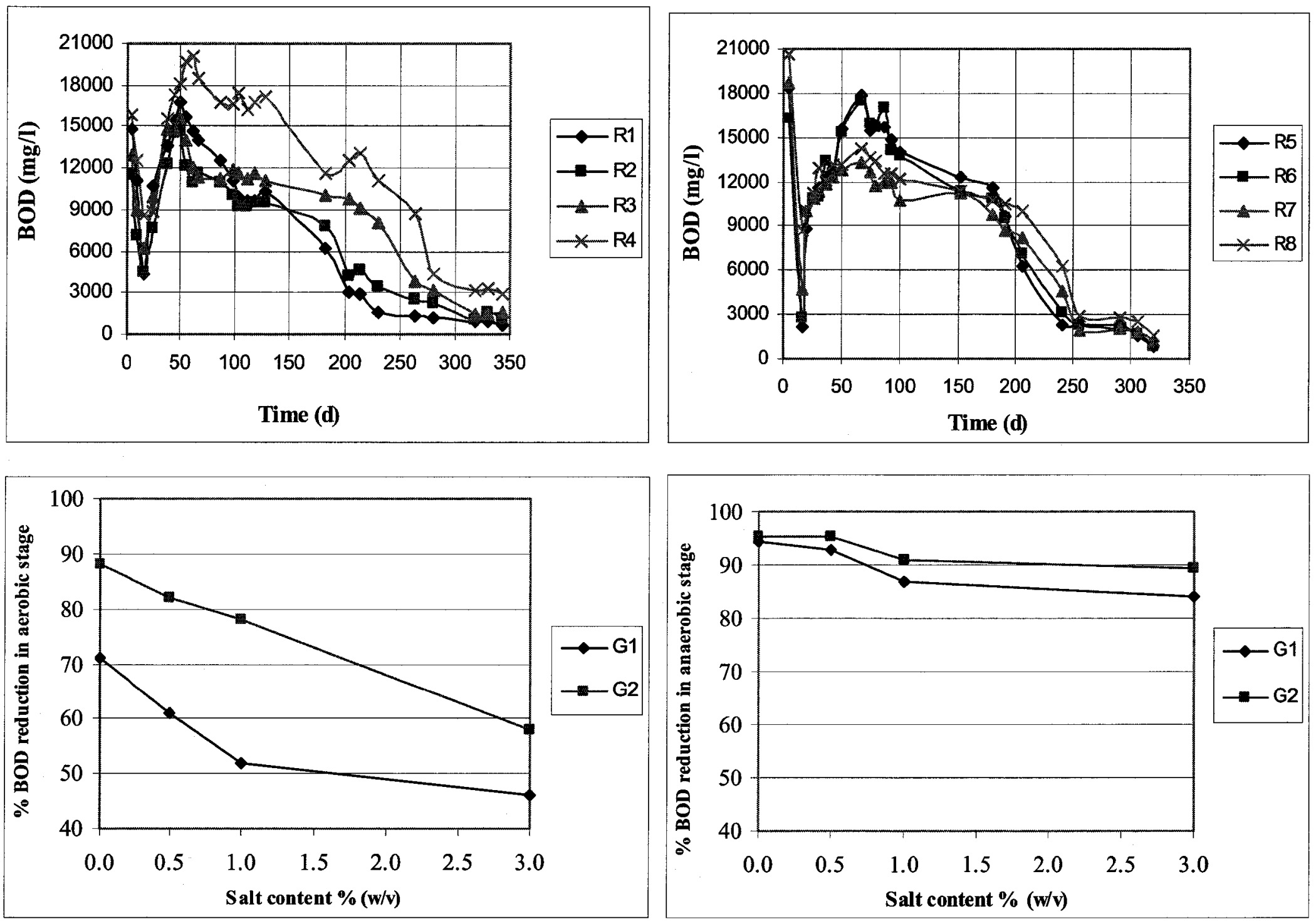

Figure 5.16: BOD variation in all bioreactors and percentage BOD peak reduction in two stages. 
Table 5.16: Results of BOD concentration and percentage peak reduction in two stages

\begin{tabular}{|c|c|c|c|c|c|c|c|c|}
\hline $\mathrm{BOD}(\mathrm{mg} / \mathrm{l})$ & R1 & $\mathrm{R} 2$ & R3 & $\mathrm{R} 4$ & R5 & R6 & R7 & $\mathrm{R} 8$ \\
\hline First peak & 14805 & 11498 & 12926 & 15880 & 18363 & 16269 & 18697 & 20664 \\
\hline $\begin{array}{l}\text { End of } \\
\text { aerobic }\end{array}$ & 4307 & 4513 & 6250 & 8568 & 2209 & 2801 & 4138 & 8676 \\
\hline $\begin{array}{l}\% \text { Reduction } \\
\text { in aerobic }\end{array}$ & 71 & 61 & 52 & 46 & 88 & 83 & 78 & 58 \\
\hline Second peak & 16800 & 14640 & 15600 & 20100 & 17820 & 17440 & 13270 & 14270 \\
\hline $\begin{array}{l}\text { End of } \\
\text { anaerobic }^{3}\end{array}$ & 960 & 1170 & 2000 & 3200 & 810 & 840 & 1220 & 1520 \\
\hline $\begin{array}{l}\text { \% Reduction } \\
\text { in anaerobic }{ }^{2}\end{array}$ & 94 & 92 & 87 & 84 & 95 & 95 & 91 & 89 \\
\hline Mean $^{4}$ & \multicolumn{4}{|c|}{$57.5^{\mathrm{Gl}}$} & \multicolumn{4}{|c|}{$76.8^{\mathrm{G} 2}$} \\
\hline Mean $^{5}$ & \multicolumn{4}{|c|}{$89.3^{\mathrm{Gl}}$} & \multicolumn{4}{|c|}{$92.5^{\mathrm{G} 2}$} \\
\hline
\end{tabular}

(1) Percentage reduction in BOD peak concentration during the aerobic stage.

(2) Percentage reduction in BOD peak concentration during the anaerobic stage.

(3) BOD concentration on day 319 .

(4) Mean BOD percentage peak reduction in two groups during aerobic stage.

(5) Mean BOD percentage peak reduction in two groups during anaerobic stage.

\section{Statistical analysis}

Table 5.17 summarizes the statistical analysis for the mean BOD concentration and for BOD percentage peak reduction during the aerobic and anaerobic stages.

\section{- BOD concentration}

1) The P-values of Bioreactors ${ }^{1}$ were less than 0.05 . This indicates that there was a significant difference in the mean BOD concentration in all bioreactors. The difference was only at R4 compared to R1 as shown in Table 3.2.5 in Appendix B.

2) The P-value of Group ${ }^{2}$ was more than 0.05. This emphasizes that there was no significant difference between the mean BOD concentration in the two groups. 
Table 5.17: Statistical analysis for the mean and percentage peak reduction in BOD concentration

\begin{tabular}{|c|c|c|c|c|c|}
\hline \multirow{4}{*}{$P$-value } & Bioreactors ${ }^{1}$ & \multicolumn{4}{|c|}{0.019} \\
\hline & Group $^{2}$ & \multicolumn{4}{|c|}{0.712} \\
\hline & Reduction $^{3}$ & Groups & 0.008 & Salt content & 0.026 \\
\hline & Reduction $^{4}$ & Groups & 0.032 & Salt content & 0.018 \\
\hline
\end{tabular}

(1) Comparison of the mean BOD concentration in all bioreactors $\left(\mathrm{F}_{7,184)}\right.$.

(2) Comparison of the mean BOD concentration in the two groups $\left(F_{1,190}\right)$.

(3) Comparison of the mean BOD peak reduction in the two groups and at different salt contents during the aerobic stage $\left(\mathrm{F}_{1,3}^{\mathrm{G}}\right.$ and $\left.\mathrm{F}_{3,3}^{\mathrm{S}}\right)$.

(4) Comparison of mean BOD peak reduction in the two groups and at different salt contents during the anaerobic stage $\left(\mathrm{F}_{1,3}^{\mathrm{G}}\right.$ and $\left.\mathrm{F}_{3,3}^{\mathrm{S}}\right)$.

- BOD percentage peak reduction

3) In the aerobic and anaerobic stages, there were significant differences in the mean BOD percentage peak reduction 1) between the two groups, and 2) at different salt contents (P-values of Reduction ${ }^{3}$ and Reduction $\left.{ }^{4}<0.05\right)$. The difference was at $3 \%$ compared to $0 \%(\mathrm{w} / \mathrm{v})$ salt content as shown in Tables 3.2.6 and 3.2.7 in Appendix B.

\subsubsection{Variations in VFA}

The concentration of VFA in the leachate of all bioreactors exhibited a similar trend to the COD concentration. Figure 5.17 shows the variation of VFA concentration over time in all bioreactors and VFA percentage peak reduction at different salt contents during the aerobic and anaerobic stages. Also, Table 5.18 summarizes the results of VFA concentrations in terms of peaks, end of stages and VFA percentage peak reduction in both stages. 
In the aerobic stage, the VFA peak reduction during this stage was $65,59,51,41,80,78$, 71 , and $65 \%$ in R1 through R8, respectively. The mean of VFA peak reduction in group two $(73.5 \%)$ was higher than group one $(54 \%)$.

In the anaerobic stage, the VFA concentration in all bioreactors increased at the beginning of this stage as a result of the accumulation of organic acids from the hydrolysis and acidogenic steps. As mentioned in chapter two, first the organic waste hydrolyzed into aqueous organic acids and then these were consumed by acidogenic bacteria to produce VFA and carbon dioxide. Then the VFA concentration dropped as the daily methane production increased and reached $2 \mathrm{~L} / \mathrm{d}$, because the methanogenic bacteria used the VFA as a substrate to produce methane, carbon dioxide and new cells. The mean VFA peak reduction in group two (98.0\%) was higher than group one $(95.6 \%)$.

Two observations could be made from the results of VFA:

1) The highest VFA percentage peak reduction was observed at $0 \%$ salt content and decreased by increasing the salt content in both groups.

2) The sludge addition in group two increased the VFA percentage peak reduction in both stages in comparison with group one. 

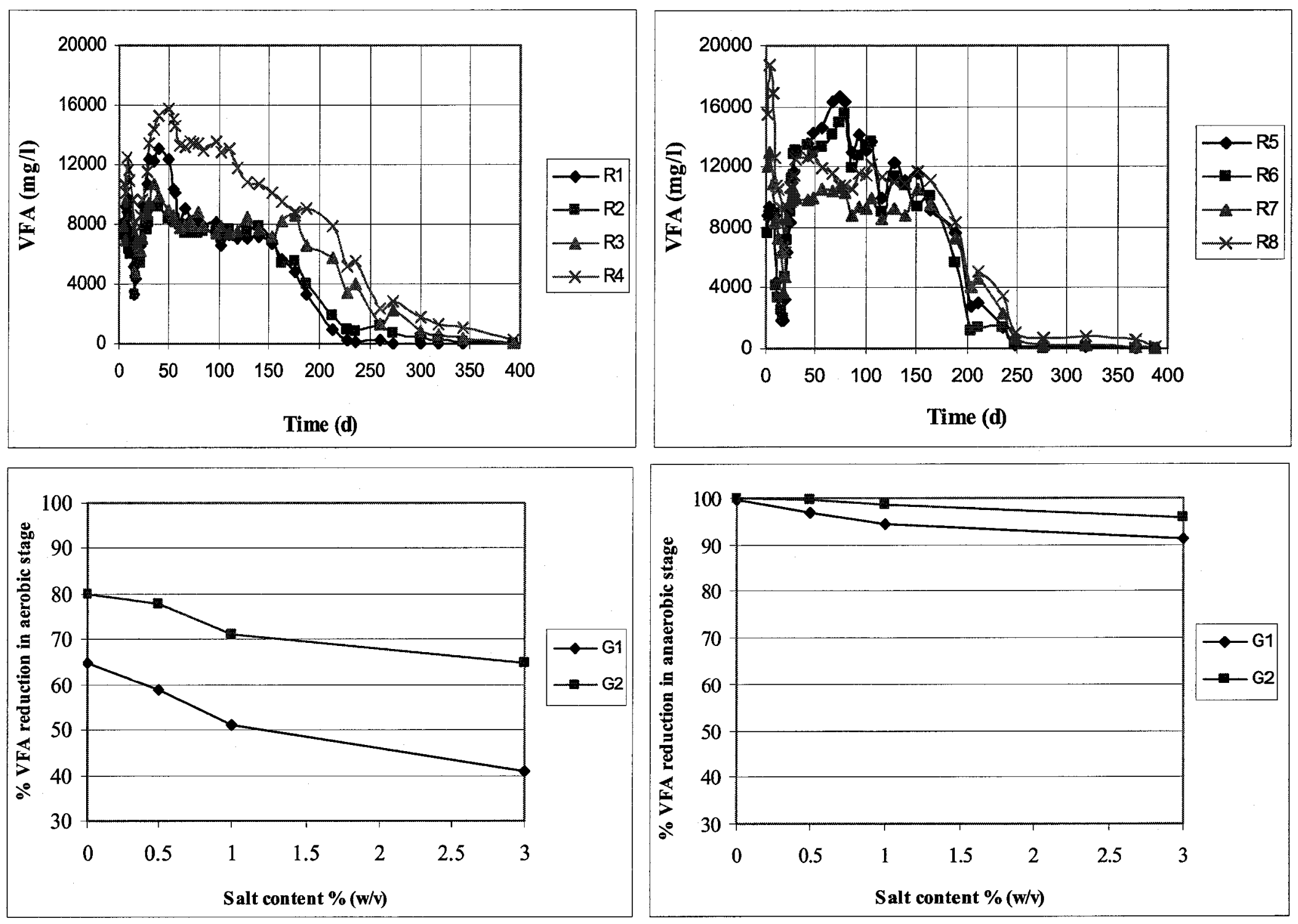

Figure 5.17: VFA variation in all bioreactors and percentage VFA peak reduction in two stages. 
Table 5.18: Results of VFA concentration and percentage peak reduction in two stages

\begin{tabular}{|c|c|c|c|c|c|c|c|c|}
\hline $\mathrm{VFA}(\mathrm{mg} / \mathrm{l})$ & $\mathrm{R} 1$ & $\mathrm{R} 2$ & R3 & $\mathrm{R} 4$ & R5 & R6 & $\mathrm{R} 7$ & $\mathrm{R} 8$ \\
\hline First peak & 9205 & 7960 & 9810 & 12425 & 9389 & 8761 & 12940 & 18700 \\
\hline $\begin{array}{l}\text { End of } \\
\text { aerobic }\end{array}$ & 3244 & 3272 & 4785 & 7372 & 1853 & 1929 & 3756 & 6449 \\
\hline $\begin{array}{l}\text { \% Reduction } \\
\text { in aerobic } \\
\end{array}$ & 65 & 59 & 51 & 41 & 80 & 78 & 71 & 65 \\
\hline Second peak & 13090 & 9120 & 10754 & 15779 & 16686 & 15463 & 12604 & 15782 \\
\hline $\begin{array}{l}\text { End of } \\
\text { anaerobic }^{3}\end{array}$ & 37 & 290 & 600 & 1350 & 59 & 80 & 201 & 819 \\
\hline $\begin{array}{l}\% \text { Reduction } \\
\text { in anaerobic }\end{array}$ & 100 & 97 & 94 & 91 & 100 & 99 & 98 & 95 \\
\hline Mean $^{4}$ & \multicolumn{4}{|c|}{$53.8^{\mathrm{G} 1}$} & \multicolumn{4}{|c|}{$73.5^{\mathrm{G} 2}$} \\
\hline Mean $^{5}$ & \multicolumn{4}{|c|}{$95.6^{\mathrm{G} 1}$} & \multicolumn{4}{|c|}{$98.0^{\mathrm{G} 2}$} \\
\hline
\end{tabular}

(1) Percentage reduction in VFA peak concentration during the aerobic stage.

(2) Percentage reduction in VFA peak concentration during the anaerobic stage.

(3) Values of VFA on day 319.

(4) Mean VFA percentage peak reduction during aerobic stage.

(5) Mean VFA percentage peak reduction during anaerobic stage.

\section{Statistical analysis}

Table 5.19 shows the statistical analysis of VFA concentration and percentage peak reduction. The statistical analysis could be summarized as follows:

- VFA concentration

1) There was a significant difference in the mean VFA concentration in all bioreactors during the study $\left(\mathrm{P}\right.$-value of Bioreactors $\left.{ }^{1}<0.05\right)$, but there was no significant difference between the mean VFA concentration in the two groups (P-value of Group $\left.{ }^{2}>0.05\right)$. The significant difference was observed in $\mathrm{R} 4$ with respect to $\mathrm{R} 1$ as shown in Table 3.3 .4 in Appendix B. 
Table 5.19: Statistical analysis for the mean and percentage peak reduction in VFA concentration

\begin{tabular}{|l|l|ll|ll|}
\hline \multicolumn{2}{|c|}{} & \multicolumn{4}{|c|}{0.000} \\
\hline \multirow{4}{*}{ P-value } & Bioreactors $^{1}$ & \multicolumn{4}{|c|}{0.085} \\
\cline { 2 - 6 } & Group $^{2}$ & & \multicolumn{4}{|c|}{} \\
\cline { 2 - 6 } & Reduction $^{3}$ & Groups & 0.002 & Salt content & 0.016 \\
\cline { 2 - 6 } & Reduction $^{4}$ & Groups & 0.073 & Salt content & 0.079 \\
\hline
\end{tabular}

(1) Comparison of the mean VFA concentration in all bioreactors $\left(\mathrm{F}_{7,308}\right)$.

(2) Comparison of the mean VFA concentration in the two groups $\left(F_{1,314}\right)$.

(3) Comparison of the mean VFA percentage peak reduction in the two groups and at different salt contents during the aerobic stage $\left(\mathrm{F}_{1,3}^{\mathrm{G}}\right.$ and $\left.\mathrm{F}_{3,3}^{\mathrm{S}}\right)$.

(4) Comparison of the mean VFA percentage peak reduction in the two groups and at different salt contents during the anaerobic stage $\left(\mathrm{F}_{1,3}^{\mathrm{G}}\right.$ and $\left.\mathrm{F}^{\mathrm{S}}{ }_{3,3}\right)$.

- VFA percentage peak reduction

2) In the aerobic stage, there were significant differences in the mean VFA percentage peak reduction 1) between the two groups, and 2) at different salt contents (P-values of Reduction $^{3}<0.05$ ). Table 3.3.5 in Appendix B shows that the difference occurred at 3\% compared to $0 \%(\mathrm{w} / \mathrm{v})$ salt content.

3) In the anaerobic stage, no significant differences were observed 1) between the mean VFA percentage peak reduction in the two groups, and 2) in the mean of VFA percentage peak reduction at different salt contents (P-values of Reduction $\left.{ }^{4}>0.05\right)$.

\subsubsection{4 pH}

The $\mathrm{pH}$ measured in leachate samples was in accordance with the conclusions withdrawn from the measurement of VFA concentration, in other words, when the VFA concentration increases the $\mathrm{pH}$ level drops. Figures 5.18 and 5.19 show the trend of $\mathrm{pH}$ in the leachate of all bioreactors, and Table 5.20 summarizes the results of $\mathrm{pH}$ during both stages, as well as the statistical analysis of the mean $\mathrm{pH}$. 


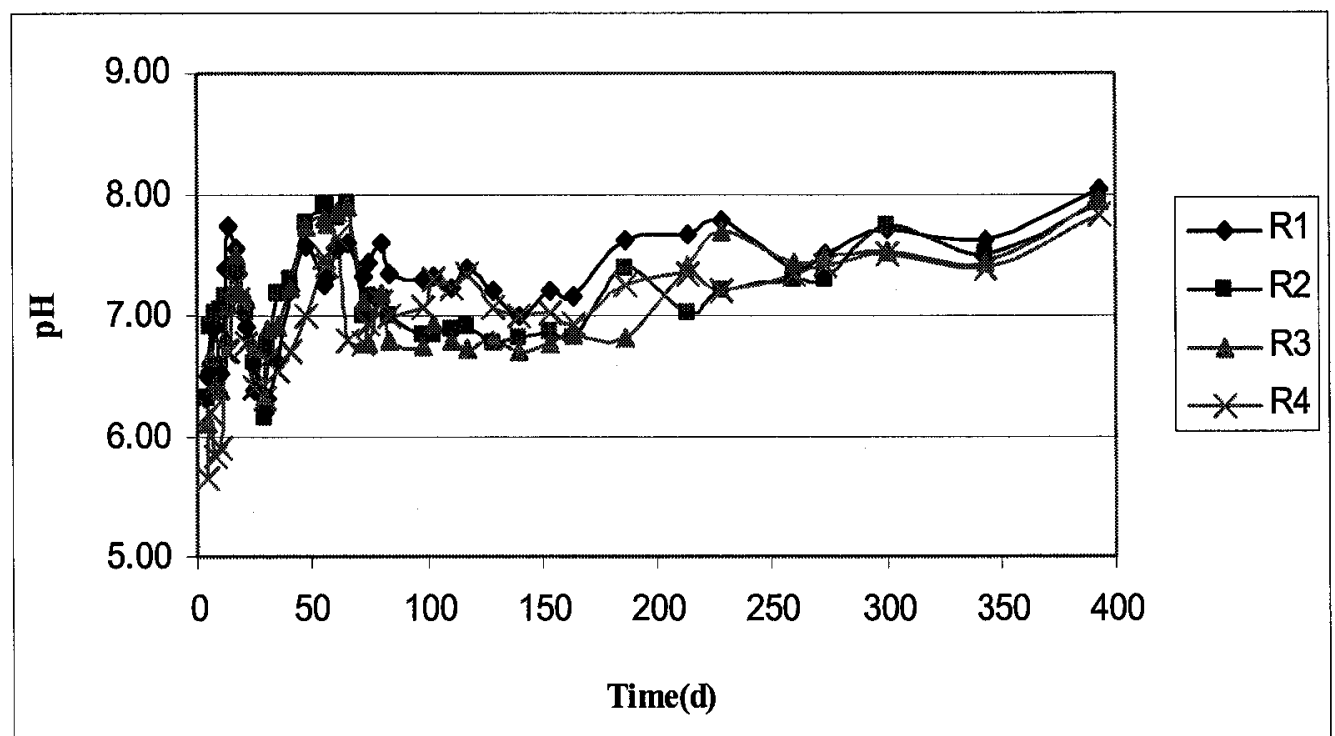

Figure 5.18: $\mathrm{pH}$ level in group one.

The initial pH level was $6.5,6.3,6.1,5.7,6.3,6.7,6.6$ and 5.7 in the leachate samples collected from $\mathrm{R} 1$ through $\mathrm{R} 8$, respectively. Then the $\mathrm{pH}$ values increased in all bioreactors due to the addition of buffer to the leachate recycle and the decrease in VFA concentration in the aerobic stage, as mentioned in Section 5.1.2.2.

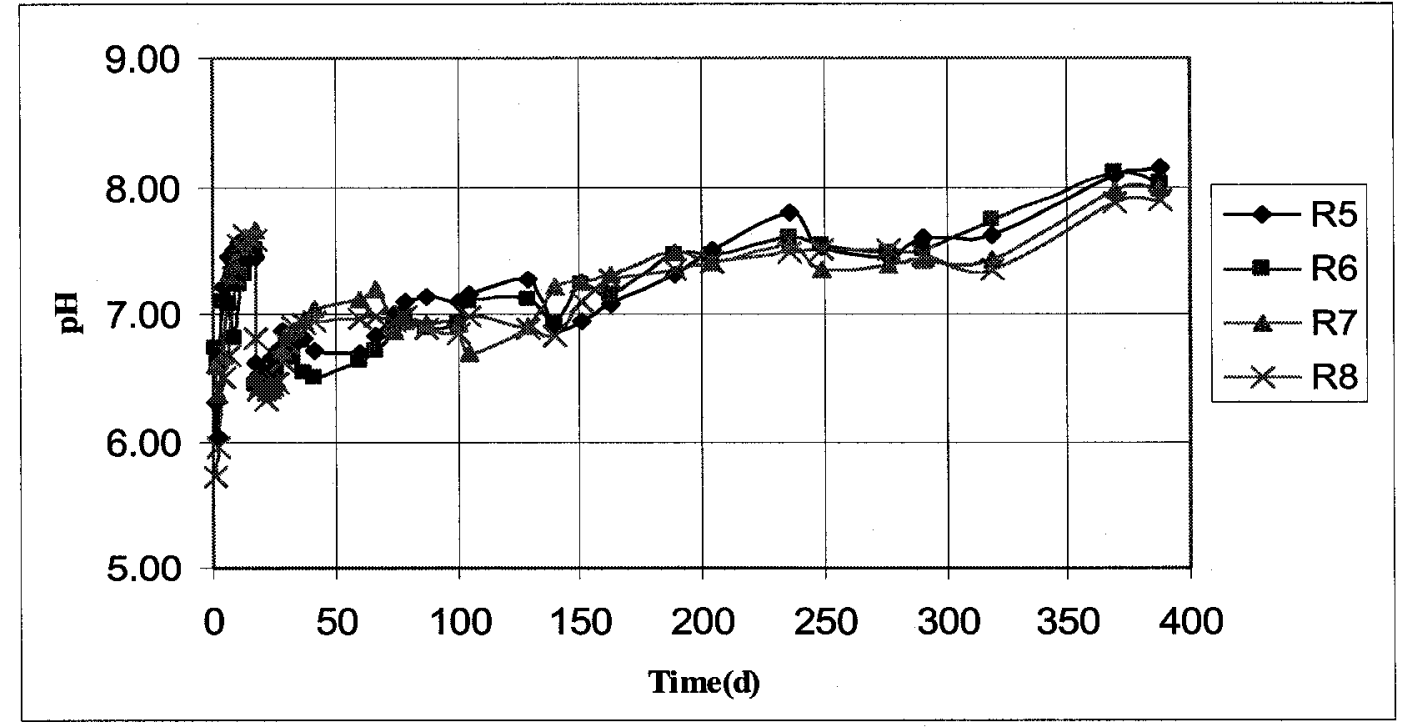

Figure 5.19: $\mathrm{pH}$ level in group two. 
The leachate $\mathrm{pH}$ values at the end of the aerobic stage were $7.56,7.42,7.50,7.26,7.45$, 7.50, 7.66 and 7.50 in R1 through R8, respectively. When the bioreactors shifted to the anaerobic condition (day 17), the $\mathrm{pH}$ decreased from approximately 7.5 to below 6.4 in all bioreactors due to the accumulation of acids from the hydrolyzation of MSW into organic acids and end products of acidogenic bacteria. The lowest $\mathrm{pH}$ values in the anaerobic stage were $6.20,6.16,6.33,6.30,6.20,6.25,6.38$ and 6.33 in R1 through R8, respectively. As the daily methane production increased above $2 \mathrm{~L} / \mathrm{d}$, it caused a decrease in the VFA concentration, this in turn produced an increase in the $\mathrm{pH}$ level of leachate in all bioreactors.

Table 5.20: Results of $\mathrm{pH}$ values in leachate samples from all bioreactors

\begin{tabular}{|l|cccc|cccc|}
\hline $\mathrm{pH}$ & $\mathrm{R} 1$ & $\mathrm{R} 2$ & $\mathrm{R} 3$ & $\mathrm{R} 4$ & $\mathrm{R} 5$ & $\mathrm{R} 6$ & $\mathrm{R} 7$ & $\mathrm{R} 8$ \\
\hline Initial value & 6.50 & 6.30 & 6.10 & 5.65 & 6.30 & 6.72 & 6.60 & 5.70 \\
\hline $\begin{array}{l}\text { End of } \\
\text { aerobic }\end{array}$ & 7.56 & 7.42 & 7.50 & 7.26 & 7.45 & 7.50 & 7.66 & 7.20 \\
\hline $\begin{array}{l}\text { Lowest in } \\
\text { anaerobic }\end{array}$ & 6.20 & 6.16 & 6.33 & 6.30 & 6.20 & 6.25 & 6.38 & 6.33 \\
\hline Maximum & 8.03 & 7.92 & 7.94 & 7.83 & 8.14 & 8.10 & 8.00 & 7.90 \\
\hline Mean & 7.23 & 7.15 & 7.08 & 6.95 & 7.11 & 7.04 & 7.07 & 7.00 \\
\hline \multirow{2}{*}{ P-value } & \multicolumn{7}{|l|}{ Bioreactors } & \multicolumn{7}{|c|}{0.223} \\
\cline { 2 - 8 }${ }^{2}$ & \multicolumn{7}{|c|}{0.361} \\
\hline
\end{tabular}

(1) Comparison of the mean $\mathrm{pH}$ value in all reactors $\left(\mathrm{F}_{7,300}\right)$.

(2) Comparison of the mean $\mathrm{pH}$ value in the two groups $\left(\mathrm{F}_{1,306}\right)$.

The low value of $\mathrm{pH}$ at the beginning of the anaerobic stage was due to the hydrolysis of the solid waste into complex dissolved organic compounds and organic acids, which the acidogenic bacteria converted into hydrogen, $\mathrm{CO}_{2}$ and VFA. Also the addition of anaerobic digested sludge to the leachate recycle in group two decreased the $\mathrm{pH}$ at the beginning of the anaerobic stage. 
Ağda $\breve{g}$ et al. (2005) found that the initial $\mathrm{pH}$ of leachate from a reactor operated with the addition of buffer was 5.3 and it reached approximately 7 after 20 days. Warith et al. (1998) found that the initial $\mathrm{pH}$ of the leachate sample with buffer addition was 6 and it stabilized at approximately 7 after 25 days. Chiemcharis et al. (2002) found that the pH of leachate from anaerobic bioreactors operated with the addition of buffer and anaerobic sludge reached 7 after 100 days in their experiments. Also, Rendra et al. (2003) found that the initial $\mathrm{pH}$ of leachate from their anaerobic bioreactor run with addition of buffer and anaerobic digested sludge was 5.7 and reached 7 after 112 days. The results from this study are consistent with results presented in the literature.

\section{Statistical analysis}

Table 5.20 summarizes the statistical analysis for the mean $\mathrm{pH}$ values during the study. The P-values of Bioreactors ${ }^{1}$ and Groups ${ }^{2}$ were more than 0.05 . This indicates that there was no significant difference 1) in the mean $\mathrm{pH}$ values in all bioreactors and, 2) between the mean $\mathrm{pH}$ values in the two groups.

\subsubsection{Variations in TVS}

The TVS followed the same trend of COD concentration in all bioreactors, as shown in Figure 5.20. Table 5.21 summarizes the results of TVS concentration in all bioreactors and TVS percentage peak reduction during the aerobic and anaerobic stages.

In the aerobic stage, TVS percentage peak reduction was $63,53,47,43,78,73,71$ and $63 \%$ in $\mathrm{R} 1$ through $\mathrm{R} 8$, respectively. The mean TVS peak reduction in group two (71.2\%) was higher than group one $(51.6 \%)$. The reason for the decrease in the TVS concentration during the 

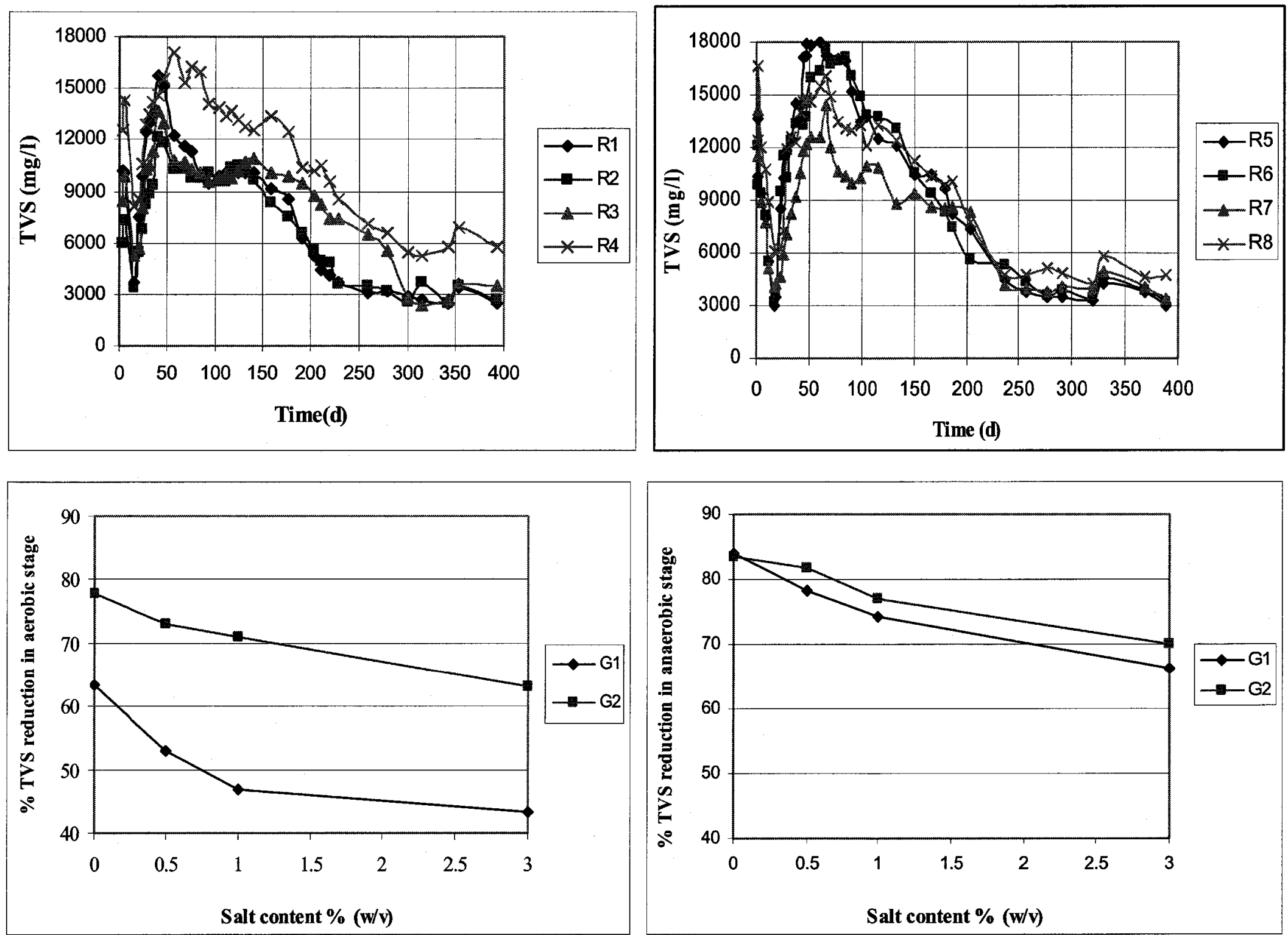

Figure 5.20: TVS variation in all bioreactors and percentage TVS peak reduction in two stages. 
Table 5.21: Results of TVS concentration and percentage peak reduction in two stages

\begin{tabular}{|c|c|c|c|c|c|c|c|c|}
\hline TVS(mg/l) & $\mathrm{R} 1$ & $\mathrm{R} 2$ & R3 & $\mathrm{R} 4$ & $\mathrm{R} 5$ & R6 & R7 & R8 \\
\hline First peak & 10088 & 7319 & 9876 & 14336 & 13652 & 12120 & 14136 & 16608 \\
\hline $\begin{array}{l}\text { End of } \\
\text { aerobic }\end{array}$ & 3700 & 3436 & 5260 & 8130 & 3028 & 3240 & 4096 & 6132 \\
\hline $\begin{array}{l}\% \text { Reduction } \\
\text { in aerobic } \\
\end{array}$ & 63 & 53 & 47 & 43 & 78 & 73 & 71 & 63 \\
\hline Second peak & 15739 & 12090 & 13707 & 17060 & 18028 & 17624 & 14460 & 16103 \\
\hline $\begin{array}{l}\text { End of } \\
\text { anaerobic }\end{array}$ & 2516 & 2636 & 3520 & 5768 & 2972 & 3200 & 3372 & 4768 \\
\hline $\begin{array}{l}\% \text { Reduction } \\
\text { in anaerobic }\end{array}$ & 84 & 78 & 74 & 66 & 84 & 82 & 77 & 70 \\
\hline Mean $^{3}$ & \multicolumn{4}{|c|}{$51.6^{\mathrm{G} 1}$} & \multicolumn{4}{|c|}{$71.2^{\mathrm{G} 2}$} \\
\hline Mean $^{4}$ & \multicolumn{4}{|c|}{$75.7^{\mathrm{G} 1}$} & \multicolumn{4}{|c|}{$78^{\mathrm{G} 2}$} \\
\hline
\end{tabular}

(1) Percentage reduction in TVS peak concentration during the aerobic stage.

(2) Percentage reduction in TVS peak concentration during the anaerobic stage.

(3) Mean TVS percentage peak reduction during the aerobic stage.

(4) Mean TVS percentage peak reduction during the anaerobic stage.

aerobic stage was that the aerobic bacteria consumed the organic matter in the leachate to produce carbon dioxide and new cells.

In the anaerobic stage, the TVS concentration increased initially in all bioreactors due to the increase of organic matter in the leachate which is the end product in the hydrolysis and acidogenic steps. As the methanogenic bacteria started to consume the organic matter in the leachate to produce new cells, methane and carbon dioxide, the TVS concentration declined to low values at the end of the experiments. The mean TVS percentage peak reduction during the anaerobic stage in group two (78\%) was higher than group one $(75.7 \%)$ 
The results of TVS percentage peak reduction showed the following:

1) The highest TVS percentage peak reduction was observed at $0 \%$ salt content during the aerobic and anaerobic stages, and decreased with increased salt content in both groups.

2) The addition of sludge into the bioreactors of group two caused an enhancement in solid waste biodegradation as suggested by the TVS percentage peak reduction in both stages.

\section{Statistical analysis}

Table 5.22 summarizes the statistical analysis for the mean TVS concentration and TVS percentage peak reduction during the aerobic and anaerobic stages.

Table 5.22: Statistical analysis for the mean and percentage peak reduction in TVS concentration

\begin{tabular}{|l|l|ll|ll|}
\hline \multicolumn{2}{|c|}{} & \multicolumn{4}{|c|}{0.000} \\
\hline \multirow{3}{*}{ P-value } & Bioreactors & \multicolumn{4}{|c|}{0.021} \\
\cline { 2 - 6 } & Group $^{2}$ & & \multicolumn{4}{|c|}{ Salt content } & 0.03 \\
\cline { 2 - 6 } & Reduction $^{3}$ & Groups & 0.002 & Salt content & 0.005 \\
\cline { 2 - 7 } & Reduction $^{4}$ & Groups & 0.095 & & \\
\hline
\end{tabular}

(1) Comparison of the mean TVS concentration in all bioreactors $\left(\mathrm{F}_{7,292}\right)$.

(2) Comparison of the mean TVS concentration in the two groups $\left(\mathrm{F}_{1,298}\right)$.

(3) Comparison of the mean TVS percentage peak reduction in the two groups and at different salt contents during the aerobic stage $\left(\mathrm{F}_{1,3}^{\mathrm{G}}\right.$ and $\left.\mathrm{F}_{3,3}^{S}\right)$.

(4) Comparison of the mean TVS percentage peak reduction in the two groups and at different salt contents during the anaerobic stage $\left(\mathrm{F}_{1,3}^{\mathrm{G}}\right.$ and $\left.\mathrm{F}_{3,3}^{\mathrm{S}}\right)$.

- TVS concentration

1) The P-values of Bioreactors ${ }^{1}$ and Groups ${ }^{2}$ were less than 0.05 . This indicates that there was a significant difference in the mean TVS concentration 1) in all bioreactors, and 2) between the two groups. The difference was in $\mathrm{R} 4$ compared to $\mathrm{R} 1$, as shown in Table

\subsection{5 in Appendix B.}


- TVS percentage peak reduction

2) In the aerobic stage, significant differences were observed 1) between the mean TVS percentage peak reduction in the two groups, and 2) in the mean TVS percentage peak reduction at different salt contents. The difference in the mean TVS percentage peak reduction was at $3 \%$ compared to $0 \%(\mathrm{w} / \mathrm{v})$ salt content, as shown in Table 3.5 .6 in Appendix B.

3) In the anaerobic stage, there was no significant difference between the mean TVS percentage peak reduction in the two groups, but there was a significant difference in the mean TVS percentage peak reduction at different salt contents. The difference was in the mean TVS peak reduction at $1 \%$ and $3 \%$ compared to $0 \%(\mathrm{w} / \mathrm{v})$ salt content, as shown in Table 3.5.7 in Appendix B.

\subsubsection{Variations in TS}

The TS concentration in the leachate samples from all bioreactors and TS percentage peak reduction during the aerobic and anaerobic stages are presented in Figure 5.21. The TS variation trends exhibited a similar behavior to TVS and COD variation trends. Table 5.23 summarizes the results of TS concentration in all bioreactors and TS percentage peak reduction during both stages.

In the aerobic stage, the TS peak reduction was $44,37,32,21,68,50,42$, and $31 \%$ in $\mathrm{R} 1$ through R8, respectively. The highest TS percentage peak reduction was observed in R5 (68\%) and the lowest in R4 (21\%). Also, the mean TS percentage peak reduction in group two $(47.8 \%)$ was higher than group one $(33.5 \%)$. The reason for the low TS percentage peak reduction in bioreactors operated with saline water, especially R4 and 

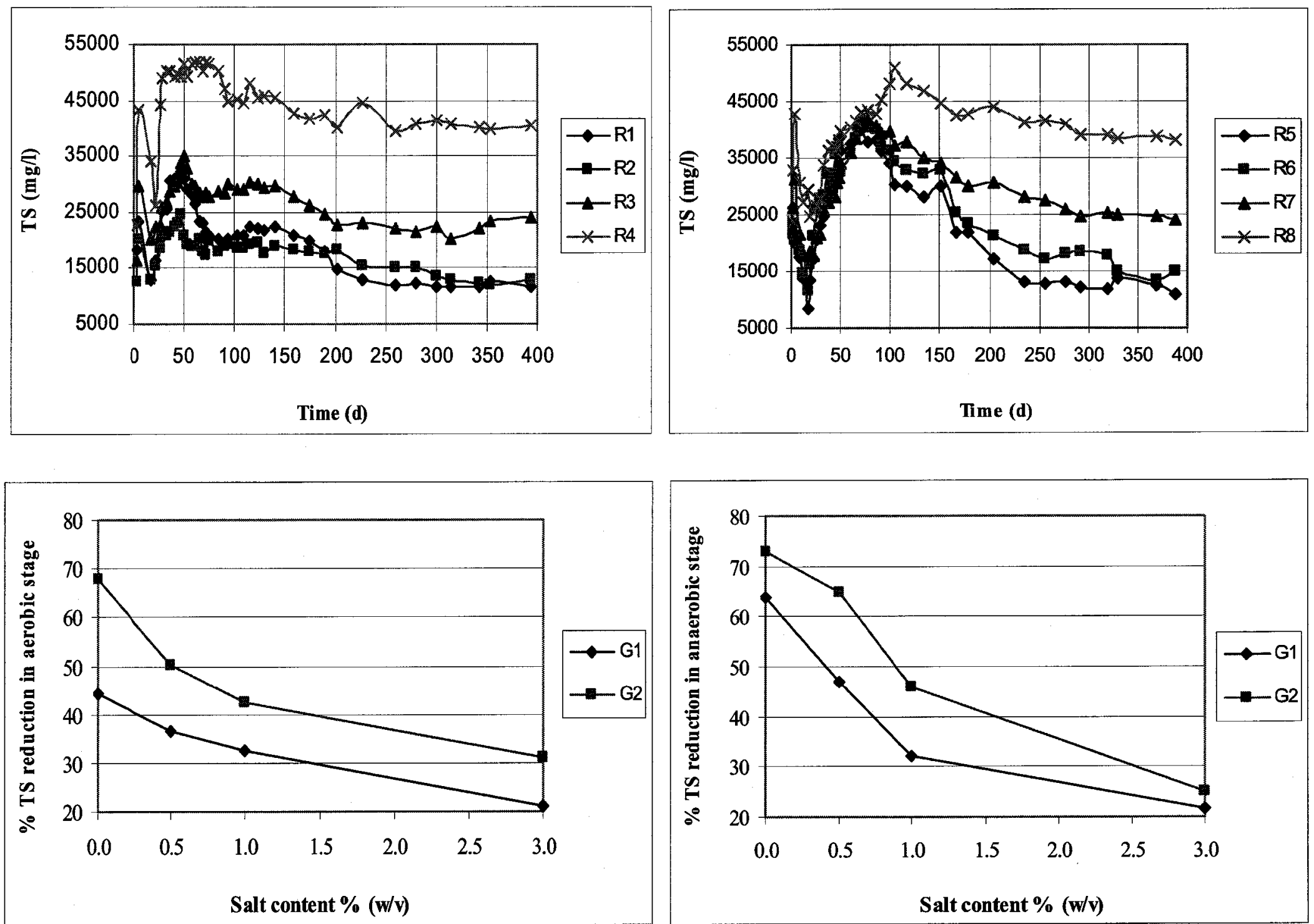

Figure 5.21: TS variations in all bioreactors and percentage TS peak reduction in two stages. 
Table 5.23: Results of TS concentration and percentage peak reduction in two stages

\begin{tabular}{|c|c|c|c|c|c|c|c|c|}
\hline $\mathrm{TS}(\mathrm{mg} / 1)$ & $\mathrm{R} 1$ & $\mathrm{R} 2$ & R3 & R4 & R5 & R6 & $\mathrm{R} 7$ & $\mathrm{R} 8$ \\
\hline First peak & 23408 & 20136 & 29736 & 43288 & 26252 & 23516 & 31184 & 42720 \\
\hline $\begin{array}{l}\text { End of } \\
\text { aerobic }\end{array}$ & 13020 & 12756 & 20120 & 34082 & 8476 & 11716 & 17956 & 29424 \\
\hline $\begin{array}{l}\text { \% Reduction } \\
\text { in aerobic }\end{array}$ & 44 & 37 & 32 & 21 & 68 & 50 & 42 & 31 \\
\hline Second peak & 32364 & 24568 & 35048 & 51824 & 40560 & 42268 & 44800 & 50868 \\
\hline $\begin{array}{l}\text { End of } \\
\text { anaerobic }\end{array}$ & 11680 & 13064 & 23844 & 40528 & 10928 & 14844 & 24164 & 38060 \\
\hline $\begin{array}{l}\% \text { Reduction } \\
\text { in anaerobic } \\
\end{array}$ & 64 & 47 & 32 & 22 & 73 & 65 & 46 & 25 \\
\hline Mean $^{3}$ & \multicolumn{4}{|c|}{$33.5^{\mathrm{G} 1}$} & \multicolumn{4}{|c|}{$47.8^{\mathrm{G} 2}$} \\
\hline Mean $^{4}$ & \multicolumn{4}{|c|}{$41.3^{\mathrm{Gl}}$} & \multicolumn{4}{|c|}{$52.3^{\mathrm{G} 2}$} \\
\hline
\end{tabular}

(1) Percentage reduction in TS peak concentration during the aerobic stage.

(2) Percentage reduction in TS peak concentration during the anaerobic stage.

(3) Mean TS percentage peak reduction during the aerobic stage.

(4) Mean TS percentage peak reduction during the anaerobic stage.

R8, was that the addition of salt inhibited the aerobic bacteria and increased the total solids content. Consequently, any change in the TS concentration compared to the peak value was negligible.

In the anaerobic stage, TS concentration increased in all bioreactors as a result of an increase in the organic matter that was produced through the hydrolysis of MSW and acidogenic bacteria. Figure 5.16 shows that bioreactors operated with sludge addition (group two) had a higher TS percentage peak reduction than bioreactors without sludge addition (group one). The high TS concentration in R4 and R8 can be attributed to a high salt content. 


\section{$\underline{\text { Statistical analysis }}$}

Table 5.24 summarizes the statistical analysis for the mean TS concentration and TS percentage peak reduction during the aerobic and anaerobic stages.

\section{- TS concentration}

1) The P-value of Bioreactors ${ }^{1}$ was less than 0.05 . This indicates that there was a significant difference in the mean TS concentration in all bioreactors. Table 3.6 .5 in Appendix B shows multiple comparisons between the mean TS concentrations in all bioreactors.

2) The P-value of Groups ${ }^{2}$ was more than 0.05 . This means that there was no significant difference between the mean TS concentration in the two groups.

Table 5.24: Statistical analysis for the mean and percentage peak reduction in TS concentration

\begin{tabular}{|c|l|ll|ll|}
\hline \multicolumn{1}{|l|}{ TS concentration } & \multicolumn{4}{|c|}{0.000} \\
\hline \multirow{4}{*}{ P-value } & Bioreactors $^{1}$ & \multicolumn{4}{|c|}{0.229} \\
\cline { 2 - 6 } & Group $^{2}$ & & \multicolumn{4}{|c|}{ Salt content } & 0.028 \\
\cline { 2 - 6 } & Reduction $^{3}$ & Groups & 0.023 & Salt content & 0.007 \\
\cline { 2 - 7 } & Reduction $^{4}$ & Groups & 0.043 & & \\
\hline
\end{tabular}

(1) Comparison of the mean TS concentration in all reactors $\left(\mathrm{F}_{7,308}\right)$.

(2) Comparison of the mean TS concentration in the two groups $\left(\mathrm{F}_{1,314}\right)$.

(3) Comparison of the mean TS percentage peak reduction in the two groups and at different salt contents during the aerobic stage $\left(\mathrm{F}_{1,3}^{\mathrm{G}}\right.$ and $\left.\mathrm{F}_{3,3}^{\mathrm{S}}\right)$.

(4) Comparison of the mean TS percentage peak reduction in the two groups and at different salt contents during the anaerobic stage $\left(\mathrm{F}_{1,3}^{\mathrm{G}}\right.$ and $\left.\mathrm{F}_{3,3}^{\mathrm{S}}\right)$.

- TS percentage peak reduction

3) In both aerobic and anaerobic stages, there was a significant difference in the mean TS percentage peak reduction 1) between the two groups, and 2) at different salt contents ( $\mathrm{P}$ values of Reduction ${ }^{3}$ and Reduction ${ }^{4}$ were less than 0.05 ). Tables 3.6.6 and 3.6.7 in 
Appendix B show multiple comparisons of the mean TS percentage peak reduction at different salt contents during the aerobic and anaerobic stages, respectively. The difference was observed at $3 \%$ compared to $0 \%(\mathrm{w} / \mathrm{v})$ salt content in the aerobic stage, while it was at $1 \%$ and $3 \%$ in the anaerobic stage.

\subsubsection{Variations in $\mathrm{NH}_{3}-\mathrm{N}$}

The results of the $\mathrm{NH}_{3}-\mathrm{N}$ concentration in the leachate samples from all bioreactors, and the percentage $\mathrm{NH}_{3}-\mathrm{N}$ peak reduction at different salt contents during the aerobic and anaerobic stages are shown in Figure 5.22. Also, Table 5.25 summarizes the results of $\mathrm{NH}_{3}-\mathrm{N}$ concentration and percentage peak reduction in both stages.

The $\mathrm{NH}_{3}-\mathrm{N}$ peak reduction during the aerobic stage was $80,65,60,38,97,94,94$, and $92 \%$ in $\mathrm{R} 1$ through $\mathrm{R} 8$, respectively. These results could be attributed to 1) part of $\mathrm{NH}_{3}-\mathrm{N}$ was consumed by aerobic bacteria to produce new cells and, 2) part of $\mathrm{NH}_{3}-\mathrm{N}$ converted to nitrate through nitrification. The mean $\mathrm{NH}_{3}-\mathrm{N}$ peak reduction in group two (94\%) was higher than group one $(61 \%)$. This indicates that the addition of sludge enhanced the $\mathrm{NH}_{3}-\mathrm{N}$ peak reduction. The high salt content inhibited the $\mathrm{NH}_{3}-\mathrm{N}$ peak reduction as in R4, and this agreed with results presented by Dincer et al. (1999). They found that the nitrification efficiency dropped dramatically and the effect of salt became significant as salt content increased above $2 \%(\mathrm{w} / \mathrm{v})$.

In the anaerobic stage, the $\mathrm{NH}_{3}-\mathrm{N}$ concentrations increased in the beginning of this stage due to the release of ammonia nitrogen from the biodegradation of protein and nitrogen compounds into the leachate. After day 70 and 45 in group one and two respectively, the $\mathrm{NH}_{3}-\mathrm{N}$ concentration started to decrease, because the $\mathrm{NH}_{3}-\mathrm{N}$ was utilized by the 

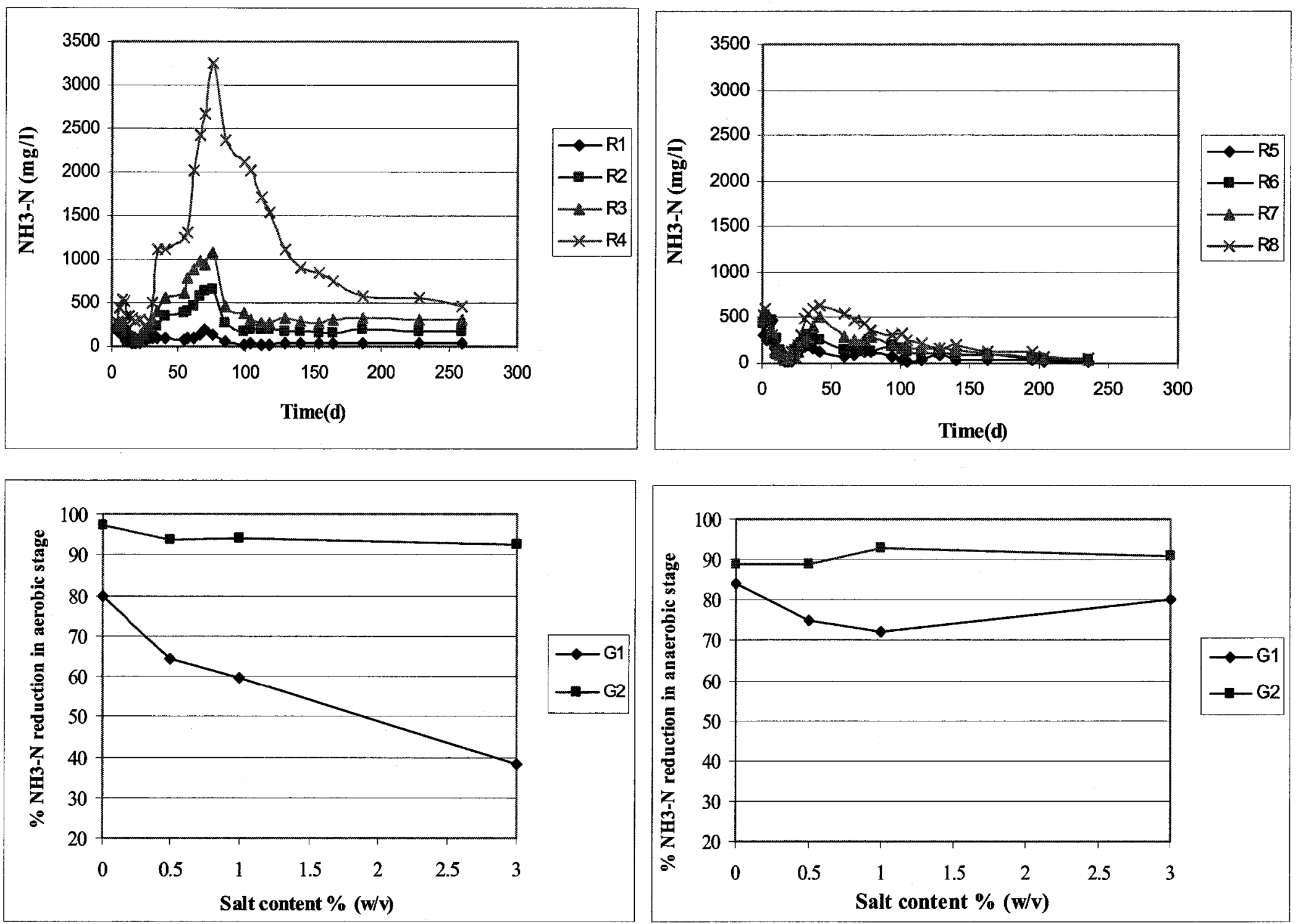

Figure 5.22: $\mathrm{NH}_{3}-\mathrm{N}$ variation in all bioreactors and percentage $\mathrm{NH}_{3}-\mathrm{N}$ peak reduction in two stages. 
Table 5.25: Results of $\mathrm{NH}_{3}-\mathrm{N}$ concentration and percentage peak reduction in two stages

\begin{tabular}{|c|c|c|c|c|c|c|c|c|}
\hline $\begin{array}{l}\mathrm{NH}_{3}-\mathrm{N} \\
(\mathrm{mg} / \mathrm{l})\end{array}$ & $\mathrm{R} 1$ & $\mathrm{R} 2$ & R3 & R4 & R5 & $\mathrm{R} 6$ & $\mathrm{R} 7$ & R8 \\
\hline First peak & 189 & 245 & 271 & 543 & 447 & 464 & 515 & 606 \\
\hline $\begin{array}{l}\text { End of } \\
\text { aerobic }\end{array}$ & 38 & 87 & 109 & 335 & 12 & 29 & 31 & 46 \\
\hline $\begin{array}{l}\text { \% Reduction } \\
\text { in aerobic }\end{array}$ & 80 & 65 & 60 & 38 & 97 & 94 & 94 & 92 \\
\hline Second peak & 237 & 657 & 1086 & 3241 & 207 & 305 & 505 & 638 \\
\hline $\begin{array}{l}\text { End of } \\
\text { anaerobic }\end{array}$ & 37 & 164 & 303 & 659 & 23 & 35 & 37 & 60 \\
\hline $\begin{array}{l}\text { \% Reduction } \\
\text { in anaerobic } \\
\end{array}$ & 84 & 75 & 72 & 80 & 89 & 89 & 93 & 91 \\
\hline Mean $^{3}$ & \multicolumn{4}{|c|}{$61^{\mathrm{G} 1}$} & \multicolumn{4}{|c|}{$94^{\mathrm{G} 2}$} \\
\hline Mean $^{4}$ & \multicolumn{4}{|c|}{$78^{\mathrm{G} 1}$} & \multicolumn{4}{|c|}{$90^{\mathrm{G} 2}$} \\
\hline
\end{tabular}

(1) Percentage reduction in $\mathrm{NH}_{3}-\mathrm{N}$ peak concentration during the aerobic stage.

(2) Percentage reduction in $\mathrm{NH}_{3}-\mathrm{N}$ peak concentration during the anaerobic stage.

(3) Mean $\mathrm{NH}_{3}-\mathrm{N}$ percentage peak reduction during the aerobic stage.

(4) Mean $\mathrm{NH}_{3}-\mathrm{N}$ percentage peak reduction during the anaerobic stage.

anaerobic bacteria to grow and produce new cells. The $\mathrm{NH}_{3}-\mathrm{N}$ peak reduction in this stage was $84,75,72,80,89,89,93$ and $91 \%$ in $R 1$ to $R 8$, respectively.

Youcai et al. (2002) found the concentration of $\mathrm{NH}_{3}-\mathrm{N}$ in bioreactors containing $76 \%$ (w/w) cooking and fruit wastes operated under anaerobic conditions, initially increased to $1500 \mathrm{mg} / \mathrm{l}$ and then dropped to less than $250 \mathrm{mg} / \mathrm{l}$ at the end of the study ( 250 days).

Sponza et al. (2004) observed the $\mathrm{NH}_{3}-\mathrm{N}$ concentration in the leachate of bioreactors operated under anaerobic conditions initially increased up to $600 \mathrm{mg} / \mathrm{l}$ and then decreased to less than $300 \mathrm{mg} / 1$ at the end of study (day 57). The composition of waste that was used in the study contained $91 \%(\mathrm{w} / \mathrm{w})$ kitchen waste.

The results of $\mathrm{NH}_{3}-\mathrm{N}$ showed the following:

1) The highest $\mathrm{NH}_{3}-\mathrm{N}$ percentage reduction occurred at $0 \%(\mathrm{w} / \mathrm{v})$ salt content in both groups and the $\mathrm{NH}_{3}-\mathrm{N}$ took longer time to be consumed in the bioreactors operating at 
$3 \%(w / v)$ salt content compared to other bioreactors.

2) The addition of sludge increased the $\mathrm{NH}_{3}-\mathrm{N}$ percentage reduction and decreased the time required to utilize the $\mathrm{NH}_{3}-\mathrm{N}$ in both stages and at different salt contents.

\section{Statistical analysis}

Table 5.26 summarizes the statistical analysis for the mean $\mathrm{NH}_{3}-\mathrm{N}$ concentration and for the $\mathrm{NH}_{3}-\mathrm{N}$ percentage peak reduction during the aerobic and anaerobic stages.

Table 5.26: Statistical analysis for the mean and percentage peak reduction of $\mathrm{NH}_{3}-\mathrm{N}$ concentration

\begin{tabular}{|c|l|ll|ll|}
\hline \multicolumn{2}{|c|}{} & \multicolumn{4}{|c|}{0.000} \\
\hline \multirow{4}{*}{ P-value } & Bioreactors & & \multicolumn{3}{|c|}{0.0000} \\
\cline { 2 - 6 } & Group $^{2}$ & & \multicolumn{4}{|c|}{0.000} & \\
\cline { 2 - 6 } & Reduction $^{3}$ & Groups & 0.022 & Salt content & 0.364 \\
\cline { 2 - 6 } & Reduction $^{4}$ & Groups & 0.009 & Salt content & 0.391 \\
\hline
\end{tabular}

(1) Comparison of the mean $\mathrm{NH}_{3}-\mathrm{N}$ concentration in all bioreactors $\left(\mathrm{F}_{7,248}\right)$.

(2) Comparison of the mean $\mathrm{NH}_{3}-\mathrm{N}$ concentration in the two groups $\left(\mathrm{F}_{1,254}\right)$.

(3) Comparison of the mean $\mathrm{NH}_{3}-\mathrm{N}$ peak reduction in two groups and at different salt contents during the aerobic stage $\left(\mathrm{F}_{1,3}^{\mathrm{G}}\right.$ and $\left.\mathrm{F}_{3,3}^{\mathrm{S}}\right)$.

(4) Comparison of the mean $\mathrm{NH}_{3}-\mathrm{N}$ peak reduction in two groups and at different salt contents during the anaerobic stage $\left(\mathrm{F}_{1,3}^{\mathrm{G}}\right.$ and $\mathrm{F}_{3,3}^{\mathrm{S}}$ ).

- $\mathrm{NH}_{3}-\mathrm{N}$ concentration

1) The P-values of Bioreactors ${ }^{1}$ and Groups ${ }^{2}$ were less than 0.05 . This indicates that there was a significant difference in the mean $\mathrm{NH}_{3}-\mathrm{N}$ concentration 1) in all bioreactors, and 2) between the two groups. The differences were in the mean $\mathrm{NH}_{3}-\mathrm{N}$ concentration of $\mathrm{R} 3$ and R4 compared to R1, as shown in Table 3.7.5 in Appendix B.

- $\mathrm{NH}_{3}-\mathrm{N}$ percentage peak reduction

1) In the aerobic and anaerobic stages there was a significant difference between the mean $\mathrm{NH}_{3}-\mathrm{N}$ percentage peak reduction in the two groups, but there was no significant difference in the mean $\mathrm{NH}_{3}-\mathrm{N}$ percentage peak reduction at different salt contents. 


\subsubsection{Salinity}

The salinity concentration in the leachate samples from R2, R3, R4, R6, R7 and R8 are shown in Figures 5.23 and 5.24. The salinity concentrations remained approximately constant at the design operation salt conditions. The small variations that took place during the study can be attributed to changes in the volume of the leachate as a result of losses through analysis, consumption by the system and water make up.

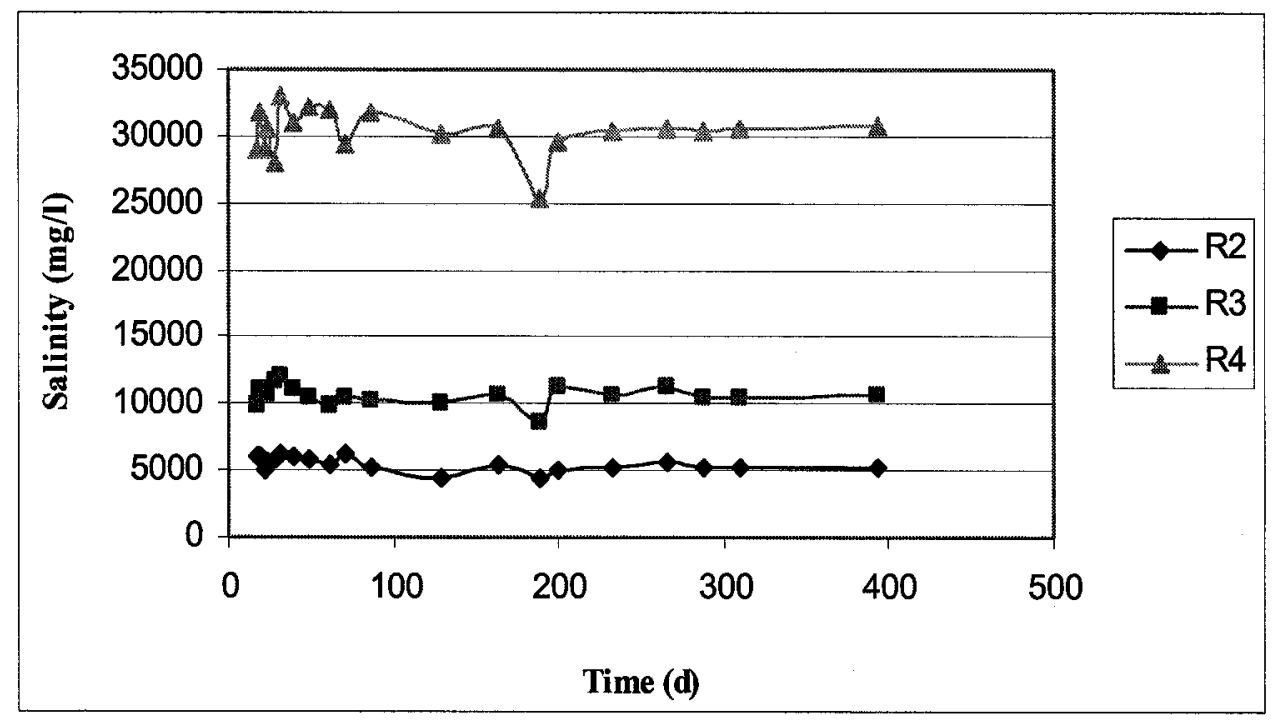

Figure 5.23: Salinity concentrations in group one.

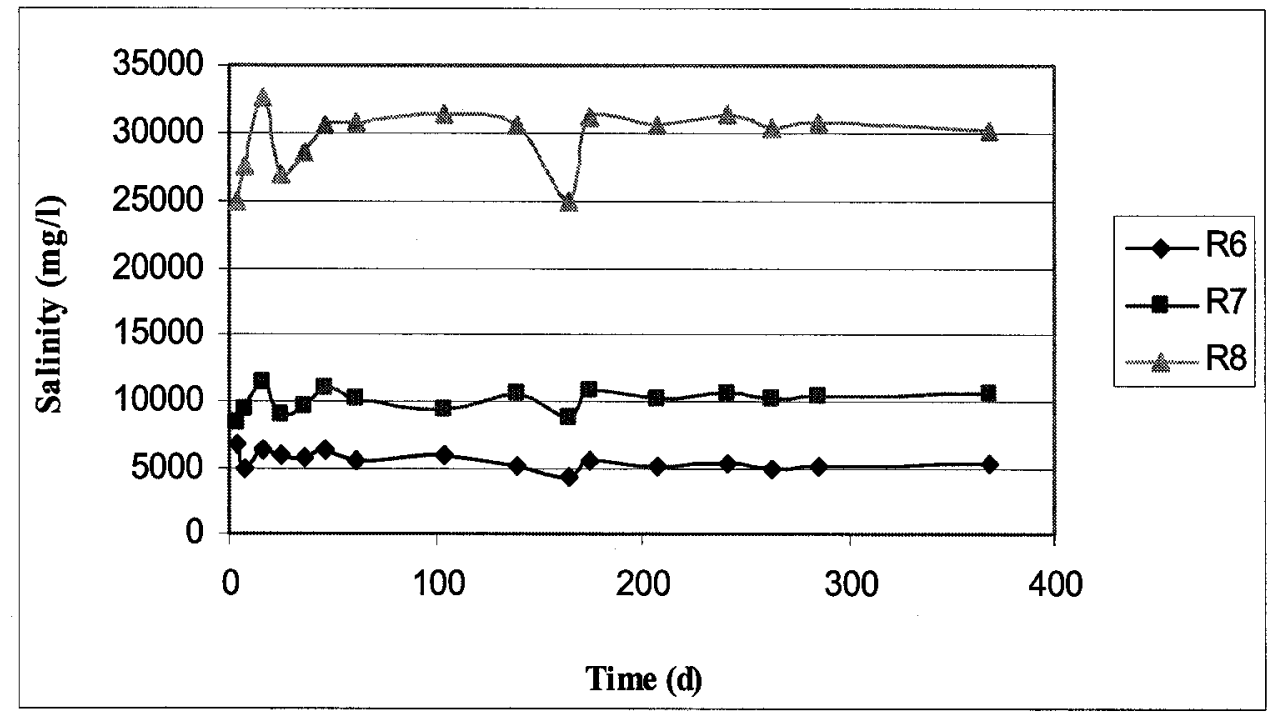

Figure 5.24: Salinity concentrations in group two. 


\subsubsection{Vertical Concentration profile in bioreactors}

Table 5.27 summarizes the results of COD concentration at different ports in R1 and R5, and the statistical analysis. Small variations in the COD concentration among the vertical profile of bioreactors were observed. As shown in the table, the P-values were more than 0.05. This emphasizes that there were no significant differences in the mean COD concentration at different ports, in other words, there was no significant concentration variations along the vertical profile of the bioreactors.

Table 5.27: COD concentration in all ports at R1 and R5

\begin{tabular}{|c|c|c|c|c|}
\hline \multicolumn{2}{|c|}{ COD (mg/l) } & Port1 (Top) & Port2 (Mid) & Port3 (bottom) \\
\hline \multirow{15}{*}{ R1 } & \multirow{3}{*}{$\begin{array}{l}\text { First analysis } \\
3 / 11 / 2005\end{array}$} & 10200 & 10700 & 10200 \\
\hline & & 10300 & 10200 & 10100 \\
\hline & & 10500 & 10300 & 9700 \\
\hline & Average & 10333 & 10400 & 10000 \\
\hline & P-value ${ }^{1}$ & & 0.117 & \\
\hline & \multirow{3}{*}{$\begin{array}{l}\text { Second analysis } \\
28 / 1 / 2006\end{array}$} & 3200 & 3400 & 3000 \\
\hline & & 3300 & 2900 & 3600 \\
\hline & & 3500 & 2600 & 3300 \\
\hline & Average & 3333 & 2967 & 3300 \\
\hline & P-value ${ }^{1}$ & & 0.549 & \\
\hline & \multirow{3}{*}{$\begin{array}{l}\text { Third analysis } \\
25 / 3 / 2006\end{array}$} & 3000 & 2625 & 2850 \\
\hline & & 2925 & 2775 & 2700 \\
\hline & & 2775 & 3075 & 2625 \\
\hline & Average & 2900 & 2825 & 2725 \\
\hline & P-value ${ }^{1}$ & & 0.464 & \\
\hline \multirow{5}{*}{ R5 } & \multirow{3}{*}{$25 / 3 / 2006$} & 3825 & 3525 & 3300 \\
\hline & & 3675 & 3225 & 3825 \\
\hline & & 3750 & 3750 & 3600 \\
\hline & Average & 3750 & 3500 & 3575 \\
\hline & P-value ${ }^{2}$ & & 0.414 & \\
\hline
\end{tabular}

(1) Comparison of the mean COD concentration of all ports in R1.

(2) Comparison of the mean COD concentration of all ports in R5. 


\subsubsection{Shortcircuiting}

The objective of this analysis was to estimate if shortcircuiting may have been taking place in the bioreactors. To evaluate the potential shortcircuiting, 7 liters of clear water were added to the bioreactors. If the system is assumed to operate as a continuously mixed system, the expected effluent can be estimated. If the system is assumed to operate as a plug flow system (in the short term), the expected effluent COD should be close to the effluent COD prior to adding the 7 liters of water.

Given the expected COD concentration and the measured concentration, the amount of shortcircuiting can be estimated using the following formulas:

- For the assumption of a completely mixed system

$$
\operatorname{COD}(\text { measured })=\left(1-\frac{x}{7}\right)\left(\frac{7 l \cdot(0 \mathrm{mg} / \mathrm{l})+\text { Vol.of leachate } \cdot\left(C O D^{1}\right)}{(\text { Vol.of leachate }+7)}\right)+x(0)
$$

- For the assumption of a plug flow system

$$
C O D(\text { measured })=\left(1-\frac{x}{7}\right)\left(C O D^{1}\right)+x(0)
$$

Where the $\operatorname{COD}^{1}$ is the effluent COD prior to adding the 7 liters of water and $\mathrm{x}$ is the volume (L) that shortcircuiting based on each assumed operating conditions. The fraction of shortcircuiting is $(\mathrm{x} / 7)$.

Table 5.28 summarizes the results of the first shortcircuiting test which was carried out on day 187 for group one, and 163 for group two. The fraction of shortcircuiting was estimated to be $0.24,0.21,0.19,0.16,0.21,0.23,0.22$, and 0.18 in $\mathrm{R} 1$ through $\mathrm{R} 8$, respectively based on the assumption of completed mixed conditions.

Also, Table 5.29 presents the results of the second shortcircuiting analysis which run on day 393 for group one, and 388 for group two. The fraction of shortcircuiting was 
estimated to be $0.25,0.23,0.21,0.19,0.23,0.23,0.21$, and 0.18 in $\mathrm{R} 1$ through $\mathrm{R} 8$, respectively based on the assumption of completed mixed conditions.

This means that the volume of leachate recycled in $1 \mathrm{D}$ bioreactors was not equal to $7 \mathrm{~L}$, but it was rather in the range of $(4.7-5.9 \mathrm{~L})$ due to the shortcircuiting. Given the negligible variation in the vertical concentration profiles within the $1 \mathrm{D}$ bioreactors, the bioreactors were assumed to operate as completely mixed systems. This is consistent with what is found in the literature (e.g. El-Fadel et al., 1996b; Katsiri et al., 1999; Pareek et al., 1999; Yadiz et al., 2004) and is the assumption made for the modeling present in Section 4.3.2. In addition, the shortcircuiting had no effect on the methane production and methane yield as compared to the methane production in the literature.

Table 5.28: First set of shortcircuiting analysis

\begin{tabular}{|l|cccc|cccc|}
\hline COD (mg/l) & R1 & $\mathbf{R 2}$ & $\mathbf{R 3}$ & $\mathbf{R 4}$ & $\mathbf{R 5}$ & $\mathbf{R 6}$ & $\mathbf{R 7}$ & R8 \\
\hline COD $^{1}$ & 9700 & 11050 & 15800 & 23100 & 25600 & 24050 & 20600 & 22850 \\
\hline Initial mass (kg) & 33.5 & 34.3 & 36.1 & 36.2 & 35.1 & 34.5 & 35.3 & 36.2 \\
\hline M.C \% (w/w) & 62.48 & 61.52 & 63.64 & 60.58 & 62.50 & 62.84 & 62.94 & 64.68 \\
\hline $\begin{array}{l}\text { Volume of } \\
\text { leachate (L) }\end{array}$ & 20.93 & 21.10 & 22.97 & 21.93 & 21.94 & 21.68 & 22.22 & 23.42 \\
\hline COD (expected) & 7269 & 8298 & 12110 & 17511 & 19408 & 18180 & 15665 & 17591 \\
\hline COD (measured) & 3540 & 6550 & 9775 & 14750 & 15250 & 13950 & 12175 & 14450 \\
\hline Fraction & 0.24 & 0.21 & 0.19 & 0.16 & 0.21 & 0.23 & 0.22 & 0.18 \\
\hline Fraction $^{5}$ & 0.43 & 0.41 & 0.38 & 0.36 & 0.40 & 0.42 & 0.41 & 0.37 \\
\hline
\end{tabular}

(1) COD concentration in the bioreactors prior to adding clean water.

(2) COD concentration based on mass balance for completely mixed bioreactors.

(3) Measured COD concentration after $24 \mathrm{hrs}$ from adding clean water to the bioreactors.

(4) Fraction of shortcircuiting based on the assumption of a completely mixed system.

(5) Fraction of shortcircuiting based on the assumption of a plug flow system. 
Table 5.29: Second set of shortcircuiting analysis

\begin{tabular}{|c|c|c|c|c|c|c|c|c|}
\hline COD $(\mathrm{mg} / \mathrm{l})$ & R1 & $\mathbf{R} 2$ & R3 & $\mathbf{R 4}$ & R5 & R6 & R7 & R8 \\
\hline $\mathrm{COD}^{1}$ & 2700 & 2725 & 3425 & 6250 & 3275 & 3525 & 4100 & 4475 \\
\hline Initial mass (kg) & 33.5 & 34.3 & 36.1 & 36.2 & 35.1 & 34.5 & 35.3 & 36.2 \\
\hline M.C \% (w/w) & 62.48 & 61.52 & 63.64 & 60.58 & 62.50 & 62.84 & 62.94 & 64.68 \\
\hline $\begin{array}{l}\text { Volume of } \\
\text { leachate (L) }\end{array}$ & 20.93 & 21.10 & 22.97 & 21.93 & 21.94 & 21.68 & 22.22 & 23.42 \\
\hline COD (expected $)^{2}$ & 2023 & 2046 & 2625 & 4738 & 2483 & 2665 & 3118 & 3445 \\
\hline COD (measured) ${ }^{3}$ & 1510 & 1575 & 2085 & 3825 & 1715 & 1800 & 2145 & 2615 \\
\hline Reduction ${ }^{4}$ & 0.25 & 0.23 & 0.21 & 0.19 & 0.31 & 0.32 & 0.31 & 0.24 \\
\hline Reduction $^{5}$ & 0.44 & 0.42 & 0.39 & 0.39 & 0.48 & 0.49 & 0.48 & 0.42 \\
\hline
\end{tabular}

(1) COD concentration in the bioreactors prior to adding clean water.

(2) COD concentration based on mass balance for completely mixed bioreactors.

(3) Measured COD concentration after $24 \mathrm{hrs}$ from adding clean water to the bioreactors.

(4) Fraction of shortcircuiting based on the assumption of a completely mixed system.

(5) Fraction of shortcircuiting based on the assumption of a plug flow system.

\subsubsection{Summary of leachate quality analysis}

- The percentage of peak reduction in all leachate parameters decreased with increasing salt contents. In other words, the salt inhibited the biodegradation of MSW.

- The highest COD, BOD, VFA, $\mathrm{NH}_{3}-\mathrm{N}, \mathrm{TVS}$, and TS percentage peak reductions were observed in R5 (0\%), and the lowest in R4 (3\%).

- The addition of sludge in both the aerobic and anaerobic stages improved the performance of the MSW bioreactors operated under saline conditions, as shown by the results of percentage reduction in all leachate parameters.

- There was a significant difference in the mean of COD, BOD, VFA, TVS, TS, and $\mathrm{NH} 3-\mathrm{N}$ concentrations in all bioreactors. The difference was observed in $\mathrm{R} 4$ compared to R1 in COD, BOD, VFA, and TVS. 
- A significant difference was observed in the mean of COD, BOD, VFA, TVS, and TS percentage peak reductions at different salt contents during the aerobic stage. The difference was at $3 \%$ compared to $0 \%(\mathrm{w} / \mathrm{v})$ salt content. Also, a significant difference was observed in the mean of COD, BOD, TVS, and TS percentage peak reductions at different salt contents during the anaerobic stage. The difference was at $3 \%$ compared to $0 \%(\mathrm{w} / \mathrm{v})$ salt content in the COD and $\mathrm{BOD}$, whereas the difference was for $1 \%$ and $3 \%$ in the TVS and TS. This indicates that the high salt contents inhibited the MSW biodegradation.

- There was significant difference in the mean $\mathrm{NH}_{3}-\mathrm{N}$ percentage peak reduction in the two groups during the aerobic and anaerobic stages.

- There was no significant difference in the COD concentration along the vertical profile of bioreactors.

- Shortcircuiting was observed in the bioreactors and it was in the range of 0.16- 0.32 based on the assumption of a completely mixed system. 


\subsection{Hydrolysis rate constant}

Two sets of BMP assays were used to estimate the hydrolysis rate constant $\left(k_{h}\right)$. The first set consisted of eight BMP assays (BR1 through BR8) with addition of $20 \%(\mathrm{v} / \mathrm{v})$ of two different inoculums (normal and acclimatized anaerobic digested sludge). The second set consisted of four BMP assays (BR9 through BR12) with addition of 30\% (v/v) normal anaerobic digested sludge as an inoculum.

\subsubsection{First set}

The first set of BMP assays was divided into two groups. The first group consisted of four BMP assays (BR1, BR2, BR3 and BR4) which were run with addition of $20 \%(\mathrm{v} / \mathrm{v})$ normal anaerobic digested sludge and at $0,1,2$, and $3 \%(w / v)$ salt contents, respectively. The second group also consisted of four BMP assays (BR5, BR6, BR7 and BR8) which were run with addition of $20 \%(\mathrm{v} / \mathrm{v})$ acclimatized anaerobic digested sludge and at $0,1,2$, and $3 \%(\mathrm{w} / \mathrm{v})$ salt contents, respectively.

The accumulative methane production and methane concentration of the first set are shown in Figure 5.25. Table 5.30 summarizes the results of methane production and the estimated hydrolysis rate constant from the first set of BMP assays.

The initial TVS concentration of supernatant was $6.23 \mathrm{~g} / 1$ and the TVS concentration of the inoculums was 12.2 and $10.5 \mathrm{~g} / 1$ for normal and acclimatized anaerobic digested sludge, respectively. The ratio of VS in the supernatant to the inoculum was 2.2 and 2.9 (g TVS of supernatant / g TVS of inoculums) for the first and second groups, respectively. 

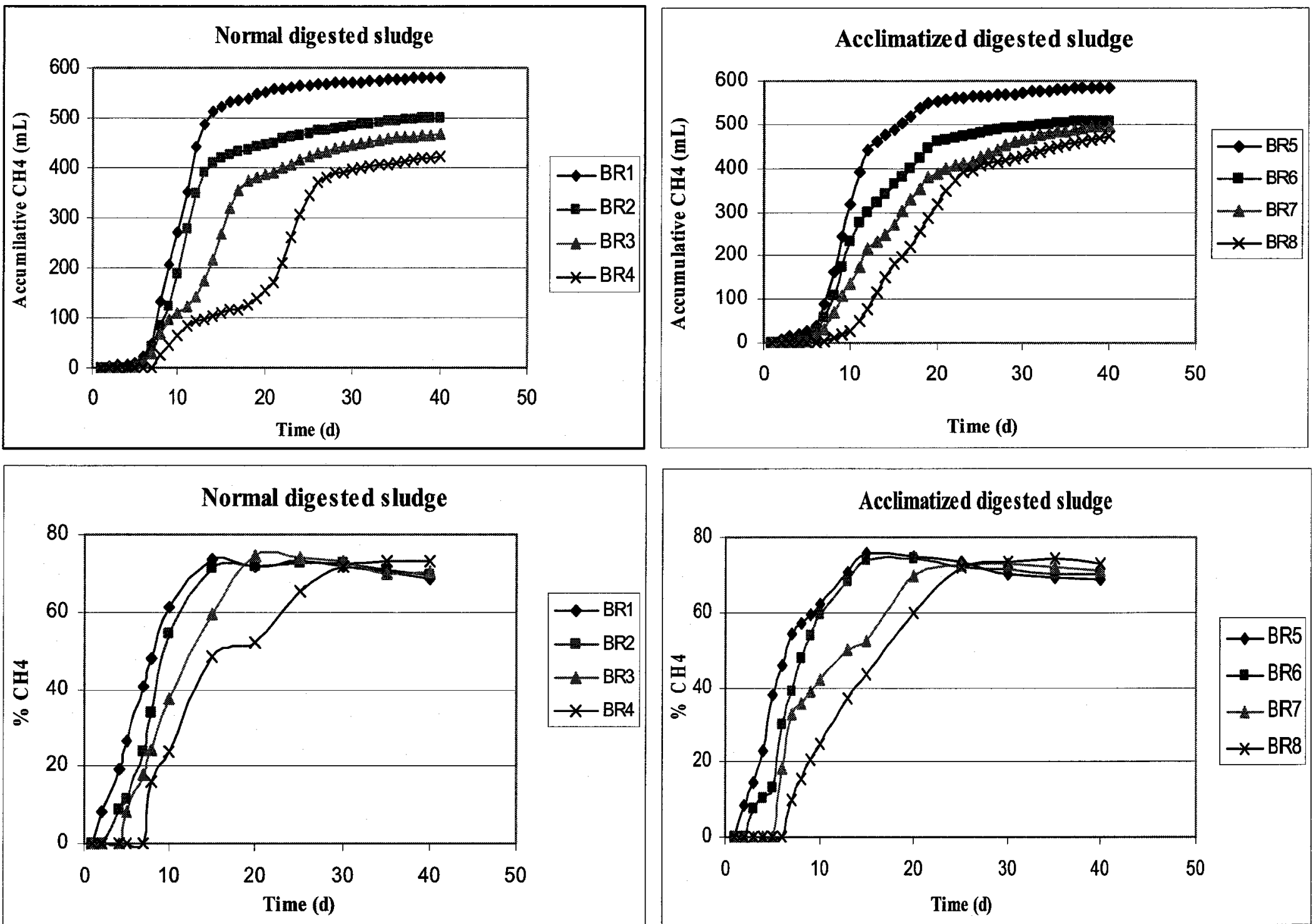

Figure 5.25: Accumulative methane production and methane concentration in first set of $k_{\mathrm{h}}$. 
Table 5.30: Results of methane produced from BMP to estimate $\mathrm{k}_{\mathrm{h}}$ using $20 \%(\mathrm{v} / \mathrm{v})$ of two types of inoculums

\begin{tabular}{|c|c|c|c|c|c|c|c|c|}
\hline & \multicolumn{4}{|c|}{ Normal digested sludge } & \multicolumn{4}{|c|}{ Acclimatized digested sludge } \\
\hline & BR1 & $\mathrm{BR} 2$ & BR3 & BR4 & BR5 & BR6 & BR7 & BR8 \\
\hline $\begin{array}{l}\text { Initial TVS of } \\
\text { substrate }(g / 1)\end{array}$ & \multicolumn{8}{|c|}{6.226} \\
\hline $\begin{array}{l}\text { TVS of } \\
\text { inoculums (g) }\end{array}$ & \multicolumn{4}{|c|}{$14.2(\mathrm{TVS}=1.42 \%)$} & \multicolumn{4}{|c|}{$10.5(\mathrm{TVS}=1.04 \%)$} \\
\hline $\begin{array}{l}\text { VS of } \\
\text { substrate / VS } \\
\text { of inoculums }\end{array}$ & \multicolumn{4}{|c|}{2.2} & \multicolumn{4}{|c|}{2.9} \\
\hline $\begin{array}{l}\text { Duration } \\
\text { time(d) }\end{array}$ & \multicolumn{8}{|c|}{40} \\
\hline Lag time (d) & 1 & 3 & 4 & 7 & 1 & 2 & 4 & 6 \\
\hline Peak (mL) & 91.9 & 81.77 & 54.1 & 51.6 & 81.1 & 65 & 43.4 & 38 \\
\hline $\begin{array}{l}\text { Time (d) to } \\
\text { reach peak }\end{array}$ & 8 & 11 & 15 & 23 & 9 & 9 & 12 & 13 \\
\hline $\begin{array}{l}\text { Total CH4 } \\
(\mathrm{mL})\end{array}$ & 582 & 501 & 466 & 423 & 585 & 508 & 493 & 471 \\
\hline $\mathrm{k}_{\mathrm{h}}\left(\mathrm{d}^{-1}\right)$ & 0.085 & 0.076 & 0.060 & 0.042 & 0.086 & 0.073 & 0.058 & 0.049 \\
\hline $\begin{array}{l}\mathrm{Y}(\mathrm{mL} / \mathrm{g} \\
\left.\mathrm{VS}_{\text {added }}\right) \\
\end{array}$ & 374.1 & 322.8 & 300.0 & 272.2 & 376.1 & 326.3 & 318.9 & 300.8 \\
\hline P-values & \multicolumn{4}{|c|}{$0.83^{1}$} & \multicolumn{4}{|c|}{$0.640^{2}$} \\
\hline
\end{tabular}

(1) Comparison between the mean $\mathrm{k}_{\mathrm{h}}$ in the two groups of inoculums.

(2) Comparison between the mean $\mathrm{Y}$ in the two groups of inoculums.

By assuming the hydrolysis rate constant followed first order kinetics, the accumulative methane production can be described by equation (11).

$$
Y=Y_{u} \cdot\left(1-\exp \left(-k_{h} \cdot t\right)\right)
$$

The hydrolysis rate constant was estimated using the nonlinear regression method for the accumulative methane production. The hydrolysis rate constant for the first group was $0.085,0.076,0.06$, and $0.042 \mathrm{~d}^{-1}$ for $\mathrm{BR} 1, \mathrm{BR} 2, \mathrm{BR} 3$ and $\mathrm{BR} 4$ respectively at $35^{\circ} \mathrm{C}$. In the second group, it was $0.086,0.073,0.058$, and $0.049 \mathrm{~d}^{-1}$ for BR5, BR6, BR7 and BR8 
respectively at $35^{\circ} \mathrm{C}$. The results of nonlinear regression are presented in Tables 4.1 through 4.8 in Appendix B.

The methane yield was $374,323,300$, and $272\left(\mathrm{~mL} / \mathrm{g} \mathrm{VS}_{\text {added }}\right)$ for BR1, BR2, BR3 and BR4, respectively. In the second group, it was $376,326,319$, and 301 (mL $/ \mathrm{g} \mathrm{VS}_{\text {added }}$ ) for BR5, BR6, BR7 and BR8, respectively.

There was no statistical difference between the mean hydrolysis rate constant and mean methane yield in the two groups of inoculums, as suggested by the P-values shown in Table 5.30. This is consistent with the results found earlier for the BMP assays completed for the leachate samples of the $1 \mathrm{D}$ bioreactors.

\subsubsection{Second set}

This set consisted of four BMP assays (BR9, BR10, BR11 and BR12) which were run at $0,1,2$, and $3 \%(\mathrm{w} / \mathrm{v})$ salt contents, respectively. The volume of anaerobic digested sludge used was $30 \%(\mathrm{v} / \mathrm{v})$ of the supernatant or $75 \mathrm{~mL}$. The initial TVS concentration of supernatant was $7.15 \mathrm{~g} / 1$ and the TVS concentration of inoculum was $12.58 \mathrm{~g} / 1$.

Figure 5.26 shows the accumulative methane production and methane concentration in the second set of BMP assays and hydrolysis rate constant at different salt contents. Also, Table 5.31 summarizes the results of methane production and hydrolysis rate constant.

Using the same formula as in the first set, the hydrolysis rate constant $\left(\mathrm{k}_{\mathrm{h}}\right)$ was estimated with nonlinear regression to fit the accumulative methane production. The $k_{h}$ was 0.086 , $0.073,0.058$ and $0.049 \mathrm{~d}^{-1}$ for BR9, BR10, BR11 and BR12, respectively at $35^{\circ} \mathrm{C}$. The results of nonlinear regression are presented in Tables 4.9 through 4.12 in Appendix B. 

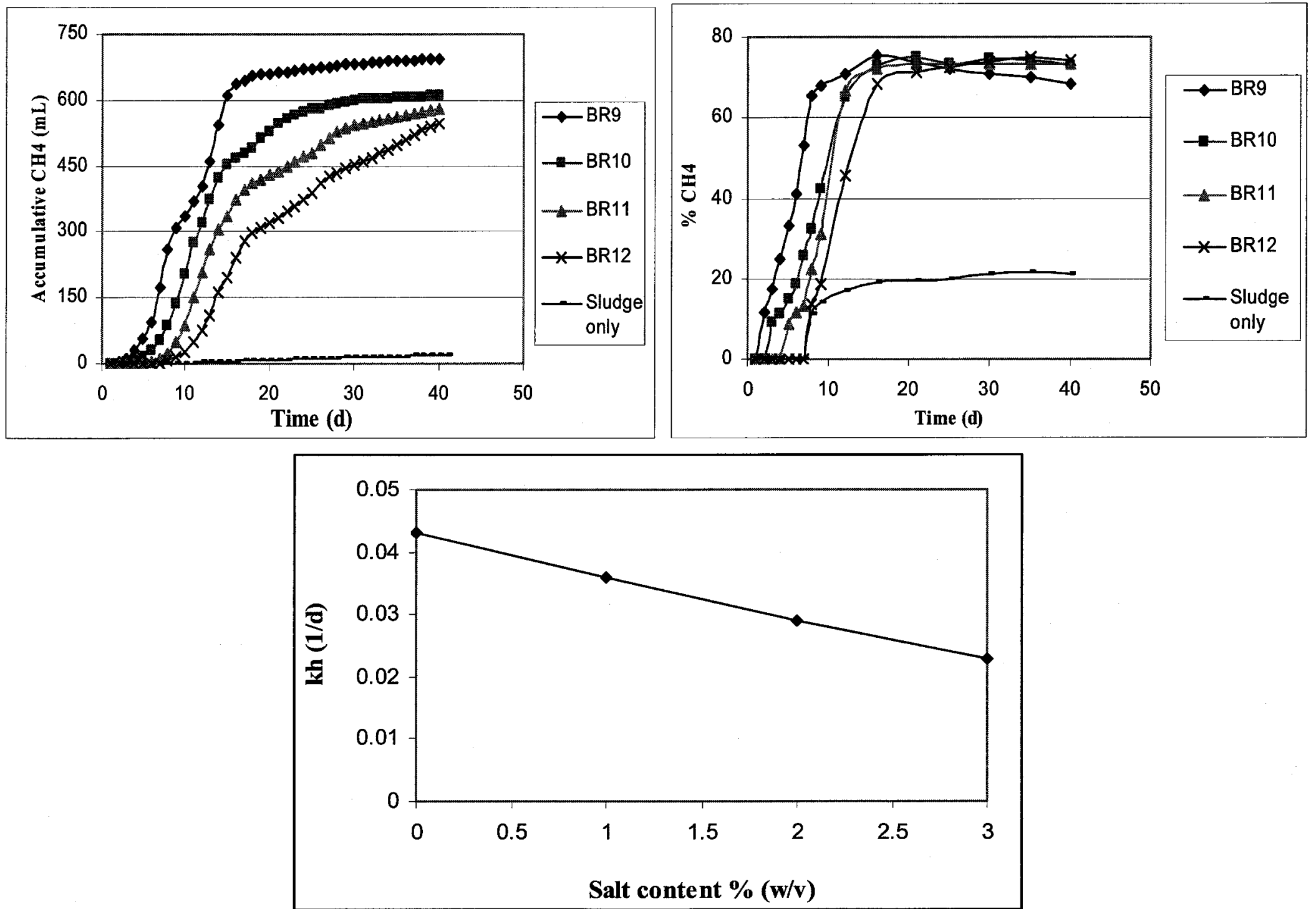

Figure 5.26: Accumulative methane production and methane concentration for the second set and hydrolysis rate constant at $23^{\circ} \mathrm{C}$. 
Table 5.31: Results of methane produced from BMP to estimate $k_{h}$ using $30 \%(v / v)$ anaerobic digested sludge

\begin{tabular}{|c|c|c|c|c|}
\hline & \multicolumn{4}{|c|}{ Normal digested sludge } \\
\hline & BR9 & BR10 & BR11 & BR12 \\
\hline $\begin{array}{l}\text { Initial TVS of } \\
\text { substrate }(\mathrm{g} / \mathrm{l})\end{array}$ & \multicolumn{4}{|c|}{7.15} \\
\hline $\begin{array}{l}\text { TVS of inoculums } \\
\text { (g) }\end{array}$ & \multicolumn{4}{|c|}{$12.58(\mathrm{TVS}=1.3 \%)$} \\
\hline $\begin{array}{l}\text { VS of substrate/ } \\
\text { VS of biomass }\end{array}$ & \multicolumn{4}{|c|}{1.9} \\
\hline Duration time (d) & \multicolumn{4}{|c|}{40} \\
\hline Lag time (d) & 1 & 2 & 4 & 7 \\
\hline Peak $(\mathrm{mL}) / \mathrm{d}$ & 84.5 & 74.1 & 63.7 & 51.84 \\
\hline $\begin{array}{l}\text { Time (d) to reach } \\
\text { peak }\end{array}$ & 8 & 11 & 12 & 14 \\
\hline Total CH4 (mL) & 694 & 611 & 578 & 548 \\
\hline $\mathrm{k}_{\mathrm{h}}\left(\mathrm{d}^{-1}\right)$ & 0.086 & 0.073 & 0.058 & 0.049 \\
\hline $\mathrm{Y}\left(\mathrm{mL} / \mathrm{g} \mathrm{VS}_{\text {added }}\right)$ & 388.2 & 341.8 & 324.5 & 306.5 \\
\hline Statistical analysis & \multicolumn{2}{|c|}{$0.95^{1}$} & \multicolumn{2}{|c|}{$0.44^{2}$} \\
\hline
\end{tabular}

(1) Comparison between the mean $\mathrm{k}_{\mathrm{h}}$ of group one in the first set and second set.

(2) Comparison between the mean $Y$ of group one in first set and second set.

The methane yield was 388, 342, 325, and 307 ( $\left.\mathrm{mL} / \mathrm{g} \mathrm{VS}_{\mathrm{added}}\right)$ for BR9, BR10, BR11 and BR12, respectively.

These results agreed with results presented by Jokela et al. (2005), Veeken et al. (1999) and Owens et al. (1993). Jokela et al. (2005) found that the hydrolysis rate constant was in the range of $0.021-0.107 \mathrm{~d}^{-1}$ at $35^{\circ} \mathrm{C}$ for ten different types of waste compounds. Also, they found that the methane yield was $58,217,228$ and 527 (mL / $/ \mathrm{VS}_{\text {added }}$ ) for newsprint, cardboard, textile and food waste, respectively. Veeken et al. (1999) found the 
hydrolysis rate constant was in the range of $0.03-0.15 \mathrm{~d}^{-1}$ at $35^{\circ} \mathrm{C}$ for leaves, straw, organic peeling and grass wastes.

Owens et al. (1993), found the $k_{h}$ was 0.075 and $0.065 \mathrm{~d}^{-1}$ at $35^{\circ} \mathrm{C}$ and the methane yield was 222 and $215\left(\mathrm{~mL} / \mathrm{VS}_{\text {added }}\right)$ for the fresh and dry waste, respectively.

P-values, as shown in Table 5.31, were more than 0.05 , which means that there was no significant difference between the mean $k_{h}$ and $Y$ of group one in the first set and the second set.

The average hydrolysis rate constant (group one of the first set and the second set) was $0.0855,0.074,0.059$, and $0.046 \mathrm{~d}^{-1}$ for $0,1,2$, and $3 \%(\mathrm{w} / \mathrm{v})$ salt contents, respectively, at $35^{\circ} \mathrm{C}$. Since the $1 \mathrm{D}$ bioreactors operated approximately at $23^{\circ} \mathrm{C}$, the hydrolysis rate constant could be calculated at $23^{\circ} \mathrm{C}$ by using the following formula (Metcalf et al., 2003):

$k_{h\left(23^{\circ} \mathrm{C}\right)}=k_{h\left(35^{\circ} \mathrm{C}\right)} \cdot 1.06^{(23-35)}$

The $\mathrm{k}_{\mathrm{h}}$ at $23^{\circ} \mathrm{C}$ was $0.043,0.036,0.029$, and $0.023 \mathrm{~d}^{-1}$ for $0,1,2$, and $3 \%(\mathrm{w} / \mathrm{v})$ salt content, respectively, as shown in Figure 5.26.

The following equation can be used to predict the hydrolysis rate constant at different salt contents $(0-3) \%(w / v)$.

$k_{\mathrm{h}\left(23^{\circ} \mathrm{C}\right)}=0.043-0.0067 \cdot X$

Where,

$k_{\mathrm{h}\left(23^{\circ} \mathrm{C}\right)}:$ hydrolysis rate constant at $23^{\circ} \mathrm{C}$

$X:$ salt content $\%(\mathrm{w} / \mathrm{v})$ 


\subsection{Model calibration}

The purpose of model calibration was to estimate the kinetics of the acidogenic and methanogenic biomasses $\left(\mu, k_{d}\right.$, and $\left.K_{S}\right)$, and the inhibition constants $\left(K_{I}\right.$ and $m$ ) to account for salt contents. The results obtained from 1D bioreactors and BMP assays were used in the model calibration. The calibration procedure was divided into two steps. In the first step, the biomass kinetics $\left(\mu, k_{d}\right.$, and $\left.K_{S}\right)$ were estimated by calibrating the model results with the $1 \mathrm{D}$ bioreactor measurements (VFA, daily and accumulative methane production) operated without salt content (R1 and R5). In the second step, the inhibition constants $\left(\mathrm{K}_{\mathrm{I}}\right.$ and $\mathrm{m}$ ) were estimated by calibrating the model result with $1 \mathrm{D}$ bioreactors operated under different salt contents $(0.5,1$, and 3$) \%(w / v)$.

The data required for the calibration was classified into five categories. First, the required initial conditions were the initial concentrations of solid biodegradable carbon $\left(C_{S}\right)$, aqueous organic acids $\left(\mathrm{C}_{\mathrm{aq}}\right)$, VFA $\left(\mathrm{C}_{\mathrm{VFA}}\right)$, acidogenic biomass $\left(\mathrm{C}_{\mathrm{XA}}\right)$, and methanogenic biomass $\left(\mathrm{C}_{\mathrm{XM}}\right)$ in terms of mass of carbon per unit volume. Second, the input parameter that were assumed fixed and equal to the values published in the literature, which only included the VFA carbon fractional formation yield coefficient $\left(\mathrm{Y}_{\mathrm{HAC}}\right)$. Third, the input parameters estimated in the laboratory were methane fraction $\left(\mathrm{Y}_{\mathrm{CH} 4}\right)$ and hydrolysis rate constant at different salt contents. Fourth, the range of values to be adjusted to calibrate the model were the kinetics of the acidogenic and methanogenic biomasses $\left(\mu, k_{d}\right.$, and $K_{S}$ ), and yield coefficients of acidogenesis $\left(Y_{A}\right)$ and methanogenesis $\left(Y_{M}\right)$. Fifth, the experimental results against which the model will be calibrated were VFA, and daily and accumulative methane production in terms of $\mathrm{kg}$ carbon per $\mathrm{kg}$ dry waste. 
The initial solid biodegradable carbon for individual waste components was estimated using the following formula (see Table 5.32 for results):

$(C)_{b i}=(C)_{i} \cdot B F_{i} \cdot M_{i}$

Where,

$(C)_{b i}$ : biodegradable carbon in the $\mathrm{i}$ component of waste, $\mathrm{kg}$ biodegradable $\mathrm{C} / \mathrm{kg}$ dry $\mathrm{i}$ component.

$(C)_{i}$ : carbon content in the $\mathrm{i}$ component of waste, $\mathrm{kg} \mathrm{C} / \mathrm{kg}$ dry $\mathrm{i}$ component, from Table 2.2.

$B F_{i}$ : biodegradable fraction of carbon content, $\mathrm{kg}$ biodegradable $\mathrm{C} / \mathrm{kg} \mathrm{C}$, from Table 2.3 $M_{i}$ : dry mass of i component, $\mathrm{kg}$ dry i component.

There was a reduction in the initial solid biodegradable carbon mass $\left(\mathrm{C}_{\mathrm{S}}\right)$ during the aerobic stage. Therefore, the initial conditions of $\left(\mathrm{C}_{\mathrm{S}}\right)$ used in the model calibration have been estimated based on the total biogas produced from $\mathrm{R} 5\left(\mathrm{CH}_{4}\right.$ and $\left.\mathrm{CO}_{2}\right)$ at the end of the anaerobic stage. Based on this and taking into account the loss of biogas during the leachate recycle, the initial $\left(\mathrm{C}_{\mathrm{S}}\right)$ was estimated to be approximately $0.12 \mathrm{~kg}$ carbon per $\mathrm{kg}$ dry waste. Therefore, the loss during the aerobic stage was assumed to be approximately $12.5 \%$.

Table 5.32: Initial biodegradable carbon content in waste components.

\begin{tabular}{|c|cccccc|}
\hline $\begin{array}{c}\text { Waste } \\
\text { components }\end{array}$ & $\begin{array}{c}\text { Wet } \\
\text { weight } \\
(\mathbf{k g})\end{array}$ & $\begin{array}{c}\text { Moisture } \\
\text { content } \% \\
(\mathbf{w} / \mathbf{w})\end{array}$ & $\begin{array}{c}\text { Dry } \\
\text { weight } \\
(\mathbf{k g})\end{array}$ & $\begin{array}{c}\mathbf{C}(\mathbf{k g} \mathbf{C} \\
\mathbf{k g ~ d r y} \\
\mathbf{w e i g h t})\end{array}$ & $\begin{array}{c}\mathbf{B F} / \mathrm{kg} \\
\mathbf{b i o} \mathbf{C} / \mathbf{k g} \\
\mathbf{C})\end{array}$ & $\begin{array}{c}\mathbf{C}_{\mathbf{b}} \text { ( kg biod. } \\
\mathbf{C} / \mathbf{k g} \text { of dry } \\
\mathbf{w a s t e})\end{array}$ \\
\hline Food & 0.6 & 0.6 & 0.21 & 0.48 & 0.8 & 0.09216 \\
Paper & 0.2 & 0.09 & 0.18 & 0.44 & 0.52 & 0.04004 \\
Plastics & 0.15 & 0.02 & 0.1485 & 0.6 & 0 & 0 \\
Textile & 0.05 & 0.11 & 0.045 & 0.55 & 0.2 & 0.0049 \\
\hline
\end{tabular}


However, the remaining initial conditions $\left(\mathrm{C}_{\mathrm{aq}}, \mathrm{C}_{\mathrm{VFA}}, \mathrm{C}_{\mathrm{XA}}\right.$, and $\left.\mathrm{C}_{\mathrm{XM}}\right)$ were adjusted to get the closest match between the simulation results and the experimental results of $\mathrm{R} 1$ for the first group and R5 for the second group. The methane fraction $\left(\mathrm{Y}_{\mathrm{CH} 4}\right)$ and hydrolysis rate constant at different salt contents used to calibrate the model were estimated and presented in Section 5.1.22 and 5.2.2, respectively. The range of kinetics and yield coefficient of biomasses (acidogenic and methanogenic) used in the model calibration are shown in Table 5.33. Finally, the experimental results of VFA, daily and accumulative methane production which were used to compare with the model results are presented in Appendix A.

The trial and error procedure has been used in the model calibration to obtain the best match between the model and experimental results. Three scenarios have been conducted to achieve the best fit of VFA, daily and accumulative methane production. In the first scenario, the total carbon content was assumed to exist as solid biodegradable carbon $\left(\mathrm{C}_{\mathrm{S}}\right)$. In the second scenario, the carbon content was divided into solid carbon, aqueous acids and VFA to represent the effect of the initial aerobic stage. In the third scenario, two hydrolysis constants were used to match the two peaks of daily methane production which were evident in the experimental results. 
Table 5.33: Range of kinetic parameters used in model calibration

\begin{tabular}{|l|l|l|}
\hline Parameter & Unit & Literature \\
\hline Acidogenesis & & \\
\hline Growth rate, $\mu_{\mathrm{A}}$ & $\mathrm{d}^{-1}$ & $(0.5-30)^{\mathrm{a}, \mathrm{b}, \mathrm{c}, \mathrm{d}}$ \\
Half saturation constant, $\mathrm{K}_{\mathrm{SA}}$ & $\mathrm{kg} \mathrm{m}^{-3}$ & $(0.03-5)^{\mathrm{b}, \mathrm{c}}$ \\
Rate of decay, $\mathrm{k}_{\mathrm{dA}}$ & $\mathrm{d}^{-1}$ & $(0.004-0.4)^{\mathrm{a}, \mathrm{b}, \mathrm{c}}$ \\
Yield, $\mathrm{Y}_{\mathrm{A}}$ & $\mathrm{kg} \mathrm{kg}^{-1}$ & $(0.1-0.5)^{\mathrm{a}, \mathrm{c}}$ \\
& & \\
\hline Methanogenesis & & \\
\hline Growth rate, $\mu_{\mathrm{M}}$ & $\mathrm{d}^{-1}$ & $(0.1-0.5)^{\mathrm{a}, \mathrm{b}, \mathrm{c}, \mathrm{d}}$ \\
Half saturation constant, $\mathrm{K}_{\mathrm{SM}}$ & $\mathrm{kg} \mathrm{m}^{-3}$ & $(0.0003-2.5)^{\mathrm{a}, \mathrm{b}}$ \\
Rate of decay, $\mathrm{k}_{\mathrm{dM}}$ & day $^{-1}$ & $(0.005-0.04)^{\mathrm{a}, \mathrm{b}, \mathrm{c}, \mathrm{d}}$ \\
Yield, $\mathrm{Y}_{\mathrm{M}}$ & $\mathrm{kg} \mathrm{kg}^{-1}$ & $(0.05-0.82)^{\mathrm{a}, \mathrm{b}, \mathrm{c}}$ \\
& & \\
\hline VFA formation yield, $\mathrm{Y}_{\mathrm{HAC}}$ & $\mathrm{kg} \mathrm{kg}^{-1}$ & $0.9^{\mathrm{a}}$ \\
\hline
\end{tabular}
a, El-Fadel et al. 1996.
b, Yildiz et al. 2004.
c, Naranjo et al. 2004.
d, Haarstrick et al. 2001. 


\subsubsection{First scenario}

The model was run while varying model parameters for each simulation to achieve the best match between the simulation and experimental results. The profiles that best fit the results are shown in Figures 5.27 through 5.30, and the model parameters and inhibition constants $\left(\mathrm{K}_{\mathrm{I}}\right.$ and $\left.\mathrm{m}\right)$ used in the calibrated model are presented in Table 5.34.

$\mathrm{CH}_{4}$ : A comparison between the predicted and measured accumulative methane production was reasonably reproduced by the model in all bioreactors, except the first peak in the daily methane production. The model was not able to simulate the two peak daily methane production rates since the conceptual model did not include any processes that could simulate a second peak.

$V F A$ : Slight deviations between the predicted and measured peak of VFA concentrations and the time required to reach the peak of VFA concentrations are observed. The best fit model simulations underestimated the VFA concentrations at early times and overestimated the VFA concentrations at later times. Also, the predicted peak VFA concentrations occurred later than the measured peak concentrations. This may be attributed to the fact that the model assumed all the carbon was initially present in the solid phase and did not account for the aerobic degradation. To improve this, the second model scenario used initial concentrations which reflected the experimental conditions in the $1 \mathrm{D}$ bioreactors after the aerobic stage. 

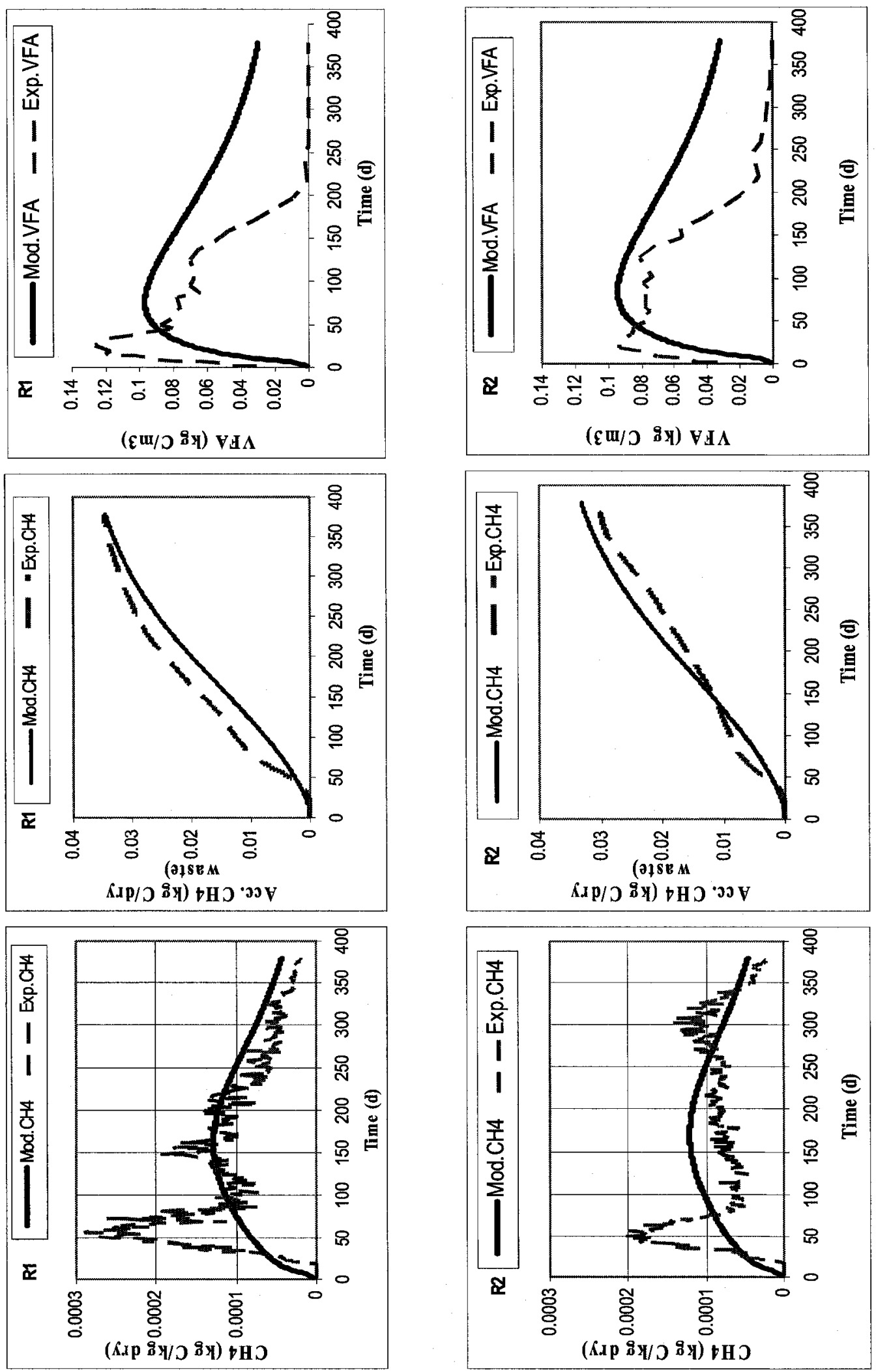

을 

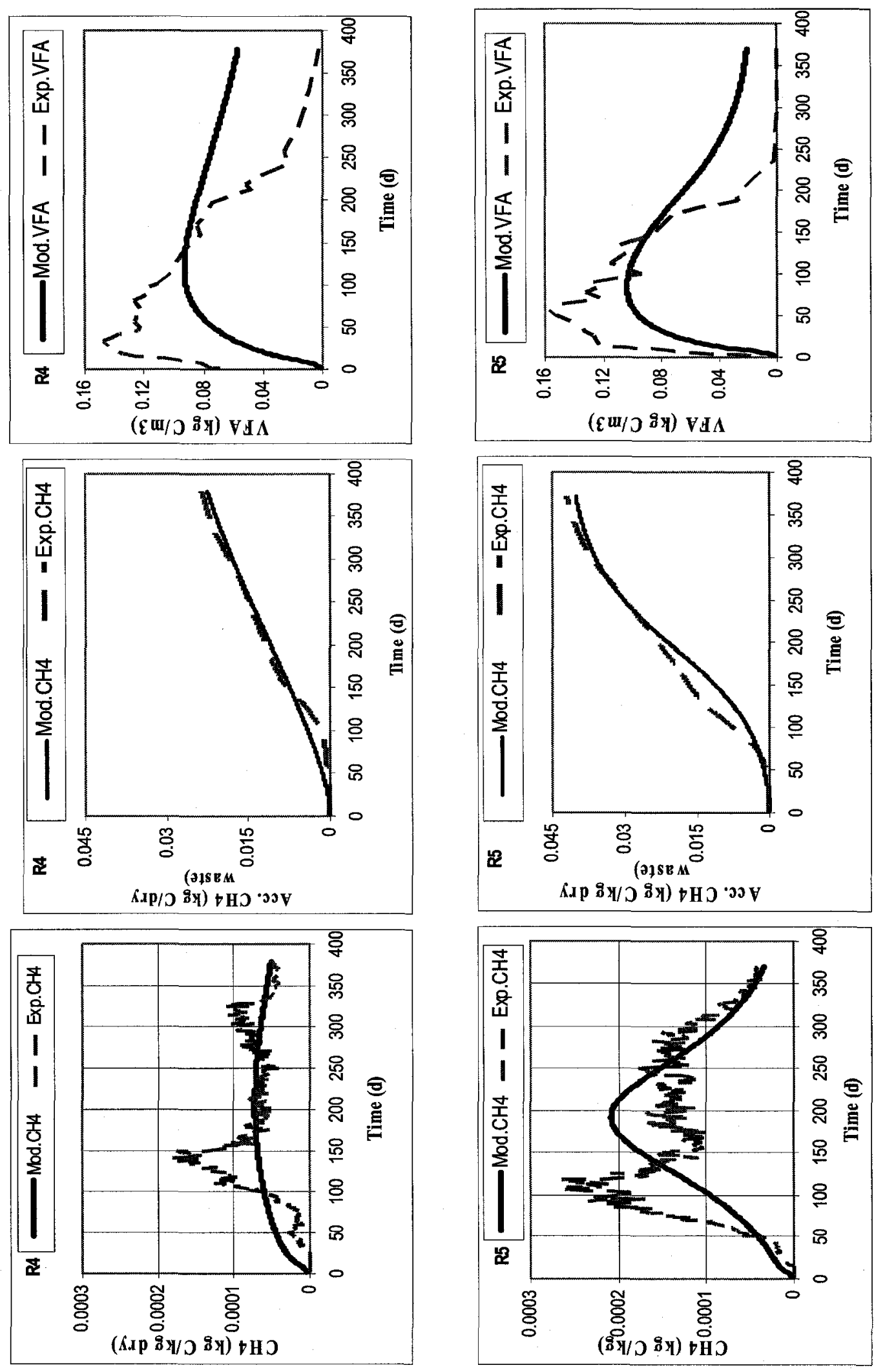

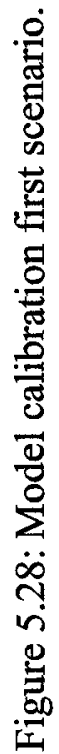



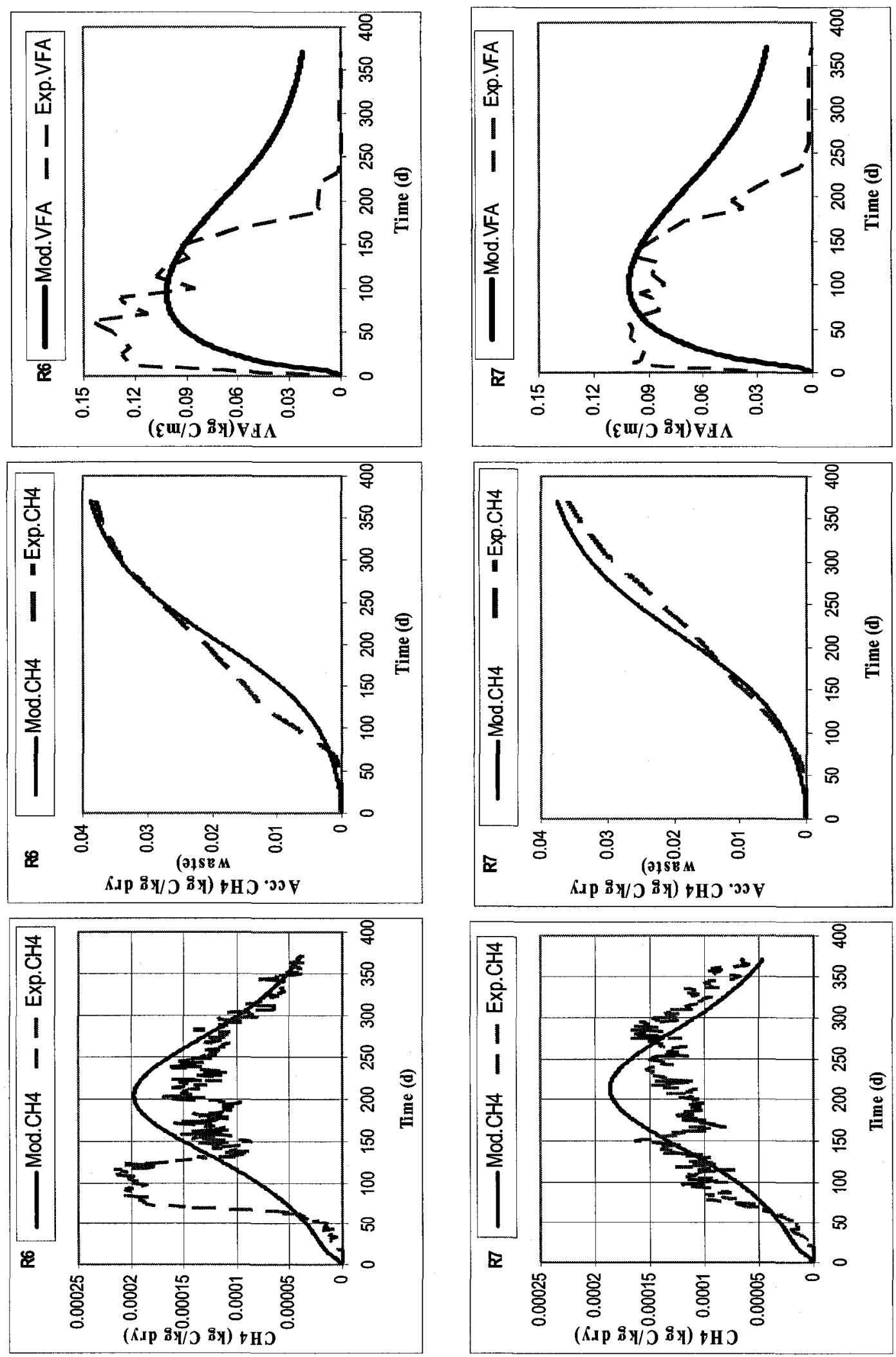

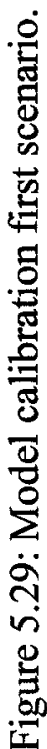



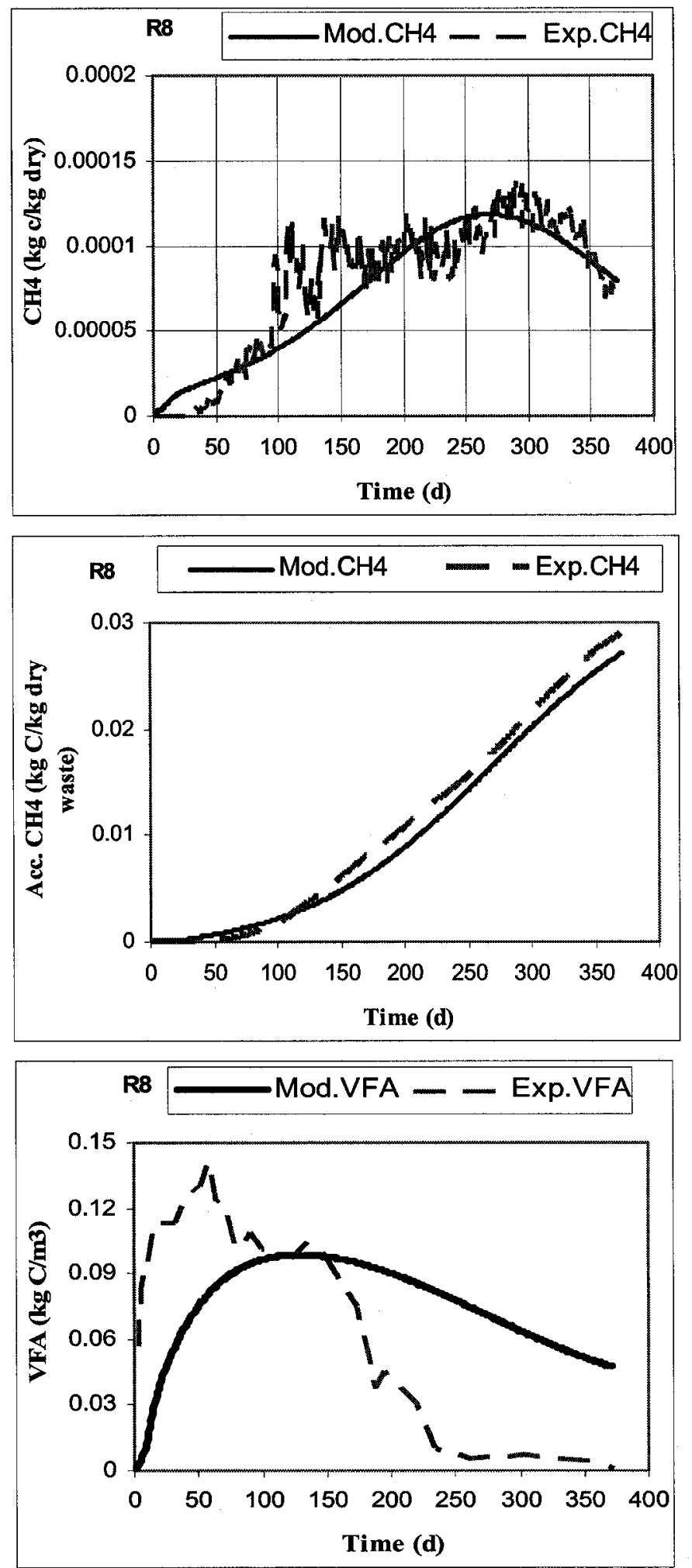

Figure 5.30: Model calibration first scenario. 
Table 5.34: Parameters used in the model calibration of the first scenario

\begin{tabular}{|c|c|c|c|c|c|}
\hline Parameter & Unit & \multicolumn{4}{|c|}{ Applied values } \\
\hline \multicolumn{6}{|l|}{ Hydrolysis } \\
\hline I & \multirow{4}{*}{$\begin{array}{l}(\mathrm{w} / \mathrm{v}) \\
\mathrm{d}^{-1} \\
(\mathrm{w} / \mathrm{v})\end{array}$} & $0 \%$ & $0.5 \%$ & $1 \%$ & $3 \%$ \\
\hline $\mathrm{k}_{\mathrm{h}}$ & & 0.043 & 0.036 & 0.033 & 0.023 \\
\hline $\mathrm{K}_{\mathrm{I}}$ & & \multicolumn{4}{|c|}{6} \\
\hline $\mathrm{m}$ & & \multicolumn{4}{|c|}{2} \\
\hline \multicolumn{6}{|l|}{ Acidogenesis } \\
\hline Growth rate, $\mu_{\mathrm{A}}$ & $d^{-1}$ & \multicolumn{4}{|c|}{5} \\
\hline Half saturation constant, $\mathrm{K}_{\mathrm{SA}}$ & $\mathrm{kg} \mathrm{m}^{-3}$ & \multicolumn{4}{|c|}{0.3} \\
\hline Rate of decay, $\mathrm{k}_{\mathrm{dA}}$ & $d^{-1}$ & \multicolumn{4}{|c|}{0.04} \\
\hline \multirow[t]{2}{*}{ Yield, $\mathrm{Y}_{\mathrm{A}}$} & $\mathrm{kg} \mathrm{kg}^{-1}$ & \multicolumn{4}{|c|}{0.15} \\
\hline & & \multicolumn{2}{|c|}{ First group } & \multicolumn{2}{|c|}{ Second group } \\
\hline \multicolumn{6}{|l|}{ Methanogenesis } \\
\hline Growth rate, $\mu_{\mathrm{M}}$ & $d^{-1}$ & \multicolumn{2}{|c|}{0.135} & \multicolumn{2}{|c|}{0.22} \\
\hline Half saturation constant, $\mathrm{K}_{\mathrm{SM}}$ & $\mathrm{kg} \mathrm{m}^{-3}$ & \multicolumn{2}{|c|}{0.7} & \multicolumn{2}{|c|}{0.53} \\
\hline Rate of decay, $\mathrm{k}_{\mathrm{dM}}$ & day $^{-1}$ & \multicolumn{2}{|c|}{0.01} & \multicolumn{2}{|c|}{0.019} \\
\hline Yield, $\mathrm{Y}_{\mathrm{M}}$ & $\mathrm{kg} \mathrm{kg}^{-1}$ & \multicolumn{2}{|c|}{0.07} & \multicolumn{2}{|c|}{0.1} \\
\hline Methane fraction yield, $\mathrm{Y}_{\mathrm{CH} 4}$ & $\mathrm{~kg} \mathrm{~kg}^{-1}$ & \multicolumn{2}{|c|}{0.41} & \multicolumn{2}{|c|}{0.43} \\
\hline VFA formation yield, $Y_{\mathrm{HAC}}$ & $\mathrm{kg} \mathrm{kg}^{-1}$ & \multicolumn{2}{|c|}{0.9} & \multicolumn{2}{|c|}{0.9} \\
\hline \multicolumn{6}{|l|}{ Initial conditions } \\
\hline $\mathbf{C}_{(\mathrm{s})}$ & $\mathrm{Kg} \mathrm{C} \mathrm{m}^{-3}$ & \multicolumn{2}{|c|}{0.12} & \multicolumn{2}{|c|}{0.12} \\
\hline $\mathbf{C}_{(\mathrm{aq})}$ & $\mathrm{Kg} \mathrm{C} \mathrm{m}^{-3}$ & \multicolumn{2}{|c|}{0.0009} & \multicolumn{2}{|c|}{0.0009} \\
\hline $\mathbf{C}_{(\mathrm{VFA})}$ & $\mathrm{Kg} \mathrm{C} \mathrm{m}$ & \multicolumn{2}{|c|}{0.0009} & \multicolumn{2}{|c|}{0.0009} \\
\hline $\mathbf{C}_{(\mathbf{X A})}$ & $\mathrm{Kg} \mathrm{C} \mathrm{m}{ }^{-3}$ & \multicolumn{2}{|c|}{0.0009} & & \\
\hline $\mathbf{C}_{(\mathrm{XM})}$ & $\mathrm{Kg} \mathrm{C} \mathrm{m}^{-3}$ & & & & \\
\hline
\end{tabular}




\subsubsection{Second scenario}

The initial biodegradable carbon content was divided into solid carbon $\left(\mathrm{C}_{\mathrm{S}}\right)$, aqueous acids $\left(\mathrm{C}_{\mathrm{aq}}\right)$ and VFA $\left(\mathrm{C}_{\mathrm{VFA}}\right)$ at time zero $(\mathrm{t}=0)$ to represent the experimental conditions in the 1D bioreactors after the aerobic stage. The best fit of the model calibration is shown in Figures 5.31 through 5.34, and Table 5.35 summarizes the value of the model parameters and inhibition constants $\left(\mathrm{K}_{\mathrm{I}}\right.$ and $\mathrm{m}$ ) used in the current scenario to get the best fit.

$\mathrm{CH}_{4}$ : The results of the model in this scenario gave a better match between the predicted and measured accumulative methane production than the first scenario. However, the model did not show the lag phase in the methane production which was observed in the experimental results. In other words, the results of the model showed that methane started to be produced from day one. This could be attributed to the high initial concentration of VFA and the presence of methanogenic biomass. The model has been used to simulate the system with a methanogens lag time, but this had a limited impact on the magnitude of methane production and time to reach its peak. This impact was observed in the early stage of methane production.

In addition to that, the model could not predict the two peaks of methane production. To improve this, the third model scenario used two hydrolysis rate constants (readily and slowly) to match the two peaks of daily methane production.

$V F A$ : There was an improvement in the simulation results of VFA concentration (time to reach the peak) compared to the first scenario. The underestimation of VFA concentrations in the early times has been eliminated in all bioreactors and the overestimation of VFA concentrations in the later times has been slightly decreased. 

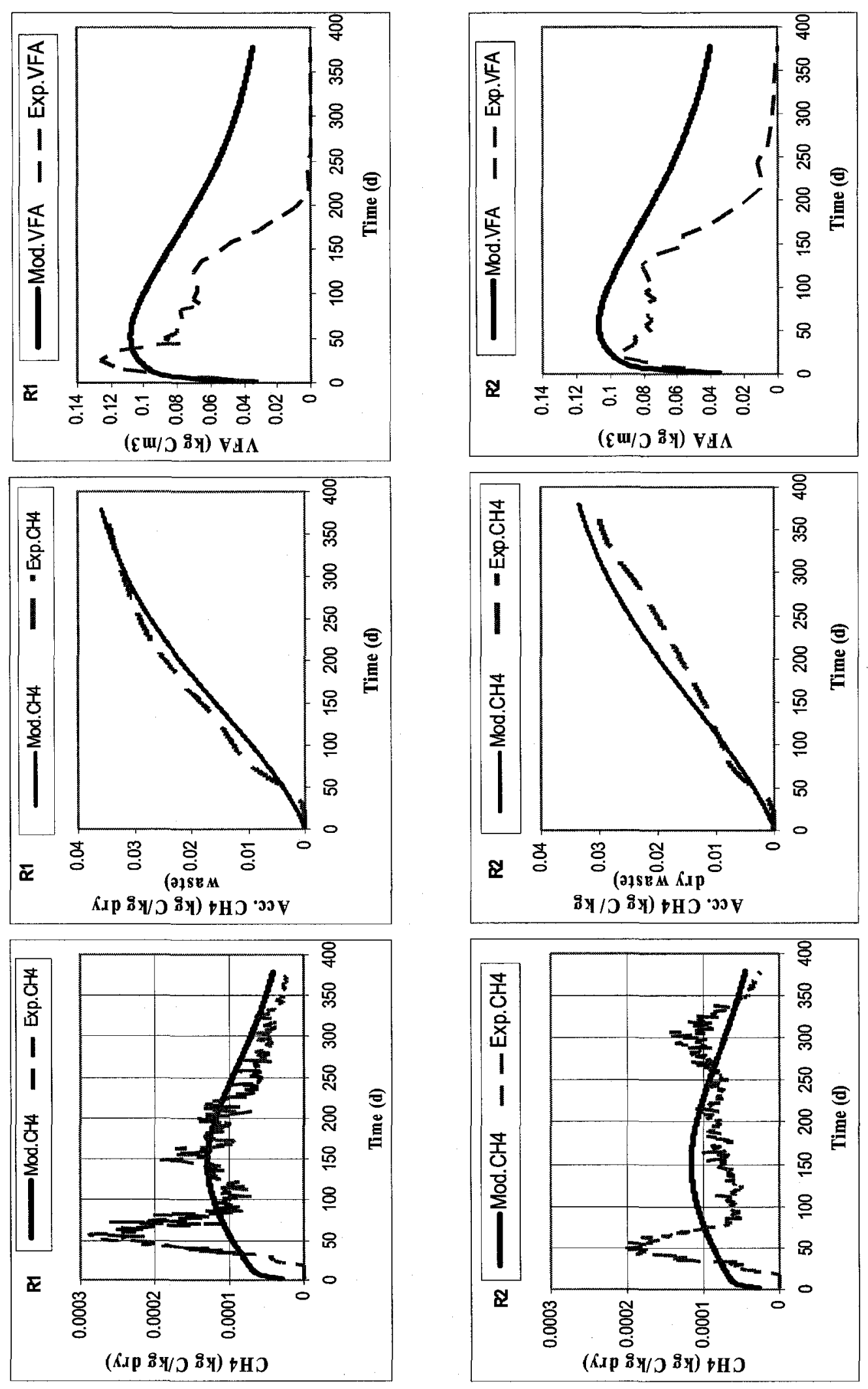

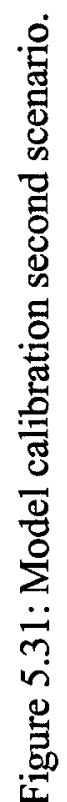



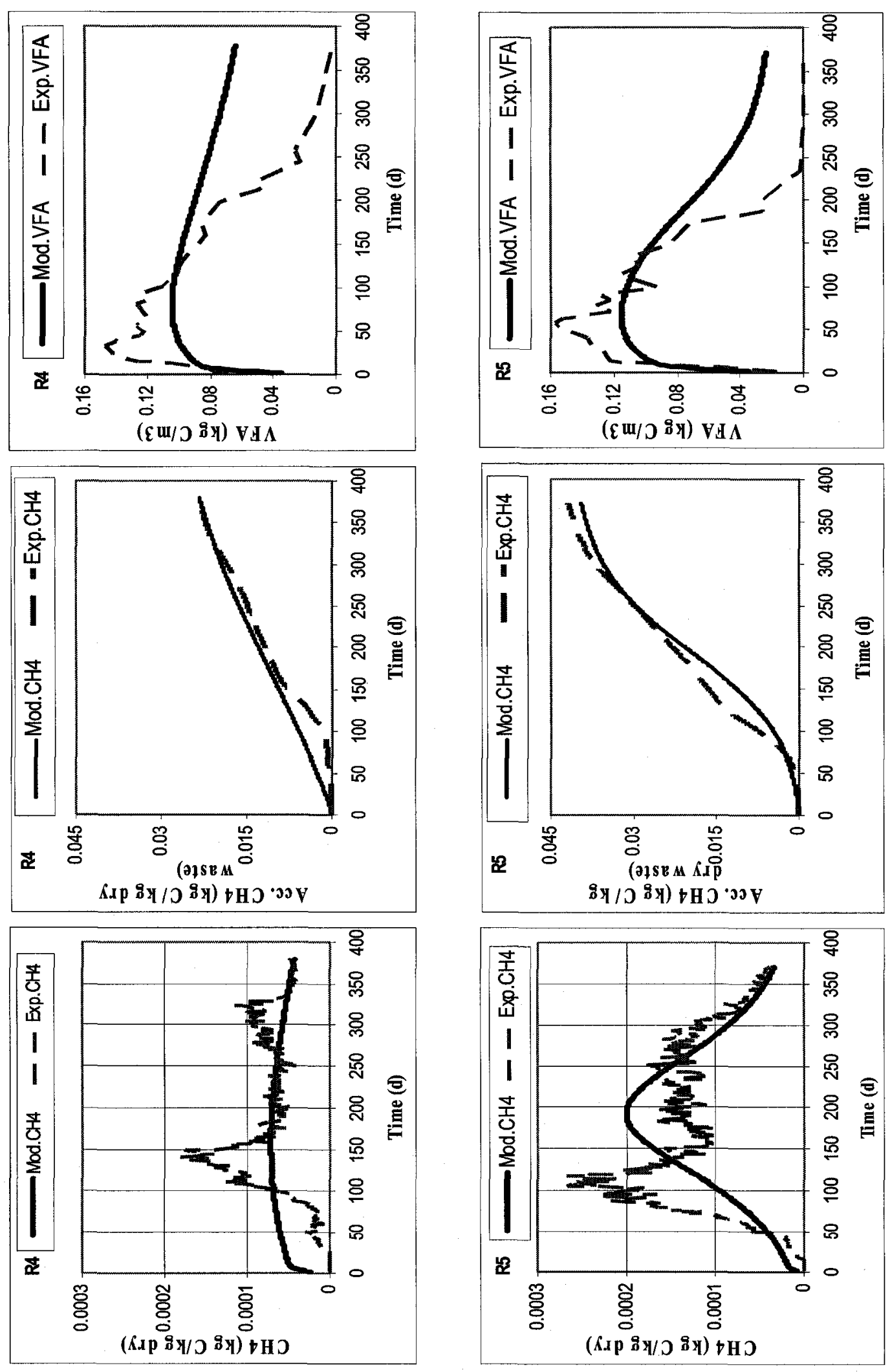

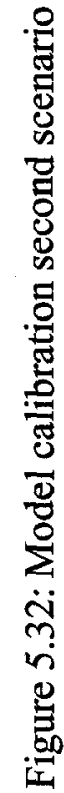



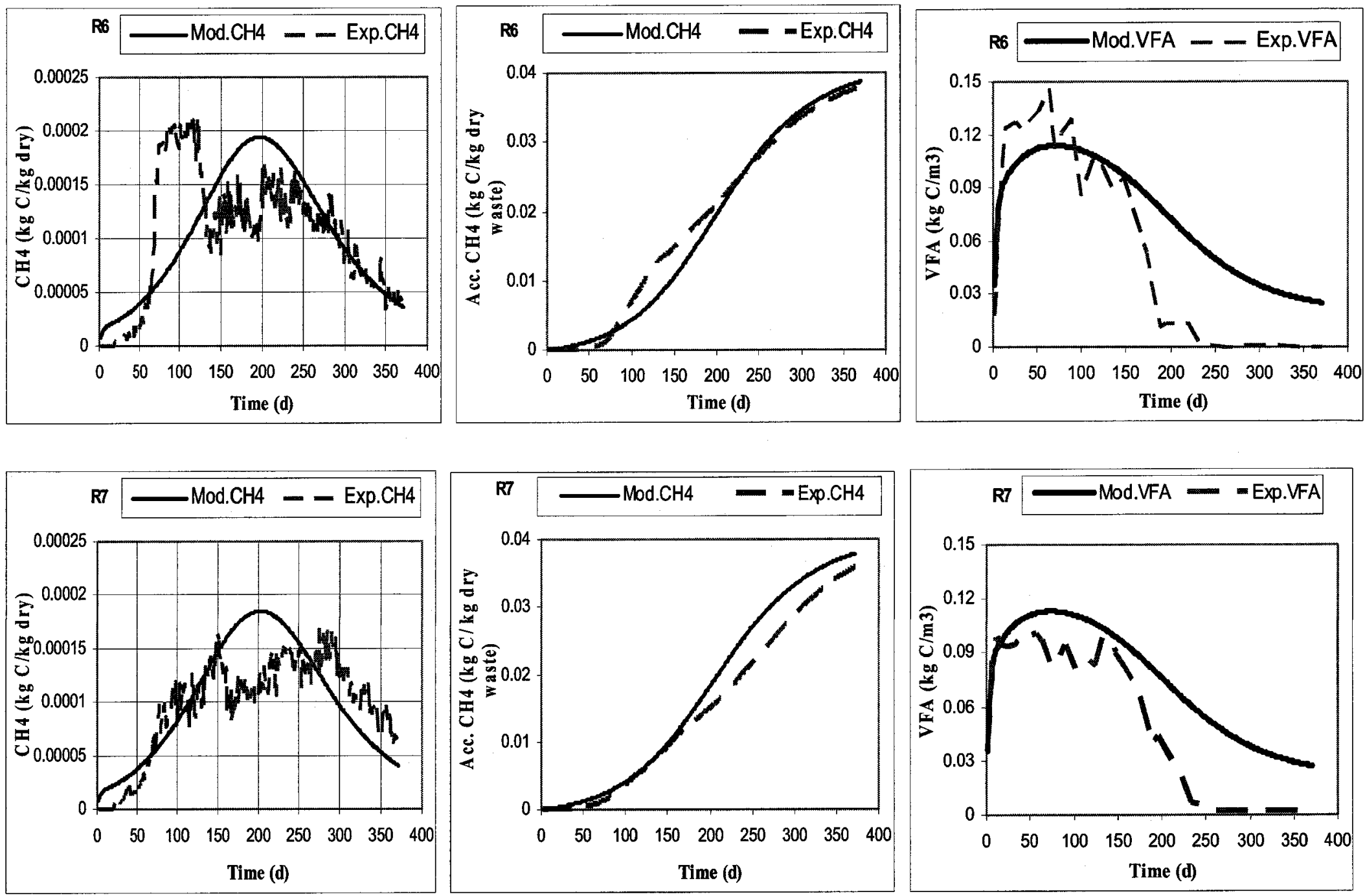

Figure 5.33: Model calibration second scenario. 

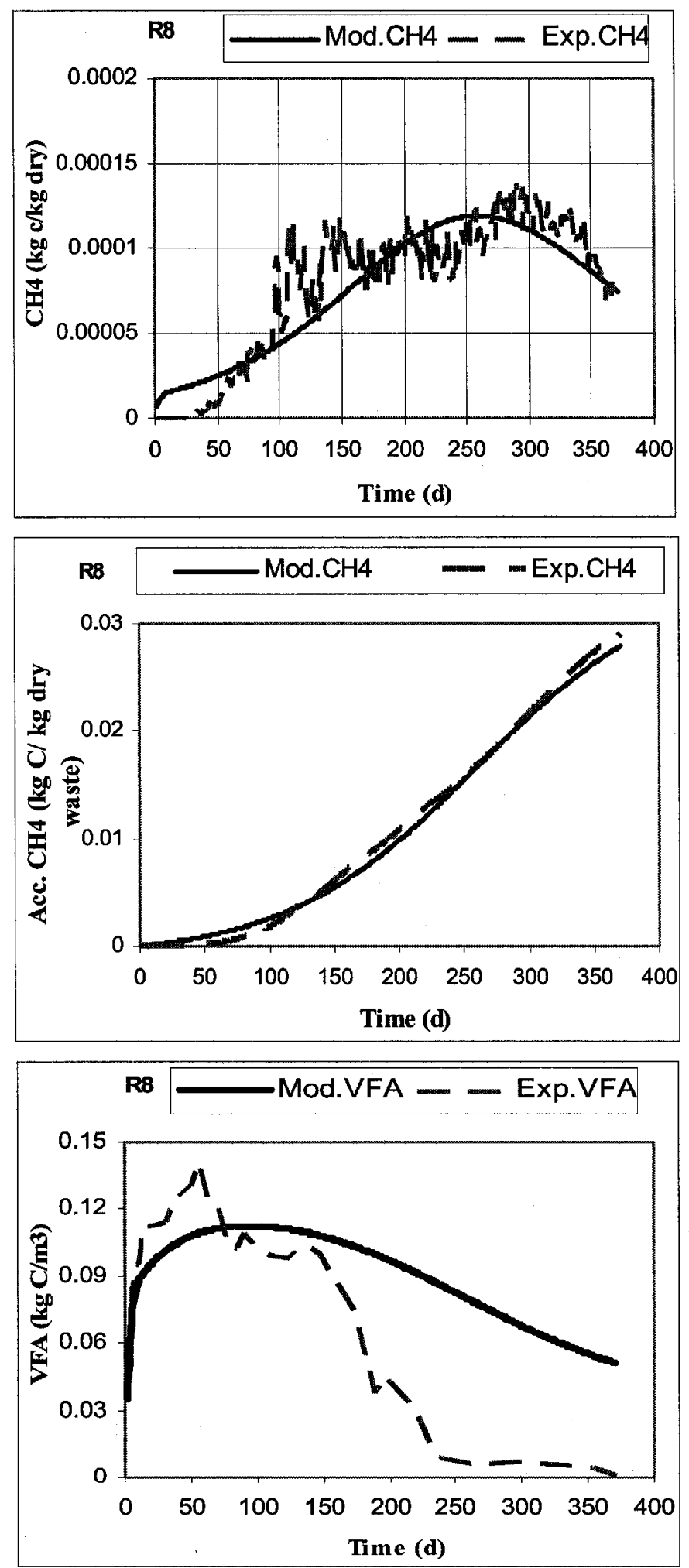

Figure 5.34: Model calibration second scenario. 
Also, there was a better match between the predicted and measured peak VFA concentrations and time to reach this peak compared to the first scenario.

Table 5.35: Parameters used in the model calibration of the second scenario

\begin{tabular}{|c|c|c|c|c|c|}
\hline Parameter & Unit & \multicolumn{4}{|c|}{ Applied values } \\
\hline \multicolumn{5}{|l|}{ Hydrolysis } & \\
\hline I & & $0 \%$ & $0.5 \%$ & $1 \%$ & $3 \%$ \\
\hline $\mathrm{k}_{\mathrm{h}}$ & & 0.043 & 0.036 & 0.033 & 0.023 \\
\hline $\mathrm{K}_{\mathrm{I}}$ & & \multicolumn{4}{|c|}{6} \\
\hline $\mathrm{m}$ & & \multicolumn{4}{|c|}{2} \\
\hline \multicolumn{6}{|l|}{ Acidogenesis } \\
\hline Growth rate, $\mu_{\mathrm{A}}$ & $d^{-1}$ & \multicolumn{4}{|c|}{5} \\
\hline Half saturation constant, $\mathrm{K}_{\mathrm{SA}}$ & $\mathrm{kg} \mathrm{m}^{-3}$ & \multicolumn{4}{|c|}{0.3} \\
\hline Rate of decay, $\mathrm{k}_{\mathrm{dA}}$ & $d^{-1}$ & \multicolumn{4}{|c|}{0.04} \\
\hline \multirow[t]{2}{*}{ Yield, $\mathrm{Y}_{\mathrm{A}}$} & $\mathrm{kg} \mathrm{kg}^{-1}$ & \multicolumn{4}{|c|}{0.15} \\
\hline & & \multicolumn{2}{|c|}{ First group } & \multicolumn{2}{|c|}{ Second group } \\
\hline \multicolumn{6}{|l|}{ Methanogenesis } \\
\hline Growth rate, $\mu_{M}$ & $d^{-1}$ & \multicolumn{2}{|c|}{0.13} & \multicolumn{2}{|c|}{0.22} \\
\hline Half saturation constant, $\mathrm{K}_{\mathrm{SM}}$ & $\mathrm{kg} \mathrm{m}^{-3}$ & \multicolumn{2}{|c|}{0.73} & \multicolumn{2}{|c|}{0.53} \\
\hline Rate of decay, $\mathrm{k}_{\mathrm{dM}}$ & day $^{-1}$ & \multicolumn{2}{|c|}{0.011} & \multicolumn{2}{|c|}{0.02} \\
\hline Yield, $\mathrm{Y}_{\mathrm{M}}$ & $\mathrm{kg} \mathrm{kg}^{-1}$ & \multicolumn{2}{|c|}{0.08} & \multicolumn{2}{|c|}{0.16} \\
\hline Methane fraction yield, $\mathrm{Y}_{\mathrm{CH} 4}$ & $\mathrm{~kg} \mathrm{~kg}^{-1}$ & \multicolumn{2}{|c|}{0.41} & \multicolumn{2}{|c|}{0.43} \\
\hline VFA formation yield, $Y_{\mathrm{HAC}}$ & $\mathrm{kg} \mathrm{kg}^{-1}$ & \multicolumn{2}{|c|}{0.9} & \multicolumn{2}{|c|}{0.9} \\
\hline \multicolumn{6}{|l|}{ Initial conditions } \\
\hline $\mathbf{C}_{(\mathrm{s})}$ & $\mathrm{Kg} \mathrm{C} \mathrm{m}^{-3}$ & \multicolumn{2}{|c|}{0.04} & \multicolumn{2}{|c|}{0.04} \\
\hline $\mathbf{C}_{\text {(aq) }}$ & $\mathrm{Kg} \mathrm{C} \mathrm{m}^{-3}$ & \multicolumn{2}{|c|}{0.05} & \multicolumn{2}{|c|}{0.05} \\
\hline $\mathrm{C}_{(\mathrm{VFA})}$ & $\mathrm{Kg} \mathrm{C} \mathrm{m}^{-3}$ & & & & \\
\hline $\mathbf{C}_{(\mathrm{XX})}$ & $\mathrm{Kg} \mathrm{C} \mathrm{m}^{-3}$ & & & & \\
\hline $\mathbf{C}_{(\mathrm{XM})}$ & $\mathrm{Kg} \mathrm{C} \mathrm{m}{ }^{-3}$ & & & & \\
\hline
\end{tabular}




\subsubsection{Third scenario}

In this scenario, the model simulates two different hydrolysis rate constants (readily and slowly) to match the two peaks of daily methane production observed in the experimental results. Based on the best matches between the predictive and measured results, the fraction of readily and slowly biodegradable matter was set to be $50 \%(\mathrm{w} / \mathrm{w})$.

The best fits of the calibrated model to the experimental results are shown in Figures 5.35 through 5.38, and Tables 5.36 summarizes the value of the parameters and inhibition constants $\left(\mathrm{K}_{\mathrm{I}}\right.$ and $\mathrm{m}$ ) used to get the best fit in this scenario. The parameters of methanogenic biomass were adjusted to achieve this fit.

$\mathrm{CH}_{4}$ : Improves the estimated time to reach the peak methane production. There was an improvement in the results of daily methane production. Simulation results of daily methane production showed two peaks. These peaks are clearer in R5 through R8. The value of peaks decreased with increasing the salt contents whereas, the time required to reach these peaks increased. These observations agreed with conclusions drawn from the experimental results (1D bioreactors and BMP assays).

VFA: The model exhibited lower VFA concentrations than those measured in all bioreactors. This may be attributed to the VFA that was produced from the readily biodegradable fraction which occurred in the early times and was consumed by the methanogenic biomass to produce the first peak of daily methane production, whereas the VFA produced from the slowly biodegradable fraction took a longer time to reach its peak. 
The values of inhibition constants $\left(\mathrm{K}_{\mathrm{I}}\right.$ and $\left.\mathrm{m}\right)$ used to get the best fit of calibrated model to the experimental results in all scenarios were $6 \%(\mathrm{w} / \mathrm{v})$ and 2 , respectively as presented in Tables 5.34 through 5.36.

In spite of the above comments, the match of model prediction to the laboratory experimental data indicates that the model was useful when employed to simulate the total methane production from lab scale bioreactors operating under saline conditions. Although the model shows good performance of a lab scale bioreactor, its application to actual bioreactor landfills needs modification to include the effect of waste composition fluctuation and weather conditions on gas production. 

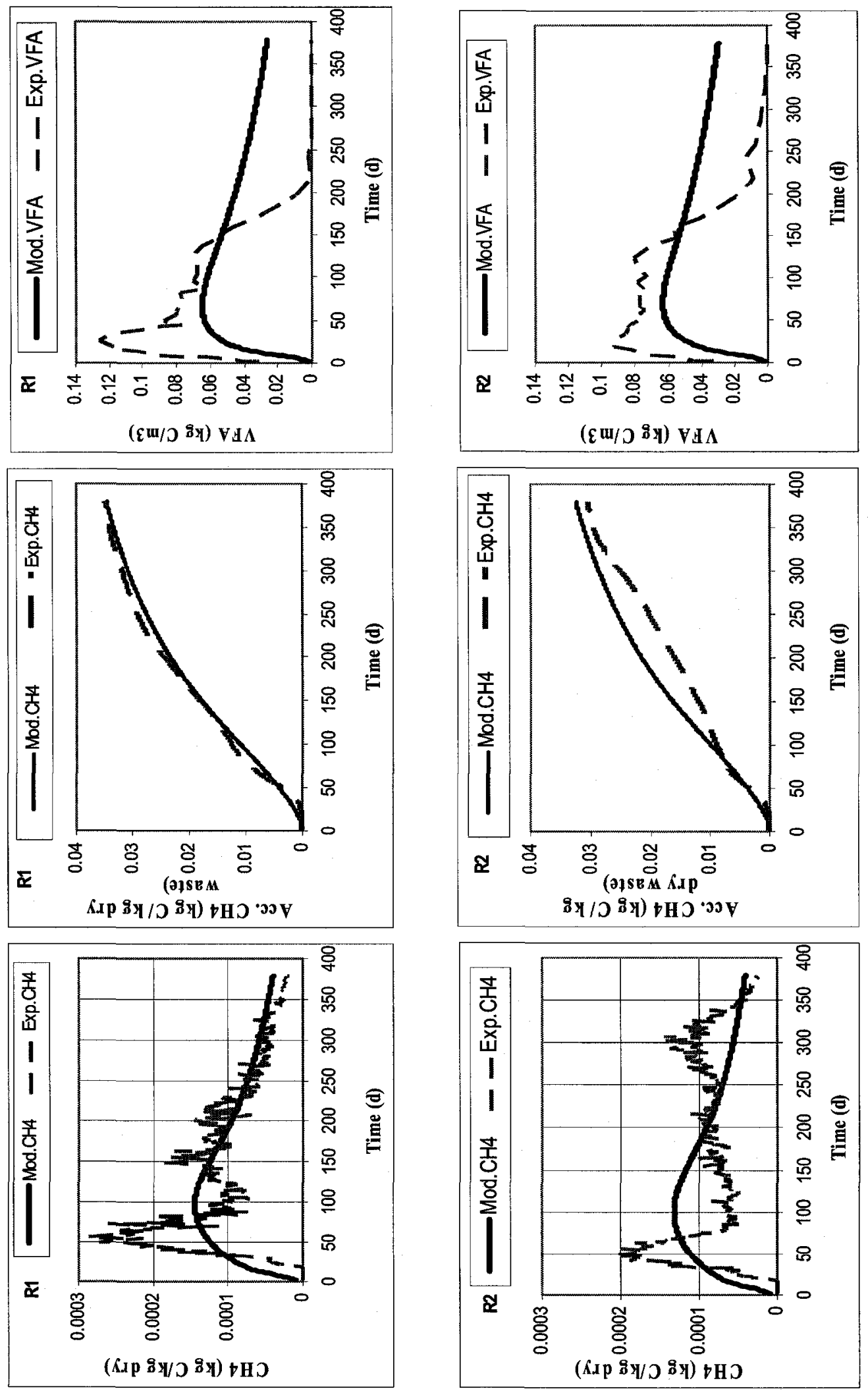

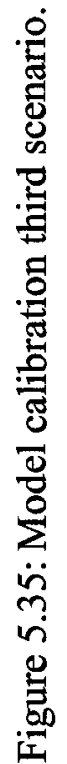



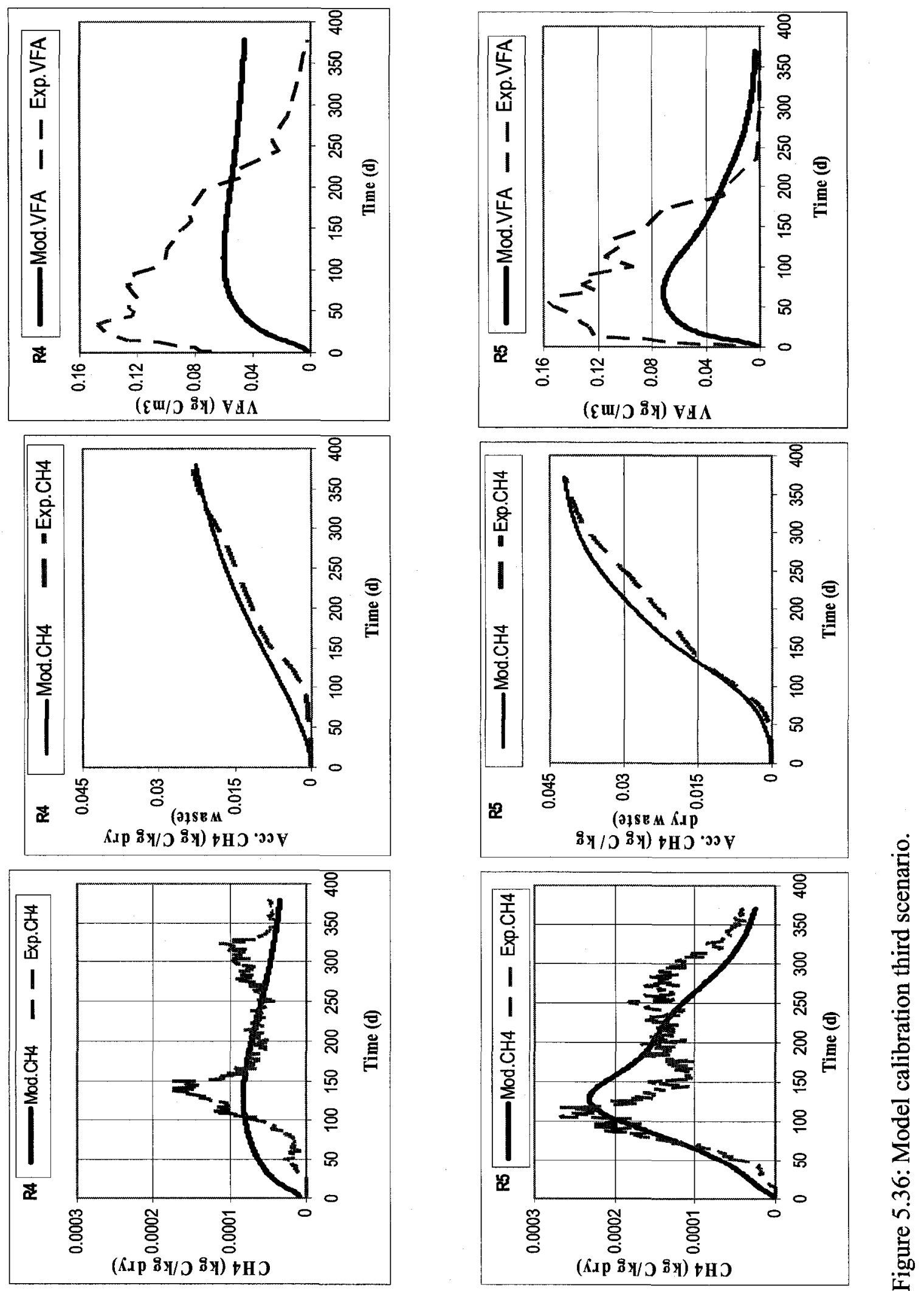

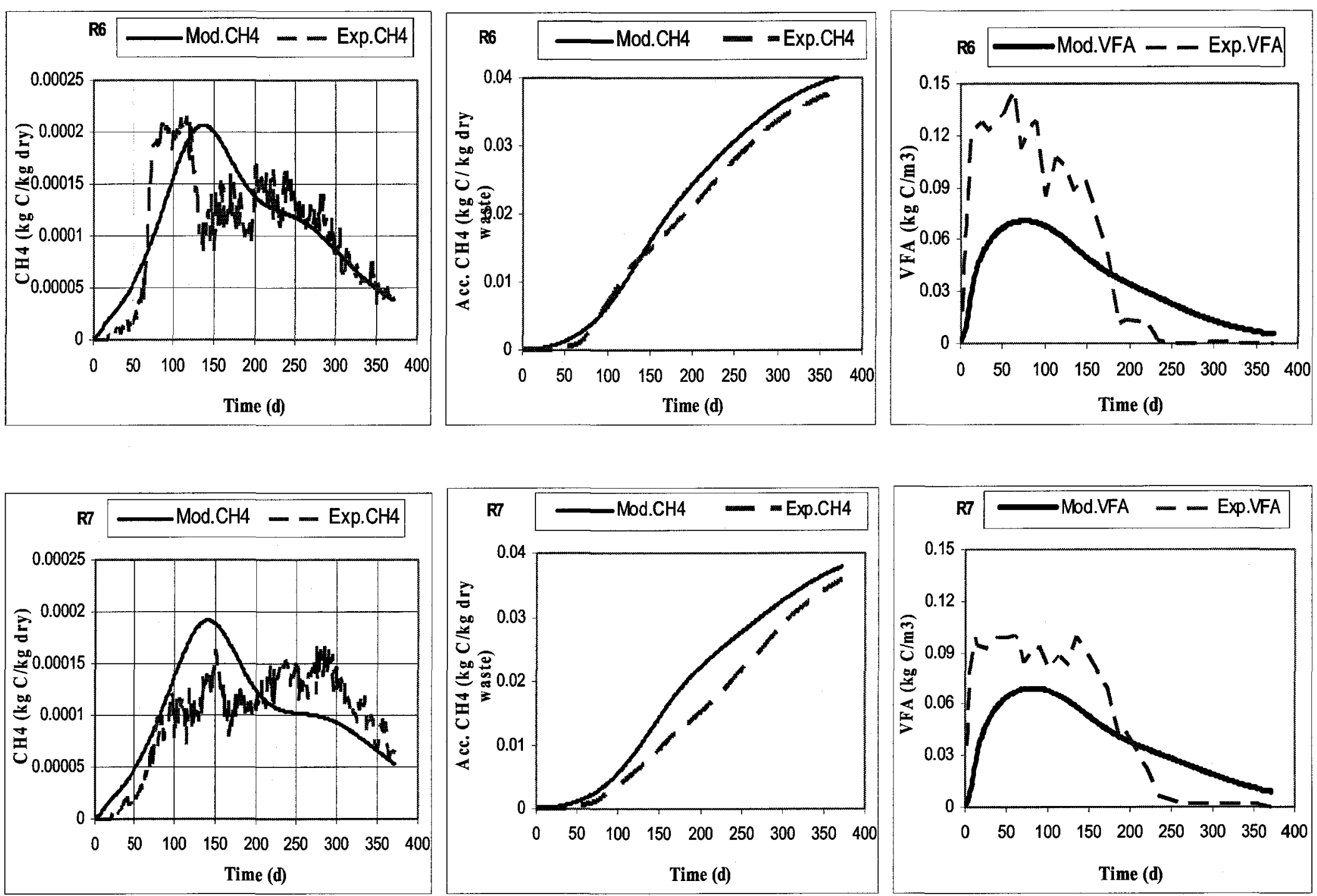

Figure 5.37: Model calibration third scenario. 

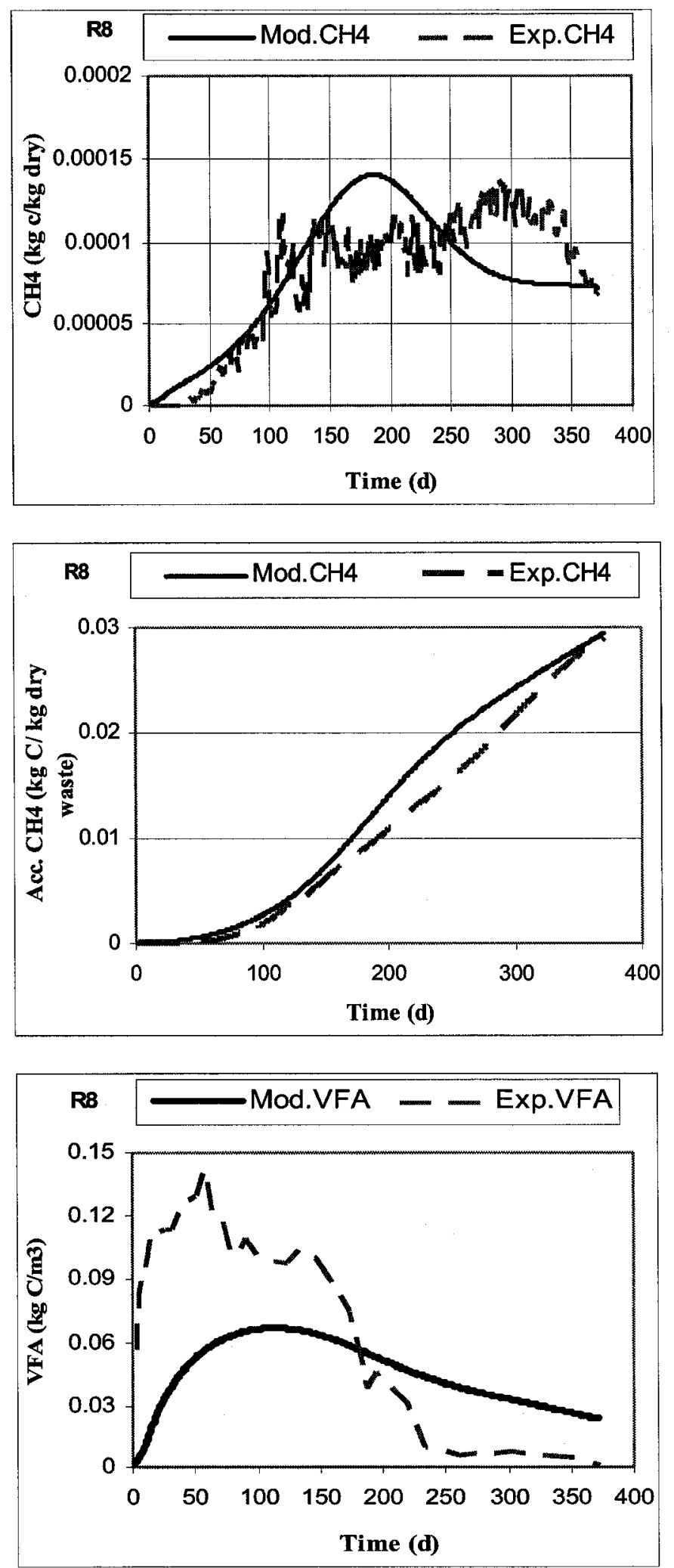

Figure 5.38: Model calibration third scenario. 
Table 5.36: Parameters used in the model calibration of the third scenario

\begin{tabular}{|c|c|c|c|c|c|}
\hline Parameter & Unit & \multicolumn{4}{|c|}{ Applied values } \\
\hline \multicolumn{5}{|l|}{ Hydrolysis } & \\
\hline I & & $0 \%$ & $0.5 \%$ & $1 \%$ & $3 \%$ \\
\hline $\mathrm{k}_{\mathrm{h}}$ (Readily) & & 0.08 & 0.07 & 0.06 & 0.033 \\
\hline \multirow{2}{*}{$\begin{array}{l}\mathrm{k}_{\mathrm{h}} \text { (Slowly) } \\
\mathrm{K}_{\mathrm{I}}\end{array}$} & & 0.008 & 0.007 & 0.006 & 0.0044 \\
\hline & & \multicolumn{4}{|c|}{6} \\
\hline $\mathrm{m}$ & & \multicolumn{4}{|c|}{2} \\
\hline \multicolumn{6}{|l|}{ Acidogenesis } \\
\hline Growth rate, $\mu_{\mathrm{A}}$ & $d^{-1}$ & \multicolumn{4}{|c|}{5} \\
\hline Half saturation constant, $\mathrm{K}_{\mathrm{SA}}$ & $\mathrm{kg} \mathrm{m}^{-3}$ & \multicolumn{4}{|c|}{0.3} \\
\hline Rate of decay, $\mathrm{k}_{\mathrm{dA}}$ & $d^{-1}$ & \multicolumn{4}{|c|}{0.04} \\
\hline \multirow[t]{2}{*}{ Yield, $\mathrm{Y}_{\mathrm{A}}$} & $\mathrm{kg} \mathrm{kg}^{-1}$ & \multicolumn{4}{|c|}{0.15} \\
\hline & & \multicolumn{2}{|c|}{ First group } & \multicolumn{2}{|c|}{ Second group } \\
\hline \multicolumn{6}{|l|}{ Methanogenesis } \\
\hline Growth rate, $\mu_{\mathrm{M}}$ & $\mathrm{d}^{-1}$ & \multicolumn{2}{|c|}{0.15} & \multicolumn{2}{|c|}{0.18} \\
\hline Half saturation constant, $\mathrm{K}_{\mathrm{SM}}$ & $\mathrm{kg} \mathrm{m}^{-3}$ & \multicolumn{2}{|c|}{0.34} & \multicolumn{2}{|c|}{0.22} \\
\hline Rate of decay, $\mathrm{k}_{\mathrm{dM}}$ & day $^{-1}$ & \multicolumn{2}{|c|}{0.01} & \multicolumn{2}{|c|}{0.007} \\
\hline Yield, $\mathrm{Y}_{\mathrm{M}}$ & $\mathrm{kg} \mathrm{kg}^{-1}$ & \multicolumn{2}{|c|}{0.08} & \multicolumn{2}{|c|}{0.15} \\
\hline Methane fraction yield, $\mathrm{Y}_{\mathrm{CH} 4}$ & $\mathrm{~kg} \mathrm{~kg}^{-1}$ & & & & \\
\hline VFA formation yield, $\mathrm{Y}_{\mathrm{HAC}}$ & $\mathrm{kg} \mathrm{kg}^{-1}$ & & & & \\
\hline \multicolumn{6}{|l|}{ Initial conditions } \\
\hline $\mathbf{C}_{(\mathrm{s})}$ & $\mathrm{Kg} \mathrm{C} \mathrm{m}^{-3}$ & \multicolumn{2}{|c|}{0.12} & \multicolumn{2}{|c|}{0.12} \\
\hline $\mathbf{C}_{(\mathbf{a q})}$ & $\mathrm{Kg} \mathrm{C} \mathrm{m}^{-3}$ & \multicolumn{2}{|c|}{0.0009} & \multicolumn{2}{|c|}{0.0009} \\
\hline $\mathrm{C}_{(\mathrm{VFA})}$ & $\mathrm{Kg} \mathrm{C} \mathrm{m}^{-3}$ & \multicolumn{2}{|c|}{0.0009} & \multicolumn{2}{|c|}{0.0009} \\
\hline $\mathbf{C}_{(\mathbf{X A})}$ & $\mathrm{Kg} \mathrm{C} \mathrm{m}^{-3}$ & \multicolumn{2}{|c|}{0.0009} & & \\
\hline $\mathbf{C}_{(\mathbf{X M})}$ & $\mathrm{Kg} \mathrm{C} \mathrm{m}^{-3}$ & & & & 25 \\
\hline
\end{tabular}




\section{Chapter 6}

\section{Conclusions and recommendations}

\subsection{Summary}

Bioreactor landfills offer great advantages in the biodegradation of MSW. They can be an excellent alternative to the traditional sanitary landfill method presently used in arid and semi-arid regions. However, they require an optimum amount of moisture to initiate the biodegradation process, which is problematic in arid regions where fresh water supplies are scarce. A solution to this problem could be to use brackish water in bioreactor landfills. This study therefore aimed to determine the effect of salinity on the biodegradation of municipal solid waste under different operational conditions, and to enhance the performance of bioreactor landfills operating under saline conditions by sludge addition. In doing so, this study also undertook to develop a mathematical model to simulate the long term performance of these bioreactor landfills and to estimate the hydrolysis rate constant of MSW at different salt contents.

Two types of experiments were used to accomplish the aims of this study. The first type consisted of $1 \mathrm{D}$ bioreactors. These bioreactors were divided into two groups. The first group (R1 through R4) was designed to study the impact of salinity on the biodegradation of MSW under different operational conditions $(0,0.5,1$, and $3 \%)(w / v)$. The second group (R5 through R8) was aimed at studying the effect of sludge addition on the performance of bioreactor landfills operating at different salt contents $(0,0.5,1$, and $3 \%)$ (w/v). The second type of experiments was the BMP assays which were conducted to estimate the anaerobic hydrolysis rate constant of the biodegradation process. 
A mathematical model was developed to predict the leachate strength (aqueous organic and VFA) and the volume of landfill gas $\left(\mathrm{CH}_{4}\right.$ and $\left.\mathrm{CO}_{2}\right)$ produced.

The model described the biodegradation in three steps: hydrolysis, acidogenesis, and methanogenesis. The hydrolysis is the rate limiting step in the solid waste biodegradation process and is assumed to follow first order kinetics with respect to solid organic concentration. Monod kinetics were used to simulate the growth rate of the acidogenic and methanogenic biomasses. An inhibition term to simulate the effect of saline environment was included in the Monod kinetics which in turn was used to simulate the methanogenic biomass. The acidogenic kinetics $\left(\mu_{\mathrm{A}}, \mathrm{k}_{\mathrm{dA}}\right.$, and $\left.\mathrm{K}_{\mathrm{SA}}\right)$ had no significant effect on the VFA concentration and methane production, as suggested by the results of the sensitivity analysis.

The output from the model was concentration of solid carbon, aqueous acids, VFA, acidogenic and methanogenic biomasses, daily $\mathrm{CH}_{4}$ and $\mathrm{CO}_{2}$, accumulation of $\mathrm{CH}_{4}$ and $\mathrm{CO}_{2}$, and total biogases produced over time. All concentrations were expressed in terms of mass of carbon per unit volume.

A sensitivity analysis was performed to asses the significance of change (hydrolysis rate constant, biomass kinetics and initial conditions) on the $\mathrm{C}_{\mathrm{aq}}, \mathrm{C}_{\mathrm{VFA}}, \mathrm{C}_{\mathrm{XA}}, \mathrm{C}_{\mathrm{XM}}$, and $\mathrm{CH}_{4}$. The sensitivity analysis indicates that the hydrolysis rate constant, methanogenic parameters $\left(\mu_{\mathrm{M}}, \mathrm{k}_{\mathrm{dM}}, \mathrm{K}_{\mathrm{SM}}\right)$, and initial concentration of methanogenic biomass had a significant impact on peaks of the VFA and daily methane produced, as well as the time required to reach them. 
Experimental data obtained from 1D bioreactors and BMP assays were applied in the model calibration. The purpose of model calibration was to estimate the kinetics $\left(\mu, \mathrm{k}_{\mathrm{d}}\right.$, and $\left.\mathrm{K}_{\mathrm{S}}\right)$ of biomass, and the inhibition constants $\left(\mathrm{K}_{\mathrm{I}}\right.$ and $\left.\mathrm{m}\right)$. These were utilized in two steps. In the first step, results of $1 \mathrm{D}$ bioreactors operated without salt content were used to estimate the kinetics $\left(\mu, \mathrm{k}_{\mathrm{d}}\right.$, and $\mathrm{K}_{\mathrm{S}}$ ) of biomass. In the second step, the results of $1 \mathrm{D}$ bioreactors operated under different salt contents $(0.5,1$, and $3 \%)(w / v)$ were used to estimate the inhibition constants $\left(\mathrm{K}_{\mathrm{I}}\right.$ and $\left.\mathrm{m}\right)$.

The results of this study revealed that saline water up to $1-2 \%(\mathrm{w} / \mathrm{v})$ concentration could be used to bring the moisture content up to optimum levels in the biodegradation of MSW. Sludge addition had several advantages in the enhancement of bioreactor landfill performance operated under saline conditions. This could serve as a starting point for further research and investigation in the use of sludge as an enhancement method for MSW biodegradation in saline environments.

\subsection{Conclusions}

Based on the analysis of 1D bioreactor results, the following conclusions can be drawn:

- The average settlement in the aerobic stage was greater than in the anaerobic stage. The total settlements were higher in bioreactors operated with sludge addition and it decreased with increasing the salt content. This emphasizes that sludge addition enhances the biodegradation in terms of settlement. Statistically, there were significant differences in the mean settlements at $1 \%$ and $3 \%$, compared to the mean of settlement at $0 \%(\mathrm{w} / \mathrm{v})$ salt contents. This indicates that high salt contents inhibited the biodegradation of MSW, as suggested by the results of settlement. 
- The results of biogas showed the highest methane production was recorded in R5, bioreactor with sludge addition and $0 \%(\mathrm{w} / \mathrm{v})$ salt content, and it decreased by increasing the salt content in all bioreactors. The increase in salt content causes a reduction in the volume of total and daily methane productions and methane yield; and an increase in the lag time, the time to reach the peak of daily methane production and the stabilization time. Bioreactors in group two, which operated with sludge addition, showed a higher methane yield and total methane production than in group one, which operated without sludge addition. In other words, addition of anaerobic digested sludge enhanced the biodegradation of MSW operated at different salt conditions. Statistically, there were significant differences in the mean daily methane production, methane concentration and methane yield 1) between the two groups, 2) in all bioreactors, and 3$)$ at different salt contents $(0,0.5,1$ and $3 \%)(\mathrm{w} / \mathrm{v})$.

- Results from the BMP assays were consistent with the results from the $1 \mathrm{D}$ bioreactors. The increase in salt concentration caused an increase in the lag phase of methane production, and a decrease in the daily volume of methane production. Using acclimatized anaerobic digested sludge as an inoculum in BMP assays, causes a reduction in the lag time of methane production at different salt contents. Statistically speaking, no significant difference was observed when using the two types of inoculums salt acclimatized anaerobic digested sludge vs. the normal anaerobic digested sludge, in BMP assays.

- The results of leachate quality showed the percentage peak reduction in all leachate parameters (COD, BOD, VFA, $\mathrm{NH}_{3}-\mathrm{N}$, TVS and TS) decreased with increasing the salt contents. In other words, salt inhibited the biodegradation of MSW. The highest 
COD, BOD, VFA, $\mathrm{NH}_{3}-\mathrm{N}$, TVS and TS percentage peak reductions were observed in R5 (0\%), and the lowest in R4 (3\%). Bioreactors operated with sludge addition (group two) showed a higher percentage peak reduction in all leachate parameters in both the aerobic and anaerobic stages compared with bioreactors of group one. That meant that the addition of sludge improved the performance of bioreactors operated under different saline conditions. Statistically, there was a significant difference between the mean of COD, BOD, VFA, TVS, and TS percentage peak reductions at different salt contents during the aerobic stage. The difference was at $3 \%$ compared to $0 \%(\mathrm{w} / \mathrm{v})$ salt content. Also, a significant difference was observed in the mean of COD, BOD, TVS, and TS percentage peak reductions at different salt contents during the anaerobic stage. The difference was at $3 \%$ compared to $0 \%(\mathrm{w} / \mathrm{v})$ salt content in the COD and BOD, whereas the difference was for $1 \%$ and $3 \%$ in the TVS and TS. This indicates that the high salt contents inhibited the MSW biodegradation.

- From the results of settlement, the landfill biogas quality and quantity, and leachate quality, it can be concluded that saline water inhibited the MSW biodegradation and that the enhancement of MSW biodegradation occurred with sludge addition.

- The hydrolysis rate constant was $0.043,0.036,0.029$, and $0.023 \mathrm{~d}^{-1}$ for $0,1,2$, and $3 \%$ (w/v) salt content, respectively, at $23^{\circ} \mathrm{C}$.

There were other important findings from the 1D bioreactor experiments:

- There was no statistical difference in the moisture content along the vertical profile of bioreactors.

- There was no statistical difference in the temperature among the bioreactors. 
- There was no significant difference in the concentration along the vertical profile of bioreactors.

- Shortcircuiting was observed in the bioreactors and the fraction of shortcircuiting based on the assumption of a completely mixed system was in the range of 0.16 to 0.32 .

Based on the sensitivity analysis and model calibration, the following points should be highlighted:

- The model results were highly sensitive to the hydrolysis rate constant followed by kinetics $\left(\mu, \mathrm{k}_{\mathrm{d}}\right.$, and $\left.\mathrm{K}_{\mathrm{S}}\right)$ and initial condition of methanogenic biomass.

- No significant impact was observed when changing the acidogenic biomass parameters on the peak VFA and daily methane production. There was only a variation in the time to reach the peaks.

- The initial concentration of the methanogenic biomass had a greater impact on the methane production than other initial concentrations $\left(\mathrm{C}_{\mathrm{aq}}, \mathrm{C}_{\mathrm{VFA}}\right.$, and $\left.\mathrm{C}_{\mathrm{XA}}\right)$.

- The model showed good agreement with the results of methane production from the 1D bioreactors.

- The developed model able to predict the two peaks of daily methane production and simulate the effect of salt on the value of these peaks, as well as the time to reach them. The model has the potential to simulate the effect of salt on MSW biodegradation.

- The value of the inhibition constants $\mathrm{K}_{\mathrm{I}}$ and $\mathrm{m}$ were $6 \%(\mathrm{w} / \mathrm{v})$ and 2 , respectively. 
If designers of bioreactor landfills plan to use saline water to increase the moisture content to optimum levels in the biodegradation of MSW, they should expect the time for waste stabilization to increase and the methane yield to decrease. The lab-scale bioreactors used in this study indicated a $33 \%$ reduction in the volume of methane produced when the salt concentration was increased to $3 \%(w / v)$ without sludge (R4). The reduction was $13 \%$ in the volume of total methane produced when the salt concentration was raised to $3 \%(\mathrm{w} / \mathrm{v})$ with sludge addition (R8).

\subsection{Recommendations}

Based on the experience gained with experiments from this study, several recommendations are suggested to improve the performance of bioreactor landfills operating under saline conditions.

- Use sea sediment as potential enhancement method because it contains biomass which is already acclimatized to salt conditions.

- Sludge addition improved the biodegradation of MSW. The leachate produced from bioreactors (in the methanogenic stage) operated with salt addition could be added to fresh MSW as a source of acclimatized biomass. This may reduce the lag phase for methane production and increase the daily methane production. In other words, it may enhance the MSW biodegradation in the presence of salt media.

- Study the effect of saline water on the heavy metal concentrations in the leachate.

- Estimate the hydrolysis rate constant for individual waste fraction (paper, textile, food, etc.) at different salt contents. 
Text imcomplete; leaves $238-247$ onitted. 


\section{References}

Agdag, O. N., \& Sponza, D. T. (2005). Effect of alkalinity on the performance of a simulated landfill bioreactor digesting organic solid wastes. Chemosphere, 59(6), 871-879.

Al-Yaqout, A. F., Hamoda, M. F. \& Zafar, M. (2005). "Characteristics of wastes, leachate, and gas at landfills operated in arid climate". Practice Periodical of Hazardous, Toxic, and Radioactive Waste Management, Volume. 9, No.2.

Al-Yousfi, B. \& Pohland, F. (1998). Strategies for simulation, design and management of solid wastes disposal sites as landfill bioreactors. Practice Periodical of Hazardous, Toxic, and Radioactive Waste Management, Vol.2, No.1, 13- 21.

Anderottola G. (1992) .Chemical and biological characteristics of landfill leachate. Landfilling of waste: Leachate edited by Christensen, T.H., Cossu, R. and Stegmann, R, Elsevier Applied Science, 6, London and New York,65-88.

Anderson, G., (1990). Treatment of wastes by composting. In microbiology of landfill sites(E. Senior, ed.). Boca Raton, FL, U.S.A.: CRC Press, Inc., 59-80.

Anderson, G. \& Yang, G. (1992). Determination of bicarbonate and total volatile acid concentrations in anaerobic digestion using a simple titration, Water Environmental Research, Vol.64 : 53-59.

Arnold E. G., Lenore, S. C. \& Andrew, D. E. (1992). Standard methods (APHA) for the examination of water and wastewater, $18^{\text {th }}$ edition .

Aspe, E., Marti, M. C., \& Roeckel, M. (1997). Anaerobic treatment of fishery wastewater using a marine sediment inoculum. Water Research, 31(9), 2147-2160.

Bae, J. H., Cho, K. W., Lee, S. J., Bum, B. S., \& Yoon, B. H. (1998). Effects of leachate recycle and anaerobic digester sludge recycle on the methane production from solid wastes. Water Science and Technology, 38(2), 159-168.

Baldwin, T., Stinson, J. \& Ham, R. K. (1998) .Decomposition of specific materials buried within sanitary landfills. Journal of Environmental Engineering, Vol. 124, No. 12, 1193- 1202.

Barlaz, M., Schaefer, D. M. \& Ham, R. K. (1989) . Bacterial population development and chemical characteristics of refuse decomposition in asumulated sanitary landfill. Applied and Environmental Microbiology, Vol. 55, No.1, 55-65.

Barlaz, M. A., Ham, R. K., \& Schaefer, D. M. (1989). Mass-balance analysis of anaerobically decomposed refuse. Journal of Environmental Engineering-ASCE, $115(6), 1088-1102$. 
Barlaz, M. A., Ham, R. K., \& Schaefer, D. M. (1990). Methane production from municipal refuse - a review of enhancement techniques and microbial dynamics. Critical Reviews in Environmental Control, 19(6), 557-584.

Barlaz, M. A., Ham, R. K., \& Schaefer, D. M. (1992). Microbial, chemical and methane production characteristics of anaerobically decomposed refuse with and without leachate recycling. Waste Management \& Research, 10(3), 257-267.

Batstone, D. J., Picioreanu, C., Loosdrechi, M. C. M., (2006). Multidimensional modeling to investigate interspecies hydrogen transfer in anaerobic biofilms. Water Research, 40, 3099- 3108

Beker, I. D (1987). Control of acid degradation. In:Christensen, T.H., Cossu, R. and Stegmann, R. (eds). Proceeding Sardinia 87', First International landfill Symposium. Volume 2. Cagliari, Italy: CISA. Pp. 1-22. Cited in Komilis et al., (1999a)

Bingemer, H. G., \& Crutzen, P. J. (1987). The production of methane from solid-wastes. Journal of Geophysical Research-Atmospheres, 92(D2), 2181-2187.

Bleiker, D.E., Farquhar, G. \& McBean E. (1995). Landfill settlement and the impact on site capacity and refuse hydraulic conductivity. Waste Management \& Research, 13, 533-554.

Bogner, J., \& Spokas, K. (1993). Landfill $\mathrm{CH}_{4}$ - rates, fates, and role in global carboncycle. Chemosphere, 26(1-4), 369-386.

Booker, T. J., Asce, A. M. \& R.K. Ham. (1982). Stabilzation of solid waste in landfills. Journal of Environmental Engineering, 108(6), 1089.

Borzacconi, L., Lopez, I., \& Anido, C. (1997). Hydrolysis constant and VFA inhibition in acidogenic phase of MSW anaerobic degradation. Water Science and Technology, $36(6-7), 479-484$.

Buivid, M. et al. (1981). Fuel gas enhancement by controlled landfilling of municipal solid waste. Resour. Recovery Conserv., 6, 3. Cited in Barlaz et al., (1990)

Chan, G. Y. S., Chu, L. M., \& Wong, M. H. (2002). Effects of leachate recirculation on biogas production from landfill co-disposal of municipal solid waste, sewage sludge and marine sediment. Environmental Pollution, 118(3), 393-399.

Chanthikul, S., Qasim, S. R., Mukhopadhyay, B., \& Chiang, W. W. (2004). Computer simulation of leachate quality by recirculation in a sanitary landfill bioreactor. Journal of Environmental Science and Health Part A-Toxic/hazardous Substances \& Environmental Engineering, 39(2), 493-505. 
Chiemchaisri, C., Chiemchaisri, W. Nonthapund, U. \& Sittichoktam, S. (2002). Acceleration of solid waste biodegradation in tropical landfill using bioreactor landfill, concept, $5^{\text {th }}$ Asian symposium on academic activities for waste management Sep.2002 Kuala Lumpur.

Christ, O., Wilderer, P., Angerhofer, R. \& Faulstich M. (2000). Mathematical modeling of the hydrolysis of anaerobic processes. Water Science and Technology, 41(3), 6165 .

Christensen, T.H. \& Kjeldsen, P. (1989). Basic biochemical process in landfills. Sanitary landfilling: Process, Technology and Environmental Impact, Eds. Christensen, T.H., Cossu, R. and Stegmann, R., Academic press, London UK, pp 29-49.

Christensen, T.H., Kjeldsen, P. \& Stegmann, R. (1992) . Effects of landfill management procedures on landfill stabilization and leachate and gas quality. Landfilling of waste: Leachate edited by Christensen, T.H., Cossu, R. and Stegmann, R, Elsevier Applied Science, 6, London and New York,119 - 137.

Christensen, T.H. , Kjeldsen, P. \& Lindhardt, B. (1996). Gas generating processes in landfills. Landfilling of waste: Biogas, T.H. Christensen et al., E\&FN Spon, London, UK, 27-50.

Chugh, S., Chynoweth, D., Clarke, W., Pullammanappallil, P. \& Rudolph V. (1998). Effect of recirculated leachate volume on MSW degradation. Waste Management Research, Vol.16, 564-573.

Demetracopoulos, A. C., Sehayek, L., \& Erdogan, H. (1986). Modeling leachate production from municipal landfills. Journal of Environmental Engineering-ASCE, 112(5), 849-866.

Dincer, A. R. \& Kargi, F. (1999). Salt inhibition of nitrification and denitrification in saline waste water. Environmental Technology. Vol. 20, 1147- 1153.

Dixon, N., \& Jones, D. R. V. (2005). Engineering properties of municipal solid waste. Geotextiles and Geomembranes, 23(3), 205-233.

Eleazer, W. E., Odle, W. S., Wang, Y. S., \& Barlaz, M. A. (1997). Biodegradability of municipal solid waste components in laboratory-scale landfills. Environmental Science \& Technology, 31(3), 911-917.

El-Fadel, M. (1991) Numerical Modelling of gas and heat generation and transport in sanitary landfills, Ph.D. Dissertation, Stanford University, Stanford, CA, U.S.A.

El-Fadel, M., Findikakis, A. N., \& Leckie, J. O. (1996a). Estimating and enhancing methane yield from municipal solid waste. Hazardous Waste \& Hazardous Materials, 13(3), 309-331. 
El-Fadel, M., Findikakis, A. N., \& Leckie, J. O. (1996b). Numerical modelling of generation and transport of gas and heat in landfills .1. Model formulation. Waste Management \& Research, 14(5), 483-504.

El-Fadel, M., Findikakis, A. N., \& Leckie, J. O. (1996c). Numerical modelling of generation and transport of gas and heat in sanitary landfills .2. Model application. Waste Management \& Research, 14(6), 537-551.

El-Fadel, M., Findikakis, A. N., \& Leckie, J. O. (1997a). Modeling leachate generation and transport in solid waste landfills. Environmental Technology, 18(7), 669-686.

El-Fadel, M., Findikakis, A. N., \& Leckie, J. O. (1997b). Numerical modelling of generation and transport of gas and heat in sanitary landfills .2 . Sensitivity analysis. Waste Management \& Research, 14(6), 537-551.

Fang (1983) cited on Oweis et al. (1998).

Farquhar, G. J. (1989). Leachate - production and characterization. Canadian Journal of Civil Engineering, 16(3), 317-325.

Franklin, M. (2002). Solid waste stream characteristics . Handbook of Solid Management. Eds. Tchobanoglous G. and Kreith F., McGraw Hill, Second edition.

Gau, S. H., \& Chow, J. D. (1998). Landfill leachate characteristics and modeling of municipal solid wastes combined with incinerated residuals. Journal of Hazardous Materials, 58(1-3), 249-259.

Gharsallah, N., Khannous, L., Souissi, N., \& Nasri, M. (2002). Biological treatment of saline wastewaters from marine-products processing factories by a fixed-bed reactor. Journal of Chemical Technology and Biotechnology, 77(8), 865-870.

Gonullu, M. T. (1994a). Analytical modeling of inorganic contaminants in leachate. Waste Management \& Research, 12(4), 339-350.

Gonullu, M. T. (1994b). Analytical modeling of organic contaminants in leachate. Waste Management \& Research, 12(2), 141-150.

Grady, C.P., Daigger, G. \& Lim, H. (1999) Biological Wastewater Treatment. Marcel Dekker , NEW York, Second edition.

Haarstrick, A., Hempel, D. C., Ostermann, L., Ahrens, H., \& Dinkler, D. (2001). Modelling of the biodegradation of organic matter in municipal landfills. Waste Management \& Research, 19(4), 320-331.

Halvadakis, G.P. (1983). Methanogenesis in solid waste landfill bioreactors. Ph.D. thesis, Stanford University. 
Halvadakis, G. P., Findikakis, A. N., Papelis C., \& Leckie, J. O. (1998). The Mountain View controlled landfill project field experiment. . Waste Management \& Research, 19(6), 103-114.

Ham, R.K. (1979). Predicting gas generation from landfills. Waste age, November, 50-58

Ham, R. K., \& Bookter, T. J. (1982). Decomposition of solid-waste in test lysimeters. Journal of the Environmental Engineering Division-ASCE, 108(6), 1147-1170.

Ham, R.K. \& M.A. Barlaz, (1989) “ Measurement and prediction of landfill gas quality and quantity, in sanitary landfilling: process technology and environmental impact, Christensen, T.H., R. Cossu and R. Stegmann, Eds., Academic Press, Orlando, FL: 155.

Hamoda, M. F., \& Alattar, I. M. S. (1995). Effects of high sodium-chloride concentrations on activated-sludge treatment. Water Science and Technology, 31(9), 61-72.

Hartz, K. E., Klink, R. E., \& Ham, R. K. (1982). Temperature effects - methane generation from landfill samples. Journal of the Environmental Engineering Division-ASCE, 108(4), 629-638.

Haug, R.T. (1993). The practical handbook of compost Engineering. Lewis Publishers.

Heukelekian H. (1958). Basic principal of sludge digestion in Biological Treatment of sewage and industrial waste. McCabe, J. and Eckenfelder, W. W., Jr. Eds., Reinhold Publishing, New York, 25.

Hill, C. (1977). An Introduction to Chemical Engineering Kinetics and Rector Deign. John Wiley \& Son, New York. Cited in Pavlostathis et al. (1991).

IWA. (2002). Anaerobic Digestion Model No.1 (ADM1). International water association Scientific and Technical Report No. 13, IWA Publishing London, UK

Jin, H. \& Warith, M. (2006). Biodegradation of high moisture and organic content solid waste in bioreactor landfills. Annual general conference of the Canadian society for civil engineering, Calgary, Alberta, Canada, May 23-26.

Jokela, J. P. Y., Vavilin, V. A., \& Rintala, J. A. (2005). Hydrolysis rates, methane production and nitrogen solubilisation of grey waste components during anaerobic degradation. Bioresource Technology, 96(4), 501-508.

Kargi, F., \& Dincer, A. R. (1996). Effect of salt concentration on biological treatment of saline wastewater by fed-batch operation. Enzyme and Microbial Technology, 19(7), 529-537. 
Kargi, F., \& Dincer, A. R. (1997). Biological treatment of saline wastewater by fed-batch operation. Journal of Chemical Technology and Biotechnology, 69(2), 167-172.

Kargi, F., \& Uygur, A. (1997). Biological treatment of saline wastewater in a rotating biodisc contactor by using halophilic organisms. Bioprocess Engineering, 17(2), 8185 .

Kargi, F., \& Dincer, A. R. (1998). Saline wastewater treatment by halophilesupplemented activated sludge culture in an aerated rotating biodisc contactor. Enzyme and Microbial Technology, 22(6), 427-433.

Kargi, F. (2002). Empirical models for biological treatment of saline wastewater in rotating biodisc contactor. Process Biochemistry, 38(3), 399-403.

Kargi, F. (2002). Enhanced biological treatment of saline wastewater by using halophilic bacteria. Biotechnology Letters, 24(19), 1569-1572.

Kasali, G. B., \& Senior, E. (1989). Effects of temperature and moisture on the anaerobicdigestion of refuse. Journal of Chemical Technology and Biotechnology, 44(1), 3141 .

Katsiri A. K., Bosdgianni A., \& Christoulas D. (1999). Prediction of leachate quality from landfills. Journal of Environmental Engineering, Vol.125, No.10: 950-958.

Klink, R. E., \& Ham, R. K. (1982). Effects of moisture movement on methane production in solid-waste landfill samples. Resources and Conservation, 8(1), 29-41.

Komilis, D. P., Ham, R. K., \& Stegmann, R. (1999a). The effect of landfill design and operation practices on waste degradation behavior: A review. Waste Management \& Research, 17(1), 20-26.

Komilis, D. P., Ham, R. K., \& Stegmann, R. (1999b). The effect of municipal solid waste pretreatment on landfill behavior: A literature review. Waste Management \& Research, 17(1), 10-19.

Korfiatis, G. P., Demetracopoulos, A. C., Bourodimos, E. L., \& Nawy, E. G. (1984). Moisture transport in a solid-waste column. Journal of Environmental EngineeringASCE, 110(4), 780-796.

Laquidara, M. J., Leuschner, A. P., \& Wise, D. L. (1986). Procedure for determining potential gas quantities in an existing sanitary-landfill. Water Science and Technology, 18(12), 151-162.

Ledakowicz, S. \& Kaczorek, K. (2004). The effect of advanced oxidation process on leachate biodegradation in recycling lysimeters. Waste Management Research, Vol. $22,149-157$. 
Lee, N. H. (1997). Development of landfill gas control and utilization technologies. Rep. No. EPA/ 9-3-4, Seoul. Cited in Suk et al. (2000).

Lee, K. K., Suk, H., Choi, S. I., Lee, C. H., \& Chung, S. Y. (2001). Numerical evaluation of landfill stabilization by leachate circulation. Journal of Environmental Engineering-ASCE, 127(6), 555-563.

Lehninger, A. L. (1975), Biochemistry, $2^{\text {nd }}$ ed. Worth Publishers, New York. Cited in Pavlostathis et al. (1991).

Leuschner A. (1982) .Enhancement of degradation: Laboratory- scale experiments. In sanitary landfilling process, Technology and Environmental Impact, Christensen, T.H., Cossu R. and Stegmann R. eds, Academic Press, London, UK, 83- 102.

McCarty, P.L. 1964. Anaerobic waste treatment fundamentals. Parts 1, 2, 3 and 4. Public works, 95 (9), 107-12, (10), 123-6, (11), 91-4, (12), 95-9. Cited in Christensen et al., (1989).

Metcalf \& Eddy (2003). Wastewater Engineering: Treatment and Reuse. McGraw Hill, Boston.

Mora-Naranjo, N., Meima, J. A., Haarstrick, A., \& Hempel, D. C. (2004). Modelling and experimental investigation of environmental influences on the acetate and methane formation in solid waste. Waste Management, 24(8), 763-773.

Oweis, I.S., Khera, R., 1986. Criteria for geotechnical construction on sanitary landfills. International Symposium on Environmental Geotechnology, Volume I (Fang, H.Y. ed.). Allentown U.S.A.: Envo Publishing Company Inc., (205-222). Cited in Bleiker et al. (1995).

Oweis, I. S., Smith, D. A., Ellwood, R. B., \& Greene, D. S. (1990). Hydraulic characteristics of municipal refuse. Journal of Geotechnical Engineering-ASCE, $116(4), 539-553$.

Oweis I. \& Khera R. (1998). Geotechnology of Waste Management. PWS Publishing Company, Second edition.

Owens, J.M. \& Chynoweth, D.P (1993). Biochemical methane potential of municipal solid waste (MSW) components. Water science technology, 27(2), 1-14.

Pacey J. (1989) “Enhancement of degradation: large- scale experiments”, In sanitary landfilling process, Technology and Environmental Impact, Christensen, T.H., Cossu R. and Stegmann R. eds, Academic Press, London, UK, 103- 119. 
Panswad, T., \& Anan, C. (1999). Impact of high chloride wastewater on an anaerobic/anoxic/aerobic process with and without inoculation of chloride acclimated seeds. Water Research, 33(5), 1165-1172.

Pareek, S., Matsui, S., Kim, S. K., \& Shimizu, Y. (1999). Mathematical modeling and simulation of methane gas production in simulated landfill column reactors under sulfidogenic and methanogenic environments. Water Science and Technology, 39(7), 235-242.

Pavlostathis S. \& Giraldo-Gomez E. (1991). Kinetics of anaerobic treatment : a critical review. Critical Review in Environmental Control, 21 (5, 6): 411- 490.

Peer, R. L., Thorneloe, S. A., \& Epperson, D. L. (1993). A comparison of methods for estimating global methane emissions from landfills. Chemosphere, 26(1-4), 387-400.

Pohland, F. G. (1975). Sanitary Landfill Stabilization with Leachate Recycle and Residual Treatment. U.S. EPA, Cincinnati, EPA-600/22-75-043. Cited in Straub et al. (1982b) and Chanthikul et al. (2004).

Pohland, F. G. (1980). Leachate recycle as landfill management option. Journal of the Environmental Engineering Division-ASCE, 106(6), 1057-1069.

Pohland, F. G. (1992). Assessment of Solid Waste and Remaining Stabilization Potential after Exposure to Leachate Recirculation at a Municipal Landfill. Prepared for Post, Buckley, Schuh \& Jernigan, Inc. Project No. 07-584.18 . Cited in Al-Yousfi et al. (1998).

Pohland F. (1996). Landfill bioreactors: Fundamentals and practice. Waster quality Intl. Septemeber/October, 18-22.

Pohland, F. G., \& Kim, J. C. (1999). In situ anaerobic treatment of leachate in landfill bioreactors. Water Science and Technology, 40(8), 203-210.

Powrie, W. \& Beaven, R.P., (1999). Hydraulic properties of household waste and implications for landfills. Institution of Civil Engineers Geotechnical Engineering Journal 137, 235-247. Cited in Bleiker et al. (1995).

Purushottam D., Tamke G. R. \& Stoffel C. M. (1977) .Leachate production at sanitary landfill sites. Journal of Environmental Engineering Division 103, EE6, 981- 989.

Rees, J. F. (1980). The fate of carbon-compounds in the landfill disposal of organicmatter. Journal of Chemical Technology and Biotechnology, 30(4), 161-175.

Rees J.F \& Grainger J.M (1982). Rubblish dump of fermenter prospects for the control of refuse fermentation to methane in landfills. Process Biochemistry, 17 (6), 41-4. cited in Christensen et al., (1992). 
Reinhart, D. R. (1996). Full-scale experiences with leachate recirculating landfills: Case studies. Waste Management \& Research, 14(4), 347-365.

Reinhart, D. R., \& AlYousfi, A. B. (1996). The impact of leachate recirculation on municipal solid waste landfill operating characteristics. Waste Management \& Research, 14(4), 337-346.

Reinhart, D. R., McCreanor, P. T., \& Townsend, T. (2002). The bioreactor landfill: Its status and future. Waste Management \& Research, 20(2), 172-186.

Rendra S., Fernandes L. \& Warith M. (2003). Degradation of municipal solid waste in simulated aerobic and anaerobic bioreactor landfills. Journal of Solid Waste Technology and Management, Vol. 29, n3, 145- 153.

Rohrs, L. H., Fourie, A. B., \& Blight, G. E. (1998). Effects of sewage sludge and refuse composition on the rate of degradation and leachate quality of co-disposed waste in a water-deficient environment. Water $S a, 24(2), 137-146$.

San, I., \& Onay, T. T. (2001). Impact of various leachate recirculation regimes on municipal solid waste degradation. Journal of Hazardous Materials, 87(1-3), 259271.

Sanders, W.T.M. (2001). Anaerobic hydrolysis of complex substrates. Ph-D theses, Wageningen University, The Netherlands. ISBN 90-5808-375-6.

Santos, C. A., Vieira, A. M., Fernandes, H. L., Empis, J. A., \& Novais, J. M. (2001). Optimisation of the biological treatment of hypersaline wastewater from dunaliella salina carotenogenesis. Journal of Chemical Technology and Biotechnology, 76(11), 1147-1153.

Sponza, D. T., \& Agdag, O. N. (2004). Impact of leachate recirculation and recirculation volume on stabilization of municipal solid wastes in simulated anaerobic bioreactors. Process Biochemistry, 39(12), 2157-2165.

Sponza, D. T., \& Agdag, O. N. (2005). Effects of shredding of wastes on the treatment of municipal solid wastes (MSWs) in simulated anaerobic recycled reactors. Enzyme and Microbial Technology, 36(1), 25-33.

Stegman R. (1983) . New aspects on enhancing biological processes in sanitary landfill. Waste Management and Research, 1, 201- 211.

Stegmann R. \& Spendlin H. (1996) " Enhancement of degradation: German experiences" Landfilling of waste: Biogas, edited by Christensen, T.H., Cossu, R. and Stegmann, R., E\&FN Spon, London, UK, 61-81. 
Stessel, R. I., \& Murphy, R. J., (1992). A lysimeter study of the aerobic landfill concept. Waste Management and Research. 10, 485-503.

Straub, W. A., \& Lynch, D. R. (1982a). Models of landfill leaching - moisture flow and inorganic strength. Journal of the Environmental Engineering Division-ASCE, 108(2), 231-250.

Straub, W. A., \& Lynch, D. R. (1982b). Models of landfill leaching - moisture flow and inorganic strength. Journal of the Environmental Engineering Division-ASCE, 108(2), 231-250.

Suk, H., Lee, K. K., \& Lee, C. H. (2000). Biologically reactive multispecies transport in sanitary landfill. Journal of Environmental Engineering-ASCE, 126(5), 419-427.

Tchobanouglous G. et al. (1977) .Solid wastes: engineering principles and management issues. New York : McGraw-Hill.

Tchobanouglous G., Theisen H. \& Vigil S. (1993) .Integrated solid waste management : engineering principles and management issues. Hilary Theisen, Samuel Vigil. New York : McGraw-Hil.

Tchobanouglous G. \& Frank Kreith (2002) .Handbook of solid waste management. New York : McGraw-Hill.

Townsend, T. G., Miller, W. L., Lee, H. J., \& Earle, J. F. K. (1996). Acceleration of landfill stabilization using leachate recycle. Journal of Environmental EngineeringASCE, 122(4), 263-268.

Veeken, A.H.M.\& Hamelers, B.V.M., (1999). Effect of temperature on hydrolysis rates of selected biowaste components. Bioresource Technol. 69 (3), 249-254.

Veeken, A., Kalyuzhnyi, S., Scharff, H. \& Hamelers, B. (2000). Effect of pH and VFA on hydrolysis of organic solid waste, Journal of Environmental Engineering December: 1076-1081.

Vidal, G., Aspe, E., Marti, M. C., \& Roeckel, M. (1997). Treatment of recycled wastewaters from fishmeal factory by an anaerobic filter. Biotechnology Letters, 19(2), 117-121.

Warith M. \& Sharma R. (1998). Technical review of methods to enhance biological degradation in sanitary landfill. Water Quality. Res. J. Canada, Vol. 33, No. 3: 417437.

Warith, M. A., Zekry, W., \& Gawri, N. (1999). Effect of leachate recirculation on municipal solid waste biodegradation. Water Quality Research Journal of Canada, 34(2), 267-280. 
Warith, M. (2002). Bioreactor landfills: Experimental and field results. Waste Management, 22(1), 7-17.

Warith, M. A. (2003). Solid Waste Management: New trends in landfill design. Emirates Journal of Engineering Research, Vol.8, No. 1: 61-70.

White J., Ren Q. \& Robinson J. (2003). A framework to contain a spatially distributed model of the degradation of solid waste in landfills. Waste Management and Research Vol. 21 : 330- 345.

White, J., Robinson, J., \& Ren, Q. C. (2004). Modelling the biochemical degradation of solid waste in landfills. Waste Management, 24(3), 227-240.

Woolard, C. R., \& Irvine, R. L. (1994). Biological treatment of hypersaline waste-water by a biofilm of halophilic bacteria. Water Environment Research, 66(3), 230-235.

Yari, S. (1986). Fate of selected organic priority pollutants during the methane phase of landfill stabilization. MS. Thesis, Georgia Inst. Of Technology.

Yildiz, E. D., Unlu, K., \& Rowe, R. K. (2004). Modelling leachate quality and quantity in municipal solid waste landfills. Waste Management \& Research, 22(2), 78-92.

Youcai, Z., Luochun. W., Renhua, H., Dimin, X. \& Guowei, G. (2002). A comparison of refuse attenuation in laboratory and field scale lysimeters. Waste management 22, 29-35.

Young, A. (1989). Mathematical-modeling of landfill degradation. Journal of Chemical Technology and Biotechnology, 46(3), 189-208.

Zacharof, A. I., \& Butler, A. P. (2004). Stochastic modelling of landfill leachate and biogas production incorporating waste heterogeneity. model formulation and uncertainty analysis. Waste Management, 24(5), 453-462.

www.alain-airport.gov.ae/alinfact.htm

http://www.unu.edu/unupress/unupbooks/uu02fe/uu02fe08.htm 


\section{Appendix A: Results of experimental works}

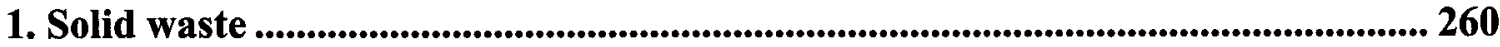

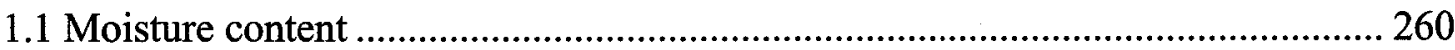

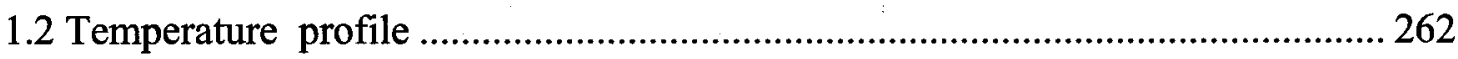

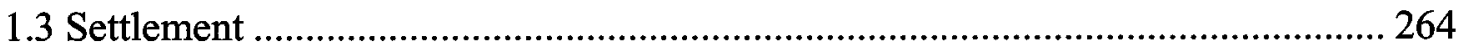

2. Landfill gas ..................................................................................................................... 265

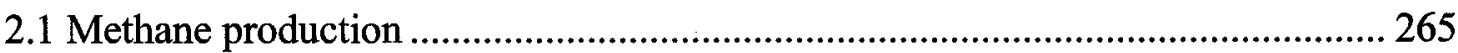

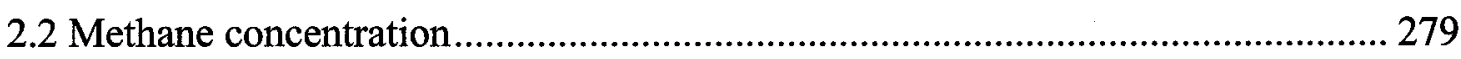

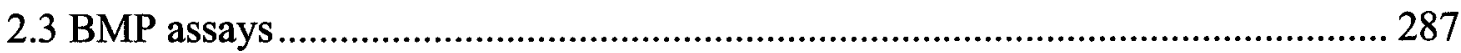

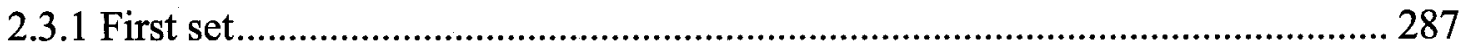

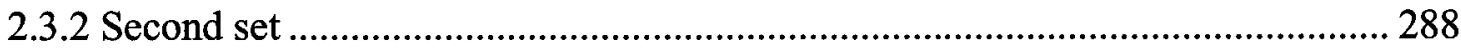

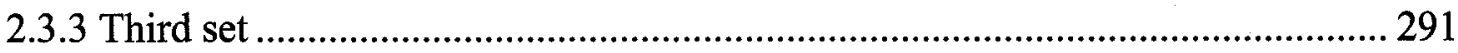

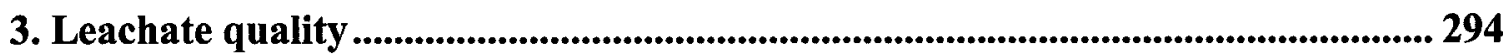

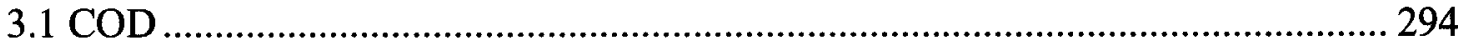

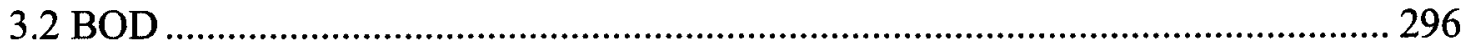

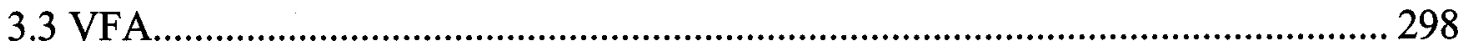

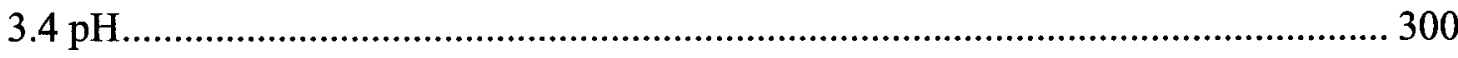

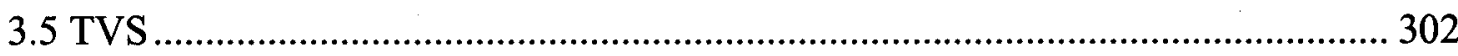

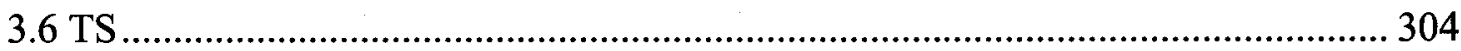

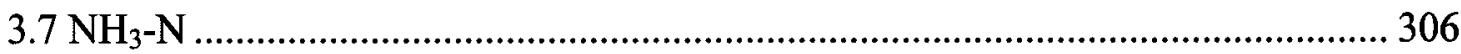

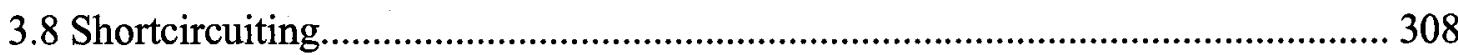

4. Hydrolysis ........................................................................................................................... 309

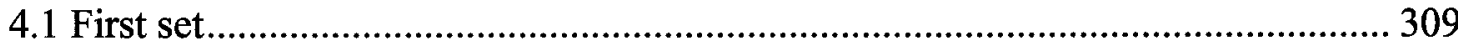

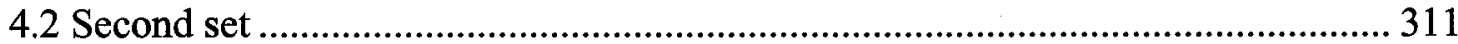




\section{Solid waste}

\subsection{Moisture content}

Initial moisture content

\begin{tabular}{|ccccc|}
\hline Reactors & Plate $(\mathrm{g})$ & Plate +sample & $\mathrm{M}\left(105^{\circ} \mathrm{C}\right)(\mathrm{g})$ & \% Moisture content \\
\hline R1 & 26.905 & 32.587 & 30.37 & $39.02 \%$ \\
R2 & 26.561 & 32.12 & 29.89548 & $40.02 \%$ \\
R3 & 29.731 & 32.852 & 31.72527 & $36.10 \%$ \\
R4 & 26.65 & 32.832 & 30.11192 & $44.00 \%$ \\
R5 & 26.937 & 34.329 & 31.22343 & $42.01 \%$ \\
R6 & 28.929 & 40.563 & 35.69412 & $41.85 \%$ \\
R7 & 26.6131 & 44.249 & 36.66556 & $43.00 \%$ \\
R8 & 29.696 & 50.4968 & 41.93467 & $41.16 \%$ \\
\hline
\end{tabular}

Final moisture content

\begin{tabular}{|lcccc|}
\hline R1 & Plate $(\mathrm{g})$ & Plate + sample $(\mathrm{g})$ & $\mathrm{M}\left(105^{\circ} \mathrm{C}\right)(\mathrm{g})$ & \% Moisture content \\
\hline R1-1-1 & 58.9212 & 102.0802 & 75.275 & $62.11 \%$ \\
R1-1-2 & 58.8459 & 98.7225 & 76.909 & $54.70 \%$ \\
R1-1-3 & 60.2342 & 100.7861 & 76.003 & $61.11 \%$ \\
R1-2-1 & 59.955 & 107.2716 & 78.939 & $59.88 \%$ \\
R1-2-2 & 66.716 & 109.3606 & 85.228 & $56.59 \%$ \\
R1-2-3 & 56.6513 & 100.768 & 71.839 & $65.57 \%$ \\
R1-3-1 & 58.279 & 99.2207 & 70.812 & $69.39 \%$ \\
R1-3-2 & 61.748 & 108.5869 & 77.591 & $66.18 \%$ \\
R1-3-3 & 61.8319 & 101.8786 & 75.133 & $66.79 \%$ \\
\hline
\end{tabular}

\begin{tabular}{|lcccc|}
\hline R2 & Plate $(\mathrm{g})$ & Plate + sample $(\mathrm{g})$ & $\mathrm{M}\left(105^{\circ} \mathrm{C}\right)(\mathrm{g})$ & \% Moisture content \\
\hline $\mathrm{R} 2-1-1$ & 62.354 & 122.8582 & 82.253 & $67.11 \%$ \\
$\mathrm{R} 2-1-2$ & 57.1088 & 115.1513 & 85.191 & $51.62 \%$ \\
$\mathrm{R} 2-1-3$ & 61.2062 & 109.2186 & 83.023 & $54.56 \%$ \\
$\mathrm{R} 2-2-1$ & 55.8064 & 99.7867 & 73.363 & $60.08 \%$ \\
$\mathrm{R} 2-2-2$ & 55.876 & 108.8835 & 75.705 & $62.59 \%$ \\
$\mathrm{R} 2-2-3$ & 62.2299 & 116.827 & 80.605 & $66.34 \%$ \\
$\mathrm{R} 2-3-1$ & 59.47 & 102.137 & 73.427 & $67.29 \%$ \\
$\mathrm{R} 2-3-2$ & 58.6815 & 103.4571 & 76.294 & $60.66 \%$ \\
$\mathrm{R} 2-3-3$ & 65.3155 & 107.1807 & 80.611 & $63.46 \%$ \\
\hline
\end{tabular}




\begin{tabular}{|lcccc|}
\hline R3 & Plate $(\mathrm{g})$ & Plate +sample $(\mathrm{g})$ & $\mathrm{M}\left(105^{\circ} \mathrm{C}\right)(\mathrm{g})$ & $\%$ Moisture content \\
\hline R3-1-1 & 57.116 & 105.9366 & 75.017 & $63.33 \%$ \\
R3-1-2 & 62.92 & 107.4989 & 82.673 & $55.69 \%$ \\
R3-1-3 & 58.9381 & 117.308 & 80.344 & $63.33 \%$ \\
R3-2-1 & 60.3574 & 108.4138 & 77.17 & $65.01 \%$ \\
R3-2-2 & 57.0083 & 106.5306 & 75.34 & $62.98 \%$ \\
R3-2-3 & 59.2551 & 103.297 & 74.58 & $65.20 \%$ \\
R3-3-1 & 66.9 & 132.5614 & 90.4793 & $64.09 \%$ \\
R3-3-2 & 56.2571 & 108.0442 & 73.304 & $67.08 \%$ \\
R3-3-3 & 58.7662 & 104.928 & 74.463 & $66.00 \%$ \\
\hline
\end{tabular}

\begin{tabular}{|lcccc|}
\hline R4 & Plate $(\mathrm{g})$ & Plate +sample $(\mathrm{g})$ & $\mathrm{M}\left(105^{\circ} \mathrm{C}\right)(\mathrm{g})$ & \% Moisture content \\
\hline R4-1-1 & 58.4782 & 104.589 & 75.017 & $64.13 \%$ \\
R4-1-2 & 59.201 & 105.257 & 82.673 & $49.04 \%$ \\
R4-1-3 & 59.912 & 108.327 & 80.344 & $57.80 \%$ \\
R4-2-1 & 61.3245 & 104.31 & 80.5793 & $55.21 \%$ \\
R4-2-2 & 57.536 & 104.982 & 73.804 & $65.71 \%$ \\
R4-2-3 & 59.216 & 104.4846 & 75.063 & $64.99 \%$ \\
R4-3-1 & 56.475 & 101.149 & 77.07 & $53.90 \%$ \\
R4-3-2 & 57.6471 & 108.559 & 75.14 & $65.64 \%$ \\
R4-3-3 & 57.093 & 112.209 & 74.28 & $68.82 \%$ \\
\hline
\end{tabular}

\begin{tabular}{|lcccc|}
\hline R5 & Plate $(\mathrm{g})$ & Plate + sample $(\mathrm{g})$ & $\mathrm{M}\left(105^{\circ} \mathrm{C}\right)(\mathrm{g})$ & \% Moisture content \\
\hline R5-1-1 & 59.953 & 107.186 & 79.564 & $58.48 \%$ \\
R5-1-2 & 66.713 & 106.829 & 81.9029 & $62.14 \%$ \\
R5-1-3 & 56.645 & 101.673 & 74.203 & $61.01 \%$ \\
R5-2-1 & 58.845 & 107.724 & 76.671 & $63.53 \%$ \\
R5-2-2 & 58.915 & 108.309 & 76.376 & $64.65 \%$ \\
R5-2-3 & 60.232 & 113.926 & 81.186 & $60.98 \%$ \\
R5-3-1 & 58.274 & 103.305 & 75.1722 & $62.47 \%$ \\
R5-3-2 & 61.7478 & 114.951 & 80.0556 & $65.59 \%$ \\
R5-3-3 & 61.828 & 107.286 & 78.3335 & $63.69 \%$ \\
\hline
\end{tabular}

\begin{tabular}{|lcccc|}
\hline R6 & Plate $(\mathrm{g})$ & Plate +sample $(\mathrm{g})$ & $\mathrm{M}\left(105^{\circ} \mathrm{C}\right)(\mathrm{g})$ & \% Moisture content \\
\hline R6-1-1 & 62.354 & 108.321 & 80.2733 & $61.02 \%$ \\
R6-1-2 & 57.095 & 106.451 & 75.099 & $63.52 \%$ \\
R6-1-3 & 61.206 & 113.041 & 81.213 & $61.40 \%$ \\
R6-2-1 & 55.808 & 105.095 & 74.888 & $61.29 \%$ \\
R6-2-2 & 55.801 & 103.21 & 72.883 & $63.97 \%$ \\
R6-2-3 & 62.225 & 112.548 & 80.6839 & $63.32 \%$ \\
R6-3-1 & 59.471 & 104.106 & 75.826 & $63.36 \%$ \\
R6-3-2 & 58.681 & 107.233 & 76.2055 & $63.91 \%$ \\
R6-3-3 & 65.313 & 115.4 & 83.4774 & $63.73 \%$ \\
\hline
\end{tabular}




\begin{tabular}{|lcccc|}
\hline R7 & Plate $(\mathrm{g})$ & Plate +sample $(\mathrm{g})$ & $\mathrm{M}\left(105^{\circ} \mathrm{C}\right)(\mathrm{g})$ & \% Moisture content \\
\hline R7-1-1 & 57.107 & 101.269 & 74.5835 & $60.43 \%$ \\
R7-1-2 & 62.918 & 110.093 & 80.719 & $62.27 \%$ \\
R7-1-3 & 58.935 & 104.667 & 76.278 & $62.08 \%$ \\
R7-2-1 & 66.897 & 119.766 & 87.448 & $61.13 \%$ \\
R7-2-2 & 56.255 & 101.877 & 72.4306 & $64.54 \%$ \\
R7-2-3 & 58.756 & 115.224 & 79.527 & $63.22 \%$ \\
R7-3-1 & 61.498 & 120.77 & 83.851 & $62.29 \%$ \\
R7-3-2 & 56.999 & 104.4334 & 74.782 & $62.51 \%$ \\
R7-3-3 & 59.243 & 107.5171 & 74.6901 & $68.00 \%$ \\
\hline
\end{tabular}

\begin{tabular}{|lcccc|}
\hline R8 & Plate $(\mathrm{g})$ & Plate +sample $(\mathrm{g})$ & $\mathrm{M}\left(105^{\circ} \mathrm{C}\right)(\mathrm{g})$ & \% Moisture content \\
\hline R8-1-1 & 58.471 & 108.892 & 75.191 & $66.84 \%$ \\
R8-1-2 & 59.196 & 108.862 & 80.052 & $58.01 \%$ \\
R8-1-3 & 59.891 & 108.909 & 77.392 & $64.30 \%$ \\
R8-2-1 & 61.3211 & 132.37 & 87.559 & $63.07 \%$ \\
R8-2-2 & 57.467 & 114.009 & 76.519 & $66.30 \%$ \\
R8-2-3 & 59.21 & 123.239 & 82.829 & $63.11 \%$ \\
R8-3-1 & 56.464 & 110.791 & 76.129 & $63.80 \%$ \\
R8-3-2 & 57.635 & 110.887 & 74.332 & $68.65 \%$ \\
R8-3-3 & 57.076 & 115.806 & 75.823 & $68.08 \%$ \\
\hline
\end{tabular}

\subsection{Temperature profile}

\begin{tabular}{|c|ccc|ccc|}
\hline Time $(\mathrm{d})$ & \multicolumn{3}{|c|}{$\mathrm{R} 1\left({ }^{\circ} \mathrm{C}\right)$} & \multicolumn{3}{c|}{$\mathrm{R} 2\left({ }^{\circ} \mathrm{C}\right)$} \\
\hline Time & T(bottom) & $\mathrm{T}$ (mid) & T(top) & T(bottom) & T(mid) & T(top) \\
\hline 3 & 26 & 26.2 & 28.3 & 25.3 & 25.5 & 26.3 \\
4 & 24.2 & 25 & 25.6 & 24.2 & 24.9 & 24.8 \\
5 & 24.9 & 25.2 & 26.6 & 24.5 & 24.9 & 25.7 \\
6 & 24.3 & 24.7 & 25.6 & 24.1 & 24.5 & 25.6 \\
10 & 25.0 & 28.0 & 33.7 & 24.6 & 27.4 & 29.0 \\
11 & 27.7 & 38.2 & 34.5 & 26.4 & 30.1 & 29.4 \\
14 & 24.6 & 26.4 & 22.0 & 24.0 & 25.6 & 22.0 \\
15 & 25.5 & 26.9 & 23.5 & 24.8 & 26.4 & 25.6 \\
17 & 24.1 & 26.4 & 22.5 & 24.3 & 25.8 & 25.5 \\
22 & 24.3 & 24.6 & 24.3 & 24.3 & 24.5 & 24.5 \\
28 & 24.2 & 24.2 & 24.2 & 24.1 & 24.5 & 24.5 \\
31 & 23.8 & 24.1 & 24.0 & 23.8 & 24.2 & 24.1 \\
32 & 24.3 & 24.5 & 24.4 & 24.1 & 24.4 & 24.4 \\
\hline
\end{tabular}




\begin{tabular}{|c|ccc|ccc|}
\hline & \multicolumn{3}{|c|}{$\mathrm{R} 3\left({ }^{\circ} \mathrm{C}\right)$} & \multicolumn{3}{c|}{$\mathrm{R} 4\left({ }^{\circ} \mathrm{C}\right)$} \\
\hline Time & T(bottom) & $\mathrm{T}$ (mid) & $\mathrm{T}$ (top) & $\mathrm{T}$ (bottom) & $\mathrm{T}$ (mid) & $\mathrm{T}$ (top) \\
\hline 3 & 26.4 & 27.1 & 26.4 & 24.1 & 24.4 & 24.2 \\
4 & 24.2 & 25.2 & 25.3 & 24.0 & 24.0 & 24.2 \\
5 & 25.2 & 26.3 & 25.3 & 23.4 & 23.5 & 23.3 \\
6 & 23.9 & 24.6 & 24.8 & 24 & 24.2 & 23.9 \\
10 & 25.5 & 28.5 & 27.9 & 24 & 32.3 & 24.4 \\
11 & 26.1 & 30.8 & 27.5 & 27.4 & 30.9 & 29.9 \\
14 & 24.2 & 26.8 & 26.5 & 24.9 & 25.2 & 26.1 \\
15 & 25.7 & 26.7 & 23.8 & 25.2 & 25.1 & 22 \\
17 & 24.1 & 27.1 & 22.5 & 24.5 & 26.6 & 23.8 \\
22 & 24.4 & 24.7 & 24.8 & 24.3 & 24.5 & 24.9 \\
28 & 24.2 & 24.4 & 24.5 & 24.1 & 24.4 & 24.6 \\
31 & 23.8 & 23.9 & 24.1 & 23.9 & 24.1 & 24.1 \\
32 & 24.1 & 24.4 & 24.4 & 24.0 & 23.8 & 24.3 \\
\hline
\end{tabular}

\begin{tabular}{|c|ccc|ccc|}
\hline & \multicolumn{3}{|c|}{$\mathrm{R} 5\left({ }^{\circ} \mathrm{C}\right)$} & \multicolumn{3}{c|}{$\mathrm{R} 6\left({ }^{\circ} \mathrm{C}\right)$} \\
\hline Time & T(bottom) & $\mathrm{T}$ (mid) & $\mathrm{T}$ (top) & T(bottom) & $\mathrm{T}$ (mid) & $\mathrm{T}$ (top) \\
\hline 3 & 26.4 & 25.2 & 26.2 & 25.7 & 25.2 & 25.3 \\
4 & 24.4 & 27.6 & 24.2 & 24.4 & 24.2 & 24.6 \\
7 & 27.8 & 32.6 & 28.0 & 27.9 & 32.2 & 27.9 \\
10 & 24.5 & 24.2 & 24.0 & 24.2 & 24.9 & 24.5 \\
11 & 25.5 & 24.4 & 25.1 & 25.1 & 24.7 & 25 \\
14 & 20.3 & 25.5 & 23.4 & 21.3 & 24.4 & 21 \\
15 & 20.0 & 24.0 & 22.7 & 21 & 23.5 & 20.6 \\
17 & 20.8 & 22.8 & 25.5 & 24.4 & 24.5 & 25.9 \\
19 & 24.1 & 23.9 & 23.8 & 23.1 & 23.6 & 23.6 \\
22 & 23.8 & 23.8 & 23.6 & 23 & 23.4 & 23.3 \\
23 & 23.4 & 23.3 & 23.8 & 23.2 & 23.3 & 23.3 \\
25 & 23.3 & 23.2 & 23.1 & 23.1 & 23.6 & 23.6 \\
26 & 23.8 & 23.6 & 23.8 & 23.1 & 23.6 & 23.6 \\
\hline
\end{tabular}




\begin{tabular}{|c|ccc|ccc|}
\hline & \multicolumn{3}{|c|}{$\mathrm{R} 7\left({ }^{\circ} \mathrm{C}\right)$} & \multicolumn{3}{c|}{$\mathrm{R} 8\left({ }^{\circ} \mathrm{C}\right)$} \\
\hline Time & T(bottom) & $\mathrm{T}$ (mid) & $\mathrm{T}$ (top) & T(bottom) & $\mathrm{T}$ (mid) & T(top) \\
\hline 3 & 22.6 & 23.9 & 24.5 & 23.4 & 23.7 & 25.0 \\
4 & 24.1 & 25.5 & 27.5 & 24.2 & 25.9 & 24.7 \\
7 & 23.8 & 25.1 & 25.8 & 24.1 & 25.6 & 24.7 \\
10 & 23.9 & 24.5 & 24.6 & 24.4 & 25.2 & 24.1 \\
11 & 23.0 & 27.3 & 22.6 & 24.5 & 26.4 & 24.6 \\
14 & 27.3 & 33.4 & 23.6 & 25.7 & 32.5 & 27.8 \\
15 & 24.5 & 29.0 & 25.1 & 26.4 & 29.4 & 26.5 \\
17 & 20.7 & 23.1 & 21.6 & 24.6 & 26.2 & 24.3 \\
19 & 22.6 & 23.5 & 24.2 & 24.0 & 26.4 & 25.1 \\
22 & 24.1 & 24.0 & 26.1 & 24.2 & 24.8 & 24.7 \\
23 & 23.9 & 24.1 & 24.1 & 23.9 & 23.8 & 25.4 \\
25 & 23.0 & 23.6 & 23.8 & 23.1 & 23.6 & 23.4 \\
26 & 22.6 & 22.9 & 23.1 & 22.6 & 23.0 & 23.0 \\
\hline
\end{tabular}

\subsection{Settlement}

\begin{tabular}{|c|cccc|ccccccc|}
\hline Reactors & \multicolumn{3}{|c|}{ Aerobic stage (cm) } & \multicolumn{5}{c|}{ Anaerobic stage (cm) } \\
\hline R1 & 20.50 & 22.00 & 21.20 & 21.80 & 13.73 & 16.83 & 14.63 & 13.03 & 10.93 & 13.63 \\
R2 & 23.00 & 18.50 & 19.80 & 22.60 & 11.72 & 13.42 & 13.72 & 12.72 & 11.72 & 14.46 \\
R3 & 18.30 & 18.30 & 18.70 & 16.30 & 13.43 & 17.33 & 9.43 & 13.63 & 10.63 & 9.03 \\
R4 & 16.00 & 17.00 & 15.00 & 15.30 & 10.38 & 9.47 & 7.58 & 10.48 & 8.38 & 9.26 \\
R5 & 22.30 & 22.00 & 22.00 & 21.60 & 17.53 & 19.13 & 21.23 & 18.83 & 19.23 & 19.19 \\
R6 & 21.00 & 20.30 & 20.10 & 21.50 & 19.18 & 17.38 & 17.68 & 16.98 & 19.48 & 18.14 \\
R7 & 17.25 & 18.65 & 18.25 & 18.45 & 16.60 & 15.60 & 17.90 & 15.40 & 16.38 & 16.38 \\
R8 & 16.70 & 15.80 & 15.40 & 16.40 & 15.06 & 13.26 & 14.46 & 15.46 & 16.56 & 14.96 \\
\hline
\end{tabular}




\section{Landfill gas}

\subsection{Methane production}

$>$ Group one

\begin{tabular}{|c|c|c|c|c|c|c|}
\hline \multirow[b]{2}{*}{ Time } & \multicolumn{3}{|c|}{$\begin{array}{c}\text { Daily methane production } \\
(\mathrm{ml})\end{array}$} & \multicolumn{3}{|c|}{ Accumulative methane (ml) } \\
\hline & $\mathbf{R 1}$ & $\mathbf{R 2}$ & $\mathbf{R 4}$ & $\mathbf{R 1}$ & $\mathbf{R 2}$ & $\mathbf{R 4}$ \\
\hline 18 & 0.00 & 0.00 & 0.00 & 0.00 & 0.00 & 0.00 \\
\hline 19 & 0.00 & 0.00 & 0.00 & 0.00 & 0.00 & 0.00 \\
\hline 20 & 792.79 & 936.12 & 0.00 & 792.79 & 936.12 & 0.00 \\
\hline 21 & 701.93 & 817.61 & 0.00 & 1494.72 & 1753.73 & 0.00 \\
\hline 22 & 1158.70 & 1348.58 & 0.00 & 2653.42 & 3102.31 & 0.00 \\
\hline 23 & 1227.07 & 1315.06 & 0.00 & 3880.49 & 4417.37 & 0.00 \\
\hline 24 & 1509.20 & 1745.73 & 0.00 & 5389.69 & 6163.10 & 0.00 \\
\hline 25 & 1575.42 & 2063.94 & 0.00 & 6965.11 & 8227.04 & 0.00 \\
\hline 26 & 1736.03 & 2479.68 & 0.00 & 8701.14 & 10706.72 & 0.00 \\
\hline 27 & 1752.60 & 2531.34 & 0.00 & 10453.74 & 13238.06 & 0.00 \\
\hline 28 & 1915.91 & 2736.85 & 0.00 & 12369.65 & 15974.91 & 0.00 \\
\hline 29 & 1718.64 & 2477.41 & 0.00 & 14088.29 & 18452.32 & 0.00 \\
\hline 30 & 2571.03 & 1970.64 & 0.00 & 16659.32 & 20422.96 & 0.00 \\
\hline 31 & 2772.00 & 2532.60 & 0.00 & 19431.32 & 22955.56 & 0.00 \\
\hline 32 & 2721.18 & 2737.10 & 0.00 & 22152.50 & 25692.66 & 0.00 \\
\hline 33 & 3431.71 & 2157.06 & 0.00 & 25584.20 & 27849.72 & 0.00 \\
\hline 34 & 4889.90 & 3992.36 & 524.05 & 30474.11 & 31842.08 & 524.05 \\
\hline 35 & 3662.85 & 4842.12 & 326.34 & 34136.96 & 36684.20 & 850.39 \\
\hline 36 & 5448.52 & 5422.21 & 364.38 & 39585.48 & 42106.42 & 1214.77 \\
\hline 37 & 6115.34 & 6143.76 & 420.20 & 45700.82 & 48250.18 & 1634.97 \\
\hline 38 & 4422.61 & 5114.59 & 436.23 & 50123.43 & 53364.76 & 2071.20 \\
\hline 39 & 6905.93 & 5556.84 & 615.38 & 57029.36 & 58921.60 & 2686.58 \\
\hline 40 & 6819.17 & 5740.09 & 647.91 & 63848.52 & 64661.69 & 3334.50 \\
\hline 41 & 5285.03 & 5400.79 & 423.24 & 69133.56 & 70062.48 & 3757.74 \\
\hline 42 & 6655.57 & 7098.76 & 651.20 & 75789.13 & 77161.25 & 4408.94 \\
\hline 43 & 8057.28 & 7860.43 & 828.80 & 83846.41 & 85021.68 & 5237.74 \\
\hline 44 & 7145.60 & 7505.91 & 626.93 & 90992.01 & 92527.60 & 5864.67 \\
\hline 45 & 7946.15 & 7750.66 & 874.27 & 98938.16 & 100278.26 & 6738.94 \\
\hline 46 & 9038.75 & 7351.85 & 978.27 & 107976.92 & 107630.11 & 7717.20 \\
\hline 47 & 8290.59 & 8320.16 & 841.66 & 116267.51 & 115950.27 & 8558.86 \\
\hline 48 & 8631.86 & 8380.89 & 847.64 & 124899.37 & 124331.16 & 9406.50 \\
\hline 49 & 8244.78 & 7210.73 & 997.22 & 133144.15 & 131541.88 & 10403.73 \\
\hline 50 & 9444.73 & 8444.14 & 880.88 & 142588.88 & 139986.03 & 11284.61 \\
\hline 51 & 10560.77 & 8293.53 & 951.94 & 153149.64 & 148279.56 & 12236.54 \\
\hline 52 & 11282.35 & 7462.73 & 1217.12 & 164431.99 & 155742.29 & 13453.66 \\
\hline 53 & 10482.04 & 7430.94 & 632.90 & 174914.03 & 163173.23 & 14086.56 \\
\hline 54 & 10132.69 & 7361.52 & 797.69 & 185046.72 & 170534.75 & 14884.25 \\
\hline 55 & 9903.43 & 7087.06 & 767.01 & 194950.16 & 177621.81 & 15651.26 \\
\hline 56 & 8838.52 & 7219.95 & 612.56 & 203788.68 & 184841.76 & 16263.82 \\
\hline 57 & 11599.60 & 8400.67 & 852.75 & 215388.27 & 193242.43 & 17116.57 \\
\hline 58 & 11973.19 & 7002.00 & 672.64 & 227361.47 & 200244.43 & 17789.21 \\
\hline
\end{tabular}




\begin{tabular}{|c|c|c|c|c|c|c|}
\hline 59 & 11679.11 & 7172.78 & 623.42 & 239040.58 & 207417.21 & 18412.63 \\
\hline 60 & 10739.28 & 7272.97 & 882.23 & 249779.86 & 214690.18 & 19294.86 \\
\hline 61 & 10165.76 & 6519.05 & 721.50 & 259945.62 & 221209.23 & 20016.36 \\
\hline 62 & 9362.15 & 6407.10 & 298.37 & 269307.77 & 227616.33 & 20314.72 \\
\hline 63 & 10514.70 & 6770.23 & 417.36 & 279822.47 & 234386.56 & 20732.08 \\
\hline 64 & 10505.65 & 7584.57 & 886.48 & 290328.12 & 241971.13 & 21618.57 \\
\hline 65 & 8711.53 & 6015.67 & 523.03 & 299039.65 & 247986.80 & 22141.60 \\
\hline 66 & 10172.50 & 6542.05 & 500.83 & 309212.15 & 254528.85 & 22642.43 \\
\hline 67 & 9398.60 & 5950.58 & 772.75 & 318610.75 & 260479.43 & 23415.18 \\
\hline 68 & 8332.75 & 5843.12 & 520.08 & 326943.50 & 266322.55 & 23935.26 \\
\hline 69 & 8484.12 & 6125.56 & 746.54 & 335427.62 & 272448.11 & 24681.80 \\
\hline 70 & 7709.16 & 5088.28 & 632.65 & 343136.79 & 277536.39 & 25314.45 \\
\hline 71 & 4618.41 & 4925.39 & 712.91 & 347755.20 & 282461.78 & 26027.36 \\
\hline 72 & 9389.74 & 5516.85 & 753.78 & 357144.94 & 287978.63 & 26781.14 \\
\hline 73 & 8841.49 & 4505.57 & 625.15 & 365986.42 & 292484.20 & 27406.29 \\
\hline 74 & 10836.61 & 4082.06 & 493.09 & 376823.04 & 296566.26 & 27899.38 \\
\hline 75 & 6534.91 & 4094.43 & 784.27 & 383357.94 & 300660.69 & 28683.65 \\
\hline 76 & 8663.19 & 4082.65 & 890.45 & 392021.13 & 304743.35 & 29574.10 \\
\hline 77 & 7598.36 & 3400.37 & 569.32 & 399619.49 & 308143.72 & 30143.42 \\
\hline 78 & 7621.04 & 3486.04 & 658.64 & 407240.53 & 311629.76 & 30802.06 \\
\hline 79 & 5668.62 & 3047.39 & 671.02 & 412909.15 & 314677.15 & 31473.07 \\
\hline 80 & 5822.92 & 2700.32 & 604.04 & 418732.07 & 317377.46 & 32077.11 \\
\hline 81 & 5278.93 & 2894.29 & 883.74 & 424011.00 & 320271.75 & 32960.85 \\
\hline 82 & 6297.11 & 2602.76 & 766.04 & 430308.10 & 322874.51 & 33726.90 \\
\hline 83 & 8354.98 & 2947.97 & 1111.81 & 438663.09 & 325822.48 & 34838.71 \\
\hline 84 & 7096.01 & 2717.21 & 1151.86 & 445759.10 & 328539.69 & 35990.56 \\
\hline 85 & 5804.98 & 3123.40 & 993.84 & 451564.08 & 331663.10 & 36984.40 \\
\hline 86 & 3655.59 & 3111.04 & 1252.46 & 455219.67 & 334774.14 & 38236.86 \\
\hline 87 & 5496.13 & 2060.12 & 970.51 & 460715.79 & 336834.26 & 39207.37 \\
\hline 88 & 3075.94 & 2214.93 & 1183.30 & 463791.73 & 339049.19 & 40390.68 \\
\hline 89 & 4419.69 & 2790.49 & 1754.26 & 468211.42 & 341839.68 & 42144.94 \\
\hline 90 & 5075.07 & 2718.58 & 1857.96 & 473286.49 & 344558.26 & 44002.89 \\
\hline 91 & 4039.63 & 2398.14 & 1660.88 & 477326.12 & 346956.40 & 45663.77 \\
\hline 92 & 5151.81 & 2590.54 & 1791.08 & 482477.93 & 349546.94 & 47454.85 \\
\hline 93 & 3578.29 & 2159.81 & 1642.49 & 486056.23 & 351706.75 & 49097.34 \\
\hline 94 & 4289.75 & 2236.72 & 1641.04 & 490345.98 & 353943.47 & 50738.38 \\
\hline 95 & 3987.54 & 2176.37 & 1736.10 & 494333.51 & 356119.84 & 52474.48 \\
\hline 96 & 4446.33 & 2450.16 & 1910.09 & 498779.85 & 358570.00 & 54384.57 \\
\hline 97 & 4164.76 & 2779.94 & 1908.31 & 502944.61 & 361349.94 & 56292.88 \\
\hline 98 & 5248.47 & 2664.33 & 2227.58 & 508193.08 & 364014.28 & 58520.46 \\
\hline 99 & 4263.15 & 2371.37 & 2056.61 & 512456.23 & 366385.65 & 60577.06 \\
\hline 100 & 4504.96 & 2528.66 & 2355.65 & 516961.20 & 368914.31 & 62932.71 \\
\hline 101 & 3862.94 & 2539.00 & 2477.78 & 520824.14 & 371453.31 & 65410.49 \\
\hline 102 & 3889.53 & 2525.03 & 2630.93 & 524713.67 & 373978.34 & 68041.42 \\
\hline 103 & 4509.94 & 2726.29 & 3306.14 & 529223.61 & 376704.63 & 71347.56 \\
\hline 104 & 3376.01 & 2423.09 & 2889.00 & 532599.62 & 379127.72 & 74236.55 \\
\hline 105 & 2943.86 & 2427.10 & 2622.41 & 535543.49 & 381554.82 & 76858.96 \\
\hline 106 & 3163.91 & 2451.71 & 3160.40 & 538707.40 & 384006.53 & 80019.36 \\
\hline 107 & 4175.71 & 2589.95 & 3766.97 & 542883.11 & 386596.48 & 83786.34 \\
\hline 108 & 4260.26 & 2864.82 & 4184.34 & 547143.37 & 389461.30 & 87970.68 \\
\hline
\end{tabular}




\begin{tabular}{|c|c|c|c|c|c|c|}
\hline 109 & 4782.13 & 2730.55 & 3763.88 & 551925.49 & 392191.85 & 91734.56 \\
\hline 110 & 4101.53 & 2345.56 & 4395.09 & 556027.03 & 394537.40 & 96129.65 \\
\hline 111 & 4131.46 & 2438.56 & 4740.91 & 560158.49 & 396975.96 & 100870.56 \\
\hline 112 & 4572.09 & 2349.23 & 4520.54 & 564730.58 & 399325.20 & 105391.10 \\
\hline 113 & 4355.79 & 2602.16 & 5147.19 & 569086.36 & 401927.35 & 110538.29 \\
\hline 114 & 3234.62 & 3495.10 & 4093.29 & 572320.98 & 405422.45 & 114631.58 \\
\hline 115 & 3156.81 & 2440.75 & 4227.38 & 575477.79 & 407863.20 & 118858.96 \\
\hline 116 & 4673.13 & 2368.88 & 4928.36 & 580150.92 & 410232.08 & 123787.32 \\
\hline 117 & 3303.30 & 2638.37 & 4279.22 & 583454.22 & 412870.45 & 128066.53 \\
\hline 118 & 3638.71 & 2566.40 & 4800.75 & 587092.93 & 415436.85 & 132867.28 \\
\hline 119 & 3621.23 & 2355.61 & 3916.67 & 590714.16 & 417792.46 & 136783.96 \\
\hline 120 & 4102.56 & 2371.81 & 4232.99 & 594816.72 & 420164.26 & 141016.94 \\
\hline 121 & 4236.85 & 2293.52 & 4365.74 & 599053.57 & 422457.78 & 145382.68 \\
\hline 122 & 4288.28 & 2126.32 & 4381.11 & 603341.85 & 424584.10 & 149763.80 \\
\hline 123 & 3579.11 & 2161.08 & 4155.01 & 606920.97 & 426745.18 & 153918.80 \\
\hline 124 & 3938.70 & 2084.54 & 4622.93 & 610859.67 & 428829.73 & 158541.73 \\
\hline 125 & 4090.59 & 1907.72 & 4557.88 & 614950.26 & 430737.45 & 163099.61 \\
\hline 126 & 4879.88 & 2611.82 & 5371.66 & 619830.13 & 433349.27 & 168471.27 \\
\hline 127 & 4602.14 & 2407.64 & 5044.54 & 624432.27 & 435756.91 & 173515.81 \\
\hline 128 & 4881.18 & 2406.11 & 5193.51 & 629313.45 & 438163.02 & 178709.32 \\
\hline 129 & 5356.34 & 2546.99 & 5809.37 & 634669.79 & 440710.01 & 184518.69 \\
\hline 130 & 4915.68 & 2489.68 & 5506.13 & 639585.47 & 443199.69 & 190024.82 \\
\hline 131 & 4729.22 & 2504.27 & 5027.80 & 644314.69 & 445703.96 & 195052.62 \\
\hline 132 & 5313.92 & 2946.39 & 5609.50 & 649628.61 & 448650.35 & 200662.12 \\
\hline 133 & 4916.60 & 2201.52 & 5961.20 & 654545.21 & 450851.87 & 206623.32 \\
\hline 134 & 4926.43 & 2283.76 & 5917.29 & 659471.65 & 453135.64 & 212540.61 \\
\hline 135 & 5395.21 & 2534.05 & 6490.20 & 664866.85 & 455669.69 & 219030.81 \\
\hline 136 & 5145.53 & 2306.22 & 6396.08 & 670012.38 & 457975.90 & 225426.88 \\
\hline 137 & 4413.56 & 2317.44 & 5961.38 & 674425.94 & 460293.34 & 231388.26 \\
\hline 138 & 5502.41 & 2886.58 & 7204.50 & 679928.35 & 463179.92 & 238592.76 \\
\hline 139 & 5254.74 & 2510.51 & 7171.52 & 685183.09 & 465690.44 & 245764.28 \\
\hline 140 & 4727.46 & 2498.07 & 6025.20 & 689910.56 & 468188.50 & 251789.48 \\
\hline 141 & 5045.04 & 2854.50 & 6951.15 & 694955.60 & 471043.01 & 258740.63 \\
\hline 142 & 5539.97 & 3064.94 & 7435.81 & 700495.56 & 474107.95 & 266176.44 \\
\hline 143 & 4392.64 & 2749.92 & 5925.10 & 704888.20 & 476857.87 & 272101.54 \\
\hline 144 & 5308.04 & 2911.45 & 6581.15 & 710196.25 & 479769.32 & 278682.70 \\
\hline 145 & 4981.79 & 2533.25 & 6238.93 & 715178.04 & 482302.57 & 284921.63 \\
\hline 146 & 5273.91 & 2825.27 & 5781.24 & 720451.95 & 485127.84 & 290702.87 \\
\hline 147 & 6168.01 & 3097.03 & 6413.10 & 726619.96 & 488224.87 & 297115.96 \\
\hline 148 & 6497.85 & 3335.26 & 6581.23 & 733117.80 & 491560.12 & 303697.19 \\
\hline 149 & 7025.59 & 3202.91 & 6893.48 & 740143.40 & 494763.03 & 310590.67 \\
\hline 150 & 8085.34 & 3589.60 & 7169.92 & 748228.73 & 498352.64 & 317760.60 \\
\hline 151 & 6631.39 & 3205.98 & 5661.69 & 754860.13 & 501558.62 & 323422.28 \\
\hline 152 & 6160.92 & 2858.28 & 5053.18 & 761021.05 & 504416.90 & 328475.46 \\
\hline 153 & 5945.19 & 3272.17 & 5124.45 & 766966.24 & 507689.08 & 333599.91 \\
\hline 154 & 5180.24 & 2874.95 & 4396.90 & 772146.47 & 510564.03 & 337996.82 \\
\hline 155 & 5957.96 & 3119.99 & 4864.19 & 778104.43 & 513684.01 & 342861.00 \\
\hline 156 & 5600.14 & 3975.67 & 4521.30 & 783704.57 & 517659.69 & 347382.30 \\
\hline 157 & 7380.14 & 3551.59 & 4610.71 & 791084.71 & 521211.27 & 351993.01 \\
\hline 158 & 7233.95 & 2713.78 & 4004.32 & 798318.66 & 523925.05 & 355997.33 \\
\hline
\end{tabular}




\begin{tabular}{|c|c|c|c|c|c|c|}
\hline 159 & 6117.93 & 3250.29 & 3802.92 & 804436.59 & 527175.34 & 359800.25 \\
\hline 160 & 5355.67 & 2774.31 & 2965.97 & 809792.26 & 529949.65 & 362766.22 \\
\hline 161 & 5829.34 & 2788.45 & 4266.32 & 815621.60 & 532738.10 & 367032.54 \\
\hline 162 & 5129.60 & 2670.20 & 3236.64 & 820751.20 & 535408.30 & 370269.18 \\
\hline 163 & 6050.24 & 3405.61 & 3427.70 & 826801.44 & 538813.91 & 373696.87 \\
\hline 164 & 7164.25 & 4220.01 & 3793.45 & 833965.69 & 543033.92 & 377490.32 \\
\hline 165 & 6006.77 & 3956.86 & 3600.89 & 839972.46 & 546990.78 & 381091.21 \\
\hline 166 & 5049.14 & 3033.81 & 2690.03 & 845021.60 & 550024.60 & 383781.25 \\
\hline 167 & 4278.93 & 2914.42 & 3646.50 & 849300.53 & 552939.01 & 387427.75 \\
\hline 168 & 4791.56 & 2964.65 & 3825.00 & 854092.09 & 555903.67 & 391252.75 \\
\hline 169 & 4713.59 & 3369.69 & 3092.80 & 858805.68 & 559273.36 & 394345.55 \\
\hline 170 & 3968.59 & 3607.86 & 2926.28 & 862774.27 & 562881.22 & 397271.82 \\
\hline 171 & 4411.83 & 3349.45 & 2725.16 & 867186.10 & 566230.67 & 399996.99 \\
\hline 172 & 4642.06 & 3117.52 & 2958.92 & 871828.16 & 569348.19 & 402955.90 \\
\hline 173 & 3847.89 & 3701.44 & 2896.23 & 875676.04 & 573049.63 & 405852.13 \\
\hline 174 & 3904.36 & 3424.74 & 3050.79 & 879580.40 & 576474.36 & 408902.92 \\
\hline 175 & 5021.05 & 3041.13 & 2854.47 & 884601.46 & 579515.50 & 411757.39 \\
\hline 176 & 4639.35 & 3103.72 & 2178.77 & 889240.81 & 582619.22 & 413936.16 \\
\hline 177 & 5505.40 & 3055.69 & 2809.52 & 894746.21 & 585674.91 & 5.68 \\
\hline 178 & 5180.62 & 2467.02 & 2512.73 & 6.83 & 1.92 & 8.40 \\
\hline 179 & 5234.74 & 3021.83 & 2783.89 & 1.57 & 591163.75 & 2.29 \\
\hline 180 & 5605.87 & 2361.62 & 3418.87 & 57.44 & 25.37 & 425461.16 \\
\hline 181 & 5493.61 & 3142.98 & 3502.16 & 61.05 & 596668.35 & 428963.33 \\
\hline 182 & 5003.05 & 3347.56 & 3352.28 & 921264.10 & 600015.91 & 432315.61 \\
\hline 183 & 5152.17 & 3483.59 & 3035.90 & 926416.27 & 603499.50 & 435351.51 \\
\hline 184 & 5447.14 & 3857.55 & 3110.03 & 931863.41 & 607357.05 & 438461.54 \\
\hline 185 & 4314.18 & 4021.21 & 2486.25 & 936177.60 & 611378.26 & 440947.79 \\
\hline 186 & 4579.80 & 3636.20 & 2905.10 & 940757.39 & 615014.46 & 443852.89 \\
\hline 187 & 5020.93 & 3583.53 & 2805.33 & 945778.33 & 618597.99 & 446658.22 \\
\hline 188 & 4557.11 & 3143.24 & 2441.37 & 950335.44 & 621741.23 & 449099.58 \\
\hline 189 & 4864.56 & 3762.89 & 2423.40 & 955200.00 & 625504.12 & 451522.98 \\
\hline 190 & 4458.14 & 3924.86 & 2485.12 & 959658.14 & 629428.98 & 454008.10 \\
\hline 191 & 5121.33 & 3863.47 & 2159.92 & 964779.47 & 633292.46 & 456168.02 \\
\hline 192 & 4630.39 & 3583.74 & 2298.60 & 969409.85 & 636876.20 & 458466.62 \\
\hline 193 & 4166.52 & 3302.39 & 2606.43 & 973576.37 & 640178.59 & 461073.05 \\
\hline 194 & 4028.37 & 3555.11 & 2135.14 & 977604.75 & 643733.70 & 463208.18 \\
\hline 195 & 4846.84 & 3833.60 & 2908.58 & 1.58 & 647567.30 & 466116.76 \\
\hline 196 & 4499.65 & 3697.33 & 2459.82 & 986951.23 & 651264.64 & 468576.58 \\
\hline 197 & 5263.40 & 3216.50 & 2294.62 & 992214.64 & 654481.14 & 470871.20 \\
\hline 198 & 5820.01 & 3151.52 & 2921.63 & 998034.65 & 657632.65 & 473792.82 \\
\hline 199 & 4777.04 & 3135.50 & 2116.42 & 1002811.69 & 660768.16 & 475909.24 \\
\hline 200 & 5547.34 & 3342.17 & 2300.61 & 1008359.03 & 664110.32 & 478209.85 \\
\hline 201 & 5804.93 & 3450.62 & 2553.87 & 1014163.96 & 667560.94 & 480763.72 \\
\hline 202 & 5850.47 & 3559.61 & 2053.33 & 1020014.43 & 671120.55 & 482817.04 \\
\hline 203 & 6018.38 & 3469.46 & 2676.48 & 1026032.81 & 674590.01 & 485493.52 \\
\hline 204 & 4721.96 & 3162.70 & 2426.59 & 1030754.77 & 677752.71 & 487920.10 \\
\hline 205 & 4022.75 & 3413.02 & 2413.82 & 1034777.52 & 681165.73 & 490333.92 \\
\hline 206 & 5449.28 & 4026.16 & 3109.34 & 1040226.80 & 685191.90 & 493443.26 \\
\hline 207 & 4259.49 & 3683.77 & 2458.85 & 1044486.29 & 688875.67 & 495902.11 \\
\hline 208 & 3403.92 & 3820.16 & 2510.26 & 1047890.21 & 692695.83 & 498412.37 \\
\hline
\end{tabular}




\begin{tabular}{|c|c|c|c|c|c|c|}
\hline 209 & 2885.20 & 3754.30 & 2465.76 & 1050775.41 & 696450.13 & 500878.13 \\
\hline 210 & 4229.95 & 3586.29 & 2943.51 & 1055005.37 & 700036.42 & 503821.64 \\
\hline 211 & 5176.13 & 4182.40 & 2355.46 & 1060181.50 & 704218.82 & 506177.11 \\
\hline 212 & 4907.89 & 4116.81 & 2719.97 & 1065089.40 & 708335.63 & 508897.07 \\
\hline 213 & 5609.75 & 3589.33 & 3265.15 & 1070699.15 & 711924.96 & 512162.22 \\
\hline 214 & 3958.71 & 3316.05 & 3005.19 & 1074657.85 & 715241.01 & 515167.41 \\
\hline 215 & 4472.61 & 3685.63 & 3338.57 & 1079130.46 & 718926.64 & 518505.98 \\
\hline 216 & 3568.11 & 3695.32 & 2536.69 & 1082698.57 & 722621.96 & 521042.67 \\
\hline 217 & 5286.40 & 4275.02 & 2589.72 & 1087984.97 & 726896.98 & 523632.39 \\
\hline 218 & 5436.30 & 4613.68 & 2753.10 & 1093421.27 & 731510.65 & 526385.49 \\
\hline 219 & 5073.25 & 3782.96 & 3015.00 & 1098494.51 & 735293.62 & 529400.49 \\
\hline 220 & 4711.50 & 3808.39 & 2864.50 & 1103206.01 & 739102.00 & 532264.98 \\
\hline 221 & 4609.86 & 3728.83 & 2307.93 & 1107815.87 & 742830.83 & 534572.91 \\
\hline 222 & 4506.48 & 3592.99 & 2661.59 & 1112322.35 & 746423.82 & 537234.50 \\
\hline 223 & 5073.34 & 3827.02 & 3058.50 & 1117395.68 & 750250.84 & 540293.00 \\
\hline 224 & 4450.60 & 3884.52 & 2572.80 & 1121846.28 & 754135.36 & 542865.80 \\
\hline 225 & 4093.03 & 3292.37 & 2734.48 & 1125939.32 & 757427.73 & 545600.29 \\
\hline 226 & 3795.87 & 2964.38 & 2413.01 & 1129735.19 & 760392.11 & 548013.30 \\
\hline 227 & 3240.23 & 3074.10 & 2614.34 & 1132975.42 & 763466.21 & 550627.64 \\
\hline 228 & 4206.96 & 3132.49 & 2433.58 & 1137182.38 & 766598.70 & 553061.21 \\
\hline 229 & 4363.23 & 3502.43 & 2735.52 & 1141545.61 & 770101.12 & 555796.73 \\
\hline 230 & 4422.25 & 3067.94 & 2715.66 & 1145967.85 & 773169.06 & 558512.39 \\
\hline 231 & 3127.10 & 3256.88 & 2212.97 & 1149094.95 & 776425.94 & 560725.36 \\
\hline 232 & 2768.95 & 3446.60 & 2233.30 & 1151863.90 & 779872.54 & 562958.66 \\
\hline 233 & 3312.07 & 3166.11 & 2857.28 & 1155175.97 & 783038.65 & 565815.94 \\
\hline 234 & 2954.58 & 3330.16 & 2414.83 & 1158130.55 & 786368.81 & 568230.77 \\
\hline 235 & 2854.58 & 3232.11 & 2777.32 & 1160985.14 & 789600.91 & 571008.09 \\
\hline 236 & 3267.36 & 3449.61 & 2455.54 & 1164252.50 & 793050.52 & 573463.63 \\
\hline 237 & 2591.34 & 3377.72 & 2355.13 & 1166843.84 & 796428.24 & 575818.76 \\
\hline 238 & 3003.38 & 3067.50 & 2254.69 & 1169847.22 & 799495.74 & 578073.45 \\
\hline 239 & 3222.89 & 3391.94 & 3040.10 & 1173070.11 & 802887.69 & 581113.55 \\
\hline 240 & 2549.50 & 3000.73 & 2476.61 & 1175619.61 & 805888.42 & 583590.16 \\
\hline 241 & 2832.67 & 3672.28 & 2617.80 & 1178452.27 & 809560.69 & 586207.95 \\
\hline 242 & 4195.84 & 3626.61 & 2396.52 & 1182648.12 & 813187.30 & 588604.47 \\
\hline 243 & 3396.78 & 3928.11 & 2416.88 & 1186044.90 & 817115.41 & 591021.36 \\
\hline 244 & 2377.84 & 3347.17 & 2094.83 & 1188422.74 & 820462.59 & 593116.19 \\
\hline 245 & 2596.41 & 3917.61 & 2397.20 & 1191019.16 & 824380.20 & 595513.38 \\
\hline 246 & 2498.18 & 3387.95 & 2498.15 & 1193517.33 & 827768.15 & 598011.53 \\
\hline 247 & 2400.19 & 3691.34 & 2256.61 & 1195917.53 & 831459.49 & 600268.14 \\
\hline 248 & 2523.23 & 3266.96 & 2518.78 & 1198440.76 & 834726.45 & 602786.92 \\
\hline 249 & 2582.95 & 3977.12 & 2357.80 & 1201023.71 & 838703.57 & 605144.72 \\
\hline 250 & 2453.75 & 3497.29 & 2438.63 & 1203477.46 & 842200.86 & 607583.35 \\
\hline 251 & 2262.05 & 2798.13 & 2116.37 & 1205739.51 & 844999.00 & 609699.72 \\
\hline 252 & 2541.48 & 3239.41 & 1673.10 & 1208280.99 & 848238.41 & 611372.82 \\
\hline 253 & 3290.20 & 3109.63 & 2681.24 & 1211571.18 & 851348.04 & 614054.06 \\
\hline 254 & 2628.71 & 3170.63 & 1875.03 & 1214199.90 & 854518.67 & 615929.08 \\
\hline 255 & 2844.04 & 3286.63 & 2318.80 & 1217043.93 & 857805.31 & 618247.89 \\
\hline 256 & 2746.67 & 3156.08 & 2298.86 & 1219790.60 & 860961.39 & 620546.74 \\
\hline 257 & 2369.00 & 3409.97 & 2319.24 & 1222159.60 & 864371.36 & 622865.98 \\
\hline 258 & 3268.65 & 3471.97 & 2440.47 & 1225428.25 & 867843.33 & 625306.46 \\
\hline
\end{tabular}




\begin{tabular}{|c|c|c|c|c|c|c|}
\hline 259 & 3606.32 & 3589.41 & 2743.27 & 1229034.57 & 871432.74 & 628049.73 \\
\hline 260 & 2204.40 & 3375.31 & 2622.49 & 1231238.98 & 874808.05 & 630672.22 \\
\hline 261 & 2294.51 & 3659.31 & 2461.34 & 1233533.49 & 878467.36 & 633133.55 \\
\hline 262 & 2415.34 & 3222.20 & 2481.75 & 1235948.82 & 881689.56 & 635615.30 \\
\hline 263 & 2769.98 & 3664.97 & 2602.58 & 1238718.81 & 885354.53 & 638217.87 \\
\hline 264 & 2637.58 & 3875.23 & 2830.32 & 1241356.39 & 889229.76 & 641048.20 \\
\hline 265 & 2475.55 & 3419.69 & 2734.49 & 1243831.94 & 892649.44 & 643782.69 \\
\hline 266 & 2684.68 & 3825.66 & 2293.27 & 1246516.62 & 896475.10 & 646075.96 \\
\hline 267 & 2769.51 & 4066.76 & 2826.33 & 1249286.13 & 900541.87 & 648902.29 \\
\hline 268 & 2546.97 & 3943.63 & 2424.29 & 1251833.10 & 904485.50 & 651326.58 \\
\hline 269 & 2876.43 & 4526.56 & 2204.40 & 1254709.53 & 909012.05 & 653530.98 \\
\hline 270 & 1800.35 & 3693.71 & 3087.95 & 1256509.87 & 912705.76 & 656618.93 \\
\hline 271 & 3620.97 & 3766.66 & 3093.82 & 1260130.84 & 916472.42 & 659712.75 \\
\hline 272 & 1911.57 & 4814.45 & 2052.78 & 1262042.41 & 921286.87 & 661765.53 \\
\hline 273 & 2087.68 & 3453.55 & 2653.10 & 1264130.09 & 924740.42 & 664418.64 \\
\hline 274 & 2262.77 & 3988.44 & 3317.50 & 1266392.87 & 928728.86 & 667736.14 \\
\hline 275 & 2075.82 & 3657.01 & 2745.72 & 1268468.68 & 932385.88 & 670481.86 \\
\hline 276 & 2489.86 & 3701.55 & 3040.46 & 1270958.54 & 936087.43 & 673522.32 \\
\hline 277 & 2363.07 & 3892.67 & 3647.12 & 1273321.61 & 939980.10 & 677169.44 \\
\hline 278 & 2565.06 & 3820.75 & 3010.37 & 1275886.67 & 943800.85 & 680179.81 \\
\hline 279 & 1933.12 & 4603.96 & 3619.22 & 1277819.78 & 948404.81 & 683799.03 \\
\hline 280 & 2164.76 & 3971.05 & 3813.54 & 1279984.54 & 952375.85 & 687612.57 \\
\hline 281 & 1774.54 & 4790.54 & 2672.00 & 1281759.08 & 957166.39 & 690284.57 \\
\hline 282 & 2459.19 & 4657.26 & 3209.08 & 1284218.28 & 961823.66 & 693493.65 \\
\hline 283 & 2700.36 & 4524.19 & 2993.13 & 1286918.63 & 966347.85 & 696486.78 \\
\hline 284 & 2318.14 & 4901.22 & 2838.43 & 1289236.77 & 971249.07 & 699325.21 \\
\hline 285 & 2291.91 & 4345.36 & 3512.23 & 1291528.68 & 975594.43 & 702837.44 \\
\hline 286 & 2235.79 & 4269.96 & 3122.97 & 1293764.48 & 979864.39 & 705960.41 \\
\hline 287 & 2209.34 & 4102.74 & 3052.17 & 1295973.82 & 983967.13 & 709012.58 \\
\hline 288 & 2033.30 & 3903.74 & 3153.32 & 1298007.11 & 987870.88 & 712165.90 \\
\hline 289 & 2275.96 & 3642.03 & 3624.24 & 1300283.07 & 991512.90 & 715790.14 \\
\hline 290 & 1769.54 & 5405.41 & 3009.23 & 1302052.62 & 996918.31 & 718799.37 \\
\hline 291 & 2012.53 & 4037.40 & 2957.84 & 1304065.14 & 1000955.72 & 721757.21 \\
\hline 292 & 2196.07 & 4298.87 & 2839.79 & 1306261.21 & 1005254.59 & 724597.00 \\
\hline 293 & 1657.07 & 5431.03 & 3472.50 & 1307918.28 & 1010685.61 & 728069.51 \\
\hline 294 & 2051.83 & 5325.23 & 3422.16 & 1309970.11 & 1016010.85 & 731491.66 \\
\hline 295 & 1752.73 & 5718.57 & 2768.39 & 1311722.84 & 1021729.42 & 734260.06 \\
\hline 296 & 1846.16 & 5048.36 & 3207.45 & 1313569.00 & 1026777.78 & 737467.50 \\
\hline 297 & 2455.13 & 4310.51 & 3965.92 & 1316024.13 & 1031088.29 & 741433.43 \\
\hline 298 & 2580.24 & 4577.78 & 3803.12 & 1318604.36 & 1035666.07 & 745236.54 \\
\hline 299 & 1763.27 & 4023.13 & 3570.42 & 1320367.63 & 1039689.19 & 748806.97 \\
\hline 300 & 2192.15 & 4481.75 & 3838.04 & 1322559.78 & 1044170.94 & 752645.01 \\
\hline 301 & 2042.96 & 4273.63 & 3740.76 & 1324602.75 & 1048444.57 & 756385.77 \\
\hline 302 & 2168.16 & 5280.01 & 3965.18 & 1326770.91 & 1053724.58 & 760350.96 \\
\hline 303 & 2110.22 & 4912.42 & 3844.12 & 1328881.12 & 1058637.00 & 764195.08 \\
\hline 304 & 2358.38 & 5959.70 & 3977.68 & 1331239.50 & 1064596.70 & 768172.76 \\
\hline 305 & 1901.77 & 4234.17 & 3060.85 & 1333141.27 & 1068830.87 & 771233.61 \\
\hline 306 & 2641.85 & 4637.37 & 4224.46 & 1335783.12 & 1073468.24 & 775458.06 \\
\hline 307 & 1968.93 & 4099.60 & 3559.55 & 1337752.05 & 1077567.84 & 779017.61 \\
\hline 308 & 1817.79 & 4276.33 & 3480.53 & 1339569.84 & 1081844.17 & 782498.14 \\
\hline
\end{tabular}




\begin{tabular}{|c|c|c|c|c|c|c|}
\hline 309 & 2190.74 & 5993.44 & 3852.53 & 1341760.58 & 1087837.61 & 786350.67 \\
\hline 310 & 1637.30 & 4469.93 & 3631.28 & 1343397.88 & 1092307.54 & 789981.95 \\
\hline 311 & 1703.68 & 4392.84 & 4009.31 & 1345101.56 & 1096700.38 & 793991.26 \\
\hline 312 & 1522.13 & 3628.81 & 3338.50 & 1346623.69 & 1100329.18 & 797329.76 \\
\hline 313 & 1837.95 & 3977.39 & 3645.66 & 1348461.64 & 1104306.57 & 800975.42 \\
\hline 314 & 1468.26 & 3836.32 & 3261.87 & 1349929.90 & 1108142.89 & 804237.29 \\
\hline 315 & 2286.90 & 4765.85 & 4472.66 & 1352216.80 & 1112908.74 & 808709.96 \\
\hline 316 & 1853.50 & 4558.58 & 4112.59 & 1354070.31 & 1117467.32 & 812822.55 \\
\hline 317 & 1669.67 & 3610.87 & 4156.89 & 1355739.97 & 1121078.19 & 816979.44 \\
\hline 318 & 1547.96 & 3407.85 & 3180.50 & 1357287.93 & 1124486.04 & 820159.94 \\
\hline 319 & 1964.09 & 4231.80 & 3510.05 & 1359252.03 & 1128717.84 & 823669.99 \\
\hline 320 & 2033.07 & 5146.96 & 3933.87 & 1361285.10 & 1133864.81 & 827603.86 \\
\hline 321 & 2070.55 & 4080.42 & 3788.71 & 1363355.64 & 1137945.23 & 831392.57 \\
\hline 322 & 1884.60 & 4450.31 & 4140.66 & 1365240.25 & 1142395.54 & 835533.23 \\
\hline 323 & 1793.70 & 4152.37 & 4042.84 & 1367033.95 & 1146547.91 & 839576.07 \\
\hline 324 & 2087.68 & 4172.14 & 4417.65 & 1369121.63 & 1150720.05 & 843993.72 \\
\hline 325 & 2737.51 & 4065.65 & 4721.05 & 1371859.14 & 1154785.70 & 848714.77 \\
\hline 326 & 1969.93 & 3205.48 & 4292.78 & 1373829.07 & 1157991.18 & 853007.55 \\
\hline 327 & 2169.88 & 4511.51 & 3300.50 & 1375998.94 & 1162502.69 & 856308.05 \\
\hline 328 & 2348.27 & 4185.81 & 4252.52 & 1378347.21 & 1166688.50 & 860560.57 \\
\hline 329 & 1853.39 & 3923.36 & 3882.05 & 1380200.60 & 1170611.87 & 864442.62 \\
\hline 330 & 1999.73 & 3414.20 & 2774.89 & 1382200.33 & 1174026.07 & 867217.51 \\
\hline 331 & 1891.71 & 3496.06 & 2495.11 & 1384092.04 & 1177522.13 & 869712.62 \\
\hline 332 & 1941.55 & 3546.49 & 2618.98 & 33.59 & 1181068.62 & 872331.60 \\
\hline 333 & 1866.12 & 3657.99 & 2504.76 & 1387899.71 & 1184726.61 & 874836.35 \\
\hline 334 & 1575.33 & 2910.78 & 2629.09 & 1389475.04 & 1187637.39 & 877465.44 \\
\hline 335 & 1564.46 & 2992.94 & 2274.94 & 1391039.50 & 1190630.33 & 879740.38 \\
\hline 336 & 1614.51 & 3165.82 & 2279.31 & 1392654.01 & 1193796.15 & 882019.69 \\
\hline 337 & 1633.46 & 2791.37 & 2115.40 & 1394287.47 & 1196587.52 & 884135.09 \\
\hline 338 & 1742.09 & 2721.72 & 2167.61 & 1396029.55 & 1199309.25 & 886302.71 \\
\hline 339 & 1699.90 & 3617.01 & 2099.36 & 1397729.45 & 1202926.26 & 888402.06 \\
\hline 340 & 1510.09 & 3214.51 & 2030.83 & 1399239.54 & 1206140.77 & 890432.89 \\
\hline 341 & 1205.25 & 2634.95 & 1986.24 & 1400444.79 & 1208775.72 & 892419.13 \\
\hline 342 & 1284.06 & 2476.97 & 1868.67 & 1401728.85 & 1211252.69 & 894287.80 \\
\hline 343 & 1159.00 & 2230.20 & 1920.49 & 1402887.86 & 1213482.89 & 896208.29 \\
\hline 344 & 1127.69 & 2166.59 & 1991.30 & 1404015.55 & 1215649.47 & 898199.58 \\
\hline 345 & 1212.28 & 2251.32 & 1844.05 & 1405227.83 & 1217900.79 & 900043.63 \\
\hline 346 & 1527.06 & 2128.74 & 1672.79 & 1406754.89 & 1220029.54 & 901716.42 \\
\hline 347 & 1294.25 & 2036.13 & 1889.40 & 1408049.14 & 1222065.67 & 903605.82 \\
\hline 348 & 1205.81 & 2150.03 & 1766.80 & 1409254.95 & 1224215.70 & 905372.62 \\
\hline 349 & 1089.02 & 1910.73 & 1910.41 & 1410343.97 & 1226126.43 & 907283.02 \\
\hline 350 & 1058.46 & 1760.35 & 1812.15 & 1411402.43 & 1227886.78 & 909095.17 \\
\hline 351 & 1199.34 & 1669.10 & 1762.34 & 1412601.77 & 1229555.87 & 910857.51 \\
\hline 352 & 1168.68 & 1519.74 & 1688.49 & 1413770.45 & 1231075.61 & 912546.00 \\
\hline 353 & 1081.21 & 1604.30 & 1735.27 & 1414851.66 & 1232679.91 & 914281.27 \\
\hline 354 & 1221.27 & 1572.06 & 1661.56 & 1416072.93 & 1234251.97 & 915942.83 \\
\hline 355 & 1275.76 & 1685.22 & 1708.28 & 1417348.69 & 1235937.19 & 917651.11 \\
\hline 356 & 1216.85 & 1478.94 & 1827.03 & 1418565.54 & 1237416.14 & 919478.14 \\
\hline 357 & 1271.14 & 1533.94 & 1993.62 & 1419836.68 & 1238950.08 & 921471.77 \\
\hline 358 & 1156.04 & 1704.24 & 1919.94 & 1420992.72 & 1240654.32 & 923391.70 \\
\hline
\end{tabular}




\begin{tabular}{|c|ccc|ccc|}
\hline 359 & 1013.21 & 1499.10 & 1966.27 & 1422005.94 & 1242153.42 & 925357.97 \\
360 & 983.27 & 1438.61 & 2012.51 & 1422989.21 & 1243592.02 & 927370.48 \\
361 & 1009.52 & 1320.91 & 1795.36 & 1423998.72 & 1244912.93 & 929165.84 \\
362 & 1091.64 & 1576.23 & 1746.00 & 1425090.36 & 1246489.16 & 930911.84 \\
363 & 1117.57 & 1515.91 & 1887.90 & 1426207.94 & 1248005.07 & 932799.74 \\
364 & 1171.30 & 1427.27 & 1766.91 & 1427379.23 & 1249432.33 & 934566.65 \\
365 & 1002.12 & 1310.48 & 1741.54 & 1428381.35 & 1250742.81 & 936308.19 \\
366 & 1028.06 & 1251.00 & 1906.91 & 1429409.41 & 1251993.81 & 938215.10 \\
367 & 1081.62 & 1333.63 & 1810.02 & 1430491.03 & 1253327.44 & 940025.12 \\
368 & 968.89 & 1415.93 & 1594.31 & 1431459.92 & 1254743.37 & 941619.43 \\
369 & 939.46 & 1469.61 & 1664.27 & 1432399.38 & 1256212.98 & 943283.71 \\
370 & 1020.45 & 1579.49 & 1710.36 & 1433419.84 & 1257792.47 & 944994.07 \\
371 & 908.44 & 1463.72 & 1780.10 & 1434328.28 & 1259256.18 & 946774.17 \\
372 & 961.70 & 1404.59 & 1731.14 & 1435289.98 & 1260660.77 & 948505.31 \\
373 & 1069.97 & 1233.54 & 1659.00 & 1436359.95 & 1261894.31 & 950164.31 \\
374 & 985.48 & 1091.15 & 1988.58 & 1437345.43 & 1262985.46 & 952152.89 \\
375 & 1038.28 & 1005.18 & 1892.26 & 1438383.70 & 1263990.64 & 954045.15 \\
376 & 932.79 & 981.23 & 1990.80 & 1439316.50 & 1264971.87 & 956035.95 \\
377 & 816.61 & 917.67 & 1747.33 & 1440133.11 & 1265889.54 & 957783.28 \\
378 & 869.41 & 1026.81 & 1840.19 & 1441002.51 & 1266916.34 & 959623.47 \\
379 & $\mathbf{8 2 3 . 0 5}$ & 981.23 & $\mathbf{2 0 3 8 . 2 0}$ & 1441825.57 & 1267897.57 & 961661.67 \\
380 & $\mathbf{7 8 4 . 9 2}$ & $\mathbf{1 0 7 7 . 8 9}$ & $\mathbf{1 9 5 4 . 7 7}$ & $\mathbf{1 4 4 2 6 1 0 . 4 9}$ & $\mathbf{1 2 6 8 9 7 5 . 4 5}$ & $\mathbf{9 6 3 6 1 6 . 4 5}$ \\
\hline
\end{tabular}

Group two

\begin{tabular}{|c|cccc|cccc|}
\hline & \multicolumn{3}{|c|}{ Daily } & methane production $(\mathbf{m l})$ & \multicolumn{4}{c|}{ Accumulative methane production } \\
\hline Time & $\mathbf{R 5}$ & $\mathbf{R 6}$ & $\mathbf{R 7}$ & $\mathbf{R 8}$ & $\mathbf{R 5}$ & $\mathbf{R 6}$ & $\mathbf{R 7}$ & $\mathbf{R 8}$ \\
\hline 17 & 360 & 0 & 0 & 0 & 360 & 0 & 0 & 0 \\
18 & 346 & 0 & 0 & 0 & 706 & 0 & 0 & 0 \\
19 & 356 & 178 & 0 & 0 & 1063 & 89 & 0 & 0 \\
20 & 341 & 207 & 0 & 0 & 1404 & 296 & 0 & 0 \\
21 & 336 & 187 & 190 & 0 & 1740 & 483 & 190 & 0 \\
22 & 448 & 242 & 135 & 0 & 2187 & 725 & 326 & 0 \\
23 & 385 & 163 & 207 & 0 & 2572 & 888 & 532 & 0 \\
24 & 405 & 192 & 119 & 0 & 2977 & 1080 & 652 & 0 \\
25 & 386 & 245 & 128 & 0 & 3364 & 1324 & 779 & 0 \\
26 & 376 & 209 & 159 & 0 & 3740 & 1533 & 938 & 0 \\
27 & 513 & 304 & 209 & 0 & 4253 & 1837 & 1147 & 0 \\
28 & 559 & 372 & 153 & 0 & 4811 & 2209 & 1301 & 0 \\
29 & 590 & 374 & 266 & 0 & 5401 & 2584 & 1567 & 0 \\
30 & 697 & 458 & 244 & 0 & 6098 & 3042 & 1811 & 0 \\
31 & 796 & 376 & 318 & 0 & 6893 & 3418 & 2129 & 0 \\
32 & 587 & 422 & 374 & 0 & 7480 & 3840 & 2503 & 0 \\
33 & 693 & 219 & 387 & 0 & 8173 & 4059 & 2890 & 0 \\
34 & 736 & 207 & 501 & 164 & 8909 & 4266 & 3392 & 164 \\
35 & 743 & 368 & 522 & 184 & 9652 & 4633 & 3914 & 348 \\
36 & 786 & 529 & 699 & 155 & 10438 & 5163 & 4612 & 503 \\
\hline
\end{tabular}




\begin{tabular}{|c|c|c|c|c|c|c|c|c|}
\hline 37 & 811 & 411 & 780 & 76 & 11250 & 5574 & 5392 & 578 \\
\hline 38 & 744 & 402 & 765 & 184 & 11993 & 5976 & 6157 & 763 \\
\hline 39 & 763 & 414 & 818 & 186 & 12756 & 6390 & 6975 & 949 \\
\hline 40 & 787 & 512 & 493 & 162 & 13544 & 6902 & 7468 & 1111 \\
\hline 41 & 891 & 477 & 893 & 209 & 14435 & 7380 & 8362 & 1320 \\
\hline 42 & 845 & 774 & 530 & 184 & 15280 & 8154 & 8891 & 1504 \\
\hline 43 & 758 & 334 & 561 & 262 & 16038 & 8488 & 9453 & 1766 \\
\hline 44 & 774 & 442 & 500 & 403 & 16812 & 8930 & 9953 & 2169 \\
\hline 45 & 791 & 539 & 566 & 341 & 17603 & 9468 & 10519 & 2510 \\
\hline 46 & 1012 & 776 & 559 & 210 & 18615 & 10244 & 11078 & 2720 \\
\hline 47 & 1117 & 608 & 669 & 409 & 19732 & 10852 & 11747 & 3129 \\
\hline 48 & 1258 & 553 & 635 & 280 & 20989 & 11405 & 12381 & 3409 \\
\hline 49 & 1403 & 515 & 685 & 345 & 22393 & 11921 & 13066 & 3755 \\
\hline 50 & 1691 & 474 & 842 & 414 & 24083 & 12395 & 13908 & 4169 \\
\hline 51 & 2293 & 691 & 718 & 319 & 26376 & 13086 & 14626 & 4487 \\
\hline 52 & 2396 & 848 & 796 & 459 & 28772 & 13934 & 15422 & 4946 \\
\hline 53 & 2238 & 918 & 708 & 518 & 31010 & 14852 & 16130 & 5464 \\
\hline 54 & 2462 & 1136 & 937 & 598 & 33472 & 15988 & 17067 & 6063 \\
\hline 55 & 2152 & 922 & 889 & 547 & 35624 & 16910 & 17956 & 6610 \\
\hline 56 & 2582 & 811 & 951 & 563 & 38206 & 17721 & 18907 & 7173 \\
\hline 57 & 2628 & 1307 & 1015 & 574 & 40834 & 19028 & 19921 & 7747 \\
\hline 58 & 2497 & 1514 & 1196 & 876 & 43331 & 20542 & 21117 & 8624 \\
\hline 59 & 2578 & 1598 & 1340 & 1017 & 45909 & 22140 & 22458 & 9640 \\
\hline 60 & 2716 & 1416 & 1254 & 844 & 48625 & 23556 & 23712 & 10484 \\
\hline 61 & 2880 & 1609 & 1112 & 764 & 51505 & 25165 & 24824 & 11247 \\
\hline 62 & 2867 & 2092 & 1218 & 846 & 54373 & 27256 & 26042 & 12093 \\
\hline 63 & 3013 & 1604 & 1429 & 1015 & 57386 & 28860 & 27471 & 13108 \\
\hline 64 & 3261 & 2479 & 1648 & 1025 & 60646 & 31339 & 29119 & 14133 \\
\hline 65 & 3131 & 2080 & 1922 & 1256 & 63778 & 33419 & 31042 & 15389 \\
\hline 66 & 3585 & 2633 & 1642 & 1116 & 67363 & 36053 & 32684 & 16505 \\
\hline 67 & 3765 & 3063 & 1924 & 1430 & 71128 & 39115 & 34608 & 17935 \\
\hline 68 & 4108 & 3409 & 2132 & 1106 & 75236 & 42524 & 36740 & 19041 \\
\hline 69 & 4023 & 3810 & 2273 & 1354 & 79258 & 46334 & 39013 & 20395 \\
\hline 70 & 3868 & 5716 & 2050 & 1167 & 83126 & 50140 & 41063 & 21563 \\
\hline 71 & 4419 & 6298 & 2477 & 1232 & 87545 & 53862 & 43540 & 22794 \\
\hline 72 & 5139 & 6094 & 2640 & 1088 & 92683 & 58456 & 46180 & 23882 \\
\hline 73 & 5342 & 6686 & 2823 & 1314 & 98026 & 61965 & 49003 & 25196 \\
\hline 74 & 4624 & 7294 & 2144 & 857 & 102650 & 66353 & 51147 & 26053 \\
\hline 75 & 5714 & 7631 & 2895 & 1705 & 108365 & 70413 & 54042 & 27758 \\
\hline 76 & 5674 & 7546 & 3213 & 1612 & 114038 & 75198 & 57255 & 29369 \\
\hline 77 & 6427 & 7602 & 3469 & 1745 & 120465 & 80245 & 60724 & 31115 \\
\hline 78 & 6367 & 7696 & 3793 & 1604 & 126832 & 85045 & 64517 & 32719 \\
\hline 79 & 6230 & 7620 & 4032 & 1624 & 133062 & 90170 & 68549 & 34343 \\
\hline 80 & 6795 & 7885 & 2878 & 1375 & 139857 & 94079 & 71427 & 35718 \\
\hline 81 & 7002 & 7692 & 3160 & 1569 & 146859 & 98643 & 74587 & 37287 \\
\hline 82 & 7237 & 7539 & 3421 & 1962 & 154096 & 103430 & 78008 & 39248 \\
\hline 83 & 6861 & 7401 & 3344 & 1552 & 160957 & 109127 & 81352 & 40801 \\
\hline 84 & 7480 & 7807 & 3959 & 1604 & 168437 & 113663 & 85312 & 42405 \\
\hline 85 & 6696 & 8300 & 3709 & 1855 & 175134 & 117121 & 89021 & 44260 \\
\hline 86 & 7491 & 8363 & 4070 & 1803 & 182625 & 120958 & 93091 & 46063 \\
\hline
\end{tabular}




\begin{tabular}{|c|c|c|c|c|c|c|c|c|}
\hline 87 & 8275 & 8465 & 3066 & 1498 & 190899 & 125771 & 96157 & 47561 \\
\hline 88 & 9018 & 8207 & 3171 & 1677 & 199918 & 131620 & 99328 & 49239 \\
\hline 89 & 8900 & 8055 & 3448 & 1740 & 208818 & 137392 & 102776 & 50979 \\
\hline 90 & 8323 & 8126 & 3519 & 1851 & 217141 & 142931 & 106295 & 52829 \\
\hline 91 & 7507 & 8376 & 3458 & 1768 & 224648 & 147463 & 109753 & 54597 \\
\hline 92 & 7381 & 8346 & 3597 & 1704 & 232028 & 151702 & 113351 & 56301 \\
\hline 93 & 9474 & 8388 & 3954 & 1796 & 241502 & 157522 & 117305 & 58097 \\
\hline 94 & 9680 & 8066 & 4054 & 1716 & 251182 & 163773 & 121358 & 59813 \\
\hline 95 & 9050 & 8288 & 4623 & 2077 & 260232 & 168309 & 125982 & 61890 \\
\hline 96 & 6907 & 7858 & 4407 & 3180 & 267139 & 174361 & 130389 & 65070 \\
\hline 97 & 9381 & 7760 & 4913 & 3597 & 276520 & 180244 & 135301 & 68667 \\
\hline 98 & 9289 & 7584 & 4806 & 4113 & 285809 & 184636 & 140107 & 72780 \\
\hline 99 & 8918 & 7459 & 4265 & 3534 & 294727 & 189559 & 144372 & 76313 \\
\hline 100 & 8153 & 8208 & 3209 & 2618 & 302879 & 194348 & 147581 & 78932 \\
\hline 101 & 7717 & 8389 & 4317 & 2531 & 310596 & 198873 & 151898 & 81462 \\
\hline 102 & 7695 & 7922 & 3480 & 2172 & 318292 & 204068 & 155377 & 83634 \\
\hline 103 & 8301 & 7868 & 4418 & 2278 & 326593 & 209366 & 159795 & 85912 \\
\hline 104 & 7443 & 8014 & 4815 & 2591 & 334036 & 214300 & 164610 & 88503 \\
\hline 105 & 9776 & 8287 & 4458 & 2438 & 343812 & 219774 & 169069 & 90941 \\
\hline 106 & 11039 & 8096 & 3787 & 2727 & 354850 & 226267 & 172856 & 93668 \\
\hline 107 & 10750 & 8191 & 4787 & 3718 & 365600 & 231154 & 177643 & 97386 \\
\hline 108 & 9660 & 7874 & 4402 & 4945 & 375260 & 236864 & 182045 & 102331 \\
\hline 109 & 10272 & 7969 & 4488 & 3882 & 385532 & 243058 & 186533 & 106214 \\
\hline 110 & 10721 & 8728 & 4837 & 4252 & 396253 & 247954 & 191370 & 110466 \\
\hline 111 & 9033 & 8488 & 4371 & 5066 & 405286 & 252740 & 195741 & 115532 \\
\hline 112 & 9306 & 8224 & 4371 & 3996 & 414592 & 257073 & 200112 & 119528 \\
\hline 113 & 9771 & 8285 & 4081 & 4231 & 424362 & 262312 & 204193 & 123758 \\
\hline 114 & 8712 & 8227 & 4002 & 4022 & 433074 & 266675 & 208196 & 127780 \\
\hline 115 & 10313 & 8614 & 2954 & 3656 & 443387 & 272232 & 211150 & 131436 \\
\hline 116 & 9908 & 8512 & 4354 & 3860 & 453295 & 276720 & 215504 & 135296 \\
\hline 117 & 10392 & 8849 & 3807 & 3260 & 463686 & 282251 & 219310 & 138556 \\
\hline 118 & 11098 & 7808 & 4778 & 3791 & 474784 & 288018 & 224088 & 142347 \\
\hline 119 & 9079 & 7568 & 5193 & 4390 & 483863 & 292957 & 229282 & 146737 \\
\hline 120 & 8244 & 7024 & 4012 & 3506 & 492108 & 297529 & 233294 & 150243 \\
\hline 121 & 8109 & 8606 & 4764 & 3149 & 500217 & 302066 & 238058 & 153392 \\
\hline 122 & 7216 & 7344 & 4412 & 3109 & 507433 & 306192 & 242470 & 156501 \\
\hline 123 & 6879 & 8384 & 3534 & 2611 & 514312 & 310214 & 246003 & 159112 \\
\hline 124 & 7366 & 7467 & 3433 & 2542 & 521678 & 314437 & 249436 & 161654 \\
\hline 125 & 8669 & 6528 & 4227 & 2501 & 530347 & 319056 & 253663 & 164155 \\
\hline 126 & 7640 & 6485 & 4740 & 3437 & 537988 & 323268 & 258403 & 167592 \\
\hline 127 & 6919 & 6616 & 4607 & 3479 & 544907 & 327546 & 263010 & 171070 \\
\hline 128 & 6548 & 5804 & 4351 & 2667 & 551455 & 331720 & 267361 & 173737 \\
\hline 129 & 7427 & 6002 & 4035 & 2866 & 558882 & 336347 & 271395 & 176603 \\
\hline 130 & 6248 & 5229 & 4208 & 3067 & 565130 & 340338 & 275604 & 179670 \\
\hline 131 & 7276 & 5645 & 3864 & 2459 & 572406 & 344235 & 279468 & 182129 \\
\hline 132 & 6311 & 4129 & 4098 & 3120 & 578717 & 349025 & 283565 & 185249 \\
\hline 133 & 6343 & 4566 & 4815 & 3978 & 585060 & 353689 & 288380 & 189227 \\
\hline 134 & 6167 & 4076 & 3988 & 3010 & 591226 & 358873 & 292367 & 192237 \\
\hline 135 & 6283 & 3806 & 5636 & 4452 & 597509 & 363695 & 298003 & 196688 \\
\hline 136 & 6795 & 3722 & 5051 & 4752 & 604304 & 368774 & 303054 & 201441 \\
\hline
\end{tabular}




\begin{tabular}{|c|c|c|c|c|c|c|c|c|}
\hline 137 & 6674 & 4595 & 5302 & 5049 & 610978 & 374204 & 308356 & 206490 \\
\hline 138 & 6091 & 3509 & 5373 & 4514 & 617069 & 378952 & 313729 & 211004 \\
\hline 139 & 6204 & 4388 & 5106 & 4595 & 623274 & 383901 & 318835 & 215599 \\
\hline 140 & 5628 & 4060 & 5729 & 4552 & 628901 & 388643 & 324564 & 220150 \\
\hline 141 & 6039 & 4785 & 5400 & 4351 & 634940 & 393956 & 329964 & 224502 \\
\hline 142 & 6265 & 5047 & 5882 & 4275 & 641205 & 398661 & 335847 & 228777 \\
\hline 143 & 5286 & 4800 & 5754 & 4766 & 646491 & 403448 & 341601 & 233542 \\
\hline 144 & 4450 & 5125 & 5693 & 4880 & 650941 & 407779 & 347293 & 238423 \\
\hline 145 & 5196 & 3909 & 4969 & 3691 & 656137 & 412498 & 352263 & 242114 \\
\hline 146 & 4950 & 4563 & 5460 & 4537 & 661087 & 417018 & 357723 & 246650 \\
\hline 147 & 5247 & 4787 & 5186 & 4049 & 666335 & 421673 & 362909 & 250699 \\
\hline 148 & 6376 & 5697 & 5472 & 4358 & 672711 & 426996 & 368381 & 255057 \\
\hline 149 & 6203 & 4537 & 6532 & 5077 & 678914 & 432092 & 374914 & 260134 \\
\hline 150 & 6548 & 3458 & 6434 & 4718 & 685461 & 437412 & 381348 & 264852 \\
\hline 151 & 5609 & 3837 & 6688 & 4606 & 691070 & 442360 & 388036 & 269457 \\
\hline 152 & 5818 & 4813 & 6449 & 4765 & 696888 & 447105 & 394485 & 274223 \\
\hline 153 & 4808 & 5849 & 5962 & 4366 & 701696 & 451614 & 400447 & 278589 \\
\hline 154 & 4452 & 5772 & 5757 & 4038 & 706149 & 456464 & 406204 & 282626 \\
\hline 155 & 4706 & 5539 & 5693 & 4028 & 710855 & 461598 & 411897 & 286655 \\
\hline 156 & 4213 & 4532 & 5841 & 4356 & 715068 & 465854 & 417738 & 291011 \\
\hline 157 & 4603 & 4239 & 5139 & 3645 & 719671 & 470628 & 422877 & 294655 \\
\hline 158 & 4335 & 5820 & 5503 & 3995 & 724006 & 475015 & 428380 & 298651 \\
\hline 159 & 4632 & 6251 & 5337 & 3870 & 728638 & 479899 & 433717 & 302520 \\
\hline 160 & 4770 & 4537 & 4823 & 3745 & 733409 & 484897 & 438540 & 306265 \\
\hline 161 & 4572 & 6052 & 5391 & 3842 & 737981 & 489412 & 443931 & 310108 \\
\hline 162 & 4353 & 5883 & 5158 & 3856 & 742334 & 493710 & 449089 & 313963 \\
\hline 163 & 4667 & 4392 & 3798 & 3623 & 747001 & 499449 & 452887 & 317586 \\
\hline 164 & 4427 & 4923 & 4371 & 4512 & 751428 & 504975 & 457258 & 322098 \\
\hline 165 & 4957 & 4790 & 4043 & 3978 & 756385 & 510040 & 461301 & 326076 \\
\hline 166 & 5198 & 4525 & 3845 & 4731 & 761584 & 515774 & 465146 & 330807 \\
\hline 167 & 4219 & 5195 & 4637 & 3941 & 765803 & 520459 & 469783 & 334748 \\
\hline 168 & 4721 & 5298 & 3278 & 3234 & 770524 & 525693 & 473061 & 337982 \\
\hline 169 & 5003 & 4934 & 3638 & 3554 & 775527 & 531108 & 476699 & 341536 \\
\hline 170 & 4359 & 5474 & 4169 & 3898 & 779886 & 536050 & 480868 & 345434 \\
\hline 171 & 5345 & 6493 & 3652 & 3223 & 785231 & 541832 & 484520 & 348657 \\
\hline 172 & 4641 & 4887 & 4325 & 4273 & 789872 & 547674 & 488845 & 352930 \\
\hline 173 & 5390 & 5710 & 3931 & 3762 & 795262 & 553247 & 492776 & 356692 \\
\hline 174 & 5501 & 6194 & 4109 & 3448 & 800763 & 559566 & 496885 & 360140 \\
\hline 175 & 4194 & 4896 & 5062 & 4390 & 804957 & 564915 & 501947 & 364530 \\
\hline 176 & 5794 & 4786 & 4033 & 3509 & 810751 & 571173 & 505981 & 368039 \\
\hline 177 & 4488 & 4333 & 4611 & 3889 & 815239 & 576775 & 510592 & 371928 \\
\hline 178 & 5287 & 5239 & 4348 & 3465 & 820526 & 583068 & 514940 & 375393 \\
\hline 179 & 5647 & 4364 & 4942 & 4032 & 826172 & 588798 & 519882 & 379425 \\
\hline 180 & 5238 & 5557 & 4564 & 3447 & 831410 & 595416 & 524446 & 382872 \\
\hline 181 & 5969 & 4488 & 5089 & 3701 & 837379 & 602828 & 529536 & 386573 \\
\hline 182 & 6318 & 5531 & 4991 & 4375 & 843698 & 609417 & 534527 & 390948 \\
\hline 183 & 6836 & 5767 & 4459 & 4222 & 850534 & 615876 & 538986 & 395170 \\
\hline 184 & 5432 & 4938 & 4941 & 4504 & 855966 & 623357 & 543927 & 399674 \\
\hline 185 & 6589 & 4572 & 4780 & 3708 & 862555 & 630682 & 548707 & 403381 \\
\hline 186 & 6833 & 4537 & 4863 & 4253 & 869387 & 638644 & 553570 & 407634 \\
\hline
\end{tabular}




\begin{tabular}{|c|c|c|c|c|c|c|c|c|}
\hline 187 & 5736 & 4125 & 4179 & 3415 & 875123 & 646210 & 557749 & 411048 \\
\hline 188 & 5523 & 4023 & 4526 & 4225 & 880647 & 654007 & 562276 & 415273 \\
\hline 189 & 6004 & 4223 & 4433 & 4566 & 886650 & 660693 & 566709 & 419839 \\
\hline 190 & 5312 & 4619 & 4629 & 3660 & 891963 & 667987 & 571338 & 423500 \\
\hline 191 & 5650 & 4212 & 4246 & 4241 & 897613 & 675618 & 575585 & 427741 \\
\hline 192 & 5030 & 4279 & 4595 & 4106 & 902642 & 683164 & 580179 & 431847 \\
\hline 193 & 6230 & 4174 & 4427 & 4362 & 908872 & 690765 & 584607 & 436209 \\
\hline 194 & 5201 & 4627 & 4703 & 4106 & 914073 & 698462 & 589310 & 440314 \\
\hline 195 & 6571 & 3992 & 4067 & 4211 & 920644 & 706081 & 593377 & 444526 \\
\hline 196 & 6861 & 3897 & 4664 & 4500 & 927505 & 713966 & 598040 & 449025 \\
\hline 197 & 6912 & 4790 & 4718 & 4394 & 934417 & 721658 & 602758 & 453419 \\
\hline 198 & 6915 & 4664 & 4624 & 4317 & 941332 & 729197 & 607382 & 457736 \\
\hline 199 & 5765 & 5184 & 4555 & 4486 & 947097 & 736598 & 611937 & 462223 \\
\hline 200 & 5094 & 6827 & 4287 & 4101 & 952191 & 744405 & 616224 & 466324 \\
\hline 201 & 6058 & 5210 & 4564 & 4465 & 958249 & 752704 & 620788 & 470789 \\
\hline 202 & 4714 & 6807 & 5239 & 5150 & 962963 & 760768 & 626027 & 475938 \\
\hline 203 & 4571 & 6906 & 4449 & 4664 & 967534 & 769233 & 630476 & 480602 \\
\hline 204 & 4886 & 6593 & 4653 & 5051 & 972421 & 777440 & 635130 & 485653 \\
\hline 205 & 6410 & 5759 & 4608 & 4831 & 978831 & 785495 & 639738 & 490484 \\
\hline 206 & 5565 & 6264 & 4812 & 4746 & 984395 & 793292 & 644550 & 495231 \\
\hline 207 & 6521 & 5941 & 4568 & 4388 & 990917 & 801068 & 649118 & 499619 \\
\hline 208 & 5331 & 6385 & 5497 & 4808 & 996248 & 809414 & 654615 & 504428 \\
\hline 209 & 5253 & 6153 & 4627 & 4795 & 1001501 & 816803 & 659243 & 509223 \\
\hline 210 & 6238 & 5915 & 4532 & 4536 & 1007739 & 824368 & 663775 & 513759 \\
\hline 211 & 6107 & 5847 & 4687 & 4138 & 1013846 & 831757 & 668462 & 517897 \\
\hline 212 & 5206 & 5510 & 4400 & 4062 & 1019052 & 839615 & 672862 & 521959 \\
\hline 213 & 5129 & 5586 & 4364 & 4468 & 1024181 & 847375 & 677226 & 526427 \\
\hline 214 & 5263 & 6593 & 5610 & 3432 & 1029444 & 854859 & 682837 & 529859 \\
\hline 215 & 5770 & 6072 & 5346 & 4214 & 1035214 & 861319 & 688183 & 534073 \\
\hline 216 & 5879 & 5238 & 5769 & 3968 & 1041093 & 869527 & 693952 & 538041 \\
\hline 217 & 5162 & 5770 & 6065 & 4781 & 1046256 & 877615 & 700017 & 542822 \\
\hline 218 & 5590 & 5549 & 5491 & 5046 & 1051846 & 885537 & 705509 & 547869 \\
\hline 219 & 6151 & 5990 & 5322 & 4766 & 1057997 & 893405 & 710831 & 552635 \\
\hline 220 & 5248 & 6307 & 5710 & 4146 & 1063245 & 899419 & 716541 & 556781 \\
\hline 221 & 5996 & 6048 & 4618 & 3563 & 1069240 & 907706 & 721159 & 560344 \\
\hline 222 & 5038 & 4637 & 5957 & 4844 & 1074279 & 913802 & 727116 & 565188 \\
\hline 223 & 5627 & 6735 & 4318 & 3484 & 1079905 & 921993 & 731434 & 568672 \\
\hline 224 & 5815 & 5762 & 5773 & 3613 & 1085720 & 929867 & 737207 & 572285 \\
\hline 225 & 5257 & 5448 & 5819 & 3472 & 1090977 & 937636 & 743026 & 575758 \\
\hline 226 & 6407 & 5447 & 5500 & 3736 & 1097384 & 946364 & 748526 & 579494 \\
\hline 227 & 5768 & 4977 & 5667 & 4440 & 1103152 & 954852 & 754194 & 583934 \\
\hline 228 & 6705 & 5821 & 5562 & 3858 & 1109857 & 963076 & 759756 & 587792 \\
\hline 229 & 6093 & 4662 & 5999 & 3684 & 1115949 & 970361 & 765755 & 591476 \\
\hline 230 & 6015 & 4845 & 5863 & 3778 & 1121964 & 978588 & 771618 & 595255 \\
\hline 231 & 6177 & 4433 & 6088 & 3872 & 1128141 & 987203 & 777706 & 599127 \\
\hline 232 & 6478 & 5361 & 6171 & 3813 & 1134620 & 995714 & 783877 & 602940 \\
\hline 233 & 6172 & 5290 & 6165 & 4120 & 1140791 & 1004563 & 790041 & 607060 \\
\hline 234 & 4822 & 4684 & 5915 & 4160 & 1145614 & 1012371 & 795957 & 611220 \\
\hline 235 & 5696 & 5481 & 5999 & 4805 & 1151310 & 1018639 & 801955 & 616025 \\
\hline 236 & 5478 & 6459 & 6236 & 4173 & 1156788 & 1024663 & 808191 & 620199 \\
\hline
\end{tabular}




\begin{tabular}{|c|c|c|c|c|c|c|c|c|}
\hline 237 & 4755 & 6589 & 6075 & 3506 & 1161542 & 1033269 & 814266 & 623704 \\
\hline 238 & 4630 & 5413 & 6104 & 3511 & 1166172 & 1039613 & 820370 & 627216 \\
\hline 239 & 4757 & 6618 & 6060 & 3821 & 1170929 & 1047997 & 826430 & 631037 \\
\hline 240 & 4988 & 5730 & 5927 & 3523 & 1175918 & 1055464 & 832357 & 634560 \\
\hline 241 & 4630 & 6292 & 5981 & 3460 & 1180548 & 1061992 & 838337 & 638020 \\
\hline 242 & 5354 & 5603 & 5221 & 4587 & 1185902 & 1069477 & 843559 & 642607 \\
\hline 243 & 6718 & 6258 & 5523 & 3913 & 1192620 & 1076893 & 849082 & 646520 \\
\hline 244 & 6486 & 5349 & 5670 & 4225 & 1199107 & 1083497 & 854752 & 650746 \\
\hline 245 & 6654 & 6319 & 5277 & 4468 & 1205761 & 1091100 & 860029 & 655213 \\
\hline 246 & 6677 & 5573 & 5576 & 4803 & 1212438 & 1099329 & 865605 & 660017 \\
\hline 247 & 6906 & 5842 & 5967 & 4721 & 1219344 & 1106974 & 871572 & 664737 \\
\hline 248 & 6906 & 5783 & 6013 & 4431 & 1226249 & 1115403 & 877585 & 669168 \\
\hline 249 & 6900 & 4942 & 6120 & 5074 & 1233150 & 1122469 & 883705 & 674242 \\
\hline 250 & 7554 & 5415 & 5824 & 4819 & 1240704 & 1129945 & 889529 & 679062 \\
\hline 251 & 7587 & 5234 & 6210 & 4497 & 1248290 & 1136772 & 895739 & 683558 \\
\hline 252 & 5336 & 5184 & 5823 & 4655 & 1253627 & 1141983 & 901561 & 688214 \\
\hline 253 & 6219 & 4822 & 4639 & 4301 & 1259846 & 1148790 & 906200 & 692514 \\
\hline 254 & 5310 & 5080 & 5392 & 5072 & 1265156 & 1155696 & 911592 & 697586 \\
\hline 255 & 5017 & 5429 & 5651 & 4955 & 1270173 & 1162889 & 917243 & 702541 \\
\hline 256 & 6173 & 4748 & 5452 & 5314 & 1276346 & 1168647 & 922695 & 707855 \\
\hline 257 & 6209 & 4949 & 5042 & 5164 & 1282555 & 1174912 & 927738 & 713019 \\
\hline 258 & 5384 & 4742 & 5482 & 5351 & 1287939 & 1180853 & 933220 & 718369 \\
\hline 259 & 6733 & 5313 & 5255 & 4497 & 1294672 & 1187238 & 938474 & 722866 \\
\hline 260 & 6539 & 4706 & 5360 & 4836 & 1301211 & 1193391 & 943835 & 727702 \\
\hline 261 & 5457 & 4786 & 5538 & 4726 & 1306668 & 1199307 & 949373 & 732429 \\
\hline 262 & 5130 & 4331 & 5473 & 4571 & 1311798 & 1205153 & 954845 & 737000 \\
\hline 263 & 5256 & 4720 & 5326 & 4284 & 1317054 & 1210663 & 960171 & 741283 \\
\hline 264 & 5910 & 4520 & 4713 & 4123 & 1322964 & 1216249 & 964884 & 745406 \\
\hline 265 & 5810 & 4655 & 5590 & 4561 & 1328774 & 1223842 & 970474 & 749967 \\
\hline 266 & 6087 & 4323 & 5739 & 4550 & 1334861 & 1231214 & 976214 & 754518 \\
\hline 267 & 5634 & 5096 & 5612 & 4782 & 1340495 & 1236452 & 981826 & 759300 \\
\hline 268 & 6087 & 5320 & 5669 & 4985 & 1346582 & 1242222 & 987495 & 764284 \\
\hline 269 & 5786 & 4948 & 5975 & 5036 & 1352368 & 1247771 & 993471 & 769321 \\
\hline 270 & 6440 & 4745 & 5628 & 4935 & 1358808 & 1254761 & 999098 & 774256 \\
\hline 271 & 6717 & 4510 & 6188 & 5202 & 1365524 & 1261468 & 1005286 & 779458 \\
\hline 272 & 6491 & 4849 & 5774 & 5286 & 1372015 & 1267516 & 1011060 & 784744 \\
\hline 273 & 4931 & 5134 & 5896 & 5494 & 1376946 & 1272153 & 1016956 & 790239 \\
\hline 274 & 6340 & 4256 & 4903 & 4551 & 1383287 & 1278887 & 1021859 & 794790 \\
\hline 275 & 5888 & 4774 & 6930 & 5446 & 1389175 & 1284650 & 1028789 & 800236 \\
\hline 276 & 5334 & 4387 & 5426 & 5752 & 1394509 & 1290098 & 1034215 & 805988 \\
\hline 277 & 6090 & 4884 & 5665 & 5618 & 1400598 & 1295545 & 1039880 & 811606 \\
\hline 278 & 5788 & 4998 & 6555 & 5451 & 1406386 & 1300522 & 1046435 & 817056 \\
\hline 279 & 6090 & 4515 & 6331 & 5282 & 1412476 & 1306343 & 1052765 & 822338 \\
\hline 280 & 5890 & 4298 & 6685 & 5590 & 1418366 & 1311005 & 1059450 & 827928 \\
\hline 281 & 5112 & 5739 & 6282 & 5302 & 1423479 & 1316351 & 1065732 & 833230 \\
\hline 282 & 5442 & 5526 & 6495 & 5652 & 1428921 & 1320784 & 1072228 & 838881 \\
\hline 283 & 6654 & 5065 & 5620 & 5012 & 1435575 & 1327146 & 1077848 & 843894 \\
\hline 284 & 6077 & 5734 & 6812 & 5714 & 1441652 & 1332436 & 1084660 & 849607 \\
\hline 285 & 6054 & 4684 & 6336 & 5649 & 1447706 & 1337547 & 1090996 & 855256 \\
\hline 286 & 4946 & 4503 & 6368 & 5711 & 1452652 & 1342050 & 1097364 & 860967 \\
\hline
\end{tabular}




\begin{tabular}{|c|c|c|c|c|c|c|c|c|}
\hline 287 & 4949 & 4526 & 5749 & 4945 & 1457601 & 1346576 & 1103113 & 865912 \\
\hline 288 & 5203 & 4807 & 5708 & 5071 & 1462804 & 1351382 & 1108821 & 870983 \\
\hline 289 & 5079 & 4212 & 6787 & 5804 & 1467883 & 1356268 & 1115608 & 876787 \\
\hline 290 & 5991 & 3973 & 6313 & 5835 & 1473874 & 1361463 & 1121922 & 882622 \\
\hline 291 & 5716 & 3876 & 6345 & 5993 & 1479590 & 1366594 & 1128266 & 888615 \\
\hline 292 & 6022 & 4296 & 6124 & 5769 & 1485611 & 1372089 & 1134390 & 894384 \\
\hline 293 & 6201 & 3707 & 6263 & 5831 & 1491813 & 1379141 & 1140654 & 900215 \\
\hline 294 & 5723 & 3897 & 6547 & 5575 & 1497535 & 1384310 & 1147201 & 905790 \\
\hline 295 & 4610 & 4790 & 6254 & 5925 & 1502146 & 1388026 & 1153455 & 911715 \\
\hline 296 & 5499 & 4664 & 5064 & 4777 & 1507645 & 1393323 & 1158519 & 916492 \\
\hline 297 & 5374 & 4350 & 5813 & 5508 & 1513019 & 1398274 & 1164332 & 922001 \\
\hline 298 & 4575 & 3106 & 5898 & 5691 & 1517595 & 1401380 & 1170230 & 927692 \\
\hline 299 & 4841 & 3127 & 6020 & 5269 & 1522435 & 1404507 & 1176250 & 932961 \\
\hline 300 & 5029 & 3654 & 5005 & 5230 & 1527464 & 1408161 & 1181255 & 938190 \\
\hline 301 & 4840 & 3450 & 5553 & 5316 & 1532305 & 1411611 & 1186808 & 943507 \\
\hline 302 & 4903 & 3470 & 5216 & 5182 & 1537208 & 1415081 & 1192024 & 948689 \\
\hline 303 & 4566 & 3602 & 5268 & 4701 & 1541773 & 1418683 & 1197292 & 953389 \\
\hline 304 & 5151 & 4430 & 4864 & 5103 & 1546924 & 1423113 & 1202157 & 958492 \\
\hline 305 & 4815 & 3225 & 5544 & 5724 & 1551739 & 1426338 & 1207701 & 964216 \\
\hline 306 & 4703 & 3329 & 5385 & 5684 & 1556442 & 1429666 & 1213086 & 969899 \\
\hline 307 & 4295 & 2685 & 5504 & 5487 & 1560737 & 1432351 & 1218591 & 975386 \\
\hline 308 & 4653 & 2568 & 5140 & 5384 & 1565390 & 1434919 & 1223730 & 980770 \\
\hline 309 & 3659 & 2755 & 5396 & 5720 & 1569049 & 1437674 & 1229126 & 986490 \\
\hline 310 & 4188 & 2612 & 4486 & 4962 & 1573237 & 1440286 & 1233612 & 991452 \\
\hline 311 & 4030 & 2469 & 4504 & 4829 & 1577266 & 1442754 & 1238116 & 996281 \\
\hline 312 & 4263 & 3257 & 4317 & 4760 & 1581529 & 1446011 & 1242433 & 1001040 \\
\hline 313 & 4350 & 3740 & 4811 & 4969 & 1585879 & 1449751 & 1247244 & 1006010 \\
\hline 314 & 3624 & 3848 & 4574 & 4961 & 1589503 & 1453599 & 1251818 & 1010971 \\
\hline 315 & 3286 & 3219 & 4710 & 5510 & 1592789 & 1456818 & 1256528 & 1016481 \\
\hline 316 & 3166 & 3382 & 4201 & 4852 & 1595955 & 1460200 & 1260729 & 1021333 \\
\hline 317 & 3096 & 3054 & 4065 & 4783 & 1599051 & 1463254 & 1264794 & 1026116 \\
\hline 318 & 2927 & 2917 & 4268 & 4899 & 1601978 & 1466172 & 1269062 & 1031015 \\
\hline 319 & 2954 & 2753 & 4369 & 4922 & 1604931 & 1468925 & 1273431 & 1035937 \\
\hline 320 & 2687 & 2616 & 4233 & 5006 & 1607618 & 1471541 & 1277664 & 1040943 \\
\hline 321 & 2787 & 2643 & 4064 & 4784 & 1610405 & 1474184 & 1281728 & 1045727 \\
\hline 322 & 3253 & 2779 & 4165 & 4838 & 1613658 & 1476963 & 1285893 & 1050565 \\
\hline 323 & 3182 & 2560 & 4063 & 4677 & 1616841 & 1479523 & 1289956 & 1055242 \\
\hline 324 & 3087 & 2451 & 3927 & 4578 & 1619927 & 1481973 & 1293883 & 1059820 \\
\hline 325 & 3751 & 2940 & 3791 & 4540 & 1623678 & 1484914 & 1297674 & 1064360 \\
\hline 326 & 3483 & 2586 & 4570 & 5172 & 1627161 & 1487499 & 1302244 & 1069533 \\
\hline 327 & 3363 & 2367 & 4468 & 4982 & 1630524 & 1489867 & 1306711 & 1074514 \\
\hline 328 & 3046 & 2258 & 4264 & 5065 & 1633570 & 1492125 & 1310975 & 1079579 \\
\hline 329 & 2704 & 2176 & 4738 & 5147 & 1636275 & 1494301 & 1315713 & 1084726 \\
\hline 330 & 2657 & 2312 & 4365 & 4988 & 1638931 & 1496612 & 1320078 & 1089714 \\
\hline 331 & 2585 & 2229 & 4466 & 5372 & 1641516 & 1498842 & 1324544 & 1095087 \\
\hline 332 & 2833 & 2419 & 4533 & 5273 & 1644349 & 1501261 & 1329077 & 1100360 \\
\hline 333 & 2712 & 2256 & 4398 & 5325 & 1647061 & 1503517 & 1333474 & 1105686 \\
\hline 334 & 2788 & 2391 & 4668 & 5166 & 1649849 & 1505908 & 1338142 & 1110852 \\
\hline 335 & 2543 & 2228 & 4836 & 5128 & 1652391 & 1508136 & 1342979 & 1115980 \\
\hline 336 & 2223 & 2254 & 3483 & 4491 & 1654615 & 1510390 & 1346462 & 1120471 \\
\hline
\end{tabular}




\begin{tabular}{|c|c|c|c|c|c|c|c|c|}
\hline 337 & 2299 & 2281 & 3686 & 4574 & 1656914 & 1512671 & 1350148 & 1125045 \\
\hline 338 & 2350 & 2226 & 3821 & 4477 & 1659264 & 1514897 & 1353969 & 1129521 \\
\hline 339 & 2377 & 2307 & 3550 & 4708 & 1661641 & 1517204 & 1357519 & 1134229 \\
\hline 340 & 2378 & 2388 & 3888 & 4641 & 1664019 & 1519592 & 1361406 & 1138870 \\
\hline 341 & 2430 & 2198 & 3820 & 4514 & 1666449 & 1521790 & 1365226 & 1143384 \\
\hline 342 & 2555 & 2251 & 4090 & 4803 & 1669004 & 1524041 & 1369316 & 1148188 \\
\hline 343 & 2209 & 3147 & 3987 & 5034 & 1671213 & 1527188 & 1373303 & 1153221 \\
\hline 344 & 2358 & 3340 & 3985 & 5149 & 1673571 & 1530528 & 1377288 & 1158370 \\
\hline 345 & 1737 & 2447 & 3847 & 5114 & 1675308 & 1532975 & 1381135 & 1163484 \\
\hline 346 & 1811 & 2560 & 3036 & 3987 & 1677119 & 1535535 & 1384171 & 1167472 \\
\hline 347 & 2207 & 2263 & 2933 & 3748 & 1679326 & 1537798 & 1387104 & 1171219 \\
\hline 348 & 2132 & 2457 & 2864 & 4098 & 1681458 & 1540255 & 1389968 & 1175317 \\
\hline 349 & 2132 & 1941 & 2761 & 4182 & 1683590 & 1542196 & 1392729 & 1179499 \\
\hline 350 & 1784 & 1341 & 2692 & 3914 & 1685375 & 1543537 & 1395421 & 1183413 \\
\hline 351 & 1982 & 1645 & 2993 & 3881 & 1687357 & 1545182 & 1398414 & 1187294 \\
\hline 352 & 2279 & 2223 & 3260 & 4112 & 1689636 & 1547406 & 1401674 & 1191406 \\
\hline 353 & 2254 & 1952 & 3695 & 4196 & 1691889 & 1549357 & 1405370 & 1195602 \\
\hline 354 & 2327 & 2037 & 3693 & 3870 & 1694216 & 1551394 & 1409063 & 1199472 \\
\hline 355 & 2079 & 1874 & 3624 & 3808 & 1696296 & 1553268 & 1412687 & 280 \\
\hline 356 & 1460 & 1573 & 3454 & 3746 & $169^{7}$ & 1554841 & 5141 & 1207025 \\
\hline 357 & 2103 & 1741 & 3955 & 3596 & 1699858 & 1556582 & 1420095 & 1210621 \\
\hline 358 & 2028 & 1605 & 3416 & 3505 & 1701887 & 1558187 & 1423512 & 1214126 \\
\hline 359 & 2151 & 1995 & 3481 & 3443 & 1704038 & 1560182 & 1426993 & 1217570 \\
\hline 360 & 2052 & 2025 & 3814 & 3586 & 1706090 & 1562207 & 1430807 & 1221156 \\
\hline 361 & 1681 & 1556 & 3410 & 3379 & 1707770 & 1563763 & 1434218 & 1224534 \\
\hline 362 & 1804 & 1613 & 2907 & 2997 & 1709574 & 1565376 & 1437125 & 1227531 \\
\hline 363 & 1606 & 1504 & 2772 & 3285 & 1711180 & 1566881 & 1439897 & 1230817 \\
\hline 364 & 1679 & 2092 & 2537 & 3137 & 1712859 & 1568972 & 1442434 & 1233953 \\
\hline 365 & 1827 & 1732 & 2335 & 3337 & 1714686 & 1570704 & 1444769 & 1237290 \\
\hline 366 & 1728 & 1650 & 2834 & 3102 & 1716414 & 1572354 & 1447602 & 1240392 \\
\hline 367 & 1826 & 1876 & 2599 & 3476 & 1718240 & 1574230 & 1450201 & 1243868 \\
\hline 368 & 1653 & 1766 & 2697 & 3270 & 1719893 & 1575996 & 1452898 & 1247137 \\
\hline 369 & 1776 & 1628 & 2762 & 3064 & 1721669 & 1577625 & 1455661 & 1250202 \\
\hline 370 & 1554 & 1715 & 2561 & 2946 & 1723223 & 1579340 & 1458222 & 1253148 \\
\hline 371 & 1479 & 1492 & 2659 & 2885 & 1724702 & 1580832 & 1460881 & 1256033 \\
\hline
\end{tabular}

\subsection{Methane concentration}

\begin{tabular}{|c|cccc|cccc|}
\hline & \multicolumn{4}{|c|}{ Methane concentration \% } & \multicolumn{4}{c|}{ Methane concentration \% } \\
\hline Time & R1 & R2 & R3 & R4 & R5 & R6 & R7 & R8 \\
\hline 17 & 0.00 & 0.00 & 0.00 & 0.00 & $\mathbf{7 . 7 0}$ & 0.00 & 0.00 & 0.00 \\
18 & 0.00 & 0.00 & 0.00 & 0.00 & 8.12 & 0.00 & 0.00 & 0.00 \\
19 & 0.00 & 0.00 & 0.00 & 0.00 & 8.61 & $\mathbf{7 . 4 0}$ & 0.00 & 0.00 \\
20 & $\mathbf{1 1 . 7 0}$ & $\mathbf{9 . 9 0}$ & 0.00 & 0.00 & 8.12 & 7.50 & 0.00 & 0.00 \\
21 & 12.60 & 10.60 & $\mathbf{1 1 . 7 0}$ & 0.00 & 8.00 & 7.60 & $\mathbf{7 . 7 5}$ & 0.00 \\
22 & 13.90 & 11.40 & 12.30 & 0.00 & 8.99 & 7.90 & 7.40 & 0.00 \\
\hline
\end{tabular}




\begin{tabular}{|c|c|c|c|c|c|c|c|c|}
\hline 23 & 14.70 & 12.45 & 13.50 & 0.00 & 8.55 & 8.00 & 8.00 & 0.00 \\
\hline 24 & 16.30 & 14.00 & 14.90 & 0.00 & 8.55 & 8.20 & 7.90 & 0.00 \\
\hline 25 & 18.10 & 15.50 & 16.30 & 0.00 & 9.20 & 8.50 & 7.50 & 0.00 \\
\hline 26 & 19.20 & 16.22 & 16.30 & 0.00 & 8.71 & 8.10 & 7.63 & 0.00 \\
\hline 27 & 20.50 & 16.86 & 17.70 & 0.00 & 8.90 & 8.30 & 7.22 & 0.00 \\
\hline 28 & 21.40 & 17.16 & 18.90 & 0.00 & 9.50 & 8.50 & 8.12 & 0.00 \\
\hline 29 & 22.60 & 18.00 & 19.80 & 0.00 & 11.30 & 9.60 & 10.30 & 0.00 \\
\hline 30 & 23.00 & 21.00 & 22.30 & 0.00 & 12.35 & 10.05 & 10.76 & 0.00 \\
\hline 31 & 25.00 & 30.00 & 29.20 & 0.00 & 12.88 & 10.28 & 10.98 & 0.00 \\
\hline 32 & 23.25 & 33.42 & 31.00 & 0.00 & 13.40 & 10.50 & 11.21 & 0.00 \\
\hline 33 & 33.90 & 28.94 & 32.30 & 8.60 & 13.75 & 11.40 & 11.82 & 8.10 \\
\hline 34 & 36.42 & 31.13 & 32.51 & 10.73 & 14.10 & 12.30 & 12.43 & 8.30 \\
\hline 35 & 37.13 & 28.83 & 35.87 & 10.50 & 14.40 & 12.50 & 12.95 & 8.20 \\
\hline 36 & 40.79 & 35.38 & 36.46 & 12.31 & 14.55 & 12.60 & 13.20 & 7.90 \\
\hline 37 & 46.00 & 38.00 & 36.70 & 13.52 & 14.70 & 12.70 & 13.46 & 8.30 \\
\hline 38 & 40.39 & 34.81 & 36.90 & 13.10 & 15.30 & 13.40 & 14.99 & 9.40 \\
\hline 39 & 46.18 & 41.91 & 37.70 & 15.40 & 15.90 & 13.80 & 15.65 & 8.85 \\
\hline 40 & 49.25 & 44.06 & 37.10 & 16.52 & 16.20 & 14.00 & 15.97 & 8.58 \\
\hline 41 & 42.23 & 38.56 & 36.30 & 13.95 & 16.50 & 14.20 & 16.30 & 8.30 \\
\hline 42 & 48.36 & 41.16 & 38.70 & 16.00 & 14.83 & 12.90 & 14.25 & 8.50 \\
\hline 43 & 43.60 & 48.36 & 37.90 & 16.00 & 13.16 & 11.60 & 12.20 & 8.70 \\
\hline 44 & 46.40 & 49.85 & 39.00 & 17.65 & 14.82 & 12.93 & 13.23 & 9.13 \\
\hline 45 & 43.36 & 48.82 & 39.31 & 18.46 & 16.48 & 14.25 & 14.27 & 9.57 \\
\hline 46 & 49.74 & 49.50 & 39.20 & 20.03 & 18.14 & 15.58 & 15.30 & 10.00 \\
\hline 47 & 48.50 & 50.00 & 40.20 & 21.46 & 19.80 & 16.90 & 16.33 & 10.43 \\
\hline 48 & 50.27 & 50.20 & 42.30 & 22.46 & 20.16 & 17.39 & 17.08 & 10.82 \\
\hline 49 & 50.27 & 50.20 & 40.20 & 22.46 & 20.51 & 17.89 & 17.82 & 11.21 \\
\hline 50 & 50.27 & 50.20 & 43.60 & 22.46 & 20.87 & 18.38 & 18.57 & 11.60 \\
\hline 51 & 53.16 & 49.49 & 44.75 & 21.44 & 21.23 & 18.88 & 19.31 & 11.98 \\
\hline 52 & 52.33 & 43.55 & 46.40 & 21.93 & 21.59 & 19.37 & 20.06 & 12.37 \\
\hline 53 & 54.02 & 44.51 & 45.00 & 21.93 & 21.94 & 19.87 & 20.80 & 12.76 \\
\hline 54 & 55.06 & 48.89 & 43.36 & 20.73 & 22.30 & 20.36 & 21.55 & 13.15 \\
\hline 55 & 55.20 & 48.91 & 43.36 & 20.73 & 22.85 & 21.64 & 22.76 & 14.47 \\
\hline 56 & 54.66 & 43.41 & 40.20 & 20.19 & 23.39 & 22.92 & 23.96 & 15.78 \\
\hline 57 & 53.61 & 46.30 & 41.78 & 21.34 & 23.94 & 24.20 & 25.17 & 17.10 \\
\hline 58 & 54.56 & 45.18 & 41.61 & 22.17 & 24.48 & 25.48 & 26.37 & 18.41 \\
\hline 59 & 54.56 & 45.18 & 41.61 & 22.17 & 26.04 & 25.86 & 25.63 & 18.62 \\
\hline 60 & 52.83 & 41.23 & 43.24 & 19.87 & 27.60 & 26.23 & 24.89 & 18.83 \\
\hline 61 & 52.39 & 40.90 & 42.40 & 19.50 & 28.75 & 27.64 & 25.95 & 19.48 \\
\hline 62 & 51.96 & 40.68 & 41.70 & 19.20 & 29.32 & 28.35 & 26.48 & 19.81 \\
\hline 63 & 51.53 & 40.40 & 41.20 & 18.80 & 29.89 & 29.05 & 27.01 & 20.13 \\
\hline 64 & 51.10 & 40.13 & 40.64 & 18.43 & 31.05 & 31.54 & 29.07 & 22.53 \\
\hline 65 & 49.84 & 39.30 & 40.40 & 18.60 & 32.22 & 32.10 & 31.14 & 24.92 \\
\hline 66 & 48.57 & 38.46 & 40.94 & 18.80 & 33.38 & 33.00 & 31.40 & 24.92 \\
\hline 67 & 47.31 & 38.55 & 40.71 & 18.65 & 33.38 & 34.03 & 33.20 & 24.92 \\
\hline 68 & 46.05 & 38.65 & 40.48 & 18.50 & 34.06 & 33.82 & 33.50 & 24.31 \\
\hline 69 & 44.79 & 38.74 & 40.24 & 18.34 & 34.74 & 33.60 & 33.10 & 25.13 \\
\hline 70 & 43.53 & 38.83 & 40.01 & 18.19 & 35.42 & 33.39 & 33.90 & 23.49 \\
\hline 71 & 43.46 & 38.70 & 39.94 & 18.53 & 36.10 & 33.17 & 33.60 & 24.10 \\
\hline 72 & 43.40 & 38.58 & 39.87 & 18.86 & 36.60 & 33.29 & 33.80 & 23.90 \\
\hline
\end{tabular}




\begin{tabular}{|c|c|c|c|c|c|c|c|c|}
\hline 73 & 43.33 & 38.45 & 39.80 & 19.20 & 37.10 & 33.42 & 33.94 & 23.76 \\
\hline 74 & 42.78 & 38.34 & 39.47 & 19.60 & 37.60 & 33.54 & 33.70 & 24.00 \\
\hline 75 & 42.22 & 38.23 & 39.14 & 20.00 & 38.10 & 33.67 & 34.29 & 23.42 \\
\hline 76 & 41.67 & 38.12 & 38.81 & 20.40 & 38.60 & 33.79 & 34.46 & 23.25 \\
\hline 77 & 41.12 & 38.01 & 38.47 & 20.79 & 39.09 & 33.92 & 34.63 & 23.09 \\
\hline 78 & 40.56 & 37.90 & 38.14 & 21.19 & 39.59 & 34.04 & 34.80 & 22.92 \\
\hline 79 & 40.01 & 37.79 & 37.81 & 21.59 & 40.09 & 34.17 & 34.97 & 22.75 \\
\hline 80 & 39.59 & 37.27 & 37.41 & 22.06 & 40.59 & 34.29 & 35.15 & 22.58 \\
\hline 81 & 39.18 & 36.75 & 37.01 & 22.53 & 41.09 & 34.42 & 35.32 & 22.41 \\
\hline 82 & 38.76 & 36.24 & 36.61 & 23.00 & 41.59 & 34.54 & 35.49 & 22.24 \\
\hline 83 & 38.34 & 35.72 & 36.20 & 23.48 & 42.67 & 37.38 & 37.39 & 23.10 \\
\hline 84 & 37.92 & 36.86 & 35.80 & 23.95 & 43.75 & 40.22 & 39.28 & 23.96 \\
\hline 85 & 37.51 & 36.45 & 35.40 & 24.42 & 44.82 & 43.06 & 41.18 & 24.82 \\
\hline 86 & 37.09 & 36.05 & 35.00 & 24.89 & 45.90 & 45.90 & 43.07 & 25.68 \\
\hline 87 & 37.57 & 36.33 & 35.10 & 26.23 & 46.44 & 45.11 & 42.69 & 25.62 \\
\hline 88 & 38.05 & 36.62 & 35.20 & 27.57 & 46.97 & 44.31 & 42.30 & 25.55 \\
\hline 89 & 38.52 & 36.91 & 35.30 & 28.91 & 47.55 & 45.43 & 42.10 & 27.89 \\
\hline 90 & 39.00 & 37.20 & 35.40 & 30.25 & 47.83 & 45.99 & 42.00 & 29.05 \\
\hline 91 & 38.29 & 36.96 & 35.62 & 29.53 & 48.12 & 46.55 & 41.90 & 30.22 \\
\hline 92 & 37.59 & 36.71 & 35.84 & 28.81 & 48.43 & 47.88 & 44.96 & 29.46 \\
\hline 93 & 36.88 & 36.47 & 35.06 & 28.10 & 48.59 & 48.54 & 46.49 & 29.08 \\
\hline 94 & 36.18 & 36.23 & 35.40 & 27.38 & 48.74 & 49.20 & 48.02 & 28.70 \\
\hline 95 & 35.47 & 35.99 & 35.50 & 26.66 & 48.66 & 48.52 & 47.97 & 31.95 \\
\hline 96 & 36.78 & 36.69 & 34.90 & 28.68 & 48.57 & 47.84 & 47.91 & 35.20 \\
\hline 97 & 38.09 & 36.40 & 36.70 & 30.70 & 47.81 & 46.10 & 45.70 & 36.89 \\
\hline 98 & 39.40 & 35.60 & 36.80 & 32.72 & 47.06 & 44.36 & 43.49 & 38.58 \\
\hline 99 & 40.71 & 35.10 & 36.90 & 34.74 & 46.30 & 42.62 & 41.28 & 40.27 \\
\hline 100 & 39.80 & 34.60 & 35.60 & 35.77 & 45.55 & 40.88 & 39.07 & 41.96 \\
\hline 101 & 38.89 & 37.40 & 35.88 & 36.80 & 46.77 & 43.30 & 41.11 & 39.73 \\
\hline 102 & 37.98 & 36.40 & 36.30 & 37.82 & 46.64 & 43.33 & 41.18 & 39.77 \\
\hline 103 & 37.07 & 35.10 & 35.50 & 38.85 & 46.51 & 43.35 & 41.25 & 39.82 \\
\hline 104 & 36.24 & 36.98 & 37.73 & 38.28 & 46.37 & 43.38 & 41.32 & 39.86 \\
\hline 105 & 35.40 & 36.01 & 36.61 & 37.70 & 46.24 & 43.41 & 41.38 & 39.91 \\
\hline 106 & 35.42 & 36.03 & 36.64 & 38.13 & 46.11 & 43.43 & 41.45 & 39.95 \\
\hline 107 & 35.44 & 36.06 & 36.68 & 38.56 & 45.98 & 43.46 & 41.52 & 40.00 \\
\hline 108 & 35.47 & 36.09 & 36.71 & 39.00 & 45.85 & 43.49 & 41.59 & 40.04 \\
\hline 109 & 35.49 & 36.12 & 35.75 & 39.43 & 45.71 & 43.51 & 41.66 & 40.09 \\
\hline 110 & 35.51 & 36.15 & 34.78 & 39.86 & 45.58 & 43.54 & 41.73 & 40.13 \\
\hline 111 & 35.53 & 36.18 & 34.82 & 40.29 & 45.45 & 43.57 & 41.80 & 40.18 \\
\hline 112 & 35.56 & 36.20 & 36.85 & 40.73 & 45.45 & 43.57 & 41.80 & 40.18 \\
\hline 113 & 35.58 & 36.23 & 36.89 & 41.16 & 45.32 & 43.57 & 41.80 & 40.18 \\
\hline 114 & 35.60 & 36.26 & 36.92 & 41.59 & 45.19 & 43.59 & 41.80 & 40.18 \\
\hline 115 & 35.65 & 36.21 & 35.77 & 42.01 & 45.05 & 43.62 & 41.87 & 40.18 \\
\hline 116 & 35.70 & 36.16 & 35.61 & 42.42 & 44.79 & 43.70 & 42.14 & 40.40 \\
\hline 117 & 35.75 & 36.10 & 34.46 & 42.84 & 47.43 & 42.98 & 42.26 & 40.45 \\
\hline 118 & 35.80 & 36.05 & 35.30 & 43.25 & 50.07 & 42.25 & 42.37 & 40.50 \\
\hline 119 & 35.90 & 35.95 & 37.01 & 41.35 & 49.88 & 42.44 & 42.27 & 40.68 \\
\hline 120 & 36.00 & 35.86 & 35.71 & 39.45 & 49.70 & 42.63 & 42.18 & 40.87 \\
\hline 121 & 36.20 & 35.69 & 35.18 & 39.86 & 49.51 & 42.83 & 42.08 & 41.05 \\
\hline 122 & 36.40 & 35.53 & 34.66 & 40.28 & 49.32 & 43.02 & 41.98 & 41.23 \\
\hline
\end{tabular}




\begin{tabular}{|c|c|c|c|c|c|c|c|c|}
\hline 123 & 36.60 & 35.36 & 34.13 & 40.69 & 49.13 & 43.21 & 41.89 & 41.42 \\
\hline 124 & 36.80 & 35.20 & 33.60 & 41.10 & 48.95 & 43.40 & 41.79 & 41.60 \\
\hline 125 & 37.15 & 35.63 & 34.10 & 41.90 & 48.76 & 43.59 & 41.69 & 41.78 \\
\hline 126 & 37.50 & 36.05 & 34.60 & 42.70 & 48.57 & 43.78 & 41.60 & 41.97 \\
\hline 127 & 38.56 & 36.75 & 34.93 & 43.42 & 48.39 & 43.98 & 41.50 & 42.15 \\
\hline 128 & 39.62 & 37.44 & 35.27 & 44.14 & 48.20 & 44.17 & 41.40 & 42.33 \\
\hline 129 & 40.68 & 38.14 & 35.60 & 44.86 & 48.01 & 44.36 & 41.31 & 42.52 \\
\hline 130 & 39.90 & 38.00 & 36.10 & 44.29 & 47.82 & 44.55 & 41.21 & 42.70 \\
\hline 131 & 39.12 & 37.86 & 36.60 & 43.72 & 47.64 & 44.74 & 41.11 & 42.88 \\
\hline 132 & 38.34 & 37.72 & 37.09 & 43.15 & 47.45 & 44.93 & 41.02 & 43.07 \\
\hline 133 & 37.56 & 37.58 & 37.59 & 42.58 & 47.26 & 45.13 & 40.92 & 43.25 \\
\hline 134 & 37.42 & 37.76 & 38.11 & 43.67 & 47.07 & 45.32 & 40.82 & 43.43 \\
\hline 135 & 37.27 & 37.95 & 38.62 & 44.76 & 46.89 & 45.51 & 40.73 & 43.62 \\
\hline 136 & 37.13 & 38.13 & 39.14 & 45.85 & 46.70 & 45.70 & 40.63 & 43.80 \\
\hline 137 & 36.98 & 38.32 & 39.66 & 46.94 & 46.51 & 45.40 & 40.94 & 43.98 \\
\hline 138 & 36.84 & 38.50 & 40.17 & 48.03 & 46.32 & 45.09 & 41.25 & 44.17 \\
\hline 139 & 36.69 & 38.69 & 40.69 & 49.12 & 46.13 & 44.79 & 41.57 & 44.35 \\
\hline 140 & 36.55 & 38.87 & 41.20 & 50.21 & 45.94 & 44.48 & 41.88 & 44.54 \\
\hline 141 & 36.40 & 39.06 & 41.72 & 51.30 & 45.75 & 44.18 & 42.19 & 44.72 \\
\hline 142 & 37.47 & 39.55 & 41.63 & 50.76 & 45.56 & 43.88 & 42.50 & 44.90 \\
\hline 143 & 38.55 & 40.05 & 41.55 & 50.21 & 45.37 & 43.57 & 42.81 & 45.09 \\
\hline 144 & 39.62 & 40.54 & 41.46 & 49.67 & 45.18 & 43.27 & 43.13 & 45.27 \\
\hline 145 & 40.69 & 41.03 & 41.37 & 49.13 & 44.99 & 42.96 & 43.44 & 45.46 \\
\hline 146 & 41.76 & 41.52 & 41.28 & 48.58 & 44.80 & 42.66 & 43.75 & 45.64 \\
\hline 147 & 42.84 & 42.02 & 41.20 & 48.04 & 44.85 & 42.88 & 43.80 & 45.54 \\
\hline 148 & 42.84 & 42.02 & 41.20 & 48.04 & 44.90 & 43.10 & 43.85 & 45.44 \\
\hline 149 & 42.84 & 42.02 & 41.20 & 48.04 & 44.95 & 43.32 & 43.90 & 45.33 \\
\hline 150 & 46.05 & 43.49 & 40.93 & 46.41 & 45.00 & 43.54 & 43.95 & 45.23 \\
\hline 151 & 46.05 & 43.49 & 40.93 & 46.41 & 45.05 & 43.75 & 44.00 & 45.13 \\
\hline 152 & 48.20 & 44.48 & 40.76 & 45.32 & 45.10 & 43.97 & 44.05 & 45.02 \\
\hline 153 & 47.96 & 44.39 & 40.83 & 44.75 & 45.15 & 44.19 & 44.10 & 44.92 \\
\hline 154 & 47.71 & 44.31 & 40.90 & 44.19 & 45.20 & 44.41 & 44.15 & 44.82 \\
\hline 155 & 47.47 & 44.22 & 40.97 & 43.63 & 45.25 & 44.63 & 44.20 & 44.71 \\
\hline 156 & 47.23 & 44.13 & 41.03 & 43.06 & 45.30 & 44.84 & 44.25 & 44.61 \\
\hline 157 & 46.98 & 44.04 & 41.10 & 42.50 & 45.35 & 45.06 & 44.30 & 44.50 \\
\hline 158 & 46.74 & 43.96 & 41.17 & 41.93 & 45.16 & 45.30 & 44.10 & 44.35 \\
\hline 159 & 45.66 & 43.35 & 41.05 & 41.56 & 44.98 & 45.53 & 43.89 & 44.19 \\
\hline 160 & 44.59 & 42.75 & 40.92 & 41.19 & 44.79 & 45.77 & 43.68 & 44.03 \\
\hline 161 & 43.51 & 42.15 & 40.80 & 40.83 & 44.61 & 46.00 & 43.48 & 43.88 \\
\hline 162 & 42.43 & 41.55 & 40.67 & 40.46 & 44.42 & 46.24 & 43.27 & 43.72 \\
\hline 163 & 41.36 & 40.95 & 40.55 & 40.09 & 44.24 & 46.47 & 43.06 & 43.56 \\
\hline 164 & 40.28 & 40.35 & 40.43 & 39.72 & 44.05 & 46.71 & 42.85 & 43.40 \\
\hline 165 & 39.20 & 39.75 & 40.30 & 39.35 & 43.87 & 46.94 & 42.65 & 43.25 \\
\hline 166 & 38.12 & 39.15 & 40.18 & 38.99 & 43.68 & 47.18 & 42.44 & 43.09 \\
\hline 167 & 37.05 & 38.55 & 40.05 & 39.00 & 43.50 & 47.41 & 42.23 & 42.93 \\
\hline 168 & 35.97 & 37.95 & 39.93 & 38.25 & 43.31 & 47.65 & 42.02 & 42.77 \\
\hline 169 & 40.54 & 38.48 & 36.42 & 38.66 & 43.13 & 47.88 & 41.82 & 42.62 \\
\hline 170 & 38.75 & 36.71 & 34.67 & 35.47 & 42.94 & 48.12 & 41.61 & 42.46 \\
\hline 171 & 38.45 & 36.42 & 34.38 & 34.94 & 42.76 & 48.35 & 41.40 & 42.30 \\
\hline 172 & 38.16 & 36.12 & 34.08 & 34.41 & 42.58 & 48.58 & 41.19 & 42.14 \\
\hline
\end{tabular}




\begin{tabular}{|c|c|c|c|c|c|c|c|c|}
\hline 173 & 37.86 & 35.83 & 33.79 & 33.87 & 42.95 & 48.71 & 41.73 & $\overline{42.36}$ \\
\hline 174 & 37.56 & 35.53 & 33.50 & 33.34 & 43.32 & 48.85 & 42.28 & 42.57 \\
\hline 175 & 37.26 & 35.24 & 33.21 & 32.81 & 43.69 & 48.98 & 42.82 & 42.79 \\
\hline 176 & 36.96 & 34.94 & 32.92 & 32.28 & 44.06 & 49.12 & 43.37 & 43.00 \\
\hline 177 & 36.67 & 34.65 & 32.62 & 31.75 & 44.43 & 49.26 & 43.92 & 43.21 \\
\hline 178 & 36.37 & 34.35 & 32.33 & 31.21 & 44.80 & 49.39 & 44.46 & 43.42 \\
\hline 179 & 37.56 & 35.53 & 33.50 & 33.34 & 45.17 & 49.53 & 45.01 & 43.64 \\
\hline 180 & 37.72 & 36.75 & 35.78 & 37.57 & 45.55 & 49.66 & 45.55 & 43.85 \\
\hline 181 & 37.75 & 36.95 & 36.16 & 38.28 & 45.92 & 49.80 & 46.10 & 44.06 \\
\hline 182 & 37.78 & 37.16 & 36.54 & 38.98 & 46.29 & 49.93 & 46.64 & 44.28 \\
\hline 183 & 37.80 & 37.36 & 36.92 & 39.69 & 46.66 & 50.07 & 47.19 & 44.49 \\
\hline 184 & 37.83 & 37.57 & 37.30 & 40.39 & 47.03 & 50.21 & 47.74 & 44.70 \\
\hline 185 & 37.86 & 37.77 & 37.68 & 41.10 & 47.40 & 50.34 & 48.28 & 44.92 \\
\hline 186 & 37.88 & 37.97 & 38.06 & 41.80 & 47.78 & 50.48 & 48.83 & 45.12 \\
\hline 187 & 37.91 & 38.18 & 38.44 & 42.51 & 47.80 & 50.38 & 48.88 & 45.29 \\
\hline 188 & 37.94 & 38.38 & 38.82 & 43.21 & 47.82 & 50.29 & 48.93 & 45.45 \\
\hline 189 & 37.83 & 37.57 & 37.30 & 40.39 & 47.84 & 50.19 & 48.99 & 45.62 \\
\hline 190 & 38.34 & 38.22 & 38.10 & 38.83 & 47.86 & 50.10 & 49.04 & 45.78 \\
\hline 191 & 38.45 & 38.33 & 38.21 & 38.57 & 47.88 & 50.00 & 49.09 & 45.95 \\
\hline 192 & 38.55 & 38.44 & 38.32 & 38.31 & 47.90 & 49.91 & 49.14 & 46.11 \\
\hline 193 & 38.65 & 38.54 & 38.44 & 38.05 & 47.92 & 49.81 & 49.19 & 46.28 \\
\hline 194 & 38.75 & 38.65 & 38.55 & 37.79 & 47.94 & 49.72 & 49.25 & 46.44 \\
\hline 195 & 38.86 & 38.76 & 38.66 & 37.53 & 47.96 & 49.62 & 49.30 & 46.61 \\
\hline 196 & 38.96 & 38.87 & 38.77 & 37.27 & 47.98 & 49.53 & 49.35 & 46.78 \\
\hline 197. & 39.06 & 38.97 & 38.89 & 37.01 & 48.00 & 49.43 & 49.40 & 46.94 \\
\hline 198 & 39.16 & 39.08 & 39.00 & 36.75 & 48.02 & 49.34 & 49.45 & 47.11 \\
\hline 199 & 39.27 & 39.19 & 39.11 & 36.49 & 48.04 & 49.24 & 49.51 & 47.27 \\
\hline 200 & 39.37 & 39.30 & 39.23 & 36.23 & 48.06 & 49.15 & 49.56 & 47.44 \\
\hline 201 & 39.47 & 39.40 & 39.34 & 35.97 & 48.08 & 49.05 & 49.61 & 47.60 \\
\hline 202 & 39.57 & 39.51 & 39.45 & 35.71 & 48.10 & 48.96 & 49.66 & 47.77 \\
\hline 203 & 39.68 & 39.62 & 39.56 & 35.45 & 48.12 & 48.86 & 49.71 & 47.93 \\
\hline 204 & 39.06 & 39.22 & 39.38 & 36.49 & 48.14 & 48.77 & 49.77 & 48.10 \\
\hline 205 & 39.88 & 39.83 & 39.79 & 37.72 & 48.16 & 48.67 & 49.82 & 48.27 \\
\hline 206 & 39.98 & 39.94 & 39.90 & 37.92 & 48.18 & 48.58 & 49.87 & 48.43 \\
\hline 207 & 40.09 & 40.05 & 40.01 & 38.12 & 48.20 & 48.48 & 49.92 & 48.60 \\
\hline 208 & 40.19 & 40.16 & 40.13 & 38.32 & 48.22 & 48.39 & 49.97 & 48.76 \\
\hline 209 & 40.29 & 40.26 & 40.24 & 38.53 & 48.24 & 48.29 & 50.03 & 48.93 \\
\hline 210 & 40.39 & 40.37 & 40.35 & 38.73 & 48.26 & 48.20 & 50.08 & 49.09 \\
\hline 211 & 40.50 & 40.48 & 40.46 & 38.93 & 48.28 & 48.10 & 50.13 & 49.26 \\
\hline 212 & 40.60 & 40.59 & 40.58 & 39.14 & 48.30 & 48.11 & 50.00 & 49.18 \\
\hline 213 & 40.70 & 40.70 & 40.69 & 39.34 & 48.31 & 48.12 & 49.88 & 49.10 \\
\hline 214 & 40.80 & 40.80 & 40.80 & 39.54 & 48.33 & 48.12 & 49.75 & 49.02 \\
\hline 215 & 40.91 & 40.91 & 40.92 & 39.74 & 48.35 & 48.13 & 49.62 & 48.95 \\
\hline 216 & 41.01 & 41.02 & 41.03 & 39.95 & 48.37 & 48.14 & 49.50 & 48.87 \\
\hline 217 & 41.11 & 41.13 & 41.14 & 40.15 & 48.38 & 48.15 & 49.37 & 48.79 \\
\hline 218 & 40.81 & 40.69 & 40.56 & 39.33 & 48.40 & 48.16 & 49.25 & 48.71 \\
\hline 219 & 42.51 & 40.30 & 41.29 & 40.20 & 48.42 & 48.16 & 49.12 & 48.63 \\
\hline 220 & 42.79 & 40.85 & 41.42 & 40.35 & 48.43 & 48.17 & 48.99 & 48.55 \\
\hline 221 & 43.07 & 41.39 & 41.54 & 40.49 & 48.45 & 48.18 & 48.87 & 48.47 \\
\hline 222 & 43.35 & 41.94 & 41.66 & 40.64 & 48.47 & 48.19 & 48.74 & 48.40 \\
\hline
\end{tabular}




\begin{tabular}{|c|c|c|c|c|c|c|c|c|}
\hline 223 & 43.63 & 42.48 & 41.79 & 40.78 & 48.48 & 48.20 & 48.61 & 48.32 \\
\hline 224 & 42.50 & 40.30 & 41.30 & 40.20 & 48.50 & 48.20 & 48.49 & 48.24 \\
\hline 225 & 42.19 & 40.83 & 41.21 & 40.21 & 48.52 & 48.21 & 48.36 & 48.16 \\
\hline 226 & 42.13 & 40.92 & 41.19 & 40.22 & 48.54 & 48.22 & 48.23 & 48.08 \\
\hline 227 & 42.08 & 41.00 & 41.18 & 40.22 & 48.55 & 48.23 & 48.11 & 48.00 \\
\hline 228 & 42.03 & 41.09 & 41.16 & 40.22 & 48.57 & 48.24 & 47.98 & 47.93 \\
\hline 229 & 41.97 & 41.18 & 41.15 & 40.23 & 48.59 & 48.24 & 47.85 & 47.85 \\
\hline 230 & 41.92 & 41.27 & 41.13 & 40.23 & 48.60 & 48.25 & 47.73 & 47.77 \\
\hline 231 & 41.87 & 41.36 & 41.12 & 40.24 & 48.62 & 48.26 & 47.60 & 47.69 \\
\hline 232 & 41.81 & 41.45 & 41.10 & 40.24 & 48.89 & 48.21 & 47.78 & 47.78 \\
\hline 233 & 41.76 & 41.53 & 41.09 & 40.24 & 49.18 & 48.17 & 47.97 & 47.85 \\
\hline 234 & 41.71 & 41.62 & 41.08 & 40.25 & 49.46 & 48.13 & 48.15 & 47.93 \\
\hline 235 & 41.65 & 41.71 & 41.06 & 40.25 & 49.75 & 48.08 & 48.33 & 48.01 \\
\hline 236 & 41.60 & 41.80 & 41.05 & 40.25 & 50.03 & 48.04 & 48.52 & 48.08 \\
\hline 237 & 41.55 & 41.89 & 41.03 & 40.26 & 50.31 & 48.00 & 48.70 & 48.16 \\
\hline 238 & 41.49 & 41.97 & 41.02 & 40.26 & 50.60 & 47.95 & 48.89 & 48.23 \\
\hline 239 & 41.44 & 42.06 & 41.00 & 40.27 & 50.88 & 47.91 & 49.07 & 48.31 \\
\hline 240 & 41.39 & 42.15 & 40.99 & 40.27 & 51.16 & 47.87 & 49.26 & 48.39 \\
\hline 241 & 41.33 & 42.24 & 40.97 & 40.27 & 51.45 & 47.82 & 49.44 & 48.46 \\
\hline 242 & 41.28 & 42.33 & 40.96 & 40.28 & 51.73 & 47.78 & 49.63 & 48.54 \\
\hline 243 & 41.23 & 42.42 & 40.95 & 40.28 & 52.02 & 47.74 & 49.81 & 48.61 \\
\hline 244 & 41.17 & 42.50 & 40.93 & 40.29 & 52.31 & 47.70 & 50.00 & 48.68 \\
\hline 245 & 41.12 & 42.59 & 40.92 & 40.29 & 52.19 & 47.74 & 49.86 & 49.86 \\
\hline 246 & 41.07 & 42.68 & 40.90 & 40.29 & 52.06 & 47.78 & 49.73 & 49.73 \\
\hline 247 & 41.01 & 42.77 & 40.89 & 40.30 & 51.94 & 47.81 & 49.59 & 49.59 \\
\hline 248 & 40.96 & 42.86 & 40.87 & 40.30 & 51.81 & 47.85 & 49.45 & 49.45 \\
\hline 249 & 40.91 & 42.94 & 40.86 & 40.30 & 51.69 & 47.89 & 49.31 & 49.31 \\
\hline 250 & 40.86 & 43.03 & 40.85 & 40.31 & 51.56 & 47.93 & 49.18 & 49.18 \\
\hline 251 & 40.80 & 43.12 & 40.83 & 40.31 & 51.44 & 47.96 & 49.04 & 49.04 \\
\hline 252 & 40.75 & 43.21 & 40.82 & 40.32 & 51.31 & 48.00 & 48.90 & 48.90 \\
\hline 253 & 40.70 & 43.30 & 40.80 & 40.32 & 51.19 & 48.04 & 48.76 & 48.76 \\
\hline 254 & 40.64 & 43.39 & 40.79 & 40.32 & 51.06 & 48.08 & 48.63 & 48.63 \\
\hline 255 & 40.59 & 43.47 & 40.77 & 40.33 & 50.93 & 48.11 & 48.49 & 48.49 \\
\hline 256 & 40.54 & 43.56 & 40.76 & 40.33 & 50.81 & 48.15 & 48.35 & 48.35 \\
\hline 257 & 40.48 & 43.65 & 40.74 & 40.33 & 50.68 & 48.19 & 48.21 & 48.21 \\
\hline 258 & 40.43 & 43.74 & 40.73 & 40.34 & 50.56 & 48.23 & 48.08 & 48.08 \\
\hline 259 & 40.38 & 43.83 & 40.72 & 40.34 & 50.43 & 48.26 & 47.94 & 47.94 \\
\hline 260 & 40.32 & 43.92 & 40.70 & 40.35 & 50.30 & 48.30 & 47.80 & 47.00 \\
\hline 261 & 40.27 & 44.00 & 40.69 & 40.35 & 50.30 & 48.29 & 48.03 & 47.22 \\
\hline 262 & 40.22 & 44.09 & 40.67 & 40.35 & 50.30 & 48.28 & 48.26 & 47.42 \\
\hline 263 & 40.42 & 43.74 & 40.74 & 40.35 & 50.30 & 48.29 & 48.03 & 47.22 \\
\hline 264 & 40.30 & 43.94 & 40.69 & 40.43 & 50.30 & 48.28 & 48.26 & 47.42 \\
\hline 265 & 40.19 & 44.13 & 40.64 & 40.51 & 50.30 & 48.27 & 48.49 & 47.63 \\
\hline 266 & 40.08 & 44.32 & 40.59 & 40.59 & 50.30 & 48.26 & 48.72 & 4783 \\
\hline 267 & 39.96 & 44.52 & 40.54 & 40.67 & 50.31 & 48.25 & 48.95 & 4804 \\
\hline 268 & 39.85 & 4471 & 40.50 & 40.74 & 50.31 & 48.24 & 49.17 & 4825 \\
\hline 269 & 39.74 & 44.91 & 40.45 & 40.82 & 50.31 & 48.23 & 49.40 & 48.45 \\
\hline 270 & 39.63 & 45.10 & 40.40 & 40.90 & 50.31 & 48.23 & 49.63 & 48.66 \\
\hline 271 & 39.52 & 45.29 & 40.35 & 40.98 & 50.31 & 48.22 & 49.86 & 48.86 \\
\hline 272 & 39.41 & 45.49 & 40.30 & 41.06 & 50.32 & 48.21 & 50.08 & 49.07 \\
\hline
\end{tabular}




\begin{tabular}{|c|c|c|c|c|c|c|c|c|}
\hline 273 & 39.29 & 45.68 & 40.26 & 41.13 & 50.32 & 48.20 & 50.31 & 49.27 \\
\hline 274 & 39.18 & 45.88 & 40.21 & 41.21 & 50.32 & 48.19 & 50.54 & 49.48 \\
\hline 275 & 39.07 & 46.07 & 40.16 & 41.29 & 50.32 & 48.18 & 50.77 & 49.68 \\
\hline 276 & 38.96 & 46.26 & 40.11 & 41.37 & 50.32 & 48.17 & 51.00 & 49.89 \\
\hline 277 & 38.85 & 46.46 & 40.07 & 41.44 & 50.33 & 48.16 & 51.22 & 50.10 \\
\hline 278 & 38.74 & 46.65 & 40.02 & 41.52 & 50.33 & 48.15 & 51.45 & 50.30 \\
\hline 279 & 38.62 & 46.85 & 39.97 & 41.60 & 50.33 & 48.15 & 51.68 & 50.51 \\
\hline 280 & 38.51 & 47.04 & 39.92 & 41.68 & 50.34 & 48.14 & 51.90 & 50.70 \\
\hline 281 & 38.41 & 47.23 & 39.88 & 41.75 & 50.37 & 48.09 & 51.88 & 50.69 \\
\hline 282 & 38.48 & 47.39 & 39.94 & 41.95 & 50.39 & 48.03 & 51.84 & 50.68 \\
\hline 283 & 38.54 & 47.56 & 40.01 & 42.16 & 50.41 & 47.97 & 51.80 & 50.67 \\
\hline 284 & 38.60 & 47.73 & 40.08 & 42.36 & 50.43 & 47.92 & 51.76 & 50.67 \\
\hline 285 & 38.66 & 47.90 & 40.15 & 42.57 & 50.45 & 47.86 & 51.73 & 50.66 \\
\hline 286 & 38.72 & 48.07 & 40.22 & 42.78 & 50.47 & 47.80 & 51.69 & 50.65 \\
\hline 287 & 38.77 & 48.24 & 40.29 & 42.99 & 50.50 & 47.74 & 51.65 & 50.64 \\
\hline 288 & 38.83 & 48.41 & 40.35 & 43.20 & 50.52 & 47.68 & 51.61 & 50.63 \\
\hline 289 & 38.89 & 48.58 & 40.42 & 43.40 & 50.54 & 47.63 & 51.57 & 50.62 \\
\hline 290 & 38.95 & 48.75 & 40.49 & 43.61 & 50.56 & 47.57 & 51.54 & 50.61 \\
\hline 291 & 39.01 & 48.92 & 40.56 & 43.82 & 50.58 & 47.51 & 51.50 & 50.60 \\
\hline 292 & 39.07 & 49.09 & 40.63 & 44.03 & 50.60 & 47.45 & 51.46 & 50.59 \\
\hline 293 & 39.13 & 49.26 & 40.70 & 44.24 & 50.62 & 47.39 & 51.42 & 50.58 \\
\hline 294 & 39.19 & 49.43 & 40.77 & 44.44 & 50.64 & 47.33 & 51.39 & 50.57 \\
\hline 295 & 39.25 & 49.60 & 40.84 & 44.65 & 50.66 & 47.28 & 51.35 & 50.56 \\
\hline 296 & 39.31 & 49.77 & 40.90 & 44.86 & 50.69 & 47.22 & 51.31 & 50.55 \\
\hline 297 & 39.36 & 49.94 & 40.97 & 45.07 & 50.70 & 47.15 & 51.26 & 50.54 \\
\hline 298 & 39.42 & 50.11 & 41.04 & 45.28 & 50.55 & 47.05 & 51.07 & 50.46 \\
\hline 299 & 39.48 & 50.28 & 41.11 & 45.48 & 50.42 & 46.95 & 50.89 & 50.39 \\
\hline 300 & 39.54 & 50.45 & 41.18 & 45.69 & 50.29 & 46.85 & 50.71 & 50.31 \\
\hline 301 & 39.60 & 50.62 & 41.25 & 45.90 & 50.16 & 46.75 & 50.53 & 50.23 \\
\hline 302 & 39.66 & 50.79 & 41.32 & 46.11 & 50.03 & 46.64 & 50.35 & 50.15 \\
\hline 303 & 39.72 & 50.96 & 41.38 & 46.31 & 49.90 & 46.54 & 50.17 & 50.08 \\
\hline 304 & 39.78 & 51.13 & 41.45 & 46.52 & 49.77 & 46.44 & 49.99 & 50.00 \\
\hline 305 & 39.84 & 51.30 & 41.52 & 46.73 & 49.64 & 46.33 & 49.81 & 49.92 \\
\hline 306 & 39.90 & 51.47 & 41.59 & 46.94 & 49.50 & 46.23 & 49.63 & 49.84 \\
\hline 307 & 39.95 & 51.65 & 41.66 & 47.15 & 49.37 & 46.13 & 49.46 & 49.77 \\
\hline 308 & 40.01 & 51.82 & 41.73 & 47.35 & 49.24 & 46.02 & 49.28 & 49.69 \\
\hline 309 & 40.07 & 51.99 & 41.80 & 47.56 & 49.11 & 45.92 & 49.10 & 49.61 \\
\hline 310 & 40.12 & 52.17 & 41.87 & 47.78 & 48.98 & 45.82 & 48.92 & 49.53 \\
\hline 311 & 40.23 & 52.04 & 42.28 & 47.73 & 48.85 & 45.71 & 48.74 & 49.46 \\
\hline 312 & 40.34 & 51.89 & 42.71 & 47.69 & 48.72 & 45.61 & 48.56 & 49.38 \\
\hline 313 & 40.46 & 51.75 & 43.13 & 47.66 & 48.60 & 45.50 & 48.40 & 49.30 \\
\hline 314 & 40.57 & 51.61 & 43.56 & 47.62 & 48.65 & 45.48 & 48.41 & 49.21 \\
\hline 315 & 40.69 & 51.46 & 43.98 & 47.58 & 48.68 & 45.47 & 48.40 & 49.14 \\
\hline 316 & 40.80 & 51.32 & 44.40 & 47.54 & 48.71 & 45.46 & 48.40 & 49.06 \\
\hline 317 & 40.91 & 51.17 & 44.83 & 47.51 & 48.75 & 45.45 & 48.39 & 48.98 \\
\hline 318 & 41.03 & 51.03 & 45.25 & 47.47 & 48.78 & 45.44 & 48.39 & 48.91 \\
\hline 319 & 41.14 & 50.89 & 45.67 & 47.43 & 48.82 & 45.43 & 48.38 & 48.83 \\
\hline 320 & 41.26 & 50.74 & 46.10 & 47.40 & 48.85 & 45.42 & 48.38 & 48.75 \\
\hline 321 & 41.37 & 50.60 & 46.52 & 47.36 & 48.89 & 45.41 & 48.38 & 48.68 \\
\hline 322 & 41.48 & 50.46 & 46.94 & 47.32 & 48.92 & 45.40 & 48.37 & 48.60 \\
\hline
\end{tabular}




\begin{tabular}{|c|c|c|c|c|c|c|c|c|}
\hline 323 & 41.60 & 50.31 & 47.37 & 47.28 & 48.96 & 45.39 & 48.37 & 48.52 \\
\hline 324 & 41.71 & 50.17 & 47.79 & 47.25 & 48.99 & 45.38 & 48.36 & 48.45 \\
\hline 325 & 41.83 & 50.03 & 48.21 & 47.21 & 49.03 & 45.37 & 48.36 & 48.37 \\
\hline 326 & 41.94 & 49.88 & 48.64 & 47.17 & 49.06 & 45.36 & 48.35 & 48.29 \\
\hline 327 & 42.06 & 49.73 & 49.07 & 47.15 & 49.10 & 45.35 & 48.35 & 48.22 \\
\hline 328 & 41.78 & 49.58 & 48.92 & 47.25 & 49.13 & 45.34 & 48.35 & 48.14 \\
\hline 329 & 41.50 & 49.43 & 48.79 & 47.34 & 49.17 & 45.33 & 48.34 & 48.06 \\
\hline 330 & 41.22 & 49.27 & 48.65 & 47.43 & 49.20 & 45.32 & 48.34 & 47.99 \\
\hline 331 & 40.95 & 49.11 & 48.52 & 47.53 & 49.24 & 45.31 & 48.33 & 47.91 \\
\hline 332 & 40.67 & 48.95 & 48.38 & 47.62 & 49.27 & 45.31 & 48.33 & 47.83 \\
\hline 333 & 40.39 & 48.79 & 48.25 & 47.71 & 49.30 & 45.30 & 48.32 & 47.76 \\
\hline 334 & 40.12 & 48.63 & 48.12 & 47.80 & 49.34 & 45.29 & 48.32 & 47.68 \\
\hline 335 & 39.84 & 48.48 & 47.98 & 47.89 & 49.37 & 45.28 & 48.32 & 47.60 \\
\hline 336 & 39.56 & 48.32 & 47.85 & 47.99 & 49.41 & 45.27 & 48.31 & 47.53 \\
\hline 337 & 39.28 & 48.16 & 47.72 & 48.08 & 49.44 & 45.26 & 48.31 & 47.45 \\
\hline 338 & 39.01 & 48.00 & 47.58 & 48.17 & 49.48 & 45.25 & 48.30 & 47.37 \\
\hline 339 & 38.73 & 47.84 & 47.45 & 48.26 & 49.51 & 45.24 & 48.30 & 47.30 \\
\hline 340 & 38.45 & 47.69 & 47.31 & 48.35 & 49.55 & 45.23 & 48.29 & 47.22 \\
\hline 341 & 38.18 & 47.53 & 47.18 & 48.44 & 49.58 & 45.22 & 48.29 & 47.14 \\
\hline 342 & 37.90 & 47.37 & 47.05 & 48.54 & 49.62 & 45.21 & 48.29 & 47.07 \\
\hline 343 & 37.63 & 47.20 & 46.93 & 48.62 & 49.64 & 45.21 & 48.27 & 47.00 \\
\hline 344 & 37.55 & 47.11 & 46.83 & 48.57 & 49.64 & 45.26 & 48.24 & 46.97 \\
\hline 345 & 37.49 & 47.02 & 46.74 & 48.53 & 49.63 & 45.32 & 48.21 & 46.93 \\
\hline 346 & 37.42 & 46.93 & 46.66 & 48.49 & 49.61 & 45.38 & 48.19 & 46.88 \\
\hline 347 & 37.35 & 46.84 & 46.57 & 48.45 & 49.60 & 45.44 & 48.16 & 46.84 \\
\hline 348 & 37.29 & 46.75 & 46.48 & 48.41 & 49.59 & 45.50 & 48.13 & 46.80 \\
\hline 349 & 37.22 & 46.66 & 46.39 & 48.36 & 49.58 & 45.57 & 48.10 & 46.75 \\
\hline 350 & 37.15 & 46.57 & 46.31 & 48.32 & 49.57 & 45.63 & 48.07 & 46.71 \\
\hline 351 & 37.09 & 46.48 & 46.22 & 48.28 & 49.55 & 45.69 & 48.05 & 46.67 \\
\hline 352 & 37.02 & 46.39 & 46.13 & 48.24 & 49.54 & 45.75 & 48.02 & 46.62 \\
\hline 353 & 36.95 & 46.30 & 46.04 & 48.20 & 49.53 & 45.81 & 47.99 & 46.58 \\
\hline 354 & 36.89 & 46.21 & 45.95 & 48.16 & 49.52 & 45.87 & 47.96 & 46.54 \\
\hline 355 & 36.82 & 46.12 & 45.87 & 48.12 & 49.50 & 45.93 & 47.93 & 46.49 \\
\hline 356 & 36.75 & 46.03 & 45.78 & 48.08 & 49.49 & 46.00 & 47.91 & 46.45 \\
\hline 357 & 36.69 & 45.94 & 45.69 & 48.04 & 49.48 & 46.06 & 47.88 & 46.41 \\
\hline 358 & 36.62 & 45.85 & 45.60 & 48.00 & 49.47 & 46.12 & 47.85 & 46.36 \\
\hline 359 & 36.55 & 45.76 & 45.52 & 47.96 & 49.45 & 46.18 & 47.82 & 46.32 \\
\hline 360 & 36.49 & 45.67 & 45.43 & 47.92 & 49.44 & 46.24 & 47.79 & 46.28 \\
\hline 361 & 36.42 & 45.58 & 45.34 & 47.88 & 49.43 & 46.30 & 47.77 & 46.23 \\
\hline 362 & 36.35 & 45.49 & 45.25 & 47.84 & 49.42 & 46.36 & 47.74 & 46.19 \\
\hline 363 & 36.28 & 45.40 & 45.16 & 47.79 & 49.41 & 46.42 & 47.71 & 46.15 \\
\hline 364 & 36.22 & 45.31 & 45.08 & 47.75 & 49.39 & 46.49 & 47.68 & 46.10 \\
\hline 365 & 36.15 & 45.22 & 44.99 & 47.71 & 49.38 & 46.55 & 47.65 & 46.06 \\
\hline 366 & 36.08 & 45.13 & 44.90 & 47.67 & 49.37 & 46.61 & 47.63 & 46.02 \\
\hline 367 & 36.02 & 45.04 & 44.81 & 47.63 & 49.36 & 46.67 & 47.60 & 45.97 \\
\hline 368 & 35.95 & 44.95 & 44.73 & 47.59 & 49.34 & 46.73 & 47.57 & 45.93 \\
\hline 369 & 35.88 & 44.86 & 44.64 & 47.55 & 49.33 & 46.79 & 47.54 & 45.89 \\
\hline 370 & 35.82 & 44.77 & 44.55 & 47.51 & 49.32 & 46.85 & 47.51 & 45.84 \\
\hline 371 & 35.75 & 44.68 & 44.46 & 47.47 & 49.31 & 46.91 & 47.49 & 45.80 \\
\hline 372 & 35.68 & 44.59 & 44.38 & 47.43 & & & & \\
\hline
\end{tabular}




\begin{tabular}{|l|llll|l|}
\hline 373 & 35.63 & 44.50 & 44.30 & 47.40 & \\
374 & 35.55 & 44.41 & 44.20 & 47.35 & \\
375 & 35.48 & 44.32 & 44.11 & 47.31 & \\
376 & 35.63 & 44.50 & 44.30 & 47.40 & \\
377 & 35.35 & 44.14 & 43.94 & 47.23 & \\
378 & 35.28 & 44.05 & 43.85 & 47.18 & \\
379 & 35.63 & 44.50 & 44.30 & 47.40 & \\
380 & 35.15 & 43.87 & 43.67 & 47.10 & \\
\hline
\end{tabular}

\subsection{BMP assays}

2.3.1 First set

\begin{tabular}{|c|cccc|cccc|}
\hline G.1 & \multicolumn{3}{|c|}{ Accumulative methane (ml) } & \multicolumn{4}{c|}{ Methane concentration \% } \\
\hline Time & R1 & R2 & R3 & R4 & R1 & R2 & R3 & R4 \\
\hline 1 & 9.34 & 3.51 & 0.98 & 0.00 & 10.17 & 0.00 & 0.00 & 0.00 \\
2 & 39.83 & 9.86 & 2.66 & 0.00 & 27.19 & 14.89 & 0.00 & 0.00 \\
3 & 78.20 & 22.43 & 11.34 & 0.00 & 44.20 & 24.47 & 14.50 & 0.00 \\
4 & 157.12 & 31.06 & 23.32 & 0.00 & 54.27 & 34.05 & 27.60 & 0.00 \\
5 & 244.63 & 50.51 & 42.95 & 0.00 & 64.34 & 42.02 & 33.10 & 0.00 \\
6 & 350.58 & 72.93 & 66.69 & 0.00 & 70.41 & 49.98 & 38.60 & 0.00 \\
7 & 441.87 & 122.94 & 100.89 & 0.00 & 76.48 & 55.76 & 49.76 & 0.00 \\
8 & 558.82 & 171.91 & 141.87 & 0.00 & 75.90 & 61.53 & 60.91 & 0.00 \\
9 & 690.13 & 230.61 & 175.90 & 0.00 & 75.31 & 66.51 & 61.91 & 0.00 \\
10 & 895.38 & 284.92 & 219.13 & 0.00 & 75.66 & 71.49 & 62.90 & 0.00 \\
11 & 1072.42 & 358.64 & 295.29 & 0.00 & 76.00 & 73.31 & 66.62 & 8.40 \\
12 & 1269.86 & 432.11 & 367.04 & 1.85 & 74.77 & 74.13 & 70.34 & 10.67 \\
13 & 1378.39 & 563.72 & 479.32 & 6.40 & 73.54 & 72.77 & 70.87 & 14.62 \\
14 & 1441.16 & 688.72 & 572.30 & 14.05 & 72.91 & 71.40 & 71.40 & 18.56 \\
15 & 1491.87 & 831.77 & 704.94 & 25.58 & 72.27 & 71.90 & 71.90 & 22.13 \\
16 & 1512.32 & 960.09 & 828.03 & 39.52 & 70.64 & 72.40 & 72.40 & 25.70 \\
17 & 1519.30 & 1065.32 & 946.04 & 62.40 & 69.00 & 70.95 & 72.18 & 28.48 \\
18 & 1524.58 & 1158.96 & 999.65 & 91.34 & 69.40 & 71.91 & 71.95 & 31.26 \\
19 & 1530.29 & 1218.52 & 1048.70 & 126.36 & 68.70 & 72.86 & 72.91 & 33.38 \\
20 & 1536.82 & 1247.07 & 1057.79 & 166.94 & 69.40 & 71.76 & 73.86 & 35.50 \\
21 & 1545.85 & 1259.85 & 1069.62 & 196.22 & 69.32 & 70.65 & 71.11 & 37.13 \\
22 & 1553.27 & 1282.73 & 1078.52 & 215.00 & 68.40 & 70.29 & 68.35 & 38.76 \\
23 & 1556.68 & 1290.83 & 1086.37 & 231.00 & 67.30 & 69.93 & 67.83 & 40.21 \\
24 & $\mathbf{1 5 6 2 . 4 9}$ & $\mathbf{1 2 9 6 . 8 8}$ & $\mathbf{1 0 9 2 . 2 1}$ & $\mathbf{2 4 1 . 5 5}$ & 66.91 & 69.70 & 67.30 & 41.65 \\
\hline
\end{tabular}

First set (second group)

\begin{tabular}{|c|cccc|cccc|}
\hline G.2 & \multicolumn{3}{|c|}{ Accumulative methane (ml) } & \multicolumn{4}{c|}{ Methane concentration \% } \\
\hline Time & R5 & R6 & R7 & R8 & R5 & R6 & R7 & R8 \\
\hline 1 & 2.98 & 0.00 & 0.00 & 0.00 & 7.50 & 0.00 & 0.00 & 0.00 \\
2 & 6.89 & 6.93 & 4.40 & 0.00 & 10.19 & 14.30 & 10.30 & 0.00 \\
3 & 18.40 & 18.29 & 10.39 & 0.00 & 24.10 & 25.33 & 22.40 & 0.00 \\
4 & 39.56 & 33.29 & 24.53 & 0.00 & 38.00 & 33.43 & 32.03 & 0.00 \\
5 & 74.87 & 55.22 & 45.92 & 0.00 & 47.38 & 41.53 & 41.65 & 0.00 \\
6 & 128.25 & 85.35 & 82.71 & 0.00 & 56.76 & 49.58 & 48.44 & 0.00 \\
\hline
\end{tabular}




\begin{tabular}{|c|cccc|cccc|}
\hline 7 & 209.38 & 127.88 & 116.67 & 2.49 & 63.36 & 57.63 & 55.22 & 12.30 \\
8 & 298.45 & 200.56 & 170.66 & 7.37 & 69.95 & 63.99 & 59.70 & 15.68 \\
9 & 418.76 & 271.81 & 226.37 & 11.51 & 70.77 & 70.35 & 64.18 & 19.06 \\
10 & 557.05 & 382.56 & 307.25 & 20.01 & 71.59 & 73.96 & 69.87 & 21.37 \\
11 & 712.93 & 497.59 & 404.55 & 30.18 & 72.80 & 77.56 & 75.56 & 24.67 \\
12 & 865.51 & 601.46 & 511.22 & 42.60 & 74.00 & 75.57 & 73.72 & 28.14 \\
13 & 1054.07 & 743.57 & 633.42 & 58.84 & 72.00 & 73.57 & 71.88 & 31.61 \\
14 & 1151.55 & 859.66 & 759.47 & 88.44 & 69.10 & 73.95 & 70.83 & 30.32 \\
15 & 1254.48 & 1006.98 & 831.15 & 108.83 & 69.40 & 74.32 & 69.77 & 32.02 \\
16 & 1397.89 & 1135.42 & 894.76 & 142.10 & 69.80 & 70.18 & 69.79 & 32.85 \\
17 & 1573.61 & 1245.77 & 990.72 & 179.43 & 70.40 & 66.03 & 69.81 & 37.67 \\
18 & 1720.13 & 1349.37 & 1092.39 & 211.51 & 69.84 & 69.52 & 70.62 & 36.35 \\
19 & 1831.44 & 1448.66 & 1156.99 & 229.87 & 72.40 & 73.00 & 71.43 & 39.03 \\
20 & 1928.88 & 1532.86 & 1198.98 & 248.71 & 73.20 & 71.40 & 72.10 & 42.30 \\
21 & 1982.93 & 1601.61 & 1243.76 & 267.27 & 71.50 & 70.40 & 72.40 & 43.40 \\
22 & 2017.98 & 1633.97 & 1299.72 & 289.35 & 69.21 & 71.00 & 70.00 & 48.50 \\
23 & 2038.32 & 1656.40 & 1343.27 & 314.82 & 74.00 & 72.10 & 70.40 & 51.50 \\
24 & $\mathbf{2 0 5 1 . 6 7}$ & $\mathbf{1 6 7 8 . 7 7}$ & $\mathbf{1 3 6 4 . 7 4}$ & $\mathbf{3 3 6 . 1 1}$ & 75.31 & 71.90 & 73.30 & 49.30 \\
\hline
\end{tabular}

\subsubsection{Second set}

\begin{tabular}{|c|cccc|cccc|}
\hline G.1 & \multicolumn{3}{|c|}{ Accumulative methane $(\mathrm{ml})$} & \multicolumn{4}{c|}{ Methane concentration \% } \\
\hline Time & $\mathrm{R} 1$ & $\mathrm{R} 2$ & $\mathrm{R} 3$ & $\mathrm{R} 4$ & $\mathrm{R} 1$ & $\mathrm{R} 2$ & $\mathrm{R} 3$ & $\mathrm{R} 4$ \\
\hline 1 & 0 & 0.00 & 0.00 & 0.00 & 0.00 & 0.00 & 0.00 & 0.00 \\
2 & 7.55 & 0 & 0.00 & 0.00 & 10.40 & 0.00 & 0.00 & 0.00 \\
3 & 12.72 & 0.64 & 0.00 & 0.00 & 16.88 & 7.80 & 0.00 & 0.00 \\
4 & 24.17 & 2.55 & 1.08 & 0.00 & 23.35 & 12.01 & 7.10 & 0.00 \\
5 & 36.39 & 5.58 & 3.56 & 0.00 & 29.84 & 17.36 & 11.35 & 0.00 \\
6 & 53.14 & 10.37 & 6.50 & 0.00 & 36.34 & 22.75 & 15.60 & 0.00 \\
7 & 81.07 & 18.58 & 11.31 & 1.52 & 42.83 & 28.14 & 19.40 & 10.50 \\
8 & 117.65 & 26.61 & 17.50 & 4.58 & 49.32 & 33.43 & 23.60 & 14.50 \\
9 & 156.71 & 41.97 & 25.52 & 10.20 & 57.30 & 38.92 & 25.56 & 17.12 \\
10 & 220.64 & 63.37 & 34.81 & 18.83 & 61.60 & 44.31 & 29.60 & 19.34 \\
11 & 294.56 & 93.99 & 52.74 & 26.78 & 66.27 & 49.76 & 34.50 & 21.76 \\
12 & 360.24 & 131.09 & 67.77 & 40.81 & 69.40 & 52.18 & 36.72 & 28.61 \\
13 & 422.39 & 173.53 & 99.47 & 49.55 & 70.50 & 54.60 & 41.17 & 26.61 \\
14 & 483.30 & 227.05 & 132.92 & 59.94 & 71.60 & 57.02 & 45.63 & 29.03 \\
15 & 532.87 & 303.33 & 175.16 & 67.27 & 71.80 & 59.44 & 50.08 & 31.45 \\
16 & 591.66 & 389.34 & 231.98 & 71.92 & 72.50 & 61.85 & 54.54 & 33.87 \\
17 & 631.15 & 490.17 & 306.38 & 75.32 & 73.50 & 64.27 & 58.99 & 33.82 \\
18 & 641.83 & 598.21 & 398.47 & 79.22 & 73.80 & 66.69 & 60.47 & 33.85 \\
19 & 657.75 & 683.54 & 500.92 & 83.37 & 74.00 & 69.11 & 61.94 & 33.87 \\
20 & 669.35 & 777.26 & 611.61 & 85.63 & 74.15 & 71.53 & 64.48 & 35.43 \\
21 & 677.40 & 876.87 & 700.36 & 88.80 & 74.10 & 71.86 & 67.01 & 36.99 \\
22 & 681.56 & 962.74 & 787.82 & 92.39 & 73.50 & 72.19 & 69.55 & 38.54 \\
23 & 683.53 & 1038.42 & 882.04 & 96.72 & 73.20 & 72.52 & 72.09 & 40.10 \\
24 & $\mathbf{6 8 5 . 5 0}$ & 1097.13 & 972.46 & 108.87 & 73.00 & 72.85 & 72.05 & 42.73 \\
25 & & 1128.97 & 1047.93 & 115.77 & & 73.18 & 72.04 & 45.37 \\
\hline
\end{tabular}




\begin{tabular}{|c|c|c|c|c|c|c|}
\hline 26 & 1136.90 & 1115.55 & 127.65 & 73.51 & 72.01 & 48.00 \\
\hline 27 & 1140.52 & 1164.14 & 143.17 & 73.84 & 71.98 & 50.63 \\
\hline 28 & 1147.98 & 1189.89 & 170.46 & 74.17 & 71.96 & 53.26 \\
\hline 29 & 1156.56 & 1204.83 & 194.17 & 74.50 & 71.94 & 55.90 \\
\hline 30 & 1161.21 & 1218.41 & 225.45 & & 71.93 & 58.53 \\
\hline 31 & & 1227.97 & 256.79 & & 71.92 & 61.16 \\
\hline 32 & & 1235.15 & 292.56 & & 71.40 & 66.00 \\
\hline 33 & & 1242.81 & 326.60 & & 71.00 & 68.41 \\
\hline 34 & & 1247.33 & 366.73 & & 70.86 & 75.08 \\
\hline 35 & & 1249.22 & 410.72 & & 70.00 & 73.23 \\
\hline 36 & & 1251.63 & 450.59 & & 70.30 & 75.64 \\
\hline 37 & & & 487.71 & & & 78.05 \\
\hline 38 & & & 538.99 & & & 78.63 \\
\hline 39 & & & 573.95 & & & 78.34 \\
\hline 40 & & & 611.65 & & & 78.06 \\
\hline 41 & & & 645.21 & & & 77.78 \\
\hline 42 & & & 668.39 & & & 77.49 \\
\hline 43 & & & 698.87 & & & 77.21 \\
\hline 44 & & & 732.63 & & & 76.92 \\
\hline 45 & & & 782.61 & & & 76.64 \\
\hline 46 & & & 826.79 & & & 76.35 \\
\hline 47 & & & 874.16 & & & 76.07 \\
\hline 48 & & & 917.45 & & & 75.79 \\
\hline 49 & & & 967.80 & & & 75.50 \\
\hline 50 & & & 1010.22 & & & 75.22 \\
\hline 51 & & & 1066.35 & & & 75.07 \\
\hline 52 & & & 1117.97 & & & 74.92 \\
\hline 53 & & & 1168.94 & & & 74.78 \\
\hline 54 & & & 1223.10 & & & 74.63 \\
\hline 55 & & & 1266.74 & & & 74.48 \\
\hline 56 & & & 1304.29 & & & 74.34 \\
\hline 57 & & & 1341.21 & & & 74.19 \\
\hline 58 & & & 1361.73 & & & 74.04 \\
\hline 59 & & & 1390.90 & & & 73.90 \\
\hline 60 & & & 1408.62 & & & 73.75 \\
\hline 61 & & & 1432.26 & & & 73.60 \\
\hline 62 & & & 1454.77 & & & 73.46 \\
\hline 63 & & & 1460.67 & & & 75.12 \\
\hline 64 & & & 1486.63 & & & 75.65 \\
\hline 65 & & & 1494.49 & & & 78.16 \\
\hline 66 & & & 1503.33 & & & 76.72 \\
\hline 67 & & & 1511.10 & & & 77.26 \\
\hline 68 & & & 1518.35 & & & 77.80 \\
\hline 69 & & & 1522.15 & & & 77.49 \\
\hline
\end{tabular}


Second set (second group)

\begin{tabular}{|c|c|c|c|c|c|c|c|c|}
\hline G.2 & \multicolumn{4}{|c|}{ Accumulative methane (ml) } & \multicolumn{4}{|c|}{ Methane concentration $\%$} \\
\hline Time & R5 & $\mathrm{R} 6$ & R7 & R8 & $\mathrm{R} 5$ & R6 & R7 & $\mathrm{R} 8$ \\
\hline 1 & 4.15 & 0.00 & 0.00 & 0.00 & 7.03 & 0.00 & 0.00 & 0.00 \\
\hline 2 & 12.79 & 2.24 & 0.00 & 0.00 & 14.06 & 7.50 & 0.00 & 0.00 \\
\hline 3 & 22.98 & 4.37 & 0.00 & 0.00 & 21.50 & 10.08 & 0.00 & 0.00 \\
\hline 4 & 40.20 & 6.20 & 0.86 & 0.00 & 28.50 & 12.94 & 7.50 & 0.00 \\
\hline 5 & 62.30 & 8.71 & 2.29 & 0.00 & 35.12 & 16.00 & 10.40 & 0.00 \\
\hline 6 & 89.09 & 12.30 & 3.49 & 0.93 & 41.38 & 19.06 & 12.32 & 8.00 \\
\hline 7 & 121.94 & 18.26 & 6.45 & 3.30 & 47.30 & 23.71 & 17.02 & 10.57 \\
\hline 8 & 166.86 & 27.41 & 9.27 & 6.46 & 52.84 & 27.74 & 21.72 & 12.49 \\
\hline 9 & 218.27 & 37.41 & 16.39 & 11.09 & 58.01 & 31.87 & 26.41 & 14.55 \\
\hline 10 & 283.90 & 49.50 & 26.84 & 15.93 & 62.78 & 35.80 & 31.11 & 16.32 \\
\hline 11 & 345.55 & 64.81 & 37.72 & 20.15 & 67.10 & 39.82 & 35.50 & 18.24 \\
\hline 12 & 430.07 & 83.21 & 53.76 & 27.50 & 70.80 & 45.06 & 39.89 & 23.60 \\
\hline 13 & 514.68 & 106.13 & 73.11 & 33.72 & 74.02 & 47.88 & 44.09 & 22.08 \\
\hline 14 & 606.12 & 138.53 & 97.33 & 38.06 & 74.57 & 51.91 & 45.95 & 23.99 \\
\hline 15 & 711.55 & 172.49 & 122.18 & 42.08 & 75.12 & 55.93 & 47.81 & 24.16 \\
\hline 16 & 844.03 & 223.33 & 140.69 & 46.51 & 75.67 & 59.96 & 49.66 & 27.83 \\
\hline 17 & 1000.63 & 283.18 & 178.73 & 51.38 & 76.22 & 63.30 & 55.82 & 29.26 \\
\hline 18 & 1135.32 & 364.66 & 205.69 & 55.68 & 76.77 & 64.79 & 53.37 & 33.00 \\
\hline 19 & 1235.14 & 449.53 & 242.52 & 64.43 & 76.87 & 65.92 & 55.23 & 35.56 \\
\hline 20 & 1304.77 & 553.46 & 288.57 & 70.49 & 77.00 & 67.05 & 57.09 & 38.12 \\
\hline 21 & 1342.64 & 679.91 & 349.12 & 81.97 & 76.41 & 68.18 & 58.94 & 40.68 \\
\hline 22 & 1374.18 & 801.38 & 420.52 & 102.31 & 75.83 & 69.30 & 60.80 & 43.24 \\
\hline 23 & 1382.89 & 904.24 & 510.81 & 130.52 & 75.24 & 71.10 & 60.70 & 48.14 \\
\hline 24 & 1391.53 & 1012.54 & 614.67 & 174.95 & 74.65 & 71.56 & 63.19 & 48.36 \\
\hline 25 & 1399.84 & 1114.84 & 708.38 & 201.47 & 74.06 & 72.69 & 65.24 & 50.92 \\
\hline 26 & 1411.80 & 1207.55 & 792.36 & 244.81 & 73.48 & 73.82 & 67.29 & 53.48 \\
\hline 27 & 1421.82 & 1286.42 & 870.23 & 279.67 & 72.89 & 74.95 & 69.35 & 56.04 \\
\hline 28 & 1426.52 & 1360.37 & 961.42 & 323.76 & 72.30 & 76.08 & 71.40 & 58.60 \\
\hline 29 & & 1431.31 & 1052.00 & 348.54 & & 77.21 & 73.45 & 61.16 \\
\hline 30 & & 1484.92 & 1139.11 & 369.70 & & 78.03 & 76.97 & 62.23 \\
\hline 31 & & 1515.99 & 1216.61 & 383.61 & & 77.60 & 77.55 & 66.28 \\
\hline 32 & & 1543.97 & 1284.81 & 401.04 & & 77.50 & 79.60 & 68.84 \\
\hline 33 & & 1552.42 & 1352.09 & 434.25 & & 76.88 & 80.62 & 71.73 \\
\hline 34 & & 1558.72 & 1403.54 & 476.31 & & 76.00 & 79.42 & 71.78 \\
\hline 35 & & 1565.91 & 1438.10 & 516.42 & & 73.00 & 78.22 & 72.00 \\
\hline 36 & & 1572.69 & 1476.99 & 566.05 & & 72.00 & 77.01 & 72.21 \\
\hline 37 & & & 1499.11 & 607.83 & & & 75.80 & 72.20 \\
\hline 38 & & & 1510.64 & 660.90 & & & 75.86 & 72.63 \\
\hline 39 & & & 1516.04 & 696.74 & & & 75.91 & 72.84 \\
\hline 40 & & & 1524.59 & 737.44 & & & 75.97 & 73.05 \\
\hline 41 & & & 1531.67 & 802.10 & & & 76.02 & 73.27 \\
\hline 42 & & & 1539.99 & 878.65 & & & 76.08 & 73.48 \\
\hline 43 & & & 1543.17 & 941.55 & & & 76.13 & 73.69 \\
\hline 44 & & & & 1037.79 & & & & 73.90 \\
\hline 45 & & & & 1119.29 & & & & 74.11 \\
\hline
\end{tabular}




\begin{tabular}{|l|r|r|}
\hline 46 & 1195.10 & 74.32 \\
47 & 1256.09 & 74.60 \\
48 & 1332.58 & 74.46 \\
49 & 1390.11 & 74.32 \\
50 & 1444.85 & 74.18 \\
51 & 1491.99 & 74.04 \\
52 & 1517.65 & 73.90 \\
53 & 1532.59 & 73.76 \\
54 & 1543.78 & 73.62 \\
55 & 1546.44 & 73.48 \\
56 & 1549.62 & 73.34 \\
57 & 1550.68 & 73.20 \\
\hline
\end{tabular}

\subsubsection{Third set}

Third set (Normal digested anaerobic sludge)

\begin{tabular}{|c|cccc|rrrr|}
\hline & \multicolumn{3}{|c}{ Accumulative methane $(\mathrm{ml})$} & \multicolumn{3}{c|}{ Methane concentration \% } \\
\hline Time & N0\% & N1\% & N2\% & N3\% & N0\% & N1\% & N2\% & N3\% \\
\hline 1 & 5.11 & 0.00 & 0.00 & 0.00 & 6.2 & 0 & 0 & 0 \\
2 & 10.99 & 0.00 & 0.00 & 0.00 & 12.49 & 0 & 0 & 0 \\
3 & 21.51 & 0.44 & 0.00 & 0.00 & 20.77 & 2.65 & 0 & 0 \\
4 & 40.47 & 1.45 & 0.00 & 0.00 & 29.1 & 5.14 & 0 & 0 \\
5 & 66.31 & 2.09 & 0.00 & 0.00 & 37.41 & 7.48 & 0 & 0 \\
6 & 106.87 & 3.61 & 0.00 & 0.00 & 45.72 & 9.659 & 0 & 0 \\
7 & 151.91 & 5.35 & 0.00 & 0.00 & 51.225 & 11.68 & 0 & 0 \\
8 & 207.79 & 7.53 & 0.00 & 0.00 & 56.73 & 13.54 & 0 & 0 \\
9 & 273.25 & 10.22 & 0.00 & 0.00 & 62.23 & 15.258 & 0 & 0 \\
10 & 368.17 & 13.45 & 0.00 & 0.00 & 67.74 & 16.8 & 0 & 0 \\
11 & 464.54 & 17.90 & 0.30 & 0.00 & 70.55 & 18.28 & 4.25 & 0 \\
12 & 615.15 & 24.53 & 1.20 & 0.00 & 73.37 & 20.84 & 7.878 & 0 \\
13 & 762.28 & 29.04 & 2.09 & 0.00 & 76.19 & 24.47 & 10.88 & 0 \\
14 & 921.96 & 40.49 & 2.72 & 0.15 & 75.338 & 29.165 & 13.256 & 3.1 \\
15 & 1068.13 & 53.79 & 3.42 & 0.44 & 74.48 & 34.93 & 15.003 & 5.77 \\
16 & 1144.71 & 77.72 & 5.89 & 0.73 & 73.634 & 41.764 & 16.13 & 8.07 \\
17 & 1179.57 & 106.18 & 7.07 & 2.11 & 72.78 & 49.66 & 16.63 & 10.07 \\
18 & 1190.01 & 145.08 & 9.47 & 2.35 & 71.93 & 58.64 & 16.51 & 12.26 \\
19 & 1198.62 & 191.00 & 10.93 & 2.77 & 70.73 & 58.5 & 18.6 & 13.38 \\
20 & 1206.80 & 249.85 & 13.45 & 3.34 & 69.53 & 60.7 & 20.76 & 14.51 \\
21 & 1218.81 & 314.84 & 17.58 & 5.56 & 69.54 & 64.43 & 26.95 & 16.2 \\
22 & 1231.38 & 391.92 & 23.60 & 8.40 & 69.58 & 67.72 & 32.631 & 17.61 \\
23 & 1235.47 & 465.62 & 30.27 & 10.80 & 69.59 & 70.59 & 37.8 & 19.07 \\
24 & 1239.84 & 556.47 & 39.78 & 13.31 & 69.6 & 73.02 & 42.47 & 20.66 \\
25 & 1242.30 & 658.93 & 55.88 & 16.40 & 69.61 & 75.01 & 46.64 & 22.45 \\
26 & 1245.58 & 762.03 & 73.46 & 20.15 & 69.61 & 76.58 & 50.3 & 24.49 \\
27 & 1254.29 & 860.07 & 95.69 & 28.26 & 69.34 & 76.62 & 53.45 & 26.84 \\
\hline
\end{tabular}




\begin{tabular}{|c|c|c|c|c|c|c|c|c|}
\hline 28 & 1262.15 & 936.50 & 119.92 & 37.78 & 69.07 & 76.67 & 56.1 & 29.58 \\
\hline 29 & 1263.77 & 1011.78 & 150.54 & 48.46 & 68.8 & 76.72 & 58.23 & 32.77 \\
\hline 30 & 1273.46 & 1059.68 & 176.86 & 64.63 & 68.536 & 76.75 & 59.87 & 36.46 \\
\hline 31 & 1275.07 & 1116.05 & 207.60 & 81.25 & 68.26 & 76.8 & 60.72 & 40.72 \\
\hline 32 & 1285.74 & 1150.14 & 243.40 & 99.87 & 68 & 76.86 & 61.62 & 45.61 \\
\hline 33 & 1287.34 & 1167.30 & 279.53 & 115.09 & 67.85 & 76.7 & 64.37 & 49.09 \\
\hline 34 & 1295.31 & 1183.55 & 324.58 & 136.55 & 67.71 & 76.66 & 67.12 & 52.57 \\
\hline 35 & 1300.09 & 1195.81 & 375.74 & 157.25 & 67.59 & 76.2 & 68.6 & 55.525 \\
\hline 36 & 1301.41 & 1216.07 & 433.27 & 175.05 & 67.47 & 75.913 & 70.13 & 58.13 \\
\hline 37 & 1306.70 & 1224.97 & 501.88 & 205.87 & 67.35 & 75.54 & 71.65 & 60.4 \\
\hline 38 & 1310.92 & 1230.87 & 578.83 & 233.74 & 67.23 & 75.16 & 73.15 & 62.29 \\
\hline 39 & 1317.77 & 1239.09 & 674.95 & 268.82 & 67.11 & 74.79 & 74.66 & 63.84 \\
\hline 40 & 1323.03 & 1243.18 & 754.47 & 316.82 & 66.99 & 74.42 & 76.17 & 65.05 \\
\hline 41 & & & 875.90 & 332.43 & & & 76.2 & 66.3 \\
\hline 42 & & & 953.72 & 377.47 & & & 76.25 & 67.5 \\
\hline 43 & & & 1010.62 & 382.92 & & & 76.3 & 69.4 \\
\hline 44 & & & 1046.58 & 438.97 & & & 76.35 & 71.4 \\
\hline 45 & & & 1073.57 & 484.56 & & & 76.4 & 72.6 \\
\hline 46 & & & 1094.58 & 527.95 & & & 76.5 & 73.7 \\
\hline 47 & & & 1112.61 & 571.94 & & & 76.55 & 74.72 \\
\hline 48 & & & 1125.77 & 621.93 & & & 76.2 & 74.91 \\
\hline 49 & & & 1137.64 & 686.78 & & & 75.6 & 75.1 \\
\hline 50 & & & 1148.29 & 742.34 & & & 75.4 & 75.3 \\
\hline 51 & & & 1157.14 & 793.97 & & & 75.1 & 75.6 \\
\hline 52 & & & 1167.14 & 862.83 & & & 74.99 & 75.62 \\
\hline 53 & & & 1176.53 & 923.99 & & & 74.7 & 74.91 \\
\hline 54 & & & 1183.51 & 971.88 & & & 74.1 & 74.4 \\
\hline 55 & & & 1189.30 & 1018.49 & & & 73.8 & 74.23 \\
\hline 56 & & & 1195.08 & 1064.49 & & & 73.6 & 74.17 \\
\hline 57 & & & 1202.57 & 1090.64 & & & 73.4 & 74.02 \\
\hline 58 & & & 1208.31 & 1110.95 & & & 73.1 & 73.92 \\
\hline 59 & & & & 1128.34 & & & & 73.85 \\
\hline 60 & & & & 1143.95 & & & & 73.67 \\
\hline 61 & & & & 1157.79 & & & & 73.43 \\
\hline 62 & & & & 1169.89 & & & & 73.38 \\
\hline 63 & & & & 1176.21 & & & & 73.29 \\
\hline 64 & & & & 1179.09 & & & & 73.2 \\
\hline
\end{tabular}

Third set (Acclimatized digested anaerobic sludge)

\begin{tabular}{|c|cccc|cccc|}
\hline & \multicolumn{3}{|c|}{ Accumulative methane (ml) } & \multicolumn{4}{c|}{ Methane concentration \% } \\
\hline Time & S0\% & S1\% & S2\% & S3\% & S0\% & S1\% & S2\% & S3\% \\
\hline 1 & 4.50 & 2.18 & 0.00 & 0.00 & 7.03 & 3.05 & 0.00 & 0 \\
2 & 13.88 & 4.90 & 0.00 & 0.00 & 14.06 & 7.21 & 0.00 & 0 \\
3 & 24.93 & 9.99 & 2.14 & 0.00 & 21.50 & 13.10 & 6.81 & 0 \\
4 & 43.61 & 17.73 & 5.00 & 0.00 & 28.50 & 18.60 & 13.02 & 0 \\
5 & 67.60 & 27.14 & 11.87 & 0.67 & 35.12 & 23.76 & 18.62 & 9.44 \\
\hline
\end{tabular}




\begin{tabular}{|c|c|c|c|c|c|c|c|c|}
\hline 6 & 96.67 & 39.13 & 16.42 & 2.49 & 41.38 & 28.55 & 23.63 & 11.91 \\
\hline 7 & 132.32 & 51.30 & 25.54 & 4.52 & 47.30 & 32.98 & 28.02 & 14 \\
\hline 8 & 181.06 & 65.55 & 35.91 & 6.94 & 52.84 & 37.04 & 31.82 & 15.8 \\
\hline 9 & 236.84 & 83.62 & 44.71 & 9.05 & 58.01 & 40.75 & 35.01 & 17.3 \\
\hline 10 & 308.05 & 108.38 & 56.95 & 11.58 & 62.78 & 44.10 & 37.60 & 18.43 \\
\hline 11 & 374.95 & 127.90 & 68.83 & 13.03 & 67.10 & 48.76 & 40.90 & 20.5 \\
\hline 12 & 466.65 & 151.77 & 82.26 & 17.53 & 70.80 & 52.90 & 43.85 & 22.5 \\
\hline 13 & 558.46 & 176.67 & 95.57 & 18.78 & 74.02 & 56.64 & 46.45 & 24.55 \\
\hline 14 & 657.68 & 214.02 & 110.67 & 23.25 & 74.57 & 59.84 & 48.70 & 26.49 \\
\hline 15 & 772.08 & 248.36 & 125.75 & 25.26 & 75.12 & 62.50 & 50.56 & 28.4 \\
\hline 16 & 915.83 & 286.50 & 144.15 & 29.29 & 75.67 & 64.78 & 52.10 & 30.2 \\
\hline 17 & 1025.92 & 334.53 & 162.77 & 34.69 & 76.22 & 66.50 & 53.30 & 32 \\
\hline 18 & 1143.74 & 378.15 & 181.45 & 37.08 & 76.77 & 67.77 & 54.07 & 33.75 \\
\hline 19 & 1191.71 & 432.39 & 197.87 & 39.80 & 76.87 & 69.10 & 57.30 & 34.75 \\
\hline 20 & 1206.82 & 494.65 & 215.23 & 44.72 & 77.00 & 70.50 & 60.59 & 35.75 \\
\hline 21 & 1217.60 & 568.07 & 240.07 & 51.62 & 74.20 & 71.94 & 63.28 & 36.67 \\
\hline 22 & 1221.82 & 668.07 & 267.65 & 58.72 & 71.70 & 73.21 & 65.68 & 37.66 \\
\hline 23 & 1230.55 & 747.12 & 294.79 & 64.49 & 69.50 & 74.32 & 67.80 & 38.72 \\
\hline 24 & 1233.74 & 831.65 & 323.48 & 73.26 & 67.70 & 75.30 & 69.60 & 39.86 \\
\hline 25 & 1241.79 & 914.03 & 354.76 & 79.53 & 66.20 & 76.05 & 71.17 & 41 \\
\hline 26 & 1253.27 & 978.73 & 390.58 & 87.01 & 65.00 & 76.67 & 72.43 & 42.33 \\
\hline 27 & 1262.95 & 1033.82 & 433.44 & 95.56 & 64.88 & 76.70 & 72.80 & 43.6 \\
\hline 28 & 1265.49 & 1072.08 & 476.25 & 104.59 & 64.80 & 76.75 & 73.20 & 45.07 \\
\hline 29 & 1275.65 & 1096.80 & 530.42 & 117.00 & 64.70 & 76.80 & 73.40 & 46.5 \\
\hline 30 & 1276.62 & 1117.91 & 586.17 & 126.44 & 64.67 & 76.83 & 73.60 & 48.1 \\
\hline 31 & 1284.23 & 1130.27 & 648.45 & 137.36 & 64.60 & 76.80 & 73.80 & 49.7 \\
\hline 32 & 1285.24 & 1145.66 & 710.85 & 155.32 & 64.56 & 76.90 & 73.95 & 51.4 \\
\hline 33 & 1286.76 & 1157.09 & 764.16 & 170.59 & 64.32 & 75.44 & 74.63 & 51.9 \\
\hline 34 & 1287.26 & 1167.83 & 823.87 & 186.88 & 64.20 & 73.98 & 75.31 & 52.51 \\
\hline 35 & 1287.76 & 1177.92 & 882.72 & 205.00 & 64.00 & 73.40 & 75.72 & 54.2 \\
\hline 36 & 1290.77 & 1183.63 & 938.31 & 222.10 & 63.80 & 72.76 & 76.14 & 55.85 \\
\hline 37 & 1292.27 & 1186.46 & 1008.02 & 242.87 & 63.63 & 72.20 & 76.56 & 57.52 \\
\hline 38 & 1295.75 & 1189.83 & 1062.35 & 260.99 & 63.42 & 71.50 & 76.90 & 59.2 \\
\hline 39 & 1298.24 & 1198.18 & 1104.72 & 287.24 & 63.31 & 70.90 & 77.10 & 60.8 \\
\hline 40 & 1300.22 & 1207.02 & 1132.21 & 306.39 & 63.22 & 70.40 & 77.82 & 62.54 \\
\hline 41 & & & 1164.58 & 332.13 & & & 77.80 & 64.3 \\
\hline 42 & & & 1192.02 & 353.01 & & & 77.70 & 66.5 \\
\hline 43 & & & 1218.28 & 374.46 & & & 77.80 & 68.3 \\
\hline 44 & & & 1236.61 & 425.93 & & & 77.80 & 70.5 \\
\hline 45 & & & 1259.82 & 460.03 & & & 77.83 & 72.4 \\
\hline 46 & & & 1264.41 & 503.48 & & & 77.85 & 73.8 \\
\hline 47 & & & 1269.30 & 545.13 & & & 77.88 & 75.8 \\
\hline 48 & & & 1275.38 & 589.62 & & & 77.50 & 77.64 \\
\hline 49 & & & 1282.06 & 651.52 & & & 77.30 & 77.3 \\
\hline 50 & & & 1285.69 & 701.43 & & & 77.10 & 76.6 \\
\hline 51 & & & 1290.52 & 751.87 & & & 76.90 & 75.6 \\
\hline 52 & & & 1294.74 & 818.51 & & & 76.87 & 75.13 \\
\hline 53 & & & 1298.94 & 879.16 & & & 76.40 & 75.01 \\
\hline
\end{tabular}




\begin{tabular}{|c|rr|rrr|}
\hline 54 & 1303.71 & 936.20 & 76.00 & 74.91 \\
55 & 1310.83 & 980.59 & 75.60 & 74.4 \\
56 & 1317.91 & 1026.62 & 75.10 & 74.23 \\
57 & 1322.02 & 1073.20 & 74.90 & 74.17 \\
58 & 1326.12 & 1110.97 & 74.60 & 74.02 \\
59 & & 1142.89 & & 73.92 \\
60 & 1167.82 & & 73.85 \\
61 & 1188.63 & & 73.67 \\
62 & & 1205.93 & & 73.43 \\
63 & 1223.21 & & 73.38 \\
64 & & $\mathbf{1 2 2 8 . 9 6}$ & & 73.29 \\
\hline
\end{tabular}

\section{Leachate quality}

\subsection{COD}

\begin{tabular}{|c|cccc|}
\hline First group & \multicolumn{4}{|c|}{ COD (mg/l) } \\
\hline Time & $\mathbf{R 1}$ & $\mathbf{R 2}$ & $\mathbf{R 3}$ & $\mathbf{R 4}$ \\
\hline 1 & 13600 & 15650 & 15700 & 20700 \\
2 & $\mathbf{2 9 5 5 0}$ & $\mathbf{2 2 9 5 0}$ & $\mathbf{2 5 8 0 0}$ & 29700 \\
5 & 21750 & 14900 & 18650 & 29000 \\
6 & 21533 & 14833 & 20933 & $\mathbf{3 0 9 3 3}$ \\
8 & 21700 & 13766 & 20700 & 30033 \\
10 & 21800 & 13800 & 20050 & 29060 \\
12 & 18900 & 12666 & 18633 & 26533 \\
14 & 14166.6 & 10500 & 15450 & 21266 \\
$\mathbf{1 7}$ & $\mathbf{9 2 6 6 . 6 7}$ & $\mathbf{9 1 3 3}$ & $\mathbf{1 3 0 0 0}$ & $\mathbf{1 7 6 0 0}$ \\
18 & 10166 & $\mathbf{9 8 5 0}$ & 16266 & 17933 \\
22 & 15933 & 13266 & 18600 & 19365 \\
25 & 21100 & 14833 & 21900 & 20700 \\
29 & 24800 & 16566 & 22403 & 27200 \\
35 & 28533 & 16900 & 24060 & 28900 \\
41 & 29900 & 22000 & 26600 & 32900 \\
49 & $\mathbf{3 2 4 0 0}$ & 25300 & $\mathbf{2 7 6 0 0}$ & $\mathbf{3 8 8 0 0}$ \\
55 & 30900 & $\mathbf{2 6 6 0 0}$ & 27000 & 38200 \\
57 & 29600 & 24700 & 26400 & 38700 \\
66 & 26066 & 21200 & 22800 & 37530 \\
72 & 24000 & $\mathbf{1 9 7 0 0}$ & 22700 & 37003 \\
80 & 21800 & 19700 & 22000 & 36500 \\
84 & 21000 & 20100 & 20900 & 35050 \\
94 & 20700 & 20100 & 19700 & 35500 \\
98 & 18900 & 19800 & 19800 & 34600 \\
103 & 19100 & 20126 & 19700 & 35436 \\
\hline
\end{tabular}




\begin{tabular}{|l|cccc|}
\cline { 2 - 5 } 111 & 18700 & 19100 & 20000 & 33700 \\
117 & 19400 & 20100 & 19800 & $\mathbf{3 4 8 0 0}$ \\
124 & 19200 & 20140 & 20450 & 28856 \\
129 & 18765 & 20000 & 20200 & 27250 \\
140 & 18700 & 20500 & 20200 & 25300 \\
153 & 15200 & 18300 & 18500 & 22700 \\
164 & 15000 & 16200 & 17800 & 22100 \\
175 & 13030 & 14800 & 16300 & 20000 \\
187 & 9700 & 11050 & 15800 & 23100 \\
203 & 5300 & 9200 & 16100 & 19050 \\
213 & 4750 & 7900 & 15750 & 17850 \\
218 & 4250 & 7300 & 14800 & 18850 \\
228 & 3900 & 6250 & 14000 & 18200 \\
235 & 3400 & 4700 & 12600 & 17000 \\
260 & $\mathbf{2 8 5 0}$ & $\mathbf{3 5 5 0}$ & 6100 & 13000 \\
273 & 3225 & 3900 & 6375 & 11425 \\
287 & 3937.5 & 4050 & 6712.5 & $\mathbf{8 8 1 2 . 5}$ \\
301 & 2925 & 2550 & 5635 & 8520 \\
315 & 3637 & 3262 & 4300 & 8380 \\
343 & 2850 & 3187.5 & 3375 & 7012.5 \\
354 & 2287.5 & 2925 & 3300 & 6450 \\
393 & $\mathbf{2 7 0 0}$ & $\mathbf{2 7 2 5}$ & $\mathbf{3 4 2 5}$ & $\mathbf{6 2 5 0}$ \\
\hline
\end{tabular}

\begin{tabular}{|c|cccc|}
\hline Second group & \multicolumn{4}{|c|}{ COD (mg/l) } \\
\hline Time & R5 & R6 & R7 & R8 \\
\hline 1 & 28250 & 26650 & 33200 & 33100 \\
4 & $\mathbf{2 4 0 4 5}$ & $\mathbf{2 4 6 5 0}$ & $\mathbf{3 0 6 5 0}$ & $\mathbf{3 4 8 0 0}$ \\
7 & 19900 & 21850 & 25300 & 30250 \\
9 & 18300 & 17900 & 20800 & 30900 \\
11 & 11650 & 12700 & 19950 & 29400 \\
13 & 9350 & 9550 & 17000 & 25550 \\
15 & 7000 & 7300 & 14100 & 23700 \\
$\mathbf{1 7}$ & $\mathbf{4 7 0 0}$ & $\mathbf{5 8 0 0}$ & $\mathbf{8 5 5 0}$ & $\mathbf{1 5 0 5 0}$ \\
19 & 12100 & 15150 & 7500 & 15500 \\
22 & 14100 & 16100 & 8750 & 16687 \\
26 & 20000 & 22900 & 10417 & 16271 \\
28 & 22600 & 26900 & 12500 & 17250 \\
30 & 24450 & 26800 & 12500 & 18530 \\
33 & 28550 & 29850 & 19050 & 21650 \\
42 & 32100 & 33350 & $\mathbf{2 4 6 0 0}$ & 25250 \\
48 & 34250 & 34100 & 25256 & 26900 \\
$\mathbf{5 6}$ & 32500 & 33300 & 27300 & 29868 \\
60 & 33700 & 34000 & 28213 & 29900 \\
70 & 35400 & 34500 & 30500 & 32700 \\
73 & $\mathbf{3 7 6 8 5}$ & 36200 & $\mathbf{3 3 2 0 0}$ & $\mathbf{3 3 6 3 1}$ \\
$\mathbf{7 9}$ & 37125 & 36731 & 29747 & 32500 \\
\hline
\end{tabular}




\begin{tabular}{|c|cccc|}
\hline 87 & 34312 & 36563 & 28456 & 30654 \\
94 & 36000 & $\mathbf{3 6 8 0 0}$ & 27563 & 29813 \\
101 & 31443 & 35212 & 27618 & 31162 \\
106 & 29137 & 31894 & 23063 & 28518 \\
116 & 27200 & $\mathbf{2 4 9 0 6}$ & 25312 & 28743 \\
129 & $\mathbf{2 7 1 1 2}$ & 25987 & 22800 & 27000 \\
140 & 27650 & 25350 & 23062 & 26437 \\
151 & 26600 & 25500 & 21750 & 24550 \\
163 & 25050 & 24050 & 20600 & 22850 \\
179 & 21050 & 19400 & 18000 & 20100 \\
189 & 17650 & 15000 & 16600 & 20350 \\
194 & 13600 & 12900 & 15050 & 18950 \\
204 & 12750 & 11000 & 13700 & 16500 \\
211 & 8100 & 7520 & 13000 & 14100 \\
236 & 6150 & 5250 & 8100 & 10050 \\
249 & $\mathbf{3 8 2 5}$ & $\mathbf{3 1 5 0}$ & $\mathbf{4 5 0 0}$ & $\mathbf{7 6 6 2}$ \\
263 & 4950 & 4538 & 5400 & 6788 \\
277 & 3563 & 4200 & 4463 & 5438 \\
291 & 3750 & 4088 & 4800 & 5250 \\
319 & 3825 & 3975 & 4913 & 4538 \\
330 & 3075 & 3000 & 3863 & 4125 \\
369 & 3275 & 3525 & 4100 & 4475 \\
388 & $\mathbf{2 9 2 5}$ & $\mathbf{3 1 0 0}$ & $\mathbf{3 5 5 0}$ & $\mathbf{4 1 2 0}$ \\
\hline
\end{tabular}

3.2 BOD

\begin{tabular}{|c|cccc|}
\hline First group & \multicolumn{4}{|c|}{ BOD (mg/l) } \\
\hline Time & $\mathbf{R 1}$ & $\mathbf{R 2}$ & $\mathbf{R 3}$ & $\mathbf{R 4}$ \\
\hline 5 & $\mathbf{1 4 8 0 5}$ & $\mathbf{1 1 4 9 8}$ & $\mathbf{1 2 9 2 6}$ & $\mathbf{1 5 8 8 0}$ \\
10 & 11074 & 7176 & 9023 & 12496 \\
17 & $\mathbf{4 3 0 7}$ & $\mathbf{4 5 1 3}$ & $\mathbf{6 2 5 0}$ & $\mathbf{8 5 6 8}$ \\
25 & 10719 & 7713 & 9855 & 8901 \\
38 & 13560 & 12330 & 14800 & 15530 \\
44 & 15400 & 14520 & 14800 & 17300 \\
50 & $\mathbf{1 6 8 0 0}$ & $\mathbf{1 4 6 4 0}$ & $\mathbf{1 5 6 0 0}$ & 18100 \\
55 & 15720 & 12180 & 14010 & 19700 \\
61 & 14700 & 11000 & 12000 & $\mathbf{2 0 1 0 0}$ \\
66 & 14000 & 11600 & 11400 & 18450 \\
86 & 12500 & 11000 & 11200 & 16800 \\
98 & 11100 & 10000 & 11900 & 16700 \\
103 & 9900 & 9300 & 11600 & 17400 \\
111 & 9600 & 9200 & 11200 & 16300 \\
117 & 9700 & 9500 & 11600 & 16800 \\
128 & 10300 & 9500 & 11100 & 17160 \\
183 & 6200 & 7830 & 10000 & 11600 \\
204 & 3000 & 4290 & 9720 & 12500 \\
\hline
\end{tabular}




\begin{tabular}{|l|cccc|}
\hline 214 & 2940 & 4650 & 9100 & 13050 \\
230 & 1590 & 3450 & 8100 & 11160 \\
264 & 1360 & 2490 & 3800 & 8700 \\
280 & 1196 & 2300 & 3200 & 4400 \\
$\mathbf{3 1 9}$ & $\mathbf{9 6 0}$ & $\mathbf{1 1 7 0}$ & $\mathbf{2 0 0 0}$ & $\mathbf{3 2 0 0}$ \\
330 & 880 & 1580 & 1500 & 3300 \\
343 & 660 & 1050 & 1550 & 2900 \\
\hline
\end{tabular}

\begin{tabular}{|c|cccc|}
\hline Second group & \multicolumn{4}{|c|}{ BOD (mg/l) } \\
\hline Time & R5 & R6 & R7 & R8 \\
\hline 5 & $\mathbf{1 8 3 6 3}$ & $\mathbf{1 6 2 6 9}$ & $\mathbf{1 8 6 9 7}$ & $\mathbf{2 0 6 6 4}$ \\
17 & $\mathbf{2 2 0 9}$ & $\mathbf{2 8 0 1}$ & $\mathbf{4 1 3 8}$ & $\mathbf{8 6 7 6}$ \\
20 & 8820 & 9930 & 9960 & 9960 \\
26 & 10820 & 10920 & 10830 & 11270 \\
31 & 11610 & 11000 & 11320 & 12900 \\
37 & 12310 & 13380 & 11870 & 12060 \\
42 & 12720 & 12540 & 12300 & 13100 \\
50 & 15570 & 15360 & 12810 & 13170 \\
67 & $\mathbf{1 7 8 2 0}$ & $\mathbf{1 7 4 4 0}$ & $\mathbf{1 3 2 7 0}$ & $\mathbf{1 4 2 7 0}$ \\
74 & 15500 & 15900 & 12730 & 13600 \\
79 & 15830 & 15650 & 11730 & 13400 \\
87 & 15730 & 17060 & 12000 & 12560 \\
93 & 14890 & 14170 & 11910 & 12600 \\
100 & 14000 & 13700 & 10770 & 12180 \\
152 & 12300 & 11300 & 11270 & 11350 \\
180 & 11600 & 10910 & 9730 & 10800 \\
190 & 9600 & 9570 & 8640 & 10550 \\
206 & 6270 & 7070 & 8180 & 9980 \\
240 & 2313 & 3137 & 4554 & 6331 \\
256 & 2310 & 2310 & 1980 & 2880 \\
291 & 2250 & 2100 & 2100 & 2790 \\
306 & 1550 & 1630 & 1850 & 2500 \\
$\mathbf{3 1 9}$ & $\mathbf{8 1 0}$ & $\mathbf{8 4 0}$ & $\mathbf{1 2 2 0}$ & $\mathbf{1 5 2 0}$ \\
\hline
\end{tabular}


3.3 VFA

\begin{tabular}{|c|cccc|}
\hline First group & \multicolumn{4}{|c|}{ VFA (mg/l) } \\
\hline Time & $\mathbf{R 1}$ & $\mathbf{R 2}$ & $\mathbf{R 3}$ & $\mathbf{R 4}$ \\
\hline 5 & 8171 & 7308 & 7935 & 10715 \\
6 & $\mathbf{9 2 0 5}$ & $\mathbf{7 9 6 0}$ & 6915 & 10119 \\
8 & 8817 & 6774 & $\mathbf{9 8 1 0}$ & $\mathbf{1 2 4 2 5}$ \\
10 & 7269 & 6331 & 9510 & 11598 \\
12 & 7498 & 6042 & 8650 & 11000 \\
14 & 5124 & 7174 & 7660 & 9606 \\
17 & $\mathbf{3 2 4 4}$ & $\mathbf{3 2 7 2}$ & $\mathbf{4 7 8 5}$ & $\mathbf{7 3 7 2}$ \\
18 & 4350 & 4420 & 6677 & 8083 \\
22 & 6554 & 5443 & 6238 & 8636 \\
25 & 9347 & 6813 & 7052 & 9645 \\
29 & 10730 & 7658 & 8685 & 11477 \\
31 & 12409 & 8075 & 9437 & 13454 \\
35 & 12177 & 9120 & $\mathbf{1 0 7 5 5}$ & 14409 \\
41 & $\mathbf{1 3 0 9 0}$ & $\mathbf{9 1 2 0}$ & 9930 & 15270 \\
50 & 12358 & 8400 & 8970 & $\mathbf{1 5 7 7 9}$ \\
55 & 10316 & 8260 & 8630 & 15014 \\
57 & 10060 & 8320 & 8260 & 14636 \\
61 & 8006 & 7964 & 7776 & 13312 \\
66 & 9016 & 7401 & 7889 & 13155 \\
72 & 8265 & 7664 & 8227 & 13560 \\
75 & 8265 & 7401 & 7851 & 13449 \\
80 & 8190 & 7401 & 8791 & 13449 \\
84 & 7889 & 7551 & 7851 & 12950 \\
98 & 8077 & 7551 & 7401 & 13569 \\
103 & 6612 & 7081 & 7889 & 12784 \\
111 & 7269 & 7701 & 7401 & 13093 \\
118 & 7025 & 7175 & $\mathbf{7 5 1 3}$ & 11763 \\
129 & 7003 & 7551 & 8507 & 10858 \\
140 & 7213 & 7904 & 7682 & 10662 \\
153 & 6721 & $\mathbf{6 9 8 7}$ & 7175 & 10068 \\
163 & 5687 & 5433 & 8266 & 9543 \\
175 & 4874 & 5527 & 8534 & 8843 \\
187 & 3286 & 4000 & 6589 & 9080 \\
213 & 973 & 1870 & 5770 & 7901 \\
228 & 201 & 989 & 3364 & 5200 \\
235 & 103 & 848 & 4003 & 5543 \\
260 & 228 & 1223 & 1295 & 2390 \\
273 & 40 & 726 & 2218 & 2800 \\
301 & 35 & 390 & 800 & 1750 \\
$\mathbf{3 1 9}$ & $\mathbf{3 7}$ & $\mathbf{2 9 0}$ & $\mathbf{6 0 0}$ & $\mathbf{1 3 5 0}$ \\
343 & 20 & 148 & 390 & 1012 \\
393 & 1 & 1 & 1 & 294 \\
\hline & & & & \\
\hline
\end{tabular}




\begin{tabular}{|c|c|c|c|c|}
\hline Second group & \multicolumn{4}{|c|}{ VFA (mg/l) } \\
\hline Time & $\mathbf{R 5}$ & R6 & $\mathbf{R 7}$ & $\mathbf{R 8}$ \\
\hline 1 & 8731 & 7659 & 12064 & 15546 \\
\hline 4 & 9389 & 8761 & 12940 & 18700 \\
\hline 7 & 8784 & 8933 & 10856 & 16932 \\
\hline 9 & 8784 & 8933 & 8308 & 12600 \\
\hline 11 & 4408 & 4107 & 8533 & 10783 \\
\hline 13 & 3393 & 3337 & 7255 & 10507 \\
\hline 15 & 2872 & 2556 & 6345 & 9300 \\
\hline 17 & 1853 & 1929 & 3756 & 6449 \\
\hline 19 & 3248 & 4701 & 4716 & 6326 \\
\hline 22 & 6335 & 7201 & 8512 & 9395 \\
\hline 24 & 8313 & 9044 & 9743 & 10654 \\
\hline 26 & 9542 & 11173 & 9843 & 10659 \\
\hline 28 & 11665 & 12861 & 10430 & 11450 \\
\hline 30 & 13045 & 13030 & 9965 & 12540 \\
\hline 42 & 13572 & 13464 & 9798 & 12650 \\
\hline 48 & 14198 & 12981 & 9923 & 12700 \\
\hline 56 & 14612 & 13318 & 10488 & 13956 \\
\hline 67 & 16250 & 14059 & 11447 & 14507 \\
\hline 74 & 16686 & 14880 & 12604 & 15782 \\
\hline 79 & 16262 & 15463 & 11276 & 13736 \\
\hline 87 & 13003 & 11896 & 8839 & 13500 \\
\hline 94 & 14100 & 12753 & 9348 & 11512 \\
\hline 101 & 13067 & 13381 & 9269 & 11400 \\
\hline 106 & 13600 & 13660 & 9913 & 12186 \\
\hline 116 & 9937 & 9005 & 8518 & 11300 \\
\hline 129 & 12300 & 11347 & 9300 & 11017 \\
\hline 140 & 11117 & 10805 & 8791 & 10897 \\
\hline 151 & 11611 & 9327 & 10501 & 11641 \\
\hline 163 & 9100 & 10100 & 9534 & 11108 \\
\hline 189 & 7679 & 5608 & 7296 & 8356 \\
\hline 204 & 2803 & 1182 & 4001 & 4217 \\
\hline 211 & 2978 & 1400 & 4592 & 5055 \\
\hline 236 & 1333 & 1360 & 2340 & 3420 \\
\hline 249 & 250 & 200 & 663 & 1082 \\
\hline 277 & 92 & 17 & 239 & 654 \\
\hline 319 & 59 & 80 & 201 & 819 \\
\hline 369 & 10 & 10 & 150 & 530 \\
\hline 388 & 1 & 1 & 1 & 140 \\
\hline
\end{tabular}




\section{$3.4 \mathrm{pH}$}

\begin{tabular}{|c|c|c|c|c|}
\hline First group & \multicolumn{4}{|c|}{$\mathbf{p H}$} \\
\hline Time & $\mathbf{R 1}$ & $\mathbf{R 2}$ & $\mathbf{R 3}$ & R4 \\
\hline 5 & 6.50 & 6.30 & 6.10 & 5.65 \\
\hline 6 & 6.54 & 6.90 & 6.66 & 6.20 \\
\hline 8 & 6.91 & 7.03 & 6.43 & 5.82 \\
\hline 10 & 6.51 & 7.05 & 6.38 & 5.90 \\
\hline 12 & 7.40 & 7.15 & 6.81 & 6.70 \\
\hline 14 & 7.74 & 7.10 & 7.10 & 6.70 \\
\hline 17 & 7.56 & 7.42 & $\mathbf{7 . 5 0}$ & 7.26 \\
\hline 18 & 7.35 & 7.37 & 7.20 & 7.14 \\
\hline 22 & 6.91 & 7.02 & 7.14 & 6.78 \\
\hline 25 & 6.38 & 6.61 & 6.72 & 6.40 \\
\hline 29 & 6.20 & 6.16 & 6.33 & 6.30 \\
\hline 31 & 6.30 & 6.72 & 6.88 & 6.63 \\
\hline 35 & 6.60 & 7.18 & 6.90 & 6.55 \\
\hline 41 & 7.20 & 7.30 & 7.22 & 6.71 \\
\hline 48 & 7.57 & 7.77 & 7.73 & 7.01 \\
\hline 55 & 7.26 & 7.90 & 7.80 & 7.48 \\
\hline 57 & 7.32 & 7.90 & 7.76 & 7.41 \\
\hline 61 & 7.56 & 7.81 & 7.85 & 7.65 \\
\hline 66 & 7.60 & 7.91 & 7.90 & 6.80 \\
\hline 72 & 7.33 & 7.00 & 7.11 & 6.77 \\
\hline 75 & 7.44 & 7.15 & 6.76 & 6.92 \\
\hline 80 & 7.60 & 7.14 & 7.18 & 7.11 \\
\hline 84 & 7.34 & 7.00 & 6.80 & 7.00 \\
\hline 98 & 7.29 & 6.83 & 6.75 & 7.07 \\
\hline 103 & 7.32 & 6.85 & 6.92 & 7.31 \\
\hline 111 & 7.22 & 6.88 & 6.79 & 7.22 \\
\hline 117 & 7.38 & 6.91 & 6.72 & 7.34 \\
\hline 129 & 7.20 & 6.76 & 6.80 & 7.07 \\
\hline 140 & 7.00 & 6.82 & 6.71 & 7.00 \\
\hline 154 & 7.20 & 6.86 & 6.76 & 7.02 \\
\hline 164 & 7.15 & 6.81 & 6.85 & 6.92 \\
\hline 187 & 7.61 & 7.40 & 6.81 & 7.26 \\
\hline 213 & 7.66 & 7.03 & 7.41 & 7.34 \\
\hline 228 & 7.78 & 7.20 & 7.69 & 7.20 \\
\hline 260 & 7.40 & 7.30 & 7.43 & 7.35 \\
\hline 273 & 7.50 & 7.29 & 7.49 & 7.41 \\
\hline 301 & 7.72 & 7.73 & 7.53 & 7.50 \\
\hline 343 & 7.63 & 7.50 & 7.44 & 7.39 \\
\hline 393 & 8.03 & 7.92 & 7.94 & 7.83 \\
\hline
\end{tabular}




\begin{tabular}{|c|c|c|c|c|}
\hline Second group & \multicolumn{4}{|c|}{ pH } \\
\hline Time & R5 & R6 & $\mathbf{R 7}$ & $\mathbf{R 8}$ \\
\hline 1 & 6.30 & 6.72 & 6.60 & 5.72 \\
\hline 2 & 6.02 & 6.61 & 6.35 & 5.95 \\
\hline 4 & 7.22 & 7.10 & 6.67 & 6.50 \\
\hline 7 & 7.45 & 7.07 & 7.32 & 6.67 \\
\hline 9 & 7.50 & 6.80 & 7.41 & 7.30 \\
\hline 11 & 7.56 & 7.23 & 7.34 & 7.45 \\
\hline 13 & 7.40 & 7.32 & 7.52 & 7.53 \\
\hline 17 & 7.45 & 7.50 & 7.66 & 7.50 \\
\hline 18 & 6.62 & 6.43 & 6.50 & 6.80 \\
\hline 19 & 6.52 & 6.45 & 6.42 & 6.40 \\
\hline 22 & 6.50 & 6.50 & 6.48 & 6.43 \\
\hline 24 & 6.20 & 6.25 & 6.38 & 6.33 \\
\hline 26 & 6.70 & 6.58 & 6.46 & 6.46 \\
\hline 28 & 6.87 & 6.67 & 6.71 & 6.63 \\
\hline 31 & 6.85 & 6.80 & 6.85 & 6.77 \\
\hline 33 & 6.75 & 6.65 & 6.87 & 6.90 \\
\hline 37 & 6.80 & 6.53 & 6.95 & 6.92 \\
\hline 41 & 6.70 & 6.50 & 7.03 & 6.94 \\
\hline 60 & 6.68 & 6.63 & 7.11 & 6.96 \\
\hline 67 & 6.82 & 6.70 & 7.19 & 6.98 \\
\hline 74 & 7.00 & 6.88 & 6.87 & 6.94 \\
\hline 79 & 7.10 & 6.98 & 6.95 & 6.98 \\
\hline 87 & 7.14 & 6.89 & 6.92 & 6.88 \\
\hline 101 & 7.10 & 6.92 & 6.92 & 6.84 \\
\hline 105 & 7.16 & 7.10 & 6.69 & 6.98 \\
\hline 129 & 7.28 & 7.12 & 6.91 & 6.88 \\
\hline 140 & 6.89 & 6.92 & 7.22 & 6.83 \\
\hline 151 & 6.95 & 7.23 & 7.26 & 7.10 \\
\hline 163 & 7.08 & 7.16 & 7.31 & 7.28 \\
\hline 189 & 7.31 & 7.46 & 7.48 & 7.35 \\
\hline 204 & 7.50 & 7.47 & 7.40 & 7.41 \\
\hline 236 & 7.80 & 7.61 & 7.54 & 7.49 \\
\hline 249 & 7.53 & 7.55 & 7.34 & 7.50 \\
\hline 277 & 7.45 & 7.48 & 7.39 & 7.50 \\
\hline 291 & 7.60 & 7.51 & 7.43 & 7.46 \\
\hline 319 & 7.63 & 7.73 & 7.42 & 7.35 \\
\hline 369 & 8.08 & 8.10 & 7.98 & 7.87 \\
\hline 388 & 8.14 & 8.03 & 8.00 & 7.90 \\
\hline
\end{tabular}




\subsection{TVS}

\begin{tabular}{|c|c|c|c|c|}
\hline First group & \multicolumn{4}{|c|}{ TVS (mg/l) } \\
\hline Time & $\mathbf{R} 1$ & $\mathbf{R} 2$ & $\mathbf{R 3}$ & R4 \\
\hline 3 & 10152 & 5972 & 8400 & 12500 \\
\hline 5 & 10088 & 7319 & 9876 & 14336 \\
\hline 17 & 3700 & 3436 & 5260 & 8130 \\
\hline 22 & 7484 & 5440 & 5680 & 8520 \\
\hline 26 & 9924 & 6804 & 8060 & 10560 \\
\hline 28 & 12452 & 8212 & 10236 & 12884 \\
\hline 32 & 13000 & 8800 & 10500 & 13502 \\
\hline 36 & 13489 & 9338 & 11270 & 14236 \\
\hline 41 & 15740 & 12090 & 13707 & 14648 \\
\hline 47 & 15170 & 11871 & 13002 & 15516 \\
\hline 57 & 12270 & 10270 & 10800 & 17060 \\
\hline 68 & 11600 & 10310 & 10692 & 15360 \\
\hline 75 & 11280 & 9741 & 10280 & 16216 \\
\hline 84 & 9850 & 9800 & 10031 & 15948 \\
\hline 94 & 9464 & 10080 & 9600 & 14080 \\
\hline 104 & 9924 & 9570 & 9744 & 13920 \\
\hline 111 & 10080 & 9552 & 10016 & 13348 \\
\hline 117 & 10260 & 10384 & 9816 & 13730 \\
\hline 125 & 10056 & 10540 & 10140 & 13200 \\
\hline 131 & 10040 & 10180 & 10710 & 12800 \\
\hline 141 & 10080 & 9676 & 10940 & 12550 \\
\hline 159 & 9200 & 8300 & 10060 & 13333 \\
\hline 176 & 8508 & 7484 & 9880 & 12450 \\
\hline 191 & 6300 & 6552 & 9512 & 10400 \\
\hline 204 & 5260 & 5532 & 8730 & 10208 \\
\hline 211 & 4440 & 4928 & 8270 & 10472 \\
\hline 220 & 4132 & 4846 & 7360 & 9564 \\
\hline 228 & 3716 & 3588 & 7396 & 8560 \\
\hline 260 & 3116 & 3484 & 6480 & 7050 \\
\hline 280 & 3156 & 3204 & 5596 & 6576 \\
\hline 301 & 2852 & 2552 & 2772 & 5480 \\
\hline 315 & 2624 & 3684 & 2372 & 5256 \\
\hline 343 & 2516 & 2468 & 2696 & 5784 \\
\hline 354 & 3420 & 3548 & 3572 & 6860 \\
\hline 393 & 2516 & 2636 & 3520 & 5768 \\
\hline
\end{tabular}




\begin{tabular}{|c|c|c|c|c|}
\hline Second group & \multicolumn{4}{|c|}{ TVS (mg/l) } \\
\hline Time & $\mathbf{R 5}$ & R6 & $\mathbf{R 7}$ & $\mathbf{R 8}$ \\
\hline 1 & 10370 & 9830 & 11470 & 12410 \\
\hline 2 & 13652 & 12120 & 14136 & 16608 \\
\hline 4 & 9380 & 9372 & 8904 & 12032 \\
\hline 8 & 8016 & 8160 & 7756 & 10748 \\
\hline 12 & 5560 & 5532 & 5128 & 8884 \\
\hline 17 & 3028 & 3240 & 4096 & 6132 \\
\hline 19 & 3500 & 3644 & 4212 & 5986 \\
\hline 23 & 8528 & 9508 & 4608 & 6215 \\
\hline 26 & 10220 & 11516 & 5896 & 7276 \\
\hline 29 & 11832 & 10224 & 7092 & 11870 \\
\hline 33 & 12508 & 12364 & 8240 & 12600 \\
\hline 37 & 14492 & 13336 & 9208 & 12300 \\
\hline 42 & 14372 & 13468 & 10512 & 14028 \\
\hline 44 & 17100 & 13304 & 11768 & 14616 \\
\hline 47 & 17200 & 13720 & 12204 & 14800 \\
\hline 48 & 17932 & 14540 & 12184 & 14596 \\
\hline 51 & 17820 & 15952 & 12620 & 14648 \\
\hline 60 & 18028 & 16400 & 12568 & 15452 \\
\hline 66 & 17248 & 17624 & 14460 & 16103 \\
\hline 70 & 17010 & 16728 & 11952 & 14870 \\
\hline 78 & 17016 & 16976 & 10644 & 13500 \\
\hline 85 & 16972 & 17084 & 10400 & 13110 \\
\hline 91 & 15160 & 16068 & 9948 & 12950 \\
\hline 99 & 13428 & 14856 & 10228 & 13260 \\
\hline 105 & 13772 & 13796 & 10886 & 12060 \\
\hline 116 & 12520 & 13732 & 10828 & 13212 \\
\hline 134 & 12080 & 13100 & 8760 & 12408 \\
\hline 151 & 10420 & 10560 & 9388 & 11268 \\
\hline 166 & 10500 & 9400 & 8584 & 10372 \\
\hline 179 & 9704 & 8360 & 8500 & 9868 \\
\hline 186 & 8252 & 7436 & 8620 & 10080 \\
\hline 204 & 7324 & 5572 & 8280 & 7756 \\
\hline 236 & 4476 & 5300 & 4160 & 4772 \\
\hline 256 & 3804 & 4344 & 3936 & 4700 \\
\hline 277 & 3471.2 & 3620 & 3812 & 5140 \\
\hline 291 & 3464 & 3852 & 4052 & 4844 \\
\hline 319 & 3244 & 3340 & 3956 & 4264 \\
\hline 330 & 4276 & 4520 & 4956 & 5840 \\
\hline 369 & 3792 & 3876 & 4052 & 4663 \\
\hline 388 & 2972 & 3200 & 3372 & 4768 \\
\hline
\end{tabular}




\subsection{TS}

\begin{tabular}{|c|c|c|c|c|}
\hline First group & \multicolumn{4}{|c|}{ TS (mg/l) } \\
\hline Time & $\mathbf{R 1}$ & $\mathbf{R 2}$ & $\mathbf{R 3}$ & $\mathbf{R 4}$ \\
\hline 3 & 18320 & 12736 & 16436 & 22628 \\
\hline 5 & $\mathbf{2 3 4 0 8}$ & $\mathbf{2 0 1 3 6}$ & $\mathbf{2 9 7 3 6}$ & $\mathbf{4 3 2 8 8}$ \\
\hline 17 & $\mathbf{1 3 0 2 0}$ & $\mathbf{1 2 7 5 6}$ & $\mathbf{2 0 1 2 0}$ & $\mathbf{3 4 0 8 2}$ \\
\hline 22 & 16268 & 15332 & 22440 & 36052 \\
\hline 26 & 20320 & 18528 & 22712 & 40320 \\
\hline 28 & 25096 & 20924 & 26040 & 44020 \\
\hline 32 & 25500 & 20860 & 26828 & 49136 \\
\hline 36 & 30732 & 21336 & 28676 & 50268 \\
\hline 41 & 30924 & 22324 & 29532 & 49396 \\
\hline 43 & 31012 & 23068 & 30312 & 49588 \\
\hline 47 & $\mathbf{3 2 3 6 4}$ & $\mathbf{2 4 5 6 8}$ & 33752 & 49416 \\
\hline 50 & 30980 & 20972 & $\mathbf{3 5 0 4 8}$ & 51572 \\
\hline 53 & 29152 & 19304 & 32740 & 49400 \\
\hline 57 & 27944 & 19056 & 30152 & 51640 \\
\hline 61 & 26508 & 18768 & 29804 & 51740 \\
\hline 66 & 23252 & 20212 & 28512 & 51728 \\
\hline 68 & 22900 & 17916 & 27636 & 50252 \\
\hline 72 & 21420 & 17320 & 28324 & $\mathbf{5 1 8 2 4}$ \\
\hline 75 & 20928 & 19856 & 27892 & 51612 \\
\hline 84 & 20328 & 18096 & 28600 & 50280 \\
\hline 90 & 19688 & 19000 & 28356 & 47188 \\
\hline 94 & 20144 & 19276 & 29884 & 44752 \\
\hline 102 & 20712 & 18672 & 28952 & 45316 \\
\hline 109 & 20828 & 18492 & 28956 & 44576 \\
\hline 115 & 22376 & 19196 & 30308 & 48000 \\
\hline 123 & 22112 & 19496 & 30036 & 45408 \\
\hline 129 & 21800 & 17784 & 29424 & 45688 \\
\hline 140 & 22272 & 19071 & 29708 & 45436 \\
\hline 158 & 20800 & 18212 & 27760 & 42756 \\
\hline 175 & 19916 & 17824 & 26136 & 41732 \\
\hline 190 & 17956 & 17696 & 24688 & 42332 \\
\hline 203 & 14944 & 18292 & 22784 & 40248 \\
\hline 228 & 12824 & 15552 & 23100 & 44584 \\
\hline 260 & 11892 & 14991 & 22148 & 39356 \\
\hline 280 & 12196 & 15156 & 21568 & 40728 \\
\hline 301 & 11688 & 13388 & 22476 & 41376 \\
\hline 315 & 11696 & 13060 & 20060 & 40692 \\
\hline 343 & 11712 & 12340 & 22128 & 40136 \\
\hline 354 & 12504 & 12104 & 23364 & 39904 \\
\hline 393 & $\mathbf{1 1 6 8 0}$ & $\mathbf{1 3 0 6 4}$ & $\mathbf{2 3 8 4 4}$ & $\mathbf{4 0 5 2 8}$ \\
\hline & & & & \\
\hline & & &
\end{tabular}




\begin{tabular}{|c|c|c|c|c|}
\hline Second group & \multicolumn{4}{|c|}{ TVS (mg/l) } \\
\hline Time & R5 & R6 & R7 & R8 \\
\hline 1 & 23540 & 21450 & 22530 & 23650 \\
2 & $\mathbf{2 6 2 5 2}$ & $\mathbf{2 3 5 1 6}$ & 26184 & 32720 \\
4 & 20000 & 20896 & $\mathbf{3 1 1 8 4}$ & $\mathbf{4 2 7 2 0}$ \\
8 & 17596 & 18616 & 21516 & $\mathbf{3 0 5 0 8}$ \\
12 & 13668 & 14728 & 18096 & 27308 \\
17 & $\mathbf{8 4 7 6}$ & $\mathbf{1 1 7 1 6}$ & $\mathbf{1 7 9 5 6}$ & $\mathbf{2 9 4 2 4}$ \\
19 & 13292 & 16192 & 18537 & 30641 \\
23 & 17120 & 21352 & 19879 & 31478 \\
26 & 20572 & 25836 & 20908 & 34616 \\
29 & 23128 & 27692 & 21716 & 33708 \\
33 & 24764 & 28368 & 25976 & 36712 \\
37 & 29092 & 32128 & 27220 & 36184 \\
42 & 28980 & 30888 & 29224 & 37204 \\
44 & 31524 & 35552 & 28220 & 36240 \\
47 & 37240 & 30664 & 30540 & 36874 \\
48 & 38420 & 31612 & 31615 & 38266 \\
50 & 36184 & 32540 & 34057 & 39723 \\
60 & 37456 & 35880 & 37924 & 40392 \\
66 & $\mathbf{4 0 5 6 0}$ & 38348 & 40304 & 41568 \\
70 & 39948 & 41096 & 42732 & 43256 \\
78 & 37852 & $\mathbf{4 2 2 6 8}$ & $\mathbf{4 4 8 0 0}$ & 43284 \\
85 & 38196 & 39912 & 43512 & 42768 \\
91 & 36276 & 37228 & 40236 & 45436 \\
99 & 33980 & 36368 & 39628 & 48068 \\
105 & 30444 & 34496 & 37096 & $\mathbf{5 0 8 6 8}$ \\
116 & 30096 & 32956 & 37840 & 48080 \\
134 & 28128 & 32092 & 35120 & 46784 \\
151 & 30016 & 32884 & 34208 & 44716 \\
166 & 21784 & 25276 & 31676 & 42412 \\
179 & 21728 & 23284 & 29996 & 42748 \\
204 & 17332 & 21272 & 30536 & 44136 \\
236 & 13248 & 18780 & 28260 & 41268 \\
256 & 12844 & 17188 & 27616 & 41540 \\
277 & 13043 & 18280 & 25956 & 40908 \\
291 & 12104 & 18380 & 24688 & 39112 \\
319 & 11920 & 17908 & 25352 & 39048 \\
330 & 13840 & 15032 & 25032 & 38332 \\
369 & 12448 & 13532 & 24812 & 38756 \\
388 & $\mathbf{1 0 9 2 8}$ & $\mathbf{1 4 8 4 4}$ & $\mathbf{2 4 1 6 4}$ & $\mathbf{3 8 0 6 0}$ \\
\hline & & & & \\
\hline & & & \\
\hline 19 & & &
\end{tabular}




\section{7 $\mathrm{NH}_{3}-\mathrm{N}$}

\begin{tabular}{|c|c|c|c|c|}
\hline First group & \multicolumn{4}{|c|}{$\mathrm{NH}_{3}-\mathrm{N}(\mathrm{mg} / \mathrm{l})$} \\
\hline Time & $\mathbf{R 1}$ & $\mathbf{R 2}$ & $\mathbf{R 3}$ & $\mathbf{R 4}$ \\
\hline 5 & 188.75 & 192.62 & 239.70 & 263.10 \\
\hline 6 & 159.88 & 244.61 & 270.67 & 432.98 \\
\hline 8 & 236.81 & 191.06 & 285.30 & 543.21 \\
\hline 10 & 207.18 & 87.09 & 237.77 & 519.54 \\
\hline 12 & 178.35 & 45.19 & 188.75 & 339.58 \\
\hline 14 & 79.99 & 64.00 & 164.47 & 339.58 \\
\hline 17 & 37.96 & 86.73 & 109.26 & 335.48 \\
\hline 18 & 37.81 & 70.55 & 81.95 & 294.70 \\
\hline 22 & 28.94 & 61.72 & 79.02 & 300.73 \\
\hline 25 & 50.82 & 94.05 & 139.31 & 228.33 \\
\hline 29 & 91.79 & 146.25 & 226.49 & 292.32 \\
\hline 31 & 92.54 & 157.31 & 303.17 & 492.90 \\
\hline 35 & 101.99 & 222.85 & 410.78 & 1112.48 \\
\hline 41 & 104.07 & 340.95 & 558.83 & 1112.48 \\
\hline 55 & 84.31 & 392.88 & 613.39 & 1251.13 \\
\hline 57 & 101.99 & 399.29 & 782.11 & 1308.12 \\
\hline 61 & 103.23 & 454.55 & 876.03 & 2017.67 \\
\hline 66 & 131.10 & 567.96 & 977.26 & 2421.03 \\
\hline 70 & 237.4 & 631.03 & 949.94 & 2668.17 \\
\hline 75 & 129.52 & 657.11 & 1085.78 & 3240.72 \\
\hline 84 & 48.41 & 277.33 & 460.45 & 2362.32 \\
\hline 98 & 25.73 & 169.89 & 380.43 & 2112.68 \\
\hline 103 & 37.05 & 198.15 & 312.65 & 2012.21 \\
\hline 111 & 26.91 & 196.56 & 273.98 & 1713.01 \\
\hline 117 & 24.71 & 191.84 & 275.09 & 1545.43 \\
\hline 129 & 34.03 & 170.58 & 335.48 & 1109.86 \\
\hline 140 & 35.87 & 164.47 & 297.09 & 901.22 \\
\hline 154 & 30.02 & 152.91 & 269.58 & 837.86 \\
\hline 164 & 40.18 & 162.49 & 313.16 & 742.00 \\
\hline 187 & 34.45 & 184.97 & 328.75 & 767.96 \\
\hline 228 & 36.75 & 164.47 & 303.17 & 658.83 \\
\hline 260 & 39.86 & 165.14 & 301.95 & 467.62 \\
\hline
\end{tabular}




\begin{tabular}{|c|c|c|c|c|}
\hline Second group & \multicolumn{4}{|c|}{$\mathrm{NH}_{3}-\mathrm{N}(\mathrm{mg} / \mathrm{l})$} \\
\hline Time & R5 & $\mathrm{R} 6$ & R7 & R8 \\
\hline 1 & 303.17 & 436.50 & 488.92 & 532.32 \\
\hline 2 & 447.24 & 463.84 & 515.35 & 605.98 \\
\hline 4 & 248.60 & 265.24 & 528.03 & 452.71 \\
\hline 7 & 463.84 & 479.12 & 339.58 & 316.98 \\
\hline 9 & 159.88 & 221.95 & 135.97 & 142.74 \\
\hline 11 & 163.15 & 266.32 & 116.57 & 104.50 \\
\hline 13 & 149.24 & 139.31 & 104.07 & 88.87 \\
\hline 15 & 56.01 & 81.29 & 68.30 & 69.98 \\
\hline 17 & 11.97 & 28.71 & 31.01 & 45.55 \\
\hline 19 & 13.79 & 35.01 & 61.72 & 72.58 \\
\hline 22 & 15.89 & 53.35 & 77.75 & 131.10 \\
\hline 24 & 95.98 & 143.32 & 80.61 & 103.23 \\
\hline 26 & 139.31 & 171.97 & 122.87 & 205.51 \\
\hline 28 & 168.63 & 220.69 & 229.26 & 310.41 \\
\hline 31 & 184.63 & 279.78 & 232.06 & 487.76 \\
\hline 33 & 207.47 & 305.18 & 277.33 & 547.52 \\
\hline 37 & 164.27 & 286.58 & 399.29 & 605.60 \\
\hline 42 & 126.92 & 259.31 & 505.02 & 638.47 \\
\hline 60 & 73.58 & 146.25 & 281.86 & 535.60 \\
\hline 67 & 97.15 & 164.47 & 256.79 & 475.63 \\
\hline 74 & 128.47 & 123.37 & 255.75 & 426.73 \\
\hline 79 & 131.06 & 135.97 & 293.51 & 366.74 \\
\hline 94 & 80.31 & 198.15 & 193.40 & 306.88 \\
\hline 101 & 39.06 & 157.31 & 169.89 & 332.77 \\
\hline 105 & 19.54 & 121.39 & 168.52 & 262.04 \\
\hline 116 & 27.68 & 116.57 & 160.52 & 223.75 \\
\hline 129 & 84.65 & 114.23 & 157.31 & 171.27 \\
\hline 140 & 33.76 & 92.17 & 141.58 & 206.34 \\
\hline 163 & 43.04 & 87.44 & 115.63 & 135.97 \\
\hline 195 & 30.51 & 60.73 & 76.81 & 119.92 \\
\hline 204 & 18.84 & 30.88 & 46.86 & 71.70 \\
\hline 236 & 22.88 & 35.30 & 36.75 & 59.75 \\
\hline
\end{tabular}




\subsection{Shortcircuiting}

First analysis for shortcircuiting

\begin{tabular}{|c|c|c|c|c|c|c|c|c|c|c|}
\hline \multirow{2}{*}{$\begin{array}{l}3 / 11 / 2005 \\
\text { Reactors }\end{array}$} & \multicolumn{3}{|c|}{ Initial COD (mg/l) } & \multirow{2}{*}{$\begin{array}{c}\text { Mass in } \\
\text { bioreactors } \\
(\mathrm{kg})_{\text {initial }}\end{array}$} & \multirow{2}{*}{$\begin{array}{c}\text { Final } \\
\text { Moisture } \\
\text { content \% }\end{array}$} & \multirow[t]{2}{*}{$\begin{array}{l}\text { Volume } \\
\text { of } \mathrm{H}_{2} \mathrm{O}(1)\end{array}$} & \multirow{2}{*}{$\begin{array}{c}\text { Expected } \\
\text { COD } \\
(\mathrm{mg} / \mathrm{l}) \\
\end{array}$} & \multicolumn{3}{|c|}{$\begin{array}{l}\text { Measured COD out after } 24 \mathrm{hr} \\
(\mathrm{mg} / \mathrm{l})\end{array}$} \\
\hline & $\mathrm{COD}_{1}$ & $\mathrm{COD}_{2}$ & Average & & & & & $\mathrm{COD}_{1}$ & $\mathrm{COD}_{2}$ & Average \\
\hline$\overline{\text { R1 }}$ & 9400 & 10000 & 9700 & 33.5 & 62.48 & 20.93 & 7268.98 & 5240 & 5840 & 5540 \\
\hline $\mathbf{R 2}$ & 10500 & 11600 & 11050 & 34.3 & 61.52 & 21.10 & 8297.63 & 6400 & 6700 & 6550 \\
\hline R3 & 16000 & 15600 & 15800 & 36.1 & 63.64 & 22.97 & 12109.94 & 9650 & 9900 & 9775 \\
\hline R4 & 23000 & 23200 & 23100 & 36.2 & 60.58 & 21.93 & 17510.76 & 15400 & 14100 & 14750 \\
\hline $\mathbf{R 5}$ & 26100 & 25100 & 25600 & 35.1 & 62.50 & 21.94 & 19407.60 & 14900 & 15600 & 15250 \\
\hline R6 & 24400 & 23700 & 24050 & 34.5 & 62.84 & 21.68 & 18179.67 & 13900 & 14000 & 13950 \\
\hline R7 & 21000 & 20200 & 20600 & 35.3 & 62.94 & 22.22 & 15664.64 & 12150 & 12200 & 12175 \\
\hline R8 & 23400 & 22300 & 22850 & 36.2 & 64.68 & 23.42 & 17591.20 & 14300 & 14600 & 14450 \\
\hline
\end{tabular}

Second analysis for shortcircuiting

\begin{tabular}{|c|c|c|c|c|c|c|c|c|c|c|}
\hline \multirow{2}{*}{$\begin{array}{l}3 / 11 / 2005 \\
\text { Reactors }\end{array}$} & \multicolumn{3}{|c|}{ Initial COD (mg/l) } & \multirow{2}{*}{$\begin{array}{c}\text { Mass in } \\
\text { bioreactors } \\
(\mathrm{kg})_{\text {initial }}\end{array}$} & \multirow{2}{*}{$\begin{array}{c}\text { Final } \\
\text { Moisture } \\
\text { content \% }\end{array}$} & \multirow[t]{2}{*}{$\begin{array}{l}\text { Volume } \\
\text { of } \mathrm{H}_{2} \mathrm{O}(\mathrm{l})\end{array}$} & \multirow{2}{*}{$\begin{array}{c}\text { Expected } \\
\text { COD } \\
\text { (mg/l) }\end{array}$} & \multicolumn{3}{|c|}{$\begin{array}{l}\text { Measured COD out after } 24 \mathrm{hr} \\
(\mathrm{mg} / \mathrm{l})\end{array}$} \\
\hline & $\mathrm{COD}_{1}$ & $\mathrm{COD}_{2}$ & Average & & & & & $\mathrm{COD}_{1}$ & $\mathrm{COD}_{2}$ & Average \\
\hline R1 & $\mathbf{2 7 5 0}$ & 2650 & 2700 & 33.5 & 62.48 & 20.93 & 2023.33 & 1350 & 1670 & 1510 \\
\hline $\mathbf{R 2}$ & 2800 & 2650 & 2725 & 34.3 & 61.52 & 21.10 & 2046.25 & 1700 & 1450 & 1575 \\
\hline $\mathbf{R 3}$ & 3500 & 3350 & 3425 & 36.1 & 63.64 & 22.97 & 2625.10 & 2070 & 2100 & 2085 \\
\hline R4 & 6100 & 6400 & 6250 & 36.2 & 60.58 & 21.93 & 4737.76 & 3900 & 3750 & 3825 \\
\hline R5 & 3050 & 2800 & 2925 & 35.1 & 62.50 & 21.94 & 2217.47 & 1640 & 1790 & 1715 \\
\hline R6 & 3150 & 3050 & 3100 & 34.5 & 62.84 & 21.68 & 2343.33 & 1650 & 1950 & 1800 \\
\hline R7 & 3500 & 3600 & 3550 & 35.3 & 62.94 & 22.22 & 2699.49 & 2150 & 2140 & 2145 \\
\hline R8 & 4200 & 4050 & 4120 & 36.2 & 64.68 & 23.42 & 3171.81 & 2500 & 2730 & 2615 \\
\hline
\end{tabular}




\section{Hydrolysis}

\subsection{First set}

(Group one, with $20 \%$ normal anaerobic digested sludge)

\begin{tabular}{|c|c|c|c|c|c|c|c|c|}
\hline & \multicolumn{4}{|c|}{ Accumulative methane $(\mathrm{ml})$} & \multicolumn{4}{|c|}{ Methane concentration $\%$} \\
\hline Time & BR1 & $\mathrm{BR2}$ & BR3 & BR4 & BR1 & $\mathrm{BR2}$ & BR3 & BR4 \\
\hline 1 & 0.00 & 0.00 & 0.00 & 0.00 & 0.00 & 0.00 & 0.00 & 0.00 \\
\hline 2 & 3.52 & 0.00 & 0.00 & 0.00 & 8.30 & 0.00 & 0.00 & 0.00 \\
\hline 3 & 5.15 & 0.00 & 0.00 & 0.00 & 17.50 & 0.00 & 0.00 & 0.00 \\
\hline 4 & 6.65 & 0.55 & 0.00 & 0.00 & 19.14 & 8.70 & 0.00 & 0.00 \\
\hline 5 & 9.10 & 2.43 & 1.38 & 0.00 & 26.30 & 11.25 & 8.30 & 0.00 \\
\hline 6 & 21.57 & 13.85 & 10.97 & 0.00 & 33.46 & 17.51 & 12.00 & 0.00 \\
\hline 7 & 49.86 & 41.75 & 29.83 & 0.00 & 40.62 & 23.76 & 17.84 & 0.00 \\
\hline 8 & 131.27 & 85.08 & 69.12 & 24.57 & 47.78 & 33.92 & 24.43 & 15.93 \\
\hline 9 & 205.09 & 121.93 & 97.57 & 44.89 & 54.94 & 44.08 & 31.02 & 20.52 \\
\hline 10 & 270.43 & 185.63 & 111.03 & 64.72 & 61.41 & 54.24 & 37.62 & 23.72 \\
\hline 11 & 350.99 & 267.40 & 122.63 & 82.26 & 63.81 & 64.39 & 44.21 & 31.51 \\
\hline 12 & 442.87 & 340.18 & 141.23 & 93.73 & 66.21 & 66.12 & 48.03 & 39.31 \\
\hline 13 & 488.62 & 389.42 & 172.75 & 98.12 & 68.60 & 67.84 & 51.84 & 47.10 \\
\hline 14 & 513.51 & 411.25 & 214.78 & 104.33 & 71.00 & 69.57 & 55.66 & 47.80 \\
\hline 15 & 523.05 & 419.99 & 268.87 & 109.21 & 73.40 & 71.30 & 59.47 & 48.50 \\
\hline 16 & 531.46 & 427.19 & 319.92 & 114.88 & 73.00 & 71.55 & 63.29 & 49.20 \\
\hline 17 & 535.01 & 433.88 & 356.28 & 117.69 & 72.30 & 71.80 & 67.10 & 49.90 \\
\hline 18 & 539.06 & 437.41 & 373.32 & 124.64 & 71.80 & 72.06 & 70.92 & 50.59 \\
\hline 19 & 547.29 & 442.02 & 381.38 & 137.68 & 71.42 & 72.31 & 74.73 & 52.69 \\
\hline 20 & 551.34 & 446.08 & 386.68 & 153.62 & 71.90 & 71.90 & 74.59 & 51.99 \\
\hline 21 & 557.02 & 450.14 & 390.61 & 170.64 & 72.40 & 72.00 & 74.45 & 53.00 \\
\hline 22 & 559.52 & 457.94 & 400.27 & 211.20 & 72.80 & 72.30 & 74.31 & 55.89 \\
\hline 23 & 562.58 & 460.98 & 406.63 & 262.78 & 73.40 & 72.90 & 74.17 & 59.09 \\
\hline 24 & 564.56 & 464.55 & 416.80 & 307.30 & 73.18 & 72.84 & 74.03 & 62.30 \\
\hline 25 & 565.99 & 468.65 & 422.59 & 346.64 & 72.95 & 72.78 & 73.90 & 65.50 \\
\hline 26 & 567.42 & 473.82 & 427.84 & 370.22 & 72.73 & 72.71 & 73.76 & 68.70 \\
\hline 27 & 568.31 & 476.85 & 431.99 & 382.06 & 72.50 & 72.65 & 73.62 & 69.48 \\
\hline 28 & 569.72 & 479.35 & 437.76 & 389.65 & 72.28 & 72.59 & 73.48 & 70.27 \\
\hline 29 & 570.08 & 482.37 & 441.89 & 391.04 & 72.05 & 72.53 & 73.34 & 71.05 \\
\hline 30 & 570.96 & 484.32 & 444.41 & 395.62 & 71.83 & 72.46 & 73.20 & 71.83 \\
\hline 31 & 572.36 & 486.81 & 447.86 & 398.65 & 71.60 & 72.40 & 70.50 & 72.62 \\
\hline 32 & 573.76 & 489.28 & 451.84 & 402.79 & 71.28 & 72.06 & 70.41 & 73.40 \\
\hline 33 & 575.68 & 492.27 & 455.80 & 405.31 & 70.96 & 71.71 & 70.32 & 73.35 \\
\hline 34 & 576.54 & 494.20 & 458.21 & 407.44 & 70.63 & 71.37 & 70.23 & 73.30 \\
\hline 35 & 576.89 & 495.59 & 460.11 & 411.04 & 70.31 & 71.02 & 70.14 & 73.25 \\
\hline 36 & 577.75 & 496.46 & 461.48 & 412.47 & 69.99 & 70.68 & 70.05 & 73.20 \\
\hline 37 & 579.12 & 498.36 & 462.85 & 414.99 & 69.67 & 70.34 & 69.96 & 73.15 \\
\hline 38 & 580.48 & 500.25 & 464.74 & 418.25 & 69.35 & 69.99 & 69.87 & 73.10 \\
\hline 39 & 581.32 & 501.10 & 465.60 & 420.22 & 69.02 & 69.65 & 69.78 & 73.05 \\
\hline 40 & 581.66 & 501.95 & 466.46 & 423.26 & 68.70 & 69.30 & 70.30 & 73.00 \\
\hline
\end{tabular}


(Group two, 20\% Acclimatized anaerobic digested sludge)

\begin{tabular}{|c|c|c|c|c|c|c|c|c|}
\hline & \multicolumn{4}{|c|}{ Accumulative methane (ml) } & \multicolumn{4}{|c|}{ Methane concentration \% } \\
\hline Time & BR5 & BR6 & BR7 & BR8 & BR5 & BR6 & BR7 & BR8 \\
\hline 1 & 0.00 & 0.00 & 0.00 & 0.00 & 0.00 & 0.00 & 0.00 & 0.00 \\
\hline 2 & 7.17 & 0.00 & 0.00 & 0.00 & 8.50 & 0.00 & 0.00 & 0.00 \\
\hline 3 & 15.27 & 5.25 & 0.00 & 0.00 & 14.50 & 7.50 & 0.00 & 0.00 \\
\hline 4 & 19.06 & 7.21 & 0.00 & 0.00 & 23.00 & 10.40 & 0.00 & 0.00 \\
\hline 5 & 28.39 & 9.30 & 4.53 & 0.00 & 37.68 & 13.10 & 10.00 & 0.00 \\
\hline 6 & 40.44 & 28.20 & 13.69 & 0.00 & 45.93 & 30.00 & 18.40 & 0.00 \\
\hline 7 & 90.51 & 58.93 & 31.79 & 3.22 & 54.17 & 38.80 & 32.53 & 9.60 \\
\hline 8 & 161.90 & 107.38 & 68.50 & 12.37 & 56.88 & 47.50 & 35.73 & 15.60 \\
\hline 9 & 243.03 & 172.29 & 107.63 & 18.17 & 59.59 & 53.60 & 38.93 & 20.40 \\
\hline 10 & 318.49 & 231.76 & 136.03 & 27.01 & 62.30 & 59.60 & 42.13 & 24.70 \\
\hline 11 & 391.10 & 275.64 & 172.93 & 50.59 & 65.01 & 62.35 & 45.33 & 30.63 \\
\hline 12 & 440.24 & 299.94 & 216.36 & 76.77 & 67.72 & 65.22 & 48.53 & 33.70 \\
\hline 13 & 460.79 & 321.31 & 232.75 & 114.82 & 70.43 & 68.09 & 49.88 & 36.77 \\
\hline 14 & 475.68 & 340.96 & 248.07 & 152.18 & 73.14 & 70.95 & 51.23 & 40.11 \\
\hline 15 & 487.76 & 363.05 & 269.60 & 182.11 & 75.85 & 73.82 & 52.58 & 43.44 \\
\hline 16 & 502.04 & 380.82 & 300.80 & 199.20 & 75.64 & 73.98 & 53.93 & 46.78 \\
\hline 17 & 517.40 & 398.63 & 328.73 & 220.82 & 75.43 & 74.13 & 57.82 & 50.11 \\
\hline 18 & 538.79 & 420.85 & 353.54 & 254.45 & 75.23 & 74.29 & 61.72 & 53.37 \\
\hline 19 & 547.99 & 444.21 & 377.51 & 287.63 & 75.02 & 74.44 & 65.61 & 56.63 \\
\hline 20 & 552.76 & 458.84 & 388.08 & 318.76 & 74.81 & 74.60 & 69.50 & 59.89 \\
\hline 21 & 556.97 & 463.61 & 400.34 & 348.33 & 74.63 & 74.75 & 70.43 & 63.15 \\
\hline 22 & 560.08 & 468.81 & 407.51 & 372.20 & 74.72 & 73.10 & 71.36 & 65.33 \\
\hline 23 & 561.55 & 472.36 & 411.06 & 390.41 & 74.81 & 72.40 & 72.28 & 67.52 \\
\hline 24 & 563.55 & 476.43 & 415.67 & 395.36 & 74.18 & 72.26 & 72.42 & 69.70 \\
\hline 25 & 564.99 & 480.50 & 426.70 & 404.70 & 73.55 & 72.11 & 72.55 & 71.88 \\
\hline 26 & 566.42 & 484.56 & 434.01 & 410.90 & 72.92 & 71.97 & 72.68 & 72.18 \\
\hline 27 & 567.31 & 488.08 & 442.93 & 414.99 & 72.29 & 71.83 & 72.81 & 72.48 \\
\hline 28 & 568.19 & 491.07 & 451.88 & 417.48 & 71.66 & 71.68 & 72.95 & 72.79 \\
\hline 29 & 570.63 & 493.53 & 459.22 & 423.22 & 71.03 & 71.54 & 73.08 & 73.09 \\
\hline 30 & 573.05 & 495.46 & 463.35 & 427.36 & 70.40 & 71.40 & 73.21 & 73.39 \\
\hline 31 & 575.46 & 497.38 & 470.16 & 432.60 & 70.19 & 71.17 & 73.02 & 73.69 \\
\hline 32 & 576.83 & 498.77 & 477.48 & 438.95 & 69.98 & 70.94 & 72.83 & 73.99 \\
\hline 33 & 578.20 & 500.16 & 480.51 & 445.87 & 69.77 & 70.71 & 72.64 & 74.30 \\
\hline 34 & 579.57 & 501.54 & 482.46 & 450.08 & 69.56 & 70.48 & 72.45 & 74.60 \\
\hline 35 & 581.44 & 503.43 & 484.94 & 453.73 & 69.35 & 70.25 & 72.26 & 74.52 \\
\hline 36 & 583.30 & 505.32 & 488.48 & 456.84 & 69.14 & 70.02 & 72.06 & 74.44 \\
\hline 37 & 583.64 & 506.18 & 492.00 & 460.49 & 68.93 & 69.79 & 71.87 & 74.36 \\
\hline 38 & 583.98 & 507.03 & 493.93 & 464.67 & 68.72 & 69.56 & 71.68 & 74.28 \\
\hline 39 & 584.82 & 507.37 & 495.86 & 467.77 & 68.51 & 69.33 & 71.49 & 74.20 \\
\hline 40 & 585.66 & $\mathbf{5 0 7 . 7 1}$ & 497.26 & 471.40 & 68.30 & 69.10 & 71.30 & 74.12 \\
\hline
\end{tabular}




\subsection{Second set}

$(30 \%(\mathrm{v} / \mathrm{v})$ normal digested sludge)

\begin{tabular}{|c|c|c|c|c|c|c|c|c|}
\hline & \multicolumn{4}{|c|}{ Accumulative methane (ml) } & \multicolumn{4}{|c|}{ Methane concentration \% } \\
\hline Time & $\overline{\mathrm{BR} 1}$ & BR2 & BR3 & BR4 & BR1 & $\mathrm{BR} 2$ & $\mathrm{BR} 3$ & BR4 \\
\hline 1 & $\overline{0}$ & 0 & 0 & 0 & 0.00 & 0.00 & 0.00 & 0.00 \\
\hline 2 & 5.44 & 0 & 0 & 0 & 8.50 & 0.00 & 0.00 & 0.00 \\
\hline 3 & 12.39 & 2.78 & 0 & 0 & 14.50 & 7.50 & 0.00 & 0.00 \\
\hline 4 & 28.84 & 7.61 & 0 & 0 & 23.00 & 10.40 & 0.00 & 0.00 \\
\hline 5 & 56.21 & 16.31 & 0 & 0 & 37.68 & 13.10 & 10.00 & 0.00 \\
\hline 6 & 93.89 & 29.42 & 4.29 & 0 & 45.93 & 30.00 & 18.40 & 0.00 \\
\hline 7 & 174.84 & 51.64 & 10.66 & 1.86 & 54.17 & 38.80 & 32.53 & 9.60 \\
\hline 8 & 259.34 & 85.98 & 23.40 & 7.51 & 56.88 & 47.50 & 35.73 & 15.60 \\
\hline 9 & 308.65 & 135.77 & 48.35 & 14.63 & 59.59 & 53.60 & 38.93 & 20.40 \\
\hline 10 & 335.96 & 202.56 & 85.48 & 26.15 & 62.30 & 59.60 & 42.13 & 24.70 \\
\hline 11 & 370.08 & 276.57 & 149.14 & 49.93 & 65.01 & 62.35 & 45.33 & 30.63 \\
\hline 12 & 402.71 & 320.83 & 207.73 & 76.61 & 67.72 & 65.22 & 48.53 & 33.70 \\
\hline 13 & 460.02 & 374.88 & 260.14 & 110.63 & 70.43 & 68.09 & 49.88 & 36.77 \\
\hline 14 & 543.04 & 423.48 & 307.07 & 162.47 & 73.14 & 70.95 & 51.23 & 40.11 \\
\hline 15 & 611.16 & 453.13 & 334.61 & 196.54 & 75.85 & 73.82 & 52.58 & 43.44 \\
\hline 16 & 635.34 & 465.86 & 371.66 & 241.65 & 75.64 & 73.98 & 53.93 & 46.78 \\
\hline 17 & 643.52 & 478.43 & 396.85 & 277.16 & 75.43 & 74.13 & 57.82 & 50.11 \\
\hline 18 & 654.42 & 489.88 & 411.25 & 298.27 & 75.23 & 74.29 & 61.72 & 53.37 \\
\hline 19 & 658.64 & 511.29 & 417.55 & 310.60 & 75.02 & 74.44 & 65.61 & 56.63 \\
\hline 20 & 660.10 & 528.80 & 428.17 & 320.37 & 74.81 & 74.60 & 69.50 & 59.89 \\
\hline 21 & 663.18 & 547.41 & 437.70 & 333.33 & 74.63 & 74.75 & 70.43 & 63.15 \\
\hline 22 & 664.62 & 556.06 & 447.78 & 346.86 & 74.72 & 73.10 & 71.36 & 65.33 \\
\hline 23 & 666.06 & 564.15 & 459.47 & 358.33 & 74.81 & 72.40 & 72.28 & 67.52 \\
\hline 24 & 670.68 & 574.43 & 469.55 & 373.03 & 74.18 & 72.26 & 72.42 & 69.70 \\
\hline 25 & 672.62 & 578.66 & 480.16 & 389.92 & 73.55 & 72.11 & 72.55 & 71.88 \\
\hline 26 & 675.60 & 581.77 & 496.71 & 409.55 & 72.92 & 71.97 & 72.68 & 72.18 \\
\hline 27 & 676.48 & 586.54 & 513.80 & 424.95 & 72.29 & 71.83 & 72.81 & 72.48 \\
\hline 28 & 678.93 & 590.20 & 529.27 & 433.95 & 71.66 & 71.68 & 72.95 & 72.79 \\
\hline 29 & 681.37 & 594.40 & 536.64 & 443.51 & 71.03 & 71.54 & 73.08 & 73.09 \\
\hline 30 & 682.24 & 599.70 & 542.40 & 451.48 & 70.40 & 71.40 & 73.21 & 73.39 \\
\hline 31 & 683.63 & 601.16 & 547.62 & 458.40 & 70.19 & 71.17 & 73.02 & 73.69 \\
\hline 32 & 685.54 & 602.08 & 551.21 & 468.62 & 69.98 & 70.94 & 72.83 & 73.99 \\
\hline 33 & 687.45 & 602.99 & 555.35 & 477.78 & 69.77 & 70.71 & 72.64 & 74.30 \\
\hline 34 & 688.31 & 604.42 & 558.41 & 487.53 & 69.56 & 70.48 & 72.45 & 74.60 \\
\hline 35 & 688.66 & 605.33 & 562.54 & 496.70 & 69.35 & 70.25 & 72.26 & 74.52 \\
\hline 36 & 689.52 & 606.23 & 565.60 & 509.15 & 69.14 & 70.02 & 72.06 & 74.44 \\
\hline 37 & 690.88 & 607.67 & 569.20 & 519.93 & 68.93 & 69.79 & 71.87 & 74.36 \\
\hline 38 & 691.73 & 608.57 & 571.72 & 531.24 & 68.72 & 69.56 & 71.68 & 74.28 \\
\hline 39 & 692.58 & 609.47 & 575.85 & 539.24 & 68.51 & 69.33 & 71.49 & 74.20 \\
\hline 40 & 693.92 & 610.90 & 579.99 & 547.77 & 68.30 & 69.10 & 71.30 & 74.12 \\
\hline
\end{tabular}




\section{Appendix B: Results of statistical analysis}

1. Solid waste

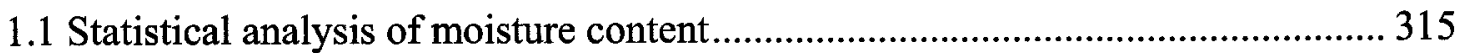

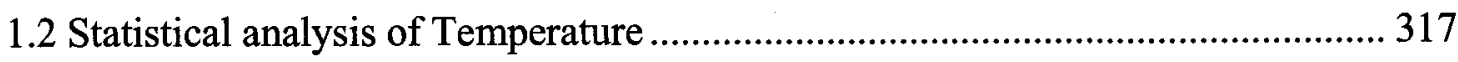

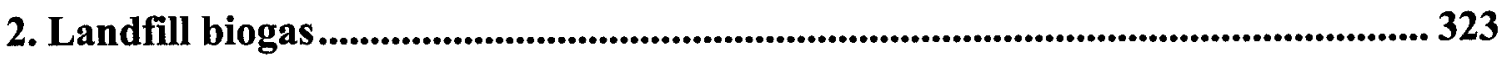

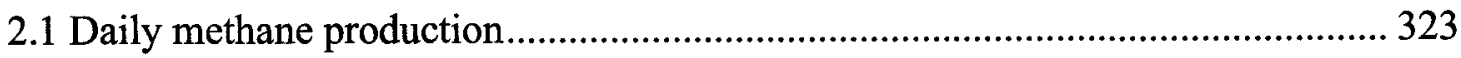

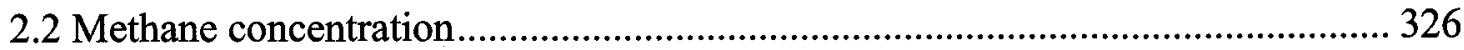

2.3 BMP assays using leachate produced from bioreactors as substrate ................... 328

2.3.1 First set of BMP assays (in growth phase) .................................................... 328

2.3.2 Second set of BMP assays (in decline phase) ............................................... 332

2.3.3 Third set of BMP (Comparison between two types of inoculums) ................... 338

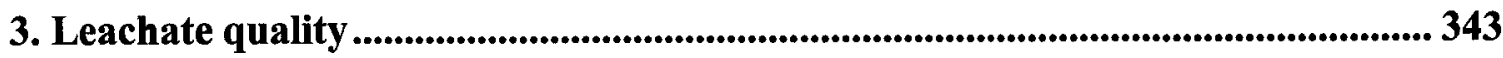

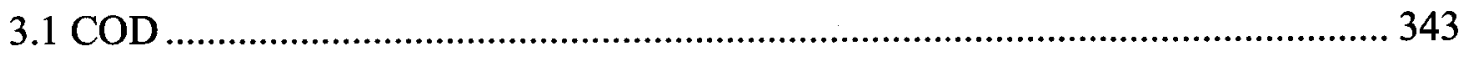

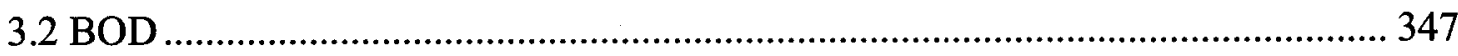

3.3 VFA

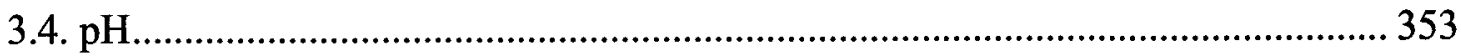

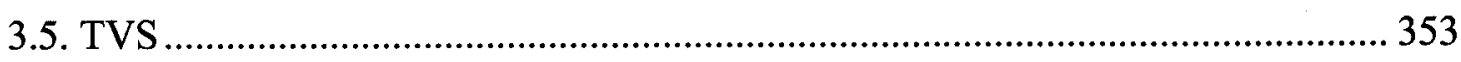

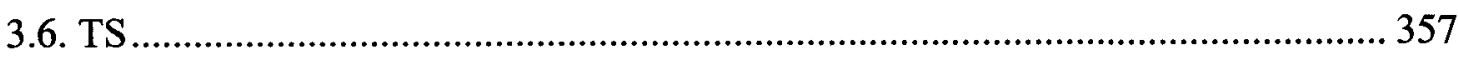

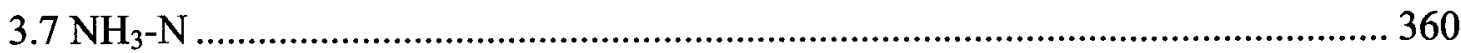

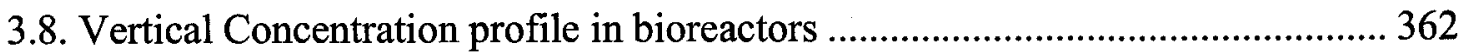

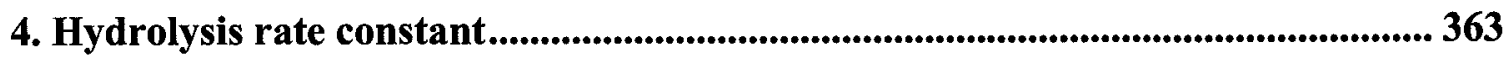

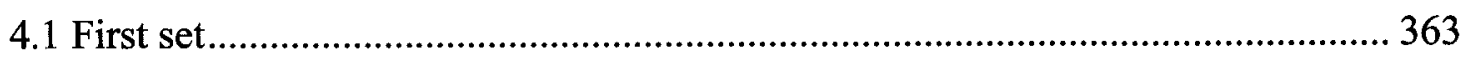

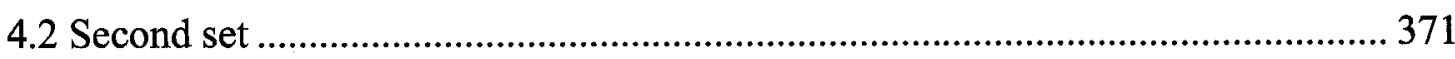




\section{Statistical methods}

\section{ANOVA}

Analysis of variance (ANOVA) is a statistical procedure that is used to compare the means of parameters in different groups (e.g bioreactors). There are two types, one way and two way ANOVA.

\section{- One way ANOVA}

It is designed to compare the mean of one parameters in different groups (e.g compare the mean COD concentration in all bioreactors).In this method, the null hypothesis is assumed that the means COD are equal in all bioreactors and the alternatives are not equal. This table shows an example of one way ANOVA table

\begin{tabular}{|l|r|r|r|r|r|}
\hline & \multicolumn{1}{|c|}{$\begin{array}{c}\text { Sum of } \\
\text { Squares }\end{array}$} & df & \multicolumn{1}{c|}{$\begin{array}{c}\text { Mean } \\
\text { Square }\end{array}$} & F & Sig. \\
\hline Between & 3541693830 & 7 & 505956261 & 5.543 & $\mathbf{0 . 0 0 2}$ \\
Groups & 32496375655 & 356 & 91281954 & & \\
Within Groups & 36038069485 & 363 & & & \\
Total & 3605 \\
\hline
\end{tabular}

Since the significant or (P-value) is less than 0.05 , then the null hypothesis is rejected and it is concluded that there was a significant difference in the mean COD in all bioreactors at $5 \%$ significance different.

If the significant difference is identified, then multiple comparison procedures could be used to determine where the difference is. This procedure compares all possible pairs of COD means simultaneously. There are different types of multiple comparisons such as Tukey, Bonferroni and Duncan. 


\section{- Two way ANOVA}

The two way ANOVA introduces blocking variables which are used to associate some of the variations in the observation. It allows testing two different null hypotheses.

So, if we would like to compare the mean methane yield in two treatments (with and without sludge additions) at different salt contents $(0.0 .5,1,3) \%(w / v)$. The two null hypotheses could be

1) No difference in the mean methane yield at different salt contents.

2) No difference in the mean methane yield in two treatments.

This table presents an example of two way ANOVA table

\begin{tabular}{|l|r|r|r|r|r|}
\hline Source & \multicolumn{1}{|c|}{$\begin{array}{c}\text { Type III } \\
\text { Sum of } \\
\text { Squares }\end{array}$} & df & \multicolumn{1}{c|}{$\begin{array}{c}\text { Mean } \\
\text { Square }\end{array}$} & \multicolumn{1}{c|}{ F } & \multicolumn{1}{c|}{ Sig. } \\
\hline Corrected & 1077.817 & 4 & 269.454 & 402.838 & .000 \\
Model & & & & 52901.2 & .000 \\
Intercept & 35385.086 & 1 & 35385.086 & 47 & .000 \\
Salt & 610.621 & 3 & 203.540 & 304.296 & $\mathbf{. 0 0 0}$ \\
Group & 499.320 & 1 & 499.320 & 367.816 & $\mathbf{. 0 0}$ \\
Error & 4.073 & 3 & 1.358 & & \\
Total & 36784.086 & 8 & & & \\
Corrected & 1123.539 & 7 & & & \\
Total & & & & & \\
\hline
\end{tabular}

Since the P-values were less than 0.05. Then the null hypotheses were rejected and it can be concluded that there were significant differences in the mean methane yield in two treatments and at different salt contents.

\section{$\underline{\text { References }}$}

MeBean, E. \& Rovers, F. (1998). Statistical procedures for analysis environmental monitoring data and risk assessment, Prentic Hall PTR.

Hoshmand A. (1998). Statistical methods for environmental and agriculture sciences, CRC Press LLC. 


\section{Solid waste}

1.1 Statistical analysis of moisture content

Table 1.1.1: One way ANOVA table for the mean of initial and final moisture content

\begin{tabular}{|l|r|r|r|r|r|}
\hline & \multicolumn{1}{|c|}{$\begin{array}{c}\text { Sum of } \\
\text { squares }\end{array}$} & \multicolumn{1}{c|}{ df } & Mean square & \multicolumn{1}{c|}{ F } & Sig. \\
\hline Between & 1857.610 & 1 & 1857.610 & 1070.779 & $\mathbf{0 . 0 0 0}$ \\
groups & 24.288 & 14 & 1.735 & & \\
Within groups & 1881.898 & 15 & & & \\
Total & & & & \\
\hline
\end{tabular}

Table 1.1.2: One way ANOVA table for moisture profile in R1

\begin{tabular}{|l|r|r|r|r|c|}
\hline & \multicolumn{1}{|c|}{$\begin{array}{c}\text { Sum of } \\
\text { squares }\end{array}$} & df & Mean square & F & Sig. \\
\hline Between & 114.132 & 2 & 57.066 & 4.311 & $\mathbf{0 . 0 6 9}$ \\
groups & 79.424 & 6 & 13.237 & & \\
Within groups & 193.557 & 8 & & & \\
Total & & & & \\
\hline
\end{tabular}

Table 1.1.3: One way ANOVA table for moisture profile in R2

\begin{tabular}{|l|r|r|r|r|r|}
\hline & \multicolumn{1}{|c|}{$\begin{array}{c}\text { Sum of } \\
\text { squares }\end{array}$} & \multicolumn{1}{c|}{ df } & Mean square & F & \multicolumn{1}{c|}{ Sig. } \\
\hline Between & 64.579 & 2 & 32.290 & 1.092 & $\mathbf{0 . 3 9 4}$ \\
Groups & 177.367 & 6 & 29.561 & & \\
Within Groups & 241.947 & 8 & & & \\
Total & & & & \\
\hline
\end{tabular}

Table 1.1.4: One way ANOVA table for moisture profile in R3

\begin{tabular}{|l|r|r|r|r|c|}
\hline & \multicolumn{1}{|c|}{$\begin{array}{c}\text { Sum of } \\
\text { squares }\end{array}$} & \multicolumn{1}{c|}{ df } & Mean square & F & Sig. \\
\hline Between & 39.220 & 2 & 19.610 & 2.529 & $\mathbf{0 . 1 6 0}$ \\
groups & 46.526 & 6 & 7.754 & & \\
Within groups & 85.746 & 8 & & & \\
Total & & & & \\
\hline
\end{tabular}

Table 1.1.5: One way ANOVA table for moisture profile in R4

\begin{tabular}{|l|r|r|r|r|c|}
\hline & \multicolumn{1}{|c|}{$\begin{array}{c}\text { Sum of } \\
\text { squares }\end{array}$} & \multicolumn{1}{c|}{ df } & Mean square & F & \multicolumn{1}{c|}{ Sig. } \\
\hline Between & 59.069 & 2 & 29.534 & .577 & $\mathbf{0 . 5 9 0}$ \\
groups & 307.159 & 6 & 51.193 & & \\
Within groups & 366.228 & 8 & & & \\
Total & & & & \\
\hline
\end{tabular}


Table 1.1.6: One way ANOVA table for moisture profile in R5

\begin{tabular}{|l|r|r|r|r|r|}
\hline & \multicolumn{1}{|c|}{$\begin{array}{c}\text { Sum of } \\
\text { squares }\end{array}$} & \multicolumn{1}{c|}{ df } & Mean square & F & \multicolumn{1}{c|}{ Sig. } \\
\hline Between & 18.425 & 2 & 9.212 & 2.902 & $\mathbf{0 . 1 3 1}$ \\
groups & 19.044 & 6 & 3.174 & & \\
Within groups & 37.469 & 8 & & & \\
Total & & & & \\
\hline
\end{tabular}

Table 1.1.7: One way ANOVA table for moisture profile in R6

\begin{tabular}{|l|r|r|r|r|r|}
\hline & \multicolumn{1}{|c|}{$\begin{array}{c}\text { Sum of } \\
\text { squares }\end{array}$} & \multicolumn{1}{c|}{ df } & Mean square & F & \multicolumn{1}{c|}{ Sig. } \\
\hline Between & 4.270 & 2 & 2.135 & 1.665 & $\mathbf{0 . 2 6 6}$ \\
groups & 7.695 & 6 & 1.283 & & \\
Within groups & 11.965 & 8 & & & \\
Total & & & & \\
\hline
\end{tabular}

Table 1.1.8: One way ANOVA table for moisture profile in R7

\begin{tabular}{|l|r|r|r|r|r|}
\hline & \multicolumn{1}{|c|}{$\begin{array}{c}\text { Sum of } \\
\text { squares }\end{array}$} & \multicolumn{1}{c|}{ df } & Mean square & F & Sig. \\
\hline Between & 10.722 & 2 & 5.361 & 1.113 & $\mathbf{0 . 3 8 8}$ \\
groups & 28.892 & 6 & 4.815 & & \\
Within groups & 39.614 & 8 & & & \\
Total &
\end{tabular}

Table 1.1.9: One way ANOVA table for moisture profile in $\mathrm{R} 8$

\begin{tabular}{|l|r|r|r|r|r|}
\hline & \multicolumn{1}{|c|}{$\begin{array}{c}\text { Sum of } \\
\text { squares }\end{array}$} & \multicolumn{1}{c|}{ df } & Mean square & F & Sig. \\
\hline Between & 22.822 & 2 & 11.411 & 1.100 & $\mathbf{0 . 3 9 2}$ \\
groups & 62.254 & 6 & 10.376 & & \\
Within groups & 85.075 & 8 & & & \\
Total &
\end{tabular}

Table 1.1.10: One way ANOVA table for mean final moisture content in all bioreactors

\begin{tabular}{|l|r|r|r|r|r|}
\hline & \multicolumn{1}{|c|}{$\begin{array}{c}\text { Sum of } \\
\text { squares }\end{array}$} & \multicolumn{1}{c|}{ df } & Mean square & F & Sig. \\
\hline Between & 94.835 & 7 & 13.548 & 1.301 & $\mathbf{0 . 2 6 4}$ \\
groups & 666.417 & 64 & 10.413 & & \\
Within groups & 761.252 & 71 & & & \\
Total &
\end{tabular}




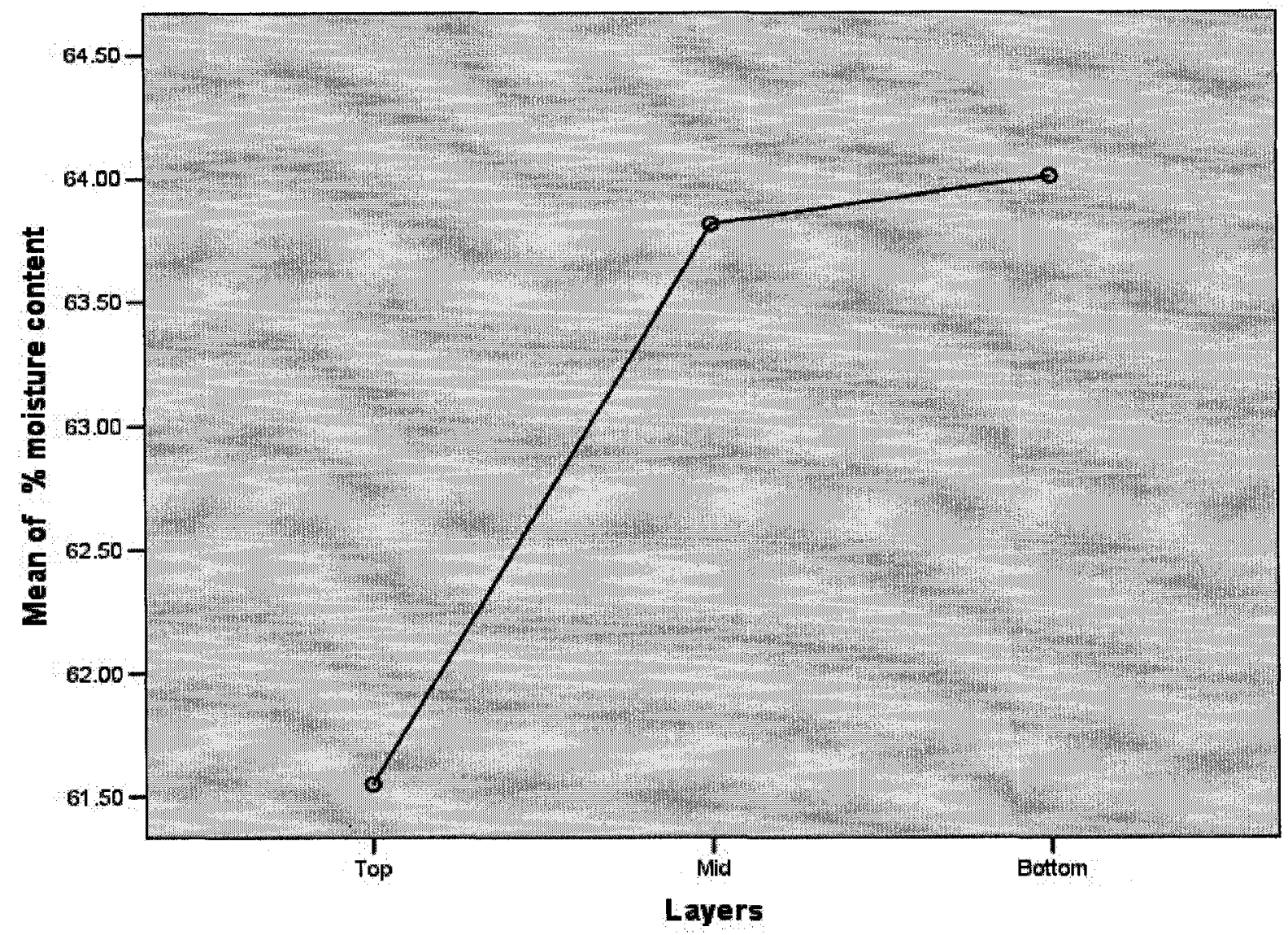

Figure 1.1: Mean moisture content in the layers in all bioreactors

\subsection{Statistical analysis of Temperature}

Table 1.2.1: One way ANOVA table for Temperature profile in R1

\begin{tabular}{|l|r|r|r|r|r|}
\hline & Sum of squares & \multicolumn{1}{c|}{ df } & Mean square & F & \multicolumn{1}{c|}{ Sig. } \\
\hline Between & 20.427 & 2 & 10.214 & .993 & $\mathbf{0 . 3 8 1}$ \\
groups & 360.107 & 35 & 10.289 & & \\
Within groups & 380.534 & 37 & & & \\
Total &
\end{tabular}

Table 1.2.2: One way ANOVA table for Temperature profile in R2

\begin{tabular}{|l|r|r|r|r|r|}
\hline & Sum of squares & \multicolumn{1}{c|}{ df } & Mean square & F & Sig. \\
\hline Between & 9.481 & 2 & 4.740 & 2.032 & $\mathbf{0 . 1 4 6}$ \\
groups & 83.998 & 36 & 2.333 & & \\
Within groups & 93.479 & 38 & & & \\
Total &
\end{tabular}


Table 1.2.3: One way ANOVA table for Temperature profile in R3

\begin{tabular}{|l|r|r|r|r|r|}
\hline & Sum of squares & df & Mean square & F & \multicolumn{1}{l|}{ Sig. } \\
\hline Between & 14.025 & 2 & 7.013 & 3.019 & $\mathbf{0 . 0 6 1}$ \\
groups & 83.618 & 36 & 2.323 & & \\
Within groups & 97.644 & 38 & & & \\
Total & & & \\
\hline
\end{tabular}

Table 1.2.4: One way ANOVA table for Temperature profile in R4

\begin{tabular}{|l|r|r|r|r|r|}
\hline & Sum of squares & df & Mean square & F & \multicolumn{1}{c|}{ Sig. } \\
\hline Between & 10.552 & 2 & 5.276 & 1.305 & $\mathbf{0 . 2 8 4}$ \\
groups & 145.558 & 36 & 4.043 & & \\
Within groups & 156.111 & 38 & & & \\
Total & & & \\
\hline
\end{tabular}

Table 1.2.5: One way ANOVA table for Temperature profile in R5

\begin{tabular}{|l|r|r|r|r|r|}
\hline & Sum of squares & df & Mean square & F & \multicolumn{1}{l|}{ Sig. } \\
\hline Between & 9.908 & 2 & 4.954 & 1.047 & $\mathbf{0 . 3 6 1}$ \\
groups & 170.288 & 36 & 4.730 & & \\
Within groups & 180.196 & 38 & & & \\
Total & & & \\
\hline
\end{tabular}

Table 1.2.6: One way ANOVA table for Temperature profile in R6

\begin{tabular}{|l|r|r|r|r|r|}
\hline & Sum of squares & df & Mean square & F & \multicolumn{1}{c|}{ Sig. } \\
\hline Between & 5.668 & 2 & 2.834 & .683 & $\mathbf{0 . 5 1 1}$ \\
groups & 149.326 & 36 & 4.148 & & \\
Within groups & 154.994 & 38 & & & \\
Total & & & \\
\hline
\end{tabular}

Table 1.2.7: One way ANOVA table for Temperature profile in R7

\begin{tabular}{|l|r|r|r|r|r|}
\hline & Sum of squares & df & Mean square & F & \multicolumn{1}{c|}{ Sig. } \\
\hline Between & 21.887 & 2 & 10.943 & 2.433 & $\mathbf{0 . 1 0 2}$ \\
groups & 161.948 & 36 & 4.499 & & \\
Within groups & 183.834 & 38 & & & \\
Total & & & \\
\hline
\end{tabular}


Table 1.2.8: One way ANOVA table for Temperature profile in R8

\begin{tabular}{|l|r|r|r|r|r|}
\hline & Sum of squares & df & Mean square & F & Sig. \\
\hline Between & 17.934 & 2 & 8.967 & 2.898 & $\mathbf{0 . 0 6 8}$ \\
groups & 111.375 & 36 & 3.094 & & \\
Within Groups & 129.310 & 38 & & & \\
Total &
\end{tabular}

Table 1.2.9: One way ANOVA table for mean Temperature in all reactors

\begin{tabular}{|l|r|r|r|r|r|}
\hline & Sum of squares & \multicolumn{1}{c|}{ df } & Mean square & F & Sig. \\
\hline Between & 86.543 & 7 & 12.363 & 2.727 & $\mathbf{0 . 0 0 9}$ \\
groups & 1378.135 & 304 & 4.533 & & \\
Within groups & 1464.679 & 311 & & & \\
Total &
\end{tabular}

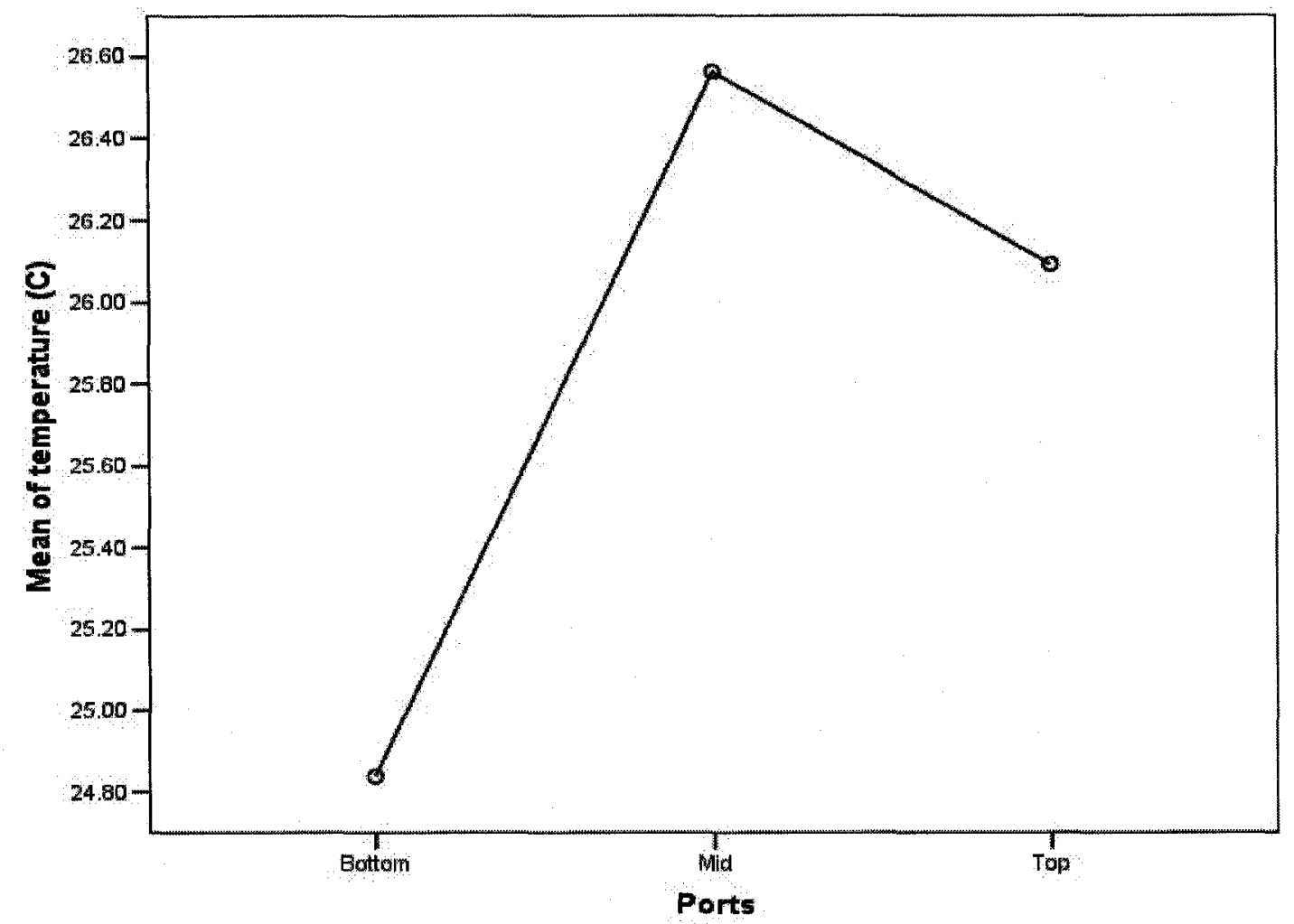

Figure 1.2: Mean temperature in layers in all bioreactors 


\subsection{Statistical analysis of settlement}

Table 1.3.1: One way ANOVA table for mean settlement occurring during the aerobic stage in all bioreactors

\begin{tabular}{|l|r|r|r|r|r|}
\hline & Sum of squares & df & \multicolumn{1}{c|}{$\begin{array}{c}\text { Mean } \\
\text { square }\end{array}$} & F & Sig. \\
\hline Between & 167.245 & 7 & 23.892 & 22.768 & $\mathbf{0 . 0 0 0}$ \\
groups & 25.185 & 24 & 1.049 & & \\
Within groups & 192.430 & 31 & & & \\
Total &
\end{tabular}

Table 1.3.2 Two way ANOVA table for settlement occurring during the aerobic stage as a function of salt content and groups

\begin{tabular}{|l|r|r|r|r|r|}
\hline Source & $\begin{array}{c}\text { Type III sum of } \\
\text { squares }\end{array}$ & \multicolumn{1}{c|}{ df } & $\begin{array}{c}\text { Mean } \\
\text { square }\end{array}$ & \multicolumn{1}{c|}{ F } & \multicolumn{1}{c|}{ Sig. } \\
\hline Corrected & 41.650 & 4 & 10.412 & 170.289 & .001 \\
model & 2927.273 & 1 & 2927.273 & 47873.624 & .000 \\
Intercept & .090 & 1 & .090 & 1.477 & $\mathbf{0 . 3 1 1}$ \\
Group & 41.560 & 3 & 13.853 & 226.560 & $\mathbf{0 . 0 0 0}$ \\
Salt & .183 & 3 & .061 & & \\
Error & 2969.106 & 8 & & & \\
Total & 41.833 & 7 & & & \\
Corrected total & & & & & \\
\hline
\end{tabular}

Table 1.3.3: One way ANOVA table for mean settlement occurring during the anaerobic stage in all bioreactors

\begin{tabular}{|l|r|r|r|r|r|}
\hline & Sum of Squares & \multicolumn{1}{c|}{ df } & \multicolumn{1}{c|}{$\begin{array}{c}\text { Mean } \\
\text { Square }\end{array}$} & F & Sig. \\
\hline Between & 445.662 & 7 & 63.666 & 24.654 & $\mathbf{0 . 0 0 0}$ \\
Groups & 103.293 & 40 & 2.582 & & \\
Within Groups & 548.955 & 47 & & & \\
Total & & & & \\
\hline
\end{tabular}

Table 1.3.4: Two way ANOVA table for mean settlement occurring during the anaerobic stage as a function of salt content and groups

\begin{tabular}{|l|r|r|r|r|r|}
\hline Source & Sum of squares & df & \multicolumn{1}{c|}{$\begin{array}{c}\text { Mean } \\
\text { square }\end{array}$} & \multicolumn{1}{c|}{ F } & \multicolumn{1}{c|}{ Sig. } \\
\hline Corrected & 73.638 & 4 & 18.409 & 80.163 & .002 \\
model & 1708.786 & 1 & 1708.786 & 7440.826 & .000 \\
Intercept & 52.122 & 1 & 52.122 & 226.963 & $\mathbf{0 . 0 0 1}$ \\
Group & 21.516 & 3 & 7.172 & 31.230 & $\mathbf{0 . 0 0 9}$ \\
Salt & .689 & 3 & .230 & & \\
Error & 1783.113 & 8 & & & \\
Total & & & & & \\
\hline
\end{tabular}


Table 1.3.5: Multiple comparisons of mean settlement occurred in aerobic stage as function of salt content and groups

Multiple Comparisons

Dependent Variable: Aerobic

Tukey HSD

\begin{tabular}{|c|c|c|c|c|c|c|}
\hline \multirow[b]{2}{*}{ (I) Salt } & \multirow[b]{2}{*}{ (J) Salt } & \multirow{2}{*}{$\begin{array}{c}\text { Mean } \\
\text { Difference } \\
(1-J)\end{array}$} & \multirow[b]{2}{*}{ Std. Error } & \multirow[b]{2}{*}{ Sig. } & \multicolumn{2}{|c|}{ 95\% Confidence Interval } \\
\hline & & & & & Lower Bound & Upper Bound \\
\hline \multirow[t]{3}{*}{.00} & & .8250 & .24728 & .126 & -.3683 & 2.0183 \\
\hline & 1.00 & $3.6550^{*}$ & .24728 & .002 & 2.4617 & 4.8483 \\
\hline & 3.00 & $5.7250^{*}$ & .24728 & .001 & 4.5317 & 6.9183 \\
\hline \multirow[t]{3}{*}{.50} & .00 & -.8250 & .24728 & .126 & -2.0183 & .3683 \\
\hline & 1.00 & $2.8300^{*}$ & .24728 & .004 & 1.6367 & 4.0233 \\
\hline & 3.00 & $4.9000^{*}$ & .24728 & .001 & 3.7067 & 6.0933 \\
\hline \multirow[t]{3}{*}{1.00} & .00 & $-3.6550^{*}$ & .24728 & .002 & -4.8483 & -2.4617 \\
\hline & .50 & $-2.8300^{*}$ & .24728 & .004 & -4.0233 & -1.6367 \\
\hline & 3.00 & $2.0700^{*}$ & .24728 & .011 & .8767 & 3.2633 \\
\hline \multirow[t]{3}{*}{3.00} & .00 & $-5.7250^{*}$ & .24728 & .001 & -6.9183 & -4.5317 \\
\hline & .50 & $-4.9000^{*}$ & .24728 & .001 & -6.0933 & -3.7067 \\
\hline & 1.00 & $-2.0700^{*}$ & .24728 & .011 & -3.2633 & -.8767 \\
\hline
\end{tabular}

Based on observed means.

*. The mean difference is significant at the .05 level.

Table 1.3.6: Multiple comparisons of mean settlement occurred in anaerobic stage

Multiple Comparisons

Dependent Variable: Anaerobic

Tukey HSD

\begin{tabular}{|c|c|c|c|c|c|c|}
\hline \multirow[b]{2}{*}{ (I) Salt } & \multirow[b]{2}{*}{ (J) Salt } & \multirow{2}{*}{$\begin{array}{c}\text { Mean } \\
\text { Difference } \\
(\mid-J)\end{array}$} & \multirow[b]{2}{*}{ Std. Error } & \multirow[b]{2}{*}{ Sig. } & \multicolumn{2}{|c|}{ 95\% Confidence Interval } \\
\hline & & & & & Lower Bound & Upper Bound \\
\hline \multirow[t]{3}{*}{.00} & .50 & .9400 & .47922 & .365 & -1.3725 & 3.2525 \\
\hline & 1.00 & 2.1800 & .47922 & .058 & -.1325 & 4.4925 \\
\hline & 3.00 & $4.3800^{*}$ & .47922 & .008 & 2.0675 & 6.6925 \\
\hline \multirow[t]{3}{*}{.50} & .00 & -.9400 & .47922 & .365 & -3.2525 & 1.3725 \\
\hline & 1.00 & 1.2400 & .47922 & .220 & -1.0725 & 3.5525 \\
\hline & 3.00 & $3.4400^{*}$ & .47922 & .017 & 1.1275 & 5.7525 \\
\hline \multirow[t]{3}{*}{1.00} & .00 & -2.1800 & .47922 & .058 & -4.4925 & .1325 \\
\hline & .50 & -1.2400 & .47922 & .220 & -3.5525 & 1.0725 \\
\hline & 3.00 & 2.2000 & .47922 & .057 & -.1125 & 4.5125 \\
\hline \multirow[t]{3}{*}{3.00} & .00 & $-4.3800^{\star}$ & .47922 & .008 & -6.6925 & -2.0675 \\
\hline & .50 & $-3.4400^{*}$ & .47922 & .017 & -5.7525 & -1.1275 \\
\hline & 1.00 & -2.2000 & .47922 & .057 & -4.5125 & .1125 \\
\hline
\end{tabular}

Based on observed means.

*. The mean difference is significant at the .05 level. 
Table 1.3.7: Two way ANOVA table for mean of total settlement occurred in the study as function of salt content and groups

\begin{tabular}{|l|r|r|r|r|r|}
\hline Source & Sum of Squares & df & $\begin{array}{c}\text { Mean } \\
\text { Square }\end{array}$ & \multicolumn{1}{c|}{ F } & \multicolumn{1}{c|}{ Sig. } \\
\hline Corrected & 178.284 & 4 & 44.571 & 141.998 & .001 \\
Model & 9107.101 & 1 & 9107.10 & 29014.286 & .000 \\
Intercept & 56.498 & 1 & 56.498 & 179.998 & $\mathbf{0 . 0 0 1}$ \\
Group & 121.785 & 3 & 40.595 & 129.332 & $\mathbf{0 . 0 0 1}$ \\
Salt & .942 & 3 & .314 & & \\
Error & 9286.326 & 8 & & & \\
Total & 179.225 & 7 & & & \\
Corrected & & & & \\
Total & & & & & \\
\hline
\end{tabular}

Table 1.3.8: Multiple comparisons between mean of total settlement at different salt contents

\section{Multiple Comparisons}

Dependent Variable: Total

Tukey HSD

\begin{tabular}{|c|c|c|c|c|c|c|}
\hline \multirow[b]{2}{*}{ (I) Salt } & \multirow[b]{2}{*}{ (J) Salt } & \multirow{2}{*}{$\begin{array}{c}\text { Mean } \\
\text { difference } \\
(\mathrm{I}-\mathrm{J})\end{array}$} & \multirow[b]{2}{*}{ Std. Error } & \multirow[b]{2}{*}{ Sig. } & \multicolumn{2}{|c|}{$95 \%$ Confidence interval } \\
\hline & & & & & Lower bound & Upper bound \\
\hline \multirow[t]{3}{*}{.00} & .50 & 1.7650 & .56025 & .144 & -.9386 & 4.4686 \\
\hline & 1.00 & $5.8300^{*}$ & .56025 & .006 & 3.1264 & 8.5336 \\
\hline & 3.00 & $10.1050^{*}$ & .56025 & .001 & 7.4014 & 12.8086 \\
\hline \multirow[t]{3}{*}{.50} & .00 & -1.7650 & .56025 & .144 & -4.4686 & .9386 \\
\hline & 1.00 & $4.0650^{*}$ & .56025 & .016 & 1.3614 & 6.7686 \\
\hline & 3.00 & $8.3400^{*}$ & .56025 & .002 & 5.6364 & 11.0436 \\
\hline \multirow[t]{3}{*}{1.00} & .00 & $-5.8300^{*}$ & .56025 & .006 & -8.5336 & -3.1264 \\
\hline & .50 & $-4.0650^{*}$ & .56025 & .016 & -6.7686 & -1.3614 \\
\hline & 3.00 & $4.2750^{*}$ & .56025 & .014 & 1.5714 & 6.9786 \\
\hline \multirow[t]{3}{*}{3.00} & .00 & $-10.1050^{*}$ & .56025 & .001 & -12.8086 & -7.4014 \\
\hline & .50 & $-8.3400^{*}$ & .56025 & .002 & -11.0436 & -5.6364 \\
\hline & 1.00 & $-4.2750^{*}$ & .56025 & .014 & -6.9786 & -1.5714 \\
\hline
\end{tabular}

Based on observed means.

*. The mean difference is significant at the .05 level. 


\section{Landfill biogas}

\subsection{Daily methane production}

Table 2.1.1: ANOVA table for mean of methane production in all bioreactors

\begin{tabular}{|l|r|r|r|r|r|}
\hline & Sum of squares & df & Mean square & F & Sig. \\
\hline Between & 1103832982.792 & 6 & 183972163.79 & 46.471 & $\mathbf{. 0 0 0}$ \\
groups & 9901029989.023 & 2501 & 3958828.464 & & \\
Within groups & 11004862971.815 & 2507 & & & \\
Total & & & & \\
\hline
\end{tabular}

Table 2.1.2: ANOVA table for mean of daily methane production in two groups

\begin{tabular}{|l|r|r|r|r|r|}
\hline & \multicolumn{1}{|c|}{ Sum of squares } & \multicolumn{1}{c|}{ df } & Mean square & F & \multicolumn{1}{c|}{ Sig. } \\
\hline Between & 486054062.165 & 1 & 486054062.165 & 115.844 & $\mathbf{. 0 0 0}$ \\
groups & & & & \\
Within groups & 10518808925.561 & 2507 & 4195775.399 & & \\
Total & 11004862987.727 & 2508 & & & \\
\hline
\end{tabular}

Table 2.1.3: Two way ANOVA table for mean of daily methane produced as function of salt content and groups

\begin{tabular}{|l|r|r|r|r|r|}
\hline Source & $\begin{array}{c}\text { Type III Sum } \\
\text { of Squares }\end{array}$ & df & Mean Square & F & \multicolumn{1}{c|}{ Sig. } \\
\hline Corrected Model & 1077.817 & 4 & 269.454 & 402.838 & .000 \\
Intercept & 35385.086 & 1 & 35385.086 & 52901.247 & .000 \\
Group & 467.196 & 1 & 467.196 & 698.465 & $\mathbf{. 0 0 0}$ \\
Salt & 610.621 & 3 & 203.540 & 304.296 & $\mathbf{. 0 0 0}$ \\
Error & 2.007 & 3 & .669 & & \\
Total & 36464.910 & 8 & & & \\
Corrected Total & 1079.824 & 7 & & & \\
\hline
\end{tabular}


Table 2.1.4: Multiple comparisons of mean daily methane production in all bioreactors

\section{Multiple Comparisons}

Dependent Variable: $\mathrm{CH} 4$

Tukey HSD

\begin{tabular}{|c|c|c|c|c|c|c|}
\hline \multirow[b]{2}{*}{ (I) Reactors } & \multirow[b]{2}{*}{ (J) Reactors } & \multirow{2}{*}{$\begin{array}{c}\text { Mean } \\
\text { Difference } \\
(I-J)\end{array}$} & \multirow[b]{2}{*}{ Std. Error } & \multirow[b]{2}{*}{ Sig. } & \multicolumn{2}{|c|}{ 95\% Confidence Interval } \\
\hline & & & & & Lower Bound & Upper Bound \\
\hline \multirow[t]{6}{*}{ R1 } & $\mathrm{R} 2$ & $478.29659^{*}$ & 147.68794 & .021 & 42.5095 & 914.0837 \\
\hline & R4 & $1319.50597^{*}$ & 147.68794 & .000 & 883.7189 & 1755.2930 \\
\hline & R5 & $-884.21940^{*}$ & 148.51765 & .000 & -1322.4547 & -445.9841 \\
\hline & R6 & -426.57149 & 148.51765 & .062 & -864.8068 & 11.6638 \\
\hline & R7 & -226.31926 & 148.51765 & .730 & -664.5546 & 211.9161 \\
\hline & R8 & 382.79881 & 148.62367 & .134 & -55.7494 & 821.3470 \\
\hline \multirow[t]{6}{*}{$\overline{\mathrm{R} 2}$} & R1 & $-478.29659^{*}$ & 147.68794 & .021 & -914.0837 & -42.5095 \\
\hline & R4 & $841.20938^{*}$ & 147.68794 & .000 & 405.4223 & 1276.9965 \\
\hline & R5 & $-1362.5160^{\star}$ & 148.51765 & .000 & -1800.7513 & -924.2807 \\
\hline & R6 & $-904.86808^{*}$ & 148.51765 & .000 & -1343.1034 & -466.6327 \\
\hline & $\mathrm{R} 7$ & $-704.61585^{\star}$ & 148.51765 & .000 & -1142.8512 & -266.3805 \\
\hline & R8 & -95.49778 & 148.62367 & .995 & -534.0459 & 343.0504 \\
\hline \multirow[t]{6}{*}{ R4 } & R1 & $-1319.5060^{*}$ & 147.68794 & .000 & -1755.2930 & -883.7189 \\
\hline & $\mathrm{R} 2$ & $-841.20938^{*}$ & 147.68794 & .000 & -1276.9965 & -405.4223 \\
\hline & R5 & $-2203.7254^{*}$ & 148.51765 & .000 & -2641.9607 & -1765.4900 \\
\hline & R6 & $-1746.0775^{\star}$ & 148.51765 & .000 & -2184.3128 & -1307.8421 \\
\hline & $\mathrm{R} 7$ & $-1545.8252^{*}$ & 148.51765 & .000 & -1984.0606 & -1107.5899 \\
\hline & R8 & $-936.70716^{*}$ & 148.62367 & .000 & -1375.2553 & -498.1590 \\
\hline \multirow[t]{6}{*}{ R5 } & $\mathrm{R} 1$ & $884.21940^{*}$ & 148.51765 & .000 & 445.9841 & 1322.4547 \\
\hline & $\mathrm{R} 2$ & $1362.51599^{*}$ & 148.51765 & .000 & 924.2807 & 1800.7513 \\
\hline & R4 & $2203.72537^{*}$ & 148.51765 & .000 & 1765.4900 & 2641.9607 \\
\hline & $\mathrm{R} 6$ & $457.64792^{\star}$ & 149.34276 & .036 & 16.9779 & 898.3179 \\
\hline & $\mathrm{R} 7$ & $657.90015^{\star}$ & 149.34276 & .000 & 217.2302 & 1098.5701 \\
\hline & R8 & $1267.01821^{*}$ & 149.44819 & .000 & 826.0371 & 1707.9993 \\
\hline \multirow[t]{6}{*}{$\overline{R 6}$} & R1 & 426.57149 & 148.51765 & .062 & -11.6638 & 864.8068 \\
\hline & $\mathrm{R} 2$ & $904.86808^{*}$ & 148.51765 & .000 & 466.6327 & 1343.1034 \\
\hline & R4 & $1746.07745^{*}$ & 148.51765 & .000 & 1307.8421 & 2184.3128 \\
\hline & $\mathrm{R} 5$ & $-457.64792^{*}$ & 149.34276 & .036 & -898.3179 & -16.9779 \\
\hline & $\mathrm{R} 7$ & 200.25223 & 149.34276 & .833 & -240.4178 & 640.9222 \\
\hline & $\mathrm{R} 8$ & $809.37029^{*}$ & 149.44819 & .000 & 368.3892 & 1250.3514 \\
\hline \multirow[t]{6}{*}{ R7 } & $\overline{\mathrm{R} 1}$ & 226.31926 & 148.51765 & .730 & -211.9161 & 664.5546 \\
\hline & $\mathrm{R} 2$ & $704.61585^{\star}$ & 148.51765 & .000 & 266.3805 & 1142.8512 \\
\hline & R4 & $1545.82522^{*}$ & 148.51765 & .000 & 1107.5899 & 1984.0606 \\
\hline & R5 & $-657.90015^{\star}$ & 149.34276 & .000 & -1098.5701 & -217.2302 \\
\hline & R6 & -200.25223 & 149.34276 & .833 & -640.9222 & 240.4178 \\
\hline & $\mathbf{R} 8$ & $609.11806^{*}$ & 149.44819 & .001 & 168.1370 & 1050.0992 \\
\hline \multirow[t]{6}{*}{ R8 } & R1 & -382.79881 & 148.62367 & .134 & -821.3470 & 55.7494 \\
\hline & $\mathrm{R} 2$ & 95.49778 & 148.62367 & .995 & -343.0504 & 534.0459 \\
\hline & $\mathrm{R} 4$ & $936.70716^{*}$ & 148.62367 & .000 & 498.1590 & 1375.2553 \\
\hline & R5 & $-1267.0182^{*}$ & 149.44819 & .000 & -1707.9993 & -826.0371 \\
\hline & $\mathrm{R} 6$ & $-809.37029^{*}$ & 149.44819 & .000 & -1250.3514 & -368.3892 \\
\hline & $\mathrm{R} 7$ & $-609.11806^{*}$ & 149.44819 & .001 & -1050.0992 & -168.1370 \\
\hline
\end{tabular}

${ }^{*}$. The mean difference is significant at the .05 level. 
Table 2.1.5: Two way ANOVA table for methane yield as function of salt contents and Groups

\begin{tabular}{|l|r|r|r|r|r|}
\hline Source & $\begin{array}{c}\text { Type III Sum of } \\
\text { Squares }\end{array}$ & df & Mean Square & \multicolumn{1}{c|}{ F } & \multicolumn{1}{c|}{ Sig. } \\
\hline Corrected & 1051.464 & 4 & 262.866 & 95.693 & .002 \\
Model & 35401.944 & 1 & 35401.944 & 12887.650 & .000 \\
Intercept & 632.123 & 3 & 210.708 & 76.706 & $\mathbf{0 . 0 0 2}$ \\
Salt & 419.341 & 1 & 419.341 & 152.656 & $\mathbf{0 . 0 0 1}$ \\
Group & 8.241 & 3 & 2.747 & & \\
Error & 36461.649 & 8 & & & \\
Total & 1059.705 & 7 & & & \\
Corrected & & & & \\
Total & & & & \\
\hline
\end{tabular}

Table 2.1.6: Multiple comparisons for the mean methane yield at different salt contents.

\section{Multiple Comparisons}

Dependent Variable: Ym

Tukey HSD

\begin{tabular}{|c|c|c|c|c|c|c|}
\hline \multirow[b]{2}{*}{ (1) Salt } & \multirow[b]{2}{*}{ (J) Salt } & \multirow{2}{*}{$\begin{array}{c}\text { Mean } \\
\text { Difference } \\
(I-J)\end{array}$} & \multirow[b]{2}{*}{ Std. Error } & \multirow[b]{2}{*}{ Sig. } & \multicolumn{2}{|c|}{$95 \%$ Confidence Interval } \\
\hline & & & & & Lower Bound & Upper Bound \\
\hline \multirow[t]{3}{*}{.00} & .50 & 7.4650 & 1.65740 & .060 & -.5331 & $\overline{15.4631}$ \\
\hline & 1.00 & $12.7200^{\star}$ & 1.65740 & .014 & 4.7219 & 20.7181 \\
\hline & 3.00 & $24.4050^{*}$ & 1.65740 & .002 & 16.4069 & 32.4031 \\
\hline \multirow[t]{3}{*}{.50} & .00 & -7.4650 & 1.65740 & .060 & -15.4631 & .5331 \\
\hline & 1.00 & 5.2550 & 1.65740 & .142 & -2.7431 & 13.2531 \\
\hline & 3.00 & $16.9400^{*}$ & 1.65740 & .006 & 8.9419 & 24.9381 \\
\hline \multirow[t]{3}{*}{1.00} & .00 & $-12.7200^{*}$ & 1.65740 & .014 & -20.7181 & -4.7219 \\
\hline & .50 & -5.2550 & 1.65740 & .142 & -13.2531 & 2.7431 \\
\hline & 3.00 & $11.6850^{*}$ & 1.65740 & .018 & 3.6869 & 19.6831 \\
\hline \multirow[t]{3}{*}{3.00} & .00 & $-24.4050^{*}$ & 1.65740 & .002 & -32.4031 & -16.4069 \\
\hline & .50 & $-16.9400^{*}$ & 1.65740 & .006 & -24.9381 & -8.9419 \\
\hline & 1.00 & $-11.6850^{*}$ & 1.65740 & .018 & -19.6831 & -3.6869 \\
\hline
\end{tabular}

Based on observed means.

*. The mean difference is significant at the .05 level. 


\subsection{Methane concentration}

Table 2.2.1: One way ANOVA table for mean methane concentration in all bioreactors

\begin{tabular}{|l|r|r|r|r|r|}
\hline & Sum of squares & df & Mean square & F & \multicolumn{1}{c|}{ Sig. } \\
\hline Between & 10159.304 & 7 & 1452.218 & 13.065 & $\mathbf{0 . 0 0 0}$ \\
groups & 318330.393 & 2864 & 111.151 & & \\
$\begin{array}{l}\text { Within groups } \\
\text { Total }\end{array}$ & 328489.698 & 2871 & & & \\
\hline
\end{tabular}

Table 2.2.2: One way ANOVA table for mean methane concentration in two groups

\begin{tabular}{|l|r|r|r|r|r|}
\hline & Sum of squares & df & Mean square & F & Sig. \\
\hline Between & 3768.090 & 1 & 3768.090 & 33.302 & $\mathbf{0 . 0 0 0}$ \\
groups & 324734.161 & 2870 & 113.148 & & \\
$\begin{array}{l}\text { Within groups } \\
\text { Total }\end{array}$ & 328502.251 & 2871 & & & \\
\hline
\end{tabular}

Table 2.2.3: One way ANOVA table for mean methane concentration at different salt contents

\begin{tabular}{|l|r|r|r|c|c|}
\hline & Sum of squares & df & Mean square & F & Sig. \\
\hline Between & 5030.513 & 3 & 1676.838 & 14.867 & $\mathbf{0 . 0 0 0}$ \\
groups & 323471.738 & 2868 & 112.787 & & \\
$\begin{array}{l}\text { Within groups } \\
\text { Total }\end{array}$ & 328502.251 & 2871 & & & \\
\hline
\end{tabular}


Table 2.2.4: Multiple comparisons for mean methane concentration in all bioreactors

Multiple Comparisons

Dependent Variable: $\mathrm{CH} 4$

\begin{tabular}{|c|c|c|c|c|c|c|}
\hline \multirow[b]{2}{*}{ (I) Reactors } & \multirow[b]{2}{*}{ (J) Reactors } & \multirow{2}{*}{$\begin{array}{c}\text { Mean } \\
\text { Difference } \\
(\mathrm{l}-\mathrm{J})\end{array}$} & \multirow[b]{2}{*}{ Std. Error } & \multirow[b]{2}{*}{ Sig. } & \multicolumn{2}{|c|}{$95 \%$ Confidence Interval } \\
\hline & & & & & Lower Bound & Upper Bound \\
\hline \multirow[t]{7}{*}{ R1 } & $\mathrm{R} 2$ & 2.08047 & .78269 & .136 & -.2935 & 4.4545 \\
\hline & R3 & 1.83939 & .78269 & .267 & -.5346 & 4.2134 \\
\hline & R4 & $4.33523^{*}$ & .78269 & .000 & 1.9612 & 6.7092 \\
\hline & R5 & -2.09039 & .78709 & .137 & -4.4777 & .2970 \\
\hline & R6 & -.27301 & .78709 & 1.000 & -2.6604 & 2.1143 \\
\hline & $\mathrm{R} 7$ & -.50619 & .78709 & .998 & -2.8935 & 1.8811 \\
\hline & R8 & 1.95358 & .78765 & .204 & -.4355 & 4.3426 \\
\hline \multirow[t]{7}{*}{ R2 } & R1 & -2.08047 & .78269 & .136 & -4.4545 & .2935 \\
\hline & R3 & -.24107 & .78269 & 1.000 & -2.6151 & 2.1329 \\
\hline & R4 & 2.25477 & .78269 & .077 & -.1192 & 4.6288 \\
\hline & R5 & $-4.17086^{\star}$ & .78709 & .000 & -6.5582 & -1.7835 \\
\hline & R6 & -2.35348 & .78709 & .057 & -4.7408 & .0339 \\
\hline & R7 & $-2.58666^{\star}$ & .78709 & .023 & -4.9740 & -.1993 \\
\hline & $\mathbf{R 8}$ & -.12689 & .78765 & 1.000 & -2.5159 & 2.2622 \\
\hline \multirow[t]{7}{*}{ R3 } & R1 & -1.83939 & .78269 & .267 & -4.2134 & .5346 \\
\hline & $\mathbf{R} 2$ & .24107 & .78269 & 1.000 & -2.1329 & 2.6151 \\
\hline & R4 & $2.49584^{*}$ & .78269 & .031 & .1218 & 4.8698 \\
\hline & R5 & $-3.92978^{*}$ & .78709 & .000 & -6.3171 & -1.5424 \\
\hline & R6 & -2.11240 & .78709 & .128 & -4.4997 & .2749 \\
\hline & $\mathrm{R} 7$ & -2.34559 & .78709 & .058 & -4.7329 & .0418 \\
\hline & R8 & .11419 & .78765 & 1.000 & -2.2749 & 2.5032 \\
\hline \multirow[t]{7}{*}{ R4 } & R1 & $-4.33523^{*}$ & .78269 & .000 & -6.7092 & -1.9612 \\
\hline & $\mathrm{R} 2$ & -2.25477 & .78269 & .077 & -4.6288 & .1192 \\
\hline & R3 & $-2.49584^{*}$ & .78269 & .031 & -4.8698 & -.1218 \\
\hline & R5 & $-6.42562^{*}$ & .78709 & .000 & -8.8130 & -4.0383 \\
\hline & R6 & $-4.60824^{*}$ & .78709 & .000 & -6.9956 & -2.2209 \\
\hline & R7 & $-4.84143^{*}$ & .78709 & .000 & -7.2288 & -2.4541 \\
\hline & R8 & -2.38165 & .78765 & .051 & -4.7707 & .0074 \\
\hline \multirow[t]{7}{*}{ R5 } & R1 & 2.09039 & .78709 & .137 & -.2970 & 4.4777 \\
\hline & R2 & $4.17086^{\star}$ & .78709 & .000 & 1.7835 & 6.5582 \\
\hline & R3 & $3.92978^{*}$ & .78709 & .000 & 1.5424 & 6.3171 \\
\hline & R4 & $6.42562^{*}$ & .78709 & .000 & 4.0383 & 8.8130 \\
\hline & R6 & 1.81738 & .79146 & .296 & -.5832 & 4.2180 \\
\hline & $\mathrm{R} 7$ & 1.58420 & .79146 & .481 & -.8164 & 3.9848 \\
\hline & $\mathbf{R 8}$ & $4.04397^{*}$ & .79202 & .000 & 1.6417 & 6.4463 \\
\hline \multirow[t]{7}{*}{$\overline{R 6}$} & R1 & .27301 & .78709 & 1.000 & -2.1143 & 2.6604 \\
\hline & R2 & 2.35348 & .78709 & .057 & -.0339 & 4.7408 \\
\hline & R3 & 2.11240 & .78709 & .128 & -.2749 & 4.4997 \\
\hline & R4 & $4.60824^{*}$ & .78709 & .000 & 2.2209 & 6.9956 \\
\hline & R5 & -1.81738 & .79146 & .296 & -4.2180 & .5832 \\
\hline & $\mathrm{R7}$ & -.23318 & .79146 & 1.000 & -2.6338 & 2.1674 \\
\hline & $\mathrm{R} 8$ & 2.22659 & .79202 & .093 & -.1757 & 4.6289 \\
\hline \multirow[t]{7}{*}{ R7 } & R1 & .50619 & .78709 & .998 & -1.8811 & 2.8935 \\
\hline & R2 & $2.58666^{*}$ & .78709 & .023 & .1993 & 4.9740 \\
\hline & R3 & 2.34559 & .78709 & .058 & -.0418 & 4.7329 \\
\hline & R4 & $4.84143^{*}$ & .78709 & .000 & 2.4541 & 7.2288 \\
\hline & R5 & -1.58420 & .79146 & .481 & -3.9848 & .8164 \\
\hline & R6 & .23318 & .79146 & 1.000 & -2.1674 & 2.6338 \\
\hline & $\mathrm{R} 8$ & $2.45977^{*}$ & .79202 & .040 & .0575 & 4.8621 \\
\hline \multirow[t]{7}{*}{ R8 } & R1 & -1.95358 & .78765 & .204 & -4.3426 & .4355 \\
\hline & $\mathbf{R} 2$ & .12689 & .78765 & 1.000 & -2.2622 & 2.5159 \\
\hline & R3 & -.11419 & .78765 & 1.000 & -2.5032 & 2.2749 \\
\hline & R4 & 2.38165 & .78765 & .051 & -.0074 & 4.7707 \\
\hline & R5 & $-4.04397^{*}$ & .79202 & .000 & -6.4463 & -1.6417 \\
\hline & R6 & -2.22659 & .79202 & .093 & -4.6289 & .1757 \\
\hline & $\mathrm{R} 7$ & $-2.45977^{*}$ & .79202 & .040 & -4.8621 & -.0575 \\
\hline
\end{tabular}

*, The mean difference is significant at the .05 level. 


\subsection{BMP assays using leachate produced from bioreactors as substrate}

\subsubsection{First set of BMP assays (in growth phase)}

Hint: group one refers to use the leachate produced form group one of $1 \mathrm{D}$ bioreactors (R1, R2, R3, and R4), whereas, the group two to leachate produced from group two of 1D bioreactors (R5, R6, R7 and R8).

Table 2.3.1: One way ANOVA for mean daily methane production from all BMP assysas

\begin{tabular}{|l|r|r|r|r|r|}
\hline & Sum of squares & \multicolumn{1}{c|}{ df } & Mean square & F & Sig. \\
\hline Between & 134819.170 & 7 & 19259.881 & 9.061 & $\mathbf{0 . 0 0 0}$ \\
groups & 391125.429 & 184 & 2125.682 & & \\
Within groups & 525944.599 & 191 & & & \\
Total &
\end{tabular}

Table 2.3.2: One way ANOVA for mean daily methane production from two groups of BMP assyas

\begin{tabular}{|l|r|r|r|r|r|}
\hline & Sum of squares & \multicolumn{1}{c|}{ df } & Mean square & F & Sig. \\
\hline Between & 5482.260 & 1 & 5482.260 & 2.072 & $\mathbf{0 . 1 5 2}$ \\
groups & 502626.417 & 190 & 2645.402 & & \\
$\begin{array}{l}\text { Within groups } \\
\text { Total }\end{array}$ & 508108.677 & 191 & & & \\
\hline
\end{tabular}

Table 2.3.3: Two way ANOVA table for lag time to production methane in two groups of BMP assays and at different salt contents.

\begin{tabular}{|l|c|c|c|c|c|}
\hline Source & $\begin{array}{c}\text { Type III sum of } \\
\text { squares }\end{array}$ & df & Mean square & F & Sig. \\
\hline Corrected & 82.500 & 4 & 20.625 & 11.512 & .036 \\
model & & & & & \\
Intercept & 55.125 & 1 & 55.125 & 30.767 & .012 \\
Group & 3.125 & 1 & 3.125 & 1.744 & $\mathbf{0 . 2 7 8}$ \\
Salt & 79.375 & 3 & 26.458 & 14.767 & $\mathbf{0 . 0 2 7}$ \\
Error & 5.375 & 3 & 1.792 & & \\
Total & 143.000 & 8 & & & \\
Corrected total & 87.875 & 7 & & & \\
\hline
\end{tabular}


Table 2.3.4: Multiple comparisons for mean daily methane production from all BMP assays

Multiple Comparisons

Dependent Variable: $\mathrm{CH} 4$ Tukey HSD

\begin{tabular}{|c|c|c|c|c|c|c|}
\hline \multirow[b]{2}{*}{ (I) Reactor } & \multirow[b]{2}{*}{ (J) Reactor } & \multirow{2}{*}{$\begin{array}{c}\text { Mean } \\
\text { Difference } \\
(1-J)\end{array}$} & \multirow[b]{2}{*}{ Std. Error } & \multirow[b]{2}{*}{ Sig. } & \multicolumn{2}{|c|}{$95 \%$ Confidence Interval } \\
\hline & & & & & Lower Bound & Upper Bound \\
\hline \multirow[t]{7}{*}{ R1 } & $\mathrm{R} 2$ & 9.70042 & 13.30940 & .996 & -31.1081 & 50.5089 \\
\hline & R3 & 19.00292 & 13.30940 & .843 & -21.8056 & 59.8114 \\
\hline & R4 & $62.59875^{*}$ & 13.30940 & .000 & 21.7902 & 103.4073 \\
\hline & R5 & -17.60917 & 13.30940 & .889 & -58.4177 & 23.1994 \\
\hline & R6 & -2.07125 & 13.30940 & 1.000 & -42.8798 & 38.7373 \\
\hline & $\mathrm{R} 7$ & 11.01208 & 13.30940 & .991 & -29.7964 & 51.8206 \\
\hline & R8 & $56.95208^{*}$ & 13.30940 & .001 & 16.1436 & 97.7606 \\
\hline \multirow[t]{7}{*}{ R2 } & R1 & -9.70042 & 13.30940 & .996 & -50.5089 & 31.1081 \\
\hline & R3 & 9.30250 & 13.30940 & .997 & -31.5060 & 50.1110 \\
\hline & R4 & $52.89833^{\star}$ & 13.30940 & .003 & 12.0898 & 93.7069 \\
\hline & R5 & -27.30958 & 13.30940 & .450 & -68.1181 & 13.4989 \\
\hline & $\mathrm{R} 6$ & -11.77167 & 13.30940 & .987 & -52.5802 & 29.0369 \\
\hline & $\mathrm{R} 7$ & 1.31167 & 13.30940 & 1.000 & -39.4969 & 42.1202 \\
\hline & R8 & $47.25167^{*}$ & 13.30940 & .011 & 6.4431 & 88.0602 \\
\hline \multirow[t]{7}{*}{ R3 } & R1 & -19.00292 & 13.30940 & .843 & -59.8114 & 21.8056 \\
\hline & $\mathrm{R} 2$ & -9.30250 & 13.30940 & .997 & -50.1110 & 31.5060 \\
\hline & R4 & $43.59583^{*}$ & 13.30940 & .027 & 2.7873 & 84.4044 \\
\hline & R5 & -36.61208 & 13.30940 & .114 & -77.4206 & 4.1964 \\
\hline & $\mathrm{R} 6$ & -21.07417 & 13.30940 & .760 & -61.8827 & 19.7344 \\
\hline & $\mathrm{R} 7$ & -7.99083 & 13.30940 & .999 & -48.7994 & 32.8177 \\
\hline & R8 & 37.94917 & 13.30940 & .089 & -2.8594 & 78.7577 \\
\hline \multirow[t]{7}{*}{$\overline{\mathrm{R} 4}$} & R1 & $-62.59875^{*}$ & 13.30940 & .000 & -103.4073 & -21.7902 \\
\hline & $\mathrm{R} 2$ & $-52.89833^{*}$ & 13.30940 & .003 & -93.7069 & -12.0898 \\
\hline & R3 & $-43.59583^{*}$ & 13.30940 & .027 & -84.4044 & -2.7873 \\
\hline & R5 & $-80.20792^{*}$ & 13.30940 & .000 & -121.0164 & -39.3994 \\
\hline & R6 & $-64.67000^{*}$ & 13.30940 & .000 & -105.4785 & -23.8615 \\
\hline & $\mathrm{R} 7$ & $-51.58667^{*}$ & 13.30940 & .004 & -92.3952 & -10.7781 \\
\hline & R8 & -5.64667 & 13.30940 & 1.000 & -46.4552 & 35.1619 \\
\hline \multirow[t]{7}{*}{ R5 } & R1 & 17.60917 & 13.30940 & .889 & -23.1994 & 58.4177 \\
\hline & $\mathrm{R} 2$ & 27.30958 & 13.30940 & .450 & -13.4989 & 68.1181 \\
\hline & R3 & 36.61208 & 13.30940 & .114 & -4.1964 & 77.4206 \\
\hline & R4 & $80.20792^{\star}$ & 13.30940 & .000 & 39.3994 & 121.0164 \\
\hline & $\mathrm{R} 6$ & 15.53792 & 13.30940 & .940 & -25.2706 & 56.3464 \\
\hline & $\mathrm{R} 7$ & 28.62125 & 13.30940 & .387 & -12.1873 & 69.4298 \\
\hline & R8 & $74.56125^{*}$ & 13.30940 & .000 & 33.7527 & 115.3698 \\
\hline \multirow[t]{7}{*}{$\mathrm{R} 6$} & R1 & 2.07125 & 13.30940 & 1.000 & -38.7373 & 42.8798 \\
\hline & $\mathrm{R} 2$ & 11.77167 & 13.30940 & .987 & -29.0369 & 52.5802 \\
\hline & R3 & 21.07417 & 13.30940 & .760 & -19.7344 & 61.8827 \\
\hline & R4 & $64.67000^{*}$ & 13.30940 & .000 & 23.8615 & 105.4785 \\
\hline & R5 & -15.53792 & 13.30940 & .940 & -56.3464 & 25.2706 \\
\hline & $\mathrm{R} 7$ & 13.08333 & 13.30940 & .976 & -27.7252 & 53.8919 \\
\hline & $\mathrm{R} 8$ & $59.02333^{*}$ & 13.30940 & .000 & 18.2148 & 99.8319 \\
\hline \multirow[t]{7}{*}{ R7 } & R1 & -11.01208 & 13.30940 & .991 & -51.8206 & 29.7964 \\
\hline & $\mathrm{R} 2$ & -1.31167 & 13.30940 & 1.000 & -42.1202 & 39.4969 \\
\hline & $\mathrm{R3}$ & 7.99083 & 13.30940 & .999 & -32.8177 & 48.7994 \\
\hline & R4 & $51.58667^{*}$ & 13.30940 & .004 & 10.7781 & 92.3952 \\
\hline & R5 & -28.62125 & 13.30940 & .387 & -69.4298 & 12.1873 \\
\hline & $\mathrm{R} 6$ & -13.08333 & 13.30940 & .976 & -53.8919 & 27.7252 \\
\hline & $\mathrm{R} 8$ & $45.94000^{*}$ & 13.30940 & .016 & 5.1315 & 86.7485 \\
\hline \multirow[t]{7}{*}{ R8 } & R1 & $-56.95208^{*}$ & 13.30940 & .001 & -97.7606 & -16.1436 \\
\hline & $\mathrm{R} 2$ & $-47.25167^{\star}$ & 13.30940 & .011 & -88.0602 & -6.4431 \\
\hline & R3 & -37.94917 & 13.30940 & .089 & -78.7577 & 2.8594 \\
\hline & $\mathrm{R} 4$ & 5.64667 & 13.30940 & 1.000 & -35.1619 & 46.4552 \\
\hline & R5 & $-74.56125^{*}$ & 13.30940 & .000 & -115.3698 & -33.7527 \\
\hline & R6 & $-59.02333^{*}$ & 13.30940 & .000 & -99.8319 & -18.2148 \\
\hline & $\mathrm{R} 7$ & $-45.94000^{*}$ & 13.30940 & .016 & -86.7485 & -5.1315 \\
\hline
\end{tabular}

*. The mean difference is significant at the .05 level. 
Table 2.3.5: Multiple comparisons for mean lag time of methane production in two groups at different salt contents

Multiple Comparisons

Dependent Variable: Lag

Tukey HSD

\begin{tabular}{|c|c|c|c|c|c|c|}
\hline \multirow[b]{2}{*}{ (I) Salt } & \multirow[b]{2}{*}{ (J) Salt } & \multirow{2}{*}{$\begin{array}{c}\text { Mean } \\
\text { Difference } \\
(1-J)\end{array}$} & \multirow[b]{2}{*}{ Std. Error } & \multirow[b]{2}{*}{ Sig. } & \multicolumn{2}{|c|}{ 95\% Confidence Interval } \\
\hline & & & & & Lower Bound & Upper Bound \\
\hline \multirow[t]{3}{*}{.00} & .50 & -1.0000 & 1.33853 & .873 & -7.4593 & 5.4593 \\
\hline & 1.00 & -1.5000 & 1.33853 & .705 & -7.9593 & 4.9593 \\
\hline & 3.00 & $-8.0000^{*}$ & 1.33853 & .028 & -14.4593 & -1.5407 \\
\hline \multirow[t]{3}{*}{.50} & .00 & 1.0000 & 1.33853 & .873 & -5.4593 & 7.4593 \\
\hline & 1.00 & -.5000 & 1.33853 & .979 & -6.9593 & 5.9593 \\
\hline & 3.00 & $-7.0000^{*}$ & 1.33853 & .040 & -13.4593 & -.5407 \\
\hline \multirow[t]{3}{*}{1.00} & .00 & 1.5000 & 1.33853 & .705 & -4.9593 & 7.9593 \\
\hline & .50 & .5000 & 1.33853 & .979 & -5.9593 & 6.9593 \\
\hline & 3.00 & $-6.5000^{*}$ & 1.33853 & .049 & -12.9593 & -.0407 \\
\hline \multirow[t]{3}{*}{3.00} & .00 & $8.0000^{*}$ & 1.33853 & .028 & 1.5407 & 14.4593 \\
\hline & .50 & $7.0000^{*}$ & 1.33853 & .040 & .5407 & 13.4593 \\
\hline & 1.00 & $6.5000^{*}$ & 1.33853 & .049 & .0407 & 12.9593 \\
\hline
\end{tabular}

Based on observed means.

*. The mean difference is significant at the .05 level.

Table 2.3.6: Two way ANOVA table for time required to reach the peak methane production in two groups and at different salt contents.

\begin{tabular}{|l|r|r|r|r|r|}
\hline Source & $\begin{array}{r}\text { Type III Sum } \\
\text { of Squares }\end{array}$ & df & Mean Square & \multicolumn{1}{c|}{ F } & \multicolumn{1}{c|}{ Sig. } \\
\hline Corrected & 99.000 & 4 & 24.750 & 8.735 & .053 \\
Model & & & & & \\
Intercept & 1860.500 & 1 & 1860.500 & 656.647 & .000 \\
Group & .500 & 1 & .500 & .176 & $\mathbf{0 . 7 0 3}$ \\
Salt & 98.500 & 3 & 32.833 & 11.588 & $\mathbf{0 . 0 3 7}$ \\
Error & 8.500 & 3 & 2.833 & & \\
Total & 1968.000 & 8 & & & \\
Corrected & 107.500 & 7 & & & \\
Total & & & & & \\
\hline
\end{tabular}


Table 2.3.7: Multiple comparisons for mean time required to reach the peak methane production in two groups at different salt contents

Multiple Comparisons

Dependent Variable: TimePeak

Tukey HSD

\begin{tabular}{|c|c|c|c|c|c|c|}
\hline \multirow[b]{2}{*}{ (I) Salt } & \multirow[b]{2}{*}{ (J) Salt } & \multirow{2}{*}{$\begin{array}{c}\text { Mean } \\
\text { Difference } \\
(\mathrm{I}-\mathrm{J})\end{array}$} & \multirow[b]{2}{*}{ Std. Error } & \multirow[b]{2}{*}{ Sig. } & \multicolumn{2}{|c|}{$95 \%$ Confidence Interval } \\
\hline & & & & & Lower Bound & Upper Bound \\
\hline \multirow[t]{3}{*}{.00} & .50 & -2.5000 & 1.68325 & .538 & -10.6228 & 5.6228 \\
\hline & 1.00 & -3.0000 & 1.68325 & .423 & -11.1228 & 5.1228 \\
\hline & 3.00 & $-9.5000^{*}$ & 1.68325 & .033 & -17.6228 & -1.3772 \\
\hline \multirow[t]{3}{*}{.50} & .00 & 2.5000 & 1.68325 & .538 & -5.6228 & 10.6228 \\
\hline & 1.00 & -.5000 & 1.68325 & .989 & -8.6228 & 7.6228 \\
\hline & 3.00 & -7.0000 & 1.68325 & .074 & -15.1228 & 1.1228 \\
\hline \multirow[t]{3}{*}{1.00} & .00 & 3.0000 & 1.68325 & .423 & -5.1228 & 11.1228 \\
\hline & .50 & .5000 & 1.68325 & .989 & -7.6228 & 8.6228 \\
\hline & 3.00 & -6.5000 & 1.68325 & .089 & -14.6228 & 1.6228 \\
\hline \multirow[t]{3}{*}{3.00} & .00 & $9.5000^{*}$ & 1.68325 & .033 & 1.3772 & 17.6228 \\
\hline & .50 & 7.0000 & 1.68325 & .074 & -1.1228 & 15.1228 \\
\hline & 1.00 & 6.5000 & 1.68325 & .089 & -1.6228 & 14.6228 \\
\hline
\end{tabular}

Based on observed means.

*. The mean difference is significant at the .05 level.

Table 2.3.8: Two way ANOVA table for methane yield production from BMP assays in two groups and at different salt contents.

\begin{tabular}{|l|r|r|r|r|r|}
\hline Source & $\begin{array}{c}\text { Type III Sum } \\
\text { of Squares }\end{array}$ & \multicolumn{1}{c|}{ df } & Mean Square & \multicolumn{1}{c|}{ F } & \multicolumn{1}{c|}{ Sig. } \\
\hline Corrected & 175438.000 & 4 & 43859.500 & 246.633 & .000 \\
Model & & & & & \\
Intercept & 800112.500 & 1 & 800112.500 & 4499.22 & .000 \\
& & & & 7 & \\
Group & 420.500 & 1 & 420.500 & 2.365 & $\mathbf{0 . 2 2 2}$ \\
Salt & 175017.500 & 3 & 58339.167 & 328.055 & $\mathbf{0 . 0 0 0}$ \\
Error & 533.500 & 3 & 177.833 & & \\
Total & 976084.000 & 8 & & & \\
Corrected & 175971.500 & 7 & & & \\
Total & & & & & \\
\hline
\end{tabular}


Table 2.3.9: Multiple comparisons for mean methane yield in two groups at different salt contents

\section{Multiple Comparisons}

Dependent Variable: $Y m$

Tukey HSD

\begin{tabular}{|ll|c|c|r|r|r|}
\hline & & \multirow{2}{*}{$\begin{array}{c}\text { Mean } \\
\text { Difference }\end{array}$} & & & \multicolumn{2}{|c|}{} \\
(I) Salt & $(\mathrm{J})$ Salt & $(\mid-J)$ & Std. Error & Sig. & \multicolumn{2}{|c|}{$95 \%$ Confidence Interval } \\
\cline { 5 - 7 } & .50 & 17.0000 & 13.33542 & .632 & -47.3523 & 81.3523 \\
& 1.00 & $74.0000^{*}$ & 13.33542 & .034 & 9.6477 & 138.3523 \\
& 3.00 & $366.0000^{*}$ & 13.33542 & .000 & 301.6477 & 430.3523 \\
\hline .50 & .00 & -17.0000 & 13.33542 & .632 & -81.3523 & 47.3523 \\
& 1.00 & 57.0000 & 13.33542 & .069 & -7.3523 & 121.3523 \\
& 3.00 & $349.0000^{*}$ & 13.33542 & .000 & 284.6477 & 413.3523 \\
\hline 1.00 & .00 & $-74.0000^{*}$ & 13.33542 & .034 & -138.3523 & -9.6477 \\
& .50 & -57.0000 & 13.33542 & .069 & -121.3523 & 7.3523 \\
& 3.00 & $292.0000^{*}$ & 13.33542 & .001 & 227.6477 & 356.3523 \\
\hline 3.00 & .00 & $-366.0000^{*}$ & 13.33542 & .000 & -430.3523 & -301.6477 \\
& .50 & $-349.0000^{*}$ & 13.33542 & .000 & -413.3523 & -284.6477 \\
& 1.00 & $-292.0000^{*}$ & 13.33542 & .001 & -356.3523 & -227.6477 \\
\hline
\end{tabular}

Based on observed means.

*. The mean difference is significant at the .05 level.

\subsubsection{Second set of BMP assays (in decline phase)}

Table 2.3.10: One way ANOVA for mean daily methane production from all BMP assysas

\begin{tabular}{|l|r|r|r|r|r|}
\hline & Sum of squares & df & Mean square & F & Sig. \\
\hline Between & 25423.495 & 7 & 3631.928 & 3.526 & $\mathbf{0 . 0 0 1}$ \\
groups & & & & & \\
$\begin{array}{l}\text { Within groups } \\
\text { Total }\end{array}$ & 322420.503 & 313 & 1030.097 & & \\
\hline
\end{tabular}

Table 2.3.11: One way ANOVA for mean daily methane production from two groups of BMP assyas

\begin{tabular}{|l|r|r|r|r|r|}
\hline & Sum of squares & df & Mean square & F & \multicolumn{1}{c|}{ Sig. } \\
\hline Between & 4756.314 & 1 & 4756.314 & 4.410 & $\mathbf{0 . 0 3 7}$ \\
groups & 338688.828 & 314 & 1078.627 & & \\
$\begin{array}{l}\text { Within groups } \\
\text { Total }\end{array}$ & 343445.142 & 315 & & & \\
\hline
\end{tabular}


Table 2.3.12: Multiple comparisons for mean daily methane production from all BMP

Assays in second set

Multiple Comparisons

Dependent Variable: $\mathrm{CH} 4$

Tukey HSD

\begin{tabular}{|c|c|c|c|c|c|c|}
\hline \multirow[b]{2}{*}{ (I) Reactor } & \multirow[b]{2}{*}{ (J) Reactor } & \multirow{2}{*}{$\begin{array}{c}\text { Mean } \\
\text { Difference } \\
(\mathrm{l}-\mathrm{J})\end{array}$} & \multirow[b]{2}{*}{ Std. Error } & \multirow[b]{2}{*}{ Sig. } & \multicolumn{2}{|c|}{$95 \%$ Confidence Interval } \\
\hline & & & & & Lower Bound & Upper Bound \\
\hline \multirow[t]{7}{*}{ R1 } & R2 & -12.84011 & 9.54139 & .880 & -41.9595 & 16.2792 \\
\hline & R3 & -6.30138 & 9.10274 & .997 & -34.0820 & 21.4792 \\
\hline & R4 & 6.40617 & 8.31685 & .994 & -18.9760 & 31.7883 \\
\hline & R5 & -22.48083 & 9.54139 & .267 & -51.6002 & 6.6385 \\
\hline & R6 & -15.21952 & 9.10274 & .705 & -43.0001 & 12.5611 \\
\hline & R7 & -7.52764 & 8.84308 & .990 & -34.5158 & 19.4605 \\
\hline & R8 & 1.26088 & 8.50376 & 1.000 & -24.6917 & 27.2135 \\
\hline \multirow[t]{7}{*}{$\mathrm{R} 2$} & R1 & 12.84011 & 9.54139 & .880 & -16.2792 & 41.9595 \\
\hline & R3 & 6.53873 & 8.08869 & .993 & -18.1471 & 31.2246 \\
\hline & R4 & 19.24628 & 7.19285 & .134 & -2.7056 & 41.1981 \\
\hline & R5 & -9.64071 & 8.57936 & .951 & -35.8240 & 16.5426 \\
\hline & R6 & -2.37940 & 8.08869 & 1.000 & -27.0653 & 22.3065 \\
\hline & R7 & 5.31248 & 7.79533 & .997 & -18.4781 & 29.1030 \\
\hline & R8 & 14.10099 & 7.40818 & .550 & -8.5080 & 36.7100 \\
\hline \multirow[t]{7}{*}{ R3 } & R1 & 6.30138 & 9.10274 & .997 & -21.4792 & 34.0820 \\
\hline & R2 & -6.53873 & 8.08869 & .993 & -31.2246 & 18.1471 \\
\hline & R4 & 12.70755 & 6.59990 & .534 & -7.4347 & 32.8498 \\
\hline & R5 & -16.17945 & 8.08869 & .483 & -40.8653 & 8.5064 \\
\hline & R6 & -8.91814 & 7.56628 & .938 & -32.0096 & 14.1734 \\
\hline & R7 & -1.22626 & 7.25182 & 1.000 & -23.3580 & 20.9055 \\
\hline & R8 & 7.56226 & 6.83394 & .955 & -13.2942 & 28.4188 \\
\hline \multirow[t]{7}{*}{ R4 } & R1 & -6.40617 & 8.31685 & .994 & -31.7883 & 18.9760 \\
\hline & $\mathrm{R} 2$ & -19.24628 & 7.19285 & .134 & -41.1981 & 2.7056 \\
\hline & R3 & -12.70755 & 6.59990 & .534 & -32.8498 & 7.4347 \\
\hline & R5 & $-28.88700^{*}$ & 7.19285 & .002 & -50.8388 & -6.9352 \\
\hline & R6 & $-21.62569^{*}$ & 6.59990 & .026 & -41.7679 & -1.4835 \\
\hline & R7 & -13.93381 & 6.23690 & .334 & -32.9682 & 5.1006 \\
\hline & R8 & -5.14529 & 5.74569 & .986 & -22.6805 & 12.3900 \\
\hline \multirow[t]{7}{*}{ R5 } & R1 & 22.48083 & 9.54139 & .267 & -6.6385 & 51.6002 \\
\hline & $\mathbf{R} 2$ & 9.64071 & 8.57936 & .951 & -16.5426 & 35.8240 \\
\hline & R3 & 16.17945 & 8.08869 & .483 & -8.5064 & 40.8653 \\
\hline & R4 & $28.88700^{*}$ & 7.19285 & .002 & 6.9352 & 50.8388 \\
\hline & R6 & 7.26131 & 8.08869 & .986 & $-17,4245$ & 31.9472 \\
\hline & $\mathbf{R 7}$ & 14.95319 & 7.79533 & .539 & -8.8374 & 38.7437 \\
\hline & R8 & $23.74170^{*}$ & 7.40818 & .032 & 1.1327 & 46.3507 \\
\hline \multirow[t]{7}{*}{$\bar{R} 6$} & R1 & 15.21952 & 9.10274 & .705 & -12.5611 & 43.0001 \\
\hline & R2 & 2.37940 & 8.08869 & 1.000 & -22.3065 & 27.0653 \\
\hline & R3 & 8.91814 & 7.56628 & .938 & -14.1734 & 32.0096 \\
\hline & R4 & $21.62569^{*}$ & 6.59990 & .026 & 1.4835 & 41.7679 \\
\hline & R5 & -7.26131 & 8.08869 & .986 & -31.9472 & 17.4245 \\
\hline & R7 & 7.69188 & 7.25182 & .964 & -14.4399 & 29.8237 \\
\hline & R8 & 16.48039 & 6.83394 & .239 & -4.3761 & 37.3369 \\
\hline \multirow[t]{7}{*}{ R7 } & R1 & 7.52764 & 8.84308 & .990 & -19.4605 & 34.5158 \\
\hline & R2 & -5.31248 & 7.79533 & .997 & -29.1030 & 18.4781 \\
\hline & R3 & 1.22626 & 7.25182 & 1.000 & -20.9055 & 23.3580 \\
\hline & R4 & 13.93381 & 6.23690 & .334 & -5.1006 & 32.9682 \\
\hline & R5 & -14.95319 & 7.79533 & .539 & -38.7437 & 8.8374 \\
\hline & $R 6$ & -7.69188 & 7.25182 & .964 & -29.8237 & 14.4399 \\
\hline & R8 & 8.78851 & 6.48406 & .876 & -11.0002 & 28.5772 \\
\hline \multirow[t]{7}{*}{ R8 } & R1 & -1.26088 & 8.50376 & 1.000 & -27.2135 & 24.6917 \\
\hline & R2 & -14.10099 & 7.40818 & .550 & -36.7100 & 8.5080 \\
\hline & R3 & -7.56226 & 6.83394 & .955 & -28.4188 & 13.2942 \\
\hline & R4 & 5.14529 & 5.74569 & .986 & -12.3900 & 22.6805 \\
\hline & R5 & $-23.74170^{*}$ & 7.40818 & .032 & -46.3507 & -1.1327 \\
\hline & R6 & -16.48039 & 6.83394 & .239 & -37.3369 & 4.3761 \\
\hline & R7 & -8.78851 & 6.48406 & .876 & -28.5772 & 11.0002 \\
\hline
\end{tabular}

*. The mean difference is significant at the .05 level. 
Table 2.3.13: One way ANOVA table for mean lag time of methane production in two groups

\begin{tabular}{|l|r|r|r|r|r|}
\hline & Sum of squares & \multicolumn{1}{c|}{ df } & Mean square & F & Sig. \\
\hline Between & 2.000 & 1 & 2.000 & .429 & $\mathbf{0 . 5 3 7}$ \\
groups & 28.000 & 6 & 4.667 & & \\
Within groups & 30.000 & 7 & & & \\
Total &
\end{tabular}

Table 2.3.14: One way ANOVA table for mean lag time of methane production at different salt contents

\begin{tabular}{|l|r|r|r|r|r|}
\hline & Sum of squares & \multicolumn{1}{c|}{ df } & Mean square & F & Sig. \\
\hline Between & 28.000 & 3 & 9.333 & 18.667 & $\mathbf{0 . 0 0 8}$ \\
groups & 2.000 & 4 & .500 & & \\
Within groups & 30.000 & 7 & & & \\
Total &
\end{tabular}

Table 2.3.15: Multiple comparisons for mean lag time of methane production in two groups at different salt contents

\section{Multiple Comparisons}

Dependent Variable: Lag

Tukey HSD

\begin{tabular}{|c|c|c|c|c|c|c|}
\hline \multirow[b]{2}{*}{ (I) Salt } & \multirow[b]{2}{*}{ (J) Salt } & \multirow{2}{*}{$\begin{array}{c}\text { Mean } \\
\text { Difference } \\
(1-J)\end{array}$} & \multirow[b]{2}{*}{ Std. Error } & \multirow[b]{2}{*}{ Sig. } & \multicolumn{2}{|c|}{ 95\% Confidence Interval } \\
\hline & & & & & Lower Bound & Upper Bound \\
\hline \multirow[t]{3}{*}{.00} & .50 & -1.00000 & .70711 & .553 & -3.8785 & 1.8785 \\
\hline & 1.00 & -2.00000 & .70711 & .146 & -4.8785 & .8785 \\
\hline & 3.00 & $-5.00000^{*}$ & .70711 & .007 & -7.8785 & -2.1215 \\
\hline \multirow[t]{3}{*}{.50} & .00 & 1.00000 & .70711 & .553 & -1.8785 & 3.8785 \\
\hline & 1.00 & -1.00000 & .70711 & .553 & -3.8785 & 1.8785 \\
\hline & 3.00 & $-4.00000^{*}$ & .70711 & .016 & -6.8785 & -1.1215 \\
\hline \multirow[t]{3}{*}{1.00} & .00 & 2.00000 & .70711 & .146 & -.8785 & 4.8785 \\
\hline & .50 & 1.00000 & .70711 & .553 & -1.8785 & 3.8785 \\
\hline & 3.00 & $-3.00000^{*}$ & .70711 & .044 & -5.8785 & -.1215 \\
\hline \multirow[t]{3}{*}{3.00} & .00 & $5.00000^{\star}$ & .70711 & .007 & 2.1215 & 7.8785 \\
\hline & .50 & $4.00000^{*}$ & .70711 & .016 & 1.1215 & 6.8785 \\
\hline & 1.00 & $3.00000^{*}$ & .70711 & .044 & .1215 & 5.8785 \\
\hline
\end{tabular}

*. The mean difference is significant at the .05 level. 
Table 2.3.16: Two way ANOVA table for time required to reach the peak methane production in two groups and at different salt contents.

\begin{tabular}{|l|r|r|r|r|r|}
\hline Source & $\begin{array}{c}\text { Type III sum of } \\
\text { squares }\end{array}$ & df & Mean square & \multicolumn{1}{c|}{ F } & \multicolumn{1}{c|}{ Sig. } \\
\hline Corrected & 1429.500 & 4 & 357.375 & 14.015 & 0.028 \\
model & 5202.000 & 1 & 5202.000 & 204.000 & 0.001 \\
Intercept & 12.500 & 1 & 12.500 & .490 & $\mathbf{0 . 5 3 4}$ \\
Group & 1417.000 & 3 & 472.333 & 18.523 & $\mathbf{0 . 0 1 9}$ \\
Salt & 76.500 & 3 & 25.500 & & \\
Error & 6708.000 & 8 & & & \\
Total & 1506.000 & 7 & & & \\
Corrected total & & & & \\
\hline
\end{tabular}

Table 2.3.17: Multiple comparisons for mean time required to reach the peak methane production in two groups at different salt contents

\section{Multiple Comparisons}

Dependent Variable: TimePeak

Tukey HSD

\begin{tabular}{|c|c|c|c|c|c|c|}
\hline \multirow[b]{2}{*}{ (1) Salt } & \multirow[b]{2}{*}{ (J) Salt } & \multirow{2}{*}{$\begin{array}{c}\text { Mean } \\
\text { Difference } \\
(I-J)\end{array}$} & \multirow[b]{2}{*}{ Std. Error } & \multirow[b]{2}{*}{ Sig. } & \multicolumn{2}{|c|}{ 95\% Confidence Interval } \\
\hline & & & & & Lower Bound & Upper Bound \\
\hline \multirow[t]{3}{*}{.00} & .50 & -5.5000 & 5.04975 & .720 & -29.8684 & 18.8684 \\
\hline & 1.00 & -8.0000 & 5.04975 & .497 & -32.3684 & 16.3684 \\
\hline & 3.00 & $-34.5000^{\star}$ & 5.04975 & .019 & -58.8684 & -10.1316 \\
\hline \multirow[t]{3}{*}{.50} & .00 & 5.5000 & 5.04975 & .720 & -18.8684 & 29.8684 \\
\hline & 1.00 & -2.5000 & 5.04975 & .955 & -26.8684 & 21.8684 \\
\hline & 3.00 & $-29.0000^{*}$ & 5.04975 & .031 & -53.3684 & -4.6316 \\
\hline \multirow[t]{3}{*}{1.00} & .00 & 8.0000 & 5.04975 & .497 & -16.3684 & 32.3684 \\
\hline & .50 & 2.5000 & 5.04975 & .955 & -21.8684 & 26.8684 \\
\hline & 3.00 & $-26.5000^{*}$ & 5.04975 & .040 & -50.8684 & -2.1316 \\
\hline \multirow[t]{3}{*}{3.00} & .00 & $34.5000^{*}$ & 5.04975 & .019 & 10.1316 & 58.8684 \\
\hline & .50 & $29.0000^{*}$ & 5.04975 & .031 & 4.6316 & 53.3684 \\
\hline & 1.00 & $26.5000^{*}$ & 5.04975 & .040 & 2.1316 & 50.8684 \\
\hline
\end{tabular}

Based on observed means.

*. The mean difference is significant at the .05 level. 
Table 2.3.18: Two way ANOVA table of stabilization time for methane production in two groups and at different salt contents.

\begin{tabular}{|l|r|r|r|r|r|}
\hline Source & $\begin{array}{c}\text { Type III sum of } \\
\text { squares }\end{array}$ & \multicolumn{1}{c|}{ df } & Mean square & \multicolumn{1}{c|}{ F } & \multicolumn{1}{c|}{ Sig. } \\
\hline Corrected & 1581.000 & 4 & 395.250 & 9.680 & .046 \\
nodel & & & & & \\
Intercept & 12960.500 & 1 & 12960.500 & 317.400 & .000 \\
Group & 4.500 & 1 & 4.500 & .110 & $\mathbf{0 . 7 6 2}$ \\
Salt & 1576.500 & 3 & 525.500 & 12.869 & $\mathbf{0 . 0 3 2}$ \\
Error & 122.500 & 3 & 40.833 & & \\
Total & 14664.000 & 8 & & & \\
Corrected total & 1703.500 & 7 & & & \\
\hline
\end{tabular}

Table 2.3.19: Multiple comparisons for stabilization time of methane production in two groups at different salt contents

\section{Multiple Comparisons}

Dependent Variable: Stabilization

Tukey HSD

\begin{tabular}{|c|c|c|c|c|c|c|}
\hline \multirow[b]{2}{*}{ (I) Salt } & \multirow[b]{2}{*}{ (J) Salt } & \multirow{2}{*}{$\begin{array}{c}\text { Mean } \\
\text { Difference } \\
(\mathrm{I}-\mathrm{J})\end{array}$} & \multirow[b]{2}{*}{ Std. Error } & \multirow[b]{2}{*}{ Sig. } & \multicolumn{2}{|c|}{$95 \%$ Confidence Interval } \\
\hline & & & & & Lower Bound & Upper Bound \\
\hline \multirow[t]{3}{*}{.00} & .50 & -8.0000 & 6.49038 & .651 & -39.3204 & 23.3204 \\
\hline & 1.00 & -14.5000 & 6.49038 & .292 & -45.8204 & 16.8204 \\
\hline & 3.00 & $-38.0000^{*}$ & 6.49038 & .030 & -69.3204 & -6.6796 \\
\hline \multirow[t]{3}{*}{.50} & .00 & 8.0000 & 6.49038 & .651 & -23.3204 & 39.3204 \\
\hline & 1.00 & -6.5000 & 6.49038 & .761 & -37.8204 & 24.8204 \\
\hline & 3.00 & -30.0000 & 6.49038 & .056 & -61.3204 & 1.3204 \\
\hline \multirow[t]{3}{*}{1.00} & .00 & 14.5000 & 6.49038 & .292 & -16.8204 & 45.8204 \\
\hline & .50 & 6.5000 & 6.49038 & .761 & -24.8204 & 37.8204 \\
\hline & 3.00 & -23.5000 & 6.49038 & .104 & -54.8204 & 7.8204 \\
\hline \multirow[t]{3}{*}{3.00} & .00 & $38.0000^{*}$ & 6.49038 & .030 & 6.6796 & 69.3204 \\
\hline & .50 & 30.0000 & 6.49038 & .056 & -1.3204 & 61.3204 \\
\hline & 1.00 & 23.5000 & 6.49038 & .104 & -7.8204 & 54.8204 \\
\hline
\end{tabular}

Based on observed means.

*. The mean difference is significant at the .05 level. 
Table 2.3.20: Two way ANOVA table of methane yield in two groups and at different salt contents.

\begin{tabular}{|l|r|r|r|r|r|}
\hline Source & $\begin{array}{c}\text { Type III sum of } \\
\text { squares }\end{array}$ & df & Mean square & \multicolumn{1}{c|}{ F } & \multicolumn{1}{c|}{ Sig. } \\
\hline Corrected & 2923.500 & 4 & 730.875 & 3.341 & .175 \\
model & 1483503.125 & 1 & 1483503.125 & 6780.43 & .000 \\
Intercept & 120.125 & 1 & 120.125 & .549 & $\mathbf{0 . 5 1 2}$ \\
Group & 2803.375 & 3 & 934.458 & 4.271 & $\mathbf{0 . 1 3 2}$ \\
Salt & 656.375 & 3 & 218.792 & & \\
Error & 1487083.000 & 8 & & & \\
Total & 3579.875 & 7 & & & \\
Corrected total & & & & & \\
\hline
\end{tabular}




\subsubsection{Third set of BMP (Comparison between two types of inoculums)}

In this set, leachate from R1 used as substrate for the BMP assays and operated at $0,1,2$, and $3 \%(\mathrm{w} / \mathrm{v})$ salt content. Two types of inoculums (normal and acclimatized digested sludge) were used in this set.

Group one (N) refer to the BMP using normal digested sludge as inoculums, whereas, the group two (S) using acclimatized digested sludge as inoculums.

Table 2.3.21: One way ANOVA for mean daily methane production from all BMP assysas

\begin{tabular}{|l|r|r|r|r|r|}
\hline & Sum of squares & \multicolumn{1}{c|}{ df } & Mean square & \multicolumn{1}{c|}{ F } & \multicolumn{1}{c|}{ Sig. } \\
\hline Between & 12974.424 & 7 & 1853.489 & 2.156 & $\mathbf{0 . 0 3 7}$ \\
Groups & 340466.804 & 396 & 859.765 & & \\
Within Groups & 353441.229 & 403 & & & \\
Total & & & \\
\hline
\end{tabular}

Table 2.3.22: One way ANOVA for mean daily methane production from two groups of BMP assyas

\begin{tabular}{|l|r|r|r|r|r|}
\hline & Sum of squares & \multicolumn{1}{c|}{ df } & Mean square & \multicolumn{1}{c|}{ F } & \multicolumn{1}{c|}{ Sig. } \\
\hline Between & 10.383 & 1 & 10.383 & .012 & $\mathbf{0 . 9 1 4}$ \\
Groups & 353430.845 & 402 & 879.181 & & \\
Within Groups & 353441.229 & 403 & & & \\
Total & & & \\
\hline
\end{tabular}

Table 2.3.23: Two way ANOVA table for lag time of methane production in two groups of BMP assays and at different salt contents.

\begin{tabular}{|l|r|r|r|r|r|}
\hline \multicolumn{1}{|c|}{ Source } & $\begin{array}{c}\text { Type III sum of } \\
\text { squares }\end{array}$ & df & Mean square & \multicolumn{1}{c|}{ F } & \multicolumn{1}{c|}{ Sig. } \\
\hline Corrected & 158.000 & 4 & 39.500 & 3.485 & 0.167 \\
model & 128.000 & 1 & 128.000 & 11.294 & 0.044 \\
Intercept & 50.000 & 1 & 50.000 & 4.412 & $\mathbf{0 . 1 2 7}$ \\
Group & 108.000 & 3 & 36.000 & 3.176 & $\mathbf{0 . 1 8 4}$ \\
Salt & 34.000 & 3 & 11.333 & & \\
Error & 320.000 & 8 & & & \\
Total & 192.000 & 7 & & & \\
Corrected total & & & & & \\
\hline
\end{tabular}


Table 2.3.24: Multiple comparisons for mean daily methane production from all BMP assays

Multiple Comparisons

Dependent Variable: $\mathrm{CH}_{4}$

Tukey HSD

\begin{tabular}{|c|c|c|c|c|c|c|}
\hline \multirow[b]{2}{*}{ (1) Reactor } & \multirow[b]{2}{*}{ (J) Reactor } & \multirow{2}{*}{$\begin{array}{c}\text { Mean } \\
\text { Difference } \\
(\mid-J)\end{array}$} & \multirow[b]{2}{*}{ Std. Error } & \multirow[b]{2}{*}{ Sig. } & \multicolumn{2}{|c|}{$95 \%$ Confidence Interval } \\
\hline & & & & & Lower Bound & Upper Bound \\
\hline \multirow[t]{7}{*}{ NO\% } & $\mathrm{N} 1 \%$ & 1.99650 & 6.55654 & 1.000 & -17.9827 & 21.9757 \\
\hline & $\mathrm{N} 2 \%$ & 12.24280 & 6.02641 & .462 & -6.1210 & 30.6066 \\
\hline & N3\% & 14.40641 & 5.92800 & .230 & -3.6575 & 32.4703 \\
\hline & $50 \%$ & 1.29405 & 6.51644 & 1.000 & -18.5629 & 21.1510 \\
\hline & $\mathrm{S} 1 \%$ & 2.90125 & 6.55654 & 1.000 & -17.0779 & 22.8804 \\
\hline & $\$ 2 \%$ & 10.21228 & 6.02641 & .691 & -8.1515 & 28.5761 \\
\hline & $\mathrm{S} 3 \%$ & 13.87391 & 5.90999 & .271 & -4.1351 & 31.8829 \\
\hline \multirow[t]{7}{*}{$\mathrm{N} 1 \%$} & No\% & -1.99650 & 6.55654 & 1.000 & -21.9757 & 17.9827 \\
\hline & $\mathrm{N} 2 \%$ & 10.24630 & 6.02641 & .687 & -8.1175 & 28.6101 \\
\hline & $\mathrm{N} 3 \%$ & 12.40991 & 5.92800 & .421 & -5.6540 & 30.4738 \\
\hline & so\% & -.70245 & 6.51644 & 1.000 & -20.5594 & 19.1545 \\
\hline & $\mathrm{S} 1 \%$ & .90475 & 6.55654 & 1.000 & -19.0744 & 20.8839 \\
\hline & $\mathrm{S} 2 \%$ & 8.21578 & 6.02641 & .873 & -10.1480 & 26.5796 \\
\hline & $53 \%$ & 11.87741 & 5.90999 & .477 & -6.1316 & 29.8864 \\
\hline \multirow[t]{7}{*}{$\mathrm{N} 2 \%$} & N0\% & -12.24280 & 6.02641 & .462 & -30.6066 & 6.1210 \\
\hline & $\mathrm{N} 1 \%$ & -10.24630 & 6.02641 & .687 & -28.6101 & 8.1175 \\
\hline & N3\% & 2.16361 & 5.33578 & 1.000 & -14.0957 & 18.4229 \\
\hline & S0\% & -10.94875 & 5.98276 & .600 & -29.1795 & 7.2820 \\
\hline & $\mathbf{S 1 \%}$ & -9.34155 & 6.02641 & .780 & -27.7053 & 9.0222 \\
\hline & $\mathrm{S} 2 \%$ & -2.03052 & 5.44491 & 1.000 & -18.6223 & 14.5613 \\
\hline & S3\% & 1.63110 & 5.31576 & 1.000 & -14.5672 & 17.8294 \\
\hline \multirow[t]{7}{*}{ N3\% } & N0\% & -14.40641 & 5.92800 & .230 & -32.4703 & 3.6575 \\
\hline & N1\% & -12.40991 & 5.92800 & .421 & -30.4738 & 5.6540 \\
\hline & $\mathrm{N} 2 \%$ & -2.16361 & 5.33578 & 1.000 & -18.4229 & 14.0957 \\
\hline & S0\% & -13.11235 & 5.88362 & .337 & -31.0410 & 4.8163 \\
\hline & $\mathrm{s} 1 \%$ & -11.50516 & 5.92800 & .524 & -29.5690 & 6.5587 \\
\hline & S2\% & -4.19412 & 5.33578 & .994 & -20.4534 & 12.0651 \\
\hline & S3\% & -.53250 & 5.20393 & 1.000 & -16.3900 & 15.3250 \\
\hline \multirow[t]{7}{*}{ S0\% } & $\mathrm{N} 0 \%$ & -1.29405 & 6.51644 & 1.000 & -21.1510 & 18.5629 \\
\hline & $\mathrm{N} 1 \%$ & .70245 & 6.51644 & 1.000 & -19.1545 & 20.5594 \\
\hline & $\mathrm{N} 2 \%$ & 10.94875 & 5.98276 & .600 & -7.2820 & 29.1795 \\
\hline & N3\% & 13.11235 & 5.88362 & .337 & -4.8163 & 31.0410 \\
\hline & $\mathbf{S 1 \%}$ & 1.60720 & 6.51644 & 1.000 & -18.2498 & 21.4642 \\
\hline & S2\% & 8.91823 & 5.98276 & .812 & -9.3125 & 27.1490 \\
\hline & $\mathrm{S} 3 \%$ & 12.57985 & 5.86547 & .388 & -5.2935 & 30.4532 \\
\hline \multirow[t]{7}{*}{$\mathbf{S} 1 \%$} & N0\% & -2.90125 & 6.55654 & 1.000 & -22.8804 & 17.0779 \\
\hline & N1\% & -.90475 & 6.55654 & 1.000 & -20.8839 & 19.0744 \\
\hline & $\mathrm{N} 2 \%$ & 9.34155 & 6.02641 & .780 & -9.0222 & 27.7053 \\
\hline & N3\% & 11.50516 & 5.92800 & .524 & -6.5587 & 29.5690 \\
\hline & $\mathrm{S} 0 \%$ & -1.60720 & 6.51644 & 1.000 & -21.4642 & 18.2498 \\
\hline & $\mathrm{S} 2 \%$ & 7.31103 & 6.02641 & .928 & -11.0527 & 25.6748 \\
\hline & S3\% & 10.97266 & 5.90999 & .582 & -7.0363 & 28.9816 \\
\hline \multirow[t]{7}{*}{$\$ 2 \%$} & No\% & -10.21228 & 6.02641 & .691 & -28.5761 & 8.1515 \\
\hline & N1\% & -8.21578 & 6.02641 & .873 & -26.5796 & 10.1480 \\
\hline & N2\% & 2.03052 & 5.44491 & 1.000 & -14.5613 & 18.6223 \\
\hline & N3\% & 4.19412 & 5.33578 & .994 & -12.0651 & 20.4534 \\
\hline & $50 \%$ & -8.91823 & 5.98276 & .812 & -27.1490 & 9.3125 \\
\hline & $\mathrm{S} 1 \%$ & -7.31103 & 6.02641 & .928 & -25.6748 & 11.0527 \\
\hline & $\mathrm{S} 3 \%$ & 3.66162 & 5.31576 & .997 & -12.5366 & 19.8599 \\
\hline \multirow[t]{7}{*}{ S3\% } & NO\% & -13.87391 & 5.90999 & .271 & -31.8829 & 4.1351 \\
\hline & N1\% & -11.87741 & 5.90999 & .477 & -29.8864 & 6.1316 \\
\hline & N2\% & -1.63110 & 5.31576 & 1.000 & -17.8294 & 14.5672 \\
\hline & N3\% & .53250 & 5.20393 & 1.000 & -15.3250 & 16.3900 \\
\hline & S0\% & -12.57985 & 5.86547 & .388 & -30.4532 & 5.2935 \\
\hline & $\mathrm{S} 1 \%$ & -10.97266 & 5.90999 & .582 & -28.9816 & 7.0363 \\
\hline & S2\% & -3.66162 & 5.31576 & .997 & -19.8599 & 12.5366 \\
\hline
\end{tabular}


Table 2.3.25: Two way ANOVA table for time required to reach the peak methane production in two groups and at different salt contents.

\begin{tabular}{|l|r|r|r|r|r|}
\hline \multicolumn{1}{|c|}{ Source } & $\begin{array}{c}\text { Type III sum of } \\
\text { squares }\end{array}$ & df & Mean square & \multicolumn{1}{c|}{ F } & \multicolumn{1}{c|}{ Sig. } \\
\hline Corrected & 1468.500 & 4 & 367.125 & 106.157 & 0.001 \\
model & 8128.125 & 1 & 8128.125 & 2350.301 & 0.000 \\
Intercept & 6.125 & 1 & 6.125 & 1.771 & $\mathbf{0 . 2 7 5}$ \\
Group & 1462.375 & 3 & 487.458 & 140.952 & $\mathbf{0 . 0 0 1}$ \\
Salt & 10.375 & 3 & 3.458 & & \\
Error & 9607.000 & 8 & & & \\
Total & 1478.875 & 7 & & & \\
Corrected total & & & & & \\
\hline
\end{tabular}

Table 2.3.26: Multiple comparisons for mean time required to reach the peak methane production in two groups at different salt contents

\section{Multiple Comparisons}

Dependent Variable: TimePeak

Tukey HSD

\begin{tabular}{|c|c|c|c|c|c|c|}
\hline \multirow[b]{2}{*}{ (l) Salt } & \multirow[b]{2}{*}{ (J) Salt } & \multirow{2}{*}{$\begin{array}{c}\text { Mean } \\
\text { Difference } \\
(1-J)\end{array}$} & \multirow[b]{2}{*}{ Std. Error } & \multirow[b]{2}{*}{ Sig. } & \multicolumn{2}{|c|}{$95 \%$ Confidence Interval } \\
\hline & & & & & Lower Bound & Upper Bound \\
\hline \multirow[t]{3}{*}{.00} & 1.00 & $-9.0000^{*}$ & 1.85966 & .050 & -17.9741 & -.0259 \\
\hline & 2.00 & $-23.0000^{*}$ & 1.85966 & .003 & -31.9741 & -14.0259 \\
\hline & 3.00 & $-35.5000^{*}$ & 1.85966 & .001 & -44.4741 & -26.5259 \\
\hline \multirow[t]{3}{*}{1.00} & .00 & $9.0000^{*}$ & 1.85966 & .050 & .0259 & 17.9741 \\
\hline & 2.00 & $-14.0000^{*}$ & 1.85966 & .015 & -22.9741 & -5.0259 \\
\hline & 3.00 & $-26.5000^{*}$ & 1.85966 & .002 & -35.4741 & -17.5259 \\
\hline \multirow[t]{3}{*}{2.00} & .00 & $23.0000^{*}$ & 1.85966 & .003 & 14.0259 & 31.9741 \\
\hline & 1.00 & $14.0000^{*}$ & 1.85966 & .015 & 5.0259 & 22.9741 \\
\hline & 3.00 & $-12.5000^{*}$ & 1.85966 & .020 & -21.4741 & -3.5259 \\
\hline \multirow[t]{3}{*}{3.00} & .00 & $35.5000^{*}$ & 1.85966 & .001 & 26.5259 & 44.4741 \\
\hline & 1.00 & $26.5000^{*}$ & 1.85966 & .002 & 17.5259 & 35.4741 \\
\hline & 2.00 & $12.5000^{*}$ & 1.85966 & .020 & 3.5259 & 21.4741 \\
\hline
\end{tabular}

Based on observed means.

*. The mean difference is significant at the .05 level. 
Table 2.3.27: Two way ANOVA for mean total methane production in two groups at different salt contents

\begin{tabular}{|l|r|r|r|r|r|}
\hline Source & $\begin{array}{c}\text { Type III Sum } \\
\text { of Squares }\end{array}$ & \multicolumn{1}{c|}{ df } & Mean Square & \multicolumn{1}{c|}{ F } & \multicolumn{1}{c|}{ Sig. } \\
\hline Corrected & 15081.500 & 4 & 3770.375 & 1.481 & .389 \\
Model & 12537528.125 & 1 & 12537528.1 & 4923.5 & .000 \\
Intercept & 1485.125 & 1 & 1485.125 & .583 & $\mathbf{0 . 5 0 1}$ \\
Group & 13596.375 & 3 & 4532.125 & 1.780 & $\mathbf{0 . 3 2 4}$ \\
Salt & 7639.375 & 3 & 2546.458 & & \\
Error & 12560249.000 & 8 & & & \\
Total & 22720.875 & 7 & & & \\
Corrected & & & & \\
Total & & & & & \\
\hline
\end{tabular}

Table 2.3.28: Two way ANOVA table of stabilization time of methane production in two groups and at different salt contents.

\begin{tabular}{|l|r|r|r|r|r|}
\hline Source & $\begin{array}{r}\text { Type III sum of } \\
\text { squares }\end{array}$ & df & Mean square & \multicolumn{1}{c|}{ F } & \multicolumn{1}{c|}{ Sig. } \\
\hline Corrected & 1809.000 & 4 & 452.250 & 193.821 & .001 \\
model & & & & & \\
Intercept & 15842.000 & 1 & 15842.000 & 6789.429 & .000 \\
Group & 8.000 & 1 & 8.000 & 3.429 & $\mathbf{0 . 1 6 1}$ \\
Salt & 1801.000 & 3 & 600.333 & 257.286 & $\mathbf{0 . 0 0 0}$ \\
Error & 7.000 & 3 & 2.333 & & \\
Total & 17658.000 & 8 & & & \\
Corrected total & 1816.000 & 7 & & & \\
\hline
\end{tabular}


Table 2.3.29: Multiple comparisons for stabilization time of methane production in two groups at different salt contents

Multiple Comparisons

Dependent Variable: Stabilization

Tukey HSD

\begin{tabular}{|c|c|c|c|c|c|c|}
\hline \multirow[b]{2}{*}{ (I) Salt } & \multirow[b]{2}{*}{ (J) Salt } & \multirow{2}{*}{$\begin{array}{c}\text { Mean } \\
\text { Difference } \\
(\mathrm{l}-\mathrm{J})\end{array}$} & \multirow[b]{2}{*}{ Std. Error } & \multirow[b]{2}{*}{ Sig. } & \multicolumn{2}{|c|}{$95 \%$ Confidence Interval } \\
\hline & & & & & Lower Bound & Upper Bound \\
\hline \multirow[t]{3}{*}{.00} & 1.00 & $-14.0000^{*}$ & 1.56791 & .009 & -21.5662 & -6.4338 \\
\hline & 2.00 & $-28.0000^{*}$ & 1.56791 & .001 & -35.5662 & -20.4338 \\
\hline & 3.00 & $-40.5000^{*}$ & 1.56791 & .000 & -48.0662 & -32.9338 \\
\hline \multirow[t]{3}{*}{1.00} & .00 & $14.0000^{*}$ & 1.56791 & .009 & 6.4338 & 21.5662 \\
\hline & 2.00 & $-14.0000^{*}$ & 1.56791 & .009 & -21.5662 & -6.4338 \\
\hline & 3.00 & $-26.5000^{*}$ & 1.56791 & .001 & -34.0662 & -18.9338 \\
\hline \multirow[t]{3}{*}{2.00} & .00 & $28.0000^{*}$ & 1.56791 & .001 & 20.4338 & 35.5662 \\
\hline & 1.00 & $14.0000^{*}$ & 1.56791 & .009 & 6.4338 & 21.5662 \\
\hline & 3.00 & $-12.5000^{*}$ & 1.56791 & .012 & -20.0662 & -4.9338 \\
\hline \multirow[t]{3}{*}{3.00} & .00 & $40.5000^{*}$ & 1.56791 & .000 & 32.9338 & 48.0662 \\
\hline & 1.00 & $26.5000^{*}$ & 1.56791 & .001 & 18.9338 & 34.0662 \\
\hline & 2.00 & $12.5000^{*}$ & 1.56791 & .012 & 4.9338 & 20.0662 \\
\hline
\end{tabular}

Based on observed means.

*. The mean difference is significant at the .05 level.

Table 2.3.30: Two way ANOVA table for average methane production in two groups and at different salt contents.

\begin{tabular}{|l|r|r|r|r|r|}
\hline \multicolumn{1}{|c|}{ Source } & \multicolumn{1}{c|}{$\begin{array}{c}\text { Type III sum } \\
\text { of squares }\end{array}$} & \multicolumn{1}{c|}{ df } & Mean suare & \multicolumn{1}{c|}{ F } & \multicolumn{1}{c|}{ Sig. } \\
\hline Corrected & 274.150 & 4 & 68.537 & 74.922 & 0.002 \\
model & 5417.885 & 1 & 5417.885 & 5922.615 & 0.000 \\
Intercept & .221 & 1 & .221 & .242 & $\mathbf{0 . 6 5 7}$ \\
Group & 273.929 & 3 & 91.310 & 99.816 & $\mathbf{0 . 0 0 2}$ \\
Salt & 2.744 & 3 & .915 & & \\
Error & 5694.779 & 8 & & & \\
Total & 276.894 & 7 & & & \\
Corrected total & & & &
\end{tabular}


Table 2.3.31: Multiple comparisons for average methane production in two groups at different salt contents

\section{Multiple Comparisons}

Dependent Variable: Average

Tukey HSD

\begin{tabular}{|c|c|c|c|c|c|c|}
\hline \multirow[b]{2}{*}{ (I) Salt } & \multirow[b]{2}{*}{ (J) Salt } & \multirow{2}{*}{$\begin{array}{c}\text { Mean } \\
\text { Difference } \\
(I-J)\end{array}$} & \multirow[b]{2}{*}{ Std. Error } & \multirow[b]{2}{*}{ Sig. } & \multicolumn{2}{|c|}{$95 \%$ Confidence Interval } \\
\hline & & & & & Lower Bound & Upper Bound \\
\hline \multirow[t]{3}{*}{.00} & 1.00 & 2.1500 & .95644 & .289 & -2.4655 & 6.7655 \\
\hline & 2.00 & $10.9550^{*}$ & .95644 & .004 & 6.3395 & 15.5705 \\
\hline & 3.00 & $14.0000^{*}$ & .95644 & .002 & 9.3845 & 18.6155 \\
\hline \multirow[t]{3}{*}{1.00} & .00 & -2.1500 & .95644 & .289 & -6.7655 & 2.4655 \\
\hline & 2.00 & $8.8050^{*}$ & .95644 & .008 & 4.1895 & 13.4205 \\
\hline & 3.00 & $11.8500^{*}$ & .95644 & .003 & 7.2345 & 16.4655 \\
\hline \multirow[t]{3}{*}{2.00} & .00 & $-10.9550^{*}$ & .95644 & .004 & -15.5705 & -6.3395 \\
\hline & 1.00 & $-8.8050^{*}$ & .95644 & .008 & -13.4205 & -4.1895 \\
\hline & 3.00 & 3.0450 & .95644 & .140 & -1.5705 & 7.6605 \\
\hline \multirow[t]{3}{*}{3.00} & .00 & $-14.0000^{*}$ & .95644 & .002 & -18.6155 & -9.3845 \\
\hline & 1.00 & $-11.8500^{*}$ & .95644 & .003 & -16.4655 & -7.2345 \\
\hline & 2.00 & -3.0450 & .95644 & .140 & -7.6605 & 1.5705 \\
\hline
\end{tabular}

Based on observed means.

*. The mean difference is significant at the .05 level.

\section{Leachate quality}

\subsection{COD}

Table 3.1.1: One way ANOVA table for the mean of COD in all bioreactors

\begin{tabular}{|l|r|r|r|r|r|}
\hline & \multicolumn{1}{|c|}{ Sum of squares } & \multicolumn{1}{c|}{ df } & Mean square & F & Sig. \\
\hline Between & 3541693830 & 7 & 505956261 & 5.543 & $\mathbf{0 . 0 0 0}$ \\
groups & 32496375655 & 356 & 91281954 & & \\
Within groups & 36038069485 & 363 & & & \\
Total & &
\end{tabular}

Table 3.1.2: One way ANOVA table for the mean of COD in two groups

\begin{tabular}{|l|r|r|r|c|c|}
\hline & Sum of squares & df & Mean square & F & Sig. \\
\hline $\begin{array}{l}\text { Between } \\
\text { groups }\end{array}$ & 245244160.885 & 1 & 245244160.8 & 2.480 & $\mathbf{0 . 1 1 6}$ \\
Within groups & 35792825324.266 & 362 & 98875208.07 & & \\
Total & 36038069485.151 & 363 & 8 & & \\
\hline
\end{tabular}


Table 3.1.3: Two way ANOVA table for COD reduction in aerobic stage function of salt content and groups.

\begin{tabular}{|l|r|r|r|r|r|}
\hline Source & \multicolumn{1}{|c|}{$\begin{array}{c}\text { Type III Sum } \\
\text { of squares }\end{array}$} & \multicolumn{1}{c|}{ df } & Mean square & \multicolumn{1}{c|}{ F } & \multicolumn{1}{c|}{ Sig. } \\
\hline Corrected & 1188.925 & 4 & 297.231 & 27.819 & .010 \\
Model & & & & & \\
Intercept & 32133.660 & 1 & 32133.660 & 3007.549 & .000 \\
Salt & 671.792 & 3 & 223.931 & 20.959 & $\mathbf{0 . 0 1 6}$ \\
Group & 517.133 & 1 & 517.133 & 48.401 & $\mathbf{0 . 0 0 6}$ \\
Error & 32.053 & 3 & 10.684 & & \\
Total & 33354.638 & 8 & & & \\
Corrected & 1220.978 & 7 & & & \\
Total & & & & & \\
\hline
\end{tabular}

Table 3.1.4: Two way ANOVA table for COD reduction in anaerobic stage function of salt content and groups.

\begin{tabular}{|l|r|r|r|r|r|}
\hline Source & $\begin{array}{c}\text { Type III Sum } \\
\text { of Squares }\end{array}$ & df & Mean Square & \multicolumn{1}{c|}{ F } & \multicolumn{1}{c|}{ Sig. } \\
\hline Corrected & 49.450 & 4 & 12.363 & 10.370 & 0.042 \\
model & 63724.500 & 1 & 63724.500 & 53455.666 & 0.000 \\
Intercept & 9.159 & 1 & 9.159 & 7.683 & $\mathbf{0 . 0 6 9}$ \\
Group & 40.291 & 3 & 13.430 & 11.266 & $\mathbf{0 . 0 3 9}$ \\
Salt & 3.576 & 3 & 1.192 & & \\
Error & 63777.527 & 8 & & & \\
Total & 53.027 & 7 & & & \\
Corrected total & & & & \\
\hline
\end{tabular}


Table 3.1.5: Multiple comparisons for mean COD concentration in all bioreactors

Multiple Comparisons

Dependent Variable: $C O D$

TukeyHSD

\begin{tabular}{|c|c|c|c|c|c|c|}
\hline \multirow[b]{2}{*}{ (I) Reactors } & \multirow[b]{2}{*}{ (J) Reactors } & \multirow{2}{*}{$\begin{array}{c}\text { Mean } \\
\text { difference } \\
(\mid-J)\end{array}$} & \multirow[b]{2}{*}{ Std. Error } & \multirow[b]{2}{*}{ Sig. } & \multicolumn{2}{|c|}{$95 \%$ Confidence interval } \\
\hline & & & & & Lower bound & Upper bound \\
\hline \multirow{7}{*}{ R1 } & R2 & 1810.84766 & 1970.873 & .984 & -4198.4500 & 7820.1453 \\
\hline & R3 & -1526.7268 & 1970.873 & .994 & -7536.0245 & 4482.5709 \\
\hline & R4 & $-8721.5885^{*}$ & 1970.873 & .000 & -14730.8862 & -2712.2908 \\
\hline & R5 & -3791.7430 & 2004.185 & .557 & -9902.6135 & 2319.1275 \\
\hline & R6 & -4051.7601 & 2004.185 & .469 & -10162.6305 & 2059.1104 \\
\hline & R7 & -1774.2498 & 2004.185 & .987 & -7885.1203 & 4336.6206 \\
\hline & R8 & -5389.8569 & 2004.185 & .129 & -11500.7273 & 721.0136 \\
\hline \multirow[t]{7}{*}{$\mathbf{R} 2$} & R1 & -1810.8477 & 1970.873 & .984 & -7820.1453 & 4198.4500 \\
\hline & R3 & -3337.5745 & 1970.873 & .692 & -9346.8721 & 2671.7232 \\
\hline & R4 & $-10532.436^{*}$ & 1970.873 & .000 & -16541.7338 & -4523.1385 \\
\hline & R5 & -5602.5907 & 2004.185 & .099 & -11713.4611 & 508.2798 \\
\hline & R6 & -5862.6077 & 2004.185 & .071 & -11973.4782 & 248.2628 \\
\hline & $\mathrm{R} 7$ & -3585.0975 & 2004.185 & .628 & -9695.9680 & 2525.7730 \\
\hline & $\mathrm{R} 8$ & $-7200.7045^{\star}$ & 2004.185 & .009 & -13311.5750 & -1089.8341 \\
\hline \multirow[t]{7}{*}{ R3 } & R1 & 1526.72681 & 1970.873 & .994 & -4482.5709 & 7536.0245 \\
\hline & $\mathrm{R} 2$ & 3337.57447 & 1970.873 & .692 & -2671.7232 & 9346.8721 \\
\hline & R4 & $-7194.8617^{\star}$ & 1970.873 & .007 & -13204.1594 & -1185.5640 \\
\hline & R5 & -2265.0162 & 2004.185 & .950 & -8375.8867 & 3845.8543 \\
\hline & R6 & -2525.0332 & 2004.185 & .913 & -8635.9037 & 3585,8372 \\
\hline & $\mathrm{R} 7$ & -247.52302 & 2004.185 & 1.000 & -6358.3935 & 5863.3474 \\
\hline & $\mathrm{R} 8$ & -3863.1301 & 2004.185 & .533 & -9974.0005 & 2247.7404 \\
\hline \multirow[t]{7}{*}{$\overline{\mathrm{R} 4}$} & R1 & $8721.58851^{\star}$ & 1970.873 & .000 & 2712.2908 & 14730.8862 \\
\hline & $\mathrm{R} 2$ & $10532.436^{*}$ & 1970.873 & .000 & 4523.1385 & 16541,7338 \\
\hline & R3 & $7194.86170^{*}$ & 1970.873 & .007 & 1185.5640 & 13204,1594 \\
\hline & R5 & 4929.84550 & 2004.185 & .216 & -1181.0250 & 11040.7160 \\
\hline & R6 & 4669.82846 & 2004.185 & .280 & -1441.0420 & 10780.6989 \\
\hline & $\mathrm{R} 7$ & $6947.33868^{*}$ & 2004.185 & .014 & 836.4682 & 13058.2091 \\
\hline & R8 & 3331.73164 & 2004.185 & .712 & -2779.1388 & 9442.6021 \\
\hline \multirow[t]{7}{*}{ R5 } & R1 & 3791.74301 & 2004.185 & .557 & -2319.1275 & 9902.6135 \\
\hline & R2 & 5602.59067 & 2004.185 & .099 & -508.2798 & 11713.4611 \\
\hline & R3 & 2265.01620 & 2004.185 & .950 & -3845.8543 & 8375.8867 \\
\hline & R4 & -4929.8455 & 2004.185 & .216 & -11040.7160 & 1181.0250 \\
\hline & $\mathrm{R} 6$ & -260.01705 & 2036.954 & 1.000 & -6470.7994 & 5950.7653 \\
\hline & R7 & 2017.49318 & 2036.954 & .976 & -4193.2891 & 8228.2755 \\
\hline & $\mathrm{R} 8$ & -1598.1139 & 2036.954 & .994 & -7808.8962 & 4612.6685 \\
\hline \multirow[t]{7}{*}{ R6 } & R1 & 4051.76005 & 2004.185 & .469 & -2059.1104 & 10162,6305 \\
\hline & $R 2$ & 5862.60771 & 2004.185 & .071 & -248.2628 & 11973.4782 \\
\hline & R3 & 2525.03324 & 2004.185 & .913 & -3585.8372 & 8635.9037 \\
\hline & R4 & -4669.8285 & 2004.185 & .280 & -10780.6989 & 1441.0420 \\
\hline & R5 & 260.01705 & 2036.954 & 1.000 & -5950.7653 & 6470.7994 \\
\hline & $\mathrm{R} 7$ & 2277.51023 & 2036.954 & .953 & -3933.2721 & 8488.2926 \\
\hline & $\mathrm{R} 8$ & -1338.0968 & 2036.954 & .998 & -7548.8791 & 4872.6855 \\
\hline \multirow[t]{7}{*}{ R7 } & R1 & 1774.24983 & 2004.185 & .987 & -4336.6206 & 7885.1203 \\
\hline & $\mathrm{R} 2$ & 3585.09749 & 2004.185 & .628 & -2525.7730 & 9695.9680 \\
\hline & R3 & 247.52302 & 2004.185 & 1.000 & -5863.3474 & 6358.3935 \\
\hline & $\mathrm{R} 4$ & $-6947.3387^{\star}$ & 2004.185 & .014 & -13058.2091 & -836.4682 \\
\hline & R5 & -2017.4932 & 2036.954 & .976 & -8228.2755 & 4193.2891 \\
\hline & R6 & -2277.5102 & 2036.954 & .953 & -8488.2926 & 3933.2721 \\
\hline & R8 & -3615.6070 & 2036.954 & .637 & -9826.3894 & 2595.1753 \\
\hline \multirow[t]{7}{*}{ R8 } & R1 & 5389.85687 & 2004.185 & .129 & -721.0136 & 11500.7273 \\
\hline & $\mathrm{R} 2$ & $7200.70453^{*}$ & 2004.185 & .009 & 1089.8341 & 13311.5750 \\
\hline & R3 & 3863.13006 & 2004.185 & .533 & -2247.7404 & 9974.0005 \\
\hline & R4 & -3331.7316 & 2004.185 & .712 & -9442.6021 & 2779.1388 \\
\hline & R5 & 1598.11386 & 2036.954 & .994 & -4612.6685 & 7808.8962 \\
\hline & $\mathrm{R} 6$ & 1338.09682 & 2036.954 & .998 & -4872.6855 & 7548.8791 \\
\hline & R7 & 3615.60705 & 2036.954 & .637 & -2595.1753 & 9826.3894 \\
\hline
\end{tabular}

*. The mean difference is significant at the .05 level. 
Table 3.1.6: Multiple comparisons for mean COD reduction in aerobic stage at different salt contents

\section{Multiple Comparisons}

Dependent Variable: Aerobic

Tukey HSD

\begin{tabular}{|c|c|c|c|c|c|c|}
\hline \multirow[b]{2}{*}{ (I) Salt } & \multirow[b]{2}{*}{ (J) Salt } & \multirow{2}{*}{$\begin{array}{c}\text { Mean } \\
\text { Difference } \\
(\mathrm{I}-\mathrm{J})\end{array}$} & \multirow[b]{2}{*}{ Std. Error } & \multirow[b]{2}{*}{ Sig. } & \multicolumn{2}{|c|}{$95 \%$ Confidence Interval } \\
\hline & & & & & Lower Bound & Upper Bound \\
\hline \multirow[t]{3}{*}{.00} & .50 & 6.3100 & 3.26869 & .375 & -9.4636 & 22.0836 \\
\hline & 1.00 & 13.7400 & 3.26869 & .072 & -2.0336 & 29.5136 \\
\hline & 3.00 & $24.6200^{*}$ & 3.26869 & .015 & 8.8464 & 40.3936 \\
\hline \multirow[t]{3}{*}{.50} & .00 & -6.3100 & 3.26869 & .375 & -22.0836 & 9.4636 \\
\hline & 1.00 & 7.4300 & 3.26869 & .283 & -8.3436 & 23.2036 \\
\hline & 3.00 & $18.3100^{*}$ & 3.26869 & .033 & 2.5364 & 34.0836 \\
\hline \multirow[t]{3}{*}{1.00} & .00 & -13.7400 & 3.26869 & .072 & -29.5136 & 2.0336 \\
\hline & .50 & -7.4300 & 3.26869 & .283 & -23.2036 & 8.3436 \\
\hline & 3.00 & 10.8800 & 3.26869 & .127 & -4.8936 & 26.6536 \\
\hline \multirow[t]{3}{*}{3.00} & .00 & $-24.6200^{*}$ & 3.26869 & .015 & -40.3936 & -8.8464 \\
\hline & .50 & $-18.3100^{*}$ & 3.26869 & .033 & -34.0836 & -2.5364 \\
\hline & 1.00 & -10.8800 & 3.26869 & .127 & -26.6536 & 4.8936 \\
\hline
\end{tabular}

Based on observed means.

${ }^{*}$. The mean difference is significant at the .05 level.

Table 3.1.7: Multiple comparisons for mean COD reduction in anaerobic stage at different salt contents

Multiple Comparisons

Dependent Variable: Anaerobic

Tukey HSD

\begin{tabular}{|c|c|c|c|c|c|c|}
\hline \multirow[b]{2}{*}{ (I) Salt } & \multirow[b]{2}{*}{ (J) Salt } & \multirow{2}{*}{$\begin{array}{c}\text { Mean } \\
\text { Difference } \\
(\mid-J)\end{array}$} & \multirow[b]{2}{*}{ Std. Error } & \multirow[b]{2}{*}{ Sig. } & \multicolumn{2}{|c|}{ 95\% Confidence Interval } \\
\hline & & & & & Lower Bound & Upper Bound \\
\hline \multirow[t]{3}{*}{.00} & .50 & 1.3800 & 1.09183 & .637 & -3.8888 & 6.6488 \\
\hline & 1.00 & 3.5050 & 1.09183 & .138 & -1.7638 & 8.7738 \\
\hline & 3.00 & $5.9350^{*}$ & 1.09183 & .036 & .6662 & 11.2038 \\
\hline \multirow[t]{3}{*}{.50} & .00 & -1.3800 & 1.09183 & .637 & -6.6488 & 3.8888 \\
\hline & 1.00 & 2.1250 & 1.09183 & .370 & -3.1438 & 7.3938 \\
\hline & 3.00 & 4.5550 & 1.09183 & .073 & -.7138 & 9.8238 \\
\hline \multirow[t]{3}{*}{1.00} & .00 & -3.5050 & 1.09183 & .138 & -8.7738 & 1.7638 \\
\hline & .50 & -2.1250 & 1.09183 & .370 & -7.3938 & 3.1438 \\
\hline & 3.00 & 2.4300 & 1.09183 & .294 & -2.8388 & 7.6988 \\
\hline \multirow[t]{3}{*}{3.00} & .00 & $-5.9350^{*}$ & 1.09183 & .036 & -11.2038 & -.6662 \\
\hline & .50 & -4.5550 & 1.09183 & .073 & -9.8238 & .7138 \\
\hline & 1.00 & -2.4300 & 1.09183 & .294 & -7.6988 & 2.8388 \\
\hline
\end{tabular}

Based on observed means.

*. The mean difference is significant at the .05 level. 


\subsection{BOD}

Table 3.2.1: One way ANOVA table for mean BOD in all bioreactors

\begin{tabular}{|l|l|r|l|l|l|}
\hline & Sum of squares & df & Mean square & F & Sig. \\
\hline $\begin{array}{l}\text { Between } \\
\text { groups }\end{array}$ & 443202311.282 & 7 & 63314615.897 & 2.464 & $\mathbf{0 . 0 1 9}$ \\
$\begin{array}{l}\text { Within Groups } \\
\text { Total }\end{array}$ & 4728617892.74 & 184 & 25699010.287 & & \\
\hline
\end{tabular}

Table 3.2.2: One way ANOVA table for mean BOD in two groups

\begin{tabular}{|l|r|r|r|r|c|}
\hline & Sum of squares & df & Mean square & F & Sig. \\
\hline $\begin{array}{l}\text { Between } \\
\text { groups }\end{array}$ & 3662906.317 & 1 & 3662906.317 & .137 & $\mathbf{0 . 7 1 2}$ \\
$\begin{array}{l}\text { Within groups } \\
\text { Total }\end{array}$ & 5094496420.78 & 190 & 26813139.057 & & \\
\hline
\end{tabular}

Table 3.2.3: Two way ANOVA table for BOD reduction in aerobic stage function of salt content and groups.

\begin{tabular}{|l|r|r|r|r|r|}
\hline Source & $\begin{array}{r}\text { Type III sum of } \\
\text { squares }\end{array}$ & \multicolumn{1}{c|}{ df } & Mean square & \multicolumn{1}{c|}{ F } & \multicolumn{1}{c|}{ Sig. } \\
\hline Corrected & 1561.500 & 4 & 390.375 & 21.149 & .016 \\
model & & & & & \\
Intercept & 36046.125 & 1 & 36046.125 & 1952.837 & .000 \\
Group & 741.125 & 1 & 741.125 & 40.151 & $\mathbf{0 . 0 0 8}$ \\
Salt & 820.375 & 3 & 273.458 & 14.815 & $\mathbf{0 . 0 2 6}$ \\
Error & 55.375 & 3 & 18.458 & & \\
Total & 37663.000 & 8 & & & \\
Corrected total & 1616.875 & 7 & & & \\
\hline
\end{tabular}

Table 3.2.4: Two way ANOVA table for BOD reduction in anaerobic stage function of salt content and groups.

\begin{tabular}{|l|r|r|r|r|r|}
\hline Source & $\begin{array}{r}\text { Type III Sum of } \\
\text { Squares }\end{array}$ & \multicolumn{1}{c|}{ df } & Mean Square & \multicolumn{1}{c|}{ F } & \multicolumn{1}{c|}{ Sig. } \\
\hline Corrected & 106.500 & 4 & 26.625 & 18.257 & .019 \\
Model & & & & & \\
Intercept & 66066.125 & 1 & 66066.125 & 45302.486 & .000 \\
Group & 21.125 & 1 & 21.125 & 14.486 & $\mathbf{0 . 0 3 2}$ \\
Salt & 85.375 & 3 & 28.458 & 19.514 & $\mathbf{0 . 0 1 8}$ \\
Error & 4.375 & 3 & 1.458 & & \\
Total & 66177.000 & 8 & & & \\
Corrected & 110.875 & 7 & & & \\
Total & & & & & \\
\hline
\end{tabular}


Table 3.2.5: Multiple comparisons between the mean of BOD in all bioreactors

\begin{tabular}{|c|c|c|c|c|c|c|}
\hline \multicolumn{7}{|c|}{ Multiple Comparisons } \\
\hline \multicolumn{7}{|c|}{$\begin{array}{l}\text { Dependent Variable: BOD } \\
\text { Tukey HSD }\end{array}$} \\
\hline \multirow{3}{*}{$\frac{\text { (1) Reactors }}{1.00}$} & \multirow[b]{2}{*}{ (J) Reactors } & \multirow{2}{*}{$\begin{array}{c}\text { Mean } \\
\text { Difference } \\
(\mid-J)\end{array}$} & \multirow[b]{2}{*}{ Std. Error } & \multirow[b]{2}{*}{ Sig. } & \multicolumn{2}{|c|}{$95 \%$ Confidence Interval } \\
\hline & & & & & Lower Bound & Upper Bound \\
\hline & 2.00 & 743.63793 & 1433.848 & 1.000 & -3652.7455 & 5140.0214 \\
\hline & 3.00 & -964.88327 & 1433.848 & .998 & -5361.2667 & 3431.5002 \\
\hline & 4.00 & $-4594.9313^{*}$ & 1433.848 & .034 & -8991.3147 & -198.5478 \\
\hline & 5.00 & -1682.9991 & 1464.687 & .945 & -6173.9393 & 2807.9411 \\
\hline & 6.00 & -1673.9947 & 1464.687 & .946 & -6164.9349 & 2816.9454 \\
\hline & 7.00 & -755.33605 & 1464.687 & 1.000 & -5246.2762 & 3735.6041 \\
\hline & 8.00 & -1940.2165 & 1464.687 & .888 & -6431.1566 & 2550.7237 \\
\hline 2.00 & 1.00 & -743.63793 & 1433.848 & 1.000 & -5140.0214 & 3652.7455 \\
\hline & 3.00 & -1708.5212 & 1433.848 & .933 & -6104.9047 & 2687.8623 \\
\hline & 4.00 & $-5338.5692^{\star}$ & 1433.848 & .006 & -9734.9527 & -942.1857 \\
\hline & 5.00 & -2426.6370 & 1464.687 & .715 & -6917.5772 & 2064.3031 \\
\hline & 6.00 & -2417.6327 & 1464.687 & .719 & -6908.5728 & 2073.3075 \\
\hline & 7.00 & -1498.9740 & 1464.687 & .970 & -5989.9141 & 2991.9662 \\
\hline & 8.00 & -2683.8544 & 1464.687 & .599 & -7174.7946 & 1807.0857 \\
\hline 3.00 & 1.00 & 964.88327 & 1433.848 & .998 & -3431.5002 & 5361.2667 \\
\hline & 2.00 & 1708.52120 & 1433.848 & .933 & -2687.8623 & 6104.9047 \\
\hline & 4.00 & -3630.0480 & 1433.848 & .189 & -8026.4315 & 766.3355 \\
\hline & 5.00 & -718.11583 & 1464.687 & 1.000 & -5209.0560 & 3772.8243 \\
\hline & 6.00 & -709.11148 & 1464.687 & 1.000 & -5200.0516 & 3781.8287 \\
\hline & 7.00 & 209.54722 & 1464.687 & 1.000 & -4281.3929 & 4700.4874 \\
\hline & 8.00 & -975.33322 & 1464.687 & .998 & -5466.2734 & 3515.6069 \\
\hline 4.00 & 1.00 & $4594.93127^{*}$ & 1433.848 & .034 & 198.5478 & 8991.3147 \\
\hline & 2.00 & $5338.56920^{*}$ & 1433.848 & .006 & 942.1857 & 9734.9527 \\
\hline & 3.00 & 3630.04800 & 1433.848 & .189 & -766.3355 & 8026.4315 \\
\hline & 5.00 & 2911.93217 & 1464.687 & .493 & -1579.0080 & 7402.8723 \\
\hline & 6.00 & 2920.93652 & 1464.687 & .489 & -1570.0036 & 7411.8767 \\
\hline & 7.00 & 3839.59522 & 1464.687 & .155 & -651.3449 & 8330.5354 \\
\hline & 8.00 & 2654.71478 & 1464.687 & .612 & -1836.2254 & 7145.6549 \\
\hline 5.00 & 1.00 & 1682.99909 & 1464.687 & .945 & -2807.9411 & 6173.9393 \\
\hline & 2.00 & 2426.63703 & 1464.687 & .715 & -2064.3031 & 6917.5772 \\
\hline & 3.00 & 718.11583 & 1464.687 & 1.000 & -3772.8243 & 5209.0560 \\
\hline & 4.00 & -2911.9322 & 1464.687 & .493 & -7402.8723 & 1579.0080 \\
\hline & 6.00 & 9.00435 & 1494.890 & 1.000 & -4574.5423 & 4592.5510 \\
\hline & 7.00 & 927.66304 & 1494.890 & .999 & -3655.8836 & 5511.2097 \\
\hline & 8.00 & -257.21739 & 1494.890 & 1.000 & -4840.7640 & 4326.3292 \\
\hline 6.00 & 1.00 & 1673.99474 & 1464.687 & .946 & -2816.9454 & 6164.9349 \\
\hline & 2.00 & 2417.63268 & 1464.687 & .719 & -2073.3075 & 6908.5728 \\
\hline & 3.00 & 709.11148 & 1464.687 & 1.000 & -3781.8287 & 5200.0516 \\
\hline & 4.00 & -2920.9365 & 1464.687 & .489 & -7411.8767 & 1570.0036 \\
\hline & 5.00 & -9.00435 & 1494.890 & 1.000 & -4592.5510 & 4574.5423 \\
\hline & 7.00 & 918.65870 & 1494.890 & .999 & -3664.8879 & 5502.2053 \\
\hline & 8.00 & -266.22174 & 1494.890 & 1.000 & -4849.7684 & 4317.3249 \\
\hline 7.00 & 1.00 & 755.33605 & 1464.687 & 1.000 & -3735.6041 & 5246.2762 \\
\hline & 2.00 & 1498.97398 & 1464.687 & .970 & -2991.9662 & 5989.9141 \\
\hline & 3.00 & -209.54722 & 1464.687 & 1.000 & -4700.4874 & 4281.3929 \\
\hline & 4.00 & -3839.5952 & 1464.687 & .155 & -8330.5354 & 651.3449 \\
\hline & 5.00 & -927.66304 & 1494.890 & .999 & -5511.2097 & 3655.8836 \\
\hline & 6.00 & -918.65870 & 1494.890 & .999 & -5502.2053 & 3664.8879 \\
\hline & 8.00 & -1184.8804 & 1494.890 & .993 & -5768.4270 & 3398.6662 \\
\hline 8.00 & 1.00 & 1940.21648 & 1464.687 & .888 & -2550.7237 & 6431.1566 \\
\hline & 2.00 & 2683.85442 & 1464.687 & .599 & -1807.0857 & 7174.7946 \\
\hline & 3.00 & 975.33322 & 1464.687 & .998 & -3515.6069 & 5466.2734 \\
\hline & 4.00 & -2654.7148 & 1464.687 & .612 & -7145.6549 & 1836.2254 \\
\hline & 5.00 & 257.21739 & 1494.890 & 1.000 & -4326.3292 & 4840.7640 \\
\hline & 6.00 & 266.22174 & 1494.890 & 1.000 & -4317.3249 & 4849.7684 \\
\hline & 7.00 & 1184.88043 & 1494.890 & .993 & -3398.6662 & 5768.4270 \\
\hline
\end{tabular}

". The mean difference is significant at the .05 level. 
Table 3.2.6: Multiple comparisons of mean BOD percentage reduction in aerobic stage at different salt contents

\section{Multiple Comparisons}

Dependent Variable: Aerobic

Tukey HSD

\begin{tabular}{|c|c|c|c|c|c|c|}
\hline \multirow[b]{2}{*}{ (l) Salt } & \multirow[b]{2}{*}{ (J) Salt } & \multirow{2}{*}{$\begin{array}{c}\text { Mean } \\
\text { Difference } \\
(1-J)\end{array}$} & \multirow[b]{2}{*}{ Std. Error } & \multirow[b]{2}{*}{ Sig. } & \multicolumn{2}{|c|}{$95 \%$ Confidence Interval } \\
\hline & & & & & Lower Bound & Upper Bound \\
\hline \multirow[t]{3}{*}{.00} & .50 & 7.5000 & 4.29632 & .436 & -13.2326 & 28.2326 \\
\hline & 1.00 & 14.5000 & 4.29632 & .123 & -6.2326 & 35.2326 \\
\hline & 3.00 & $27.5000^{*}$ & 4.29632 & .023 & 6.7674 & 48.2326 \\
\hline \multirow[t]{3}{*}{.50} & .00 & -7.5000 & 4.29632 & .436 & -28.2326 & 13.2326 \\
\hline & 1.00 & 7.0000 & 4.29632 & .479 & -13.7326 & 27.7326 \\
\hline & 3.00 & 20.0000 & 4.29632 & .055 & -.7326 & 40.7326 \\
\hline \multirow[t]{3}{*}{1.00} & .00 & -14.5000 & 4.29632 & .123 & -35.2326 & 6.2326 \\
\hline & .50 & -7.0000 & 4.29632 & .479 & -27.7326 & 13.7326 \\
\hline & 3.00 & 13.0000 & 4.29632 & .158 & -7.7326 & 33.7326 \\
\hline \multirow[t]{3}{*}{3.00} & .00 & $-27.5000^{*}$ & 4.29632 & .023 & -48.2326 & -6.7674 \\
\hline & .50 & -20.0000 & 4.29632 & .055 & -40.7326 & .7326 \\
\hline & 1.00 & -13.0000 & 4.29632 & .158 & -33.7326 & 7.7326 \\
\hline
\end{tabular}

Based on observed means.

*. The mean difference is significant at the .05 level.

Table 3.2.7: Multiple comparisons of mean BOD percentage reduction in anaerobic stage at different salt contents

Multiple Comparisons

Dependent Variable: Anaerobic

Tukey HSD

\begin{tabular}{|c|c|c|c|c|c|c|}
\hline \multirow[b]{2}{*}{ (I) Salt } & \multirow[b]{2}{*}{ (J) Salt } & \multirow{2}{*}{$\begin{array}{c}\text { Mean } \\
\text { Difference } \\
(\mathrm{l}-\mathrm{J})\end{array}$} & \multirow[b]{2}{*}{ Std. Error } & \multirow[b]{2}{*}{ Sig. } & \multicolumn{2}{|c|}{ 95\% Confidence Interval } \\
\hline & & & & & Lower Bound & Upper Bound \\
\hline \multirow[t]{3}{*}{.00} & .50 & 1.0000 & 1.20761 & .840 & -4.8275 & 6.8275 \\
\hline & 1.00 & 5.5000 & 1.20761 & .058 & -.3275 & 11.3275 \\
\hline & 3.00 & $8.0000^{*}$ & 1.20761 & .021 & 2.1725 & 13.8275 \\
\hline \multirow[t]{3}{*}{.50} & .00 & -1.0000 & 1.20761 & .840 & -6.8275 & 4.8275 \\
\hline & 1.00 & 4.5000 & 1.20761 & .097 & -1.3275 & 10.3275 \\
\hline & 3.00 & $7.0000^{*}$ & 1.20761 & .030 & 1.1725 & 12.8275 \\
\hline \multirow[t]{3}{*}{1.00} & .00 & -5.5000 & 1.20761 & .058 & -11.3275 & .3275 \\
\hline & .50 & -4.5000 & 1.20761 & .097 & -10.3275 & 1.3275 \\
\hline & 3.00 & 2.5000 & 1.20761 & .334 & -3.3275 & 8.3275 \\
\hline \multirow[t]{3}{*}{3.00} & .00 & $-8.0000^{*}$ & 1.20761 & .021 & -13.8275 & -2.1725 \\
\hline & .50 & $-7.0000^{\star}$ & 1.20761 & .030 & -12.8275 & -1.1725 \\
\hline & 1.00 & -2.5000 & 1.20761 & .334 & -8.3275 & 3.3275 \\
\hline
\end{tabular}

Based on observed means.

*. The mean difference is significant at the .05 level. 


\subsection{VFA}

Table 3.3.1: One way ANOVA table for the mean of VFA in all bioreactors

\begin{tabular}{|l|r|r|r|r|r|}
\hline & \multicolumn{1}{|c|}{ Sum of squares } & \multicolumn{1}{c|}{ df } & Mean square & F & \multicolumn{1}{c|}{ Sig. } \\
\hline Between & 603247849.933 & 7 & 86178264.276 & 5.061 & $\mathbf{0 . 0 0 0}$ \\
groups & 5244251311.188 & 308 & 17026789.971 & & \\
Within groups & 5847499161.121 & 315 & & & \\
Total & & & & \\
\hline
\end{tabular}

Table 3.3.2: One way ANOVA table for mean of VFA in two groups

\begin{tabular}{|l|r|r|r|r|r|}
\hline & Sum of squares & df & Mean square & F & Sig. \\
\hline Between & 54917442.638 & 1 & 54917442.638 & 2.977 & $\mathbf{0 . 0 8 5}$ \\
groups & 5792581718.483 & 314 & 18447712.479 & & \\
Within groups & 5847499161.121 & 315 & & & \\
Total & & & \\
\hline
\end{tabular}

Table 3.3.3: Two way ANOVA table for VFA reduction in aerobic stage function of salt content and groups.

\begin{tabular}{|l|r|r|r|r|r|}
\hline Source & $\begin{array}{c}\text { Type III sum of } \\
\text { squares }\end{array}$ & df & Mean square & \multicolumn{1}{c|}{ F } & \multicolumn{1}{c|}{ Sig. } \\
\hline Corrected & 1205.000 & 4 & 301.250 & 44.085 & .005 \\
model & 32512.500 & 1 & 32512.500 & 4757.927 & .000 \\
Intercept & 760.500 & 1 & 760.500 & 111.293 & $\mathbf{0 . 0 0 2}$ \\
Group & 444.500 & 3 & 148.167 & 21.683 & $\mathbf{0 . 0 1 6}$ \\
Salt & 20.500 & 3 & 6.833 & & \\
Error & 33738.000 & 8 & & & \\
Total & 1225.500 & 7 & & & \\
Corrected total & & & & \\
\hline
\end{tabular}


Table 3.3.4: Multiple comparisons between the mean of VFA concentration in all bioreactors

\begin{tabular}{|c|c|c|c|c|c|c|}
\hline \multicolumn{7}{|c|}{ Multiple Comparisons } \\
\hline \multicolumn{7}{|c|}{$\begin{array}{l}\text { Dependent Variable: VFA } \\
\text { Tukey HSD }\end{array}$} \\
\hline \multirow[b]{2}{*}{ (I) Reactors } & \multirow[b]{2}{*}{ (J) Reactors } & \multirow{2}{*}{$\begin{array}{c}\text { Mean } \\
\text { Difference } \\
(\mid-J)\end{array}$} & \multirow[b]{2}{*}{ Std. Error } & \multirow[b]{2}{*}{ Sig. } & \multicolumn{2}{|c|}{$95 \%$ Confidence Interval } \\
\hline & & & & & Lower Bound & Upper Bound \\
\hline \multirow[t]{7}{*}{ R1 } & $\mathbf{R} 2$ & 654.47262 & 911.35894 & .996 & -2126.9008 & 3435.8461 \\
\hline & R3 & -488.97652 & 911.35894 & .999 & -3270.3500 & 2292.3969 \\
\hline & $\mathbf{R 4}$ & $-3794.1081^{\star}$ & 911.35894 & .001 & -6575.4816 & -1012.7346 \\
\hline & R5 & -1731.1574 & 929.17220 & .577 & -4566.8951 & 1104.5803 \\
\hline & $\mathbf{R} 6$ & -1377.0071 & 929.17220 & .817 & -4212.7448 & 1458.7305 \\
\hline & $\mathbf{R 7}$ & -1055.3820 & 929.17220 & .948 & -3891.1197 & 1780.3557 \\
\hline & $\mathrm{R} 8$ & -2802.5170 & 929.17220 & .055 & -5638.2547 & 33.2207 \\
\hline \multirow[t]{7}{*}{$\overline{R 2}$} & R1 & -654.47262 & 911.35894 & .996 & -3435.8461 & 2126.9008 \\
\hline & R3 & $-\$ 143.4491$ & 911.35894 & .914 & -3924.8226 & 1637.9243 \\
\hline & R4 & $-4448.5807^{*}$ & 911.35894 & .000 & -7229.9542 & -1667.2073 \\
\hline & R5 & -2385.6300 & 929.17220 & .172 & -5221.3677 & 450.1077 \\
\hline & $\mathbf{R 6}$ & -2031.4798 & 929.17220 & .363 & -4867.2174 & 804.2579 \\
\hline & R7 & -1709.8546 & 929.17220 & .593 & -4545.5923 & 1125.8831 \\
\hline & $\mathrm{R} 8$ & $-3456.9896^{*}$ & 929.17220 & .006 & -6292.7273 & -621.2519 \\
\hline \multirow[t]{7}{*}{$\mathbf{R 3}$} & R1 & 488.97652 & 911.35894 & .999 & -2292.3969 & 3270.3500 \\
\hline & R2 & 1143.44913 & 911.35894 & .914 & -1637.9243 & 3924.8226 \\
\hline & R4 & $-3305.1316^{*}$ & 911.35894 & .008 & -6086.5050 & -523.7581 \\
\hline & R5 & -1242.1809 & 929.17220 & .884 & -4077.9185 & 1593.5568 \\
\hline & R6 & -888.03062 & 929.17220 & .980 & -3723.7683 & 1947.7071 \\
\hline & $\mathrm{R} 7$ & -566.40549 & 929.17220 & .999 & -3402.1432 & 2269.3322 \\
\hline & R8 & -2313.5405 & 929.17220 & .204 & -5149.2782 & 522.1972 \\
\hline \multirow[t]{7}{*}{ R4 } & R1 & $3794.10810^{*}$ & 911.35894 & .001 & 1012.7346 & 6575.4816 \\
\hline & $\mathrm{R} 2$ & $4448.58072^{*}$ & 911.35894 & .000 & 1667.2073 & 7229.9542 \\
\hline & R3 & $3305.13159^{*}$ & 911.35894 & .008 & 523.7581 & 6086.5050 \\
\hline & R5 & 2062.95073 & 929.17220 & .343 & -772.7870 & 4898.6884 \\
\hline & R6 & 2417.10096 & 929.17220 & .159 & -418.6367 & 5252.8387 \\
\hline & R7 & 2738.72609 & 929.17220 & .067 & -97.0116 & 5574.4638 \\
\hline & R8 & 991.59109 & 929.17220 & .963 & -1844.1466 & 3827.3288 \\
\hline \multirow[t]{7}{*}{ R5 } & R1 & 1731.15738 & 929.17220 & .577 & -1104.5803 & 4566.8951 \\
\hline & R2 & 2385.62999 & 929.17220 & .172 & -450.1077 & 5221.3677 \\
\hline & R3 & 1242.18086 & 929.17220 & .884 & -1593.5568 & 4077.9185 \\
\hline & R4 & -2062.9507 & 929.17220 & .343 & -4898.6884 & 772.7870 \\
\hline & R6 & 354.15024 & 946.65033 & 1.000 & -2534.9289 & 3243.2294 \\
\hline & R7 & 675.77537 & 946.65033 & .997 & -2213.3038 & 3564.8545 \\
\hline & $\mathrm{R} 8$ & -1071.3596 & 946.65033 & .949 & -3960.4388 & 1817.7195 \\
\hline \multirow[t]{7}{*}{$\overline{R 6}$} & R1 & 1377.00714 & 929.17220 & .817 & -1458.7305 & 4212.7448 \\
\hline & $\mathrm{R} 2$ & 2031.47976 & 929.17220 & .363 & -804.2579 & 4867.2174 \\
\hline & R3 & 888.03062 & 929.17220 & .980 & -1947.7071 & 3723.7683 \\
\hline & R4 & -2417.1010 & 929.17220 & .159 & -5252.8387 & 418.6367 \\
\hline & R5 & -354.15024 & 946.65033 & 1.000 & -3243.2294 & 2534.9289 \\
\hline & R7 & 321.62513 & 946.65033 & 1.000 & -2567.4540 & 3210.7043 \\
\hline & $\mathrm{R} 8$ & -1425.5099 & 946.65033 & .804 & -4314.5890 & 1463.5693 \\
\hline \multirow[t]{7}{*}{ R7 } & R1 & 1055.38201 & 929.17220 & .948 & -1780.3557 & 3891.1197 \\
\hline & $\mathrm{R} 2$ & 1709.85462 & 929.17220 & .593 & -1125.8831 & 4545.5923 \\
\hline & $\mathrm{R} 3$ & 566.40549 & 929.17220 & .999 & -2269.3322 & 3402.1432 \\
\hline & R4 & -2738.7261 & 929.17220 & .067 & -5574.4638 & 97.0116 \\
\hline & R5 & -675.77537 & 946.65033 & .997 & -3564.8545 & 2213.3038 \\
\hline & $\mathrm{R} 6$ & -321.62513 & 946.65033 & 1.000 & -3210.7043 & 2567.4540 \\
\hline & $R 8$ & -1747.1350 & 946.65033 & .589 & -4636.2141 & 1141.9441 \\
\hline \multirow[t]{7}{*}{ R8 } & R1 & 2802.51701 & 929.17220 & .055 & -33.2207 & 5638.2547 \\
\hline & $\mathbf{R} 2$ & $3456.98962^{*}$ & 929.17220 & .006 & 621.2519 & 6292.7273 \\
\hline & R3 & 2313.54049 & 929.17220 & .204 & -522.1972 & 5149.2782 \\
\hline & R4 & -991.59109 & 929.17220 & .963 & -3827.3288 & 1844.1466 \\
\hline & R5 & 1071.35963 & 946.65033 & .949 & -1817.7195 & 3960.4388 \\
\hline & $\mathrm{R} 6$ & 1425.50987 & 946.65033 & .804 & -1463.5693 & 4314.5890 \\
\hline & $\mathrm{R} 7$ & 1747.13500 & 946.65033 & .589 & -1141.9441 & 4636.2141 \\
\hline
\end{tabular}

*. The mean difference is significant at the .05 level. 
Table 3.3.5: Multiple comparisons for mean VFA reduction in aerobic stage at different salt contents

\section{Multiple Comparisons}

Dependent Variable: Aerobic

Tukey HSD

\begin{tabular}{|c|c|c|c|c|c|c|}
\hline \multirow[b]{2}{*}{ (I) Salt } & \multirow[b]{2}{*}{ (J) Salt } & \multirow{2}{*}{$\begin{array}{c}\text { Mean } \\
\text { Difference } \\
(\mathrm{I}-\mathrm{J})\end{array}$} & \multirow[b]{2}{*}{ Std. Error } & \multirow[b]{2}{*}{ Sig. } & \multicolumn{2}{|c|}{$95 \%$ Confidence Interval } \\
\hline & & & & & Lower Bound & Upper Bound \\
\hline \multirow[t]{3}{*}{0} & 0.5 & 4.0000 & 2.61406 & .519 & -8.6146 & 16.6146 \\
\hline & 1 & 11.5000 & 2.61406 & .064 & -1.1146 & 24.1146 \\
\hline & 3 & $19.5000^{*}$ & 2.61406 & .015 & 6.8854 & 32.1146 \\
\hline \multirow[t]{3}{*}{0.5} & 0 & -4.0000 & 2.61406 & .519 & -16.6146 & 8.6146 \\
\hline & 1 & 7.5000 & 2.61406 & .177 & -5.1146 & 20.1146 \\
\hline & 3 & $15.5000^{*}$ & 2.61406 & .029 & 2.8854 & 28.1146 \\
\hline \multirow[t]{3}{*}{1} & 0 & -11.5000 & 2.61406 & .064 & -24.1146 & 1.1146 \\
\hline & 0.5 & -7.5000 & 2.61406 & .177 & -20.1146 & 5.1146 \\
\hline & 3 & 8.0000 & 2.61406 & .154 & -4.6146 & 20.6146 \\
\hline \multirow[t]{3}{*}{3} & 0 & $-19.5000^{*}$ & 2.61406 & .015 & -32.1146 & -6.8854 \\
\hline & 0.5 & $-15.5000^{*}$ & 2.61406 & .029 & -28.1146 & -2.8854 \\
\hline & 1 & -8.0000 & 2.61406 & .154 & -20.6146 & 4.6146 \\
\hline
\end{tabular}

Based on observed means.

*. The mean difference is significant at the .05 level.

Table 3.3.6: Two way ANOVA table for mean VFA reduction in anaerobic stage function of salt content and groups.

\begin{tabular}{|l|r|r|r|r|r|}
\hline Source & $\begin{array}{c}\text { Type III sum of } \\
\text { Squares }\end{array}$ & df & Mean square & \multicolumn{1}{c|}{ F } & \multicolumn{1}{c|}{ Sig. } \\
\hline Corrected & 55.457 & 4 & 13.864 & 6.751 & 0.074 \\
model & 75237.084 & 1 & 75237.084 & 36637.57 & 0.000 \\
Intercept & 15.180 & 1 & 15.180 & 7.392 & $\mathbf{0 . 0 7 3}$ \\
Group & 40.277 & 3 & 13.426 & 6.538 & $\mathbf{0 . 0 7 9}$ \\
Salt & 6.161 & 3 & 2.054 & & \\
Error & 75298.702 & 8 & & & \\
Total & 61.618 & 7 & & & \\
Corrected total & & & & \\
\hline
\end{tabular}




\section{4. $\mathrm{pH}$}

Table 3.4.1: One way ANOVA table for mean of $\mathrm{pH}$ values in all bioreactors

\begin{tabular}{|l|r|r|r|r|r|}
\hline & Sum of squares & df & Mean square & F & \multicolumn{1}{c|}{ Sig. } \\
\hline Between & 2.056 & 7 & .294 & 1.357 & $\mathbf{0 . 2 2 3}$ \\
groups & 64.949 & 300 & .216 & & \\
Within groups & 67.005 & 307 & & & \\
Total & & & \\
\hline
\end{tabular}

Table 3.4.2: One way ANOVA table for mean of $\mathrm{pH}$ values in two groups

\begin{tabular}{|l|r|r|r|r|r|}
\hline & Sum of squares & \multicolumn{1}{c|}{ df } & Mean square & F & \multicolumn{1}{c|}{ Sig. } \\
\hline Between & .183 & 1 & .183 & .837 & $\mathbf{0 . 3 6 1}$ \\
groups & 66.822 & 306 & .218 & & \\
Within groups & 67.005 & 307 & & & \\
Total & & & \\
\hline
\end{tabular}

\subsection{TVS}

Table 3.5.1: One way ANOVA table for the mean of TVS concentration in all bioreactors

\begin{tabular}{|l|r|r|r|r|r|}
\hline & Sum of squares & df & Mean square & F & \multicolumn{1}{l|}{ Sig. } \\
\hline Between & 567754846.6 & 7 & 81107835.2 & 5.330 & $\mathbf{0 . 0 0 0}$ \\
Groups & 4443580388.1 & 292 & 15217741.05 & & \\
Within Groups & 5011335234.7 & 299 & & & \\
Total & & & \\
\hline
\end{tabular}

Table 3.5.2: One way ANOVA table for mean of TVS concentration in two groups

\begin{tabular}{|l|r|r|r|r|r|}
\hline & Sum of squares & df & Mean square & F & \multicolumn{1}{l|}{ Sig. } \\
\hline Between & 88465907.234 & 1 & 88465907.23 & 5.355 & $\mathbf{0 . 0 2 1}$ \\
groups & 4922869327.5 & 298 & 16519695.73 & & \\
Within groups & 5011335234.7 & 299 & & & \\
Total & & & \\
\hline
\end{tabular}


Table 3.5.3: Two way ANOVA table for mean TVS reduction in aerobic stage function of salt content and groups.

\begin{tabular}{|l|r|r|r|r|r|}
\hline Source & $\begin{array}{c}\text { Type III sum of } \\
\text { squares }\end{array}$ & \multicolumn{1}{c|}{ df } & Mean square & \multicolumn{1}{c|}{ F } & \multicolumn{1}{c|}{ Sig. } \\
\hline Corrected & 1092.461 & 4 & 273.115 & 34.030 & .008 \\
model & & & & & \\
Intercept & 30159.236 & 1 & 30159.236 & 3757.832 & .000 \\
Group & 770.134 & 1 & 770.134 & 95.958 & $\mathbf{0 . 0 0 2}$ \\
Salt & 322.328 & 3 & 107.443 & 13.387 & $\mathbf{0 . 0 3 0}$ \\
Error & 24.077 & 3 & 8.026 & & \\
Total & 31275.775 & 8 & & & \\
Corrected total & 1116.539 & 7 & & & \\
\hline
\end{tabular}

Table 3.5.4: Two way ANOVA table for TVS reduction in anaerobic stage function of salt content and groups.

\begin{tabular}{|l|r|r|r|r|r|}
\hline Source & $\begin{array}{c}\text { Type III Sum } \\
\text { of Squares }\end{array}$ & \multicolumn{1}{c|}{ df } & Mean Square & \multicolumn{1}{c|}{ F } & \multicolumn{1}{c|}{ Sig. } \\
\hline Corrected & 283.452 & 4 & 70.863 & 35.342 & .007 \\
Model & & & & & \\
Intercept & 47290.264 & 1 & 47290.264 & 23585.46 & .000 \\
& 11.607 & 1 & 11.607 & 5.789 & $\mathbf{0 . 0 9 5}$ \\
Group & 271.846 & 3 & 90.615 & 45.193 & $\mathbf{0 . 0 0 5}$ \\
Salt & 6.015 & 3 & 2.005 & & \\
Error & 47579.731 & 8 & & & \\
Total & 289.467 & 7 & & & \\
Corrected & & & & & \\
Total & & & & & \\
\hline
\end{tabular}


Table 3.5.5: Multiple comparisons for mean TVS concentration in all bioreactors.

Multiple Comparisons

Dependent Variable: TVS

\begin{tabular}{|c|c|c|c|c|c|c|}
\hline \multirow[b]{2}{*}{ (I) Reactors } & \multirow[b]{2}{*}{ (J) Reactors } & \multirow{2}{*}{$\begin{array}{c}\text { Mean } \\
\text { Difference } \\
(\mathrm{I}-\mathrm{J})\end{array}$} & \multirow[b]{2}{*}{ Std. Error } & \multirow[b]{2}{*}{ Sig. } & \multicolumn{2}{|c|}{$95 \%$ Confidence Interval } \\
\hline & & & & & Lower Bound & Upper Bound \\
\hline \multirow[t]{7}{*}{ R1 } & R2 & 1033.45714 & 932.51552 & .955 & -1813.5619 & 3880.4762 \\
\hline & R3 & -251.91429 & 932.51552 & 1.000 & -3098.9333 & 2595.1047 \\
\hline & R4 & $-3216.5600^{*}$ & 932.51552 & .015 & -6063.5790 & -369.5410 \\
\hline & R5 & -2384.7571 & 902.90427 & .146 & -5141.3715 & 371.8572 \\
\hline & R6 & -2026.2071 & 902.90427 & .329 & -4782.8215 & 730.4072 \\
\hline & $\mathrm{R} 7$ & -154.90714 & 902.90427 & 1.000 & -2911.5215 & 2601.7072 \\
\hline & $\mathrm{R} 8$ & -2223.1071 & 902.90427 & .216 & -4979.7215 & 533.5072 \\
\hline \multirow[t]{7}{*}{ R2 } & R1 & -1033.4571 & 932.51552 & .955 & -3880.4762 & 1813.5619 \\
\hline & R3 & -1285.3714 & 932.51552 & .867 & -4132.3904 & 1561.6476 \\
\hline & R4 & $-4250.0171^{*}$ & 932.51552 & .000 & -7097.0362 & -1402.9981 \\
\hline & R5 & $-3418.2143^{*}$ & 902.90427 & .005 & -6174.8286 & -661.6000 \\
\hline & R6 & $-3059.6643^{*}$ & 902.90427 & .018 & -5816.2786 & -303.0500 \\
\hline & R7 & -1188.3643 & 902.90427 & .892 & -3944.9786 & 1568.2500 \\
\hline & $\mathbf{R} 8$ & $-3256.5643^{*}$ & 902.90427 & .009 & -6013.1786 & -499.9500 \\
\hline \multirow[t]{7}{*}{ R3 } & R1 & 251.91429 & 932.51552 & 1.000 & -2595.1047 & 3098.9333 \\
\hline & $\mathrm{R} 2$ & 1285.37443 & 932.51552 & .867 & -1561.6476 & 4132.3904 \\
\hline & R4 & $-2964.6457^{*}$ & 932.51552 & .035 & -5811.6647 & -117.6267 \\
\hline & R5 & -2132.8429 & 902.90427 & .264 & -4889.4572 & 623.7715 \\
\hline & R6 & -1774.2929 & 902.90427 & .507 & -4530.9072 & 982.3215 \\
\hline & $\mathrm{R} 7$ & 97.00714 & 902.90427 & 1.000 & -2659.6072 & 2853.6215 \\
\hline & $\mathrm{R} 8$ & -1971.1929 & 902.90427 & .365 & -4727.8072 & 785.4215 \\
\hline \multirow[t]{7}{*}{ R4 } & R1 & $3216.56000^{*}$ & 932.51552 & .015 & 369.5410 & 6063.5790 \\
\hline & $\mathrm{R} 2$ & $4250.01714^{*}$ & 932.51552 & .000 & 1402.9981 & 7097.0362 \\
\hline & R3 & $2964.64571^{*}$ & 932.51552 & .035 & 117.6267 & 5811.6647 \\
\hline & R5 & 831.80286 & 902.90427 & .984 & -1924.8115 & 3588.4172 \\
\hline & R6 & 1190.35286 & 902.90427 & .891 & -1566.2615 & 3946.9672 \\
\hline & R7 & $3061.65286^{*}$ & 902.90427 & .018 & 305.0385 & 5818.2672 \\
\hline & $\mathbf{R 8}$ & 993.45286 & 902.90427 & .956 & -1763.1615 & 3750.0672 \\
\hline \multirow[t]{7}{*}{ R5 } & $\mathrm{R} 1$ & 2384.75714 & 902.90427 & .146 & -371.8572 & 5141.3715 \\
\hline & R2 & $3418.21429^{*}$ & 902.90427 & .005 & 661.6000 & 6174.8286 \\
\hline & R3 & 2132.84286 & 902.90427 & .264 & -623.7715 & 4889.4572 \\
\hline & R4 & -831.80286 & 902.90427 & .984 & -3588.4172 & 1924.8115 \\
\hline & R6 & 358.55000 & 872.28840 & 1.000 & -2304.5924 & 3021.6924 \\
\hline & $\mathrm{R} 7$ & 2229.85000 & 872.28840 & .177 & -433.2924 & 4892.9924 \\
\hline & $R 8$ & 161.65000 & 872.28840 & 1.000 & -2501.4924 & 2824.7924 \\
\hline \multirow[t]{7}{*}{$\mathrm{R} 6$} & $\mathbf{R 1}$ & 2026.20714 & 902.90427 & .329 & -730.4072 & 4782.8215 \\
\hline & $\mathrm{R} 2$ & $3059.66429^{*}$ & 902.90427 & .018 & 303.0500 & 5816.2786 \\
\hline & R3 & 1774.29286 & 902.90427 & .507 & -982.3215 & 4530.9072 \\
\hline & R4 & -1190.3529 & 902.90427 & .891 & -3946.9672 & 1566.2615 \\
\hline & R5 & -358.55000 & 872.28840 & 1.000 & -3021.6924 & 2304.5924 \\
\hline & $\mathbf{R} 7$ & 1871.30000 & 872.28840 & .388 & -791.8424 & 4534.4424 \\
\hline & $\mathrm{R} 8$ & -196.90000 & 872.28840 & 1.000 & -2860.0424 & 2466.2424 \\
\hline \multirow[t]{7}{*}{$\mathbf{R 7}$} & R1 & 154.90714 & 902.90427 & 1.000 & -2601.7072 & 2911.5215 \\
\hline & R2 & 1188.36429 & 902.90427 & .892 & -1568.2500 & 3944.9786 \\
\hline & R3 & -97.00714 & 902.90427 & 1.000 & -2853.6215 & 2659.6072 \\
\hline & R4 & $-3061.6529^{*}$ & 902.90427 & .018 & -5818.2672 & -305.0385 \\
\hline & R5 & -2229.8500 & 872.28840 & .177 & -4892.9924 & 433.2924 \\
\hline & R6 & -1871.3000 & 872.28840 & .388 & -4534.4424 & 791.8424 \\
\hline & Ro & -2068.2000 & 872.28840 & .260 & -4731.3424 & 594.9424 \\
\hline \multirow[t]{7}{*}{ R8 } & $\mathrm{R} 1$ & 2223.10714 & 902.90427 & .216 & -533.5072 & 4979.7215 \\
\hline & $\mathrm{R} 2$ & $3256.56429^{*}$ & 902.90427 & .009 & 499.9500 & 6013.1786 \\
\hline & R3 & 1971.19286 & 902.90427 & .365 & -785.4215 & 4727.8072 \\
\hline & R4 & -993.45286 & 902.90427 & .956 & -3750.0672 & 1763.1615 \\
\hline & R5 & -161.65000 & 872.28840 & 1.000 & -2824.7924 & 2501.4924 \\
\hline & R6 & 196.90000 & 872.28840 & 1.000 & -2466.2424 & 2860.0424 \\
\hline & $R 7$ & 2068.20000 & 872.28840 & .260 & -594.9424 & 4731.3424 \\
\hline
\end{tabular}

*. The mean difference is significant at the .05 level. 
Table 3.5.6: Multiple comparisons for mean TVS percentage reduction in aerobic stage at different salt contents

\section{Multiple Comparisons}

Dependent Variable: Aerobic

Tukey HSD

\begin{tabular}{|c|c|c|c|c|c|c|}
\hline \multirow[b]{2}{*}{ (1) Salt } & \multirow[b]{2}{*}{ (J) Salt } & \multirow{2}{*}{$\begin{array}{c}\text { Mean } \\
\text { Difference } \\
(\mathrm{I}-\mathrm{J})\end{array}$} & \multirow[b]{2}{*}{ Std. Error } & \multirow[b]{2}{*}{ Sig. } & \multicolumn{2}{|c|}{$95 \%$ Confidence Interval } \\
\hline & & & & & Lower Bound & Upper Bound \\
\hline \multirow[t]{3}{*}{.00} & .50 & 7.5714 & 2.83297 & .206 & -6.0995 & 21.2424 \\
\hline & 1.00 & 11.6895 & 2.83297 & .075 & -1.9815 & 25.3604 \\
\hline & 3.00 & $17.4266^{*}$ & 2.83297 & .026 & 3.7557 & 31.0976 \\
\hline \multirow[t]{3}{*}{.50} & .00 & -7.5714 & 2.83297 & .206 & -21.2424 & 6.0995 \\
\hline & 1.00 & 4.1180 & 2.83297 & .551 & -9.5529 & 17.7890 \\
\hline & 3.00 & 9.8552 & 2.83297 & .114 & -3.8158 & 23.5261 \\
\hline \multirow[t]{3}{*}{1.00} & .00 & -11.6895 & 2.83297 & .075 & -25.3604 & 1.9815 \\
\hline & .50 & -4.1180 & 2.83297 & .551 & -17.7890 & 9.5529 \\
\hline & 3.00 & 5.7371 & 2.83297 & .346 & -7.9338 & 19.4081 \\
\hline \multirow[t]{3}{*}{3.00} & .00 & $-17.4266^{*}$ & 2.83297 & .026 & -31.0976 & -3.7557 \\
\hline & .50 & -9.8552 & 2.83297 & .114 & -23.5261 & 3.8158 \\
\hline & 1.00 & -5.7371 & 2.83297 & .346 & -19.4081 & 7.9338 \\
\hline
\end{tabular}

Based on observed means.

*. The mean difference is significant at the .05 level.

Table 3.5.7: Multiple comparisons for mean TVS percentage reduction in anaerobic stage at different salt contents

\section{Multiple Comparisons}

Dependent Variable: Anaerobic

Tukey HSD

\begin{tabular}{|c|c|c|c|c|c|c|}
\hline \multirow[b]{2}{*}{ (I) Salt } & \multirow[b]{2}{*}{ (J) Salt } & \multirow{2}{*}{$\begin{array}{c}\text { Mean } \\
\text { Difference } \\
(l-J)\end{array}$} & \multirow[b]{2}{*}{ Std. Error } & \multirow[b]{2}{*}{ Sig. } & \multicolumn{2}{|c|}{$95 \%$ Confidence Interval } \\
\hline & & & & & Lower Bound & Upper Bound \\
\hline \multirow[t]{3}{*}{.00} & .50 & 3.7447 & 1.41600 & .210 & -3.0884 & 10.5779 \\
\hline & 1.00 & $8.1047^{\star}$ & 1.41600 & .032 & 1.2715 & 14.9378 \\
\hline & 3.00 & $15.6697^{*}$ & 1.41600 & .005 & 8.8365 & 22.5028 \\
\hline \multirow[t]{3}{*}{.50} & .00 & -3.7447 & 1.41600 & .210 & -10.5779 & 3.0884 \\
\hline & 1.00 & 4.3600 & 1.41600 & .152 & -2.4732 & 11.1931 \\
\hline & 3.00 & $11.9250^{*}$ & 1.41600 & .011 & 5.0918 & 18.7581 \\
\hline \multirow[t]{3}{*}{1.00} & .00 & $-8.1047^{*}$ & 1.41600 & .032 & -14.9378 & -1.2715 \\
\hline & .50 & -4.3600 & 1.41600 & .152 & -11.1931 & 2.4732 \\
\hline & 3.00 & $7.5650^{*}$ & 1.41600 & .038 & .7318 & 14.3981 \\
\hline \multirow[t]{3}{*}{3.00} & .00 & $-15.6697^{*}$ & 1.41600 & .005 & -22.5028 & -8.8365 \\
\hline & .50 & $-11.9250^{*}$ & 1.41600 & .011 & -18.7581 & -5.0918 \\
\hline & 1.00 & $-7.5650^{*}$ & 1.41600 & .038 & -14.3981 & -.7318 \\
\hline
\end{tabular}

Based on observed means.

*. The mean difference is significant at the .05 level. 


\subsection{TS}

Table 3.6.1: One way ANOVA table for mean of TS concentration in all bioreactors

\begin{tabular}{|l|r|r|r|r|r|}
\hline & Sum of squares & \multicolumn{1}{c|}{ df } & Mean square & \multicolumn{1}{c|}{ F } & \multicolumn{1}{c|}{ Sig. } \\
\hline Between & 22155266765 & 7 & 3165038109.221 & 71.258 & $\mathbf{0 . 0 0 0}$ \\
groups & 13680366617 & 308 & 44416774.732 & & \\
Within groups & 35835633381 & 315 & & & \\
Total & & & \\
\hline
\end{tabular}

Table 3.6.2: One way ANOVA table for mean of TS concentration in two groups

\begin{tabular}{|l|r|r|r|r|r|}
\hline & Sum of squares & df & Mean square & F & Sig. \\
\hline Between & 164785482.023 & 1 & 164785482.023 & 1.451 & $\mathbf{0 . 2 2 9}$ \\
groups & 35670847899.88 & 314 & 113601426.433 & & \\
Within groups & 35835633381.90 & 315 & & & \\
Total & 350.9 \\
\hline
\end{tabular}

Table 3.6.3: Two way ANOVA table for mean TS percentage reduction in the aerobic stage function of salt content and groups.

\begin{tabular}{|l|r|r|r|r|r|}
\hline Source & \multicolumn{1}{|c|}{$\begin{array}{c}\text { Type III sum of } \\
\text { squares }\end{array}$} & df & Mean square & \multicolumn{1}{c|}{ F } & \multicolumn{1}{c|}{ Sig. } \\
\hline Corrected & 1349.500 & 4 & 337.375 & 15.249 & .025 \\
model & & & & & \\
Intercept & 13203.125 & 1 & 13203.125 & 596.751 & .000 \\
Group & 406.125 & 1 & 406.125 & 18.356 & $\mathbf{0 . 0 2 3}$ \\
Salt & 943.375 & 3 & 314.458 & 14.213 & $\mathbf{0 . 0 2 8}$ \\
Error & 66.375 & 3 & 22.125 & & \\
Total & 14619.000 & 8 & & & \\
Corrected total & 1415.875 & 7 & & & \\
\hline
\end{tabular}

Table 3.6.4: Two way ANOVA table for TS percentage reduction in the anaerobic stage function of salt content and groups.

\begin{tabular}{|l|r|r|r|r|r|}
\hline Source & $\begin{array}{r}\text { Type III sum of } \\
\text { squares }\end{array}$ & df & Mean square & \multicolumn{1}{c|}{ F } & \multicolumn{1}{c|}{ Sig. } \\
\hline Corrected & 2560.500 & 4 & 640.125 & 30.482 & .009 \\
model & & & & & \\
Intercept & 17484.500 & 1 & 17484.500 & 832.595 & .000 \\
Group & 242.000 & 1 & 242.000 & 11.524 & $\mathbf{0 . 0 4 3}$ \\
Salt & 2318.500 & 3 & 772.833 & 36.802 & $\mathbf{0 . 0 0 7}$ \\
Error & 63.000 & 3 & 21.000 & & \\
Total & 20108.000 & 8 & & & \\
Corrected total & 2623.500 & 7 & & & \\
\hline
\end{tabular}


Table 3.6.5: Multiple comparisons for mean TS concentration in all bioreactors

Multiple Comparisons

Dependent Variable: Ts

Tukey HSD

\begin{tabular}{|c|c|c|c|c|c|c|}
\hline \multirow[b]{2}{*}{ (1) Reactors } & \multirow[b]{2}{*}{ (J) Reactors } & \multirow{2}{*}{$\begin{array}{c}\text { Mean } \\
\text { Difference } \\
(1-J)\end{array}$} & \multirow[b]{2}{*}{ Std. Error } & \multirow[b]{2}{*}{ Sig. } & \multicolumn{2}{|c|}{$95 \%$ Confidence Interval } \\
\hline & & & & & Lower Bound & Upper Bound \\
\hline \multirow[t]{7}{*}{1.00} & 2.00 & 2877.05500 & 1490.248 & .531 & -1671.0278 & 7425.1378 \\
\hline & 3.00 & $-6021.4000^{*}$ & 1490.248 & .002 & -10569.4828 & -1473.3172 \\
\hline & 4.00 & $-23971.550^{\star}$ & 1490.248 & .000 & -28519.6328 & -19423.4672 \\
\hline & 5.00 & -3709.1308 & 1499.770 & .211 & -8286.2751 & 868.0135 \\
\hline & 6.00 & $-5427.8692^{*}$ & 1499.770 & .008 & -10005.0135 & -850.7249 \\
\hline & 7.00 & $-6290.9462^{\star}$ & 1499.770 & .001 & -10868.0904 & -1713.8019 \\
\hline & 8.00 & $-17465.459^{\star}$ & 1499.770 & .000 & -22042.6033 & -12888.3147 \\
\hline \multirow[t]{7}{*}{2.00} & 1.00 & -2877.0550 & 1490.248 & .531 & -7425.1378 & 1671.0278 \\
\hline & 3.00 & $-8898.4550^{*}$ & 1490.248 & .000 & -13446.5378 & -4350.3722 \\
\hline & 4.00 & $-26848.605^{*}$ & 1490.248 & .000 & -31396.6878 & -22300.5222 \\
\hline & 5.00 & $-6586.1858^{*}$ & 1499.770 & .000 & -11163.3301 & -2009.0415 \\
\hline & 6.00 & $-8304.9242^{*}$ & 1499.770 & .000 & -12882.0685 & -3727.7799 \\
\hline & 7.00 & $-9168.0012^{*}$ & 1499.770 & .000 & -13745.1454 & -4590.8569 \\
\hline & 8.00 & $-20342.514^{*}$ & 1499.770 & .000 & -24919.6583 & -15765.3697 \\
\hline \multirow[t]{7}{*}{3.00} & 1.00 & $6021.40000^{*}$ & 1490.248 & .002 & 1473.3172 & 10569.4828 \\
\hline & 2.00 & $8898.45500^{*}$ & 1490.248 & .000 & 4350.3722 & 13446.5378 \\
\hline & 4.00 & $-17950.150^{\star}$ & 1490.248 & .000 & -22498.2328 & -13402.0672 \\
\hline & 5.00 & 2312.26923 & 1499.770 & .784 & -2264.8751 & 6889.4135 \\
\hline & 6.00 & 593.53077 & 1499.770 & 1.000 & -3983.6135 & 5170.6751 \\
\hline & 7.00 & -269.54615 & 1499.770 & 1.000 & -4846.6904 & 4307.5981 \\
\hline & 8.00 & $-11444.059^{*}$ & 1499.770 & .000 & -16021.2033 & -6866.9147 \\
\hline \multirow[t]{7}{*}{4.00} & 1.00 & $23971.550^{*}$ & 1490.248 & .000 & 19423.4672 & 28519.6328 \\
\hline & 2.00 & $26848.605^{*}$ & 1490.248 & .000 & 22300.5222 & 31396.6878 \\
\hline & 3.00 & $17950.150^{*}$ & 1490.248 & .000 & 13402.0672 & 22498.2328 \\
\hline & 5.00 & $20262.419^{*}$ & 1499.770 & .000 & 15685.2749 & 24839.5635 \\
\hline & 6.00 & $18543.681^{*}$ & 1499.770 & .000 & 13966.5365 & 23120.8251 \\
\hline & 7.00 & $17680.604^{*}$ & 1499.770 & .000 & 13103.4596 & 22257.7481 \\
\hline & 8.00 & $6506.09103^{*}$ & 1499.770 & .001 & 1928.9467 & 11083.2353 \\
\hline \multirow[t]{7}{*}{5.00} & 1.00 & 3709.13077 & 1499.770 & .211 & -868.0135 & 8286.2751 \\
\hline & 2.00 & $6586.18577^{*}$ & 1499.770 & .000 & 2009.0415 & 11163.3301 \\
\hline & 3.00 & -2312.2692 & 1499.770 & .784 & -6889.4135 & 2264.8751 \\
\hline & 4.00 & $-20262.419^{*}$ & 1499.770 & .000 & -24839.5635 & -15685.2749 \\
\hline & 6.00 & -1718.7385 & 1509.233 & .948 & -6324.7609 & 2887.2840 \\
\hline & 7.00 & -2581.8154 & 1509.233 & .680 & -7187.8378 & 2024.2071 \\
\hline & 8.00 & $-13756.328^{*}$ & 1509.233 & .000 & -18362.3507 & -9150.3057 \\
\hline \multirow[t]{7}{*}{6.00} & 1.00 & $5427.86923^{*}$ & 1499.770 & .008 & 850.7249 & 10005.0135 \\
\hline & 2.00 & $8304.92423^{*}$ & 1499.770 & .000 & 3727.7799 & 12882.0685 \\
\hline & 3.00 & -593.53077 & 1499.770 & 1.000 & -5170.6751 & 3983.6135 \\
\hline & 4.00 & $-18543.681^{*}$ & 1499.770 & .000 & -23120.8251 & -13966.5365 \\
\hline & 5.00 & 1718.73846 & 1509.233 & .948 & -2887.2840 & 6324.7609 \\
\hline & 7.00 & -863.07692 & 1509.233 & .999 & -5469.0994 & 3742.9455 \\
\hline & 8.00 & $-12037.590^{\star}$ & 1509.233 & .000 & -16643.6122 & -7431.5673 \\
\hline \multirow[t]{7}{*}{7.00} & 1.00 & $6290.94615^{*}$ & 1499.770 & .001 & 1713.8019 & 10868.0904 \\
\hline & 2.00 & $9168.00115^{\star}$ & 1499.770 & .000 & 4590.8569 & 13745.1454 \\
\hline & 3.00 & 269.54615 & 1499.770 & 1.000 & -4307.5981 & 4846.6904 \\
\hline & 4.00 & $-17680.604^{*}$ & 1499.770 & .000 & -22257.7481 & -13103.4596 \\
\hline & 5.00 & 2581.81538 & 1509.233 & .680 & -2024.2071 & 7187.8378 \\
\hline & 6.00 & 863.07692 & 1509.233 & .999 & -3742.9455 & 5469.0994 \\
\hline & 8.00 & $-11174.513^{*}$ & 1509.233 & .000 & -15780.5353 & -6568.4904 \\
\hline \multirow[t]{7}{*}{8.00} & 1.00 & $17465.459^{*}$ & 1499.770 & .000 & 12888.3147 & 22042.6033 \\
\hline & 2.00 & $20342.514^{*}$ & 1499.770 & .000 & 15765.3697 & 24919.6583 \\
\hline & 3.00 & $11444.059^{*}$ & 1499.770 & .000 & 6866.9147 & 16021.2033 \\
\hline & 4.00 & $-6506.0910^{*}$ & 1499.770 & .001 & -11083.2353 & -1928.9467 \\
\hline & 5.00 & $13756.328^{*}$ & 1509.233 & .000 & 9150.3057 & 18362.3507 \\
\hline & 6.00 & $12037.590^{*}$ & 1509.233 & .000 & 7431.5673 & 16643.6122 \\
\hline & 7.00 & $11174.513^{*}$ & 1509.233 & .000 & 6568.4904 & 15780.5353 \\
\hline
\end{tabular}

*. The mean difference is significant at the .05 level. 
Table 3.6.6: Multiple comparisons for mean TS percentage reduction in the aerobic stage at different salt contents

Multiple Comparisons

Dependent Variable: Aerobic

Tukey HSD

\begin{tabular}{|c|c|c|c|c|c|c|}
\hline \multirow[b]{2}{*}{ (I) Salt } & \multirow[b]{2}{*}{ (J) Salt } & \multirow{2}{*}{$\begin{array}{c}\text { Mean } \\
\text { Difference } \\
(I-J)\end{array}$} & \multirow[b]{2}{*}{ Std. Error } & \multirow[b]{2}{*}{ Sig. } & \multicolumn{2}{|c|}{$95 \%$ Confidence Interval } \\
\hline & & & & & Lower Bound & Upper Bound \\
\hline \multirow[t]{3}{*}{.00} & .50 & 12.5000 & 4.70372 & .208 & -10.1986 & 35.1986 \\
\hline & 1.00 & 19.0000 & 4.70372 & .079 & -3.6986 & 41.6986 \\
\hline & 3.00 & $30.0000^{\star}$ & 4.70372 & .023 & 7.3014 & 52.6986 \\
\hline \multirow[t]{3}{*}{.50} & .00 & -12.5000 & 4.70372 & .208 & -35.1986 & 10.1986 \\
\hline & 1.00 & 6.5000 & 4.70372 & .583 & -16.1986 & 29.1986 \\
\hline & 3.00 & 17.5000 & 4.70372 & .097 & -5.1986 & 40.1986 \\
\hline \multirow[t]{3}{*}{1.00} & .00 & -19.0000 & 4.70372 & .079 & -41.6986 & 3.6986 \\
\hline & .50 & -6.5000 & 4.70372 & .583 & -29.1986 & 16.1986 \\
\hline & 3.00 & 11.0000 & 4.70372 & .268 & -11.6986 & 33.6986 \\
\hline \multirow[t]{3}{*}{3.00} & .00 & $-30.0000^{*}$ & 4.70372 & .023 & -52.6986 & -7.3014 \\
\hline & .50 & -17.5000 & 4.70372 & .097 & -40.1986 & 5.1986 \\
\hline & 1.00 & -11.0000 & 4.70372 & .268 & -33.6986 & 11.6986 \\
\hline
\end{tabular}

Based on observed means.

*. The mean difference is significant at the .05 level.

Table 3.6.7: Multiple comparisons for mean TS percentage reduction in the anaerobic stage at different salt contents

Multiple Comparisons

Dependent Variable: Anaerobic

Tukey HSD

\begin{tabular}{|c|c|c|c|c|c|c|}
\hline \multirow[b]{2}{*}{ (I) Salt } & \multirow[b]{2}{*}{ (J) Salt } & \multirow{2}{*}{$\begin{array}{c}\text { Mean } \\
\text { Difference } \\
(\mathrm{l}-\mathrm{J})\end{array}$} & \multirow[b]{2}{*}{ Std. Error } & \multirow[b]{2}{*}{ Sig. } & \multicolumn{2}{|c|}{$95 \%$ Confidence Interval } \\
\hline & & & & & Lower Bound & Upper Bound \\
\hline \multirow[t]{3}{*}{.00} & .50 & 12.5000 & 4.58258 & .197 & -9.6140 & 34.6140 \\
\hline & 1.00 & $29.5000^{*}$ & 4.58258 & .023 & 7.3860 & 51.6140 \\
\hline & 3.00 & $45.0000^{*}$ & 4.58258 & .007 & 22.8860 & 67.1140 \\
\hline \multirow[t]{3}{*}{.50} & .00 & -12.5000 & 4.58258 & .197 & -34.6140 & 9.6140 \\
\hline & 1.00 & 17.0000 & 4.58258 & .098 & -5.1140 & 39.1140 \\
\hline & 3.00 & $32.5000^{*}$ & 4.58258 & .017 & 10.3860 & 54.6140 \\
\hline \multirow[t]{3}{*}{1.00} & .00 & $-29.5000^{*}$ & 4.58258 & .023 & -51.6140 & -7.3860 \\
\hline & .50 & -17.0000 & 4.58258 & .098 & -39.1140 & 5.1140 \\
\hline & 3.00 & 15.5000 & 4.58258 & .122 & -6.6140 & 37.6140 \\
\hline \multirow[t]{3}{*}{3.00} & .00 & $-45.0000^{*}$ & 4.58258 & .007 & -67.1140 & -22.8860 \\
\hline & .50 & $-32.5000^{*}$ & 4.58258 & .017 & -54.6140 & -10.3860 \\
\hline & 1.00 & -15.5000 & 4.58258 & .122 & -37.6140 & 6.6140 \\
\hline
\end{tabular}

Based on observed means.

*. The mean difference is significant at the .05 level. 


\section{7 $\mathrm{NH}_{3}-\mathrm{N}$}

Table 3.7.1: One way ANOVA table for mean $\mathrm{NH}_{3}-\mathrm{N}$ concentration in all bioreactors

\begin{tabular}{|l|c|r|r|c|c|}
\hline & Sum of squares & df & Mean square & F & Sig. \\
\hline Between & 22791547.976 & 7 & 3255935.425 & 29.532 & $\mathbf{0 . 0 0 0}$ \\
groups & 27342170.720 & 248 & 110250.688 & & \\
Within groups & 50133718.697 & 255 & & & \\
Total & & \\
\hline
\end{tabular}

Table 3.7.2: One way ANOVA table for mean $\mathrm{NH}_{3}-\mathrm{N}$ concentration in the two groups

\begin{tabular}{|l|r|r|r|c|c|}
\hline & Sum of squares & df & Mean square & F & Sig. \\
\hline Between & 3859150.840 & 1 & 3859150.840 & 21.183 & $\mathbf{0 . 0 0 0}$ \\
groups & 46274567.857 & 254 & 182183.338 & & \\
Within groups & 50133718.697 & 255 & & & \\
Total & &
\end{tabular}

Table 3.7.3: Two way ANOVA table for mean $\mathrm{NH}_{3}-\mathrm{N}$ percentage reduction in the aerobic stage function of salt content and groups.

\begin{tabular}{|l|r|r|r|r|r|}
\hline Source & $\begin{array}{c}\text { Type III sum } \\
\text { of squares }\end{array}$ & df & Mean square & \multicolumn{1}{c|}{ F } & \multicolumn{1}{c|}{ Sig. } \\
\hline Corrected & 2837.062 & 4 & 709.265 & 6.016 & 0.086 \\
model & 48029.852 & 1 & 48029.852 & 407.373 & 0.000 \\
Intercept & 2288.600 & 1 & 2288.600 & 19.411 & $\mathbf{0 . 0 2 2}$ \\
Group & 548.462 & 3 & 182.821 & 1.551 & $\mathbf{0 . 3 6 4}$ \\
Salt & 353.704 & 3 & 117.901 & & \\
Error & 51220.618 & 8 & & & \\
Total & 3190.766 & 7 & & & \\
Corrected total & & & & & \\
\hline
\end{tabular}

Table 3.7.4: Two way ANOVA table for mean $\mathrm{NH}_{3}-\mathrm{N}$ percentage reduction in the anaerobic stage function of salt content and groups.

\begin{tabular}{|l|r|r|r|r|r|}
\hline Source & \multicolumn{1}{|c|}{$\begin{array}{c}\text { Type III sum } \\
\text { of squares }\end{array}$} & df & Mean square & \multicolumn{1}{c|}{ F } & \multicolumn{1}{c|}{ Sig. } \\
\hline Corrected & 519.500 & 4 & 129.875 & 10.153 & .043 \\
model & 58311.125 & 1 & 58311.125 & 4558.52 & .000 \\
Intercept & 465.125 & 1 & 465.125 & 36.362 & $\mathbf{0 . 0 0 9}$ \\
Group & 54.375 & 3 & 18.125 & 1.417 & $\mathbf{0 . 3 9 1}$ \\
Salt & 38.375 & 3 & 12.792 & & \\
Error & 58869.000 & 8 & & & \\
Total & 557.875 & 7 & & & \\
Corrected total & & & & \\
\hline
\end{tabular}


Table 3.7.5: Multiple comparisons for mean NH3-N concentration in all bioreactors

Multiple Comparisons

Dependent Variable: $\mathrm{NH} 3$

Tukey HSD

\begin{tabular}{|c|c|c|c|c|c|c|}
\hline \multirow[b]{2}{*}{ (I) Reactors } & \multirow[b]{2}{*}{ (J) Reactors } & \multirow{2}{*}{$\begin{array}{c}\text { Mean } \\
\text { Difference } \\
(\mid-J)\end{array}$} & \multirow[b]{2}{*}{ Std. Error } & \multirow[b]{2}{*}{ Sig. } & \multicolumn{2}{|c|}{$95 \%$ Confidence Interval } \\
\hline & & & & & Lower Bound & Upper Bound \\
\hline \multirow[t]{7}{*}{ R1 } & $\mathrm{R} 2$ & -142.51969 & 83.01005 & .676 & -396.2817 & 111.2423 \\
\hline & R3 & $-302.68094^{*}$ & 83.01005 & .008 & -556.4429 & -48.9189 \\
\hline & $\mathrm{R} 4$ & $-990.60250^{*}$ & 83.01005 & .000 & -1244.3645 & -736.8405 \\
\hline & R5 & -37.64211 & 83.01005 & 1.000 & -291.4041 & 216.1199 \\
\hline & R6 & -92.99166 & 83.01005 & .952 & -346.7537 & 160.7704 \\
\hline & $\mathrm{R} 7$ & -122.59134 & 83.01005 & .819 & -376.3534 & 131.1707 \\
\hline & R8 & -200.34194 & 83.01005 & .239 & -454.1040 & 53.4201 \\
\hline \multirow[t]{7}{*}{$\overline{R 2}$} & R1 & 142.51969 & 83.01005 & .676 & -111.2423 & 396.2817 \\
\hline & R3 & -160.16125 & 83.01005 & .532 & -413.9233 & 93.6008 \\
\hline & $\mathrm{R} 4$ & $-848.08281^{*}$ & 83.01005 & .000 & -1101.8448 & -594.3208 \\
\hline & R5 & 104.87758 & 83.01005 & .911 & -148.8844 & 358.6396 \\
\hline & R6 & 49.52803 & 83.01005 & .999 & -204.2340 & 303.2900 \\
\hline & $\mathrm{R7}$ & 19.92835 & 83.01005 & 1.000 & -233.8337 & 273.6904 \\
\hline & R8 & -57.82225 & 83.01005 & .997 & -311.5843 & 195.9398 \\
\hline \multirow[t]{7}{*}{$\mathrm{R3}$} & $\mathrm{R} 1$ & $302.68094^{*}$ & 83.01005 & .008 & 48.9189 & 556.4429 \\
\hline & $\mathrm{R} 2$ & 160.16125 & 83.01005 & .532 & -93.6008 & 413.9233 \\
\hline & R4 & $-687.92156^{\star}$ & 83.01005 & .000 & -941.6836 & -434.1596 \\
\hline & R5 & $265.03883^{\star}$ & 83.01005 & .034 & 11.2768 & 518.8008 \\
\hline & $\mathrm{R} 6$ & 209.68928 & 83.01005 & .189 & -44.0727 & 463.4513 \\
\hline & $\mathrm{R} 7$ & 180.08960 & 83.01005 & .374 & -73.6724 & 433.8516 \\
\hline & R8 & 102.33900 & 83.01005 & .921 & -151.4230 & 356.1010 \\
\hline \multirow[t]{7}{*}{$\overline{R 4}$} & R1 & $990.60250^{*}$ & 83.01005 & .000 & 736.8405 & 1244.3645 \\
\hline & $\mathrm{R} 2$ & $848.08281^{*}$ & 83.01005 & .000 & 594.3208 & 1101.8448 \\
\hline & R3 & $687.92156^{*}$ & 83.01005 & .000 & 434.1596 & 941.6836 \\
\hline & $\mathrm{R} 5$ & $952.96039^{*}$ & 83.01005 & .000 & 699.1984 & 1206.7224 \\
\hline & R6 & $897.61084^{*}$ & 83.01005 & .000 & 643.8488 & 1151.3729 \\
\hline & $\mathrm{R} 7$ & $868.01116^{*}$ & 83.01005 & .000 & 614.2491 & 1121.7732 \\
\hline & R8 & $790.26056^{\star}$ & 83.01005 & .000 & 536.4985 & 1044.0226 \\
\hline \multirow[t]{7}{*}{$\overline{R 5}$} & R1 & 37.64211 & 83.01005 & 1.000 & -216.1199 & 291.4041 \\
\hline & $\mathrm{R} 2$ & -104.87758 & 83.01005 & .911 & -358.6396 & 148.8844 \\
\hline & R3 & $-265.03883^{*}$ & 83.01005 & .034 & -518.8008 & -11.2768 \\
\hline & R4 & $-952.96039^{*}$ & 83.01005 & .000 & -1206.7224 & -699.1984 \\
\hline & $\mathbf{R 6}$ & -55.34955 & 83.01005 & .998 & -309.1116 & 198.4125 \\
\hline & $\mathrm{R} 7$ & -84.94923 & 83.01005 & .971 & -338.7112 & 168.8128 \\
\hline & $\mathrm{R} 8$ & -162.69983 & 83.01005 & .511 & -416.4618 & 91.0622 \\
\hline \multirow[t]{7}{*}{$R 6$} & $\overline{R 1}$ & 92.99166 & 83.01005 & .952 & -160.7704 & 346.7537 \\
\hline & $\mathrm{R} 2$ & -49.52803 & 83.01005 & .999 & -303.2900 & 204.2340 \\
\hline & R3 & -209.68928 & 83.01005 & .189 & -463.4513 & 44.0727 \\
\hline & R4 & $-897.61084^{*}$ & 83.01005 & .000 & -1151.3729 & -643.8488 \\
\hline & R5 & 55.34955 & 83.01005 & .998 & -198.4125 & 309.1116 \\
\hline & $\mathrm{R7}$ & -29.59968 & 83.01005 & 1.000 & -283.3617 & 224.1623 \\
\hline & R8 & -107.35028 & 83.01005 & .901 & -361.1123 & 146.4117 \\
\hline \multirow[t]{7}{*}{ R7 } & R1 & 122.59134 & 83.01005 & .819 & -131.1707 & 376.3534 \\
\hline & $\mathrm{R} 2$ & -19.92835 & 83.01005 & 1.000 & -273.6904 & 233.8337 \\
\hline & $\mathrm{R} 3$ & -180.08960 & 83.01005 & .374 & -433.8516 & 73.6724 \\
\hline & R4 & $-868.01116^{*}$ & 83.01005 & .000 & -1121.7732 & -614.2491 \\
\hline & R5 & 84.94923 & 83.01005 & .971 & -168.8128 & 338.7112 \\
\hline & R6 & 29.59968 & 83.01005 & 1.000 & -224.1623 & 283.3617 \\
\hline & R8 & -77.75060 & 83.01005 & .982 & -331.5126 & 176.0114 \\
\hline \multirow[t]{7}{*}{$\overline{\mathrm{R} 8}$} & $\overline{\mathbf{R 1}}$ & 200.34194 & 83.01005 & .239 & -53.4201 & 454.1040 \\
\hline & $\mathrm{R} 2$ & 57.82225 & 83.01005 & .997 & -195.9398 & 311.5843 \\
\hline & R3 & -102.33900 & 83.01005 & .921 & -356.1010 & 151.4230 \\
\hline & R4 & $-790.26056^{*}$ & 83.01005 & .000 & -1044.0226 & -536.4985 \\
\hline & R5 & 162.69983 & 83.01005 & .511 & -91.0622 & 416.4618 \\
\hline & $\mathbf{R} 6$ & 107.35028 & 83.01005 & .901 & -146.4117 & 361.1123 \\
\hline & $\mathrm{R7}$ & 77.75060 & 83.01005 & .982 & -176.0114 & 331.5126 \\
\hline
\end{tabular}




\subsection{Vertical Concentration profile in bioreactors}

Table 3.8.1: One way ANOVA for mean COD concentation in all ports at R1 (first analysis)

\begin{tabular}{|l|r|r|r|r|r|}
\hline & Sum of squares & \multicolumn{1}{c|}{ df } & Mean square & F & \multicolumn{1}{c|}{ Sig. } \\
\hline Between & 326666.667 & 2 & 163333.333 & 3.128 & $\mathbf{0 . 1 1 7}$ \\
Groups & 313333.333 & 6 & 52222.222 & & \\
Within Groups & 640000.000 & 8 & & & \\
Total & &
\end{tabular}

Table 3.8.2: One way ANOVA for mean COD concentation in all ports at R1 (Second analysis)

\begin{tabular}{|l|r|r|r|r|r|}
\hline & Sum of squares & \multicolumn{1}{c|}{ df } & Mean square & F & \multicolumn{1}{c|}{ Sig. } \\
\hline Between & 275555.556 & 2 & 137777.778 & .663 & $\mathbf{0 . 5 4 9}$ \\
groups & 1246666.667 & 6 & 207777.778 & & \\
Within groups & 1522222.222 & 8 & & & \\
Total & & & \\
\hline
\end{tabular}

Table 3.8.3: One way ANOVA for mean COD concentation in all ports at R1 (Third analysis)

\begin{tabular}{|l|r|r|r|r|r|}
\hline & Sum of squares & \multicolumn{1}{c|}{ df } & Mean square & \multicolumn{1}{c|}{ F } & \multicolumn{1}{c|}{ Sig. } \\
\hline Between & 46250.000 & 2 & 23125.000 & .881 & $\mathbf{0 . 4 6 2}$ \\
groups & 157500.000 & 6 & 26250.000 & & \\
Within groups & 203750.000 & 8 & & & \\
Total &
\end{tabular}

Table 3.8.4: One way ANOVA for mean COD concentation in all ports at R5 (Second analysis)

\begin{tabular}{|l|r|r|r|r|r|}
\hline & Sum of squares & \multicolumn{1}{c|}{ df } & Mean square & F & \multicolumn{1}{c|}{ Sig. } \\
\hline Between & 98750.000 & 2 & 49375.000 & 1.026 & $\mathbf{0 . 4 1 4}$ \\
groups & 288750.000 & 6 & 48125.000 & & \\
Within groups & 387500.000 & 8 & & & \\
Total &
\end{tabular}




\section{Hydrolysis rate constant}

\subsection{First set}

Table 4.1: Nonlinear regression analysis for $0 \%(\mathrm{w} / \mathrm{v})$ salt content with $20 \%(\mathrm{v} / \mathrm{v})$ normal anaerobic digested sludge

\begin{tabular}{|ccc|}
\hline Iteration number(a) & Residual sum of squares & Parameter $\left(\mathrm{k}_{\mathrm{h}}\right)$ \\
\hline 1.0 & 5328661.077 & .010 \\
1.1 & 941358.141 & .044 \\
2.0 & 941358.141 & .044 \\
2.1 & 337690.333 & .075 \\
3.0 & 337690.333 & .075 \\
3.1 & 315101.912 & .087 \\
4.0 & 315101.912 & .087 \\
4.1 & 314845.744 & .085 \\
5.0 & 314845.744 & .085 \\
5.1 & 314825.031 & $\mathbf{0 . 0 8 5}$ \\
\hline
\end{tabular}

Parameter estimates

\begin{tabular}{|c|c|c|c|c|}
\hline Parameter & Estimate & Std. Error & \multicolumn{2}{|c|}{$95 \%$ Confidence interval } \\
\hline & & & Lower bound & Upper bound \\
\hline $\mathbf{k}_{\mathbf{h}}$ & $\mathbf{0 . 0 8 5}$ & .008 & .070 & .101 \\
\hline
\end{tabular}

$\operatorname{ANOVA(a)}$

\begin{tabular}{|l|c|c|c|}
\hline Source & Sum of squares & df & Mean squares \\
\hline Regression & 8914053.895 & 1 & 8914053.895 \\
Residual & 314823.578 & 39 & 8072.399 \\
Uncorrected total & 9228877.473 & 40 & \\
Corrected total & 1869330.844 & 39 & \\
\hline
\end{tabular}

(a) R squared = 1 - (Residual Sum of Squares) / (Corrected Sum of Squares) $=\mathbf{0 . 8 5 5}$. 
Table 4.2: Nonlinear regression analysis for $1 \%(\mathrm{w} / \mathrm{v})$ salt content with $20 \%(\mathrm{v} / \mathrm{v})$ normal anaerobic digested sludge

\begin{tabular}{|ccc|}
\hline Iteration Number & Residual sum of Squares & Parameter (kh) \\
\hline 1.0 & 3563044.032 & .010 \\
1.1 & 584895.321 & .042 \\
2.0 & 584895.321 & .042 \\
2.1 & 225209.649 & .069 \\
3.0 & 225209.649 & .069 \\
3.1 & 215976.739 & .076 \\
4.0 & 215976.739 & .076 \\
4.1 & 215851.370 & .075 \\
5.0 & 215851.370 & .075 \\
5.1 & 215844.368 & $\mathbf{0 . 0 7 6}$ \\
\hline
\end{tabular}

\section{Parameter estimates}

\begin{tabular}{|c|c|c|c|c|}
\hline Parameter & Estimate & Std. Error & \multicolumn{2}{|c|}{$95 \%$ Confidence interval } \\
\hline & & & Lower bound & Upper bound \\
\hline $\mathbf{K}_{\mathbf{h}}$ & $\mathbf{0 . 0 7 6}$ & .006 & .063 & .088 \\
\hline
\end{tabular}

ANOVA(a)

\begin{tabular}{|l|l|l|l|}
\hline Source & Sum of squares & \multicolumn{1}{|c|}{ df } & \multicolumn{1}{|c|}{ Mean squares } \\
\hline Regression & 6149375.696 & 1 & 6149375.696 \\
Residual & 215844.019 & 39 & 5534.462 \\
Uncorrected total & 6365219.714 & 40 & \\
Corrected total & 1379955.993 & 39 & \\
\hline
\end{tabular}

(a) R squared $=1$ - (Residual Sum of Squares) $/$ (Corrected Sum of Squares) $=0.869$. 
Table 4.3: Nonlinear regression analysis for $2 \%(\mathrm{w} / \mathrm{v})$ salt content with $20 \%(\mathrm{v} / \mathrm{v})$ normal anaerobic digested sludge

\begin{tabular}{|ccc|}
\hline Iteration number & Residual sum of squares & Parameter $\left(\mathrm{k}_{\mathrm{h}}\right)$ \\
\hline 1.0 & 2509659.118 & .010 \\
1.1 & 373629.857 & .039 \\
2.0 & 373629.857 & .039 \\
2.1 & 193239.442 & .058 \\
3.0 & 193239.442 & .058 \\
3.1 & 192510.234 & .060 \\
4.0 & 192510.234 & .060 \\
4.1 & 192483.264 & $\mathbf{0 . 0 6 0}$ \\
\hline
\end{tabular}

Parameter estimates

\begin{tabular}{|c|c|c|c|c|}
\hline Parameter & Estimate & Std. Error & \multicolumn{2}{|c|}{$95 \%$ Confidence interval } \\
\hline & & & Lower bound & Upper bound \\
\hline $\mathbf{k}_{\mathbf{h}}$ & $\mathbf{. 0 6 0}$ & .005 & .051 & .069 \\
\hline
\end{tabular}

\section{ANOVA(a)}

\begin{tabular}{|l|l|l|l|}
\hline Source & Sum of squares & \multicolumn{1}{c|}{ df } & \multicolumn{1}{|c|}{ Mean squares } \\
\hline Regression & 4578230.453 & 1 & 4578230.453 \\
Residual & 192481.780 & 39 & 4935.430 \\
Uncorrected total & 4770712.233 & 40 & \\
Corrected total & 1246224.050 & 39 & \\
\hline
\end{tabular}

(a) R squared $=1$ - (Residual Sum of Squares) $/$ (Corrected Sum of Squares) $=0.885$ 
Table 4.4: Nonlinear regression analysis for $3 \%(\mathrm{w} / \mathrm{v})$ salt content with $20 \%(\mathrm{v} / \mathrm{v})$ normal anaerobic digested sludge

\begin{tabular}{|ccc|}
\hline Iteration number & Residual sum of squares & Parameter $\left(\mathrm{k}_{\mathrm{h}}\right)$ \\
\hline 1.0 & 1411018.020 & .010 \\
1.1 & 305733.089 & .034 \\
2.0 & 305733.089 & .034 \\
2.1 & 265174.077 & .043 \\
3.0 & 265174.077 & .043 \\
3.1 & 264967.551 & .042 \\
4.0 & 264967.551 & .042 \\
4.1 & 264955.838 & .042 \\
5.0 & 264955.838 & .042 \\
5.1 & 264955.273 & $\mathbf{0 . 0 4 2}$ \\
\hline
\end{tabular}

\section{Parameter estimates}

\begin{tabular}{|c|c|c|c|c|}
\hline Parameter & Estimate & Std. Error & \multicolumn{2}{|c|}{$95 \%$ Confidence interval } \\
\hline & & & Lower bound & Upper bound \\
\hline $\mathbf{k}_{\mathbf{h}}$ & $\mathbf{0 . 0 4 2}$ & .004 & .034 & .051 \\
\hline
\end{tabular}

\section{ANOVA(a)}

\begin{tabular}{|l|c|c|c|}
\hline Source & Sum of squares & df & Mean squares \\
\hline Regression & 2670052.542 & 1 & 2670052.542 \\
Residual & 264955.243 & 39 & 6793.724 \\
Uncorrected total & 2935007.786 & 40 & \\
Corrected total & 1080882.939 & 39 & \\
\hline
\end{tabular}

(a) R squared $=1$ - (Residual Sum of Squares) $/$ (Corrected Sum of Squares) $=0.841$ 
Table 4.5: Nonlinear regression analysis for $0 \%(\mathrm{w} / \mathrm{v})$ salt content with $20 \%(\mathrm{v} / \mathrm{v})$ acclimatized anaerobic digested sludge

\begin{tabular}{|ccc|}
\hline Iteration number & Residual sum of squares & Parameter $\left(\mathrm{k}_{\mathrm{h}}\right)$ \\
\hline 1.0 & 5276966.767 & .010 \\
1.1 & 869468.283 & .044 \\
2.0 & 869468.283 & .044 \\
2.1 & 256841.545 & .074 \\
3.0 & 256841.545 & .074 \\
3.1 & 230816.589 & .087 \\
4.0 & 230816.589 & .087 \\
4.1 & 230668.395 & .085 \\
5.0 & 230668.395 & .085 \\
5.1 & 230659.519 & $\mathbf{0 . 0 8 6}$ \\
\hline
\end{tabular}

Parameter estimates

\begin{tabular}{|c|c|c|c|c|}
\hline Parameter & Estimate & Std. Error & \multicolumn{2}{|c|}{$95 \%$ Confidence Interval } \\
\hline & & & Lower Bound & Upper Bound \\
\hline $\mathbf{k}_{\mathbf{h}}$ & $\mathbf{0 . 0 8 6}$ & .007 & .072 & .099 \\
\hline
\end{tabular}

$\operatorname{ANOVA(a)}$

\begin{tabular}{|l|c|c|c|}
\hline Source & Sum of squares & df & Mean squares \\
\hline Regression & 8981149.082 & 1 & 8981149.082 \\
Residual & 230659.043 & 39 & 5914.334 \\
Uncorrected total & 9211808.125 & 40 & \\
Corrected total & 1725708.380 & 39 & \\
\hline
\end{tabular}

(a) $\mathrm{R}$ squared $=1$ - (Residual Sum of Squares) $/$ (Corrected Sum of Squares) $=0.887$ 
Table 4.6: Nonlinear regression analysis for $1 \%(\mathrm{w} / \mathrm{v})$ salt content with $20 \%(\mathrm{v} / \mathrm{v})$ acclimatized anaerobic digested sludge

\begin{tabular}{|c|c|c|}
\hline Iteration number & Residual sum of Squares & Parameter $\left(\mathrm{k}_{\mathrm{h}}\right)$ \\
\hline 1.0 & 3508143.725 & .010 \\
1.1 & 514239.056 & .042 \\
2.0 & 514239.056 & .042 \\
2.1 & 168625.938 & .067 \\
3.0 & 168625.938 & .067 \\
3.1 & 161121.329 & .074 \\
4.0 & 161121.329 & .074 \\
4.1 & 161003.240 & .073 \\
5.0 & 161003.240 & .073 \\
5.1 & 160996.943 & $\mathbf{0 . 0 7 3}$ \\
\hline
\end{tabular}

\section{Parameter Estimates}

\begin{tabular}{|c|c|c|c|c|}
\hline Parameter & Estimate & Std. Error & \multicolumn{2}{|c|}{ 95\% Confidence interval } \\
\hline & & & Lower bound & Upper bound \\
\hline $\mathbf{K}_{\mathbf{h}}$ & $\mathbf{0 . 0 7 3}$ & .005 & .063 & .084 \\
\hline
\end{tabular}

ANOVA(a)

\begin{tabular}{|l|c|c|c|}
\hline Source & Sum of squares & df & Mean squares \\
\hline Regression & 6198577.809 & 1 & 6198577.809 \\
Residual & 160996.640 & 39 & 4128.119 \\
Uncorrected total & 6359574.449 & 40 & \\
Corrected total & 1337109.679 & 39 & \\
\hline
\end{tabular}

(a) R squared = 1 - (Residual Sum of Squares) $/$ (Corrected Sum of Squares) = 0.914. 
Table 4.7: Nonlinear regression analysis for $2 \%(\mathrm{w} / \mathrm{v})$ salt content with $20 \%(\mathrm{v} / \mathrm{v})$ acclimatized anaerobic digested sludge

\begin{tabular}{|ccc|}
\hline Iteration number & Residual sum of squares & Parameter $\left(\mathrm{k}_{\mathrm{h}}\right)$ \\
\hline 1.0 & 2643404.579 & .010 \\
1.1 & 345844.595 & .039 \\
2.0 & 345844.595 & .039 \\
2.1 & 156662.740 & .056 \\
3.0 & 156662.740 & .056 \\
3.1 & 155734.036 & .058 \\
4.0 & 155734.036 & .058 \\
4.1 & 155710.095 & .058 \\
5.0 & 155710.095 & .058 \\
5.1 & 155709.190 & $\mathbf{0 . 0 5 8}$ \\
\hline
\end{tabular}

\section{Parameter estimates}

\begin{tabular}{|c|c|c|c|c|}
\hline Parameter & Estimate & Std. Error & \multicolumn{2}{|c|}{ 95\% Confidence interval } \\
\hline & & & Lower bound & Upper bound \\
\hline $\mathbf{k}_{\mathbf{h}}$ & $\mathbf{0 . 0 5 8}$ & .004 & .050 & .066 \\
\hline
\end{tabular}

ANOVA(a)

\begin{tabular}{|l|c|c|c|}
\hline Source & Sum of squares & df & Mean squares \\
\hline Regression & 4992191.167 & 1 & 4992191.167 \\
Residual & 155709.157 & 39 & 3992.542 \\
Uncorrected total & 5147900.324 & 40 & \\
Corrected total & 1287583.245 & 39 & \\
\hline
\end{tabular}

(a) R squared = 1 - (Residual Sum of Squares) $/$ (Corrected Sum of Squares) $=0.904$ 
Table 4.8: Nonlinear regression analysis for $3 \%(\mathrm{w} / \mathrm{v})$ salt content with $20 \%$ (v/v) acclimatized anaerobic digested sludge

\begin{tabular}{|ccc|}
\hline Iteration number & Residual sum of squares & Parameter $\left(\mathrm{k}_{\mathrm{h}}\right)$ \\
\hline 1.0 & 2050198.202 & .010 \\
1.1 & 369020.822 & .036 \\
2.0 & 369020.822 & .036 \\
2.1 & 278469.710 & .049 \\
3.0 & 278469.710 & .049 \\
3.1 & 278407.700 & .049 \\
4.0 & 278407.700 & .049 \\
4.1 & 278403.995 & $\mathbf{0 . 0 4 9}$ \\
\hline
\end{tabular}

Parameter estimates

\begin{tabular}{|c|c|c|c|c|}
\hline Parameter & Estimate & Std. Error & \multicolumn{2}{|c|}{$95 \%$ Confidence interval } \\
\hline & & & Lower bound & Upper bound \\
\hline $\mathbf{k}_{\mathbf{h}}$ & $\mathbf{0 . 0 4 9}$ & .004 & .040 & .058 \\
\hline
\end{tabular}

\section{ANOVA(a)}

\begin{tabular}{|l|c|c|c|}
\hline Source & Sum of squares & df & Mean squares \\
\hline Regression & 3812541.202 & 1 & 3812541.202 \\
Residual & 278403.780 & 39 & 7138.558 \\
Uncorrected total & 4090944.983 & 40 & \\
Corrected total & 1352803.890 & 39 & \\
\hline
\end{tabular}

(a) R squared $=1$ - (Residual Sum of Squares) $/$ (Corrected Sum of Squares) $=0.861$ 


\subsection{Second set}

Table 4.9: Nonlinear regression analysis for $0 \%(\mathrm{w} / \mathrm{v})$ salt content with $30 \%(\mathrm{v} / \mathrm{v})$ normal anaerobic digested sludge

\begin{tabular}{|lcc|}
\hline Iteration number & Residual sum of squares & Parameter $\left(\mathrm{k}_{\mathrm{h}}\right)$ \\
\hline 1.0 & 5276966.767 & .010 \\
1.1 & 869468.283 & .044 \\
2.0 & 869468.283 & .044 \\
2.1 & 256841.545 & .074 \\
3.0 & 256841.545 & .074 \\
3.1 & 230816.589 & .087 \\
4.0 & 230816.589 & .087 \\
4.1 & 230668.395 & .085 \\
5.0 & 230668.395 & .085 \\
5.1 & 230659.519 & .086 \\
6.0 & 230659.519 & $\mathbf{0 . 0 8 6}$ \\
\hline
\end{tabular}

Parameter estimates

\begin{tabular}{|c|l|l|l|c|}
\hline Parameter & Estimate & Std. Error & \multicolumn{2}{|c|}{$95 \%$ Confidence interval } \\
\hline & & & Lower bound & Upper bound \\
\hline $\mathbf{k}_{\mathbf{h}}$ & $\mathbf{0 . 0 8 6}$ & .007 & .072 & .099 \\
\hline
\end{tabular}

ANOVA(a)

\begin{tabular}{|c|c|c|c|}
\hline Source & Sum of squares & $\mathrm{df}$ & Mean squares \\
\hline $\begin{array}{l}\text { Regression } \\
\text { Residual } \\
\text { Uncorrected total } \\
\text { Corrected total }\end{array}$ & $\begin{array}{l}8981149.082 \\
230659.043 \\
9211808.125 \\
1725708.380\end{array}$ & $\begin{array}{l}1 \\
39 \\
40 \\
39\end{array}$ & $\begin{array}{l}8981149.082 \\
5914.334\end{array}$ \\
\hline
\end{tabular}

(a) $\mathbf{R}$ squared $=1$ - (Residual Sum of Squares) $/$ (Corrected Sum of Squares) $=0.906$ 
Table 4.10: Nonlinear regression analysis for $1 \%(\mathrm{w} / \mathrm{v})$ salt content with $30 \%(\mathrm{v} / \mathrm{v})$ normal anaerobic digested sludge

\begin{tabular}{|ccc|}
\hline Iteration number & Residual sum of squares & Parameter $\left(\mathrm{k}_{\mathrm{h}}\right)$ \\
\hline 1.0 & 3508143.725 & .010 \\
1.1 & 514239.056 & .042 \\
2.0 & 514239.056 & .042 \\
2.1 & 168625.938 & .067 \\
3.0 & 168625.938 & .067 \\
3.1 & 161121.329 & .074 \\
4.0 & 161121.329 & .074 \\
4.1 & 161003.240 & .073 \\
5.0 & 161003.240 & .073 \\
5.1 & 160996.943 & $\mathbf{0 . 0 7 3}$ \\
\hline
\end{tabular}

Parameter Estimates

\begin{tabular}{|c|c|c|c|c|}
\hline Parameter & Estimate & Std. Error & \multicolumn{2}{|c|}{ 95\% Confidence interval } \\
\hline & & & Lower bound & Upper bound \\
\hline $\mathbf{k}_{\mathbf{h}}$ & $\mathbf{0 . 0 7 3}$ & .005 & .063 & .084 \\
\hline
\end{tabular}

ANOVA(a)

\begin{tabular}{|l|c|c|c|}
\hline Source & Sum of squares & df & Mean squares \\
\hline Regression & 6198577.809 & 1 & 6198577.809 \\
Residual & 160996.640 & 39 & 4128.119 \\
Uncorrected total & 6359574.449 & 40 & \\
Corrected total & 1337109.679 & 39 & \\
\hline
\end{tabular}

(a) $R$ squared $=1$ - (Residual Sum of Squares) $/$ (Corrected Sum of Squares) $=0.898$ 
Table 4.11: Nonlinear regression analysis for $2 \%(\mathrm{w} / \mathrm{v})$ salt content with $30 \%(\mathrm{v} / \mathrm{v})$ normal anaerobic digested sludge

\begin{tabular}{|ccc|}
\hline Iteration number & Residual sum of squares & Parameter $\left(\mathrm{k}_{\mathrm{h}}\right)$ \\
\hline 1.0 & 2643404.579 & .010 \\
1.1 & 345844.595 & .039 \\
2.0 & 345844.595 & .039 \\
2.1 & 156662.740 & .056 \\
3.0 & 156662.740 & .056 \\
3.1 & 155734.036 & .058 \\
4.0 & 155734.036 & .058 \\
4.1 & 155710.095 & .058 \\
5.0 & 155710.095 & .058 \\
5.1 & 155709.190 & $\mathbf{0 . 0 5 8}$ \\
\hline
\end{tabular}

Parameter Estimates

\begin{tabular}{|c|l|l|c|c|}
\hline Parameter & Estimate & Std. Error & \multicolumn{2}{|c|}{ 95\% Confidence interval } \\
\hline & & & Lower bound & Upper bound \\
\hline $\mathbf{k}_{\mathbf{h}}$ & $\mathbf{0 . 0 5 8}$ & .004 & .050 & .066 \\
\hline
\end{tabular}

ANOVA(a)

\begin{tabular}{|l|c|c|c|}
\hline Source & Sum of squares & df & Mean squares \\
\hline Regression & 4992191.167 & 1 & 4992191.167 \\
Residual & 155709.157 & 39 & 3992.542 \\
Uncorrected total & 5147900.324 & 40 & \\
Corrected total & 1287583.245 & 39 & \\
\hline
\end{tabular}

(a) R squared $=1$ - (Residual Sum of Squares) $/$ (Corrected Sum of Squares) $=0.884$ 
Table 4.12: Nonlinear regression analysis for $3 \%(\mathrm{w} / \mathrm{v})$ salt content with $30 \%(\mathrm{v} / \mathrm{v})$ normal anaerobic digested sludge

\begin{tabular}{|ccc|}
\hline Iteration Number & Residual Sum of Squares & Parameter \\
\hline 1.0 & 2050198.202 & .010 \\
1.1 & 369020.822 & .036 \\
2.0 & 369020.822 & .036 \\
2.1 & 278469.710 & .049 \\
3.0 & 278469.710 & .049 \\
3.1 & 278407.700 & .049 \\
4.0 & 278407.700 & .049 \\
4.1 & 278403.995 & .049 \\
5.0 & 278403.995 & .049 \\
5.1 & 278403.792 & .049 \\
6.0 & 278403.792 & .049 \\
6.1 & 278403.781 & $\mathbf{0 . 0 4 9}$ \\
\hline
\end{tabular}

Parameter estimates

\begin{tabular}{|c|l|l|l|c|}
\hline Parameter & Estimate & Std. Error & \multicolumn{2}{|c|}{ 95\% Confidence interval } \\
\hline & & & Lower bound & Upper bound \\
\hline $\mathbf{k}_{\mathbf{h}}$ & $\mathbf{0 . 0 4 9}$ & .004 & .040 & .058 \\
\hline
\end{tabular}

$\operatorname{ANOVA(a)}$

\begin{tabular}{|l|c|c|c|}
\hline Source & Sum of squares & df & Mean squares \\
\hline Regression & 4446247.754 & 1 & 4446247.754 \\
Residual & 196807.952 & 39 & 5046.358 \\
Uncorrected total & 4643055.705 & 40 & \\
Corrected total & 1565219.482 & 39 & \\
\hline
\end{tabular}

(a) R squared $=1$ - (Residual Sum of Squares) $/($ Corrected Sum of Squares) $=.874$ 
Table 4.13: One way ANOVA for the mean $\mathrm{k}_{\mathrm{h}}$ in two types of inoculum

\begin{tabular}{|l|r|r|r|r|r|}
\hline & Sum of squares & \multicolumn{1}{c|}{ df } & Mean square & F & Sig. \\
\hline Between & .000 & 1 & .000 & .050 & $\mathbf{0 . 8 3 0}$ \\
groups & .001 & 6 & .000 & & \\
Within group & .001 & 7 & & & \\
Total &
\end{tabular}

Table 4.14: One way ANOVA for the mean $\mathrm{Y}$ in two types of inoculum

\begin{tabular}{|l|c|c|c|c|c|}
\hline & Sum of squares & df & Mean square & F & Sig. \\
\hline Between & 351.920 & 1 & 351.920 & .243 & $\mathbf{0 . 6 4 0}$ \\
groups & 8699.278 & 6 & 1449.880 & & \\
Within groups & 9051.198 & 7 & & & \\
Total &
\end{tabular}

Table 4.14: One way ANOVA for the mean $\mathrm{k}_{\mathrm{h}}$ of $\mathrm{G} .1$ in the first set and the second set.

\begin{tabular}{|l|c|c|c|c|c|}
\hline & Sum of squares & df & Mean square & F & Sig. \\
\hline Between & .000 & 1 & .000 & .004 & $\mathbf{0 . 9 5 4}$ \\
groups & .002 & 6 & .000 & & \\
$\begin{array}{l}\text { Within groups } \\
\text { Total }\end{array}$ & .002 & 7 & & & \\
\hline
\end{tabular}

Table 4.14: One way ANOVA for the mean Y of G.1 in the first set and the second set.

\begin{tabular}{|l|r|c|c|c|c|}
\hline & Sum of squares & df & Mean square & F & Sig. \\
\hline Between & 1055.012 & 1 & 1055.012 & .682 & $\mathbf{0 . 4 4 0}$ \\
groups & 9281.068 & 6 & 1546.845 & & \\
Within groups & 10336.080 & 7 & & & \\
Total & & & & \\
\hline
\end{tabular}


The inhibition terms are (Lehninger, 1975):

1. Competitive

$$
\mu=\frac{\mu_{m} C_{S}}{K_{s}\left(1+\frac{I}{K_{I}}\right)+C_{S}}
$$

2. Uncompetitive

$$
\mu=\frac{\mu_{m} C_{S}}{K_{s}+C_{S}\left(1+\frac{I}{K_{I}}\right)}
$$

3. Noncompetitive

$$
\mu=\frac{\mu_{m} C_{S}}{\left(K_{s}+C_{S}\right)\left(1+\frac{I}{K_{I}}\right)}
$$

